\title{
THE TANGANYIKA
}

PROBLEM

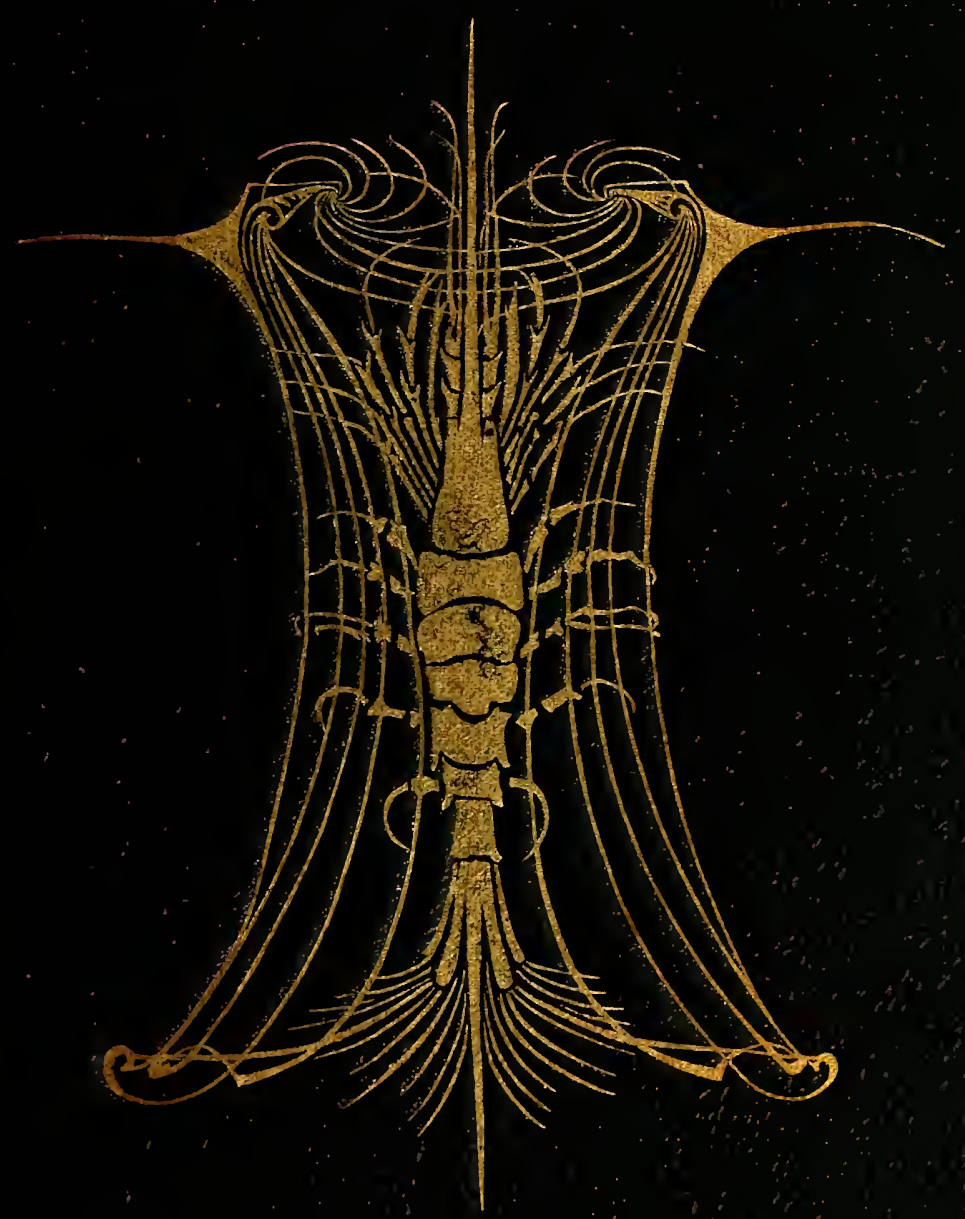

J.E. S. MOORE F.R.G.S. 
$f_{3}(10)$

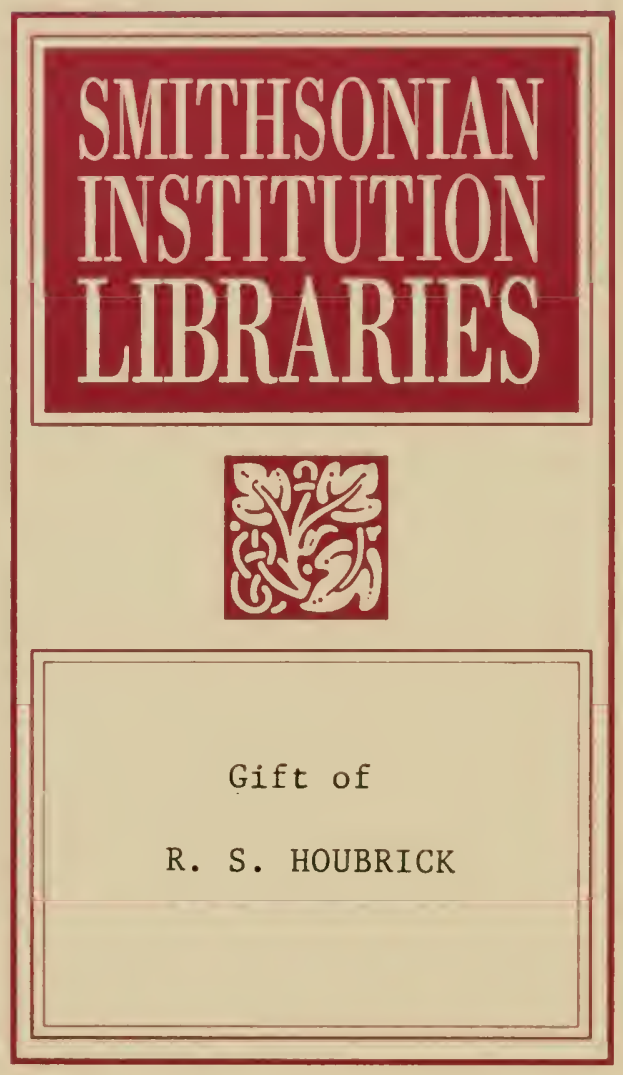


Rehard A Doubrick

DWIGHT W. TAYLOR

$H-3$

7

A.6. Unay

With

15. f. Atudersons complatuments. 



\section{THE \\ TANGANYIKA \\ PROBLEM}





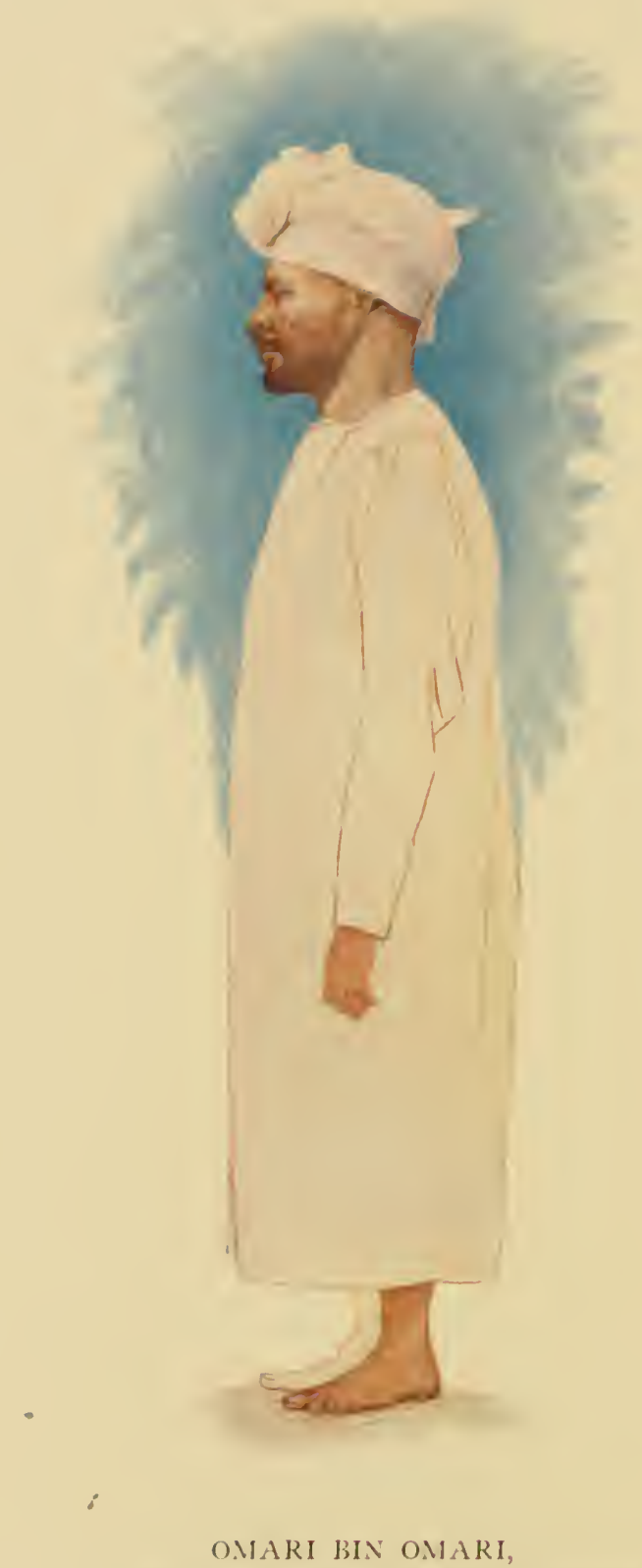

HEAD MAN OF THE SFCOND TANGANYIKA FXPFDITION.

(From a skesih b) the Aushor.) 


\section{The Tanganyika Problem}

AN ACCOUNT OF THE RESEARCHES

UNDERTAKEN CONCERNING THE EXISTENCE OF

GMARINE ANIMALS IN CENTRAL AFRICA

\section{By \\ J. E. S. MOORE, F.R.G.S.}

Author of

"To the Mountains of the Moon"

WITH NUMEROUS ILLUSTRATIONS AND MAPS

\section{LONDON}

HURST AND BLACKETT, LIMITED

I3, GREAT MARLBOROUGH STREET, W

1903

All rights reserved 


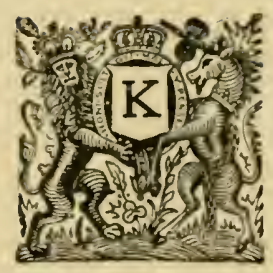

PRINTED BY

KELLY'S DIRECTORIES LTD. LONDON AND KINGSTON. 


\section{PREFACE.}

IN completing the present account of the researches which were undertaken during the two Tanganyika expeditions, I am somewhat oppressed with the possibility that the unique opportunities and material available may not have received the justice they would have done in the hands of many naturalists who have more experience than I am old enough to possess. We were actually the last zoological explorers with a great untouched field before them, and when it is remembered, that among other things, we have had to deal with nearly 200 * entirely new animal types discovered during these expeditions, it will be admitted that the labour of giving an adequate account of the faunistic characters of the great African lakes has not been exactly child's play. It should, moreover, be clearly understood that the acquisition of all this new material and information respecting Central Africa has been primarily due to the instigation and persistence of Professor Ray Lankester, and I only wish that he, instead of myself, could have found time to write the present account. On the other hand, it would perhaps have been impossible for anyone who was without a somewhat prolonged and actual acquaintance with the African interior, to attempt to deal with all the aspects the Tanganyika problem has been found to present, and I can therefore only point out to any who may feel that the present work could have been better done, that I am fully conscious of its peculiar deficiencies.

Few people here, moreover, will be able to appreciate how completely during the actual operations of exploring partics in practically unknown countries, whatever results may be obtained are due to the disinterested and gratuitous help which may or may not be extended to them by people, administrators and the like, who live

* In this connection it may be interesting to remember that the whole of the fishes, fresh water and marine, belonging to the British Islands, only represent about 240 species. 
upon the borders of such unknown lands. In the present case, all our results with respect to the fauna and topography of Nyassa, and much of the efficiency of the expedition further north, was che to the efforts of H.M. Commissioner, Mr. Alfred Sharpe, who allowed me to examine the lake from the gumboats, and facilitated our journey in many ways as far as the northern boundary of the British Central African Protectorate. In this way we were able to ascertain the actual depth of Lake Nyassa-430 fathoms-a result which is sufficiently surprising, and one which, I am happy to say, has since been closely confirmed in an adjacent area by Commander Rhoades. In like manner we received much help in the selection of men and kindness generally from General Creagh, the British Resident at Aden; from Mr. Codrington in Northern Rhodesia; and perhaps I might also say we have been particularly indebted to Captain Bethe, and his brother officers in command of the German territory north and east of Tanganyika. In the later stages of the journey a great quantity of animals in spirit, and what remained of things in general, were hurried safely through Uganda to the coast by the help of H.M. Commissioner Mr. Jackson and Mr. Pordage at Mitebi.

Turning from these details of the route to the subject of the investigations themselves, I should say at once that all the geographical work, which has resulted in the first effective mapping of the region that had so long remained in dispute between Tanganyika and the Albert Nyanza, has been due to the energy and skill of my colleague Mr. Fergusson, and in like manner much of the geological data with which I have had to deal in the sequel was originally collected and arranged by him.

The revision of the existing geological conceptions of the African interior, which the information obtained during the Tanganyika Expeditions necessitates, will possibly be found the most generally interesting result that these investigations have produced. It will be seen in the succeeding chapters that the whole of our current views of the geological nature of the Continent are radically unsound and incorrect. It can indeed be shown that eren Suess' conception of the gräben (rift valley's) by no ineans always expresses the actual structure of these remarkable depressions, they are far better described under the title of 
"Eurycolpic folds," a term recently suggested to me, and which I have intentionally introduced into the present work in preference to either " gräben," or " rift valleys," both of which are obviously misnomers, since the valleys in question are generally produced by folding, due to lateral pressure, and not either through rifting, or vertical collapse.

Since our return, and in connection with both the first and second Tanganyika expeditions, the large number of new fishes obtained have been elaborately worked out by Mr. Boulenger of the British Museum. The descriptions contained in the present volume being his simply, while the more conspicuous genera and species have been accurately illustrated by Mr. Green. The Crustacea were examined by Messrs. Cunnington and Calman, the Sponges by Mr. Evans, Professor Minchin and Herr Weltner in Berlin. For the description of the Mollusca, the Polyzoa and Protozoa, I myself have been responsible, but I have received unlimited help from Professor Ray Lankester himself, Mr. Edgar Smith and others at the British Museum. The anatomy of the celebrated jelly-fish was examined some years ago by Mr. Günther in Oxford, and in what appears in the present volume, I have consequently been able to draw largely upon his original description, only adding some drawings of the living Medusa together with information about its life history and development, which I acquired on the spot. We have been further indebted to $\mathrm{Mr}$. Prior for the complete identification of the rock specimens collected by Mr. Fergusson; and, as I have explained in the text, we have been most materially helped by Mr. Huddleston in the comparison of the Tanganyika gastropods with the shell remains of the Jurassic seas. Last, but not least, I have to thank Professor G. B. Howes, who after my return from both my first and second Tanganyika expeditions, allowed me the unlimited use of the Huxley laboratory in the Royal College of Science and of his own experience and advice.

The title which I have chosen for the present work, "The Tanganyika Problem," expresses the fact that there is a puzzle, a mystery, attached to Tanganyika, and the elucidation of this mystery has formed the single motive for several independent lines of enquiry described in the present volume. The Tan- 
ganyika problem thus lends itself to the formation of a connected story, and I can point out to the general reader, who may be attracted to the puzzle as he would be to a cock-fight, that he need not be alarmed at technicalities to follow, these having been intentionally rendered conspicuous for omission in small type. Moreover to those who know Africa, I think it may be positively refreshing to find that the interior has actually got some attributes besides a continued absence of gold, and a total unsuitability for European colonization. Further, since the present volume contains the only general, illustrated account of the animals found in the great lakes, it is hoped that it may be really of use to numbers of people, who in spite of attributes, still go out to the African interior, but who up to the present time have had no means of ascertaining the nature of the sometimes extremely good fishes they are continually eating.

Of the manner in which the second Tanganyika expedition was organised, and of the method of treating the Tanganyika problem which I have adopted in the present volume, it is not necessary to speak. I have already dealt with these matters in the introductory chapters; but I may point out that I have intentionally introduced as many illustrations and photographs of the localities described as possible, since it seems to me that no one can form any clear idea of the physical characters of an extensive area from maps and descriptions alone. So again, in chapter six, I have re-introduced matter relating to the formation of Park lands upon alluvial flats, which I had already published in a former work; while lastly, owing to a misapprehension under which Sir Harry Johnston labours with respect to the relation of his own to other explorations in the Mountains of the Moon, I have had to refer to this range at greater length than I originally intended; but I do not wish it to be understood that I undervalue Sir Harry's work in this direction; on the contrary, I think it distinctly interesting and valuable, since, although he did not reach an high an altitucle as my:elf, in all major points he has completely confirmed the results which I had previously attained.

Uctober, I902,

London. 


\section{CON TE N T S.}

\section{CHAPTER I.}

\section{N T RODUCTORY.}

Reasons for acquiring a better knowledge of the fauna of the Great African Lakes-Our first knowledge of the existence of unique animals in Tanganyika arose as a by product of Burton's journey-The shells collected by Speke on Tanganyika were marine in aspect-But the shells obtained from the other African Lakes were not so-Extension of our knowledge of the Tanganyika shells-Possibility of the lake having been connected with the sea-Intensification of the interest in the Tanganyika problem produced by Boehm's discovery of jelly-fishesFormation of the first Tanganyika expedition-As a result of this it is shown that the Tanganyika problem is larger than was supposed-Conflict between the zoological evidence and geological anticipations-Erroneous character of Murchison's geological speculations-Actual impressions of the African interior-Remarkable character of the Halolimnic shells of Tanganyika-Their similarity to those of the Jurassic seas-This comparison a possible solution of the Tanganyika problem-Insufficiency of our knowledge of the Great African Lakes-Suess' views-Possibility of a former extension of the sea into Tanganyika from the north-Geological and geographical interest of the country north of Tanganyika-Formation of the second Tanganyika expeditionArrangement of matters contained in the present work

\section{CHAPTER II.}

ON THE NATURE AND ORIGIN OF FRESH-IVATER FAUNAS AND THEIK RELATION TO THE FAUNA OF THE SEA.

Animals live in fresh-water which do not inhabit the sea-Animals live also in brackish water-It is generally accepted that fresh-water organisms have arisen from marine forms and have colonized fresh-waters from the ocean -Recent additions to our knowledge of fresh-water faunas-Beaudants' experiments-Views of Semper Sollas and Von Martens-Apparent impossibility of many marine organisms ever getting into fresh-water-Inadequacy of existing views respecting the nature of fresh-water faunas-Similarity of fresh-water faunas all over the world-Distinction of primary and secondary fresh-water stocks-Origin of the second obvious, of the first not so clear-Ancestral 
characters of primary fresh-water stocks-l'alxeontological record of the appearance of the primary fresh-water stocks-This, synchronous with other geologrical phenomena-The universal distrilution of the primary fren-water stock inex. plicalsle on the assumption of migration-Want of evidence of any capacity for migration-The zoological facts seem to suggest a former difference in the sea itself-Increase of salt in fresh-water shown to le prejudical to certain animals-liffects of this as exhibited in Iake Shirwa-. Irtificial production of similar results-Experiments of Loeb, Herlst, and others, show that a change in the character of sea-water may produce variation-General cvidence fur a continually increasing salinity in the sea-The action of this in the production of modern fresh-water faunas-l'resent view of the nature of fresh-water faunas.

\section{CHAPTER III.}

THE PHYSIOGR.APHICAL FEATLRIS OF THE AFRICAN INTERIOR.

THE, GRE.AT CENTRIL, R.INGF.

Necessity of a knowledge of the topography of the Great Lake Region-Our views are changing with respect to the interior-Recent observations lend no support to the older conceptions which sprang from .llurchison's erroneous hypothesis respecting African stability-Demonstration of the existence of a Great Central Range a chief result of the Tanganyika expeditions-Characters of this range-Scott Elliot's early appreciation of its existence-The east and west drainage slopes-The existence of (leep valleys (Eurycolpic folds) parallel with the range-These, rock valleys, not formed by ice-Disturlance of old aqueous deposits, caused ly the formation of the Great Central Range-Character of the Great Central kange in the region of Nyassa-. Absence of true volcanocs along the ridges of the range-- Wide effects of the formation of the Great Central Range-The "gräben" of Suess : Eurycolpic folds-Characters of these folds in the region of Nyassa-Characters of the folds in the region of Tanganyika-Disturbance of the valleys and ridges in relation to the Great Central Range

\section{CHAP'TER IV.}

\section{SUPERFICIAL GEOLOKF OF THE REGION OF THE CRE.IT}

\section{AFRICAX LAKES.}

Evidence respecting the nature of the central African region lefore the formation of the Great Central Range-Continuation of the movements which have produced the Great Central kange-Recent discovery of vast aqueous deposits in the interinr-Value of these in ascertaining the past history of the continentMethod of treating the subject in relation to the observations made during the Tanganyika expeditions-Vastness of the regions to be considered-Character of the southern section of the region of the Great African Lakes-Nature of 
the Shiri Highlands-Nature of the south Nyassa region-Changes in the geological character of this region in the latitude of Mount Waller-Extent of the Mount Waller sandstones-Relation of these deposits to the other African sediments-Later deposits abore them-Drummond's beds-African lake pleistocenes-Arrangement of these different deposits-Extent of Drummond's beds-Vast extent of the old African sandstones-Demonstration of the existence of a great depression in the region of the lakes before the formation of the Great Central Range-The broad features of the past history of these regions

\section{CHAPTER V.}

\section{THE GEOLOGICAL TOPOGRAPHY OF THE REGION NORTH OF}

TANGANYIKA TO THE ALBERT NYANZA.

Want of knowledge of the districts north of Tanganyika-Importance of these districts in the consideration of the Tanganyika problem-Wide geographical effects produced by the recent formation of the Mfumbiro MountainsCharacter of the country north of Tanganyika to Kivu-Former short extension of Tanganyika north-Absence of any former connection of Tanganyika with Kivu-Characters of the Rusisi channel-Characters of the Kivu basinPeculiarity of the Kivu water-The north shore of Kivu and the Ifumbiro Nountains-The volcanoes form a dam across the lake valley-Character of these mountains-The valley of Kivu continued beyond them northwardsThe fauna of Lake Kivu is totally different from that of Tanganyika, but similar to that of the Albert Edward Nyanza-Former connection of Kivu and the Albert Edward-The volcanoes have resulted in the outflow of the Kivu being turned into Tanganyika and a corresponding shrinking of the waters of the Nile-The effect of this on the districts north of Kiru-The effect of this on the districts south of Kivu-Relation of the Mountains of the Moon to the Great Central Valley of the Lakes-Structural peculiarities of these mountains They are an accentuation of the folding characteristic of the region of the Great Central Range-Misapprehensions of Sir Harry Johnston . .

\section{CHAPTER VI.}

AFRICAN PARK LANDS, THEIR APPEARANCE ON ALLUVIAL FLATS CONSIDERED AS EVIDENCE OF RECENT PHYSICAL CHANGE.

Characters of African I'ark lands-Artificial appearance of these districts-Their vast extent-Impermanance of Park scenery-A park is an artificial productRelation of African parks to alluvial plains-Zoned character of the regetation on freshly-formed alluvial plains-The relation of Euphorbias to bush patches -Gradual conversion of bush patches into forest-The production of an African park marks a phase in a gradual physical chang 


\author{
CHAPTER VII. \\ GENERAL OUTLINE OF THE ZOOLOGY OF THE GREAT \\ AFRICAN LAKES.
}

The thirteen Great African Lakes, the fauna of which is more or less completely known-The lakes examined during the two Tanganyika experlitions-Other sources of information-The fauna of Lake Nyassa - Some plyysical characters of the Nyassa valley-Limitations of the Nyassa fauna-It is that of a great pond-The fauna of Lake Shirwa-Kela-Rukwa-Bangweolo-The fauna of Lake Niwero-The fauna of Lake Kivu-The fauna of the Allert and the Albert Edward Nyanzas-The fauna of the Victoria Nyanza--Nature of the Nyanza depression-The fauna of Lake Rudolf-The fauna of Lake Tanganika-Peculiarities of the fish fauna of Lake Tanganyika-The fauna of the great rivers of Central Africa-The distinctive elements of the fauna of Lake Tanganyika-Definition of the Halolimnic group . . . . .

\title{
CHAPTER VIII.
}

\section{ON SOME CURIOUS FEATURES OF THE DISTRIBUTION OF SPECIES.}

General poorness of the African lake faunas-The faunas of the different lakes are specifically distinct-The faunas of these different lakes do not appear to intercolonize-The number of species in the Great African Lakes is directly proportional to their size-Unique climatic conditions affecting the Great African Lakes-Similarity of lacustrine faunas to island floras-On the causes which tend to the production of species characteristic of the different depressions .

\section{CHAPTER IX.}

THE FISHES OF LAKE TANGANYIK.I.

Descriptions of the eighty-seven species hitherto obtained

\section{CHAPTER X.}

THE MOLLUSCS OF LAKE TANGANYIR̈A.

The normal and Halolimnic gastropods-Details of the structure of the IIalolimnic forms

\section{CHAPTER XI. \\ THE AFFINITIES OF THE IIALOLIMNIC GASTROPODS.}

Inter-relationships of the Halolimnic forms-Their primitive characters-They are not comparable to any existing fresh-water forms, but they structurally antecede a number of existing marine genera-The Halolimnic gastropods present the appearance of an old inarine relic . . . . . . . . 


\title{
CHAPTER XII.
}

THE CRUSTACEA OF LAKE TANGANYIKA.

CHAPTER XIII.

THE NEW TANGANYIKA POLYZOAN.

Arachnoidia ray lankesteri

\section{CHAPTER XIV.}

THE TANGANYIKA MEDUSA.

General structure of this organism-Its apparent life history _ . . . . 298

\section{CHAPTER XV.}

THE SPONGES AND PROTOZOA OF LAKE TANGANYIKA.

Spongilla moorei-Affinities of Spongilla moorei-Spongilla tanganyika-Affinities of Spongilla tanganyika-Potamolepis welteneri-Livingstone's scum 309

\section{CHAP'TER XVI.}

\author{
GENERAL CONSIDERATION OF THE NATURE OF THE HALOLIMNIC
} FAUNA.

Recapitulation of certain matters discussed in earlier pages - The geographical isolation of the Halolimnic group-Its coexistence with the normal African fresh-water fauna-The distinctive character of the Tanganyika fishes-The general characters of the components of the normal Tanganyika fauna-Thesc are not structurally intermediate between those of the general African fresh-water fauna and the Halolimnic group-The Halolimnic gastropods cannot be regarded as derivitives from any recognised fresh-water typcs-Similar reasoning applies to the Tanganyika jelly-fishImpossibility of regarding the marine characters of the Halolimnic group as having been brought about through convergence-Impossibility of regarding the Halolimnic group as the relic of an old frcsh-water stock-The presencc of the Ialolimnic animals nccessitates the supposition of a former extension of the sea into Central Africa, and thereby throws light into the geological history of the continent 


\section{CHAP'TER XVII}

GENERAL CONSIDERATION OF THE NATURE OF THE HALOLIMNIC FAUNA.

On some peculiarities of the fish-fauna in lake Tanganyika-kelation of some of the characteristic forms to both sides of the Atlantic-The character of the fishes of Tanganyika indicate that part of the fish fauna may have originated from a western sea-Peculiarities of the Congo fauna-The Congo depression probably the remains of a former extension of the sea-The age and type of the Halolimnic fauna-Comparison of the hard parts of the Halolimnic animals with fossiliferous remains-The identity between the shells of the Halolimnic gastropods and a corresponding number of forms from the Jurassic seasDetails of this comparison-General consideration of the value of this comparison-No valid geological objection to it-The number of corresponding points renders it improbalsle that the correspondence is a coincidence-The IIalolimnic fauna would thus appear to be the remains of that of a Jurassic sea-The characters of the other Halolimnic animals in accord with this view-Recapitulation

I'AGE: e 


\section{LIST OF ILLUSTRATIONS.}

Head man of the Second Tanganyika Expeditions.-From a Sketch

by the Author. . . . . . . . Frontispiece

\section{CHAPTER II.}

Lake Shirwa, looking west from the middle of the lake.-From $a$ Sketch by the Author . . . . . . . .

View of the Zambesi and Shupanga, looking south-west.-From a

Sketch by the Author . . . . . . Facing 30

\section{CHAPTER III.}

View of Mount Morumbala, from the Shiri river.-From a Sketch by the Author . . . . . . . . Facing

View over the town of Ujiji and across Lake Tanganyika.-From a

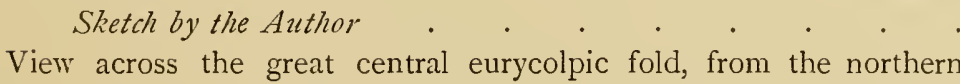
slopes of the Mfumbiro Mountains . . . . . . 4 I

Diagrams of the geology of the Nyassa Valley . . . Facing 42

Diagrams of the Nyassa and Tanganyika Valleys . . Facing 44

The east coast of Nyassa . . . . . . . . 45

View of a portion of the Livingstone Range, from Nyassa • . 47

\section{CHAPTER IV.}

View over the alluvial flats at the north of Lake Nyassa.-From a

Sketch by the Author . . . . . Fiacing 56

View of one of the alluvial flats in the region of South Nyassa . $\quad 59$

View over the forests on the Nyassa Tanganyika plateau. From a

Sketch by the Author . . . . . . . . $6_{3}$ 
PAGE

View from the top of the sandstone cliffs flanking the south-west coast of Tanganyika.-From a Sketch by the Author. .

View from the southern end of Lake Tanganyika.-Lrom a Sketch by' the Author . . . . . . . . liacing

\section{CHAPTER V.}

View of the south end of Lake Tanganyika, from Kituta.-From a Sketch by the Author . . . . . . . .

The great active cone of Kirungo cha Gongo.-From a Sketch by the Author . . . . . . . . . Fiacing 82

Diagram of Tanganyika and Kivu . . . . . . liacing $8_{3}$

View from the north end of Lake Kivu of the great active cone of Kirungo cha Gongo .

Bird's-eye view of the Mfumbiro Mountains and the north end of Lake Kivu . . . . . . . . Facing

View from the summit of Kirungo cha Gongo . . . . . . 9 I

View of the steep west coast of the Albert Edward Nyanza . 93

View up the higher portion of the Mobuko Valley.-From a Sketch

by the Author . . . . . . . . . . 95

The snow summit of Ngomwimbi . . . . . . . . 99

The northern snow ridge of Ngomwimbi . . . . . 103

The broad glacier on the northern snow ridge of Ngomwimbi . . 105

Diagram of the region north of the Albert Edward Nyanza liacing rob

\section{CHAPTER VI.}

View of the snow peak of Kanyangogwi . . . . Facing 108 Semi-diagram of the formation of Park-lands . . . . . III

\section{CHAP'TER IX.}

Protopterus æethiopicus and Polypterus congicus . . . . 154

Citharinus gibbosus . . . . . . . . 156

Barbus platyrhinus . $\quad . \quad$. . . . . . 157

Barbus altianalis . . . . . . . . . . $\quad$ I 59

Barbus tropidolepis. . . . . . . . . . I I I

Capoeta tanganicæ. . . . . . . . . . 163

Barilius tanganicæ . . . . . . . . I 65

Synoủontis granulosus . . . . . . . . . I6: 
Chrysichthys brachynema . . . . . . . . I69

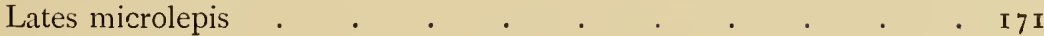

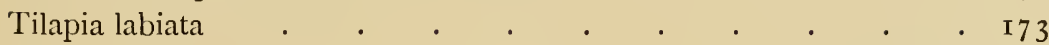

Synodontis multipunctata . . . . . . Facing $\mathbf{1} 74$

Paratilapia calliura, Ectodus longianalis and Tilapia boops _ . $\quad$ I 75

Paratilapia furcifer . . . . . . . . . . . 177

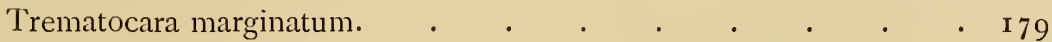

Lamprolagus modestus and Haplochilus tanganicanus . . . I8 I

Bathybates fasciatus . . . . . . . . . ${ }^{1} 8_{3}$

Bathybates ferox . . . . . . . . Facing 184

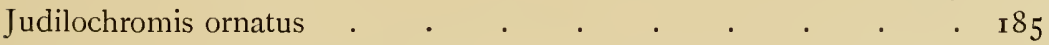

Eretmodus cyanostictus, Telmatochromis vittatus and Lamprologus

fasciatus . $\quad . \quad . \quad . \quad . \quad . \quad . \quad . \quad . \quad . \quad$ I 87

Grammatotria lemairii . . . . . . . . . . . . $\quad$ I 89

Paratilapia vittata and Xenotilapia sima . . . . . . . . I9I

Gephyrochromis moorei, Ectodus melanogenys and Tilapia grandoculis $\quad$ I93

Tilapia trematocephala, Paratilapia aurita and Paratilapia nigripinnis 195

Petrochromis polyodon . . . . . . . . . . $\quad$. 197

Lamprologus lemairii, Asprotilapia leptura and Lamprologus furcifer 199

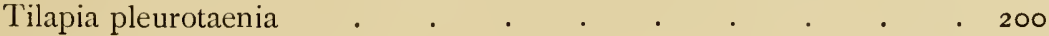

Tilapia dardennii . . . . . . . . . Facing 200

Trematocara unimaculatum and Paratilapia leptosoma . . . 20 I

Lamprologus moorei . . . . . . . . . 203

Telmatochromis temporalis . . . . . . . . 204

Tilapia microlipis and Tilapia rubropunctata . . . Facing 204

Lamprologus compressiceps, Paratilapia pfefferi and Ectodus longianilis $\quad 205$

Paratilapia dwindti, Xenotilapia ornatipinnis and Barbus serrefer . 206

Tilapia microlepis and Barilius moorei . . . . . . 208

Barilius moorei and Tropheus moorei . . . . . . 209

Paratilapia stenosoma . . . . . . . . . 2 I 1

Lamprologus elongatus, Mastacembelus taeniatus and Perissodus microlepis . . . . . . . . . . . . 2 I 3

Mastacembelus frenatus and Mastacembelus moorei . . , . 215

CHAPTER X.

Melania admirabilis, Fig. I . . . . . . . . 219

Living Typhobia horei, Fig. 2 . . . . . . . . 221

Semi-diagram of anatomy of Typhobia horei, Fig. 3 . . . . 222 
Lingual dentition of Typhobia horei, Fig. 4 . . . . 223

Semi-diagram of anatomy of Typhobia horei, l.ig. 5 . . . . 224

Section of otocyst of Typhobia horei, Fig. 6 . . . . . 225

Part of the mantle cavity of Typholia horei, Fig. 7 . . . $\quad 226$

Bathanalia howesi shell, Fig. S . . . . . . 227

Operculum of Bathanalia, Fig. 9 . . . . . . 227

Lingual teeth of Bathanalia, lig. 10 . . . . . . 228

Shell of Chytra kerkii, Fig. I I . . . . . . . 229

Living animal of Chytra, Fig. I 2 . . . . . . . 229

Nerves of afporrhais pes pelicani, Fig. I3. . . . . . 230

Lingual teeth of Chytra, Fig. I4 . . . . . . 231

Nerves of chytra, Fig. 15 . . . . . . 232

Operculum of Chytra, Fig. I6. . . . . . . . . 233

Shell of Limnotrochus, Fig. I7 . . . . . . . 233

Operculum of Limnotrochus, Fig. I $8 a$. . . . . . . 233

Lingual dentition of Limnotrochus, Fig. is . . . . . 234

Nerves of Limnotrochus, Fig. I9 . . . . . $\quad \therefore 235$

Stomach of Limnotrochus, Fig. 20 . . . . . . 237

Shell of Bythoceras, Fig. $2 \mathrm{I} . \quad . \quad . \quad . \quad . \quad 23 S$

Lingual dentition of Bjythoceras, Fig. 22 . . . . . 239

Nerves of Bjthoceras, Fig. 23 . . . . . . . 240

bjthoceras minor shell, Fig. 24 . . . . . . 242

Lingual dentition of Paramelania damoni, Fig. 25 . . . . . 243

Lingual dentition of Paramelania cranigranuluta, Fig. $26 \quad$. $\quad 244$

Shell of Paramelania damoni, Fig. 27 . . . . . . 242

Shell of Tanganyicia rufofilosa, Fig. $23.0 .0 . \quad . \quad .246$

Semi-diagram of Tanganjicia rufofilosa, Fig. 29 . . . . . 247

Lingual dentition of Tanganyicia rufofilosa, Fig. 30. . . . 248

Nerves of Tanganjicia rufofilosa, Fig. $31 \quad$. . . . . 248

Semi-diagram of Tanganyicia rufofilosa, Fig. 32 . . . . 249

Shell of Nassopsis nana, Fig. 33 . . . . . . . 250

Semi-diagram of Nassopsis nana, Fig. 34. . . . . . . 25 I

Animal of Nassopsis, Fig. 35 . . . . . . . . 252

Lingual dentition of Nassopsis nana, Fig. 36 . . . . . . 253

Nervous system of Nassopsis, Fig. 37 . . . . . . 254

Operculum of Nassopsis, Fig. 38 . . . . . . . 255

Shell of Spekia zonata, Fig. 39 . . . . . . . 256

Lingual dentition of Spekia zonata, Fig. 40 . . . . . 257 
Nervous system of Spekia zonata, Fig. 41 . . . . . . 258

Semi-diagram of Spekia, Fig. 42 . . . . . . . 259

Semi-diagram of Spekia, Fig. 43 . . . . . . 260

Shells of Veothauma, Fig. 44 . . . . . . . $26 \mathrm{I}$

Nerrous system of Neothauma, Fig. 45 . . . . . . 263

Nervous system of lïipara, Fig. 46 . . . . . . 264

CHAP'TER XI.

Diagram of molluscs

Diagram of molluscs

.+273

\section{CHAPTER XII}

Limnothelphusa maculata, Fig. I . . . . . . . $28_{\text {I }}$

Platythelphusa armata, Fig. 2 . . . . . . . . $2 S_{5}$

Limnocaridina tanganyikice, Fig. $3 . . . \quad . \quad . \quad . \quad 2 \mathrm{~S}_{7}$

Palaemon moorei, Fig. 4. . . . . . . . . 293

CHAPTER IIII.

Arachnoidiæ ray lankesteri . . . . . . . . 296

CHAPTER XIV.

Living Tanganyika medusa . . . . . . . . 299

" " $"$, another . . . . 30

Semi-diagram of medusa buds . . . . . . . . 303

Young bud . . . . . . . . . . 305

" , rather older . . . . . . . . . . 306

" , still older . . . . . . . . . . . . 307

CHAPTER XY.

Spongella moorei . . . . . . . . . . . 3 II

Skeleton of Spongella moorei. . . . . . . . . . $3^{1} 3$

Spongella tanganyike . . . . . . . . . . . . 319

Potamolepis veltneri . . . . . . . . . 323

CHAPTER XVII.

Pyrgulifera humerosa . . . . . . . . . 343

Paramelania and purpurina . . . . . . . . . 345

Nassopsis and purpurina. . . . . . . . . 347 

Amberleya and fiathanalia, $34^{8}$. . . . . . . 348 Limnotrochus and Jurassic shells . . . . . . . 349 Cliytra and Onustus . . . . . . . . . 350 Spekial and Niridomus . . . . . . . . . . . 35 I Melania admirabilis . . . . . . . . . . . . . 353

\section{A P S.}

Map of new positions on Lake Tanganyika

Facing $\mathrm{S}$

Map of the route of the Tanganyika Expeditions . . " 10

Geological Map of the Nyassa region . . . . . " , 48

Geological Map of the Tanganyika region . . . " $\quad 52$

Map of the distribution of aqueous deposits in part of the African interior . . . . . . . . . fiacing

Geological Map of the districts north of Tanganyika to the Albert Nyanza . . . . . . . . Jiacing So

Map of the districts explored north of 'Tanganyika during the Second Tanganyika Expedition by M. Fergusson . . . End of Index 


\section{BIBLIOGRAPHY OF THE TANGANYIKA EXPEDITIONS.}

Boulenger, G. A.

Report on the collection of fishes made by Mr. J. E. S. Moore in Lake Tanganyika during his expedition of 1895 and ' 96 . With an appendix by J. E. S. Moore. "Trans. Zoo. Soc.", Vol. XV., I 898 .

Boulenger, G. A.

Report on the collection of fishes made by Mr. J. E. S. Moore in Lakes Tanganyika and Kivu durnng his second expedition, I 899-1 900. " "Trans. Zoo. Soc.", Vol. XVI., I9o I.

BEDDARD, F.

On two new species of earthworms from Tanganyika. "Proc. Zoo. Soc.", г9or, ii., p. г 90.

BEDDARD, F.

On two new earthworms of the family Megascolicidæ. "Anns. and Mag. Nat. Hist.", Ser. 7, Vol. IX., June, I902.

Calman, C.

Report upon the prawns collected during the first Tanganyika expedition. " "Pro. Zoo. Soc.", I 899.

Cunnington, J.

On the fresh-water crab Limnothelphusa from Lake Tanganyika.

"Pro. Zoo. Soc.", I 899 . 
Digey, Miss L.

On the anatomy of Chytra and Limnotrochus. "Journ. I.inn. Soc. Kool.", Vol. 28.

EVENS, R.

On two new sponges from Lake Tanganyika. "Quart. Journ. Micro. Sci.", 1 S99.

MOORE, J. E. S.

On the zootogical evidence for the connection of Lake Tanganyika with the sea. "Proc. R. Soc.", LXII., I 899.

MoOre. J. E. S.

The molluscs of the great African lakes, I., distribution. "Quart. Journ. Micro. Sci.", I $\$ 9 \$$.

MoOre, J. E. S.

The molluscs of the great African lakes, II., the anatomy of Typhobia. "Quart. Journ. Micro. Sci.", 1898.

MOORE, J. E. S.

The molluscs of the great African lakes, III., Tangranjicia and the genus Spekia. "Quart. Journ. Micro. Sci." Vol. 42.

MOORE, J. E. S.

The molluscs of the great African lakes, IV., Nassopsis and Bythoceras. "Quart. Journ. Micro. Sci.", Vol. 42.

MoORk, J. E. S.

Tanganyika and the countries north of it. "Geogr. Journ.", I $90 \mathrm{~T}$.

MoOre, J. E. S.

On the hypothesis that lake Tanganyika represents an old Jurassic sea. "Quart. Journ. Micro. Sci.", Vol. 4I. 
MOORe, J. E. S.

On the zoological results of the Tanganyika expedition. "Proc. Zool. Soc.", I 897.

MOORE, J. E. S.

Further researches concerning the molluscs of the great African lakes. " Proc. Zool. Soc.", Vol. II., No. xxxi., I 90 I.

MOORE, J. E. S.

The fresh-water fauna of Lake Tanganyika. "Nature:" I897.

MOORE, J. E. S.

First ascent of one of the snow ridges of the Mountains of the Moon. "Alpine Journal," I $\delta_{92}$.

MOORE, J. E. S.

To the Mountains of the Moon (Hurst \& Blackett, London), I 89 I. 



\section{The Tanganyika Problem.}

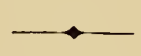

\section{CHAPTER I.}

I N T RODUCTORI.

THE desirability of obtaining a fuller knowledge of the nature of the aquatic faunæ of the great African Lakes arose when it was first ascertained that in Tanganyika there are animals which have not the appearance of those we have grown accustomed to regard as of almost invariable and universal occurrence in the fresh-waters of the globe. Our knowledge of this singular circumstance originated, curiously enough, as a by-product of Burton's celebrated journey to the lake. For although it will be generally remembered that Tanganyika was discovered by Sir Richard Burton, it may not be so generally remembered that his companion Speke picked up some shells on its shore, and that these eventually found their way into the British Museum. When examined, Speke's shells proved to be quite unlike any fresh-water forms with which naturalists were acquainted, and it was at once recognised that in their general appearance they were curiously marine.

As time went on, other great lakes in the African interior were visited by many Europeans, but no shells were ever 
brought back from these lakes at all resembling the peculiar Tanganyika forms. On the other hand, the missionaries acquired further samples of shells from Tanganyika itself, and among these collections there were forms at once so strikingly different from those of any other known freshwater lake, and so curiously marine in aspect, that when describing them Mr. Smith* drew attention to the possibility that they might eventually turn out to be relics of some former sea. But whatever interest and curiosity may thus have been raised respecting the nature of these Tanganyika molluscs was suddenly and completely eclipsed by the announcement of the further discovery of jelly-fishes in the lake by the German traveller, Dr. Böhm. Their existence in Tanganyika was subsequently confirmed by Von IVissmann, and it can, in fact, be said that it was only after these announcements that what I have termed the Tanganyika problem, as such, fairly took wing. The intensification of the general interest in the fauna of the African lakes which this discovery of jelly-fishes naturally produced, is not however far to seek, for if we except the star-fishes and seaurchins there is hardly any invertebrate type more typically marine, more characteristic of the ocean, than a jelly-fish. Like herrings, the presence of jelly-fishes in fresh-water is indicative of the past or present connection of such water with the sea. Böhm's discovery thus in fact seemed to show, that either in present or past times, organisms like jelly-fishes could get from the sea into the lake. Eventually, through the co-operation of Mr. Frederick Moir and Mr. Swann, some of these medusx were sent to England. and on examination were found to be quite unlike any

* E. A. Smith.- "On a collection of Shells from Iakes Tanganyika and Nyassa." Proceedings of the \%oological Society of I.ondon, ISSI, page 276 . 
known forms and probably of an ancient type. Nothing more, however, could be said until some naturalist had visited the spot, and this impossibility of getting any further with the Tanganyika problem became the reason of the first Tanganyika expedition. The exploration was organised by Professor Ray Lankester, who, with the help of others interested in this matter, obtained from the Royal Society the necessary grants in aid of the exploration, and I finally set out in the autumn of 1896 .

As a result of the journey we found that the original problem presented by the jelly-fish had in no wise been solved. It had, in fact, grown enormously bigger and more difficult, for it was found that in Nyassa and Shirwa there were no jelly-fishes nor anything except purely fresh-water forms; while in Tanganyika there were not only jelly-fishes but a whole series of molluscs, crabs, prawns, sponges and smaller things, none of which appeared in any of the other lakes I then knew, and all of which were distinctly marine in type. Further than this, however, I* found that none of these strange marine-looking animals were to be compared directly with any living marine forms, yet, in their structure, some of them certainly seemed to antecede a number of marine types in the evolutionary series, and in consequence they appeared to hail from the marine fauna of a departed age. The most definite result of the first Tanganyika expedition, therefore, appeared to be that the sea had at some former time been connected with the lake, but when or how remained a mystery. In discussing the inferences which could thus be directly drawn from our observations respecting the marine nature of the Tanganyika fauna before the Royal Society in 1898 , I found, however, that I had unwit-

* "On the zoological evidence for the connection of Lake Tanganyika with the sea." Proceedings of the Royal Socicty, vol. 62. 
tingly run amuck amongst some cherished geological ideas. It appeared, that in ${ }_{1} \$_{52}$ Sir Roderick Murchison, collecting such material and geological facts as were then available, had arrived at the conclusion that the interior of Africa had never been beneath the sea, and supposed, as he then said, this view to be "confirmed by the absence south of the equator of all those volcanic activities which we are accustomed to associate with oscillations of terra firma."* In the light of our newer zoological evidence, the first part of this statement would appear consequently to be wrong, on account of the anatomical characters of the Tanganyika fauna, which relegate a portion of this fauna to a marine stock, and show that this part of Africa has been at some time connected with the sea, in orcler that such marine animals could get into it. While the second part of the statement, that is, the assumed evidence respecting the permanence of the African land-mass drawn from the then apparent absence of volcanic activities south of the equator, is now, also, entirely disproved, intense volcanic activity having been found to have occurred, and to be occurring, throughout all these regions. $\uparrow$

In a number of subsequent papers dealing with different portions of the same problem, I therefore reiterated all that I had previously said with respect to Tanganyika having been connected with the sea. For the existence of the medusx

* Joumal of the Royal Geographical Society, vol. xxiv. 1864, pp. clxxv.-clxxviii.

† This is shown (I) by the discovery of the active volcanoes north of Kivu, (2) by the discovery of the recent cones and active geysers all round the north and east of the Albert Edward Nyanza, (3) by the discovery of the lava fields on the west of Tanganyika, (4) by the discovery of the existence of groups of extinct volcanic cones north of Nyassa, (5) by the presence of lava flows as far south as Shirwa, and finally (6) by the demonstration of the existence and continuance of those very oscillations of terra firma, which in equatorial Africa were said not to exist, on a scale only rivalled elsewhere in the region of the southern Andes. 
and the marine gastropods in that lake, cannot be waived in favour of the older geological speculations, which have only negative appearances to support them, and as a matter of fact the newer geological observations are not opposed, as Sir Roderick Murchison insisted, to those oscillations of terra forma which are required in order that such a state of things should have been brought about.*

Moreover, the impression to which I have alluded above that the marine animals in Tanganyika must be very old, eventually bore further fruit. I remembered having been struck while still on the shores of the lake with the fact that some of the shells there were curiously similar to other shells, either living or extinct, which I had seen elsewhere, and after searching amongst the conchological representatives of the different geological eras, I found that this peculiar character, this distinctive facies, as the geologists express it, presented by the Tanganyika shells, was again presented by the fossil remains in the beds of the old Jurassic seas, that is in the marine deposits of a little later date than the English coal. The correspondence between the shells now living in Tanganyika and these, their long extinct marine Jurassic counterparts, is most extraordinarily complete; and perhaps the most remarkable feature about the comparison is that the shell of every one of the numerous marine molluscs of Tanganyika compares in what is practically a specific sense with its individual prototype in the remains of the old Jurassic seas. $\uparrow$

This being so, it will be seen that the existence of such a correspondence between what I have termed the halolimnic

\footnotetext{
* See "Tanganyika and the Countries North of It," J. E. S. Moore, Journal of the Royal Geographical Society, January, Igor.

† J. E. S. Moore, "On the Hypothesis that Lake Tanganyika represents an old Jurassic Sea." -Quarterly Journal of Nicroscopical Scionce, vol. xli.
} 
gastropods and those of the Jurassic seas presents us at once with a possible solution of the whole Tanganyika mystery. The strange animals, the jelly-fishes, the molluses, the sponges, etc., which appear in Tanganyika, and apparently nowhere else in Africa now, may be regarded as the relic of a time when the lake basin was in connection with an ancient sea, and consequently filled with the representatives of its ancient fauna. Morcover, the date of the lake's connection with the sea, which this view of the nature and origin of the halolimnic fauna necessitates, is so remote, that it can easily be made to fit in with our revised notions of the past history of the continent; and I may point out that there is nothing unnatural or strange in the isolated persistence of even specific forms which have elsewhere become extinct or greatly changed, for such ancient forms have persisted repeatedly all over the world, like the ganoids Polypterus and Amia, the scorpions and the brachiopods.

But although in this manner, and as a result of the first Tanganyika expedition, we reached a tenable hypothesis respecting the nature and origin of the jelly-fishes and other marine organisms in Lake Tanganyika, it was very obvious that much remained to be done. We did not know; for example, whether there were marine organisms in any of the other great lakes, Kivu, the Albert Edward, the Albert Nyanza, the Victoria Nyanza or Lake Rudolf; neither did we know anything of the geology of Lake Tanganyika nor of the districts north of it, as far as the Albert Nyanza. But about the same time, Suess had put forward some most interesting views concerning the nature of these very regions. He had shown that Tanganyika lies near the south end of the more westerly, and greater, of two vast series of valleys which run from the south, through Central Africa, like a couple of converging horse troughs, until they 
unite together in the region of the Upper Nile. Thence they pass to the Red Sea near Berbera, and continue as the valley of this sea itself as far as the Gulf of Acabah, and even through the Dead Sea to the valleys of the Jordan. In the western arm of these great valleys and north of Tanganyika there lie the lakes Kivu, the Albert Edward and the Albert Nyanzas. After returning from the first Tanganyika expedition, none of these more northerly lakes were zoologically known, nor had the remaining great African lakes, the Victoria Nyanza and the chain of lakes in association with Rudolf, been sufficiently minutely examined to show whether the halolimnic fauna existed in them or not. When, therefore, we took into account the fact that both the great series of valleys united and extended as far as the Red Sea, it appeared on the face of it, at least possible that the halolimnic fauna, or something equivalent to it, would be found in the lakes north of Tanganyika, whenever these lakes came to be zoologically explored, and that the western series of valleys might itself turn out to be the channel along which the sea had reached the lake. Moreover, the districts north of Tanganyika through Lake $\mathrm{Kivu}$, as far as the Albert Nyanza, and including the Mountains of the Moon, were an almost complete terra incognita from a geographical point of view. A large stretch of this country was uncharted, and thus a further journey offered exceptional opportunities for geographical work in the hands of a competent surveyor. It was this aspect of future exploration in these regions which gave them a distinctly geographical interest, and enabled the proposal of a second Tanganyika expedition to be supported by the promise of a very liberal grant from the Royal Geographical Society. Such an expedition was thus to be recommended on zoological, on geological, and on geographical grounds, and these three 
wants with respect to our knowledge of the African interior, eventually became the definitive motive for the formation of the second Tanganyika expedition.

In the organisation of this new venture, Professor Ray Lankester took the initiative once more, and the expedition was finally despatched under the auspices of a committee of scientific men in England, which was formed by Professor Ray Lankester, and consisted of himself, Sir John Kirk, Sir William Thiselton-Dyer, Dr. Sclater, and Mr. Boulenger, and I had the honour to be invited to take command of the exploration in the spring of I 899 .

We have in this way briefly sketched the manner in which our knowledge that there was a Tanganyika problem first arose, and we have also indicated the aspect which this problem presented after the first Tanganyika expedition had returned; but, beyond this point, it would be inconvenient to treat the matter from a similar historical point of view. It will suffice to say, that on the second Tanganyika expedition an immense amount of notes and material were acquired, filling up the obvious lacunx which had presented themselves in any attempt to study the problem up to I 899. In what follows, I have dealt with the problem afresh, and with all the evidence that is now available. In the first place, I have found it necessary to consider the nature of fresh-water faunas in general, and to discuss the probabilities with respect to the origin of certain constant peculiarities which these faunas are found to present. In the next I have dealt at some length with the physical geography and geology of Central Africa, especially in relation to the fact that all the observations which have been accumulated point persistently to the conclusion that the structure and history of this portion of the continent are not what have hitherto been supposed. All the physical 


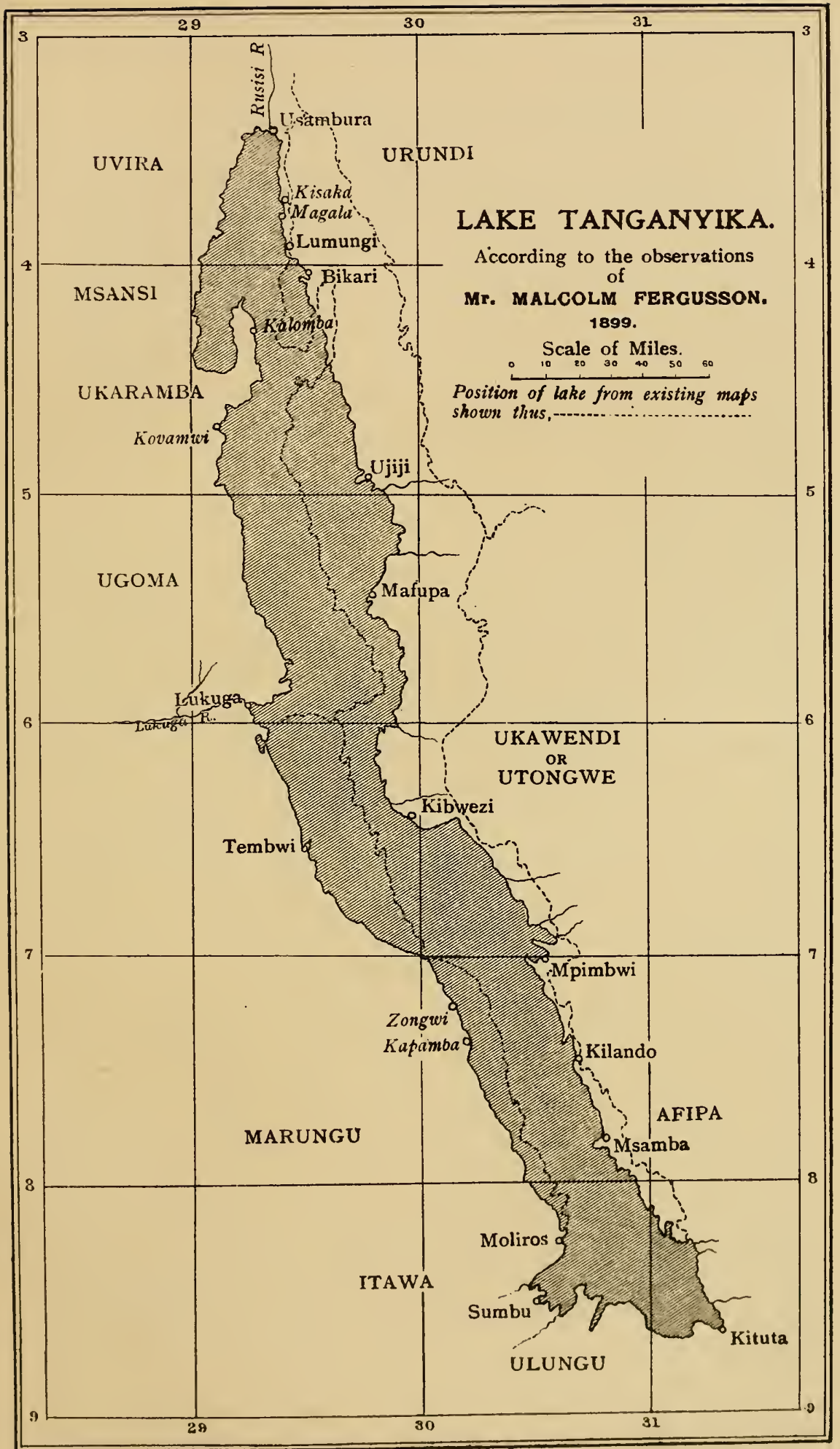

Herrist \& Blackent Led 

features of Equatorial Africa being, as a matter of fact, clearly discernible as subordinate expressions of a still continuing effort on the part of the earth to produce a great mountain chain. So far, indeed, from these regions being remarkable for their stability, it is a fact that the interior of Africa is at the present time only rivalled in instability by certain districts of South America, and in the past by those records of terrestrial disturbances which we have in relation to the Alps and other mountain chains. These matters having been discussed, a review has been made of the nature of the fresh-water fauna which is found in all the great African lakes about which anything is, as yet, definitely known; and in this way it has been shown that throughout Equatorial Africa, as in other great continents, there is a normal fresh-water fauna which has nothing peculiar about it, and is certainly not more distinctive of Africa than is that of North America distinctive of the New World. Subsequently the fauna of Lake Tanganyika has been examined in detail, and it has been shown that this lake, like all the other great lakes of Central Africa, contains the ordinary fresh-water fauna of the continent, but that in Tanganyika, and in Tanganyika alone, there are a number of organisms possessing definitely marine and somewhat archaic characters. Along with these the "halolimnic" members of the Tanganyika fauna, as I have called them, there are others, such as the prawns, sponges and protozoa, which, although, not like the previous types, unique in being found in Tanganyika for the first time as fresh-water forms, are, notwithstanding, probably portions of the same group, for they are peculiar to Tanganyika, and are not characteristic of the general fresh-water fauna of the African continent. Subsequently, in dealing specially with the fishes of Tan- 
ganyika, and in the concluding summaries, attention has been expressly drawn to the fact, that it appears probable that the African ganoids, and certain other portions of the Tanganyika fish-fauna are in reality the now more or less scattered piscine portion of the halolimnic fauna. And in this connection I have emphasised the very remarkable fact that, notwithstanding the opportunities which always exist for fishes to migrate throughout the fresh waters of a continent, actually about half the species of Cichilida belonging to the Old World are restricted to the confines of Lake Tanganyika even down to the present day. In the succeeding chapters the Tanganyika problem has been considered in the light of all the evidence which is now available. It has been shown in the first place that the halolimnic fauna cannot now be regarded in any other light than as something wholly distinct in origin from the general fresh-water fauna of Africa, and that it is also equally impossible to regard it as anything but the relic of some ancient sea. In conclusion, the possible mode of origin of this marine fauna has been considered together with the value and the significance of the remarkable correspondence which subsists between the shells of the halolimnic gastropods and the remains of those found in the deposits of the old Jurassic seas. 


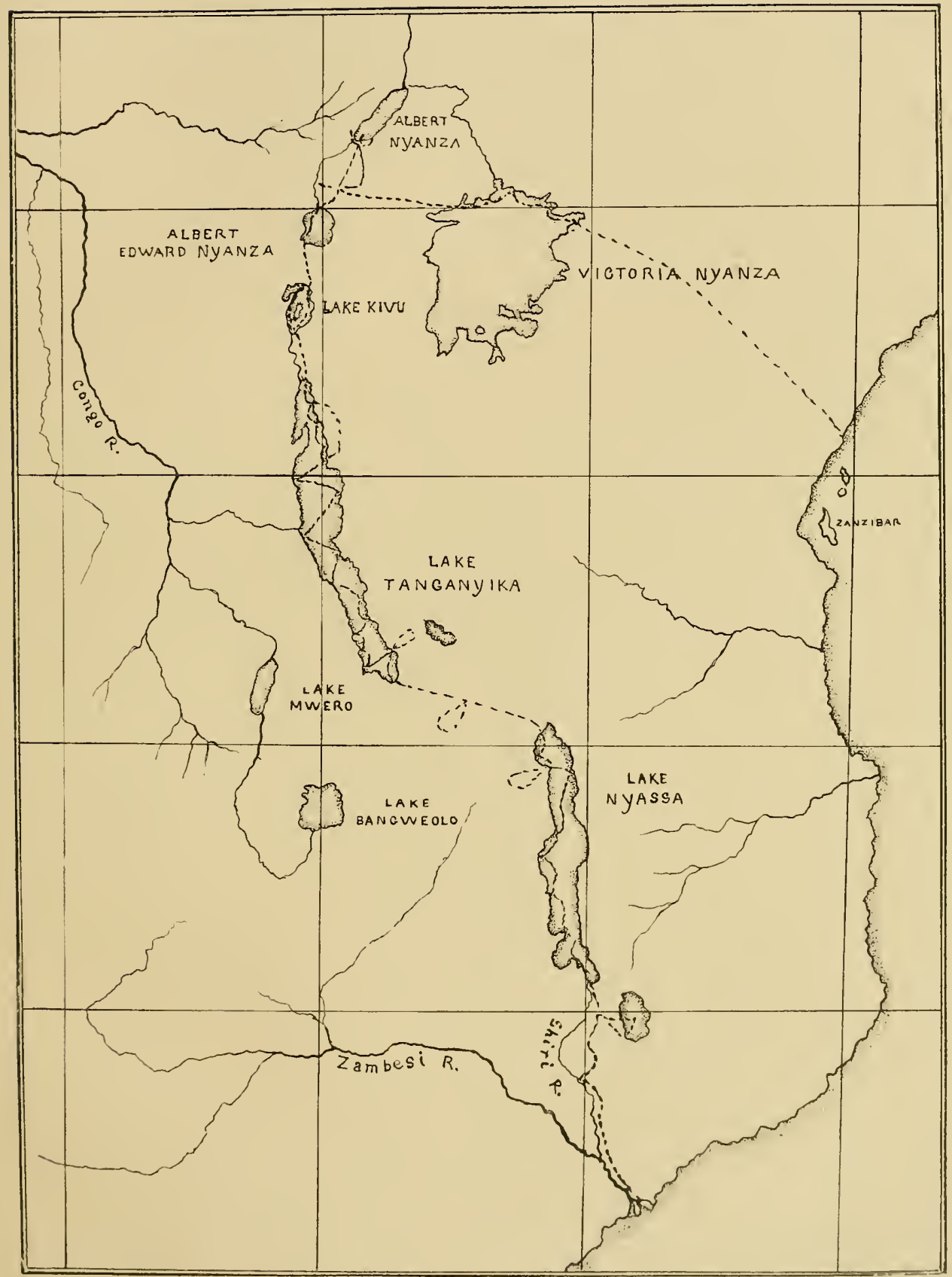

Map showing route of the Tanganyika Expedition route, thus : . . . .

L'o jixic pagr 10 


\section{CHAPTER II.}

ON THE NATURE AND ORIGIN OF FRESH-WATER FAUNAS AND THEIR RELATION TO THE FAUNA OF THE SEA.

IT is a fact that there are forms of animals inhabiting fresh-water which do not inhabit the sea, and which die if placed in the salt-water environment of the ocean; while, conversely, there are animals which habitually live in the sea, and die if they are subjected to the action of water which is fresh. This is a matter of common knowledge, and when we speak of fresh-water and marine faunas we mean to describe in general the animals which can live only in one or other of these media. But it is also a fact that there are animals which can live as well in the sea as in fresh water, such as salmon ; while, again, there are others which can live in the brackish mixtures of salt and fresh water occurring at the mouths of rivers. From a variety of reasons, some palæontological, some based on the results of comparative anatomy, and which, although they may be rather indefinite, are probably weighty, it is generally conceived by naturalists that all the animals now inhabiting the fresh-waters of the earth originally arose in the sea. Further, it has often been held that these same fresh-water types have arisen during the past through the successful efforts of different marine organisms to colonise fresh-waters from the ocean. And, following the same kind of reasoning, it has often been sug- 
gested that forms like some of the Trochoid molluscs, some jelly-fish, and many prawns which live in the brackish waters between inland lakes and the ocean constitute in themselves the modern instances of the transmutation of marine organisms into those which live in fresh-water. According to this view of the matter, fresh-water faunas are heterogeneous assemblages of organisms the forbears of which have at different times successfully colonised the fresh-waters of the earth from the ocean; and the curiously universal distribution which is characteristic of some of the constituents of these faunas, is regarded as having been brought about by the natural facilities which exisi for the distribution and dissemination over the land of such organisms and their germs. Within the last few years, however, much definite information has been added to our knowledge of the nature of fresh-water faunas, and of the composition of those which occur in different parts of the earth. It has been shown, by the experimental researches of Beudant and others, that certain marine organisms can actually be acclimatised to fresh-water if the change is carried out with sufficient slowness, but at the same time it has become apparent that one of the most striking features which all fresh-water faunas present is the smallness of the number of the types composing them when compared to the fauna of the sea. From this it would appear that very many marine groups have never made any attempt to establish themselves in lakes and rivers, and this indication has led to the investigations of Semper* and Sollas, $\uparrow$ who have shown that there are other obstacles besides the necessity of adaptation to new conditions of salinity which tend to prevent marine animals from

$$
\text { * Semper, "Animal Life," IS81, p. } 149 .
$$

+ Sollas, W. J., Trans. Roy. Soc. Dublin, vol. iii., series ii., p. 87 . 
colonising the fresh-waters of the land through the medium of the rivers which flow from them into the ocean. Semper has dwelt upon the hardness of the conditions of varying temperature, etc., which unquestionably obtain in rivers and lakes ; while Sollas has pointed out the equally unquestionable fact that a very large number of marine forms are precluded from making any attempt to colonise the rivers by the fact that they begin their existence as free-swimming larvæ, and that it is physically impossible for such larvæ either to force themselves up a stream, or to maintain themselves under the conditions which would surround them in a river. As a matter of fact, when the old question of the nature and origin of fresh-water faunas is re-examined in the newer light which these and still more recent investigations can be made to throw upon the subject, it becomes more and more apparent that none of the existing conceptions which have been entertained are fully capable of explaining the origin of such faunas, since it can be shown that no existing explanation of the peculiar composition of these faunas can be brought into accordance with our knowledge of the facts. The reasons for this statement will begin to appear if we consider the composition of the invertebrate section of the fauna in any two widely separated land masses. The fauna of a Central African lake, for example, compared with, let us say, the fauna found in the fresh-waters of the island of Celebes. To make matters still more simple we will consider only the mollusca of these two areas we have selected. If then we arrange the molluscan constituents of the Victoria Nyanza in a tabular form as on page I 4 beside those of the molluscan section of the fresh-water fauna of the island of Celebes, it will be seen that the fresh-water mollusca of these two widely separated districts present, in the first place, a 
number of genera which are common to them both, and also a number of genera which are peculiar to each. In the second place, we find that the genera which are common to both fresh-water areas are those which have been recordect in innumerable places throughout the world. We should find

T.IBI.\& I.

Molluscan fauna of the Victoria Nyanza.

Planorbis.

Limnaea.

Isidora.

I'hysopsis.

Ancylus.

Ampullaria.

Lanistes.

livipara.

Cleopatra.

Bithynia.

Melania.

Unio.

Spatha.

.Hutela.

Aetheria.
Molluscan fauna of the fresh-waters of Celches.
Plunorbis.

Limnacia.

Isidora.

Ancylus.

Protancylus.

.Miratesta.

timpullaria.

lizipara.

(?)

Melinia.

Corbicula.

batissa.

Comparison of the genera constituting the molluscan fauna of the Victoria Nyanza in Central Africa and of the fresh-waters of the Island of Celetes.

them in American fresh-waters, in the lakes of Polynesia, and even in the pools and puddles of Japan. They are, in fact, almost if not quite universal in their distribution throughout the more permanent fresh-waters of the globe. IVe have, then, in the two particular examples of fresh-water faunas that have been chosen, two distinct types of animal 
life-( I) a universal series of types, and (2) another composed of organisms which only occasionally appear in freshwater, and are related to a particular district or to a lake. If now we examine the character of the animals that form the types of the first series, we are confronted with this very curious and remarkable feature characteristic of them all. They have no counterparts or close allies in the ocean at the present day; and on anatomical examination they are found to stand in the relationship of ancestors to numerous well-known marine forms. If, on the other hand, we consider the forms which are peculiar to the two lakes in question, and more especially if we consider the forms similarly peculiar to a number of other lakes and distinct fresh-water areas, we find that these forms have almost invariably, like the prawns in the Lago di Garda, in Italy, close allies in the existing marine fauna, and generally exhibit closest affinities with some of the organisms which inhabit the sea nearest to the particular fresh-water which may be studied. We find, in fact, usually in the fresh-waters of the globe a fauna which is composed of an ancient and almost universal stock to which it appears that there may be added in any particular fresh-water a more or less large and variable stock of animals which have migrated into this area at one time or other from the nearest seas. The origin and nature of this latter series is obvious and plain, but the origin and relationships of the first-i.e., the ancient and universal series-is not so clear. It will, in the first place, therefore, be well to distinguish this universal series by a special name, and to speak of it as the primary fresh-water fauna, and, dealing with the second series in the same way, to call it the secondary fresh-zuater series. That the types representing the groups constituting the primary fresh-water fauna of the world should generally exhibit ancestral characters in their organisation is 
a very striking fact, and it is all the more interesting when we reflect that the characters possessed by the types of the primary fresh-water series are those which there is very good reason for believing were once possessed by some of the members of the normal oceanic fauna very long ago. Thus among the mollusca which we have just relegated to the primary fresh-water series we find that the Prosobranch genus Viripara is with reason regarded by students of comparative anatomy as possessing those particular structural characteristics which must have marked the transition of the old marine diatocardiate forms into the later Tanioglossa. Melania also is a form which has an extremely simple Cerithoid organisation, connecting up the Ceritho-Litterinoids with the Strombus and Natica groups. Limnea, which is found in almost every fresh water throughout the globe, is a form belonging to a series of gastropods which probably anteceded the modern marine Opisthobranchs. We are confronted with similar facts respecting the structural relationships of all the other molluses belonging to the primary fresh-water series. It is, however, not only with respect to the mollusca that we find these peculiarities among the constituents of the primary freshwater series: the same phenomena are encountered in regard to the crustacea, and markedly among the fresh-water fishes such as the Australian, African, and American ganoids and the like. From these considerations it would appear to be suggested that the primary fresh-water stock belongs to an ancient type of fauna which there is reason to believe was once widespread in the sea, but which for some reason wholly unapparent on the face of things has latterly become restricted to the fresh waters of the globe.

If, however, we examine the palcontological evidence which exists respecting the first appearance of the types 
characterising the primary fresh-water series, we find that these types, such as Vivipara, Planorbis, Limnea, and Melania among the molluscs, fresh-water prawns and crabs among the crustacea, and the immediate forerunners of the now widely dispersed groups of fresh-water fishes, such as the ganoids, arose as such about the same time. The emergence of the primary fresh-water series being as a matter of fact synchronous with a strange phenomenon already well recognised by geologists; it occurs just at the time when a curious break is manifest in the forms characteristic of the secondary and tertiary deposits, and from this we might infer, or at least think it probable, that they owe their differentiation to the same cause which produced during this period an extraordinary multiplication of new types and the extinction of old ones. From the manner in which the primary fresh-water series appears in the geological record, it in fact seems to be suggested that there came into play some cause which was efficient to kill out a disproportionately large number of ancient marine types, and at the same time, both to produce a disproportionate array of new marine forms, and to dissociate from these the representatives of the primary fresh-water series as universal inhabitants of the waters of the land; that is to say, the facts of morphology and the facts of palæontology, when taken together, seem to suggest that there has occurred something like a change in the character of the sea itself, which has affected the animals contained in it in such a manner that a large number of its old forms were definitely killed out, while others were driven into the fresh waters of the globe, and at the same time a very large number of entirely new marine types was produced. In attempting to form any clear conception of the nature and the origin of the curiously similar fresh-water faunas 
which are now found all over the world, it would, from these considerations, appear possible that we shall have to reckon with, and to define, some factor which has not hitherto been recognised, and that this is so will, I think, become quite clear if we examine the conception of the freshwater fauna problem which is detailed in the luminous paper by Professor Sollas to which I have already referred. We find that, after pointing out the unquestionable obstacles which stand in the way of any attempt on the part of many marine organisms to colonise the fresh-waters of the land, the author inclines to the conclusion that the existing freshwater faunas of the earth must have originated in pans, which were at one time part of the sea, and were subsequently cut off from it, the present fresh-water forms being survivors of this process, just as, if the Baltic were to be cut off now and become fresh, some of its marine organisms might persist as fresh-water types. The present curious universal distribution of the primary fresh-water fauna over the land's surface being assumed by Sollas to have been brought about afterwards, and to be due mainly to a capacity which fresh-water organisms possess for migration. At the time Sollas wrote, the extraordinary dispersion of many fresh-water animals throughout the world, such as Planorbis, Limnaea, Melania, Bithy'nia, and Vivipara, was not fully apparent, and still less were the facts relating to the actual capacity for migration which these and other fresh-water animals really possess. I shall refer to this matter again subsequently, but for present purposes, it may be stated, that the more recent observations of numerous investigators do not show that there is really any evidence whatever for a capacity on the part of freshwater organisms, such as the above molluscs, to spread themselves, as they are spread, into the different isolated sheets 
of water which occur on a great continental land mass, and throughout all the great continental land masses of the world. If we examine the great fresh-water basins and river systems of Africa, for example, the first fact which confronts us is the localisation of groups of varieties of the universal types. Thus, confining our attention, merely for the sake of simplicity, to the molluscs of Lake Nyassa, we find only one species-namely, Melania tuberculata-existing in this lake which occurs in any of the other great lake basins.* In Tanganyika, excluding its peculiar halolimnic group, all the species of molluscs in it are peculiar to the district : they do not even occur in the adjacent lakes of Mwero, Rukwa, or Bangweolo, such types being either unrepresented in these lakes or represented by different species. So again in Kivu there is not even a Vivipara, and the only series of great African lakes that possesses a large number of identical species is that constituted by Albert Fdward, the Albert, and the Victoria Nyanzas, which communicate with the Nile now, and were almost unquestionably once more or less connected together. These facts-and there are other similar ones connected with the distribution of species in the lakes and river systems of North America-seem to show in an unmistakable manner that many typical freshwater forms have little if any capacity to migrate from their original centres of distribution, and, consequently, that the peculiar specific varieties which they present in these centres are due either to their original character or to natural selection, having operated since their origin, in a generally similar manner, in all these particular spots. In like manner, the distribution of the Characinid fishes in the American and African fresh waters is quite inexplicable

\footnotetext{
* Shirwa is a lake in the same basin as Nyassa, and was at one time connected with it.
} 
on any supposition of their having originated as a relic fauna in some one arm of the sea which became cut off from the ocean, and ultimately fresh; for there is no evidence that there has been any connection between the remote state land masses which these fishes now inhabit, since the origin of types now common to them both. It is the same with the Cichliclie and many other forms of fish. 'The idea which Sollas advocates, that the fresh-water faunas of the world are relic faunas cmanating from the sea, may be true, but that these faunas have intercommunicated one with the other, and thus produced the universal distribution of the primary fresh-water types, does not appear to be supported by any capacity for dispersion exhibited by their present constituents. IVe seem, in fact, from the evidence which is now available, to be driven either to the supposition of such a complete parallelism in the evolution of forms of different origin in different areas, that it makes generic distinction impossible, and consequently upsets our fundamental conceptions in a manner for which there is no warrant; or we must find some other cause for the universal distribution of numerous freshwater types.

It has already been emphasised that the members of the universal fresh-water series possess the characters of forms which there is every reason to believe were once widely spread in the sea, and, this being so, it also becomes clear that if we can discover some cause which would have made their migration from the sea to fresh-waters a necessity, we shall have found an explanation of some of the most remarkable features of the fresh-water faunas of to-day; for through such a cause all the members of the primary fresh-water series might have been produced about the same time, and would consequently present all over 
the world the similar morphological characteristics which they actually possess. This similarity would not, however, have been produced as a result of intercommunication between fresh-water centres, but as a result of their all having arisen from the general sea fauna of a particular geological age. The question before us, then, is whether there is to be found in the nature of things any cause which can be regarded as sufficient to produce such an effect.

It is a fact that increase or decrease of the amount of saline matter in water does act prejudicially, on many, if not on all the organisms living in it, and this can be shown in a variety of ways, perhaps best by the study of a lake which, like Shirwa, was originally fresh, but which through losing its outlet has now become intensely salt. Shirwa is a large, oval body of water about 50 miles long, and enclosed on all sides, first by lacustrine plains and then by lofty granitoid hills. At the north there is an old channel which represents a former connection with the Lujenda River, but this, probably through rising of the ground, has now become closed, and the waters of the lake have not flowed out at any rate for many centuries. The lake is fed by numerous rivers which flow into it from the great mountains of Mlanji and Zomba, and the slight amount of salt which the rain washes off the land has accumulated in the evaporating-pan formed by the lake, until it is now a thick strong brine. One of the principal rivers which flows into Shirwa is the Mulmgoosi, and where it enters the lake, there is still an area of almost fresh water, bounded without by the brine wastes of the lake. In this fresh-water oasis, but not in the upper course of the stream, I found some Viviparas living, of the same species unicolor which inhabits Lake Nyassa. There was also the Nyassa Limnaea and Melania tuber- 
culata, as well as a few Cichlid fishes, among which there were several Nyassa species. Beyond this oasis, in the open body of the lake, and among its numerous islands, none of these animals occurred, and the only forms of life present were some curious alga, some catfish, and a small Planorbis, which lived upon the reeds and not in the lake at all. All round the marshy shores of Lake Shirwa, however, there are extensive plains which were at one time unquestionably portions of the floor of the lake, and embedded in these there are found countless millions of Viviparas and Limneas; in fact, the remains of nearly all the molluscs found now living in Nyassa. From these facts three things are obvious: (I) that Shirwa at one time flowed out and was fresh; (2) that it was once peopled by the Nyassa fauna; and (3) that it is now uninhabited by that fauna, except in the oases of fresh-water such as that which I have just described. At some time the lake ceased to have an outlet, and its somewhat profuse fauna died out as a result of the stagnation of its waters and the acquisition of their peculiar briny characters. The increase of the salinity of the water of Lake Shirwa must, however, have taken place with extreme slowness, much more slowly, in fact, than we could ever bring about a similar change of environment experimentally. Nevertheless, we find that the salt has eventually killed out the whole of the typical fresh-water molluscan fauna of Nyassa, and most of the fish. The consideration of the history of Lake Shirwa shows us, then, that a typical fresh-water fauna like that of Nyassa does not readily acclimatise itself to an increase of salt, such as that which has taken place in the lake, and this is so notwithstarding that the increase may have taken place with extreme slowness. I do not know the percentage or the exact composition of the saline materials which the 
water of Lake Shirwa contains, but, following the same line of investigation, I distributed while on Tanganyika five hundred young prawns, in equal quantities of water, among twelve vessels. Leaving two unaltered as a control to the rest, sait was added so that the solution in the remaining ten was increased daily in the proportion given in the table on p. 24 in which the course of the experiments can be seen; and from which it will be obvious that in all cases the prawns died when the quantity of salt in solution in the vessel reached 8 per cent., no matter what the rate at which the increase had been made; and some time before this point, although the prawns were plentifully supplied with food, their development was seriously interfered with, the salt producing a progressively stunting action proportionate to its increase. The effect of introducing salt into the environment of freshwater organisms such as prawns leads thus to exactly the same result as that obtained with extreme slowness by nature in the case of Lake Shirwa. In both, but more especially in the former case, we have direct evidence that fresh-water organisms can stand a certain amount of salinity, but beyond a certain point, which is probably fixed within very narrow limits for any particular type, they are suddenly killed off. When anywhere near this point has been reached, the salt acts as a poison, and, just as is now known to be the case with the action of a large number of poisons, not much effect is produced, until what may be termed the critical dose has been reached. But beyond this, wide physiological disturbances, or death, immediately occur. There is, however, another aspect of change in the environment of organisms like that produced by increased salinity which, in the present connection, it is very important to consider. It has been experimentally shown by a number of investi- 
TABLE: II.

Vessel in which water Vessels in which salt was acklerl in the proportions remained fresh. indicated in the columns.

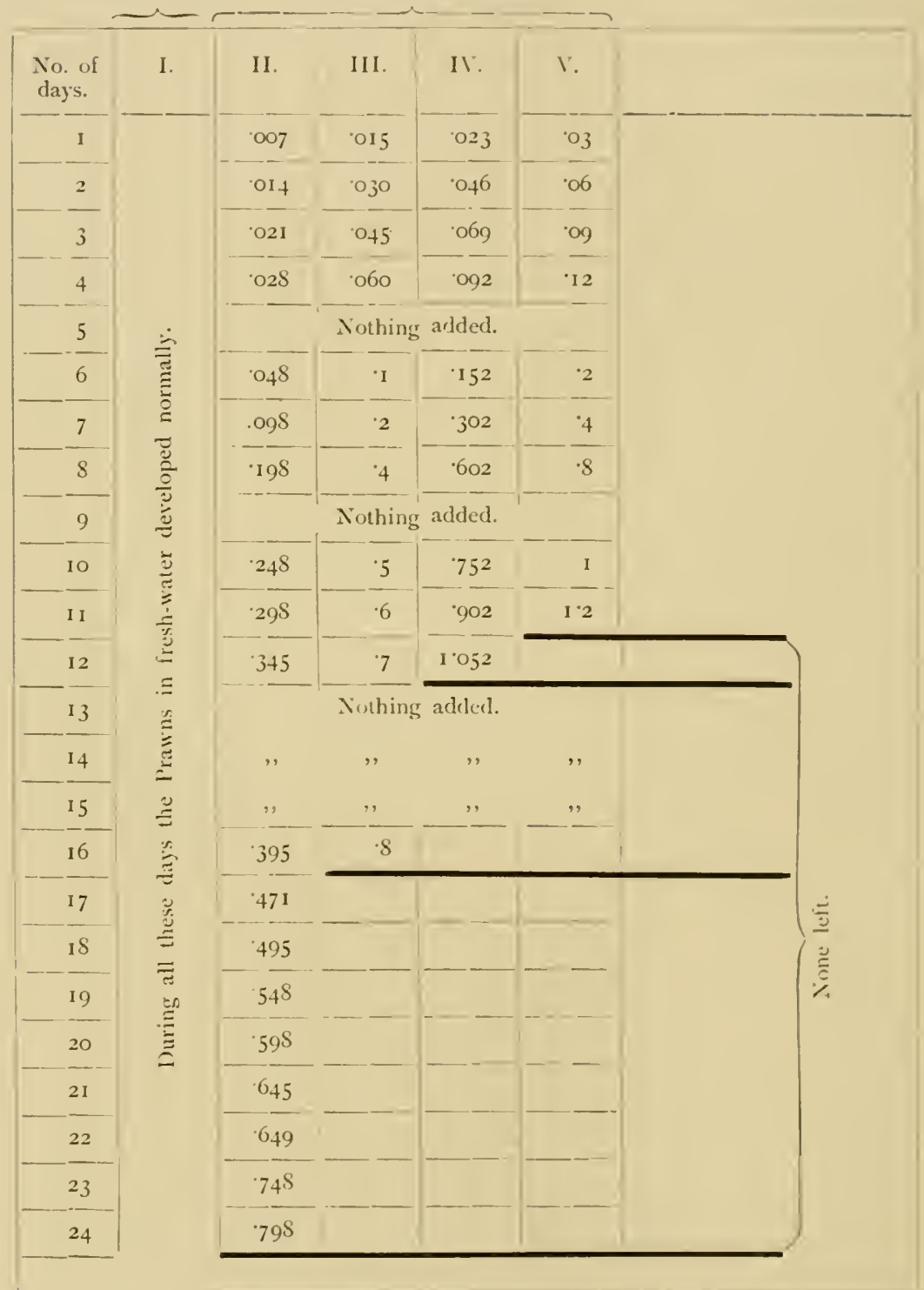

Table showing the effect of increasing the amount of common salt in the water in which Prawns were living. 
gators that long before a poisonous dose is reached the addition of chemical substances to water in which animals are normally living acts as a stimulus towards variation either in themselves or in their offspring. Thus Vernon* found that the addition of small quantities of urea and uric acid, ammonium chloride, and nitrates had an appreciable effect on the larvæ of sea-urchins which were reared in such solutions. Herbst showed that lithium salts produced very abnormal effects upon the growth of larvæ. Loebł also showed that change of salinity affected the growth of tubularians. It would thus appear that there is some reason to believe that a gradual increase in the salts normally contained in the water of the sea would produce effects analogous to those which unquestionably have taken place in the animals living in it during past times. Such an increase would, it appears, ultimately kill off some animals, weaken other stocks, cause what we may call rampant variation, and force a number of forms into the fresh-waters of the globe. From what has been observed there is also reason to believe that, had such an increase of the salinity of the sea occurred, it would as a matter of fact begin to affect large numbers of diverse organisms about the same time, or, in other words, the same percentage of salts would begin to tell on a large number of diverse types. If, then, the sea has become increasingly salt, this simple cause would be in itself efficient to account for a number of the most perplexing features which the universal fresh-water fauna of to-day presents.

The study of the general nature of fresh-water fauna

* Phil. Trans. Roy. Soc. Vol. I86в., p. 577-I895; also Naples. Mitthal, Vol. xiii., p. 341-1898.

† American Journ. Phis. Vol. iii., p. 385 .

† Archiv. Fur Entwic. Mechanik. Vol. xi., p. 617-1901. 
suggests that some change in the sea must have taken place. In consequence of this it is incumbent on us to inquire whether there are other grounds for believing that the sea has become and is becoming steadily more salt.

Turning to this matter we find that the subject has already been considered, but in general from other aspects than that which immediately concerns us at the present time. Thus, within the last few years we find both Jolly and others considering the increase of salinity of the ocean, and taking its existence for granted as a means in an attempt to ascertain the age of the earth. That the saline matters in the sea have changed in composition and increased in amount seems, indeed, almost indisputable from a variety of considerations. Thus Jolly points out that numerous analyses of the rocks of different ages show a marked contrast in the amount of common salt which they contain, the older the rocks the more the salt, and, further, that the percentage lost in the more recent deposits is matched by the amount of salt dissolved in the water of the present sea. Jolly also comes to the conclusion, and apparently with good reason, that the amount of salt which has been again lost by the sea, in the formation of rocksalt deposits, is to be considered as infinitesimal and negligible.

Indeed, the same results would be forced upon us, if we were to apply the experience we have gained in the study of fresh and salt water lakes to the study of the sea itself. IVe find that where lakes have an outflow they remain fresh, because the salt which is brought into them is always being carried away by this outflow, but in lakes which have no outflow the modicum of salt which the rivers bring down remains in the water of the lake, so that it becomes more and more saturated until finally the 
salt may crystallise out on the reeds and beaches in glittering white precipitates, as I have seen it repeatedly round Shirwa and the other salt-pans of the African interior. A lake having no outflow bears the same relation to its drainage area that the ocean does to the whole land surface of the earth, the volume of water in the sea remains constant, but vast quantities of this water are for ever evaporating into the atmosphere, and are then flung broadcast over the surface of the land, from whence they eventually drain back in the form of rivers, but each in possession of a certain quantity of salt which they add to that already in solution in the sea. The sea is nowhere nearly saturated with salt, and the above reasoning would appear to lead to the conclusion that if we had a sample of the ocean which was sufficiently old we should find that it contained less salt than does the present-day sea-water ; whether, however, we can agree with Hunt that the water sometimes enclosed in ancient rocks may be looked upon as fossil sea-water, and consequently that the ancient oceans were richer in magnesium and potassium than the present-day sea, is a matter into which we need not at present go; all that it is important to realise being, that it seems to be demonstrable from different sources that the sea has changed and is changing in composition with a gradual increase of common salt in solution, and that the indication of a physical change in the sea which we obtained from the purely zoological considerations, discussed in the preceding pages, seems to be in unison with various other lines of evidence.

There thus appears to be reason to suppose that there has been a slow increase of common salt in solution in the sea, and if this is so, it would also appear that the general course of marine evolution may have been profoundly in- 
fluenced by this slowly progressive physical change. That indeed such evolution has to a large extent been an organic reflection of this change; the change in the sea having acted as a stimulus towards variation, and also as an eliminating agent. Consequently we may have to view the primary features of distribution and character of both the fresh-water and marine faunas of the present day, as not so much due to the operation of the struggle for existence among warring animal types, as to the moulding and eliminating effect of a progressive physical change.

That physical changes of a similar character are of much greater import in biology than has hitherto been supposed I have personally not the least doubt, and that they are capable of producing changes of the above kind we shall see again in the present work, for in Chapter VII. I have had occasion to advert to the effect of progressive desiccation upon the flora of a country, as evidence of geological change, and to show that the whole floral aspect of wide areas may be completely altered, not however as a result of the struggle for existence between different plants, but through the operation of a progressive physical change which is forcibly moulding the flora of such districts into an expression of itself.

Summarising what has now been said it would appear in the first place that the sea is in exactly the same condition as an immense closed lake, and that so far as we can judge it is for ever acquiring more salt in solution than it had before, and its waters will go on getting more and more salt until they are at any rate much nearer saturation than they are at present. What effect this change will have in the future upon the animals which live in it, it is idle to speculate; but it is important to realise the following facts :- 
I. That there is progressing this change with respect to salinity.

II. That it can be shown experimentally that such a change after it reaches a certain degree is both prejudicial to some organisms and causes wild variation in others.

III. That these tendencies are competent to bring about the separation of marine from fresh-water faunas, the latter arising all over the world from the general marine fauna at about the same time.

IV. That the facts of the morphology and distribution of the existing fresh-water faunas independently point to some such cause as having operated towards their production in the past.

Accepting these various indications respecting the manner in which fresh-water faunas have become differentiated, it would appear that the present-day fresh-water faunas are to be regarded as chiefly composed of the remains of a once widely distributed and ancient sea-fauna, the ancestors of the surviving components of which were forced out of the ocean into the fresh-waters of the globe owing to a change in the character of the sea itself. This change appears to have become sufficiently strongly marked to have produced an appreciable differentiation at a period roughly corresponding to the commencement of the formation of the secondary rocks. In this manner it would appear that assemblages of similar organisms have of necessity taken to fresh-water all over the world about the same time, just as one could imagine the modern universally distributed organisms of the marine littoral, such as the Trochoid molluscs and the shore crabs, being simultaneously everywhere driven into the fresh-waters of the land if the sea became too hot to hold them. 
Once established in the fresh-waters of the globe, it is probable that the fishes and the more active of the invertebrates migrated slowly from point to point, but as we have seen, there is much evidence to show that in the great fresh-water areas of the different continents the invertebrate components of the primary fresh-water series have migrated very little from the point at which they first originated.

In many fresh-water areas however, as in the Lago di Garda in Italy, there are often to be found organisms which have not the ancient attributes of the constituents of the primary fresh-water series, and these organisms, like the Lago di Garda prawns, are to be regarded as the comparatively rare and conspicuous examples of voluntary colonisation from the sea. Still further, in a few places, as in the Caspian Sea, and, as we shall sec later, in the case of Lake Tanganyika, there are to be found whole batches of animals which have become independently detached from the sea and which bear no proximate relationship) either to the modern marine fauna, or to the primary freshwater types. Thus we find in the fresh-waters of to-day animals which can naturally be arranged under three distinct heads. We have in the first place the primary freshwater series, in the second the sporadic and voluntary colonists of fresh-water which we may call the secondary fresh-water series, and thirdly the relics of entire marine faunas which in a few places are found to persist and which, like those of the Caspian and Tanganyika, we may call the halolimnic series of the world. 


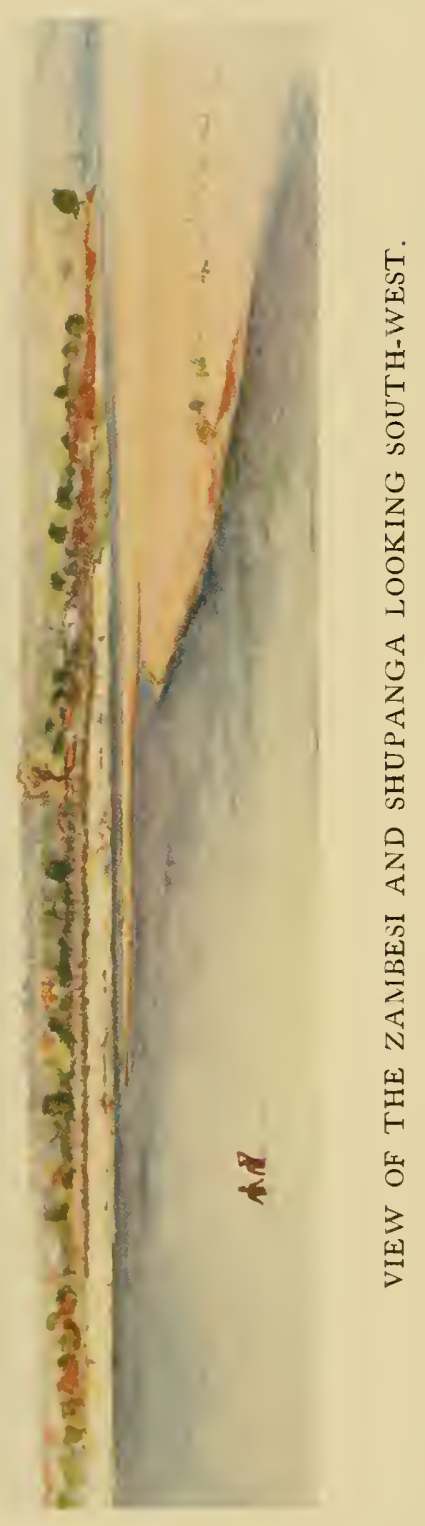





\section{CHAPTER III.}

ON THE EXISTENCE OF A GREAT CENTRAL MOUNTAIN CHAIN IN AFRICA.

Is entering upon an enquiry concerning the nature of the fauna of the great lakes of Central Africa in general, and that of Tanganyika in particular, it is, if not absolutely necessary, at any rate advisable, that a conception of the structure of the continent, as concise and accurate as existing observations will permit, should be formed first. On this account I have prefaced the chapters dealing with the zoology of the Great Lakes by some in which the structure and the geology of the vast regions in which the lakes lie has been described as fully as our yet scanty information will allow. In the present instance this course is doubly to be desired: our views respecting the continent are becoming changed, and some very definite theoretical anticipations which have been put forward concerning the gross geological features of the African continent appear, in the light of the most recent exploration, to have hardly even a shadow of support. These older geological anticipations are, moreover, diametrically opposed to some of the most salient zoological facts relating to the fauna of Lake Tanganyika, and consequently any fresh information about the geo- 
logical structure of the African interior, resulting from recent exploration, is particularly germane to the enquiry with which this work is concerned.

Most, if not all, the existing views of the nature and past history of the African land-mass have been built upon the old conception that the physical characters of the continent, the distribution of land and water upon its surface, the shape and the configuration of the equatorial region as a whole, have been almost unique in their stability and long permanence. That, in fact, the great mass of Africa, lay in waving hill, and plain, and ravine, much as it does now, even under the paleozoic sun ; or, at aliy rate, since the suns which rose over this portion of the earth, when the new red sandstone was being deposited, finally set. This conception of the past history of Africa was first definitely brought forward, now many years ago, by Sir Roderick Murchison* in a Presidential address to the Royal Geographical Society, and it has ever since formed the chord upon which those who have concerned themselves with the geology of the continent have harped. It was, for example, resuscitated by Dr. Gregoryt while discussing Suess' conception of the nature of the great Central African "gräben" (rift valleys), and from this single instance, taken at random, it will be sufficiently obvious that, although we have until lately known almost nothing of the nature of the African interior, this ignorance, as usual, has in no way deterred investigators from speculating a good deal. What we require at the present time, and for the particular investigations upon which we are entering, is a review of the most recently ascertained facts touching the geology

* Journal Royal Geographical Sociely, Vol. xxii. (IS52); Ibid. Vol. xxviii. (IS5S).

$\dagger$ The Great Rift Valley (1896). 
of the region of the great African lakes; but what we do not want is that this should proceed in the. strongly-coloured light of antecedent speculation. We must consider the matter anew, and with as few pre-conceptions as possible, and see whether the observations will themselves take colour and start legitimately into the shape of more generalised appreciations as we go.

It has been confirmed, especially as a result of the second Tanganyika expedition, that we can, in fact must, regard all Africa as constructed in relation to an elevated ridge, which runs from the mountains of Abyssinia and those flanking the Red Sea in the north, to the continuation of these same ridges in the shape of the Drakensberg in the extreme south. In some places, as for example in the region of Tanganyika and the Albert Edward Nyanza, the ridge may be broad, constituting the crest of the interior plateaux, and resembles the Ural Mountains in that it forms the gently culminating line of two long slopes from the east and from the west. So again although the great fold may be ten to twelve thousand feet in height, like the Urals it does not appear to the eye as an actual mountain chain from either side. In most places, on the other hand, as between Nyassa and Tanganyika, the culminating heights are narrow and rise abruptly above the surrounding country in the form of bold mountain chains. Everywhere along this line the axes of the chain run approximately north and south, and the crests of the higher summits are as lofty as those of the Rocky Mountains in the United States. Indeed, were Africa in any other latitude, there would be an immense range of ice and snow running from the extreme north to south; while the lonely summits of the Ruwenzori Mountains, of Kenia and Kilima-Njaro, although right under the equator, are 
ice-capped as it is. It is only comparatively recently that the existence of these interior heights has become known, and it is only quite recently that the conception of a long axial range in Africa, bearing the same relation to that continent that the Andes do to South America, has begun to be appreciated. It is indeed to Mr. Scott Elliot* that we owe the first clear apprehension of this fact, and it is such a very important fact in all questions of African physiography, that I shall attempt in this, as in a former work, $\dagger$ to emphasise the appreciation of it by giving the mountain chains a special name and by speaking of them as "The Great Central African Range."

The main river systems of Africa flow from the eastern and the western slopes of this range, and the greater rivers, partly owing to its position partly to climatic conditions respecting rainfall, flow mainly from the western slopes. The immense Congo, with all its gigantic upper tributaries, rises wholly on the west, while even the Nile, with its main components, the Albert Nile, the Sobat and the Blue Nile, drains mainly from the western slopes. So also, even the Zambesi derives most of its water from the west of the range, although it eventually cuts through the chain to an opening in the Indian Ocean.

As is the case in the region of most great mountain ranges, there are to be found in Central Africa besides the chains of lofty heights, long, deep hollows which run parallel with, and between the ridges of the range itself, and these great depressions, which are now occupied by the lakes and the rivers, are often rock valleys, like the valley of Genceva. They have not, however, been formed by ice, and are not to be viewed as wholly the products of denudation operating in the past, any more 


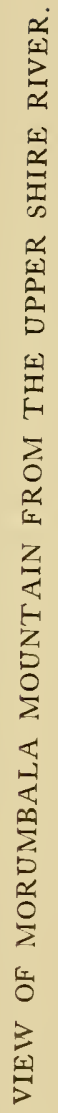



than the mountains and the great elevated plateaux of the high central ridges are to be viewed as such. Both mountains and depressions are the products of igneous forces similar to those which have raised the Alps and the Caucasus in Europe; and as is the case with the Alps, so also in Africa we find old aqueous deposits of all sorts, piled up at high angles on the flanks of the great central core. This is particularly well seen in the region of Nyassa about Mount Waller, and at the north end of the lake; all over the Tanganyika districts and beyond them to the north in the region of the Mountains of the Moon.

It will be convenient in the first place to consider the surroundings of Lake Nyassa. We find that the lake lies in a deep depression, which has the form of a vast fold in the earth's surface, and such in reality it appears to be. The depression in which the lake lies runs also along the very top of this portion of the continent, its opposite edges here representing the highest crests of the Great Central Range. In certain places there are old sandstone deposits stretching across the present site of the depression, and these deposits have been broken along its course, in such a manner that, beyond its eastern edges, they slope away towards the Indian Ocean, while on the west they trend in a similar manner towards the opposite sea coast. The existence of these deposits shows in the first place that the trough now occupied by the lake was formed subsequently to their deposition. It is evident indeed that throughout the whole length of the Great Central Range there has been much of this local elevation and depression ; for in almost every district there may be scen faulting, tilting and smashing of the old lake deposits, and other strata, which overlay these regions before such movements took place. The Central African Range appears in this region 
to be an expression of one of those linear series of gigantic earth movements which have formed the Andes and the Rocky Mountains in America, the Alps and the Caucasus in Europe. Further, as is the case with most great mountain chains of this sort, the lofty heights that have been produced along the axes of the folds, are in general not volcanic cones, or volcanoes in the ordinary sense of that term, but, at the same time, as is the case with the Alps and the Caucasus, the earth movements, the folding and the crumpling of the globe's crust, which appears to have brought these chains into existence, has also originated true volcanic activity in their vicinity, and thus matching the existence of the Auvergnes and the cones of the Puy de Dôme in relation to the Alps and the Pyrénées, Etna, Vesuvius, and Stromboli, in relation to the Appenines; so we find the Mfunbiro Mountains, Kilima-Njaro, Kenia, and innumerable smaller volcanoes, some active, some extinct, but always in their position more or less closely dogging the course of the Great African Range. The processes of elevation which find their maximum expression in the Alps and the Pyrénées have affected wide areas, especially to the north of these heights, and so also in Africa we find that the great tendency towards elevation along an axis running north and south through the continent has, in the same way, affected to a less degree an enormous area of the earth's surface east and west of the range. This is evidenced by the rising of the coast line which can be seen to have occurred at innumerable places, both on the east and the west of the continent. It is very apparent for example at Mombasa, Zanzibar, Bagamoyo, Delagoa Bay, Shupanga, and near the eastern slopes of Nount Morambala, at all of which points there are to be found marine deposits of different ages now elevated above the sea level; and 


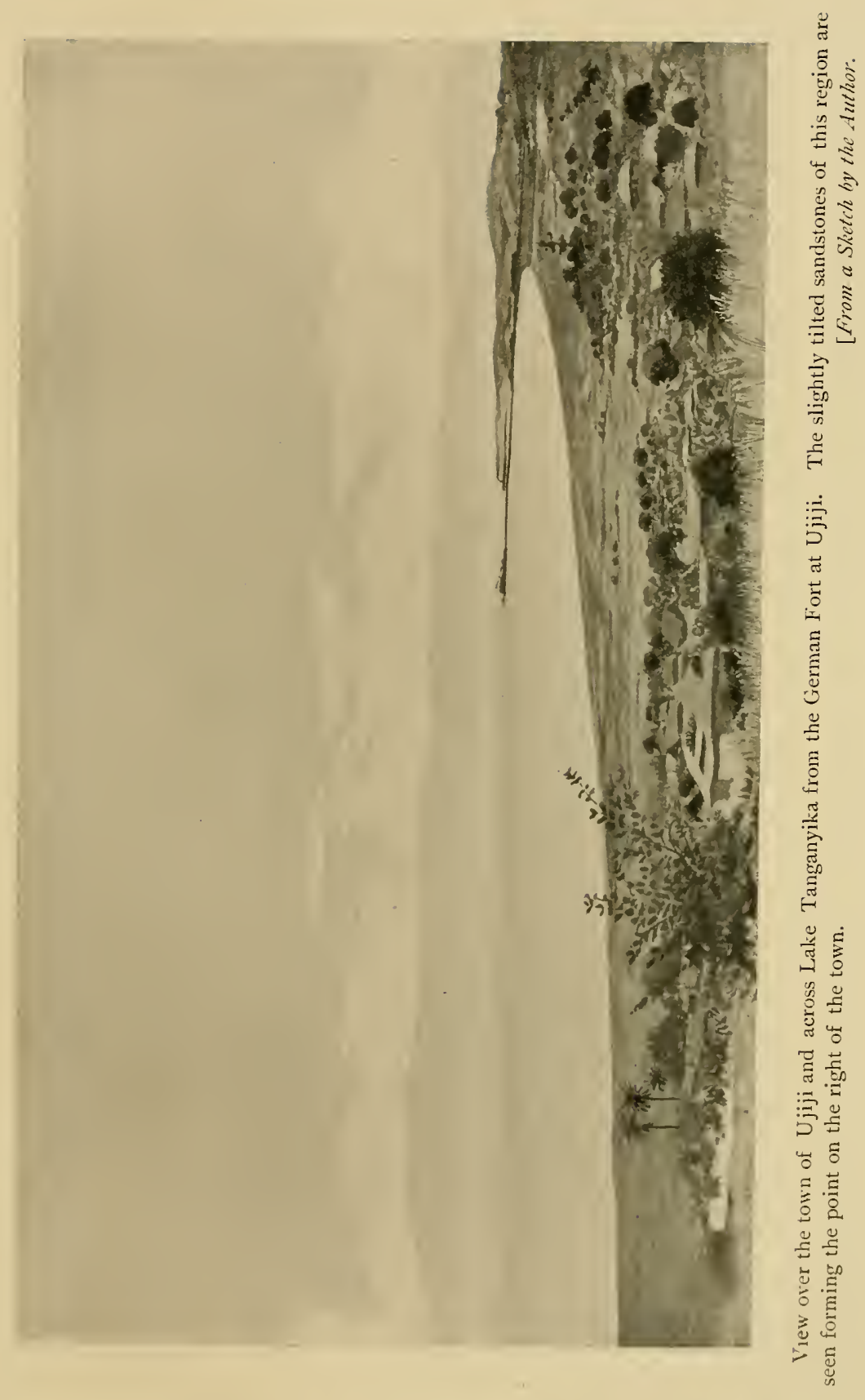



though the upthrust has been far greater along the Great Central Range in the interior of the continent, it is obvious that these same earth movements have affected in a less degree an area which is at any rate as wide as the continent itself. We are, in fact, here in Africa encountering again phenomena similar to those noticed by Darwin as having gone forward in the gradual elevation of that part of the earth's surface which finds its maximum of expression along the crests of the Southern Andes. The effect of crinkling such as this, greatest along an axial line running approximately north and south in Africa, and becoming less and less as we pass from this longitudinal axis, east and west, would if it had gone on evenly and uninterruptedly have tended to raise the continent into a great hog's back; and south of the equator, this is as a matter of fact the form which it actually possesses, the earth's surface has been bent up into a great arch; but as we become better acquainted with the phenomena, it is also apparent that the changes which have produced this effect have not operated altogether evenly; and owing to this, during their progress they have given rise to subsidiary effects : to all sorts of parallel foldings and crinklings of the surface, which in some of their expressions are extremely interesting. By far the most striking of these subordinate geological changes which the gradual upraising of the African interior has produced, are a series of great chasms, the "Gräben" of Suess, the long, deep valleys to which I have just alluded and which are found to run among, and parallel with, the ridges of the Great Central Range. These vast fold-like depressions in the surface of the earth have been noticed now by a large number of explorers. By Stanley, Stuhlmann, Cassati, Götzen, Teleki, and many others, and the accumulated information 
respecting the structural similarity of many of the grooves which wander through the African interior from south to north was luminously summarised by Professor Suess, * who showed for the first time that whatever their origin, such chasms are a related series of phenomena, and that the earth movements which have given rise to them are by no means confined to the African interior, but have brought about similar phenomena in the procluction of the vast walled chasm in which the Red Sea lies fifteen hundred miles away to the north. Similar chasms are indeed prolonged into the Gulf of Akabah and the Dead Sea even as far as the depression of the Jordan itself. More cletailed information respecting the nature of the lesser eastern depression which lies between Kenia and the New Uganda railway was given by Professor Gregoryt as the result of a short journey to Kenia from Mombasa, but the clear conception of these valleys as a phenomenon which is subordinate to the formation of a great internal line of elevation perhaps naturally escaped both Suess and his followers at the time. They regarded the "gräben" (rift valleys) as the primary geological feature of the African interior, whereas they are far more properly viewed as the interesting byproducts of the folding of a spherical surface during a modern attempt on the part of the earth to raise a grand mountain chain. Let us, however, examine the character of the great African ridge, including these valleys, in somewhat more detail than has hitherto been done. If we construct a section of the Great Central Range in the region of Southern Nyassa, through Kota Kota for example (see diagram No. I), we have the following phenomena. Beginning at a point between the lake and the east coast, there are 
encountered a succession of rising granitoid ridges and elevations, which finally culminate in the huge mountains forming the east coast of Lake Nyassa, these mountains being in fact the last and highest of a succession of granitoid ridges separated by valleys of varying

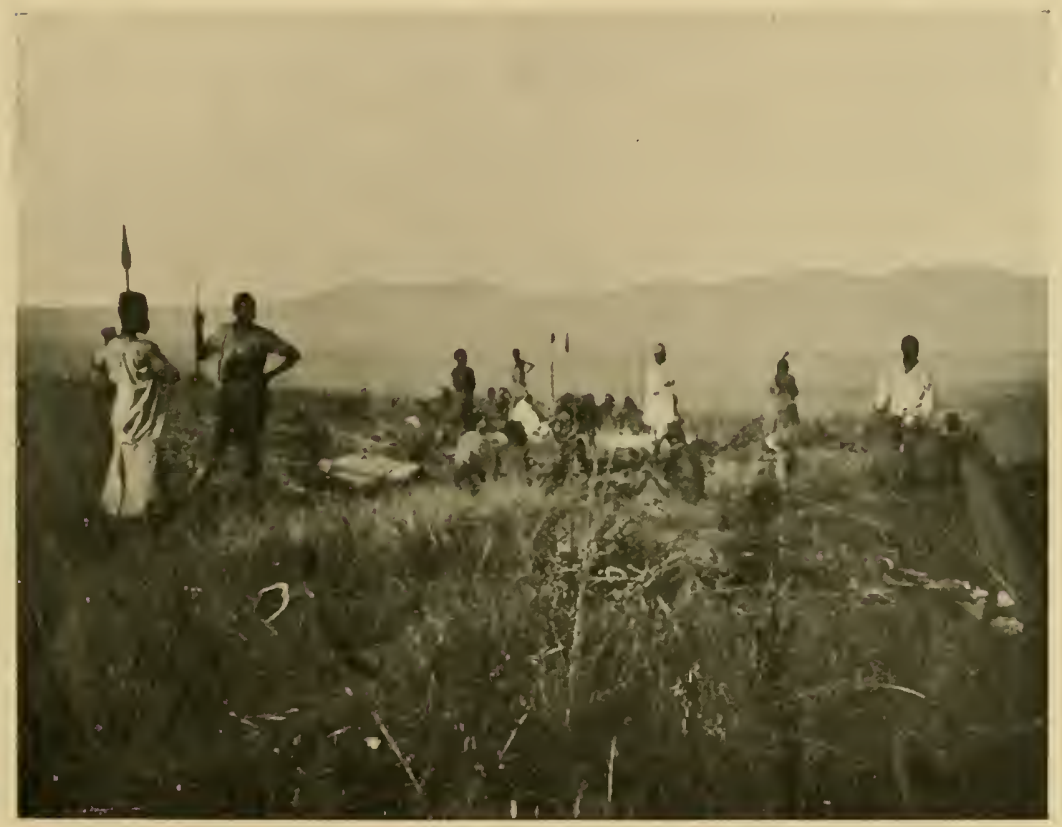

View across the great Central Eurycolpic fold from the Northern slopes of the Mfumbiro Nountains.

depth and extent. The trend of the ridges is from north to south, and the valley in which Nyassa lies is the broadest, and the deepest, which we have encountered during our supposed journey from the east. Crossing the valley of the lake towards Kota Kota, we find that it sinks to, and below the level of, the sea, and then we pass up again over the alluvial 
flats surrounding the Arab settlement, to the mountains beyond the west coast of the lake. Having scaled these, we find that we have also arrived on the western slope of the continent. The gradual rise in this region is thus seen to culminate in a high ridge with two cusps and an extremely deep narrow valley in between them. 'The trend of the granitoid rock on both sides of these cusps is directed towards them, and they are themselves evidently the loci of vertical upthrust. Accompanying these phenomena in Nyassa there are to be found all the subsidiary phenomena which usually accompany such movements of the earth: that is, we have everywhere abundant evidence of local elevation and depression of adjacent areas relatively to one another. Thus, if we take a section rather further, to the north through a conspicuous promontory known as Mount Waller (see diagram No. 2), we find that the crests on opposite sides of the lake are not here composed of granitoid material, but of stratified sandstones and conglomerates in layers. These strata on the east of Nyassa are tilted up slightly towards the lake, until they break away immediately above its shore in an imposing series of scarps. Crossing the lake from east to west, its floor is here found to be shallower and formed of sheets of nearly horizontal sandstones, similar in all respects to those composing the eastern scarps. Along the east coast at this point there is a great line of faulting, and a vast cliff face has been upraised in the cast above the beds which form the floor of the lake. On the west coast of the lake, we find the same series of phenomena repeated like a reflection on the other side. South of Deep Bay and near Mount IValler on the west there are sandstone ridges protruding above the water with a slight dip to the west (see diagram 


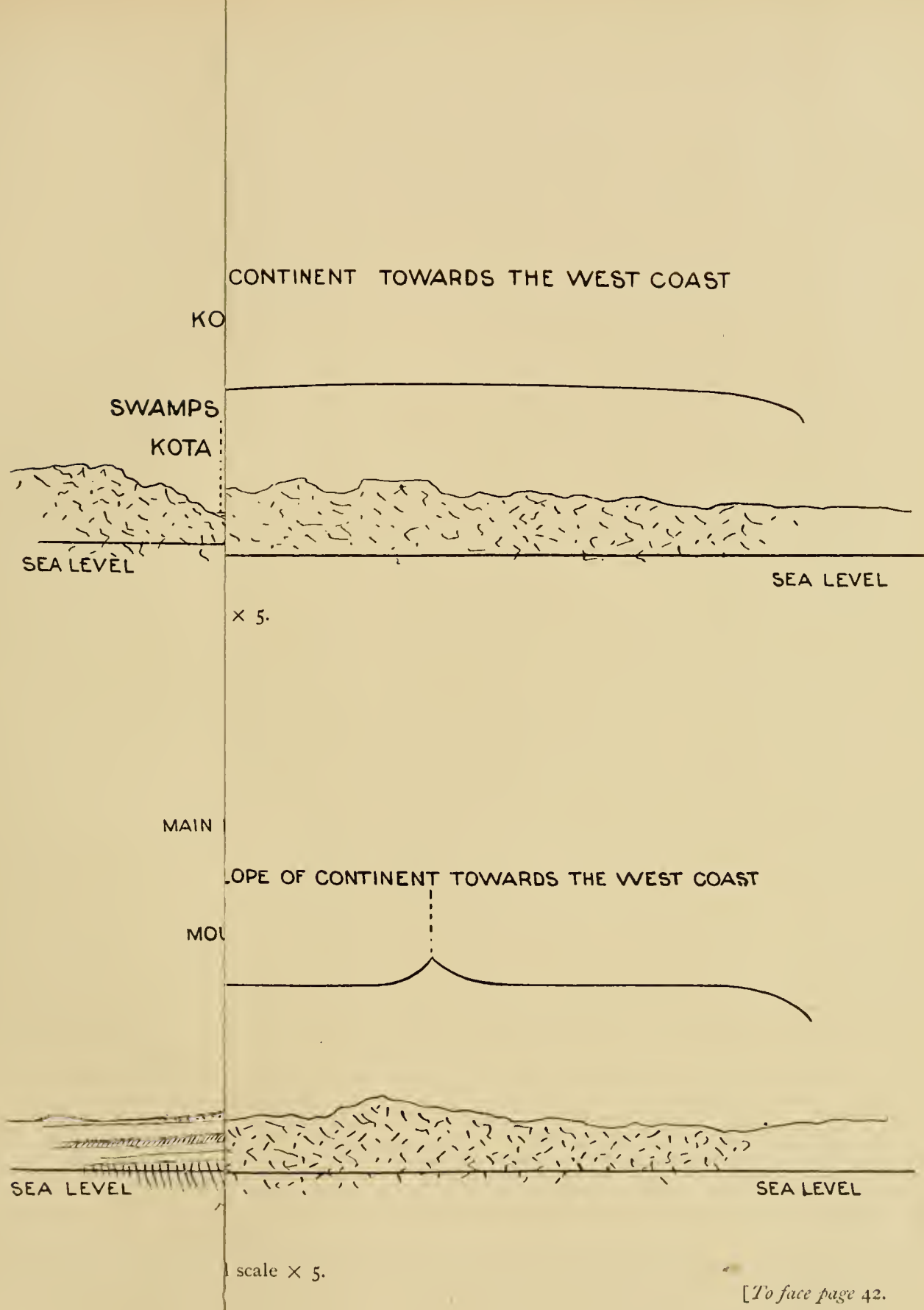





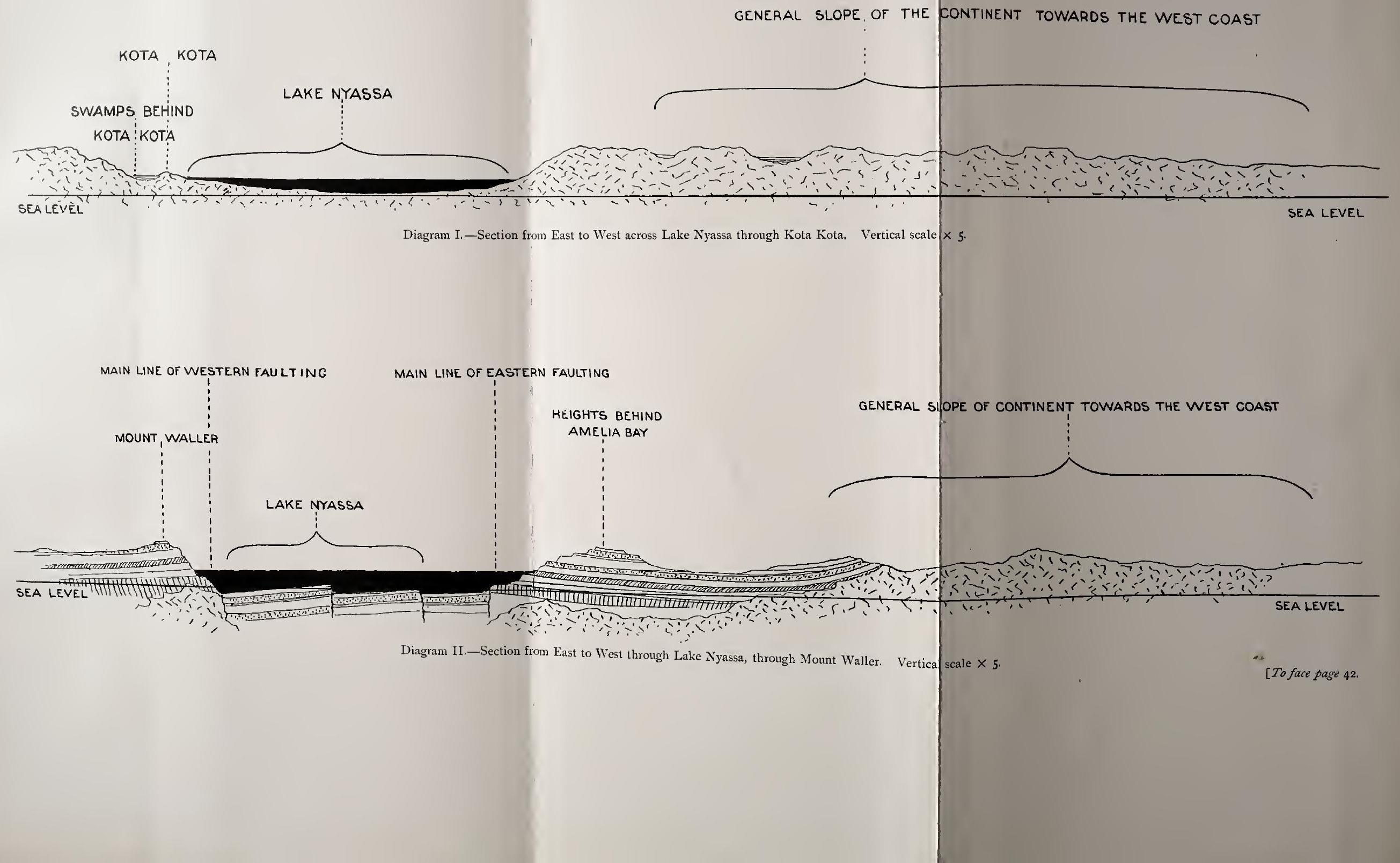



No. 3), and immediately behind these there are faulted up into the air the imposing cliffs of Mount Waller itself. At the foot of Mount Waller, the igneous base on which the two thousand and odd feet of sandstones and conglomerate rest, was exposed above the water line when I visited the region in $\mathrm{I} 896$, and near this point to the north there were other sandstone ridges which like those to the south had been faulted to a less extent than the Mount Waller mass, and bore on their upper surfaces thick stratified beds of modern chalky lake deposit. In these beds there were, moreover, fossilised shells similar in all respects to those now living in Nyassa and showing incontestably that the upthrust along the line of the west coast of the lake had been going on and had caused fresh faulting of the stratified material near the lake shore, at any rate since Nyassa contained its modern fresh water fauna. But besides thus giving evidence of modern (post pleistocene) activity and continual rising of the cusps of the great central African ridge, the phenomena I have just described near Mount Waller in Nyassa are intensely instructive in another sense. They show that where horizontal strata overlie a region where folding of this sort is going on, a typical faulted trough with vertical sides (a so-called rift valley) can be produced by the rising of the sides quite as well as by the falling in of a central strip of land. Lateral compression of the earth's surface, as by the shrinkage of the globe, would actually produce these effects, just as we can bend a piece of paper up into two folds with a valley in the middle; and in this case we see also that as the lateral pressure increases the central valley in the paper tends to deepen at the same time that the two ridges are rising. All the phenomena encountered in the Nyassa region are at once perfectly intelligible if we suppose that folding of the earth's surface 
of this nature has gone on; and the only further demonstration which is required to make the tale complete are some observations which will show that the floor of the valley of Nyassa has become, or is beconing, actually thrust down. Such evidence is readily to be obtained at the north end of the lake. 'The water of Nyassa has fallen many feet within no great number of years, and in consequence, wide plains of old lake deposit and alluvium covering what was once its floor have become dry land near Karonga and further north. At the end of I $\$ 95$, when I first visited the lake, the water of Nyassa was shown by observations made by the officers of the gunboats to be lower on the whole than it had been for many years; but notwithstanding this, I was shown to my intense surprise a number of old trees not far from Karonga, which were standing about two hundred yards in the water of the lake, and the trunks of which were then submerged some five feet. Moreover, the old natives of the district, whom Dr. Cross interrogated on this subject for me, assured us that they could remember a time when it was possible to walk out to these same trees, which were then not near the water at all, and at whatever rate the change in level has taken place, it is quite clear that it can only have been produced by local subsidence of the ground, i.e:, by the sinking of the floor of the Nyassa Valley during the life of these particular trees.

The valley of Nyassa, like that of Tanganyika, is continued beyond the lake to the north (see map, opposite p. 48), and although its magnitude becomes lessened and partially filled up, there is no doubt that the individuality of the depression can be traced as far north as the valley of I ake Rukwa, which lies to the east of the Tanganyika depression, but finally runs into and crosses it obliquely from east to west. It is in the floor of the Nyassa depression, some way to the 


\section{SEA LEVEL}

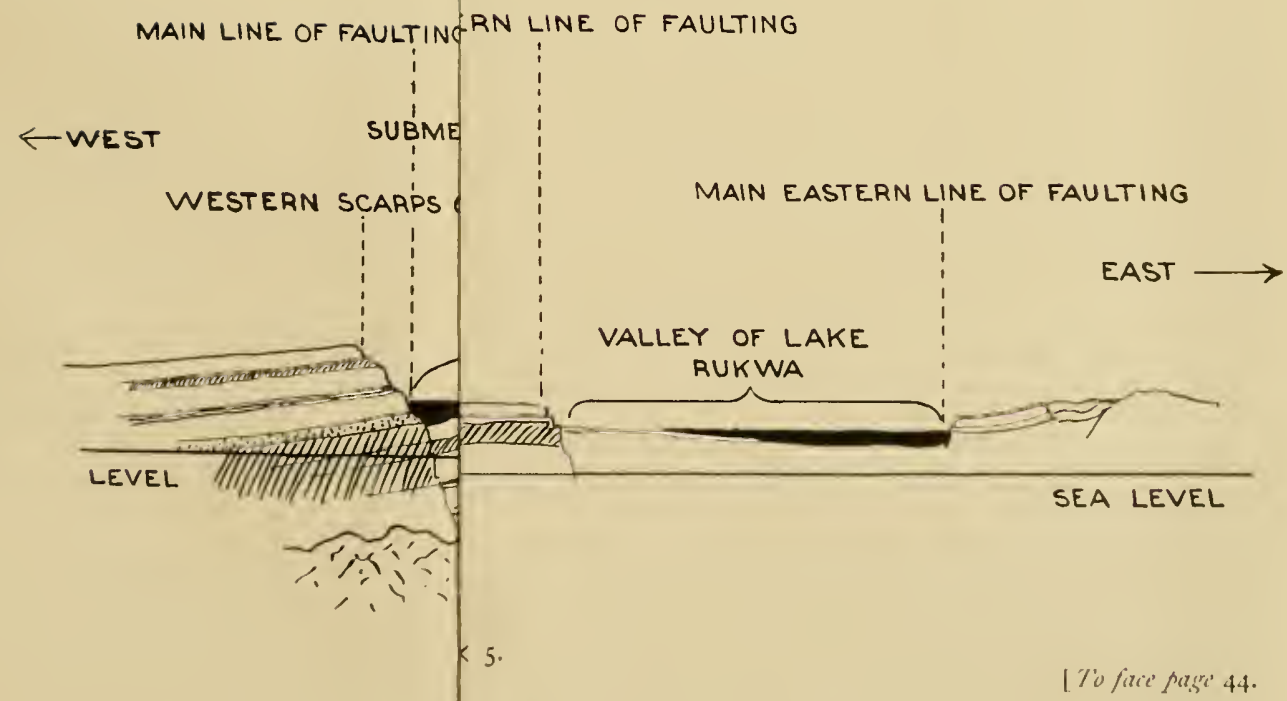



SANDSTONE CLIFFS OF THE WEST COAST

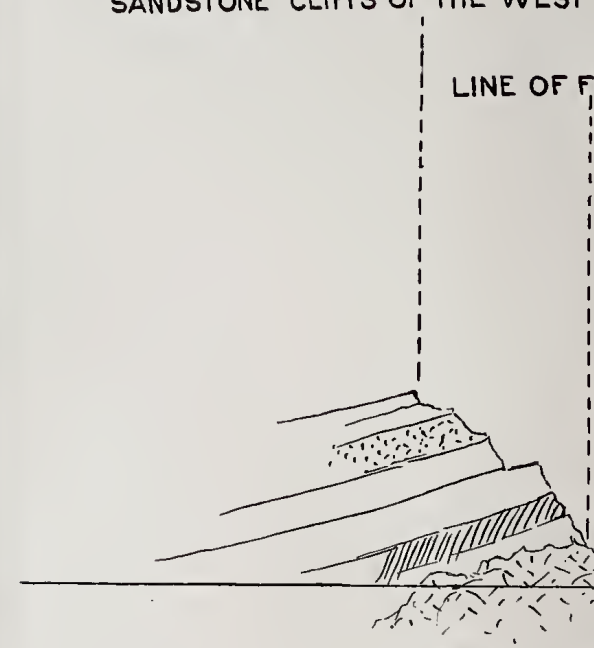

\section{AULTING}

RAISED LAKE DEPOSIT

CONTAINING MODERN SHELLS

Diagram III.-Through Mount Waller from East to West, showing Raised Lake Deposits.

\section{SUCCESSIVE FAULTING ON SLOPES OF MOUNTAINS}

FAULTING ON THE EAST SIDE OF KINYAMKOLO ISLAND OFF CAPE?

MAIN LINE OF FAULTING ON THE WEST

$\leftarrow$ WEST SUB́MERGED CLIFF

WESTERN SCAAPS 6-7000FT.

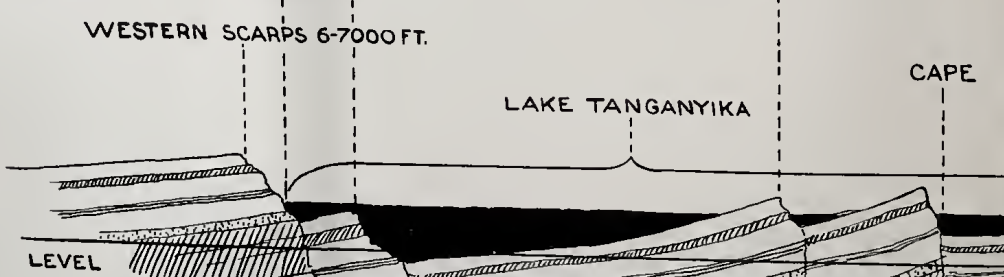

KINYAMKOLO ISLAND

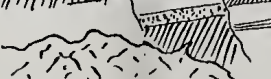

min

iाiाiा)

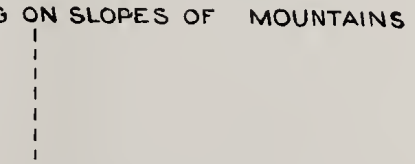

Diagram IV.-Section through Lakes Tanganyika and Rukwa from North-East to North-West. Vertical scale 

north of the present lake, that in this region we first encounter true volcanic action in the shape of a number of extinct volcanic cones, with circular craters, and deep blue crater-lakes, phenomena which here repeat those to be found in the great Tanganyika depression far to the north, and again in the floor of the Red Sea itself.

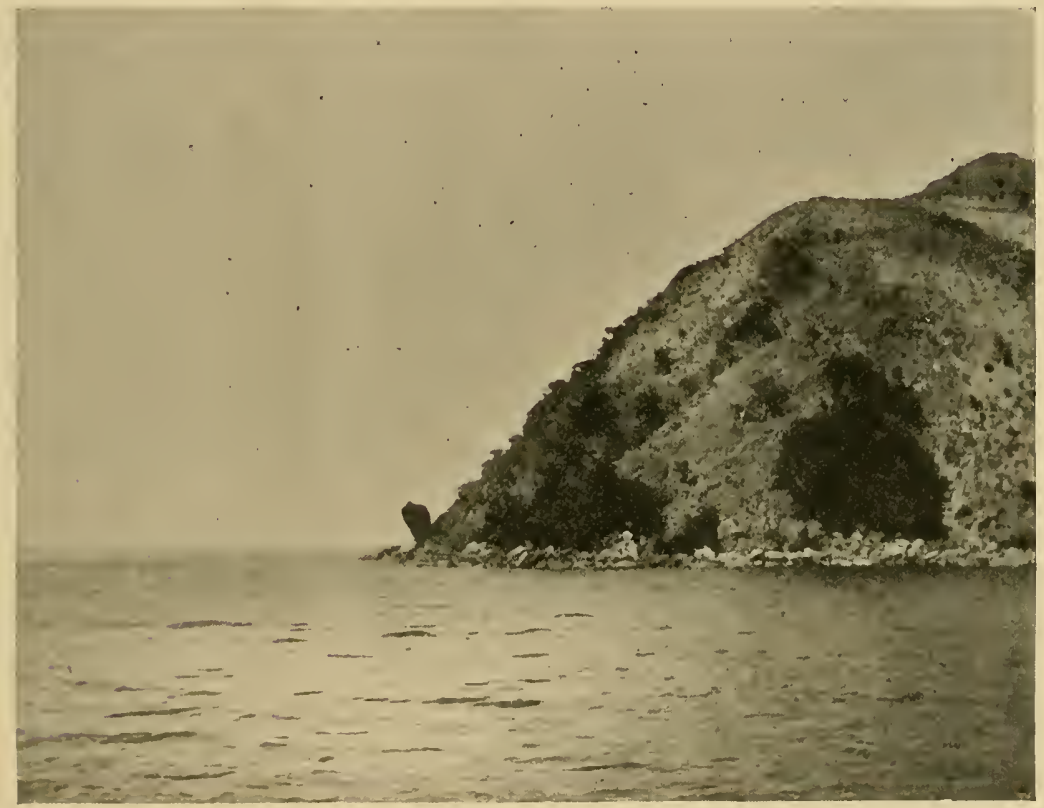

Portion of the west coast of Lake Nyassa, near Nkata Bay.

The double cusped character of the ridge of the great central chain is thus seen to be continued as far as the southern extremity of Tanganyika, but at this point a new depression of gigantic proportions begins. If we take a section through the region of Lake Rukwa, and through the southern extremity of Lake Tanganyika from east to west (see diagram No. 4), the following physical 
phenomena are apparent:- The country rises towards the eastern scarps which llank the trough-like depression of Lake Rukwa, where a line of faulting occurs. At the base of these eastern cliffs, which were found by Mr. IVallace to be about 400 feet in height, there is a flat, dusty plain of modern lake deposit, and then another series of scarps facing those on the east and marking another parallel line of faults. Above these western scarps of the Rukwa depression the land rises gradually; it is composed in places of sandstones and conglomerates, which, further to the west, are pierced by the intrusive granitoid material of the mountains flanking the east coast of Tanganyika, and these in turn overlook to the west the great depression of this lake. On the western slopes of these heights sandstones and quartzites are again found piled up at varying angles upon the intrusive core, and sloping towards Lake Tanganyika in a succession of flat-topped, forest-clad terraces, between which there arc faults represented in Diagram iv. at F.F.F. These sandstone slopes finally dip under the water of the southeastern corner of Tanganyika at a fairly high angle. Having reached this point on the shore of Lake Tanganyika, we find before us to the west a deep depression, soundings showing a depth, in places, of ISo fathoms, and away over the lake, at a distance of $\mathrm{I} S$ miles, there is the rocky promontory of Kituta and some islands. This promontory and these islands have the following structure:The eastern face of the cape is a precipitous cliff of red sandstone and quartzite, rising to a height of 600 to Soo feet; on its western side the ridge slopes much more gradually for two or three miles, until it dips uncler the channel which separates the island of Kinyamkolo from the mainland. Like that of the Kituta promontory, the 


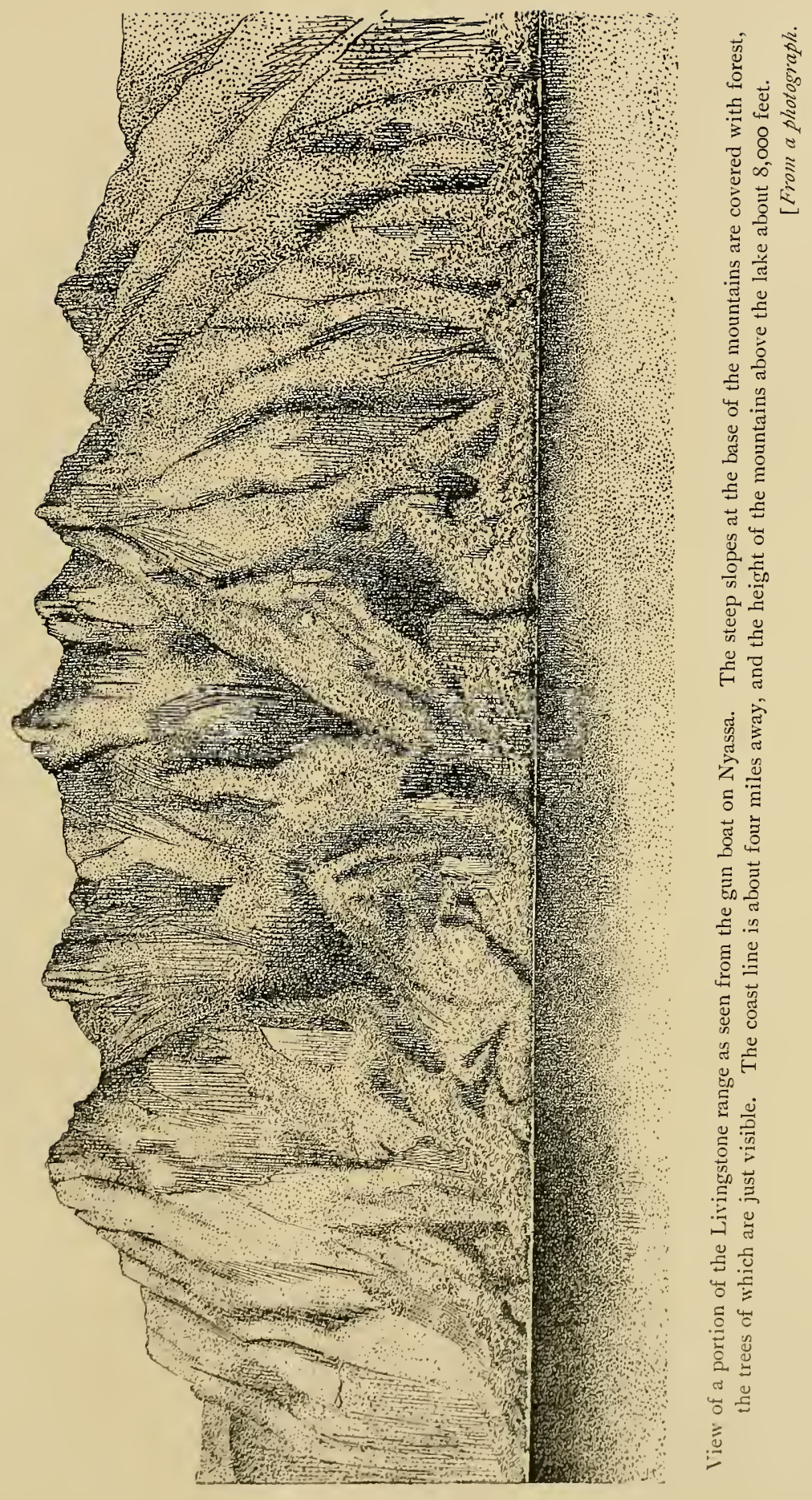


eastern faces of these islands are steep, precipitous cliffs, composed of somewhat metamorphosed sandstones, which have been worn out at their bases into caves by the great oceanlike surf of the lake. On the western side these islands slope less steeply into the lake, and from their crests can be seen, over an expanse of deep blue water, 25 miles away, the gigantic scarps of the main western coastline of Tanganyika. Soundings in the open water, between the islands of Kinyamkolo and the great western scarps, showed great depths, 200 fathoms and upwards being encountered; but not far from the abrupt west coast, some distance north of Mbeti, there is a submerged platform, which rises slightly, like the islands, from west to east, and terminates in that direction in a submerged cliff, its relation to the main western scarps being shown in Diagram facing p. 44.

Passing still westward over the western scarps, we find them to be composed of massive quartzites, sandstones, conglomerate and shales, 2,000 feet and more being exposed along the main western coast-line of the lake, and, finally, having ascended the magnificent red and yellow precipices which these exposures form, we reach a table-land, but one which has everywhere a slight dip to the west, and we are now, as a matter of fact, on the long main western slope of the whole continental mass. Through the contemplation of the above facts relating to the structure of the Great Central Range in the region of the south end of Lake Tanganyika, it will have become apparent that the phenomena presented by the crest of the ridge are here more complex than in the region of Nyassa, although it will, at the same time, have also become obvious that these phenomena are precisely similar in kind. The complexity in this region is due, in fact, simply to the existence of a 


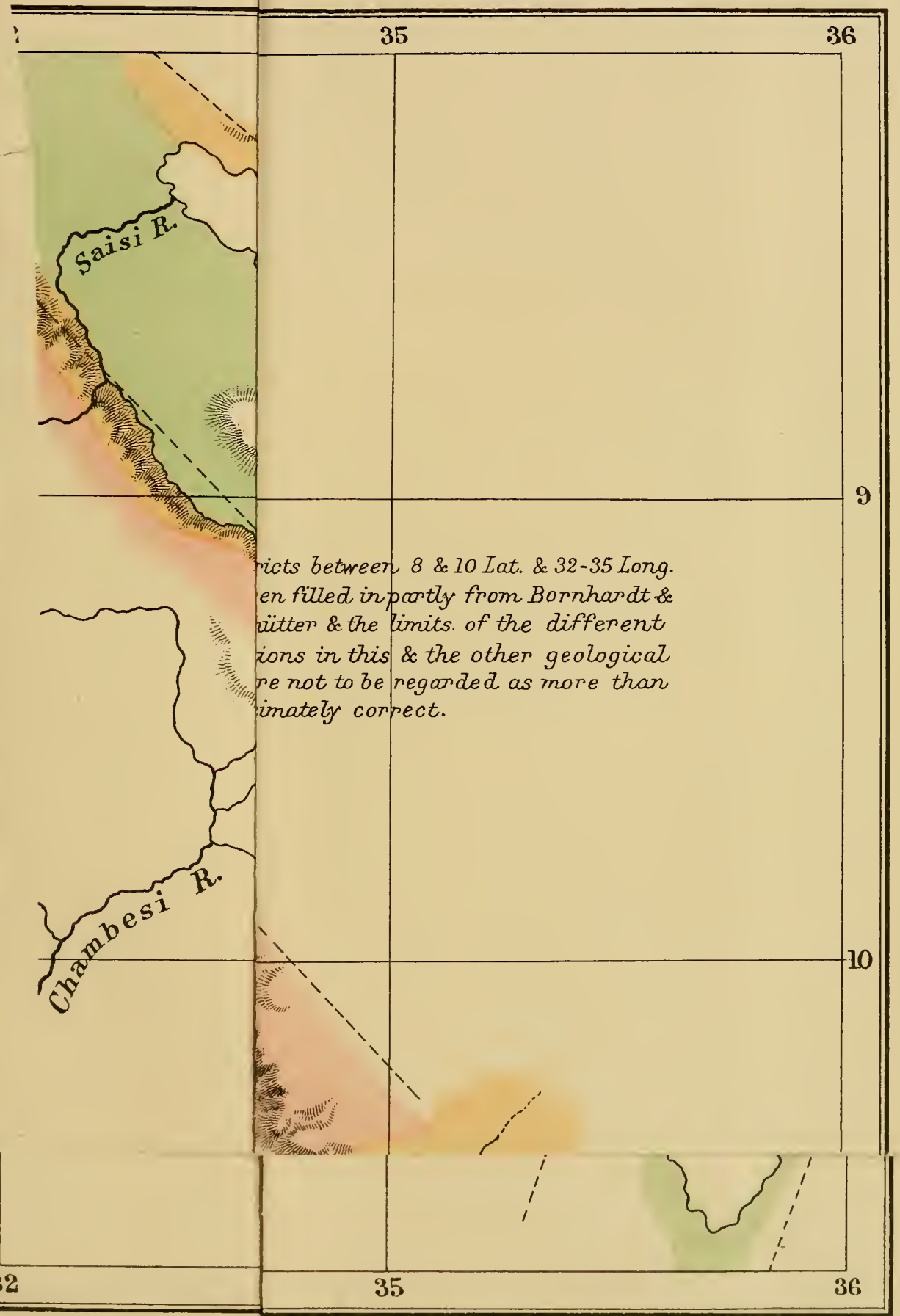





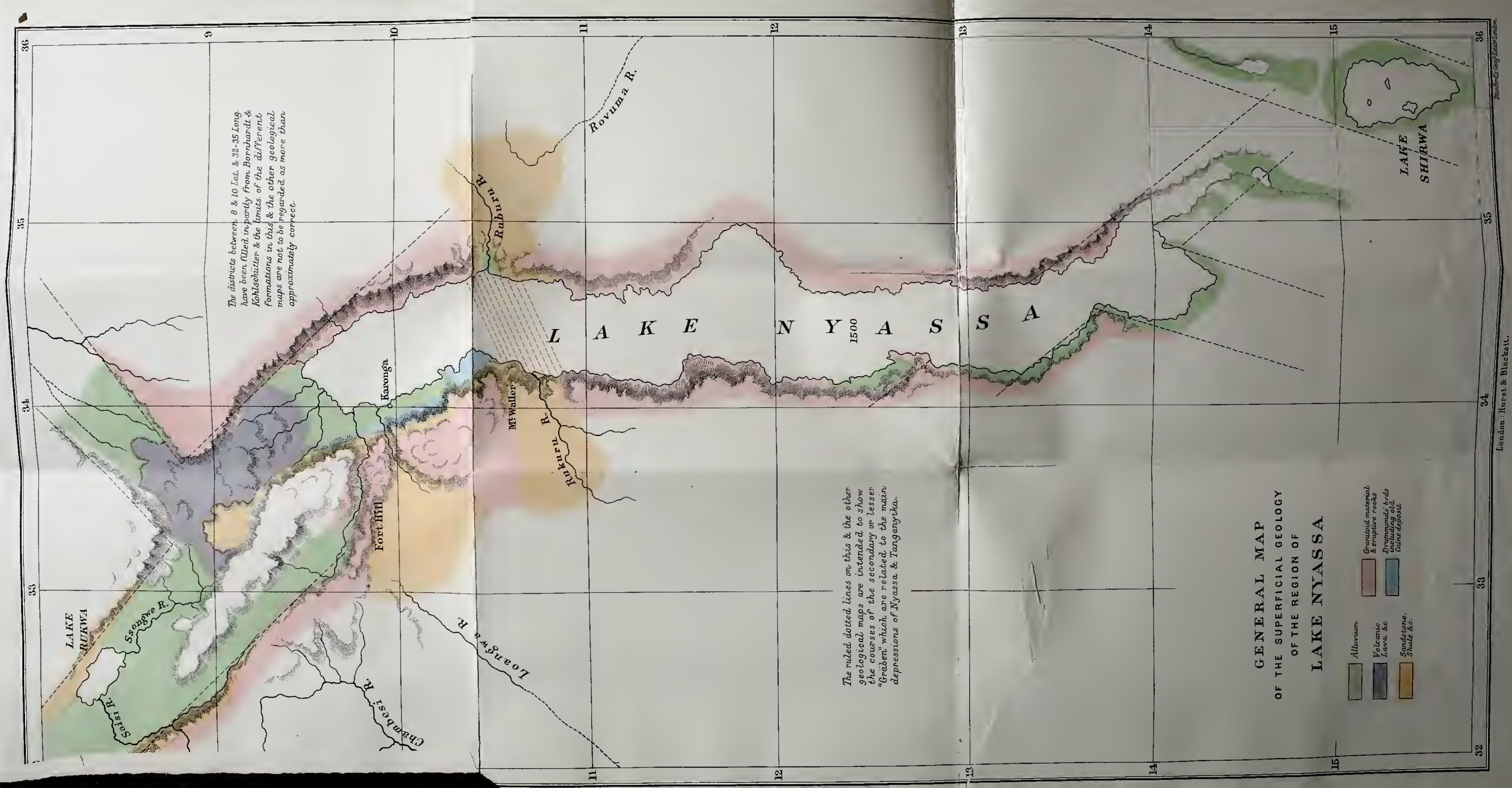



succession of ridges, or to a succession of cusps in transverse section, and, when closely compared with the cross section of Nyassa, the structure of the Great Central Range in the region of the south end of Tanganyika will be found to have the following peculiar features:-There are, first, two lines of up-push, one on either side of Lake Rukwa, then a more or less flat space, then a greater upraised ridge flanking the eastern shores of Lake Tanganyika; next there is the depression of Tanganyika itself, and then another upraised ridge. In Nyassa the phenomena would be produced, as we have seen, by a double fold in the earth's surface, like that which can be made in a sheet of paper, while in the region of the south end of Tanganyika the whole of the phenomena are at once intelligible, if we suppose that four wrinkles, four such folds, have been upraised. These are not fanciful comparisons, but appear to me to represent, in reality, exactly what has actually taken place. There is, in the physical phenomena of all this Central African region, an extraordinary simplicity, and a primitive boldness which produces on the mind an indelible impression that we are here dealing with a unique example of the initial stages in the shaping of a continental mass, and not, as in most other cases which confront the geologist, with the confused and denuded relics of activities which have long since become extinct.

From the preceding examination of portions of the great central "gräben," it will be observed that the conception which we thus gain of the nature of these valleys, as phenomena incidental to mountain building, is not by any means the same as the original conception entertained by Suess, and more recently repeated by others, all these authors having regarded the valleys as the result of vertical falling in of land from the surface 
of high and ancient plateaux. Each so-called rift, however, seems far more correctly conceived as a plait-valley, or what I shall call in future a "eurycolpic fold," the word, from the Greek єขриколтол, simply suggesting the fact that valleys having the peculiar characters of "gräben" may be caused by folding due to lateral pressure; and, as we have seen, this sort of folding has occurred all along the main central "gräben" series in Africa. Throughout this series the valleys seem invariably to have arisen as byproducts of such folding, and not through the vertical subsidence of strips of an ancient plateau.

Having thus discussed the structural features of the main eurycolpic depression, we may now endeavour to ascertain the number, extent and inter-relationships of these remarkable folds. In attempting to do this we are greatly indebted to a valuable contribution to the subject by Dr. Kohlschütter, who has recently returned from the German Gravitational Survey in East Central Africa. During the course of the investigations of this survey it was found that the great Nyassa valley, after passing to the north of the group of small volcanic cones in its floor, divides, giving off first a branch to the north-east which becomes wider, and finally appears to open out and disappear among the hills of Ussangu and Uhehe. 'The more westerly branch of the valley of Nyassa is directly continuous with the valley of Lake Rukwa, and in the vicinity of this lake the valley sends off another branch which runs to the south and appears actually to join the Nyassa valley near the region of Mount Waller. Northward the Rukwa valley has been found to run at an acute angle into the great depression of Tanganyika itself, and it appears extremely probable that it actually crosses the Tanganyika trough in the region of Karama, appearing 
on the western side of the lake as the flat-bottomed gap in the western rampart of hills, through which the Luakuga river, the outlet of Tanganyika, flows into the Congo.

It seems certain, moreover, from the surveys of $\mathrm{Mr}$. Wallace and others, that both the salt Mwero and the true Mwero depressions exist in smaller branches of the southern part of the great Tanganyika valley, while, as I* have pointed out elsewhere, the Lufu valley and the whole of Cameron gulf are included in a eurycolpic fold which runs at right angles to the Tanganyika trough.

The main Tanganyika trough, thus, both branches, and is intersected by the Rukwa valley; but beyond this point, we found it to be continued and extremely well marked as a single depression all the way to the Albert Edward Nyanza. Here another valley strikes it, from the west, and passes across the depression as the hollow in which lake Ruisamba is contained. (See map facing p. 8o.)

Whether the eastern branches of the Nyassa valley really are connected up with the lesser eastern series, which occurs to the east of Kilima Njaro and contains Lakes Beringo and Rudolf, is not, I believe, known, but it will become obvious, on referring to the geological maps, that the arrangement of these valleys is certainly extremely complex and curious. The two main systems run north and south, and both round the great depression in which the vast waters of the Victoria Nyanza have accumulated.

There is in fact nothing elsewhere, upon the earth, comparable to this unique series of rectilinear folds, which cross, and intersect one another, at all sorts of angles,

* On the physingraphical features of the Nyassa Tanganyika plateau. Joumal of the koyal Gcographical Society, Septcmler, I S97. 
throughout a great part of equatorial Africa, and the extraordinary complexity of which we are only just beginning to understand. The two greater longitudinal series, which were first known, have been likened by Suess to the cracklike "rills" that traverse the surface of the moon ; but in their present complex aspect they appear to me to be far more closely comparable to the so-called canal systems which can be seen to form a dark lacework over the equatorial portion of the planet Mars. I do not intend to push this comparison any further, but it might be fruitful to bear in mind that these equatorial, terrestrial, and martian networks, are certainly in some respects analogous.

In considering these remarkable folds still further, we find, as one of their most striking features, that their floors are more or less invariably strewn with active and extinct volcanic cones. We may say, in fact, that along any of these great valleys we have only to go far enough in order to encounter past or present evidence of intense volcanic activity and terrestrial impermanence. Thus the short series to the east opposite Mombassa contains Kilima Njaro and its associated cones. The Beringo series contains many extinct volcanoes, such as Longonot, and further to the north the active cones which have been found in the neighbourhood of Lake Rudolf, while finally, all along the floor of the vast western series of valleys in relation to Tanganyika, we have equal evidence of past and present volcanic activities. Often as in the case of the Mfumbiro chain on a gigantic scale.

This relation in Africa of the volcanoes of the continent to the floors of the eurycolpic folds is not, however, difficult to understand; we have seen that these valleys have 



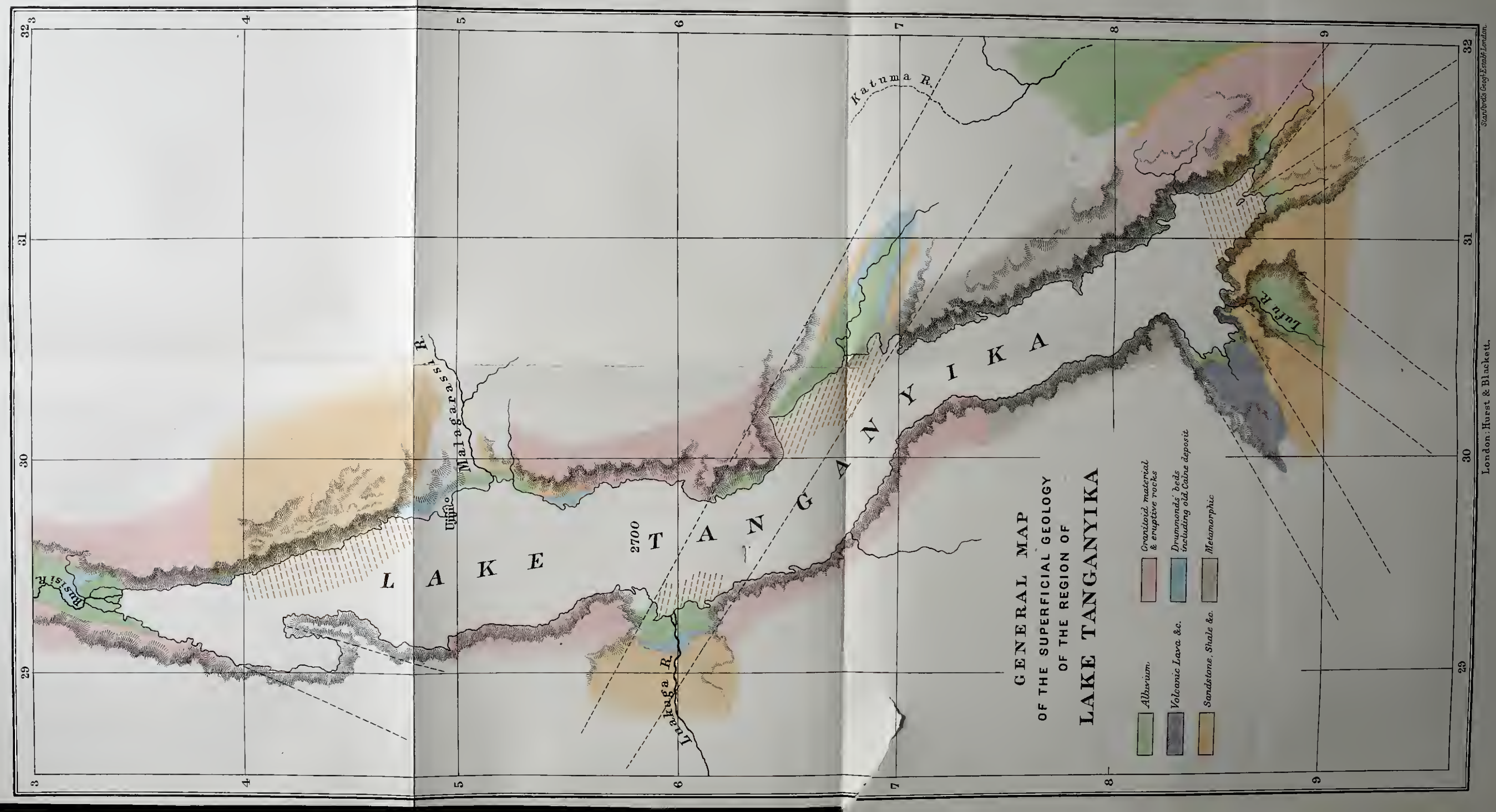



generally been produced by the formation of heights and valleys due to lateral pressure, and consequently the crushing down of their floors (which as we saw in the region of Nyassa is actually taking place at the present time) must have produced tremendous heat, while the tendency for water to accumulate in these depressions will have led naturally to the production of volcanic phenomena along the hollow courses of the folds. 


\section{CHAPTER IV.}

THE SUPERFICIAL GFOLOGY OF TIE REGIONS OF THF

GREAT LAKES.

In the preceding chapter it was seen that the whole of the geology of a very large portion of Central Africa is subordinated to, and is in fact an expression of, the gradual folding and elevation of the earth's surface in wrinkles running parallel with the theoretical axis of the Great Central Range. That there was a time in which no central range existed goes without saying, and that there were also many periods during which the characters of the interior were not those of the present day, is made clearly evident, as we have seen, by the simple fact that at some time horizontal strata stretched across the present site of greatest elevation and distortion, both in the region of Lake Nyassa and Lake Tanganyika; while, lastly; it is made clear by the observations I have described relating to the recent depression of the floor of Nyassa in the north, and the elevation elsewhere of the bottom of the lake, which has occurred as late and later than postpleistocene times, that the activity of the continent with respect to the Great Central Range is not yet dead. There has, moreover, evidently occurred a succession of efforts in such movements, and these efforts are, in several places, 
still going on. Were Africa, as it was at one time supposed to be, an ancient granitoid land-mass, without aqueous deposits of any kind on its surface beyond those of local lakes and marshes, we might show that the earth movements giving rise to its present form had been maintained through a lengthy period. But we could find no evidence which would be of any value in fixing the chronological relationships of the different outbursts of activity which have taken place in different parts of the area; nor should we be able to form any clear conception of the configuration which the continent might have possessed in ancient times. The gradual discovery by Speke and Grant, by Drummond,* Cornet, $†$ and ourselves, of extensive aqueous deposits of different ages and character, which cover enormous areas of the interior and are of enormous depth, have, however, completely altered the possible results to be obtained from a study of the geology of the African interior. By an examination of the nature of these beds, of the relationships which they bear one to another, and by the study of the manner in which they have been affected by the successive earth movements which have taken place, it is even now possible to throw some light upon this hitherto mysterious and enigmatical land-mass, and, at any rate, to show that its past history is not at all in unison with existing theoretical anticipations.

As by far the most extended and continuous geological studies of the African interior which have hitherto been made are those which were undertaken during the first, and especially by my colleague, Mr. Fergusson, during the second Tanganyika expeditions, it will be convenient to deal primarily with the facts recorded during these two

* Tropical Africa.

† J. Cornet La Gíologrie du Bassin du Congro, Le Aonvement Géogr. I \$97, Bel. 14. 
journeys, and only afterwards to attempt to bring them into relation with the more fragmentary observations made by several other investigators, more especially to the cast and to the west of the Great Central Range along which I led the expeditions of 1896 and 1900.

In bringing the results of these investigations before the reader, it will further be convenient to consider the area with which we have to deal from south to north.

In the first place we shall have the Zambesi and Nyassa districts as far as the high country which bounds Lake Nyassa immediately to the north. The second will include the territory northward as far as Ujiji on Tanganyika ; and the third the regions north of this as far as the Albert Nyanza, in the first parallel of north latitucle. But before proceeding, it should be pointed out that the area with which it is necessary to deal is immense, that it is in nearly all parts a terrible country to geologise in, or even to get through at all, and that it is to a very large extent still wholly unexplored. It has been traversed this way and that, but the wide spaces between these narrow lines are unknown wildernesses still. It is therefore extremely probable that surprises of all sorts await us in the way of geological discovery, and it is practically certain that whatever conclusions it may now be legitimate to arrive at from a contemplation of the known facts of the geology of the interior, will have to be considerably modified as time goes on.

In the more southern section of the African interior, which includes the Shiri highlands, and the province of Mozambique, part of Northern Charterland, the Marotse country, and the little known districts of the far west, the superficial geology is by no means always simple. It is, indeed, far more complex than has been generally 


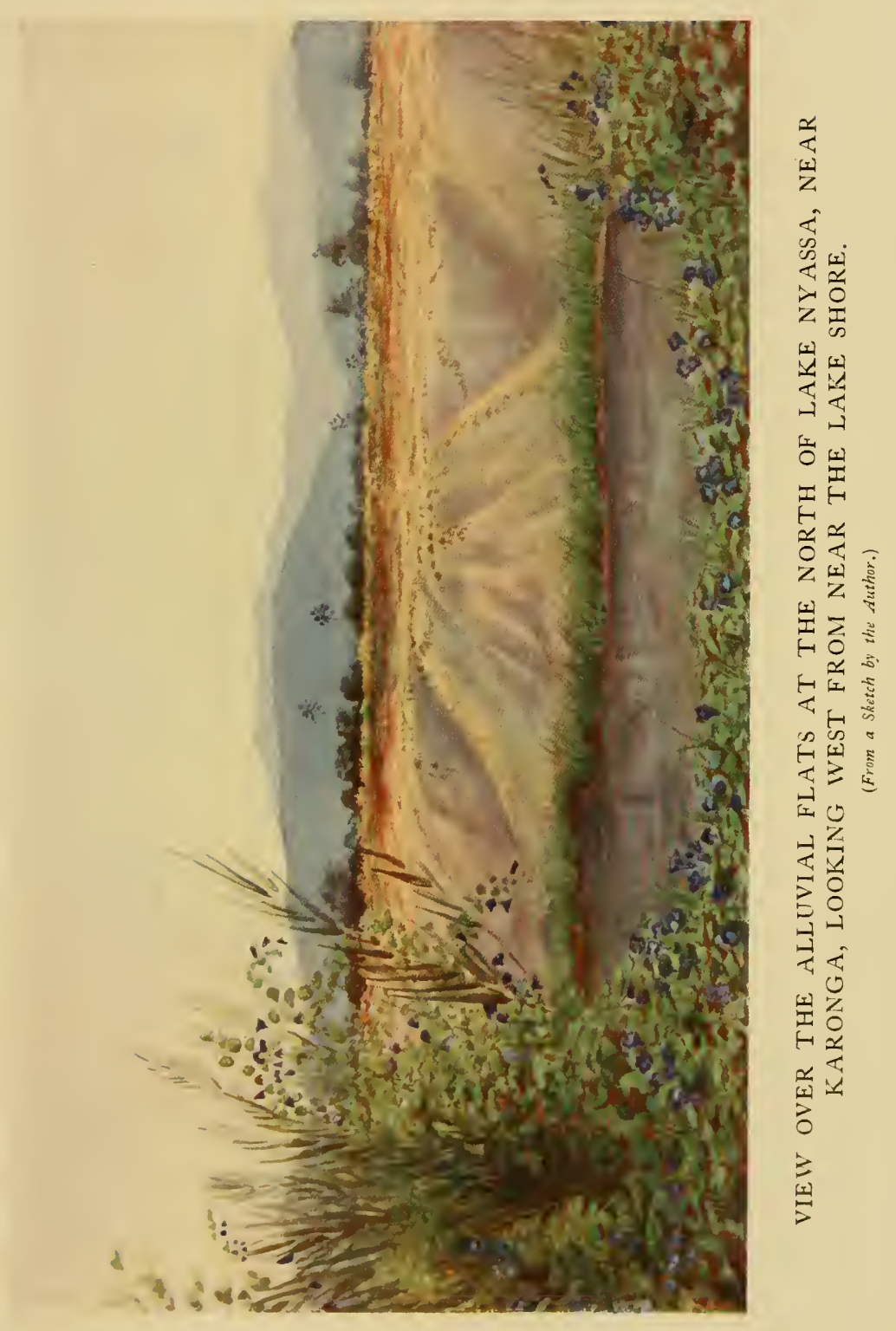



supposed, and in the neighbourhood of the central range it in general possesses none of those characters which have so often been spoken of as showing that Central Africa is, geologically speaking, without a history. Granting that portions of the continent to the north and east may be the remains of a possibly paleozoic land-mass, even these ancient terrestrial areas are by no means without interest in a geological sense. Consider for a moment the characters of the Shiri highland district. It is in reality a tongue of the mountainous interior which stretches from the east of the Shiri river into the vast Zambesi swamps. Once over the steep forest-clad hills which bound the region to the south, we are in a hilly upland country, which in the configuration of its masses closely resembles the mountainous districts encountered in the interior of Sicily. The hills are of granitoid material, and wherever they enclose extensive valleys, these valleys are true rock valleys; and are generally filled up to a certain level with the silt of old lakes, and ancient alluvium; the strange flats produced in this way between the hills presenting a very curious and typical appearance (see illustration on page 59). From the absolutely horizontal character of the layers of mud and gravel and ancient lake deposit of which these plains are composed, it is evident that they have never been disturbed by local elevation or distortion; and the mass of horizontal material encountered in such a valley is, in a sense, the measure of the disintegration which has gone on since the hills surrounding it assumed their present characters. If we could make a cutting, or sink an artesian well in the centre of such a valley, we should find it to be composed of older and older strata, and the age of these beds might, and probably would, be proclaimed by the nature of the animal remains we should encounter in the course 
of our supposed boring. Where alluvium and lake deposit has accumulated in this manner in vast masses, as it has on the Shirwa plain, for example, and in the basin of Lake Pamalombi, there are, unfortunately, no very deep water cuttings to be found, and the examination of those which exist by Sir John Kirk, ourselves and others, have revealed nothing but the semi-fossilised remains of existing land animals, such as elephants, hippopotami, and the remains of fishes and fresh-water shells. In the case of the great Shirwa plain, however, these lake deposits and layers of terrestrial alluvium are, by whatever method we may estimate them, very thick, and their deposition must have gone on without break from a remote geological antiquity until the present day. It is, therefore, quite certain that deep excavation in such localities, or their examination in some favourable spots which have yet to be discovered, would reveal in their deeper portions animal remains which differ from those now inhabiting the African lakes and plains. There is no reason why such flats as these occurring in the Shiri highlands should not contain zoological remains as different from the existing fauna, and as full of interest, as the remains recently obtained from the very similar flats in Madagascar by Mr. Forsyth Major, and more recently from Fayum by Mr. Andrews.

Passing to the west of the Shiri districts we find that in part of the Nyassa region proper, as I explained in the preceding chapter, the geological characters of the country throughout the whole district are very similar to those of the Shiri highlands; granitoid ridges run north and south, and contain between them rock valleys which are often partially filled up with horizontal masses of old lake deposit and alluvium, these masses themselves representing the wear and tear of a country that has not changed much since the 


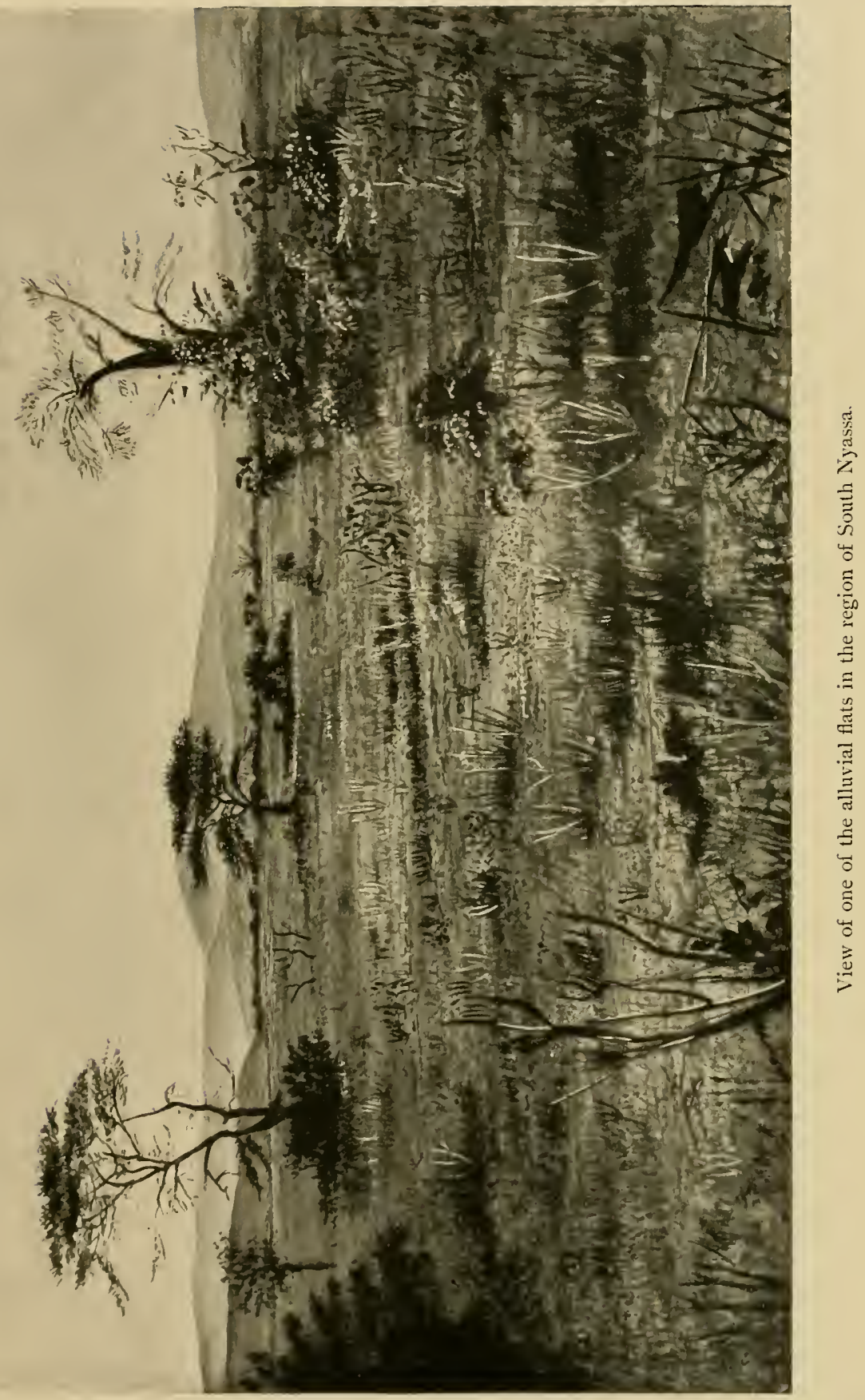



characters which its surrounding mountain masses now present were first acquired. Half way up Nyassa at Mount Waller, however, we encounter the complete change in the geological character of the country to which I alluded in the preceding chapter, thick sandstone deposits appearing sandwiched in between granitoid hills to the north and south. We in fact here encounter a stratified neck composed of sandstone, quartzites, conglomerates, and yellow and grey shales which are between two and three thousand feet thick, and stretch completely across the lake from east to west. They have been cut by two chief lines of faulting, which are coincident with the opposing shores of the lake, so that faces of the sandstone and conglomerates, etc., have been raised up into imposing lines of cliffs more than two thousand feet above the lake shore on either side. They extend to the east of Nyassa, but how far in this direction has not, I believe, been hitherto ascertained.* To the west they certainly pass into the Loangwa valley, where similar faulting has been observed, they reappear among the mountains flanking the north of the lake, and they extend along the track of the old Stevenson Road as far as the hills which flank to the north the depression which exists about Fort Hill. These sandstones are often much distorted, often metamorphosed; and at the north end of Nyassa, between Karonga and Fort Hill, they are greatly tilted and broken, sloping at a high angle out of the bed of the lake.

The massive sandstones and conglomerates just

\footnotetext{
* It appears, however, from Bornhardt's map of the German territory about the north of Lake Nyassa that these deposits actually extend into the great depression of the Rovuma valley; which in turn stretches directly to the Indian Occan. Still later, observations have come to hand, which show that similar deposits cover a considerable area to the east of Nyassa and extend probably as far south as Pemba on the coast of the Mozambique.
} 
described are a very striking series of formations, they are very similar to the sandstones and conglomerates which have been found south of the Zambesi in relation to the gold-bearing districts of Salisbury and Johannisburg. They are probably related to the extensive sandstone deposits which are said to occur north of the Zambesi in conjunction with coal arcas, and they may possibly communicate directly with these deposits round the west and south of the Nyassa region. They are also similar and probably identical with the red sandstone and conglomerates which occur in an enormous series of deposits in the region of Tanganyika, Rukwa and Mwero. They were first observed by Joseph Thompson, and have often been quite erroneously spoken of as Karoo beds.

Near Mount Waller some of the less upraised sheets of sandstone bear, as I have said, above them lake deposits of white chalky limestone, in which there are to be found the remains of the molluscs which now live in Nyassa. But between Karonga and Fort Hill there are encountered, resting unconformably on the old tilted red sandstones, masses of grey and blue stratified rock which are obviously of a different date and origin, and it was in these that Drummond found the remains of ganoid fish. These remains were examined by Professor Traquair and appear to be the fragments of four new polypteroids closely similar to several marine triassic forms. The fossil shells from the same beds were also new; and were not like the bivalves either of Nyassa or Tanganyika. They were examined by Professor Rupert Jones and regarded as probably estuarine forms. Between Nyassa and Tanganyika in this region there are also modern lake deposits lying horizontally and unconformably over the tilted sandstones and the similarly tilted Drummond scries. 


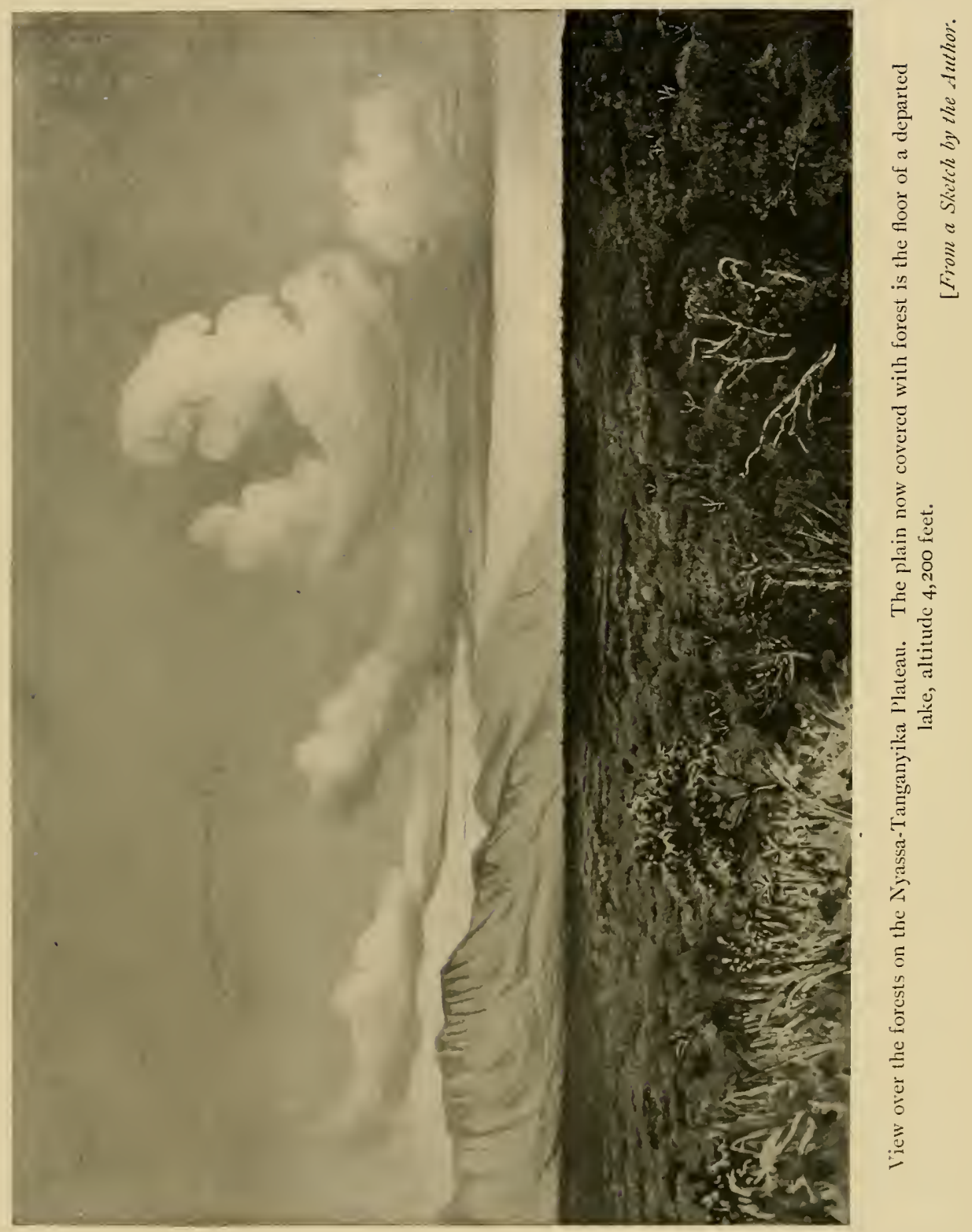



In the Nyassa region, it is thus seen that there are three very distinct types of aqueous deposit. Beginning at the top of the series, there is the undisturbed and obviously modern lake deposit, then the slightly disturbed and tilted white chalky limestones found bordering Nyassa itself (pleistocene), and beneath these are first Drummond's beds (probably triassic estuarine), and then the much older, extensive and probably marine sandstones of the Mount Waller series. All these three deposits are quite unconformable one with another, and they represent quite distinct periods in the geological history of the region in which they occur. But since they are found to appear extensively elsewhere, and will be encountered again and again as we proceed, it will be convenient to distinguish the periods to which they belong by distinctive names, and I shall therefore in the sequel speak of the lowest as the Old African sandstones, the next as Drummond's beds, and the white limestones of Nyassa as the African-lake-pleistocenes.

Drummond's beds, so far as I have encountered them, are never very extensive, they only cover a few miles at the north of Nyassa, but the Old African sandstones, on the other hand, are not only in places more than three thousand feet thick, but cover at the present time actually millions of square miles. These Old African sandstones, so far as their examination has gone, have nowhere yet proved fossiliferous ; but there is, as I have said, a close similarity between the massive sandstones of Mount Waller and the massive sandstones which flank the east and west of Lake Tanganyika, for a hundred miles from the south. All these more northerly sandstone deposits appear further to be similar to, and actually continuous with, the formations occurring to the west, in the regions of Lake Mwero, and to the east of Tanganyika, throughout the region of Rukwa, 
and to the south of it. Further north, on Tanganyika itself, these same deposits reappear and seem to cross the lake diagonally, and are found in association with beds similar to the Drummond series at Masswa south of Ujiji. They then continue with little interruption almost to the north of the lake, the tilted conglomerates and shales of the series forming the crests of some of the high mountains which flank Tanganyika on the east between Ujiji and Usambura. The massive stratified beds which appear along the northeast coast of Tanganyika are also unquestionably the same series of formations as the stratified beds first seen further north and east by Speke, and more latterly encountered by Mr. Scott Elliot west of the Victoria Nyanza. (The Karagwe series of Gregory.)

Passing far to the west, beds which almost unquestionably belong to this series have been found by Cornet on the Lualaba and the upper tributaries of the Congo.

It may be said, therefore, that there are vast aqueous deposits in the African interior (the Old African sandstones), which are of enormous thickness, and which there is reason to believe are actually continuous throughout an area as large as the whole Australian continent (see map, facing p. 75). They occur most extensively to the west of the Great Central Range, and, judging from their great thickness, from their obviously aqueous origin, and from their vast superficial extent, it would appear probable that these sandstones are to be regarded as of marine origin. They are very possibly similar to the coast beds of sandstone which occur in the Taru desert west of Mombasa, and it is quite likely that they are actually continuous with the sandstones of the north of the province of Mozambique, which occur in association with coal at Pemba. At any rate, and beyond question they show that a 


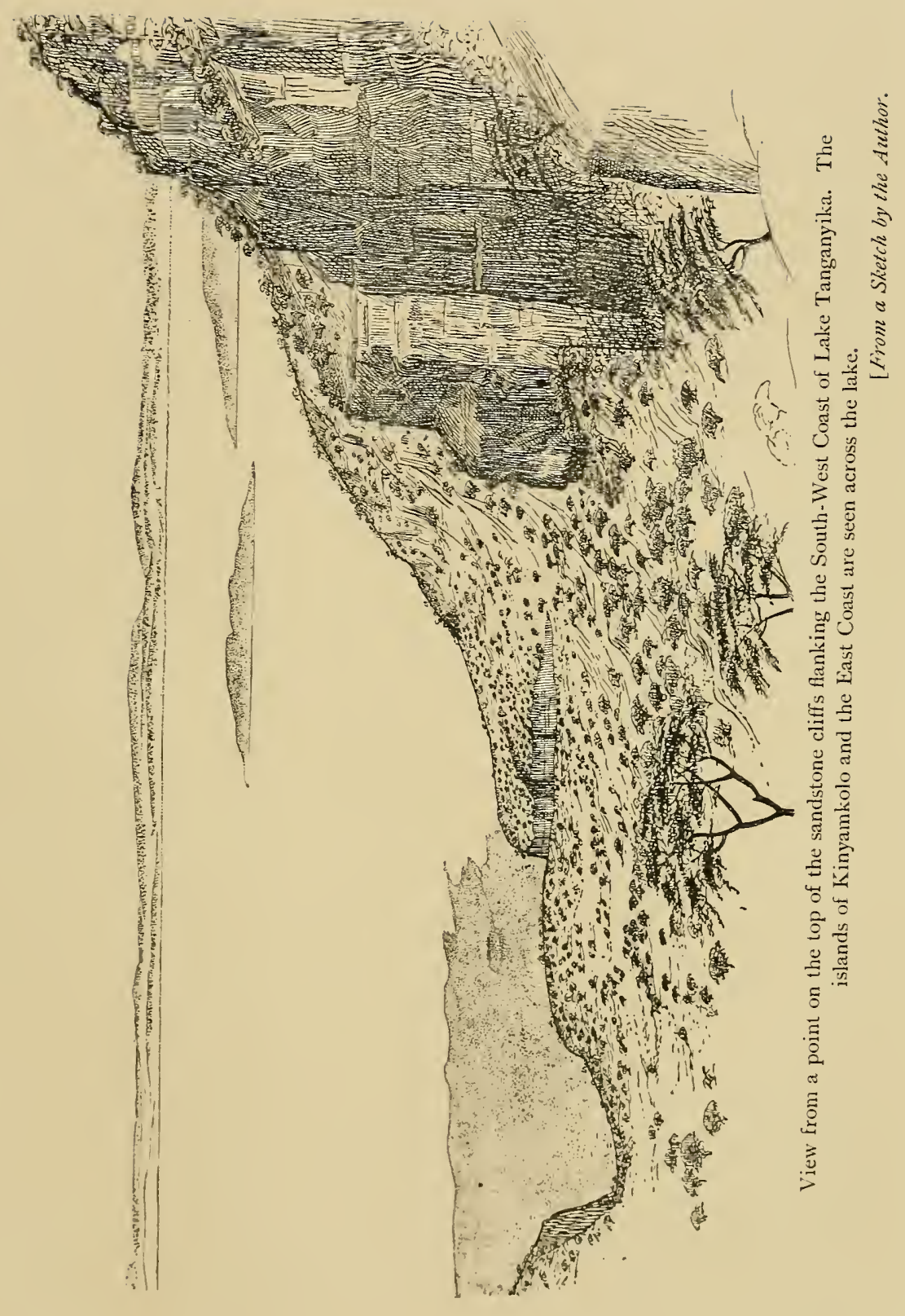


very large part of the interior, most of the region between Tanganyika and Nyassa, many districts east of this line to the north and to the south, together with huge areas to the west, were all portions of a great clepression which in many places extended across the axis of the Great Central Range. At some time or other there were wide, deep waters in these regions, so wide and so deep that more than three thousand feet of sandstones were quietly laid down in them, and, consequently, there was a time when the present Central African region was vastly different from what it is now.* It may very probably have been that portions of this area, the Shiri highlands, some of the high granitoid ridges of the Great Central Range, and portions of British and German East Africa, were even then dry land, but there must unquestionably have been wide stretches of open, deep water between whatever land-masses existed, and these land-masses in all probability formed a group of islands occupying the position of the equatorial portion of the continent of to-day. The changes which followed were produced by the initial stages in the formation of the great central chain. The arcas of ancient depression in which the Old African sandstones had been deposited became disturbed and gradually more and more involved with the extension of the folding and the crinkling of the earth's crust along axes running north and south, until in time their floors were raised up, as we have seen, into part of the hog's back of the modern African peninsula ; the sandstones and conglomerates being, finally, in places folded up and broken into the high crests and scarps of the Great Central Range as we find it now.

\footnotetext{
* It would seem indeed to be inclicated that there was at some time an east and west depression of considerable breadth which very possibly separated the northern and southern portions of the continent, and connected up the oceans on its east and west coasts (see map facing p. 75).
} 


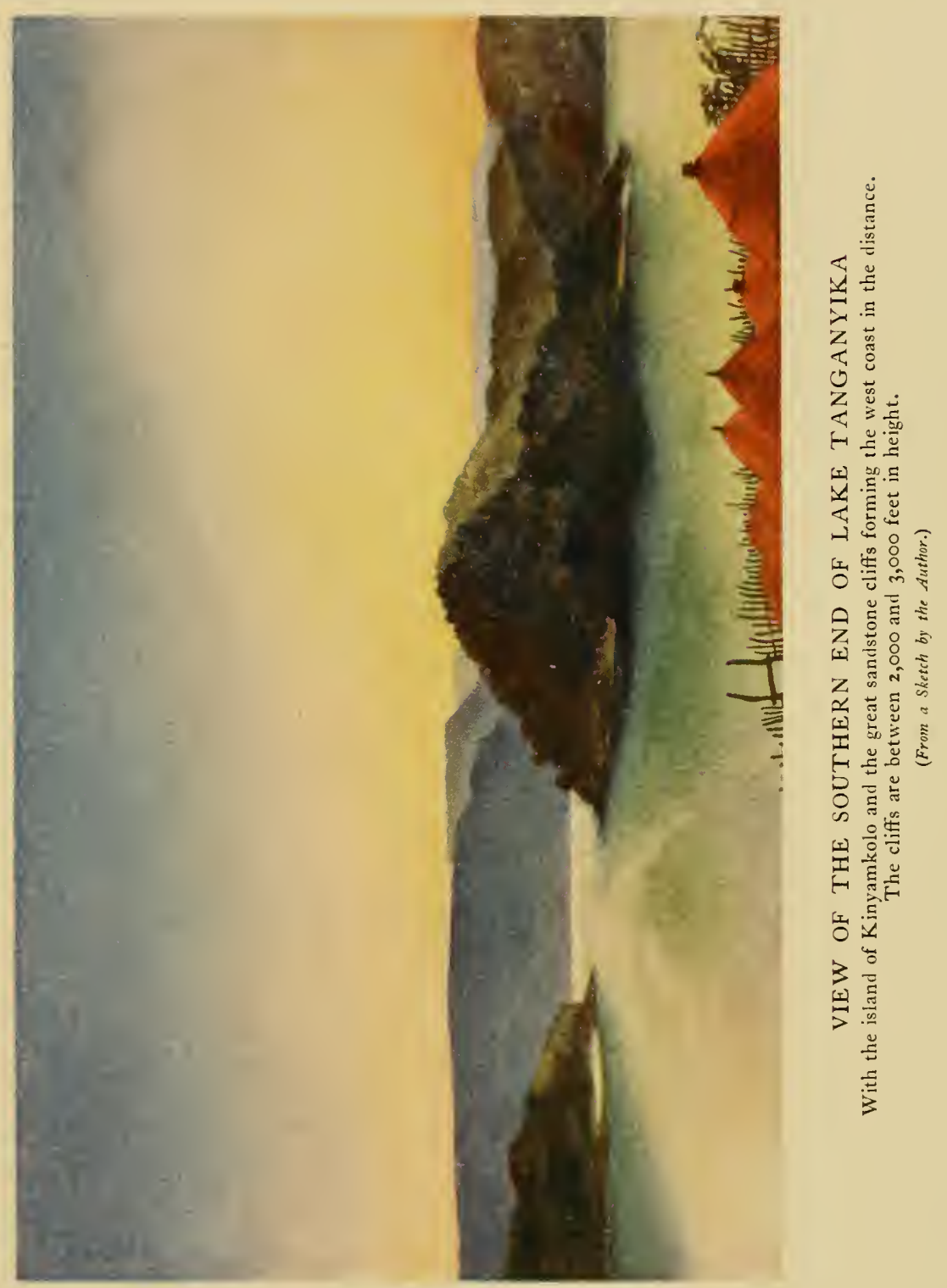



While these changes were in progress there were deposited under the more permanent of the retreating waters sediments represented by those covering the Old African sandstones at such places as Masswa on Tanganyika, round the source of the Luakuga on the same lake, and at the north end of Nyassa; and the triassic character of the organic remains which some of these, the Drummond's beds, have been found to contain gives us a clue as to the geological period during which the folding of the central range and the formation of the eurycolpic folds actually began to take place.

There does not seem to be any valid reason why the broad conclusions thus reached respecting the geological nature of the African interior, and the past history of this continent should not be accepted as, at any rate, a first approximation to a correct reading of the facts, and, although there can be no doubt that, as we become better acquainted with the country and the details of its composition, our conceptions of the history of particular portions of the area will be enormously elaborated by an infinity of fresh illustration, I have a strong conviction that our conception of the formation of the land-mass will remain dominated by the conceptions respecting its past history which have just been sketched.

$U_{p}$ to this point the geological characters of the great African lake region have been dealt with in a very general way, and from the outset this method has been intentionally pursued. There are, as we have seen, certain broad features of the structure of Africa as a land-mass which forcibly proclaim themselves now that we are becoming better acquainted with the interior, and it is above all things important that these matters should be fully apprehended during the future attempts which will 
certainly be made to deal in an exhaustive manner with the geology of different districts. It is, however, even now possible, and it is certainly interesting, to attempt to form some definite conception of the relative ages of the great lakes and the valleys in which they are contained.

If we consider the Nyassa region, there is, as we have seen, little or no evidence in its southern districts of any disturbance of the country since it acquired its present characters. Although Nyassa, P'amalombi, and Shirwa were probably all at one time connected together as a great lake, their present separation has been brought about by nothing more than the gradual silting up of the valleys, the drift of sand, and the wearing away of the rockridges underlying the Murchison cataracts. By this latter process the general water-level fell, Nyassa, Pamalombi, and Shirwa became distinct lakes, Shirwa ceased to overflow, and all three contracted in their beds, leaving wide alluvial plains and terraces exposed about their ancient margins.

One general fall of Nyassa was marked by the baobab beach terrace, to which I have referred, and which can be traced more or less distinctly all round the lake, but it is obliterated and more or less indistinct in certain districts towards the north, owing to the fact that the great structural changes which have taken place in the northern portion of Nyassa have continued down to the present time, and are still going on. During the progress of these changes it is almost certain that the character and shape of the lake has been greatly altered. The sides of the valley, as we have seen, have been bodily raised, carrying the lake deposits with them, while, as a concomitant phenomenon of the folding, the floor of the present lake has been depressed, and is still being depressed, in the north. In consequence of this 
it would appear probable that the lake must have continued to extend northwards as the fold increased, and this view of the matter seems to be supported by the very singular fact that, as we found, in several places off the Livingstone range, the bottom of the lake although the water was 270 fathoms deep, is composed of practically bare rock, and quartz fragments, whereas further south the whole floor of Nyassa is covered with fine deep mud, or, in other words, it is suggested that the origin of this portion of the lake's floor is so modern that up to the present time very little fine sediment has had time to collect upon it. Similar evidence is afforded by the upraised lake deposits in the neighbourhood of Mount Waller. These deposits are not more than 70 to roo feet thick, they do not appear to be much denuded, and consequently they cannot have been deposited for any great length of time. In the south, on the other hand, we have in the region of Fort Johnston and Pamalombi, obviously vast depressions which are filled with lake deposits, and these latter, on the very lowest estimates, must be many hundreds of feet thick. It would appear therefore that the old fold which originally contained the southern portion of Nyassa has progressively extended northward, and, consequently, we encounter here for the first time, a fact which we shall encounter again, namely, that different portions of the same Lake valley may be of very different ages.

We saw that towards the north end of Nyassa the old African sandstones and Drummond's beds were both much contorted and often sloped at a high angle out of the floor of the present lake. There is no conformity between these series, and there must consequently have been in this area, first a period when the old African sandstones were laid down in deep water, afterwards there was a rising of the 
whole region, and subsequently possibly another sinking, but after a lapse of unknown duration, the less extensive aqueous deposits, constituting the Drummond series, were deposited inconformably over the top of the old African sandstones. In these latter beds there are, as we have seen, the remains of several ganoid fishes, which, according to Professor Traquair, are similar to, but specifically distinct from, the existing African species. Now the interest in this matter lies in the fact that the existing African polypteroicls do not occur in Nyassa, nor in any of the existing rivers of this region, nor in fact anywhere south of the Congo watershed. The shells which were found in the Drummond beds tell the same story, being more or less similar to but not quite like the Lamellibranchs at present found in Tanganyika. On referring to Professor Gregory's* general account of what was known of the geology of Central Africa in 1895 , we find reference made on page 230 to the further remarkable fact that the fossilised remains of an oligocene echinoderm appear to have been brought from the neighbourhood of north Nyassa, and from this Professor Gregory argues, with much apparent reason, that there must have been an extension of a comparatively recent sea into this portion of the African interior.

It would thus appear that at some time there was in this region a fauna consisting at any rate of ganoid fishes, echinoderms and molluscs; or, in other words, a marine fauna, and that these things entirely disappeared through the great physical changes and displacement which occurred during the extension of the Nyassa fold into this particular area. There is no vestige of a marine relic in the Nyassa fauna of to-day, and it would consequently appear that Nyassa extended into this region only after 
these animals had entirely disappeared. The valley of Nyassa is, however, as we have seen, continued into that of Lake Rukwa, and this in turn has been shown by Dr. Kohlschütter to run into the great trough of Tanganyika itself. The Rukwa valley appears bodily to cross Tanganyika in the vicinity of Karema and the Luakuga gap, and to continue westward into the great Congo depression. Unfortunately little or nothing is known of the deposits in the northern extension of the Nyassa valley in which Rukwa lies, but it appears from the observations of Dr. Fülleborn that the fauna of Rukwa differs from that of Nyassa, or of any of the lakes to the south with which he was acquainted.*

Thus it would appear that there was once a marine, possibly a triassic or Jurassic, fauna in the region of the north end of Nyassa, the existence of which entirely anteceded the northward extension of the present lake; that there is now no trace of this fauna in Nyassa or to the south of it; that the structural fold in which Nyassa lies can be traced to a junction with that of Rukwa; that the fauna of Rukwa differs from that of Nyassa or any of the other African lakes with which Fülleborn was acquainted; that the valley of Rukwa intersects that of Tanganyika and passes to the west, and lastly, that at the present time there is what appears to be the remains of a marine fauna containing jelly-fishes, the old ganoids, and what are apparently Jurassic gastropods, still living in Tanganyika.

From these considerations it would appear that the old sea which was once in the vicinity of Nyassa retreated west (it may be shown eventually that it retreated east

* I do not know whether any definite result of Fülleborn's investigations of lake kukwa have yet been published, and Dr. Kohlschiitter says he does not either. 
as well)* owing to a general folding and uprising of the earth's surface in this neighbourhood. It woukl appear further that this sea continued to occupy the vicinity of at least a portion of Tanganyika for a very long time, during which the Drummond series of deposits were latid down as at Masswa, Karema, and on the west coast of 'Tanganyika near the Luakuga. Another phase of terrestrial activity then occurred, as can be seen by the smashing and faulting of the Drummond beds and more recent formations along many parts of the coast of Tanganyika. It was during these later movements that in all probability Tanganyika became cut off from the sea in the west, and the great lake assumed its modern appearance; while finally the sea swept still further to the west until it reached its present confines, but owing to the vastness and depth of the Tanganyika fold, the old marine fauna, or at least a part of it, succeeded in surviving in the lake even down to the present day.

It would also appear, just as in the case of Nyassa, that different parts of the Tanganyika valley have been formed at different times. The central part of Tanganyika, that which stretches between Karema and Ujiji, appears almost unquestionably to be the oldest, while the northern and southern portion are younger additions. This is shown by the fact that only in the middle of the lake have there been laid down deposits which are strictly comparable to the Drummond beds, and which in places have become raised and tilted during the continuation of the folds

* If we refer to the map facing page 75 , it will be seen that the areas of depression in which the old African sandstones occur stretch towards Lake Chiuta on the upper portion of the Lujenda river, and it has been reported to me that shells of one of the remarkable gastropods of Tanganyika are to be found in its vicinity. If this should be substantiated, the above suggestion that the ancient sea at one time occupying the interior of Africa retreated east as well as west would be confirmed. 



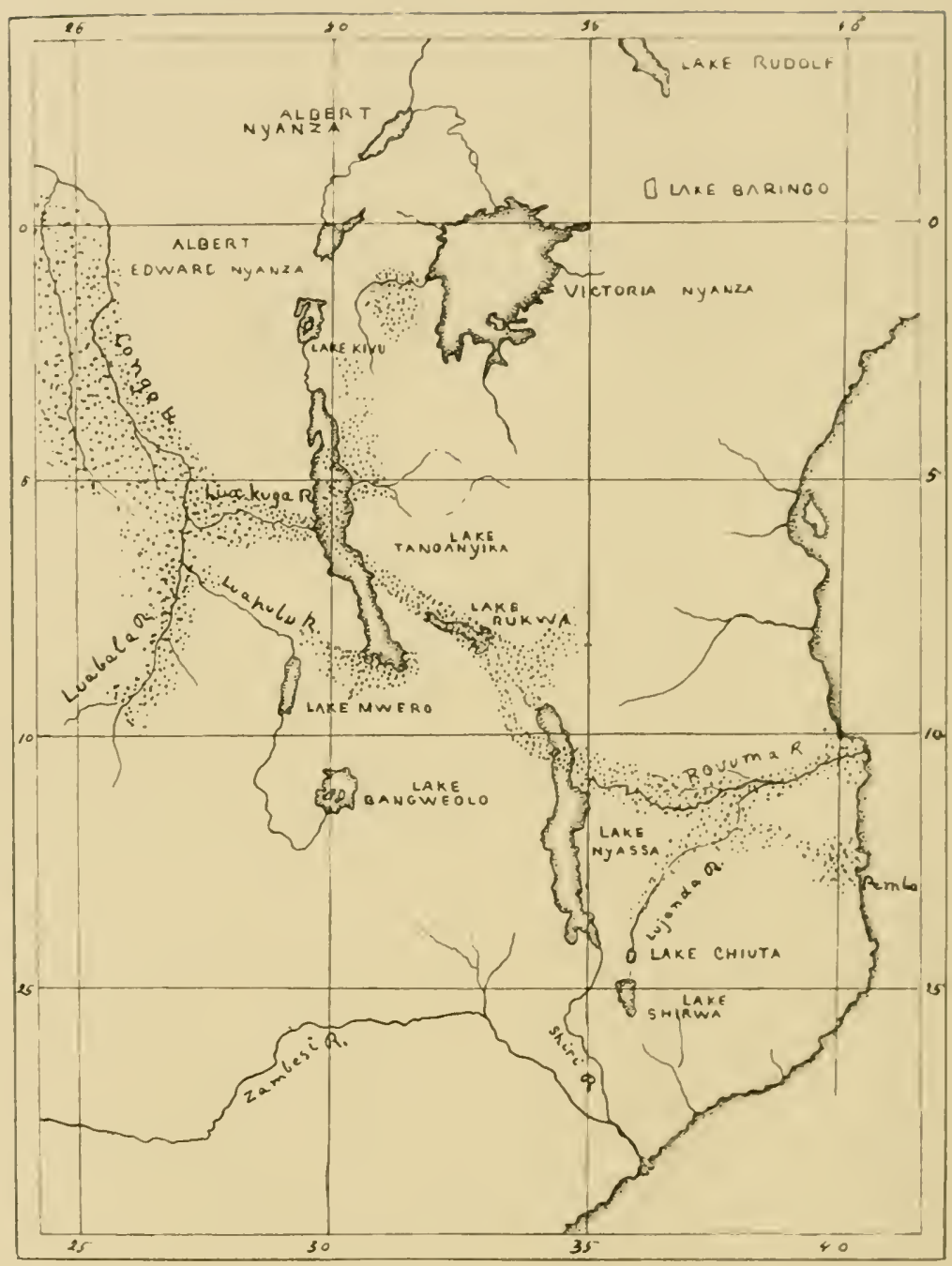

Map showing by dots the known extent of aquenus deposits in the African interior.

[ 7 o face paye 75 . 
extending the Tanganyika valley north and south. In the southern portions of Tanganyika there are no deposits of any kind besides the modern lake pleistocenes and the massive old African sandstones, while at the extreme north there are beds which extend to about twenty miles towards Kivu, and which in age appear to be intermediate between the Drummond series and the pleistocenes.*

* In this connection may be mentioned what, if the marine animals in Tanganyika are a pre-cretaceous stock, has appeared to some geologists an unaccountable factnamely, that on the west coast of the continent, to the south of the Cameroon mountains, for example, only cretaceous and post-cretaceous marine deposits have been found. This matter is now, however, in the light of our present fuller information readily intelligible. For we have seen that there were deposited in the interior, right across the valley of Tanganyika, in fact, aqueous beds, thousands of feet thick, which themselves underlie the triassic series to the south; and that subsequently the country was raised along the axis of the Great Central Range ; in consequence of which, the deposits in the interior are the oldest, and those nearer the sea, in general, progressively younger, as we proceed towards the coast. 


\section{CHAPTER V.}

TILE GEOLOGICAL TOPOGRAPHY OF TIIE REGION NORTII OF

TANGANYIKA TO THE ALBERT NYANZA.

IT has been seen that the eurycolpic folds in the more southern portions of Equatorial Africa, those in which lie Nyassa, Shirwa, Mwero, Rukwa and Tanganyika, constitute a series of depressions which have arisen as phenomena subordinate to the formation of the Great Central African Range. It is further probable, from existing observations, that the more northern and eastern series of valleys, those in which Rudolf. Stephanie and Beringo are found, have arisen in a similar manner. This more eastern series, from some way south of Beringo to Basso-Norack, has, up to the present time, been far better known than the much greater and more western series of folds, which contain Tanganyika, and extend beyond it to the Albert Nyanza on the Nile. The explorations of Thompson, Teleki, Stuhlmann and others, have resulted in the accumulation of an extensive series of observations relating to the more eastern districts. On the other hand, the northern continuations of the much broader and deeper depressions which hold Nyassa and Tanganyika, had, up to the departure of the second Tanganyika expedition, never been explored geologically at all beyond 


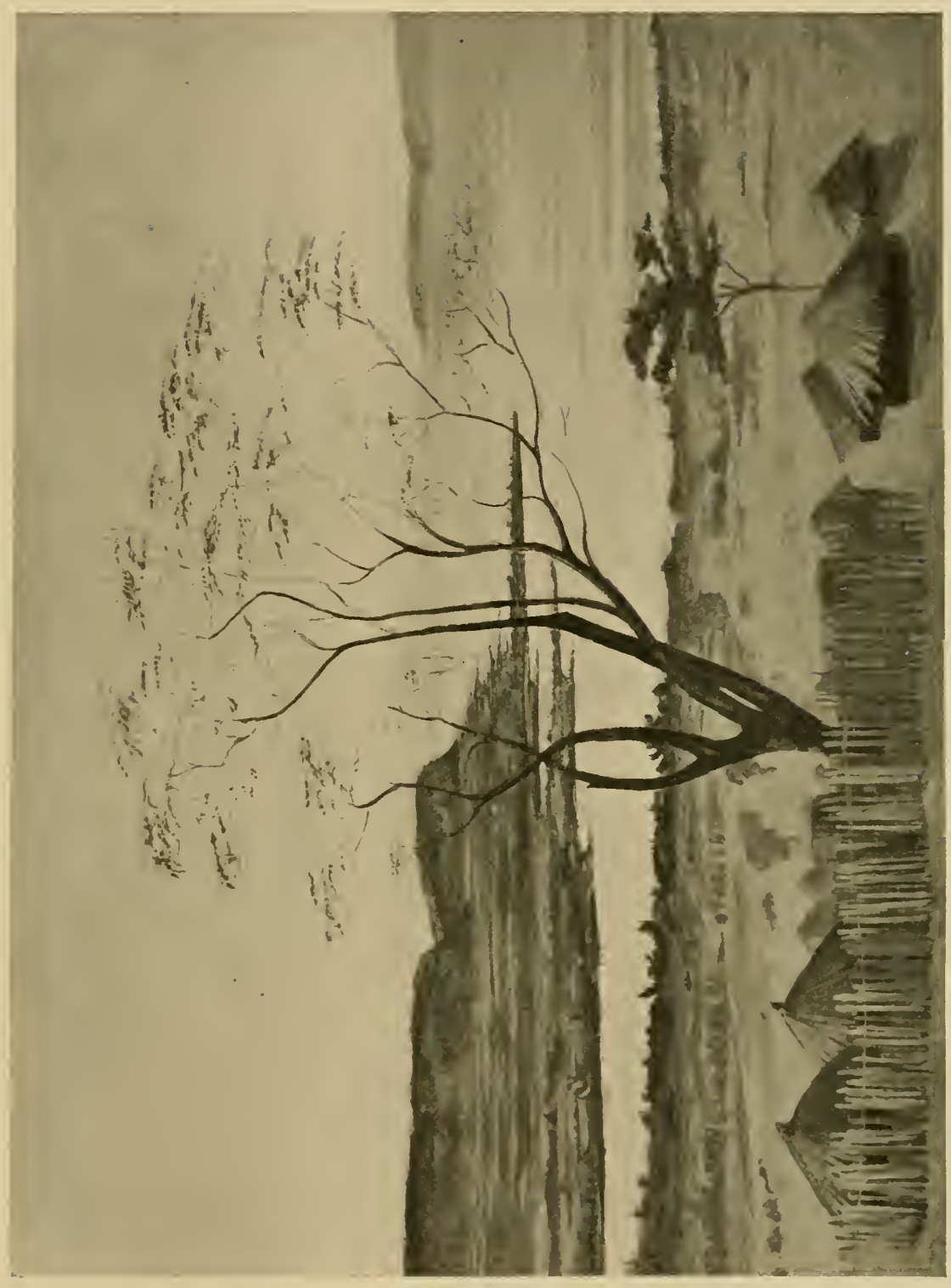

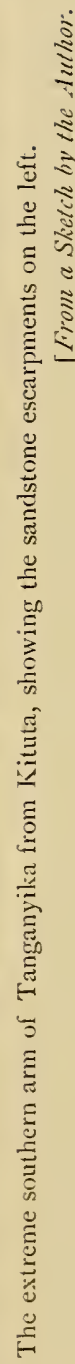



Ujiji. Our knowledge of the physiographical features of the country round Lake Kivu, the Mfumbiro Mountains, the Albert Edward Nyanza, and down the course of the Semliki River to the Albert Nyanza, was limited to some scrappy information gleaned from the observations and descriptions given by two or three travellers who had crossed the country from east to west. Thus, beginning in the south, both Baumann and Scott Elliott saw that the valley, in which Tanganyika lies, is continued north beyond the lake as a sort of channel among the hills. Götzen, crossing the continent about 150 miles further north from east to west, along the north shore of Lake Kivu, gave a very clear idea of what he saw of the valley of this lake, which could be traced beyond the Mfumbiro volcanoes in the direction of the Albert Edward Nyanza, while Stanley, and after him Stuhlmann, had examined the country which lies along the course of portions of the Semliki River to the west of the Ruwenzori Mountains.

When, therefore, these observations were considered together, it appeared probable, as, indeed, Suess had supposed, that the valley of Tanganyika was continued through the region of Kivu, the Albert Edward and the Albert Lakes, into the region of the Upper Nile, where it became confluent with the lesser eastern series of clefts in the region of Lake Rudolf. The mere possibility of this made the ascertainment of the character and structure of the districts lying between the north end of Tanganyika and the Albert Nyanza a matter of very great importance in dealing with the problem presented by the marine life of Tanganyika at the present day. For it might have been that an arm of the sea at one time stretched into Africa along these depressions, just in the same way as the Red Sea stretches 
into the African-Arabian land-mass now. It was, consequently, one of our primary objects to explore the region north of Tanganyika, as far as the Albert Nyanza itself, and in the present chapter I shall therefore give an account of these districts, as complete as the observations which we collected will permit. I have intentionally treated this part of the subject in a somewhat different manner from the districts to the south, partly because it has hitherto been almost unknown, and partly because the appreciation of the structure, and the recent geological history of these regions, is of the very utmost importance in attempting to form any broad conception of the geographical features which the greater part of Equatorial Africa now presents.

What can be shown to have occurred between Tanganyika and the Ruwenzori Mountains, probably within the last ten thousand years, has completely changed the relationship of the lakes and rivers, the watersheds and drainage areas, throughout the whole of tropical Africa, from the centre even to the very sea.

In order to understand this country it is necessary to start from some point to the south of the northern limit of Tanganyika like Ujiji, from whence on passing northward for about 70 miles, we find that the east coast of the lake is, in reality, formed by a series of gigantic scarps, one behind another. The first sweeps up precipitously from the lake shore, but on journeying inland others are found enclosing deep valleys, until, about 20 miles from the lake, I reached a kind of plateau formed by the crests of these ridges, which stood at heights varying from 7,000 to I 0,000 feet. In general the crests were composed of sandstone, conglomerates and quartzites, similar to those at the south of Tanganyika, and these crests were broken away into more or less well-formed cliff faces which looked towards 

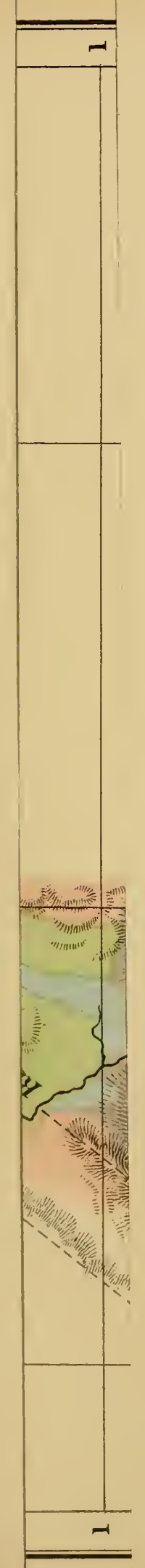



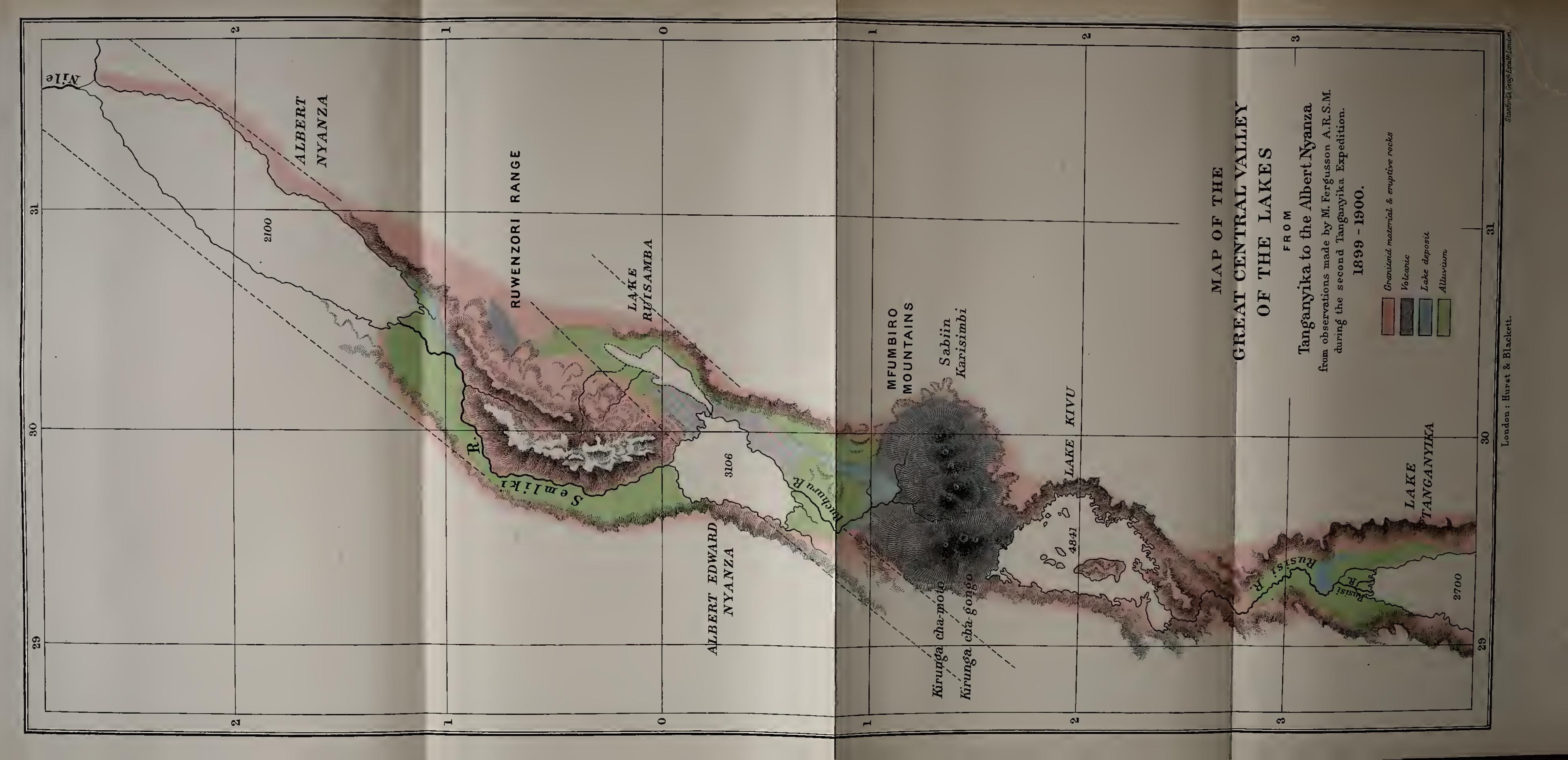



the lake. On the lake shore, at certain places, Viuwko and Lumungi, the sandstones were found to rest on granite, which can be seen just above the present water-line; but north of Lumungi the sandstone deposits disappear, and are succeeded by granites, gneiss and schists, which form the chief constituents of the great mountain range flanking the extreme north of Tanganyika on the east, and which can be seen running away north, parallel with the similar, but even higher, range encircling the lake to the west as far as the eye can see.

At several points on the shore of Tanganyika, between Ujiji and Usambora, at the extreme north end of the lake, I found, under these great sandstone scarps, layers of modern, broken lake deposit lying with the same dip, about $20^{\circ}$ to the east, as the sheets of old sandstone on which they rested. These modern lake-beds are now Ioo feet above the water-line, and contain the same peculiar halolimnic shells which are now found inhabiting the lake; but they are broken and upraised abruptly from the present floor of the lake along a line of faulting parallel to the shore, this fact in itself showing that the general upheaval, which has thrust the old sandstones Io,ooo feet into the air along the east coast, is still going vigorously on.

We found, on nearing the north end of Lake Tanganyika, that the great valley in which the lake lies (deeply enclosed by lofty, green hills) could be seen extending as a flat-bottomed trough, far beyond the northern shore; and we found also that the flat floor of this valley, after leaving Kajagga, near the inflowing Rusisi River (which comes from Kivu and opens by five mouths into the lake), was composed chiefly of modern sandstones and alluvium. At first the flat floor of the valley was covered with coarse grass and reeds; but, as we rose slowly from 
the lake, the more desiccated, inland steppes became covered with euphorbia trees, clumps of bush and groups of parktrees, the valley assuming more and more the characters of a park, until typical African-park scenery was reached some miles before the village of Buta-gata. All this country presented, in fact, in a striking manner, the peculiar zonedcharacter in its vegetation, which, as* I have shown elsewhere, marks the recession of water from land uncler a tropical sun. We were, incleed, passing over older and older ground as we moved away from the lake, and as we gradually rose from 100 to 200 feet above its surface, the plains composed of modern alluvium were found in places to be intersected by the decp cuttings formed by the storm torrents, which periodically flow from the eastern scarps, and in some of these cuttings, which were at times from so to 90 feet deep, older stratified materials were exposed. These strata were composed of brown and yellow sandstones, with a slight dip to the south, and embeckled in them there were apparent numerous fossilised remains. Examination of these showed that they consisted chiefly of the fragments of sheils, but I obtained a number of fairly preserved specimens, and these unquestionably belonged to several of the molluscs which now inhabit Tanganyika (Ncothauma, Nassopsis and Paramellania).

From these observations, it becomes clear that, at some time, Tanganyika extended many miles north of its present limit as a deep lake, and that besides its general water-level having fallen, the floor of the valley, north of Tanganyika, has also actually been raised, in the same manner that portions of the east coast have been raised, between Ujiji and Usambora. Beyond this point, i.e., north of Buta-gata, 


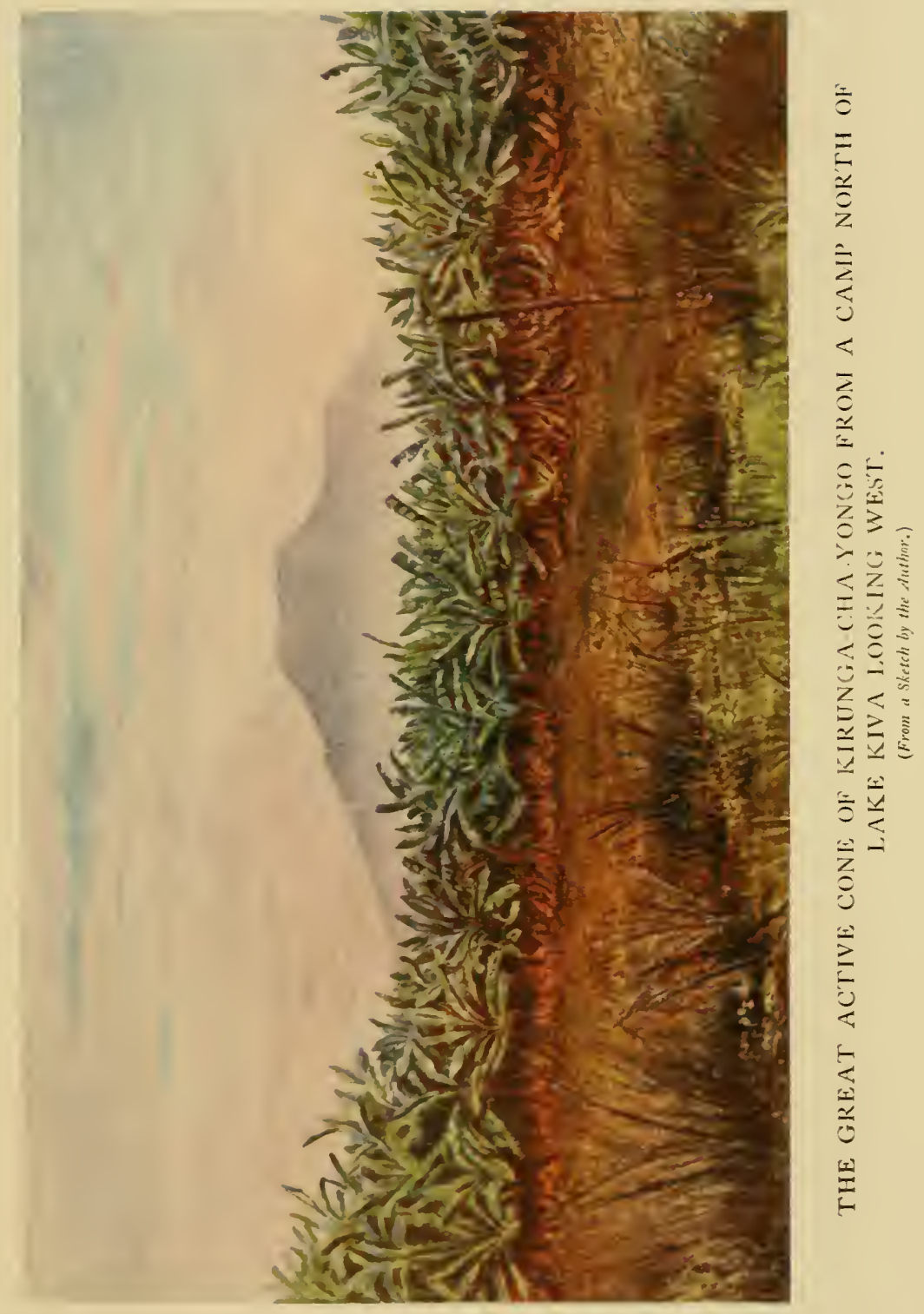






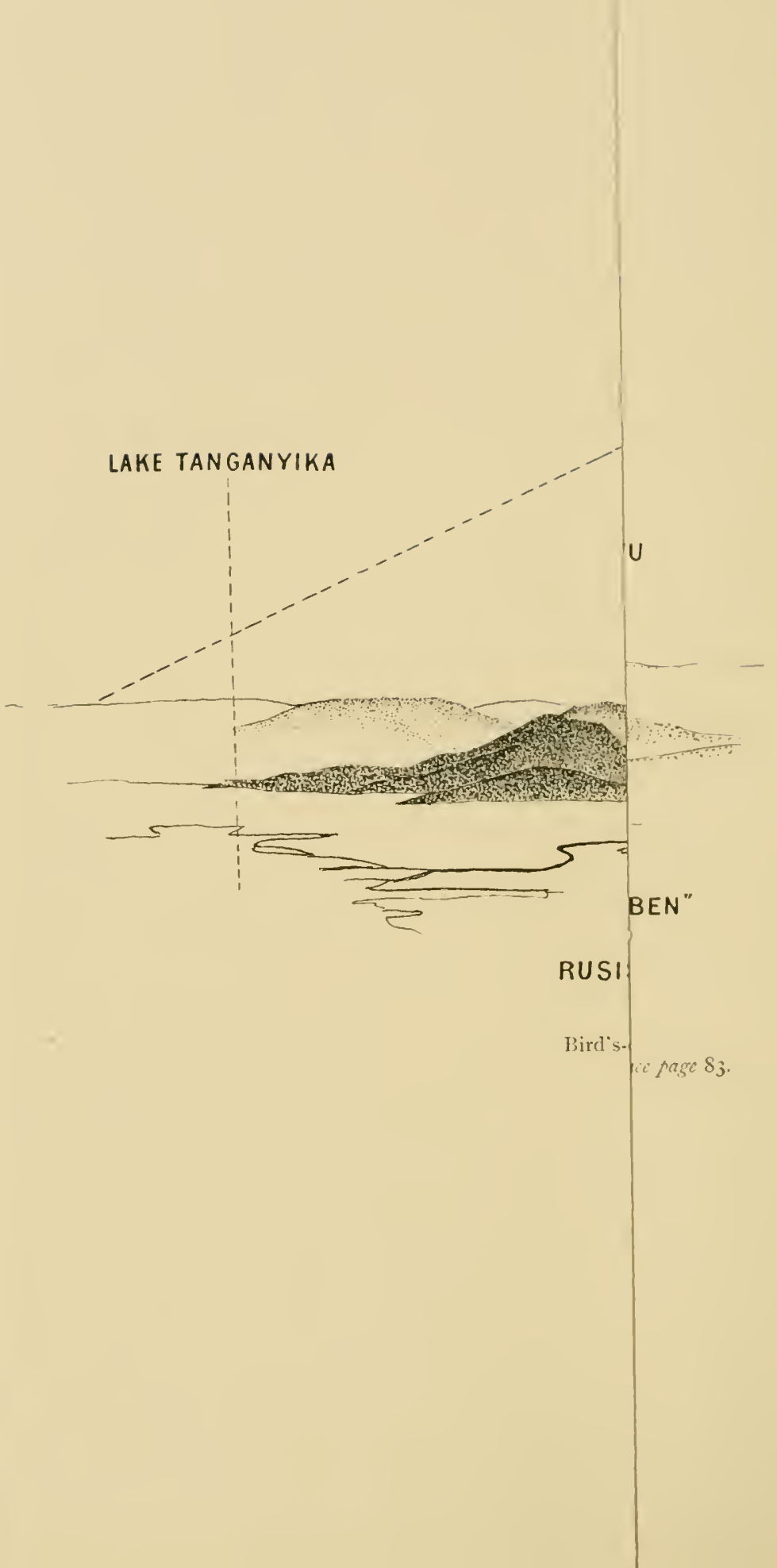


on the Rusisi River, matters change; the floor of the valley rises rapidly, for some 2,300 feet, and the rising ground is composed of old folds of gneiss and schist, covered with deep red soil, and against which the modern lake deposits to the south, finally terminate. Upon these gneissic ridges there is no trace of any lake-deposit or stratified material of any kind, and the great valley of Tanganyika is here, in fact, to a large extent filled up, but it is not actually obliterated. The flanking ranges could, as a matter of fact, be seen to continue east and west of us as we approached the southern extremity of Lake Kivu, at which point the floor of the great central eurycolpic fold begins to sink again. At present, the water of Lake Kivu stands at an altitude of 4,8or feet, and the outflow of the lake rushes away to the south in a white lace-work of foam, through a gorge in the hills as the Rusisi River, which in turn falls in a succession of swift cataracts down the great valley, until it eventually opens out by five mouths into Lake Tanganyika.

The upper part of the Rusisi gorge is not much worn, and does not appear to be very old; and from being a narrow depression in the south, the valley of Lake Kivu enlarges beyond Ishangi until it once more assumes the character of the great Tanganyika and Nyassa valleys; a broad expanse of water running north for 60 miles and about 30 to 40 miles broad, between high, flanking ranges, which, in places, reach an altitude of 10,000 feet.

Although, from a scenic point of view, the shores of Lake Kivu are exceedingly beautiful, their geological characters, with the exception of onc peculiar feature, are excessively monotonous. The flanking ranges round the lake were found to be composed entirely of schist and gneiss, which, inland, enclose deep valleys like those of Uganda, and 


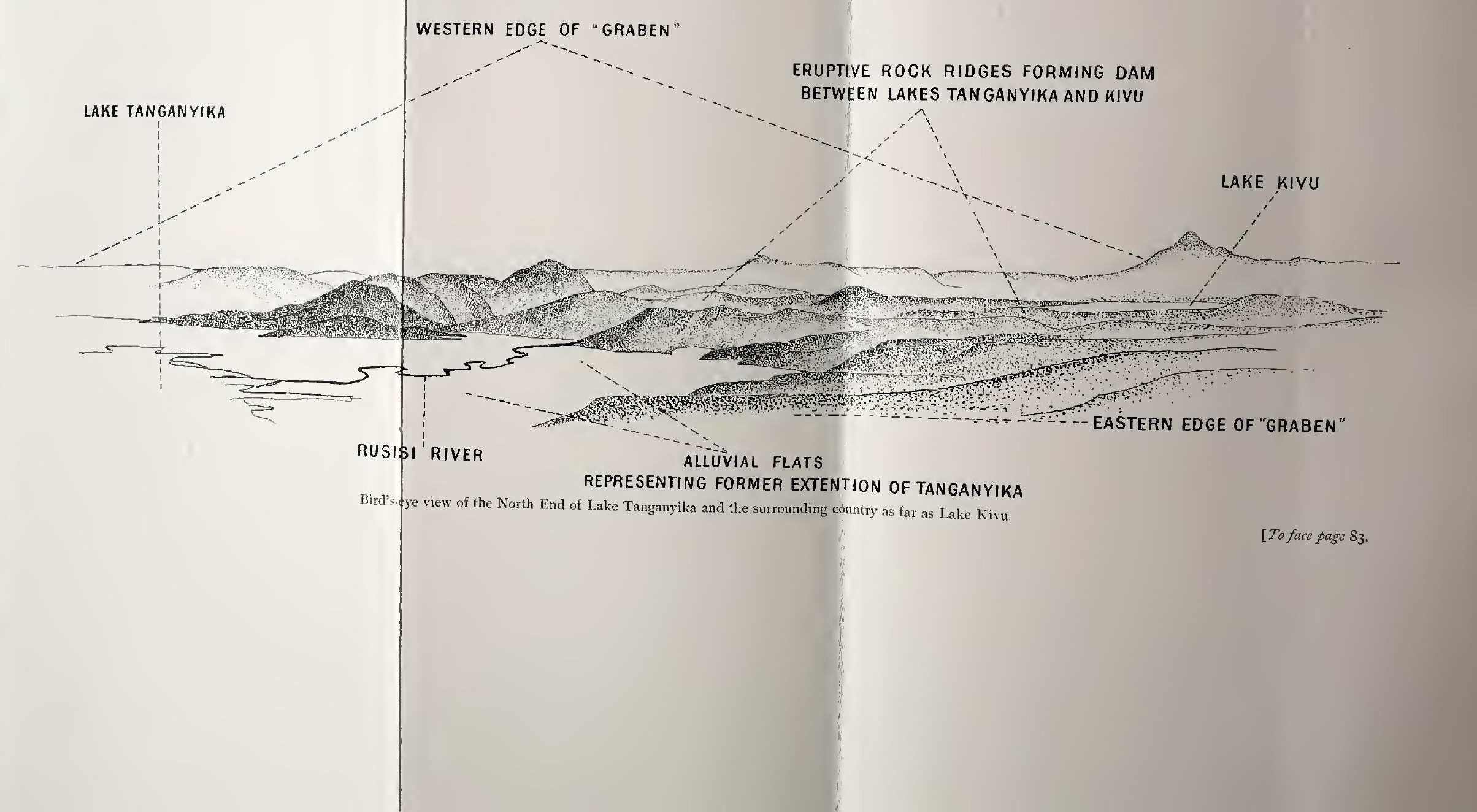



these, in like manner, contain the peculiar papyrusswamps, which characterise a large portion of central and east-central Africa. They are, in fact, the so-called rushdrains of Sir Henry Stanley, and of which Mr. Scott Elliot so aptly remarks, "they hardly ever contain rushes and nearly always require draining."

The one peculiar geological feature which the Kivu valley represents, is due to the fact that the waters of the lake are charged with saline matter to such an extent that the shores have become incrusted with a singular material, containing a high percentage of magnesium carbonate. Samples of this incrustation from the water of the lake, obtained by Mr. Fergusson, were examined under the direction of Professor Wynne, at the Royal College of Science, and "from analyses made by Mr. J. Hart-Smith, F.R.C.S., it is evident that magnesium replaces calcium in the water; the analytical and spectroscopic evidence showing that traces, only, of calcium salts are present. Fragments, obtained from the lake floor, consisted of a calcareous tufa, evidently deposited round vegetable díbris; and when analysed by Mr. W. Robinson, A.R.C.S., were found to contain $\mathrm{CaO}, 28 \cdot 65, \mathrm{MgO}, \mathrm{I} 2.66$ per cent., as a mean of two closely agreeing analyses." This substance gathers about the objects on the shore line, incrusting the pebbles and the reed-stems in such a manner, that extraordinary nodular masses of incrustation are formed, which are as hard as Roman cement. The incrustation also encloses the shells of the few molluses which exist in Kivu, and has often during its formation been pierced with old reed-stems in such a way, that the long parallel tunnels, which once enclosed the stems, look as if they had been bored by some species of pholas, until their actual nature has been ascertained. 
The water of Lake Kivu is very deep, often more than Ioo fathoms, within a few hundred yards of the shore. But, owing to the fact that we had no other boats besides native canoes, and to the persistent stormy, squally character of the weather which we encountered, we were unable to carry out any sounding operations far from the land.

The east, west and south shores of Kivu are, as I have said, composed entirely of schist and gneiss; but the northern shore of the lake is quite different. It is formed wholly of the modern volcanic materials, the layers of lava and ash, which have been ejected by the still active Mfumbiro Mountains. As we approached the northern limit of the lake, the trough-like sides of the great valley were seen to continue northwards, after the lake had come to an end, just as the sides of the same great valley were seen to run on beyond the north shore of Lake Tanganyika. But here, instead of the floor of the trough rising gently, in a series of raised alluvial flats, the whole space, between the lateral ramparts of the depression, is filled up and blocked to the north by a group of great and modern volcanic cones. These cones extend in a string or chain, not parallel with the valley, but from east to west ; forming, in fact, a vast transverse dam, which stretches in this place completely across the floor of the depression. The numerous peaks of which the chain is composed are very lofty ; one of them, Karisimbi, being often snow-capped, and reaching an altitude of about $\mathrm{I} 4,000$ feet.

An examination of the individual volcanic cones shows that those to the east are, unquestionably, the oldest. They are, in the first place, quite extinct, while their old craterwalls are much denuded, and partially enclose secondary cones, and the irregular products of the last efforts of their activity. The slopes of the two great cones to the west of 
the series abut abruptly up against the western wall of the great valley in which Kivu lies to the south, and these two western cones are quite distinct in character from any of those to the east. They are both, at present, fully active, and both present the squat, truncated form of a volcano in the first phase of its activity. The rim of the immense crater of the more southern mountain, Kirungo-cha-Gongo, we found to be I I, 350 feet above the level of the sea, and the mountain to the north-west, Kirungo-cha-Moto, is a little lower.

The whole appearance of these, the Mfumbiro Mountains, is magnificent and impressive in the extreme. And although they contain no individual eminence, anything like so high as Kilima-Njaro, they form a still vigorously active volcanic massif, which is vastly more imposing and extensive than either Kenia, Kilima-Njaro, or Elgon.

As has been said, the walls of the valley containing Lake Kivu to the south, are not really interrupted by the volcanic dam, they pass its slopes to the east and the west, and again enclose the central eurycolpic fold immediately to the north of the transverse line of cones. Having passed over the mountains, we see, in fact, that their northern slopes sweep away into the floor of the depression many miles, and the volcanic ash and lava-streams are found, finally, to run out upon the alluvial plains which bound the southern shore of the Albert Edward Nyanza. The alluvial substance of these plains runs, in fact, actually back again southwards underneath the more modern volcanic matter which has been piled upon them; and there are several facts connected with their character and structure that are of the utmost importance, when we come to interpret the phenomena which this highly peculiar district presents.

The fauna of Lake Kivu is, as I have clescribed in 

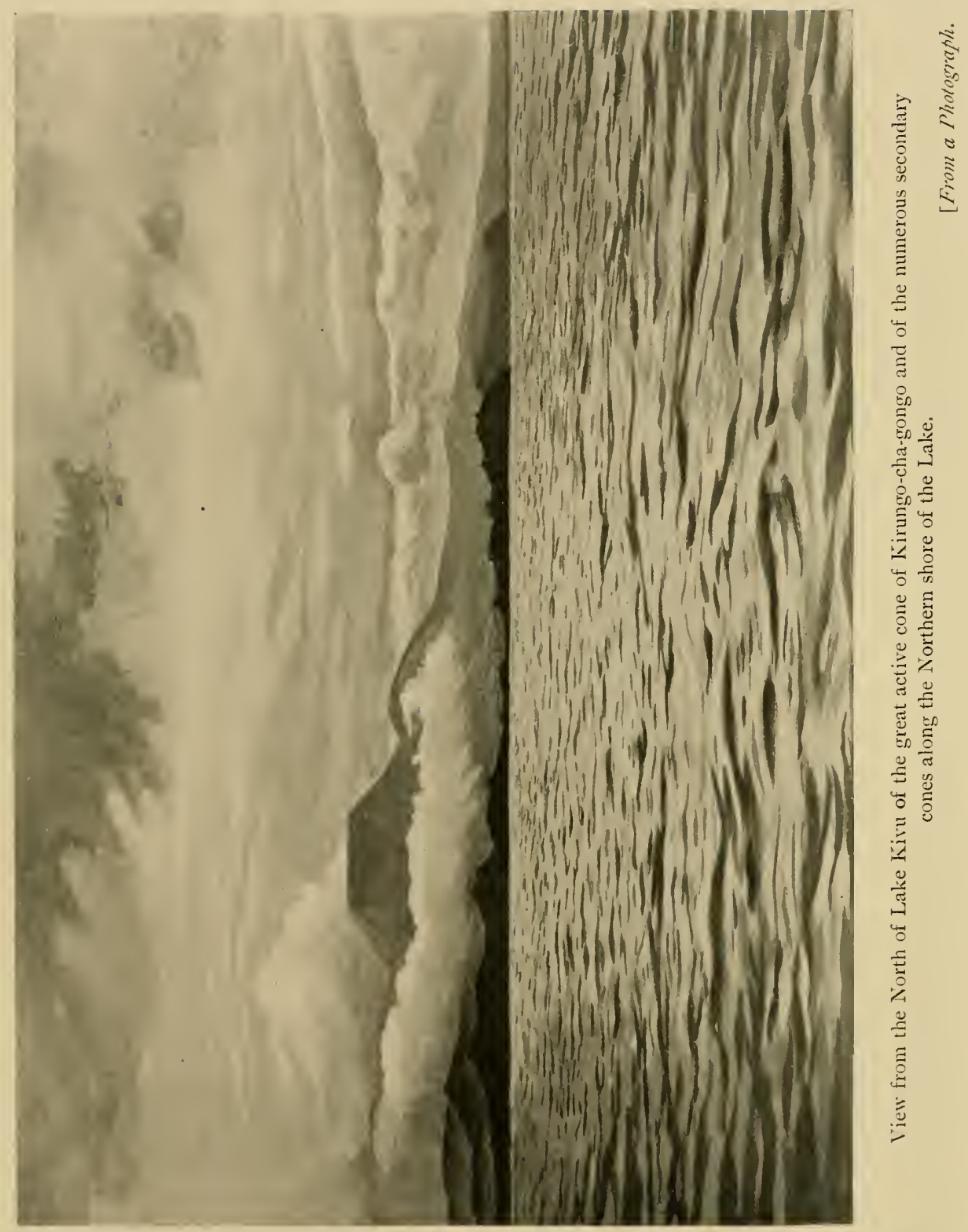




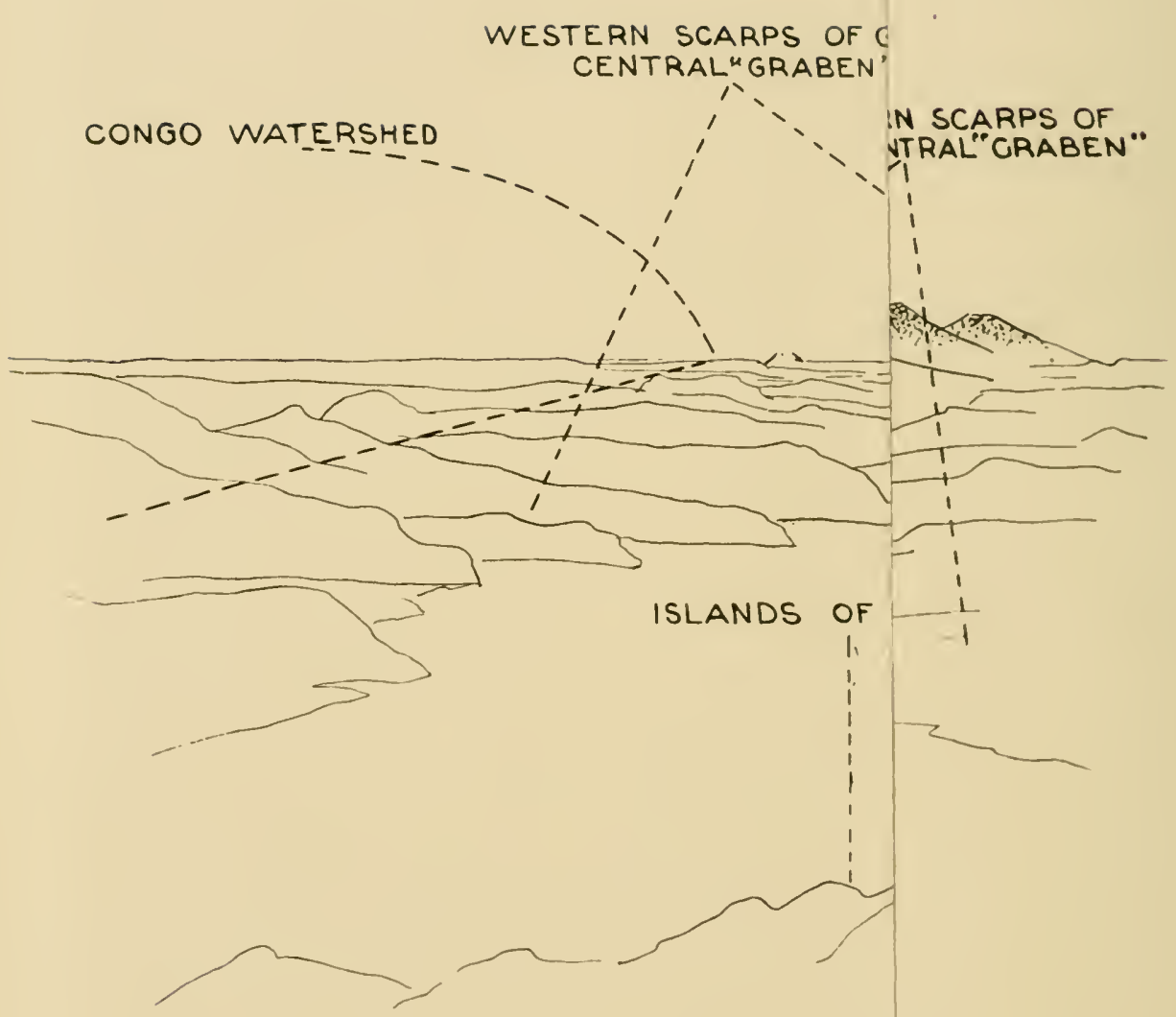

[ To face page S9. 
Chapter VII., totally different from that of Tanganyika. It is, in fact, the fauna of a great fresh-water pond, and in the plains which run southward under the modern volcanic débris of the Mfumbiro Mountains, and to the north, actually dip under the water of the Albert Edward Nyanza, there were encountered river-cuttings, in which were exposed old lake-beds, underlying the superficial drift and gravel of the valley's floor. In these beds. we found fossil-shells, all of which are identical with those now found living in Lake Kivu, and embedded in the magnesium incrustations of its shore. Further north, the Albert Edward was found to contain the same fresh-water shells alive which inhabit Kivu, and are found fossilised in the beds extending under the more modern volcanic dam between the lakes.

There is now no connection whatever between Lake Kivu, which stands at an altitude of 4,84 I feet to the south of the Mfumbiro Mountains, and the Albert Edward Nyanza, which lies 2,000 feet lower, away to the north of them, the watershed, formed by the modern volcanic cones, rising everywhere to something over 7,000 feet, between the lakes; but we have in the above facts incontestable evidence that the waters of Lake Kivu and those of Lake Albert Edward Nyanza were, at some no very remote time, in connection. The formation of the modern volcanic dam has simply resulted in the banking up of the water of Lake Kivu, until it finally flowed to the south over the high gneissic ridges, which originally separated the Kivu and Tanganyika valleys. The effect of this change in the position of the central watersheds of the African continent has unquestionably had an immense effect, both in the regions far to the north and far to the south of it. By the formation of the volcanic dam, the 
MFUMEIRO MOUNTAINS

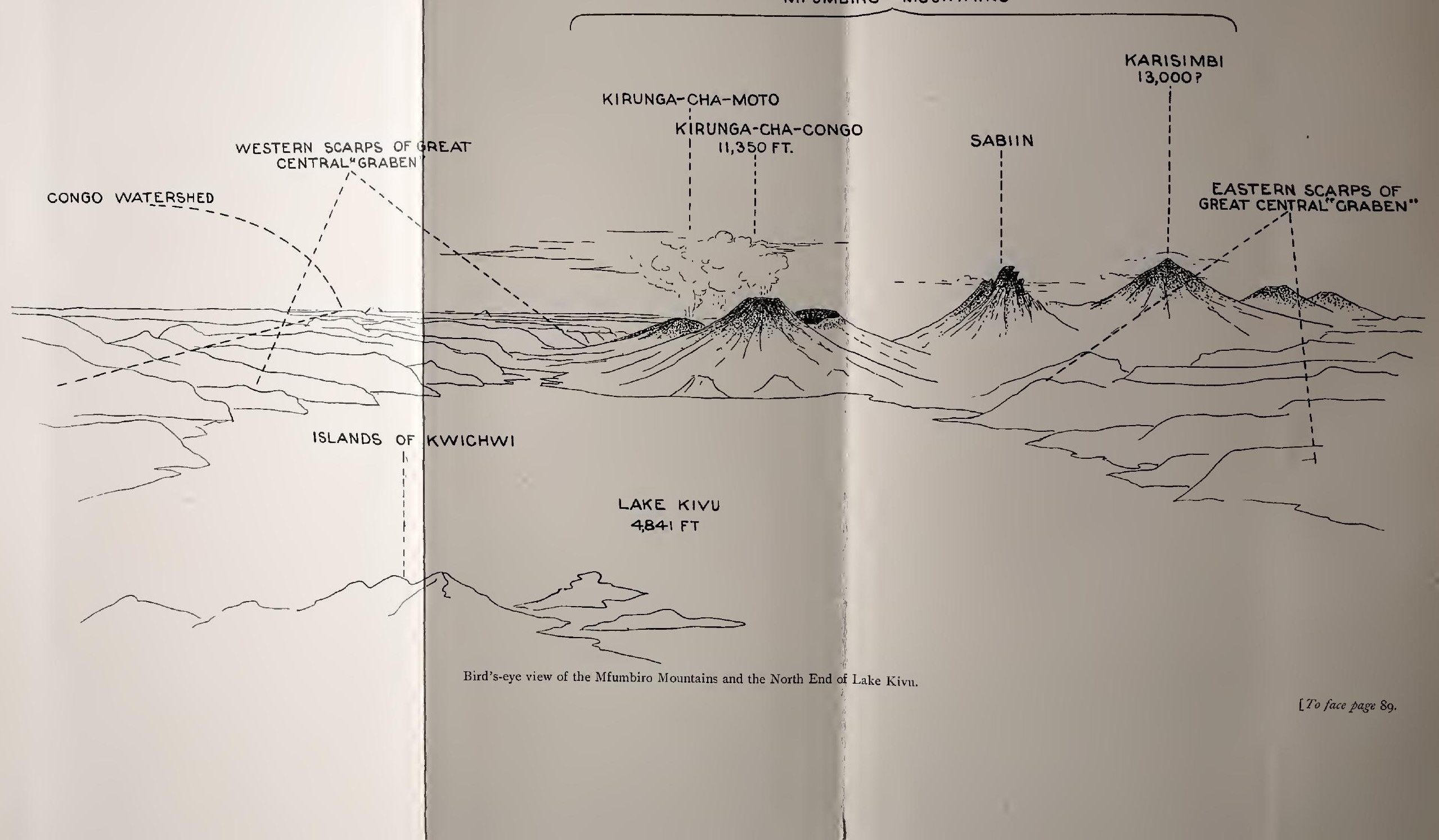



water from the whole drainage area of Kivu has been entirely cut off from the Albert Edward Nyanza and the Nile. And we see visible traces of this in the existence of old water-marks and beaches running round the shores of the Albert Edward and Albert Nyanzas, 50 fect above their present level.

Everywhere to the north along the course of the Nile there are similar physical evidences and traditions of the disappearance of old lakes, and it is extremely probable that the shrinkage of the upper waters of the great river of Egypt, which is recorded in history, is possibly still going on, and is dircetly due to the recent changes which have taken place in the modern volcanic dam between Kivu and the Albert Edward Nyanza.

Turning now to the south of the region of the volcanic dam, the effects produced by its formation have been no less conspicuous and strange. The whole drainage arca of Kivu has been added to that of Tanganyika: and it is a most remarkable fact that the outlet of Kivu, the Rusisi River, is five or six times bigger than the Luakuga, the outlet of Tanganyika itself. Were we, therefore, to cut off the Rusisi River from Tanganyika, that lake would altogether cease to overflow.

The water of Tanganyika is somewhat salt. It seems to be fresher now than when Livingstone and Stanley examined it, while, as both these explorers aver, there are traditions among the Arabs that, in the recollection of living men, it was a lake which had never flowed out at all.

From these considerations it would, therefore, secm quite probable that after Kiru had filled up through the formation of the volcanoes, its overplus of water flowed into Tanganyika for a great number of years, until the level of this lake was also raised to such a degree, that it, in like 


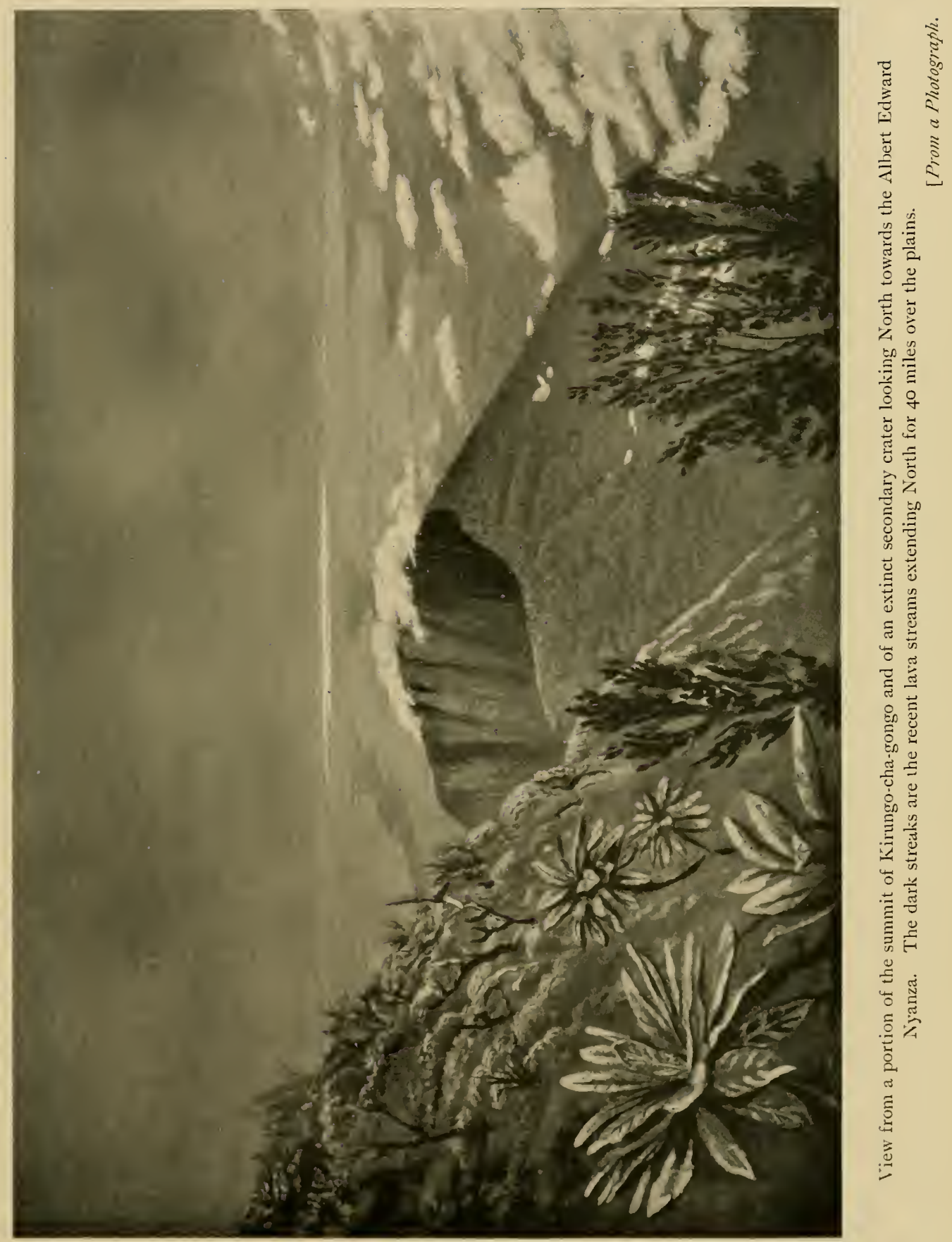



manner, succeeded in forcing its way out, and cut a channel for its overflow to the west into the Congo.

This view of the matter will at once explain the fact that Tanganyika has otherwise unaccountably fallen some 40, possibly a great many more, feet within no great number of years, the overplus of water in it having worn away the

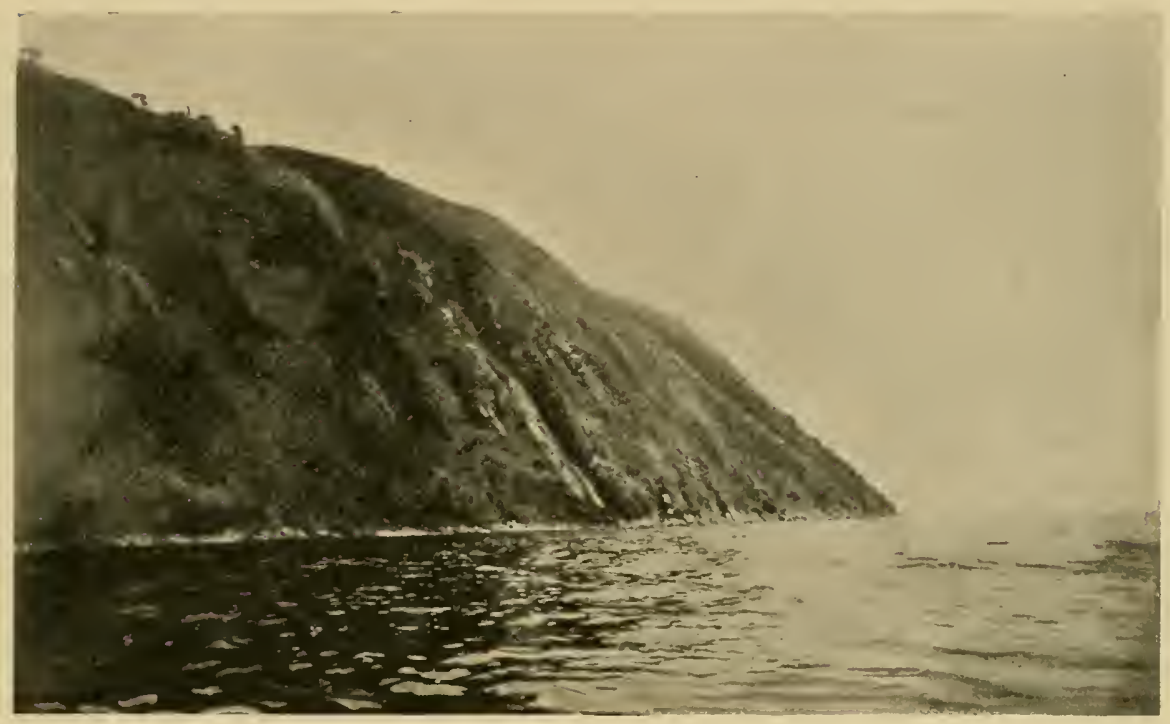

The steep West Coast of the Albert Edward Nyanza. The Western side of the Great Central eurycolpic fold.

channel to the west to such an extent that it will never regain its ancient high level.

The portion of the great central eurycolpic fold which extends beyond the Mfumbiro mountains, and contains the Albert Edward Nyanza, is similar in character to the more southern portion of the same great valley which contains Lake Tanganyika, until we reach the northern shores of the Albert Edward Lake. Here, however, a new feature 
presents itself, in the shape of the massive ranges of the Mountains of the Moon (see diagram facing p. ro6). These ranges, which rival the Alps in magnitude and in the sublimity of their scenery, lie along the eastern edge of the depression, and appear, in fact, to stand out into it beyond what was originally its eastern face. That these Mountains of the Moon are not older than this portion of the eurycolpic fold secms to be supported by many considerations. The undulating Victoria Nyanza plateau, which terminates abruptly in the eastern wall of the valley to the south of the range, and to the north of it in the abrupt east coasts of the Albert Edward and Albert Nyanzas, is generally composed of schists and gneiss; but between the Albert and Albert Edward Nyanzas the plateau terminates abruptly upon the steep eastern slopes of the Mountains of the Moon themselves. Here, however, the layers of schist, of which the plateau is composed, instead of being broken, as they are along the course of the depression to the north and south of the range, are bent and piled up upon the steep flanks of the mountains themselves; and it is only, as we found at a great height, $12,000 \mathrm{ft}$. and more, that the layers of steeply uptilted schist come to an end upon the eastern slopes of the massive old amphibolites, which form the central cores of the range, and appear to have been bodily thrust through them. That this appearance of intrusion of the cores of the mountains through what was originally a horizontal mass of gneissic material, is a reality, appears to me to be supported by numerous facts relating to the structure of the range. Thus, although the schists come to an end at a height of about I $1,000 \mathrm{ft}$. On the eastern flanks of the mountains, they reappear on the western slopes, pitching at a very high 


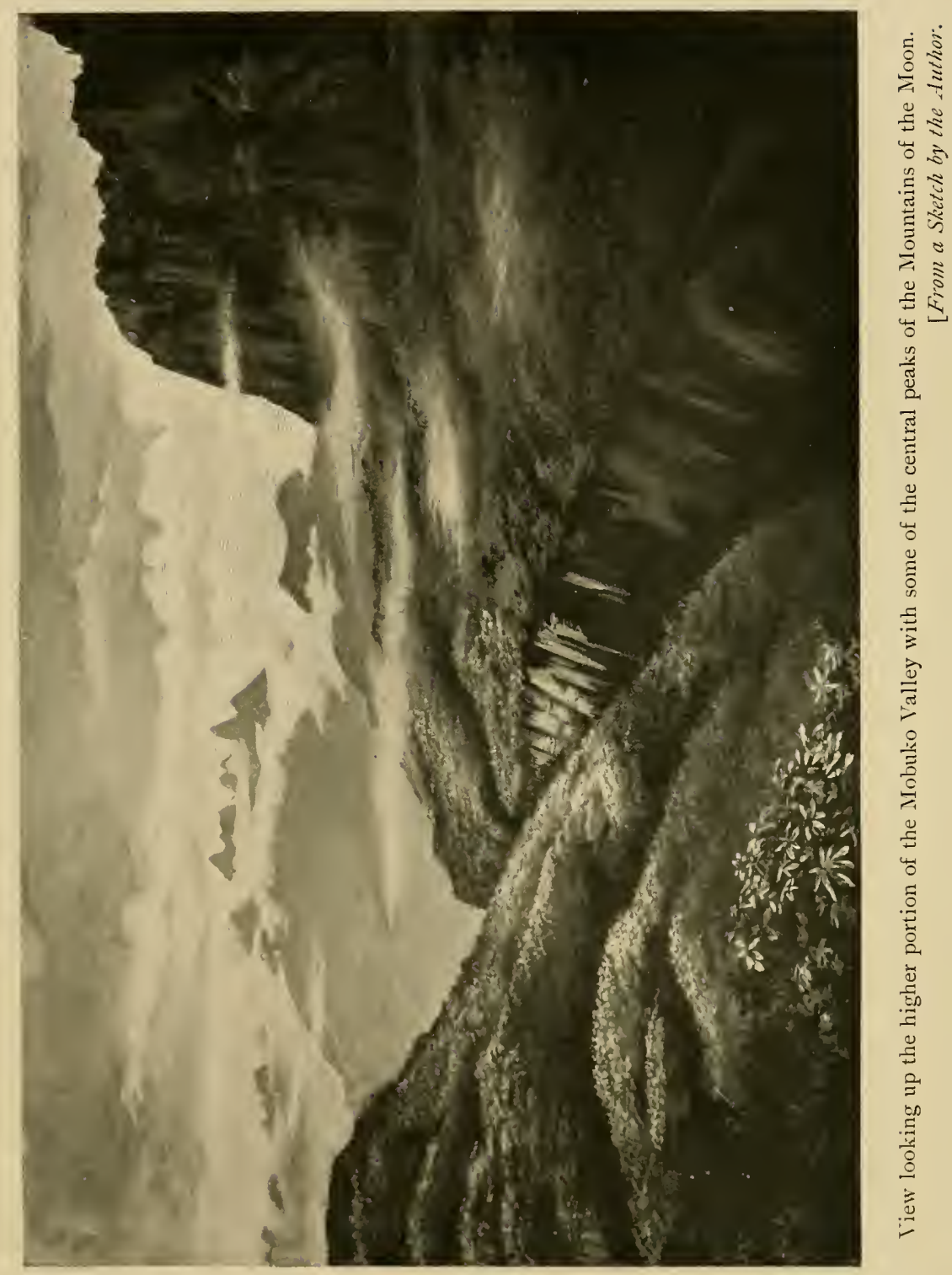



angle into the Semliki valley. If we consider a section through the Albert Edward Nyanza south of the Mountains of the Moon, we have the following structural features. Passing over the Victoria Nyanza plateau, from east to west, we find that this plateau in general slightly rises until the eastern edge of the central depression is reached, when it suddenly breaks away in a fault face, or a succession of fault faces, above the extensive plain which, here, forms the flat bottom of the lake. On the other side of the Albert Edward Nyanza, in the west, there is an opposite and corresponding series of fault faces, and instantly beyond their crests we find ourselves on the Congo watershed. If now, in comparison with this, we consider a section through the great central depression somewhat farther to the north and through the Mountains of the Moon, we have the following features. Beginning again in the east, we find that the Victoria plateau ends upon the flanks of the great range, but that where it does so the layers of schist of which it is composed are abruptly tilted and piled upon the flanks of the range. Passing still farther to the west, we find a succession of huge ridges of intrucled lower rock, which project through and above the uptilted schists; and on the other side of these intruded ridges we encounter the schists again, lying on their western flanks, and sloping at a very high angle into the floor of the Semliki valley. The surface of this valley, where I could examine it [at the source of the Semliki from the Albert Edward Nyanza, and near its mouth in the Albert Nyanza], was composed of little disturbed layers of modern alluvium and old lake deposits, containing in both situations the fossil shells of the molluscs which now live in the Albert and Albert Edward lakes. 
Passing still farther to the west, these lacustrine plains came to an end abruptly beneath the western flanks of the Semliki valley, and over these we are instantly once more on the Congo watershed. It will thus be seen, that in the regions of the Mountains of the Moon, we are still clealing with precisely the same phenomena encountered when we considered the construction of the great eurycolpic depression in the region of Nyassa and Tanganyika. That is to say, the gross, geological characteristics of the region have been brought into existence by a folding of the earth's surface along two parallel lines of up-push, cach of which is apparently coincident with the faulted walls of the depression itself. The only modification of this process which has occurred in the region of the Mountains of the Moon being, that, for about a hundred miles on the castern sicle of the Semliki river, the crinkling and uprising has been so violent that the lower rock masses underlying the Victoria Nyanza plateau have been forced through it, just as if the igneous base, upon which the sandstones of Mount Waller rest, was to be forced up and up, until it tilted the sandstones on both sides of it, and, finally, towered above these old aqueous deposits in ridges of intrusive igneous matter, I $5,000 \mathrm{ft}$. to $16,000 \mathrm{ft}$. in height. I do not think there is the least doubt that this has been the real method and nature of the formation of the Ruwenzori range, and, consequently, we must view the massif as simply a more vigorous and local expression of the flanking mountain chains which appear along the sides of the eurycolpic folds in other places, as in the region of the Livingstone range on Nyassa, or the great outstanding masses which, at several points, tower over the general level of the sides of the Tanganyika basin.

From these considerations it would appear that Stuhl- 


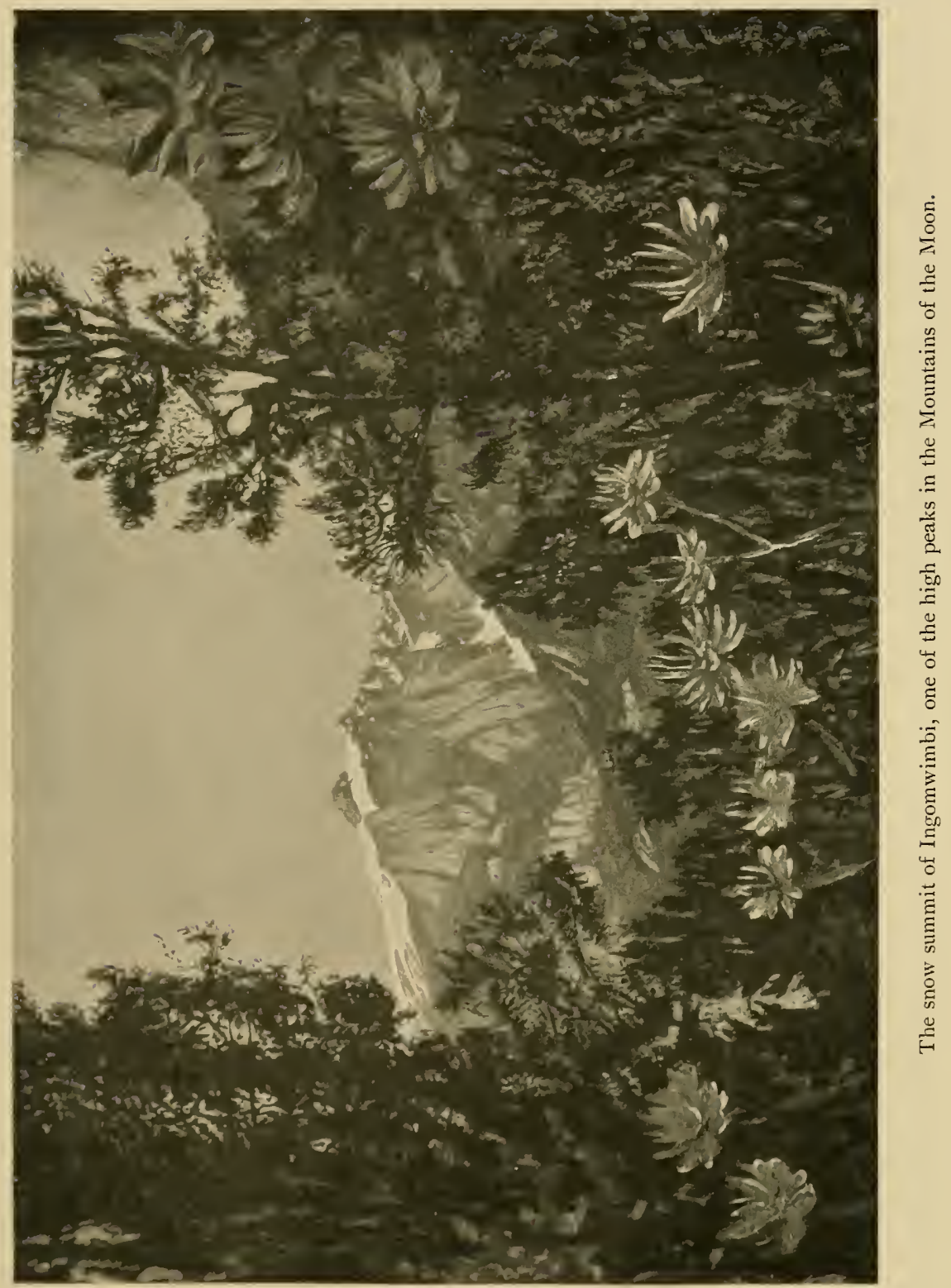



mann's* view that the range was the expression of a double line of faulting, or was in reality a block mountain, is not altogether correct. Indeed, Stuhlmann did not acquire a sufficiently extensive acquaintance with the range in order to grasp its real nature, but his view was a distinct advance upon Stairs' suggestion that the mountains were the denuded fragments of an old volcanic cone. Unquestionably, Stuhlmann's was a very shrewd guess at the nature of the mountains which confronted him, and, from his points of observation, perhaps the only supposition he could make. Scott Elliot appreciated the existence of the up-piled schists on both sides of the range, but his theory that the mountains are a sort of oval boss of raised material, independent of the surrounding geological features, cannot be made to fit in with the actual facts of the case. The range, as we have seen, seems in reality to be merely an accentuated expression of the same sort of up-push as that which has raised the eastern wall of the eurycolpic folds north and south of it. What has happened appearing to be that over this more actively raised region the lower materials, which underlay the sides of the depression, have been pushed through the surface in a succession of protruding, lenticular masses, the axes of which run north and south. The amphibolites, as I have found myself, do actually run out in this way towards the north of the range.

Although I have in the above briefly outlined the most important structural features of the Mountains of the Moon, it is necessary to refer to certain other matters in connection with them at the present time. Before my visit to the range, in March, I9oo, no one had reached the snow-line on these mountains, and consequently

\footnotetext{
* Stuhlmann. Mit Emin l'acha.
} 
the rather interesting fact that it lies as low as $13,500 \mathrm{ft}$., had not been ascertained. It was, moreover, not known whether there were glaciers on the range, Stuhlmann had expressly doubted it ; and owing to a misapprehension under which Sir Harry Johnston persistently labours with respect to his own later explorations in the district, it is necessary, although wearisome, to repeat, that prior to our visit only three explorers had made any serious attempt upon the higher portions of the range. Stairs had ascended to $10,000 \mathrm{ft}$. On the north-western spurs; Stuhlmann had reached I2,000 ft. on the west of the range, while Scott Elliot had reached heights of $\mathrm{I} 0,000 \mathrm{ft}$. and $\mathrm{I} 2,000 \mathrm{ft}$. On both the eastern and western flanks. My own exploration was made up the Mobuko valley, terminating on the northern snow riclge of Sitchwi, and occupied about three weeks. My highest point reached on the top of this ridge was $14,900 \mathrm{ft}$. After my return to Fort Jerry my colleague, Mr. Fergusson, made a separate journey to the mountains and reached a point nearer to the Mobuko glacier, I $4,600 \mathrm{ft}$. This was the point subsequently reached by Sir Harry Johnston, who makes it I 4 , Eoo ft. Still later, Mr. Wilde, an officer of the Uganda Protectorate, reached a point on the same or an adjacent ridge of $14,900 \mathrm{ft}$., but, as he was using an aneroid his altitude is probably rather over estimated. As to the question of the height attained by any of the other snow riclges and peaks of the range, I came to the conclusion that there was nothing more than a thousand feet higher than the point on which I was, either to the north or to the south, and this would give an outside altitude for the highest peaks of the range of, saly, $16.500 \mathrm{ft}$. Curiously enough, this is practically the same height which all the older explorers ascribed to the range-namely, 


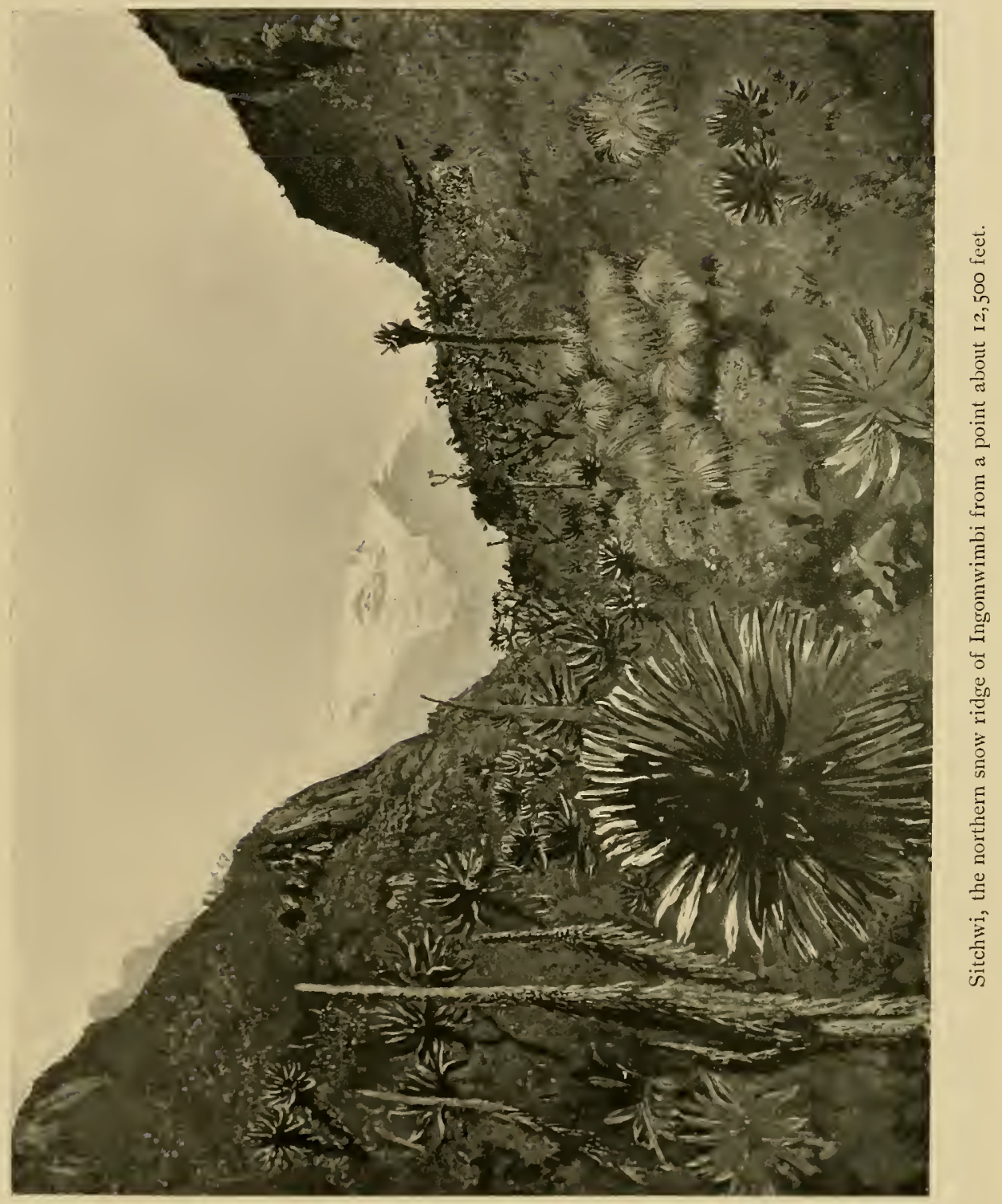



Stanley, Stuhlmann, Stairs and Scott Elliot. Sir Harry Johnston, on the other hand, who did not get as high as myself, holds $20,000 \mathrm{ft}$. as a minimum for some of the numerous peaks which he did not even attempt, but as he

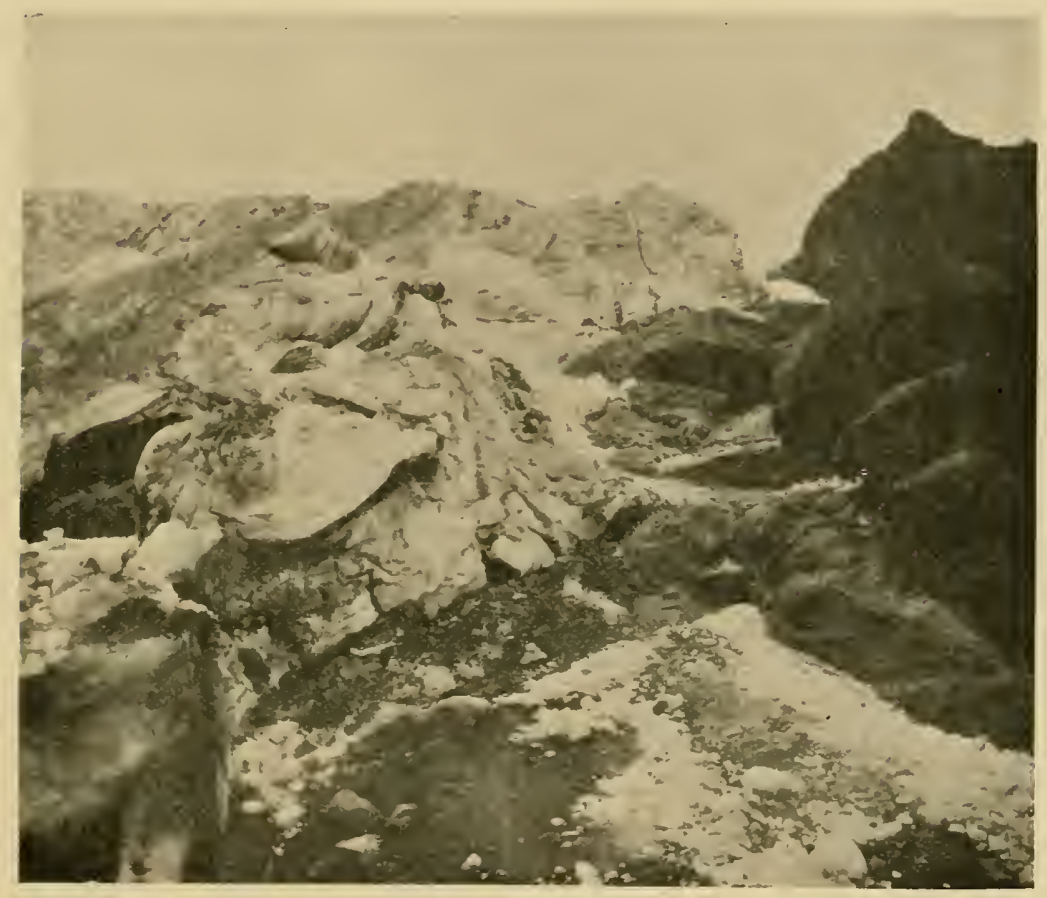

The broad glacier on Sitchwi, the Northern snow ridge of Ingomwimbi.

says he is judging simply by his eye, his contention is necessarily without any weight for actual mountaineers.*

* Those interested in this matter will find it further discussed by me in an article entitled "First ascent of one of the snow ridges in the Mountains," and published in the Alpine Journal for May, 1902 ; and if the statements contained in this are compared with Sir H. Johnston's account of his later visit to the mountains, published in the journal of the Royal Geographical Society, it will probably become apparent that my appreciation of a "literary capacity" in Sir Harry's method of treating matters of fact was not misplaced. 
A fairly reliable method is, however, afforded by a study of distant photographs of the range, now that the height of the snow-line has been ascertained. From the east the whole range may be seen rising from plains which stand at about 4,000 ft. In photographs obtained from these plains the snow, which I ascertained to begin at I 3,500 ft., only occupies a third, at the outside, of the total height of any of the peaks, above the plains. The snow-line is, therefore, $9,500 \mathrm{ft}$. above the plains, and, consequently, these data indicate that $16,700 \mathrm{ft}$. is an outside height for any of the peaks. 


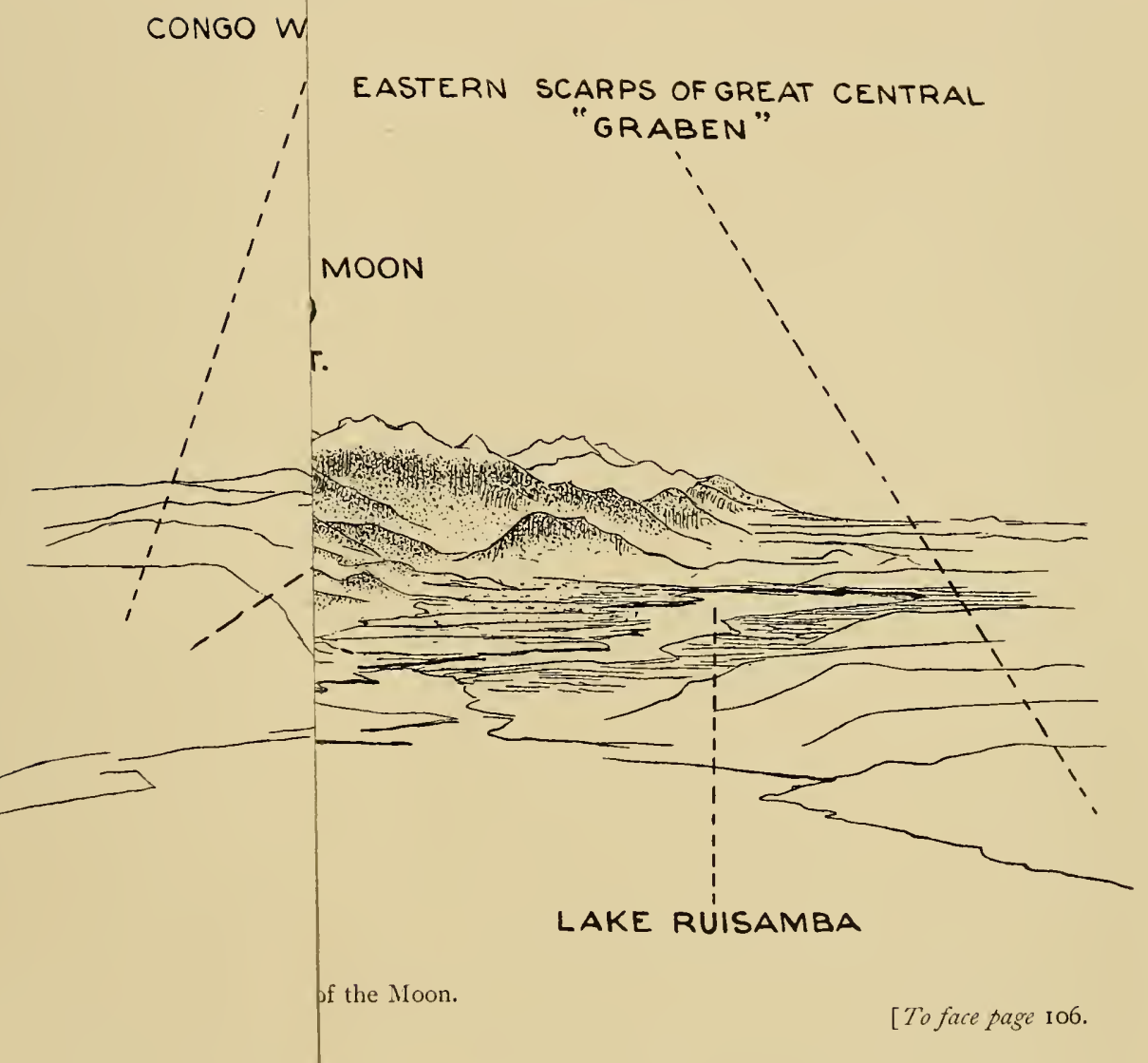





\section{CHAPTER VI.}

AFRICAN PARK-LANDS, THEIR APPEARANCE ON ALLUVIAL FLATS CONSIDERED AS EVIDENCE OF RECENT PHYSICAL CHANGE.

In the last chapters I have referred to the changes which have unquestionably gone on in the African interior in the past, and I also pointed out that there was direct and incontestable evidence to show that in some places these changes are even at the present time in full swing. It may, therefore, not be out of place to refer in the present chapter to another series of phenomena, which have for a long time been most perplexing, but which, when rightly interpreted, appear to show, in an equally conclusive manner, the extraordinary impermanence of the terrestrial conditions over very wide areas of the continent in which they occur.

These observations have nothing to do with geology as it is ordinarily understood, being related to certain features of the flora of Central Africa, which, when first encountered, are utterly perplexing, and seem to indicate the past or present operations of a landscape gardener who is not there.

If we were to land now on the banks of the Upper Shiri river, we should find, after pushing our way through 
the reeds and growths which fringe the waterside, that we had entered a country having for all practical purposes the characters of a park. It is made up of wide lawns of short grass, in which there stand clumps and isolated specimens of different sorts of trees. These trees are not, however, crowded together, but are grown just as they are in a piece of English park-land, so that they can be seen to the best advantage, with wide open spaces in between. The whole scenery in such a place is so peculiar and artificial in outward aspect, that I cannot perhaps describe it better than by saying that it bears a very remarkable and close resemblance to that area of kept ground which is known as the Arboretum in the Royal Gardens at Kew. There is no tangle, no forest, the scenery is delightful; it is in fact so extremely beautiful, that, could it be divested of its sweltering tropical concomitants, I am inclined to think that these natural parks, when compared with those of the landscape gardener at home, would be generally admitted to be the more pleasing of the two.

Unnatural-looking park-lands of this description are very characteristic of vast areas of the African interior, and they have, in consequence, naturally attracted the attention and provoked the admiration of many explorers besides myself. Thus we find Stanley and Stuhlmann, Emin Pasha and Cassati, Joseph Thomson and Sir Richard Burton, all drawing attention to the existence and peculiar appearance of these parks. As a matter of fact, they cover very large areas of tropical Africa, both in the interior and on the coast. I myself have encountered them on the plains behind Beira, on the great alluvial plains bordering the Zambesi river, on the similar flats flanking the Lower and Upper Shiri river, all over the great plains sur- 


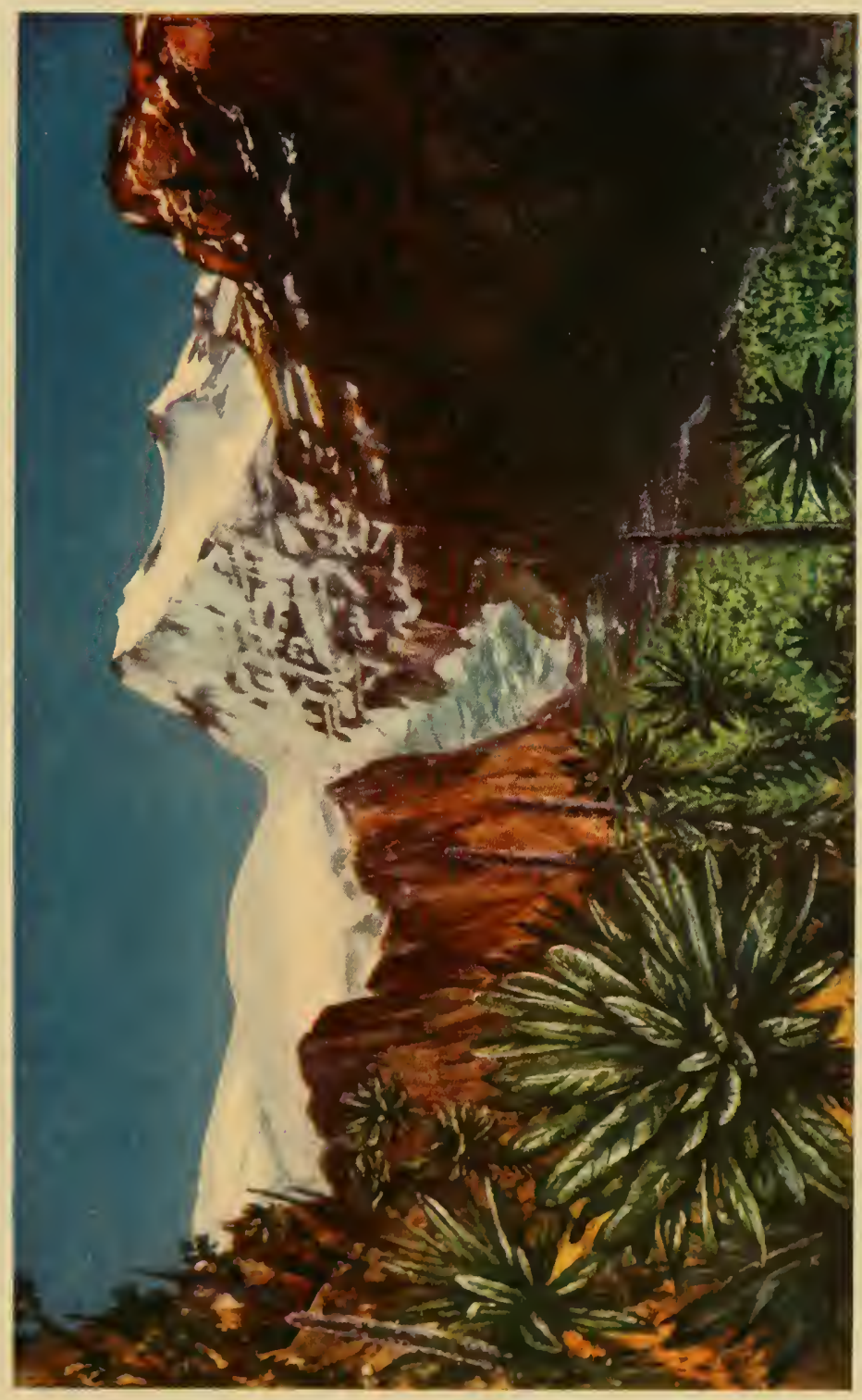

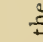

象

证

एँ :

०

$\because$

ัँ

ปั

๖ 吾

$3 \div$

ठ

乙

《

$\therefore$ ०

乙

¿

$\checkmark \sum$

द ज

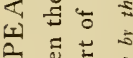

2 远

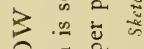

$0 \equiv$

出 气

$= \pm$

¿

(-)

?

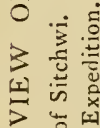

砑

荡

ป ㅁํㅁ

5

蒙

$\bar{\Xi}$ 

rounding Lake Shirwa, on the alluvial flats and plains bordering Lake Nyassa to the east, to the west and to the north. They appear again in many places on the high interior plateau between Nyassa and Tanganyika; they cover extensive regions of old lake deposits on the shores of Tanganyika itself; while they reappear on the plains south of the Albert Edward Nyanza. They are to be found again in patches mixed up with the true forest all along the course of the Semliki valley and on the shores of the Albert Nyanza. They are further to be found on old lake deposits and alluvial flats in some parts of Uganda, and I am informed that they are also a characteristic feature of many portions of the west coast of Africa, and of the hinterlands beyond it.

Park-lands, districts having the peculiar characteristics of a kept park, thus cover immense areas in the African interior. They cover, as a matter of fact, thousands upon thousands of square miles, and the more closely we examine them the more curious and perplexing their existence appears.

We have, indeed, only to look for an instant at a district such as that to which I have alluded on the Upper Shiri river, in order that a variety of questions shall present themselves, which are all more easily put than answered. In the first place, why have these districts assumed the characters of an artificial park? Why are the trees isolated as if they had been grown for show? Why is there no thick bush covering the ground, and converting the whole place into a thick jungle? Why are there so very many different sorts of trees?

If we meet with a park in England the mere fact of its existence implies the present or past operations of a parkkeeper or a landscape gardener, who was not only an agent 
independent of the natural environment of forest trees, but who acted in a persistent manner, clearing away the bushes and brambles off the lawns, in which he planted great trees and little trees, so that their limbs and foliage could grow luxuriantly and be seen. Morcover, in England, when such a park has once been formed by the agency of man, it is absolutely necessary that the operations of the gardener shall go on and continue, or the park will inevitably and quickly lose its artificial characters. Thorns and briars and bushes will quickly spring up upon the grass, and in a few years the park will have gone back again to what we are accustomed here to regarcl as a state of nature; or, in other words, it will have beconce converted into a trackless waste of old and young jungle. In England or Europe a park-land is thus an artificial product, and is an impossibility, unless there is someone ready and willing to hold the natural tendencies of the vegetation in check. In tropical Africa, on the other hand, precisely the same floral arrangement is produced, but no human agency has had anything to do with it; and the existence of these natural park-lands presents us with a ready-made and an extraordinary puzzle, which it is interesting to try to understand.

In attempting to account for the appearance of parklands, the most natural supposition to make is, of course, that of inequality of dampness or character of the soil, which is sufficient to allow some kinds of trees to grow in one place, some in another, and grass in between; but although this view of the matter looks very nice and promising at first sight, its value is absolutely destroyed by the facts of the case. I have on several occasions. when in a park-land, set my men to trench and dig in different directions, and then examined the soil, with the 


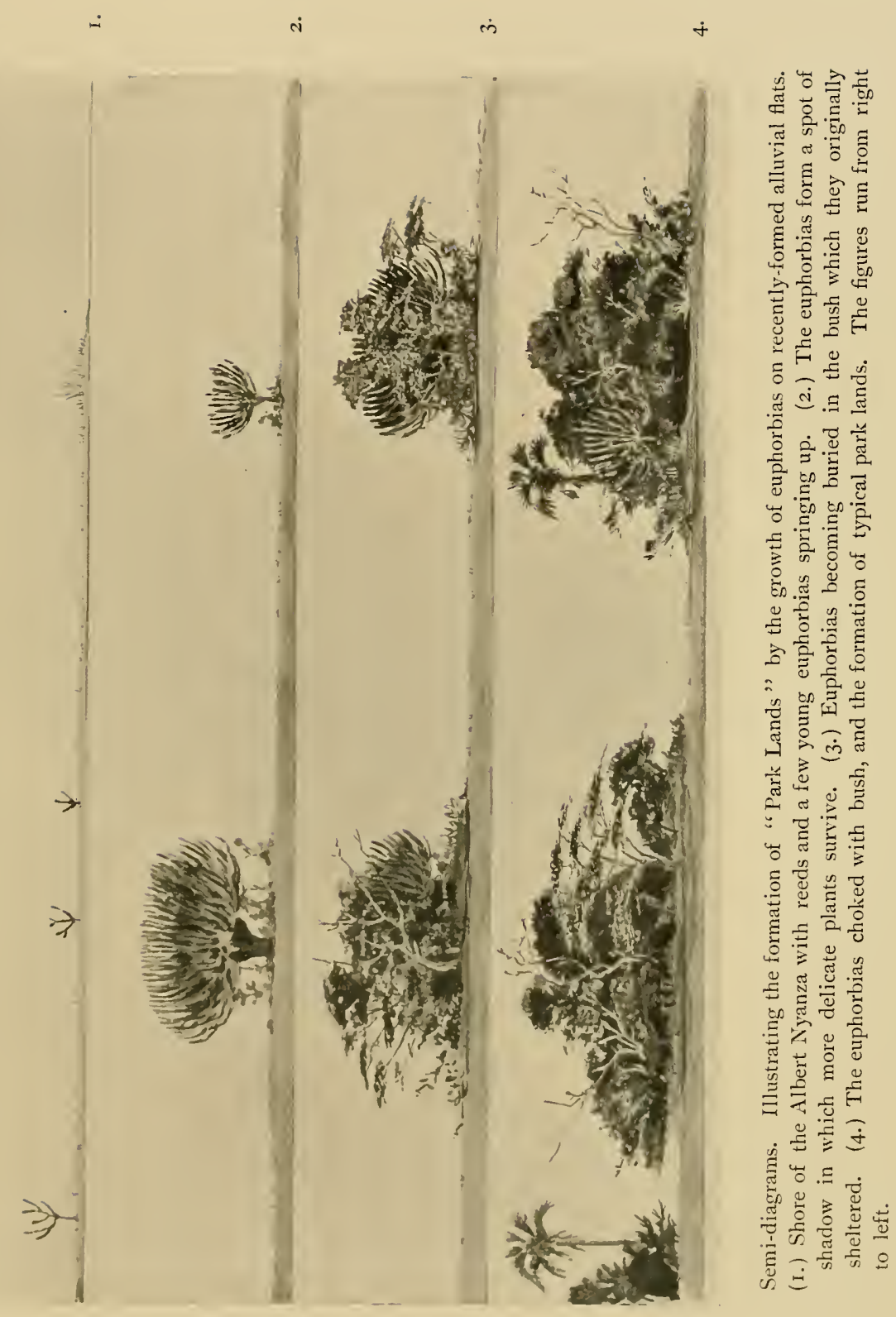



result that I could find no difference whatever, either in its dampness or its consistency, at least, any that it was possible to correlate with the different plants that grew upon it. In the soil under a great clump of acacias there was as little moisture, and it was of the same consistency as that upon which there was nothing but a scanty covering of grass; neither can difference of climate or rainfall be invoked. Park-lands occur in the Semliki valley where it is very wet, and also on the Albert Edward plains where it is very dry.

From general observations, however, it soon becomes apparent that park-lands are by no means distributed haphazard over the surface of the country; they never occur, for example, on hill sides or upon rocky ground. They are invariably found upon alluvial plains like those formed by rivers, or upon old lake deposits; that is, they only occur on flats made up either of blown sand or of ground of aqueous origin; but although they are definitely related to flats of the above sorts, this fact at first sight perhaps makes the whole matter more perplexing still, for such flats are by no means invariably covered with parks. Thus there are wide districts on the Semliki plains which are covered with heavy forest, and there are similar alluvial areas covered with heavy forest only along the Zambesi river, and indeed in many places elsewhere. What can it be, then, which in some places inaugurates and maintains a natural African park? This question is a great puzzle, and the answer to it is not at all apparent on the surface of things. I obtained, however, what there is every reason to believe is a clue to the whole matter, during my visit to the Albert Nyanza. On that journey I descended from the western slopes of the Mountains of the Moon on to the plains of the great central valley, which I 
crossed diagonally until I reached the lake itself. On this series of marches we passed off the mountain slopes on to plains of alluvium and old lake deposit in which there are the remains of fresh-water shells similar to those which still live in the lake; and from this, it is obvious that the lake once extended over these regions which are now covered with thick forest of different sorts. As we neared the lake we passed out of the forests, first into park-lands and then over steppes with only a very few trees, and finally on to the absolutely treeless salt wastes bordering the shores of the Albert Nyanza. We were travelling over the old lake deposits all the way, and the shelly remains became fresher and fresher until we actually reached the shores of the lake itself. Moreover, on the western shores of the lake we found old water marks and beaches which show, in as conclusive a manner as similar terraces on the west coast of the Albert Edward Nyanza, that the lake has steadily fallen and receded to the north during a number, but an unknown number, of years. From this it will be obvious that in our marches from the Mountains of the Moon to the shores of the Albert Nyanza, we were passing over land which had been covered with water at a more and more recent date, and conversely, as we returned over the road we had come, we were passing over land which had been land for a longer and longer time owing to the gradual northern recession of the lake; and the different age of the land was related to a clifferent type of flora which was growing on it. This difference in the character of the vegetation encountered during the journey has been represented in the figure on page I I I, which is a combination in sequence of a number of drawings and photographs I obtained of the kinds of vegetation through which we passed. By the lake shore there was a belt of reeds, and beyond this, almost desert 
steppes over which the fierce tropical sun blazed without any protection for many hours during the day. In such places the noon-day heat is fearful, and the men on this particular occasion, as is often the case on exposed plains near the Equator, were hardly able to walk with their bare

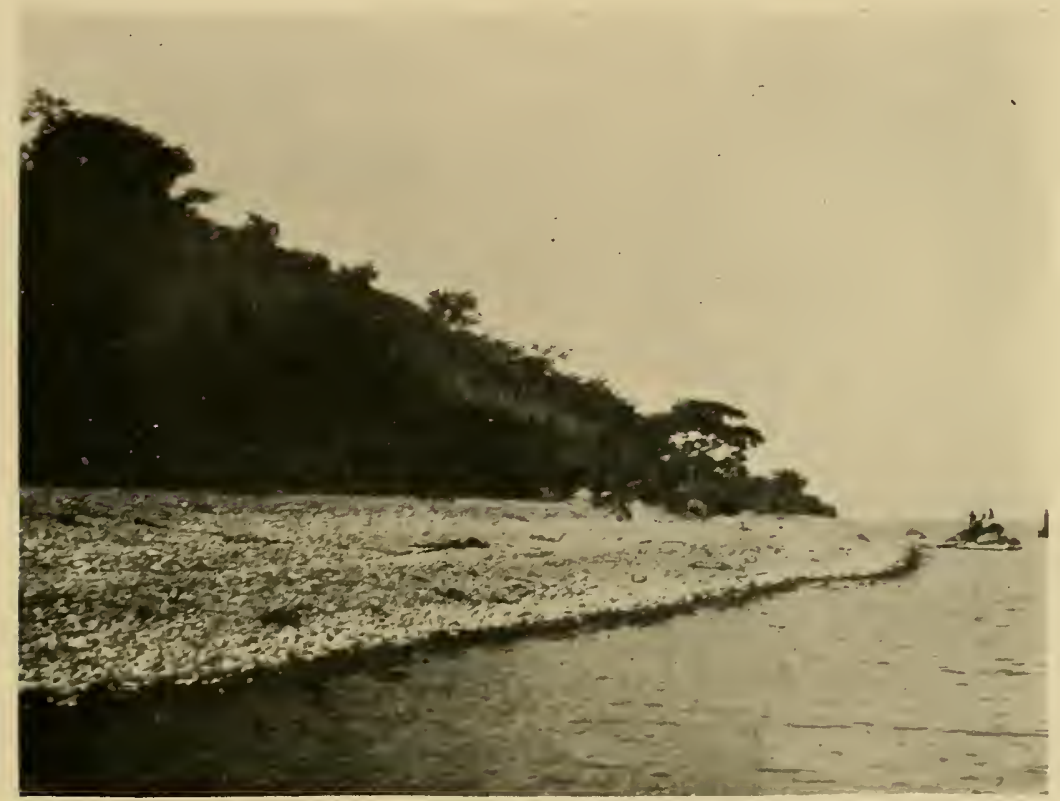

The pebble beaches of the West Coast of the Albert Edward Nyanza and old water-marks.

feet on the hot ground. The surface of the earth was desiccated and sandy, but a few inches below there was an appreciable amount of moisture, due to the occasional storms which sweep over such plains and disappear almost as quickly as they form. Nothing but grass grew near the lake, and even this had evidently had a very bad time, for it was scraggy and white and bleached, and alternated with 
patches of absolutely bare sandy soil. On these plains there were, however, in places, scattered over the surface of the ground, a few young euphorbia trees, the seeds of which had evidently been disseminated over the plains by the wind or birds, and as these hardy plants grew bigger on the older land further from the lake shore, I noticed that in the hot glare of noon their massive structures threw a patch of deep cool shadow round their feet. Farther away from the lake where the land was older and the euphorbias had consequently had time to grow proportionately bigger, the noon-day spot of shade had also correspondingly increased, and in the area of such shadow there were to be found varieties of plants, besides the grass, which here found protection from the fiery glare and heat, and were consequently able to grow. Among these plants struggling against the naturally adverse conditions of the plains under the euphorbia shadows there were thorn trees, climbing plants, and flowering shrubs, and when once these plants had in this manner got a footing on the plains they prospered like one of Germany's protected inclustries and throve amazingly ; so much so indeed, that on land that was still further from the lake, and consequently still older, the thorns and bushes of various sorts were enveloping the euphorbias, which now appeared as rather choked growths in the centre of the bushy patches. Further away again from the lake there were many clumps of bushes and trees scattered in all directions over the country; and in many of these were still to be found the dead or dying remains of the original euphorbia, to the protection of which the bush patch owed its growth. The seven lean kine had here eaten up the seven fat kine, and in such districts we entered the typical scenery of an African park. 
Once started, the groups of trees and patches of bush which marked the graves of their former benefactors, the euphorbias, spread gradually under the protection of their own shadows, until finally the patches ran together and more or less coalesced into the ragged forest which covers the higher portions of these long alluvial slopes.

It will be obvious that we have thus, in the simple natural dispersion and growth of euphorbias over desert steppes and in their mode of growth, a completely satisfactory explanation of the formation of park-lands, and their relation to steppes and forest; the process of their formation being a natural sequence of events following upon the scattering, through the agency of the wind or birds, of the seeds of a single tree. But at the same time the appearance of a park-land is seen also to be one phase in a series of changes which follow the retreat and drying up, or the change in position, of water on the face of the land. And further, it appears to be as true of the natural park as of the artificial one, that unless it is kept up, it must, in the course of time, disappear and become converted into more or less thick forest. Its appearance is simply the expression of progressive physical change. There appears to be no agency, except a park-keeper which is capable of maintaining a park, any more in Africa than in England; and perhaps the most singular, or at any rate the most interesting thing, which the foregoing observations teach us, is that the African parks are absolutely impermanent, and are, in reality, direct and incontestable evidence in themselves of wide-spread physical changes in the lands on which they exist.

But not only is the existence of a park-land evidence of recent change in any district in which it may occur, it is 
also indicative of change in one particular direction-that is, of the gradual drying up and shrinking of whatever lakes and open waters the district may possess. Hence the almost universal distribution of park-lands all over Central Africa is clearly indicative of one of two things : either the rainfall is becoming less over the whole of the equatorial regions, or the land is being gradually moved and changed and shifted in such a manner that the water on it is being drained off the interior as a whole. There is no evidence of any decrease in the rainfall, but as we have seen therc is abundant evidence of continuing geological change ; and therefore we are driven to conclude that the existence of these extensive parks must be due to movements and shifting in the watersheds, and the general configuration of the land. Now, the only direction in which earth movements on a slow and extensive scale could effect this draining, is by that of a gradual raising and humping up of the interior; and it is extremely interesting to find that the study of the features of natural parks, thus leads cxactly to the same conclusion respecting the impermancence of the terrestrial conditions of the interior, that were indicated by the geological and physiographical considerations which I discussed in the last chapter.

Although it will thus be seen that the history of African park-lands affords us another mode of demonstrating the geological impermanence of the African interior, and of the existence of a progressive series of physical changes which are still going on there, it should not be overlooked that their history is also not without a rather wide importance from a purcly biological point of view. It teaches us in an analogous way to the matters connected with the formation of fresh-ivater faunas in general, which I described in Chapter II., that the main floral characters of a country 
may not be due, as we have hitherto been in the habit of supposing, to the struggle for existence between contending species, but entirely to the sorting influence of a progressive physical change to which the biological phenomena are related in a manner of a perpetually responding reflection. The struggle for existence between contending species has had nothing to do with the chief features of the flora of vast areas in the African interior which are now covered with natural parks. 


\section{CHAPTER VII.}

GENERAL OUTLINE OF THE ZOOLOGY OF TIE GREAT AFRICAN LAKES.

Is order that a general appreciation of the nature of the Tanganyika problem may be obtained, I have prefaced the more detailed examination of the components of the fauma of the lake, with an account, or rather with a series of enumerations, of the different animals which have hitherto been recorded in each of the other great African lakes. By this means certain features of the distribution of the freshwater fauna of equatorial Africa are rendered self-evident, and numerous repetitions which would otherwise be necessary in the sequel can be avoided. But besides this, so much that is new has recently been added to our knowledge of the composition of the faunas which exist in the great African lakes, that it is now for the first time possible to deal with the general characteristics of the equatorial African fresh-water fauna, and the results of such a study lead not only to conclusions which are interesting. but which are also by no means without importance from the broader biological point of view.

There are thirteen great African lakes, about the fauna of which it can be said that something definite is known at the present time. 
Beginning in the south these lakes are :-Shirwa, Nyassa, Kela, Bangweolo, Rukwa, Mwero, Tanganyika, Kivu, the Albert Edward Nyanza, the Albert Nyanza, the Victoria Nyanza, the chain of lakes in association with Beringo, and Lake Rudolf.

The lakes actually examined during the Tanganyika expeditions were :-

Shirwa, Nyassa, Kela, Tanganyila, Kivu, the Albert Edward Nyanza, the Albert Nyanza, the Victoria Nyanza, and Lake Nivasha.

For our information about Lake Bangweolo we are dependent upon the observations of Livingstone, IVeatherley, and the late M. Foa. Rukwa has been examined geographically by Mr. Wallace, and some information respecting its fauna was collected by the German explorer, Dr. Fiilleborn.

Mwero has been examined, and the general characteristics of its fauna been ascertained through the exertions of Mr. Crawshay and H.M. Commissioner, Mr. Alfred Sharp.

Beringo and the minor lakes in association with it were examined by Professor Gregory; while for Rudolf we are dependent on the somewhat scanty observations made by Messrs. Donaldson Smith, Cavendish and Harrison.

In making a general survey of the faunistic characters of these usually vast and often remotely isolated inland waters, . it will perhaps be most convenient to begin with what is known of the fauna of Lake Nyassa. The faunistic characters of this lake are to a large extent typical of those in the majority of the African lakes, and are an individualisation of what may be called the fresh-water fauna of Africa generally, this in turn being but a slight modification of the fresh-water fauna of the world.

Nyassa lies in an immensely long and relatively narrow 
valley, the surface of the lake and the floor of the valley in which it is contained being far below the general level of the surrounding country. In consequence of this, whether the lake shores are flat and sandy or rocky and steep, they are always sooner or later backed up by precipitous flanking ranges which constitute the steep sides of the gigantic trough in which the lake lies. The surface of Nyassa is now I, 500 feet above the level of the sea, and it extends for about 350 miles north and south with an average breadth of 40 miles. In most parts of the valley the flanking ranges rise to heights varying between 7,000 and 10,000 feet, but at the extreme south there is a narrow valley lying between part of the Kirk range and the Mngochi mountains which serves to carry away the surplus waters of Nyassa over the Murchison Falls in the shape of the Shiri River which eventually opens into the Zambesi itself. Throughout the lake there is abundant evidence that its waters have fallen greatly, and also that they have fallen in a succession of drops; for almost everywhere there are to be seen at least three old water-marks, old beach terraces in fact. The most conspicuous of these stands about I 4 feet above the water level, and upon the well-marked flat top of the terrace which it makes all round the lake there are always numbers of immense baobab trees. Baobab trees are known to be extremely slow growing; they will not grow, and they die, if they are in any way submerged, and consequently it is extremely probable that many centuries have elapsed since the water of Nyassa first sank from this old beach line, and there are at least two more clearly discernible terraces above and behind it. These general falls in the water level have in all probability been due to the successive wearing away of definite obstacles in the floor of the Murchison Falls. There are 
also not wanting indications that Nyassa was at one time directly connected with Lake Shirwa, and it is probable that at some more remote period both these lakes as one threw their surplus water down the valley of Lujenda River.

Besides general falls in the level of Nyassa, there are, however, indications of local disturbances of level, such as those to which I have referred in Chapter III., and these changes are undoubtedly due to the geological distortion which is still going on along the course of the Great Central African Range, within the folds of which Nyassa lies. The floor of the lake valley is very deep indeed, reaching we found in one place 430 fathoms, and these results have been subsequently closely confirmed by my friend Lieutenant Rhoades. Over large areas, generally, in fact, the floor of the lake is as low and lower than the sea level; and consequently we may say broadly that the lake valley is a chasm, or fold, in the earth's surface over 300 miles long and about 50 miles broad, and Io,000 to I I, 000 feet deep. Owing to its latitude the climate of Nyassa is warm and tropical, but since the lake's surface is r,500 feet above the sea level, the monotonous heat experienced on the equatorial African sea coasts is perceptibly tempered, especially at night.

Observations have been made on the fauna of Nyassa by a number of explorers, by Sir John Kirk, Livingstone, Joseph Thomson, Mr. Crawshay and others, and in $\mathrm{I} \$ 95$ and 1899 extensive examinations of the lake were made by myself and my colleagues during the Tanganyika expeditions. The investigations undertaken during both these journcys extended over three months, and the results obtained throughout all the different regions of the lake which we examined were of such a definite and similar character that there can be no doubt we have pretty well 
exhausted the fresh-water fauna of Nyassa, at any rate so far as a knowledge of the different types composing it is concerned. When the fauna of Nyassa is considered in comparison with the fauna of the other great lakes of the world, it is perhaps chiefly characterised by its limitations. For it will be seen from the subjoined lists that it consists almost exclusively of fishes and mollusca. The fishes of Nyassa include representatives of seven families, and the contained genera and species which have hitherto been recorded are represented in the following table:-

\section{Cichlide.}

1. Paratilapia robusta Gthr.

2. ,, afra Gthr.

3. ," modesta Gthr.

4. , livingstonii Gthr.

5. ", intermedia Gthr.

6. ," dimidiata Gthr.

7. , longiceps Gthr.

8. ,, nototania Blgr.

9. Corematodns shiranzis Bigr.

10. Petrochromis nyassa Blgr.

I1. Tilapia shirana Blgr.

12. ,, mossambica P'trs.

13. ", kirkii Gthr.

14. , squamipinnis Gthr.

15. ,, rendalli BIgr.

16. ", lateristriga Gthr.

17. , subocularis Gthr.

I8. ," jolnstoni Gthr.

19. ", lethrinus Gthr.

20. ,, tetrastigma Gthr.

21. , callipterns Gthr.

22. ," williamsi Gthr.

23. ", anrata Blgr.

24. Docimodns jolnstoni Blgr.

25. Cyntocara moorii Blgr.

26. Hemitilafia oxy'rly'nchus BIgr.

\section{MASTACEMBELID.F.}

27. Mastacembelns shiranus Gthr.

\section{SII.URIDA.}

28. Bagrns meridionalis Gthr.

29. Anoplopterns platy'li ir Gthr.

30. Synodontis zambescusis Gthr.

\section{CYPRINIIE.}

\section{Labeo mesops Gthr.}

32. Barbus trimacnlatns P'trs.

33. Barilins guentheri $\mathrm{Blgr}$.

34. Engranlicypris pinguis Gthr.

35. Pelotrophuns microlepis Gihr.

36. ," microcephalus Gthr.

\section{Characinini:}

37. Alestes imberi l'trs.

\section{CYPRINODONTID.*.}

38. Haplochilus jolnstoni Gthr.

\section{MORMYRIIT.}

39. Mormyrus discorly'niluzs I'trs.

40. , " catostoma Gthr.

41. Mormy'rops zambancnje I'irs.

Curiously enough, beyond copepods, cyclops and other minute forms, there are no crustacea in Nyassa besides 
the fresh-water crabs. There are no shrimps or prawns in the lake, and when we pass to the molluscan section of the fauna we find it to be constituted by the following characteristic fresh-water genera and species :-

I. Limnaea natalensis Krauss.

2. Isidora nyassana E. Sm.

3. ,, succineoides E. Sm.

4. Physopsis africana Krauss.

5. Planorbis (sp. indt.).

6. Ancylus (sp. indt.).

7. Ampullaria gradata E. Sm.

S. Lanistes olivaceus Sow.

9. ,, ovum Ptrs.

Io. , ellipticus Marts.

II. , nyassanus H. Dohrn.

12. Vivipara unicolor Ol.

13. Bithynia humerosa Marts.

I4. ,, Stanleyi E. Sm.

I5. Melania tuberculata Müll.

I6. ,, simonsi E. Sm.

I7. ,, nodicincta Dohrn.

\author{
I8. Melania pergracilis Marts. \\ I9. , polymorpha E. Sm. \\ 20. ,, turritispira E. Sm. \\ 21. ,, arcuatula Marts. \\ 22. Unio mossambicensis Ptrs. \\ 23. ,, leideri Marts. \\ 24. ,, lechaptoisi Ancy. \\ 25. ,, borelli Ancy. \\ 26. ,, kirki Lea. \\ 27. , nyassaënsis Lea. \\ 28. ,, hypsiprymnus Marts. \\ 29. Spatha kirki Ancy. \\ 30. ," nyassaënsis Lea. \\ 3I. Mutela alata Lea. \\ 32. Corbicula radiata Phil. \\ 33. , , astartina Marts.
}

There are no worms in Nyassa, and I never came across any polyzoa, nor did I, after careful searching, find any hydroids, and there appeared to be only one very inconspicuous spongillid of doubtful affinity. Besides the above forms, there were representatives of the usual fresh-water protozoa, and nothing else. Nyassa, however, is extremely interesting from a zoological point of view. The fauna, as will have been seen, is typically that of a pond, and consequently it is highly instructive to ascertain how these fresh-water pond animals which stock it, and which usually live in the still waters of pools and puddles, have succeeded in colonising the deep waters of the huge lake, which sink in places to more than 400 fathoms, and over which a heavy surf is often running at all seasons of the year, a surf, in fact, which breaks in ocean-like lines of foam on 
the open beaches and wears out the hard masses of the rocky coast into fantastic points and bays. An examination of the Soo to 900 miles of coast line which Nyassa possesses showed that the fauna, including the crocodiles and the fishes, was almost exclusively restricted to a narrow littoral zone, its molluscan section living, in fact, in groups in bays and sheltered inlets, and being hardly ever found alive along the sandy surf-swept beaches which occur in many portions of the lakes. These molluscs, moreover, did not extend into the deep water of Nyassa, and it was found, both on the first and second Tanganyika expeditions, that beyond Ioo to I 50 feet the lake was practically a fresh-water desert, there being encountered in its deeper water nothing but a few dead shells, the fragments of crabs' shields and legs and other organic refuse, enclosed in fine, grey mud.*

East and south of Nyassa there exists, at about the same level, Lake Shirwa. The faunistic characters of this lake have already been described in Chapter II., and consequently need not be fully repeated here, all that it is necessary to remember being the fact that the fauna of Shirwa unquestionably appears to have been at one time identical with that of Nyassa. This is shown, as we have seen, by the semi-fossilised remains which occur around the shores of Shirwa, but, owing to the geographical change which has separated Shirwa from Nyassa, and which has finally resulted in Shirwa having no outflow, this lake has become extremely salt, and the old Nyassan fauna has been killed out of it, except in the curious freshwater oases which are still maintained at the mouths of the permanent rivers flowing into the lake.

* For tables of the bathymetric distribution of mollusca in Nyassa see paper in Quart. Jowm. Micro. Sci., Vol. 41. 
Passing north from Nyassa, we find that, with the exception of the small crater pools occupying extinct cones which occur along the continuation of the lake's valley towards Rukwa, there are encountered no fresh waters of any dimensions until we reach Kela, a small, nearly circular, mere, with practically no fauna at all in it, beyond some siluroid fishes and swarms of a minute species of Bithynia. Curiously enough, Kela is within 20 miles of Tanganyika, and yet there is not a single specific identity between the fauna characteristic of the two lakes. Far to the east of Kela lies the larger lake Rukwa; it is a shallow sheet of water occupying the floor of a continuation of the Nyassa valley. Our most definite information respecting this lake is that obtained by Mr. Wallace, ${ }^{*}$ who, in 1897 , made an extensive geographical examination of the region, but who observed nothing but minute shells, probably those of Bithynia, and a number of siluroid fishes. $\downarrow$ Far to the west, again, we have the shallow and extensive expanse of water which constitutes Lake Bangweolo. This lake is known to contain siluroid fishes, but Mr. Weatherley reports that it is "absolutely shell-less." Somewhat further to the north lies Lake Mwero, a deep lake lying in a secondary fold similar to that of Lake Rukwa, to the east of Tanganyika. It has a much more profuse fauna than either Rukwa, Bangweolo, or Kela. Among the fishes occurring in Mwero, there have been recorded the following fourteen different types:-

* Journal of the Royal Geographical Socicty, IS97.

+ I believe some further information respecting the fauna of Lake Rukwa has more recently been obtained by Dr. Fiulleborn, but no account of this appears yet to have been published. See Chapter IV., p. 73, of present work. 


\section{LAKE MIVERO.}

FISIIES.

\section{MORMYRII).F:}

I. Gnathonemus stanleyanus Blgr.

2. Mormyrus longirostris l'eters.

Charicisin.t.

3. IIydrocyon lineatus Blkr.

4. Alestes macrophthalmus Gthr.

5. Alestes lemairii Blgr.

Silurid.F.

6. Schilbe mystus L. (?)
7. Chrysichthys sharpii lilgr.

S. Auchenoglanis biscutatus Geof $r$.

9. Synodontis zamlesensis Ptrs.

Io. Synodont is ornatipinnis $[\mathrm{B} \mid \mathrm{gr}$.

\section{CiCHLII).T:}

II. I'aratilapia mairoiefhala Blgr.

12. Paratilapia mocmensis Blgr.

13. Tilapia natalensis .I. Wel).

I4. Tilapia polyacanthus blgr.

In the above list the genera and species printed in italic are endemic to Lake $\$ 1$ wero.

It is curious to note, moreover, that the Viviparas of Mwero are not absolutely unlike the Neothanma of Lake Tanganyika.

In continuing a general consideration of the faunas in the remaining great African lakes it will be convenient to pass now far to the north, omitting for the present Tanganyika altogether, and to consider the remarkable fresh water which is constituted by Lake Kivu. Kivu lies, as I have shown elsewhere, in part of the continuation of the same depression which contains Tanganyika, about Ioo miles to the south of it. But beyond the fact that the outflow of Kivu finds its way into Tanganyika, the lakes appear to have no connection one with another, and their faunas are entirely distinct. The surface of Lake Kivu is 4,800 and odd feet above the level of the sea, and its water, as I have explained in Chapter V., contains a certain percentage of magnesium carbonate in place of the more usual modicum of sodium chloride which lake waters usually possess. From its great height the climate of Kivu is distinctly cool, and the fauna is poor in the extreme. IVe obtained the following fishes :-

KIVU.

I. Tilapia nilotica L. 1757 .

2. Tilapia burtoni Gth. IS93.

3. Paratilapia vitata Blgr. I 901 .

4. l'aratilapia bloyeti Sauv. $\mathrm{ISS}_{3}$.

5. Barbus altianalis Blgr. I90I. 
There was a small variety of Planorbis, a small Bithynia and Melania tuberculata among the gastropodean molluscs, one or two species of fresh-water bivalves, closely allied to the unios found generally in the African lakes, and apparently nothing else; the most striking feature about the fauna of Lake Kivu being the apparent absence of Viviparas.

North of Kivu we have the Albert Edward and the Albert Nyanzas, the faunas of which can very well be treated together. These two lakes are distinctly interesting. They lie at the respective altitudes of 3,000 and 1,700 feet above the level of the sea; or, in other words, they repeat the conditions with respect to altitude and climate which were encountered in the case of Tanganyika and Nyassa. The fauna of both the Nyanzas is abundantperhaps quite as abundant as that of Nyassa-but in both lakes it is composed of only a very few forms of fishes, and half a dozen species of mollusca at the most. In many portions of both the Nyanzas the beach is composed of actually nothing else but the shells of Melania tuberculata. In the Albert, so far as is at present known, the fauna consists of the following types:-

\section{ALBERT NYANZA.}

\section{FISHES.}

Petrochromis Andersoni (Blgr.).*

MOLLUSCA.

I. Planorbis adowensis Bgt.

2.,$\quad$ apertus Marts.

3. Ampullaria stuhlmanni Marts.

4. Vivipara rubicunda Marts.

5. Cleopatra pirothi Jick.

6. Bithynia alberti E. Sm.

7. ", walleri E. Sm.
8. Melania tuberculata Müll.

9. " liricincta E. Sm.

Io. Unio acuminatus H. Ad.

II. ,, bakeri H. Ad.

12. Mutela nilotica Fér.

13. Corbicula radiata Phil.

14. Sphrerium species indeterminate.

* It is to be noted that most, if not all, the other species of fish found in the Albert Edward occur in the Albert as well. Only the new forms were, however, collected. 
The fauna of the Albert Edward Nyanza is practically identical with that of the Albert Nyanza, the following types having been obtained:-

\section{ALBERT EDWARD NYANZA.}

FISIIES.

L.EIIUOSIRENID.F,

I. Irotopterus aethiopicus Ileac.

\section{CYPRIVIIR.T.}

2. Barluus fergussonii Blgr.

3. , edwardianus Higr.

I. Planorbis sudanicus Marts.

2. Ampullaria erythrostoma $k v$.

3. Vivipara unicolor Ol.

4. Cleopatra pirothi Jick.

5. , exarata Marts.

6. Bithynia alberti E. Sm.
Sil.URID.T.

4. Clarias lazeras.

5. ,, moorii ligrr.

CICHIIID.T.

6. Tilapia nilutica Blgr.

MOLILLSCA.

7. Melania tuleerculata Miill.

8. Unio stuhlmanni Marts

9. ,, ngesianus Marts.

10. Corlsicula radiata l'hil.

11. Sphrerium species undetermined.

Passing to the east, we encounter the Victoria Nyanza, the largest of all the African fresh-waters. This great lake is swarming with living things, but the fauna, in a specific sense, is by no means very profuse. When the genera of which it is composed are considered, the fauna of this lake is very comparable to that of Nyassa, and up to the present is known to consist of the following types:-

\section{VIC'TORIA NYANZA. FISHES.}

\section{Cichlin.r.}

1. Paratilafia longirostris IIilg.

2. , cavifrons IIilg.

3. ", retrodens llilg.

4. ," serranus Blgr.

5. Tilapia nilotica $\mathrm{Cuv}$.

6. ,, muchisynamulata Ifilg.

7. , samz'asii Pfeff.

8. , obliquidens Hilg.

MASTACEMGELIU.E.

9. Mastacembelus, sp.
SII.URID.F.

1o. Clarias Layera C. d I:

II. Synodontis afrofischeri Hilg.

\section{CYPRINIDE.}

12. Labeo forskalii Küpp.

13. Labeo nuepfellii P'eff. ," i'ictorianus Hlgr.

14. Barbus fayenstecheri Fisch.

15. ", Trimaculalus l'irs.

1 16. Discognathus johnstoni 13lgr. 
FISHES-continued.

Characinid.e.

17. Alestes rueppellii $\mathrm{Gthr}$.

CYPRINODONTID.E.

I8. Fundulus teniopygus Hilg.
MORMYRIDE.

19. Mormy'rus oxy'hynchus Geoffr

20. , longibarbis Hilg.

LEPIDOSIRENIDE.

21. Protopterus annectens Ow.

, athiopicus Hack.

MOLLUSCA.

I. Limnæa nyanzæ Marts.

2. , debaizei Bgt.

3. Isidora trigona Marts.

4. , strigosa Marts.

5. " transversalis Marts.

6. " forskali Ehrbg.

7. Physopsis ovoidea Bgt.

S. Planorbis sudanicus Marts.

9. , choanomphalus Marts.

Io. ," victoriæ $\mathrm{E}$. Sm.

I I. Ancylus stuhlmanni Marts.

I2. Ampullaria nyanze E. Sm.

I3. ,, gordoni E. Sm.

I4. ," bukobre Marts.

I5., ovata $\mathrm{Ol}$.

I6.,$\quad$ emini Marts.

17. Lanistes schweinfurthi Ancey.

IS. Vivipara unicolor $\mathrm{Ol}$.

I9. Vivipara rubicunda Marts.

20. , meta Marts.

2I. , phthinotropis Marts.

22. ,, constricta Marts.

23. Cleopatra guillemei Bgt.

24. Bithynia humeroso Marts.

25. Melania tuberculata Müill.

26. Etheria elliptica Lm.

27. Unio lourdeli Bgt.

28. ", hauttecœuri Bgt.

29. ", multicolor Marts.

30. Spatha trapezia Marts.

3I. Mutela subdiaphana Bgt.

32. ,, bourguignati Ancey.

33. Sphærium nyanzæ E. Sm.

34. ," stuhlmanni Marts.

35. Eupera parasitica Parr.

POLYZOA.

I. Species indt.

The Victoria Nyanza stands at an altitude of nearly 4,000 feet. It is higher than either Tanganyika or Nyassa, in most parts its waters are shallow and its shores reedy swamp fringes, but there are many island archipelagoes where the coasts are steep, and the waters which surround them deep and rough. In nature the depression in which the Victoria Nyanza lies is totally unlike those of most of the other African lakes which we have hitherto considered. It is, however, very comparable to the depression occupied by Lake Bangweolo, the Victoria Nyanza being, in fact, nothing more than a gigantic rain puddle, occupying 
a shallow, saucer-shaped depression, lying between distant eastern and western lines of mountains and valleys running north and south.

Further to the east again we have another series of lakes, lying mostly along the course of the great fold which runs from the vicinity of Kilima Njaro to the Red Sea. In these lakes Rudolf, Stephani, Beringo, Nivasha, Elimantita and Nakaroo, there is little of zoological interest.

But it cannot be said the faunistic characters of Rudolf are as yet fully known, still at the same time, from the observations of Mr. Donaldson Smith and Mr. Harrison, who both spent some time about the lake, it is quite clear that neither in the direction of fishes nor shells is it faunistically remarkable in any way. In Rudolf there have been recorded the following forms of fishes:-

\section{RUDOLF:}

\section{FISHES.*}

POIYPTERID正.

1. Polypterus senegalus.

\section{CifaraciNind:}

2. Ilydrocyon forskalii.

3. Alestes baremose.

4. ,, nurse.

5. Citharinus geoffroyi.

6. Dist ichodus.

CYPRINIHE.

7. Neobola bottegi.

SILURII.T.

8. Clarias mossambicus.

9. Auchenoglanis biscutatus.

Io. Synodont is schall.

I1. , zanzibaricus.

12. , citernii.

13. Mochocus niloticus.

SERRANIINA:

I4. Lates niloticus.

\section{CICHIII).}

15. Tilapia nilotica.

I6. , zillii.

Nothing sufficiently definite appears to be known of the invertebrate fauna of Lake Rudolf to make a list advisable.

* This list of fishes from Lake Kudolf is partly taken from Vinciguerra $/ \mathrm{nn}$. M/us. Civ. Genoza (2) xix., 1898 , p. 241 , the nomenclature having been kindly revised for the present work by $\mathbf{M}$ r. Boulenger. 
From the characters of the faunas encountered in the widely separated African lakes which we have now briefly considered, it will have become clear that throughout a large number of these fresh-water lakes the fauna is the same in type although the number of genera and species composing that of any lake in particular may vary considerably.

On this account I have intentionally postponed the consideration of the fauna of Lake Tanganyika, so that the very important fact that there is a type of fresh-water fauna which generally characterises the tropics of Africa may be fully appreciated, and in order that the exceptional fauna of Lake Tanganyika may be considered in comparison with the general characteristics of the rest.

Turning now to the fauna of Tanganyika, we find that up to the present time the lake has been found to contain some 200 and odd different species of aquatic and semiaquatic animals. There are, to begin with, the hippopotami, the crocodiles, amphibia and water tortoises common to the majority of the African lakes and rivers. Next we have to deal with nearly roo different species of fishes, some 50 species of molluscs, four crustaceans, one gymnolaematus polyzoan, four sponges and cœlenterates, and perhaps 20 recognisable protozoan types. Prior to the first Tanganyika expedition only four different species of fish were known, some 15 species of molluscs had been described from their empty shells, one species of crab had been described by Milne Edwards, and there was besides one coelenterate in the shape of the famous Tanganyika jelly-fish. With the exception of the few fishes collected by the officers of the Free State, the whole of our knowledge of the fauna of Tanganyika as it exists up to date, has been acquired as a result of the 
two Tanganyika expeditions. It will be unnecessary in the present work to consider the mammalian, reptilian, and amphibian vertebrates, as they are similar to those contained in other African lakes, and are already quite well known; consequently, we may proceed at once to examine the remaining inhabitants of the lake. In roughly surveying the whole field, perhaps the most striking fact is that nearly half the total number of species representing the population of Tanganyika should be made up of different kinds of Teleostian fishes. A fish-fauna with 100 species or thereabouts, in a fresh-water lake, is extraordinary anywhere; but it is doubly strange when, as in the case of Tanganyika, we find that 76 out of the 87 species which have actually been discovered and described in the lake, are endemic forms; that is to say, they occur, so far as is at present known, nowhere else in the world. The majority of the fishes in Tanganyika are, in fact, endemic, and when we consider the profusion of species which is present, this fact is extremely interesting and suggestive in itself. Consider for a moment in comparison the fish-fauna of Lake Mwero: up to the present, only i 4 species have been found in it; so also in Nyassa we find that there have been recorded 4I species of fishes, in Rudolf only sixteen. These facts point in themselves to what is from other considerations unquestionable, i.c., that Tanganyika has been practically isolated and undisturbed for, at any rate, a considerable time, and the extraordinarily large number of endemic forms present, can only be viewed either as the result of the formation and multiplication of species through natural selection and other similar causes, in the lake itself, or as a survival in this lake of some old fauna which was rich in such types of fishes. The 87 species of Tanganyika fishes are divided among the following nine families :- 
Polypteridæ, Lepidosirenidæ, Characinidæ, Cyprinidæ, Siluridæ, Cyprinodontidæ, Serranidæ, Cichlidæ and Mastacembelidæ. Of these, the species occurring in Tanganyika which represent the Polypteridæ, Lepidosirenidæ, Characinidæ and the Siluridæ, are widely spread throughout the fresh-waters of the African continent. But all the seven species of the Cyprinidx, and the six species of Mascacembelidæ, which occur in Tanganyika, are endemic forms. The single species representing the Cyprinodontidæ and the Serranidæ are the same, while among the 2 I genera and the $5^{8}$ species of the Cichlidæ, only one species, Tilapia Burtoni, is found outside the confines of Tanganyika, this single species having made its way up the Russisi river into Lake Kivu. It is, however, only among the Cichilidæ that endemic genera occur.

The Cichlidx are found in the fresh-waters of the Old and the New World, especially in the rivers of South America, and we are further confronted by the extraordinary fact that nearly half of the Old World species are confined to the limits of Tanganyika itself, a circumstance which, on the face of it, would almost at once suggest that in Tanganyika we have the remains of the ancient point of origin from the sea of this particular group of fishes. Such a conception of the mode of origin of the Tanganyika fish-fauna would fit in admirably with a number of other facts relating to it. Thus, it was shown by Dr. Günther that the fish of the African fresh waters are related to each other in such a manner as to suggest that they have spread out from a centre to which Tanganyika would correspond; while more recently Mr. Boulenger, as the result of an examination of the fishes which I obtained during the Tanganyika expeditions, has confirmed this view, and shown that the morphological attributes of the Tanganyika 
Cichlids are on the whole primitive as far as that group is concerned. If, moreover, the above view of the origin of the Tanganyika fish-fauna be correct, the fact that the genera of Characinidre and Siluride living in Tanganyika are not endemic would be perfectly intelligible. The first of these groups is a very old one, and might easily have become a wandering fresh-water stock before Tanganyika bęcame a land-locked depression; while the second contains forms which are known to be capable of migration in a high degree. The same kind of reasoning thus obviously also applies to the non-endemic species of the latter group. Some such view of the case would at once explain other matters. If Tanganyika became stocked from an ancient western sea, this would account for the presence of Cichlidie in the Congo, and the presence of forms like bass only in the Congo, the Nile, and Tanganyika, as well as the existence of several species of the ancient ganoid Polyptems in these different waters. For it is a geographical fact, which should be clearly understood, that at certain times and at certain seasons it is possible to push one's way in a boat from the upper tributaries of the Congo into those of the Nile, the watersheds in this region being extremely ill defined.

Up to the present time there are known in Tanganyika the following series of forms :-

FISHES.

I'OLYITERID.E.

1. Polypterus congicus Blgr. I $\$ 9 \$$.

LEIIDOSIRENIID.Æ.

2. Protopterus athiopicus Heck. 185I.

CIARACINIDA:

3. Hydrocjon lineatus Blkr. I 863 .

4. Alestes macrophthalmus Gthr. I 867 .

5. ," macrolepidotus C. \& V. I $\$ 49$.

6. Citharinus gibloosus Blgr. I $\$ 99$.
CYPRINID.E.

7. Capsëta tanganica Blgr. I900.

8. I3arbus platyrhinus Blgr. 1900.

9. ,, altianalis Blgr. 1900 .

I0. ", serrifer Blgr. 1900.

II. ", tropidolepis $13 \mathrm{lgr}$. 1900.

12. Barilius moorii Blgr. I900.

13. ,, tanganiae Blgr. I900. 
FISHES-continued.

SILURIDA.

I4. Clarias robecchii Vincig. I 893 .

I5. , liocephalus Blgr. I 898 .

I6. Chrysichthys cranchii Leach, I8Io.

I7. ,, myriodon Blgr. Igoo.

I8. ,, braclynnema Blgr. I900.

19. Auchenoglanisbiscutatus Geoffr. I829.

20. Anoplopterus platychir Gthr. I 864 .

21. Synodontis granulosus Blgr. I 900.

22. ,, multipunctatus Blgr. IS9S.

23. Malopterurus electricus Lacép. I8oI.

\section{CyPRINODONTIDE.}

24. Haplochilus tanganicanzs Blgr. I898.

\section{SERRANIUA.}

25. Lates microlepis Blgr. I 898 .

\section{Cichlidie.}

26. Lamprologus tetracauthus Blgr. I 899.

27. ,, elongatus Blgr. I 898 .

28. $\quad$, $\quad$ tretocephalus Blgr. I899.

29. ", modestus Blgr. I 898 .

30. , lemairii Blgr. I 899 .

3I. , , hecqui Blgr. I899.

32. ,, moorii Blgr. I 898 .

33. , brevis Blgr. I 899 .

34. $\quad$, $\quad$ compressiceps Blgr. I 898 .

35. ,, fasciatus Blgr. I 898 .

36. ,, furcifer Blgr. I 898 .

37. Julidochromis ornatus Blgr. I 898 .

38. Paratilapia vittata Blgr. I90I.

39. ,, aurita Blgr. I90I.

40. ,, bloyeti Sauv. I $88_{3}$.

41. ,, pfefferi Blgr. I898.

42. ,, calliura Blgr. I 901 .

43. $\quad$, macrops Blgr. I 898 .

44. $\quad, \quad$ ventralis Blgr. 1898 .

45. $\quad, \quad$ dewindti Blgr. I 899 .

46. ", furcifer Blgr. I 898 .

47. ,, stenosoma Blgr. I90I.

48. , , leptosoma Blgr. I 898 .

49. ,, nigripiunis Blgr. I9OI.
50. Bathybates ferox Blgr. I 898 .

51. ," fasciatus Blgr. I 901.

52. Pelmatochromis polylepis Blgr. I90I.

53. Ectodus descampsii Blgr. I 898 .

54. , melanogenys Blgr. I 898 .

55. " longianalis Blgr. I 899.

56. Yenotilapia sima Blgr. I 899.

57. ,, ornatipinnis Blgr. I9oI.

58. Grammatotria lemairii Blgr. I 899.

59. Trematocara marginatum Blgr. I 899 .

6o. , unimaculatum Blgr. I90'1.

6r. Telnatochromis vittatus Blgr. I 898 .

62. ,, temporalis Blgr. I 898 .

63. Gephyrochromis moorii Blgr. I90I.

64. Tropheus moorii Blgr. I 898.

65. ,, annectens Blgr. I 900 .

66. Simochromis diagramma Gthr. I 893.

67. Tilapia nilotica L. I757.

68. , burtoni Gthr. I 893 .

69. , horii Gthr. I 893 .

70. ,, rubropunctata Blgr. I 899.

7. , dardennii Blgr. I899.

72. ,, labiata Blgr. I 898 .

73. ,, pleurotania Blgr. I90I.

74. ," trematocephala Blgr. I90I.

75. ,, boops Blgr. IgOI.

76. ,, grandoculis Blgr. I 899.

77. ," microlepis Blgr. I899.

78. Petrochromis polyodon Blgr. I 898.

79. ,, tanganice Gthr. I893.

8o. Asprotilapia leptura Blgr. I $90 \mathrm{I}$.

81. Eretmodus cyanostictus Blgr. I 898.

82. Spathodus erytlurodon Blgr. I90J.

83. Perissodus microlepis Blgr. I 898 .

84. Xenochrom is hecqui Blgr. I 899.

85. Plecodus paradoxus Blgr. I 898 .

Mastacembelide:

86. Mastacembelus frenatus Blgr. I90I.

87. ,, moorii Blgr. I898.

88. , , ellipsifer Blgr. I 899 .

89. , , tanganice Gthr. I\$93.

90. ,, teniatus Blgr. Igor.

9I. , ophid.um Gthr. I893.

The names of fishes in this list printed in italics are those which are endemic in the lake. It should also be noted that the five species of fishes obtained from Kivu are included in this list. 


\section{CRUSTACLA.}

BRACIIYURA.

1. Limnothelphusa maculata (Cunnington)

2. Ilatythelphusa armata (Milne Edwaris)
ATYII).T.

3. Limnocaridina Tanganyikx (Calman)

P'AL. EMIONID.X:

4. I'alitmon moorei (Calman)
I. Limnzea debaizei Bgt.

2. ,, jouberti Iigt.

3. ,, laurenti Iigt.

4. , natalensis Krauss.

5. Isidora coulhoisi Bgt.

6. ,, randabeli Bgt.

7. I'hysopsis tanganyicre Marts.

S. Planorbis sudanicus Marts.

9. ,, tanganicanus Bgt.

10. ,, tanganicensis E. Sm.

I . Ampullaria bridouxi Bgt.

I2. , ovata Ol.

I 3. Lanistes jouberti Bgt.

14. Vivipara sp. ?

15. Neothauma E. Sm.

16. Cleopatra guillemei Bgt.

17. Melania tuberculata Müill.

IS. ,, tanganyicensis E. Sm.

I9. ,, horei E. Sn.

20. Typhobia horei E. Sin.

2I. Bathanalia Howesei Moore.

22. Bythocerus iridescens Inore.

23. ,, mimor Nloore.

I. Arachnoidia lankesteri (Moore)

I. Lemnochnidia.

1. Spongilla tanganyikae Evans.

2. ,, moorei Evans.

\section{MOLLUSCA.}

24. Chytra kirkii Moore.

25. Limnotrochus Thomsoni L. Sm.

26. Paramelania Damoni E. Sn.

27. ,, cranigranulata E. Sim.

2S. Tanganyicia rufofilosa Crosse.

29. Speika zonata Woodw.

30. Nassopsis nassa E. Sin.

3I. Syrnolopsis lacustris E. Sm.

32. Stanleya neritinoides light.

33. Lumella callifera Bgt.

34. Unio böhmi Marts.

35. ,, gerrardi Marts.

36. , calathus Bgt.

37. ,, horei E. Sm.

$3_{3}$. ,, burtoni Wondw.

39. , rostralis Marts.

40. ,, tanganyicensis $1 \therefore$ Sm.

4I. ," thomsoni E. Sm.

42. Spatha tanganyicensis E. Sm.

43. Mutela soleniformis ligt.

44. Iridina spekei Woolw.

45. Burtonia tanganyicensis $\mathrm{E}$. Sm.

46. Corbicula radiata l'hil.

I'OLYZOA.

\section{HIDROZOA.}

SPONGES.

3. Potamolepis welt neri Mloore.

Associated with the above there are in Tanganyika some conspicuous Protozoa, chief among which is a curious peridinia-like form possessing cilia. This organism forms the yellow scum on the lake which was noticed by Livingstone in his last journey. Associated with it there is a large 
condylostema, and besides these, representatives of the universally distributed fresh-water protozoa.

This enumeration brings us to an end of our survey of the African lakes which have up to the present time been explored. I have no information about Chad, and there is at present little or nothing to be ascertained about the numerous minor lakes which are associated with the tributaries of the Congo, but it will be admitted that as a result of the investigations carried out during the Tanganyika expeditions, and through the scattered explorations of a number of other observers, we now know definitely what are the faunistic characters of the principal African fresh waters, and consequently we are for the first time in a position to deal in a general way with the meaning of the facts of distribution and the character of the African fresh-water faunas, and with the conspicuous anomalies which the fauna of Lake Tanganyika presents. But before proceeding to this inquiry it may be pointed out that, besides the actual lakes of Central Africa, there are the great rivers and the backwaters of these rivers, which, as Mr. Boulenger has shown, contain an extraordinary fishfauna, if nothing else. From our own experiences on the Zambesi, Shiri, Rusisi, Ruchuru, and Semliki, it would appear that in the majority of these African rivers the fauna consists of little else but fish. In backwaters and the like there are often encountered the typical fresh-water insects, mollusca, and minute crustacea which occur generally over the African interior, but in the actual course of the rivers little if anything but fish. This is, I am convinced, what will be found to be the case in the majority of African streams, both great and small, but it is perhaps to be anticipated that the Congo, its backwaters and its tributaries, will eventually prove more or less of an exception to this rule. The Congo 
is fed from Tanganyika, and numbers of the animals which, as we have seen, are peculiar to Tanganyika must be annually carried into its upper reaches, and may possibly continue to subsist in the backwaters of the river. Moreover, the Congo lies in what was probably at one time a former extension of the sea, and, as I have said, its fish-fauna is unique; it is therefore quite probable that the backwaters of this great river will be found to be zoologically fruitful. There have, indeed, been unconfirmed statements of the occurrence of jelly-fishes, whether similar to the Tanganyika form is not klown, high up in the course of the river.

If we consider the constituents of the fauna of the African lakes other than Tanganyika, described in the preceding pages, it becomes clear that the animals encountered are, at any rate in a generic sense, the same. One or other or more genera may be omitted in the case of any particular lake, but with the solitary exception of Tanganyika there is no lake which contains numerous genera peculiar to itself, and certainly no lake which contains not only genera which are peculiar to itself, but which are not found elsewhere in the fresh waters of the globe. The genera which in Lake Tanganyika possess this remarkable characteristic are constituted, as we have seen, by a whole series of invertebrates and a number of cichlid fishes. These forms however, do not replace the ordinary fresh-water fauna in the lake: they simply coexist along with it and consequently we have in Tanganyika a series of animals which are superadded to the ordinary fresh-water fauna of the continent.

With the exception of Tanganyika, the ordinary freshwater fauna of Africa has nothing novel or striking about it. In all the lakes which we have examined there is found in each case an ordinary fresh-water stock, which may or may not have become individualised by the pro- 
duction of specific varieties, and this rather monotonous sameness in the nature and composition of the fresh-water faunas of the great lakes of Central Africa has now been definitely shown to hold good as a rule, characteristic of them all with one solitary and conspicuous exception. The fauna of Lake Tanganyika alone contains forms, and many of them, which have not the characteristics of any usual freshwater types, but, although this fauna thus differs from that of all the other great African lakes, it is after all only a partial exception to the rule of uniformity in type which characterises the fauna of the great African lakes in general. It was seen that Tanganyika contains all the genera of fish and invertebrates which are found in Lake Nyassa, and the character of the normal fresh-water constituents of the fauna of Lake Tanganyika differs no more from the fresh-water types contained in the Victoria Nyanza or Nyassa than the constituents of the faunas of these two latter lakes differ from one another. Tanganyika is rendered peculiar, not by the general characters of its freshwater fauna, but simply by the additional possession of a number of forms which are peculiar to that lake. The animals forming the invertebrate section of this peculiar group have an obviously marine aspect, and on that account I have spoken of them elsewhere* as forming a halolimnic series in Lake Tanganyika-that is to say, they form a group of animals which, although living in a fresh-water lake, have at the same time the characters of animals that are typical of the sea. The Tanganyika animals which possess par excellence these characteristics, are the endemic gastropods, the gymnolematus polyzoa, and the jelly-fishes. But besides these forms there are other invertebrates which, although not so markedly marine in character,

\footnotetext{
* Proceedings of the Royal Society (loc. cit.).
} 
are nevertheless highly remarkable from the fact that they are only found in Lake Tanganyika among the fresh waters of the African interior. To this category of animals belong the prawns, some crabs, the sponges, some protozoa, and a host of Cichlid fishes. Fishes of course are highly migratory forms, and, once established in fresh water, are sure to spread to a large extent through the rivers and lakes of the continental land-mass in which they happen to be; still there is this peculiarity about the fishes which are at the present time encountered in Tanganyika; some of the cichlids, as $\mathrm{Mr}$. Boulenger has shown, are primitive representatives of the group; while, in Tanganyika, but not in Nyassa and the lakes to the south, there exists the ancient ganoid Polypterus, and several characinid fishes which although not restricted to Tanganyika, do nevertheless share the somewhat primitive characters which the other halolimnic animals undoubtedly possess. On account of this, I am inclined for the present to regard the African Polypteroids and at any rate the genera of Cichlida peculiar to Tanganyika, as a piscine portion of the halolimnic group. The reasons for the incorporation of these fishes which are not wholly restricted to Tanganyika is again discussed further on, and, as thus defined, the halolimnic fauna of Tanganyika contains the following forms:- among the Teleostei fourteen genera of Cichlida, Polypterus among the ganoids, seventeen genera of gastropods, possibly two Lamellibranchs, two crabs, two prawns, one gymnolxmatus polyzoan, one medusa and some endemic protozoa. All these forms, with the exception of Polypterus, which is obviously an animal capable of migration, are the peculiar and characteristic feature of Lake Tanganyika, and it will be admitted that if the invertebrates of this halolimnic fauna 
have had a different origin from the general African freshwater constituents, it is highly probable that some of the fishes which we now, from their dispersal, regard as belonging to the normal African fresh-water series, are in reality scattered members of this same halolimnic group. At all events it is quite clear that it is not correct to suppose that the fish-fauna of Tanganyika is at all similar to that of the other African lakes, and this strikingly distinctive character of the Tanganyika fishes constitutes the prim $\hat{a}$ facie evidence for supposing that at least some of the fishes which characterise the fauna of Lake Tanganyika are of the same stock as the halolimnic invertebrates themselves.

The halolimnic fauna consists then of a group of animals, the invertebrate section of which is rigidly confined to the lake, and which have no obvious relation to the normal African fresh-water invertebrates, but it is also indicated that some of the African fishes which we have hitherto regarded as normal fresh-water fishes of the African continent may belong in reality to the now scattered vertebrate section of the halolimnic group.

It remains for us now then to examine in much greater detail the characters of the individual components of the halolimnic group, and thereby to attempt to acquire the information necessary in order to ascertain the actual affinities of these forms; while finally we shall have to consider the question of the nature and the origin of the whole of the halolimnic group in Tanganyika, and this question itself forms the Tanganyika problem as it now exists. But before proceeding to discuss in detail the structure of the halolimnic forms, it is desirable to consider certain widespread phenomena relating to the normal fresh-water fauna of the African lakes in general. 


\section{CHAPTER VIJ.}

ON SOME CURIOUS FEATURES OF THE DISTRIBUTION OF SPECIES.

In the majority of the lakes in Equatorial Africa, in all of them in fact, with the solitary exception of Lake Tanganyika, there is a fauna which is in no way peculiar, and although the vertebrate section of this fauna is rendered distinctive of Africa by the profusion of ganoids of charicinidx and cichlidx, its invertebrate sections are distinctly poor. Thus it appears to be a fact from what we have seen that in most of the greater lakes of Central Africa the fresh-water fauna consists of fishes and of molluscs and practically of nothing else. The majority of the great African lakes do not at all support the generally prevalent idea, that the fresh waters of the tropics are in possession of a profuse fauna. In Mwero, in Beringo and in the Albert Edward Nyanza, or even in the Albert and the Victoria Nyanzas for that matter, there is hardly so much variety of life as there is in an ordinary American or European puddle. There is often an extraordinary profusion of some particular type as in the case of the Nyassa Viviparas, or of Melania tuberculata in the Albert Edward Nyanza, but there is no diversity or even modification among the constituents of the primary fresh-water series, which 
is everywhere found to people the greater and the lesser Central African lakes.

In the preceding examination of the components of the individual faunas of the different African lakes, it will have been observed that if we exclude the obviously migrating vertebrates, the fishes, the amphibia, and the like, the remaining invertebrate constituents of these faunas are almost always in a specific sense, different in each of the lakes. There are, in fact, only one or two specific forms, such as Melania tuberculata, which occur generally in all the lakes-that is to say, we have in each depression a fauna which, in the species composing it, differs from the fauna in any of the other depressions. It is obvious from this fact that even when lakes are within twenty miles of each other, as in the case of Tanganyika and Kela, the invertebrate faunas of two such depressions do not readily, at any rate, communicate with one another. There is, in fact, very little indication, if any, that the invertebrate faunas of the lakes intercommunicate or inter-colonise at all. This is particularly well seen in Lake Kivu. Kivu is a great lake and must have been in much the same condition that it is now, at any rate, for centuries, yet there is not a Vivipara to be found in it, although they swarm in the lakes a hundred miles to the north and to the south. Kivu is, in fact, in direct water connection with Tanganyika, but so far as is at present known, only one small fish, Tilapia burtoni, has ever migrated from the one lake to the other. From these facts and similar ones which we encountered again and again, and which have been further verified by the observations of numbers of other travellers who have been among the'Central African lakes, it would seem that the invertebrate components of the fauna of the different African fresh waters do not tend to migrate at all, while the fishes of 
these same fresh-water areas do not migrate with anything like the vigour that one might have been naturally led to suppose.

There is, however, another characteristic of the faunas of the different great and small African lakes which is certainly interesting, and may very possibly be of wide theoretical importance. If we examine the lists of species constituting the faunas of these lakes, we find that for some reason or another the number of different species present in any particular lake is directly proportional to its size. The fauna of Nyassa consists of about 75 species. The ordinary fresh-water fauna of Tanganyika of 80 species. The fauna of the Victoria Nyanza, although not completely known, contains about 60 species. The fauna of the Albert Nyanza, which is much less than either of the preceding lakes, contains only 20 forms. The Albert Edward, about the same number; Kivu only ro species; while the really small lakes, Kela, Elimantita, Beringo, Nivasha, Nakaroo, etc., contain only about half-a-dozen species each. It is thus obvious that from some cause or other the number of specific forms in an African lake is roughly proportional to the size of the lake itself.

The physiographical features of the African lakes are unique; nowhere else in the world have we numerous sheets of fresh-water of all sizes scattered over an area bigger than Australia, and yet all of which are under practically the same climatic conditions. In this way the faunistic phenomena presented by the African lakes are distinctly simplified; we have not to reckon with the wide climatic differences that are forced upon the faunas of the lakes which occur in the latitudes of North America, Europe and Asia, and consequently we cannot legitimately invoke difference of conditions to account for the specific richness of Nyassa as 
compared with the poorness of the fauna of the Albert Nyanza. The water of the Albert Nyanza is quite as full, if not fuller, of animals than the water of Nyassa; but the number of species which the lakes contain is, as we have seen, widely different. In this way it would appear to be a fact that the number of animals living in any particular lake may be, and probably is, related to the food supply which the lake presents, but the number of species is for some reason a function of the area of the lake and not of the food which it contains. This is a very remarkable circumstance, and has, in all probability, a wide significance; the only analogous phenomena with which I am acquainted being the contrast which has been found to subsist between continental and island floræ. It has been shown by botanical enquirers that the number of species of plants which flourish upon an island is less than the number of species which flourish upon a similar continental land area, and that, roughly speaking, the number of species which constitutes an island flora is proportional to the size of the island; the less the island, the fewer the species of plants which it supports, although the island may be just as thickly covered with vegetation as a similar continental area. From these considerations it would appear probable that in the case of the different sized lakes of Africa and in the case of island floras we are dealing with analogous phenomena. For in the one case we are dealing with sheets of water of different sizes, which are, so to speak, detached from the sea, and in the other, with different sized pieces of land occurring in the ocean which are detached from the surface of the continents.

In the case of island floras it has been found, however, that there is a distinction to be drawn between what have been called oceanic islands and continental islands, or in 
other words islands which have long been remotely isolated in the midst of the ocean, and islands which are more or less narrowly-detached annexes of a continental land-mass; the floras being different in character on these two types of islands. On comparing the floras of continental with oceanic islands, it is found that on continental islands there are more genera and fewer species as compared with the fewer genera and more species found on oceanic islands. The continentai islands are dominated by migrations of certain genera from the continent ; whereas the floras of oceanic islands are less exposed to the effect of the incursion of vigorous continental forms; and the floras of such islands are able to gradually adapt themselves to the varying conditions which the island presents in various parts, the flora of an oceanic island becoming affected by the natural restrictions which deliminate different portions of the island from one another; and in different areas individual varieties gradually attain specific rank. It is apparently the oceanic island which is most nearly comparabie to the remotely inland lake, for it is obvious that when the depressions holding lakes upon a continental area have become established, the migrations of new forms into these depressions from the ocean will have been rendered difficult or impossible, as the case may be. From what we saw in Chapter VII. it would appear that to a large extent the fresh-water fauna of a continent is something which in its origin is bound up with the origin of the continent itself, and consequently the production of species in the fresh waters of a continent is, in a sense the measure of the age of the fresh waters to which these species may belong. From general considerations it would appear that the specific varieties of the genus Melania characteristic of the fauna of Nyassa cannot have migrated into it, for they do not exist outside the lake-they are, in fact, 
characteristic of the fauna of Nyassa, and consequently they would appear to have originated in the lake itself. In a great lake like Nyassa the origin of new forms peculiar to the region appears to be related to the existence of conditions there which have already been observed to be conducive to the separation of definite variations among animal forms. As Darwin pointed out, it is definitely known that the fencing off of cattle in a park tends towards the formation of stock which differs on different sides of the fences, and in a great lake like Nyassa we find that the fauna is often actually very definitely fenced off into isolated areas by the natural conditions which exist in such a lake. Thus the molluscs in Nyassa live chiefly in the sheltered bays and creeks which communicate with the open body of the lake, each bay forming in itself a colony wherein a number of molluscs live practically isolated from all the other colonies which are distributed round the shore. Storms and floods effect the dispersion of members of these colonies at different times, and in this way every colonisable area of the lake becomes filled with molluscs, but in general the individual population of each colonisable area remains cut off and isolated from all the rest. The actual illustrations of these phenomena are often very interesting and instructive. Thus the Vivipara unicolor, which is generally found in Nyassa, and frequents more diversely conditioned parts of the lake than any other form, is replaced in Monkey Bay by a type nearly three times as large, and, so far as I know, this variety occurs in no other part of the lake. So again in Tanganyika, there are at least three very well marked varieties of the ally of the genus Vivipara Neothanma. One of these, with the type of shell represented on page $26 \mathrm{r}(a)$, occurs exclusively at the south end of the lake, swarming in the broad and more or less sheltered 
reaches into which the southern end of Tanganyika expands. In the narrow, surf-swept, and turbulent portion of the lake, which stretches between the north of Cameron Bay and Tembwi, Ncothauma is only found in the little bays and sheltered places occurring along both shores, and here the character of the form changes, the double-keeled shell of the former variety being replaced by the elongated type shown on page 26 I (b). Northward the lake terminates again in more or less sheltered expanses, like the Gulf of Ubuari, the deep bays near Ujiji, and the extreme northern extremity of Tanganyika. In these the form of the genus again changes, the two more southern varieties being generally replaced by the curious rounded form represented on page $26 \mathrm{I}(\mathrm{c})$. The same phenomenon is again remarked in the distribution of the beautiful Typhobia shells of Tanganyika. In the north we have a type which differs from that in the south. So again with regard to the distribution of the Tanganyika genus Paramclania and its allies; the shell of Paramelania damoni is represented on page $2+2$, and occurs more or less abundantly throughout the lake; but in certain areas it is to a greater or less degree replaced by several definite varicties; one of these, represented on page 238 , is so peculiar and well marked as to constitute a new generic type. This form, Bythoceras, occurs only in the southern half of the lake, and is practically exclusively related to Cameron Gulf and the bays which lie opposite the gulf on the east coast. Another variety which is much more closely related to Paramelania damoni is the form Paramelania crassigranulata, and this variety is also restricted to certain areas on Tanganyika, being encountered about Karema on the east coast of the lake. From these observations it would appear to be indicated that the cause of the production of a greater number 
of species in a great lake as compared to a small one is really due to the existence of a greater number of more or less definitely isolated aquatic areas in the greater lake as compared to the less. The greater lake corresponds to a park in which the cattle have been fenced off into a greater number of pens, and thereby a greater number of varieties have been produced, while the smaller lake corresponds to one of these areas, and contains only a single variety.

The phenomena presented by lacustrine faunas would thus seem to be very similar to the phenomena presented by island floras, for, as we have seen, the number of species encountered in the different African lakes vary directly with the size of the lake, but it should at the same time be clearly apprehended that the specific varieties characteristic of individual great African lakes are usually only so many structural changes which have been rung by time and circumstance upon the types of fresh-water organisms which are universally distributed throughout the earth. These varieties which appear in the greater African lakes have nothing to do with the halolimnic forms peculiar to Tanganyika, although these forms may and have been, as we have just seen, affected in a similar way. It is, moreover, not always the same forms which tend to vary in the different lakes. In Nyassa there are numerous endemic varieties of Melania, Ampularia, and Vivipara; in the Victoria Nyanza numerous varieties of the Melania, to which there are however added noticeable modifications of normal freshwater Lamellibranchs, as in the case of Etheria. 


\section{CHAPTER IX. \\ THE FISHES OF LAKE TANGANIIKA.}

As will have been seen in the preceding chapters, the fishes that have been recently discovered in Lake Tanganyika consist of $8_{7}$ different species, of which 74 are new to science. Of these latter, four were originally collected by Captain Hore, 2 I by the Lemaire Expedition and the officials of the Congo Free State, the remaining 49 being collected by myself and my colleagues during the first and second Tanganyika Expeditions. For the elaborate and careful working out of this somewhat unique series we have been entirely indebted to Mr. Boulenger, of the British Museum, who published two fully illustrated reports on them in the transactions of the Zoological Society.* In the present work I have consequently merely incorporated Mr. Boulenger's original descriptions accompanied by reproductions of Mr. Green's careful and accurate drawings of the most conspicuous genera and species.

In what follows the fishes have been arranged in their natural order, and only the descriptions of the few forms found in Tanganyika, which like Polypterus were already well known, being omitted.

* For references to these and other papers containing descriptions of the fishes collected during the Tanganyika expeditions by Mr. Boulenger, see bibliography of the expeditions at the end of the volume. 

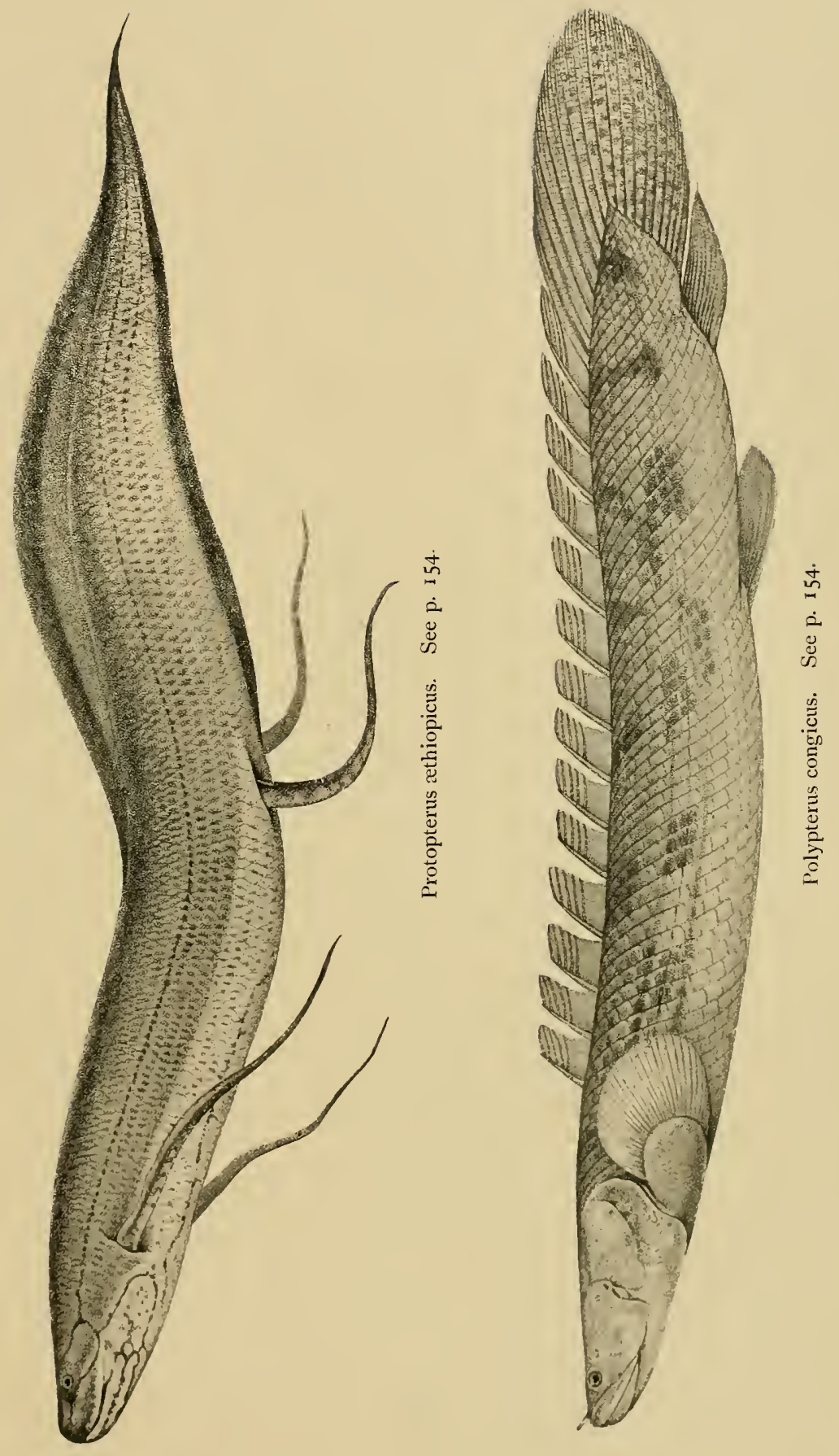
POLYPTIERII).

I. P'. Congicus.-Blgr. is98. (Fig., p. i 53, lower).

LEPIDOSIRENII) L.

2. P'rótopterus athiopicus.-Heck i 851 . (lig., p. I53, upper).

CHARACINIJ) E.

3. Hidrocyon LiNeatus.-Blkr, I $86_{3}$.

4. Alestes macrophthalaus.-Gthr. I867.

When this species was first recorded from Lake Tanganyika, it was only known from the Gaboon. It has since been found in Lake IIweru and in the Congo.

5. Alestes macrolepidotus.-C. and V. 1849.

Kalambo.

6. Citharinus gibeosus.-Blgr. IS99. (Fig., p. 155.)

Kalambo. The largest specimen measures 500 millim.

\section{CIIRINID. I:}

7. Capö̈ta tangaxic.玉.-Blgr. r9oo. (Fig., p. 163.)

Depth of body $33^{3}$ to 4 times in total length, length of head 5 times. Snout broad and rounded, as long as or slightly longer than the eye, the diameter of which is $3 \frac{1}{2}$ times in the length of the he:t and nearly twice in the intcrocular width ; the width of the mouth equals ${ }_{3}^{2}$ that of the head; a minute barlel, hidden under the lip at the angle of the mouth. Dorsal III. 9; third ray very strong, ossified, smooth ; the fin, which is equally distant from the eye and from the caudal, has the free edge notched, and its greatest depth equals the length of the head. Anal III. 5 ; the longest ray measures ${ }_{4}^{3}$ the length of the head. l'ectoral acutely pointerl, as long as the head, not reaching the ventral, which is inserted under the first rays of the dorsal. Caudal forked. Caudal peduncle twice as long as deep. Scales $68-70 \frac{13-14}{14-15}, 9$ or 10 between the lateral line and the root of the ventral. Olive above, each scale dlarker at the base, silvery white lueneath; fins greyish.

Total length, 320 millim.

Described from three specimens from the north end of Lake Tanganyika.

The discovery of a species of this genus in Lake Tanganyika is particularly interesting from the fact that only one was known from $A$ frica, viz., the $A l$ ysinnian $C$. dilloni, C. and $\mathrm{V}$. ; this is distinguished by the alsence of barbels and the greater size of the scales ( 30 to 32 in the laterai line). In the presence of a pair of barlsels and the small size of the scales, $C$. tanganiue belongs to the typical section of the genus, inhabiting south-western Asia; but it has the enlarged dorsal ray neither feclble, as in $C$. fundulus, Pall. and allied species, nor serrated, as in C. trutta, Ileck. 


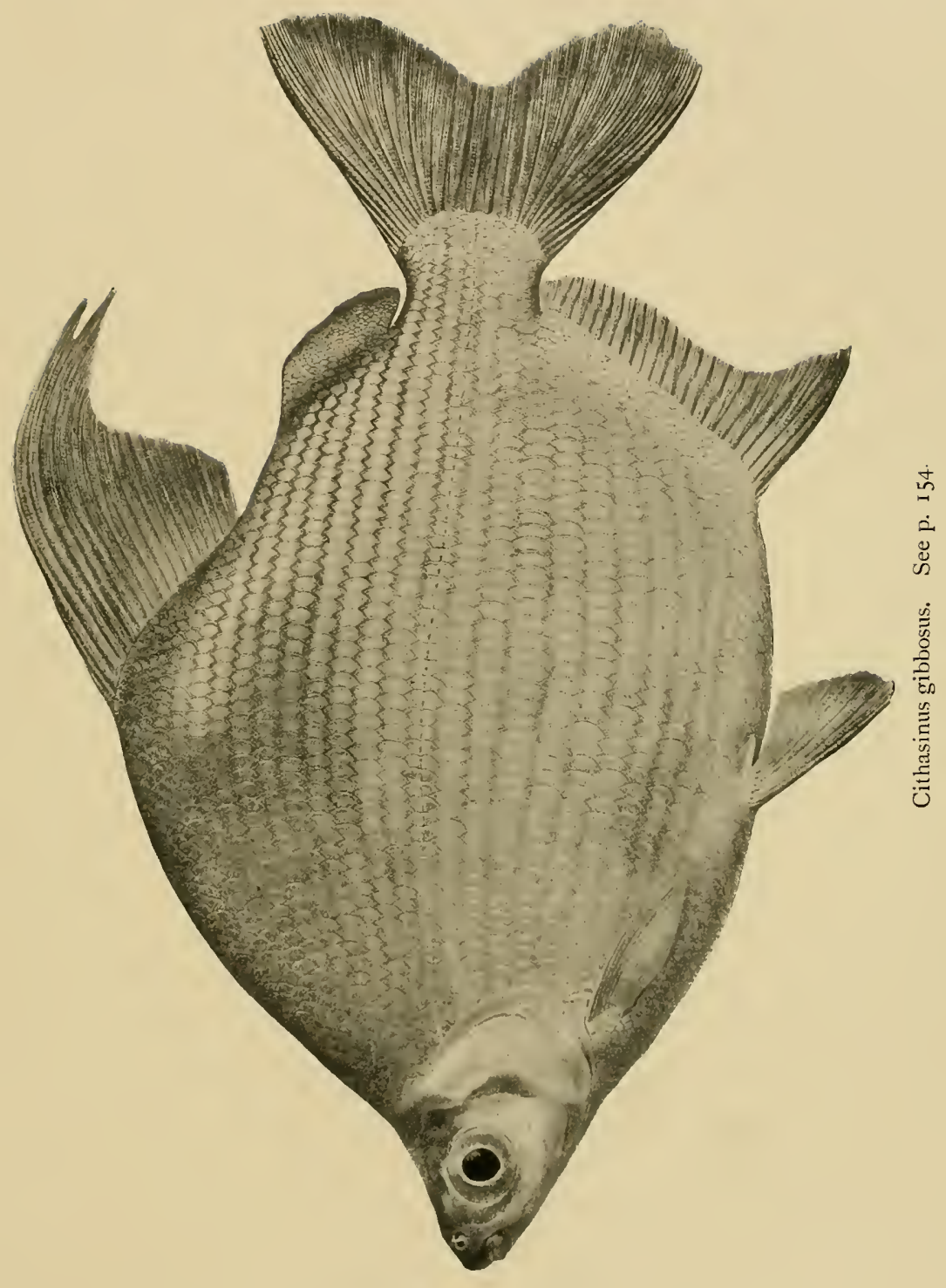




\section{S. B.ARbUS PlitVRHiNus.-Blgr. I900. (Fig., p. 157.)}

Depth of body 31 times in total length, length of head 4 times. Snout broad and rounded, twice as long as the diameter of the eye, which is contained $5 \frac{1}{2}$ times in the length of the head and $2 \frac{1}{2}$ times in the interocular width; mouth small, with two pairs of sulsequal harbels, the length of which equals the diameter of the eye. Dorsal III. S ; third ray not enlarged, not serrated ; the fin, which is expally distant from the eye and from the caudal, has the free edge convex. Anal III. 5; the longest ray not quite ${ }_{3}^{2}$ the length of the head. Peetoral a little shorter than the head, not reaching the ventral, which is inserted below the middle of the dorsal.

Caudal forked. Caudal peduncle $I_{3}^{2}$ as long as deep. Scales $40 \frac{5 \frac{1}{2}-6 \frac{1}{2}}{5 \frac{1}{2}}, 3 \frac{1}{2}$ between the lateral line and the root of the ventral. Olive-brown above the lateral line, golden yellow beneath.

Total length, 390 millim.

Deseribed from a single specimen from south of Usambura.

This speeies appears to be more nearly related to B. capensis, Smith, from which it differs in the much shorter and broader snotit.

\section{Barbe's altianalis.-Blgr. 1900. (Fig., p. 159.)}

Depth of body equal to or slightly greater than the length of the head, which is contained 4 to $4 \frac{1}{2}$ times in the total length. Snout moderately broad, rounded, scarcely projecting beyond the lower jaw; $1 \frac{1}{2}$ to $I_{\frac{2}{3}}^{2}$ times as long as the diameter of the eye, which is contained 5 to $5 \frac{1}{2}$ times in the length of the head and twice (1) twice and one-fourth in the interocular width; mouth small, with two pairs of subequal harbels, the length of which equals or exeeds a little the diameter of the eye. Dorsal III.-IV. 9; third or fourth ray very strong, ossified, not serrated; the fin, which is equally distant from the occiput and from the caudal, has the free edge notched, and its greatest depth is but slightly less than the length of the head. Anal III. 5 ; the longest ray measures alosut st the length of the head; the fin, when folded, reaches nearly the root of the caudal. l'ectoral a little shorter than the head, not reaching the ventral, the first ray of which corresponds to the origin of the dorsal. Caudal forked. Caudal peduncle nearly twice as long as deep. Scales $34-35 \frac{6 \frac{1}{2}}{5 \frac{1}{2}}, 3$ between the lateral line and the root of the ventral. Olive lurown, very dark alıove.

Total length, $450 \mathrm{millim}$.

Described from two specimens from Lake Kivu and one from the source of the Rusisi Kiver.

B. altianalis is extremely elosely related to $R$. mariyuensis, Smith. It differs only in the somewhat broader snout, the stronger third dorsal ray, and the somewhat longer caudal peduncle. 


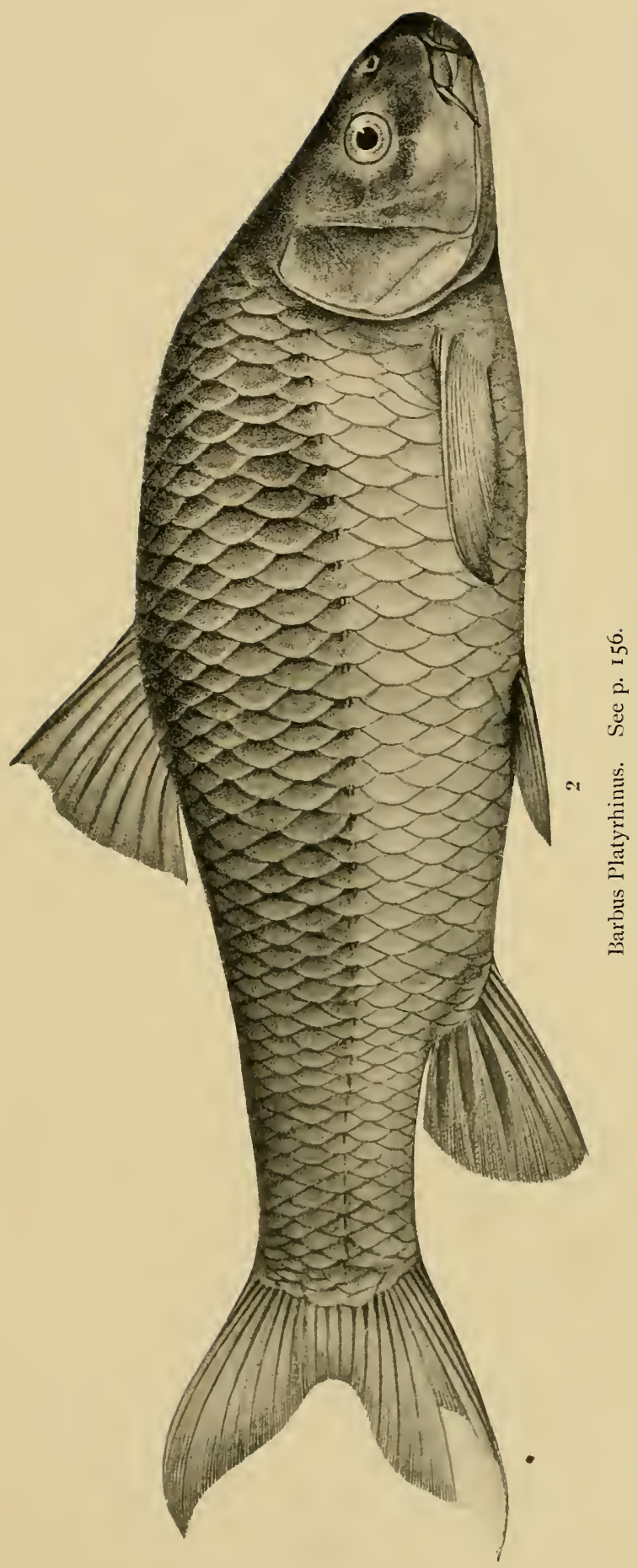


IO. BARBUS SERRIFER.-Blgr. I900. (Fig., p. 207, lower.)

Depth of body 3 to $3 \frac{1}{2}$ times in total length, length of head 4 to $4 \frac{1}{1}$ times. Snout rounded, not projecting beyond the lower jaw, as long as or a little longer than the diameter of the eye, which is contained 4 to $4 \frac{1}{3}$ times in the length of the hearl and $I_{3}^{1}$ to $I_{2}$ times in the interocular width; mouth small, with (wo) pairs of larbels, the posterior of which are the longer, and measure twice the diameten of the eye. Dorsal III. 7 ; third ray rery strong, ossified, serrated behind; the fin, which is equally distant from the eye and from the caudal, is not notched, and the largest ray is a little shorter than the head. Anal III. 5; the longest ray ${ }^{3}$ the length of the head. Pectoral 3 to ${ }_{3}^{4}$ the length of the head, reaching, or nearly reaching, the base of the ventral, the last ray of which falls under the first of the dorsal. Caudal forked. Caudal peduncle $I_{2}^{\frac{1}{2}}$ to $I_{3}^{2}$ as long as deep. Scales 2S-30 $\frac{4 \frac{1}{2}-5 \frac{1}{2}}{5 \frac{1}{2}}, 3$ between the lateral line and the root of the ventral. Olive-hrown alove, silvery white beneath; a greyish stripe along each side of the borly above the lateral line; a small blackish spot at the base of the caudal.

Total length, 120 millim.

Described from three specimens from the north end of Lake Tanganyika.

Allied to $B$. Kessleri, Stdr. Distinguished by the smaller eye, the longer larlecls, the more numerous scales, and the presence of only 7 branched clorsal rays.

\section{Ir. BARbUS tropidolepis.-Blgr. I 900 . (Fig., p. I6r.)}

Depth of body 3 times in total length, length of head 4 to $4 \frac{1}{2}$ times. Snout broad and rounded, strongly projecting beyond the mouth, $1 \frac{1}{2}$ to twice as long as the diameter of the eye, which is contained $4 \frac{1}{2}$ to 5 times in the length of the head and 2 to $2 \frac{1}{2}$ times in the interocular width; mouth small, inferior; a minute barlel almost entirely concealed in the angle of the lips. Dorsal III. 9; third ray very strong, ossified, not serrated, its length at least is that of the head; the fin, which is equally distant from the occiput and the root of the caudal, is notched. Anal II. 5 ; the longest ray alout 3 the length of the head. Pectoral aloout 3 the length of the heacl, not reaching the base of the ventral, the first ray of which falls under the origin of the dorsal. Caudal forked. Caudal peduncle $I_{2}^{1}$ to $I_{4}^{3}$ as long as deep. Scales $44-46 \frac{S_{\frac{1}{2}}}{8 \frac{1}{2}}, 5$ between the lateral line and the root of the ventral; in breeding specimens, the scales, those at least which are above the lateral line on the caudal portion of the body, bear a median swelling or obtuse keel, these keels forming together very regular longitudinal lines. Olive above, silvery white beneath.

\section{2. BARILIUS MOORH.-Blgr. I 900 . (Figs., p. 208, 209, lower.)}

Depth of body equal to length of head, 4 times in total length. Ilead a little orer twice as long as broad, with slightly curved upper profile: snout pointed, not extending beyond the lower jaw, as long as or a little longer than the diameter of 

the eye, which is contained 4 to $4 \frac{1}{2}$ times in the length of the head; interorlital width a little greater than the diameter of the eye; mouth extending to leclow the anterior thircl or the centre of the eye ; no larbels; the naked space leetween the preopercle and the suborbitals less than half the wiclth of the latter. Gill-rakers very short, almost rudimentary, $S$ on lower part of anterior arch. Dorsal III. 9, originating at equal distance from the anterior lorder of the eye and the root of the caudal; its border is not notched, and its depth equals about ? the length of the liead. Anal III. 13-14, originating under the middle of the dorsal; its anterior rays a little longer than those of the dorsal and nuch longer than the pusterior rayss. forming a rounded lole. Fectoral pointed, shorter than the head, not reaching the rentral, which extends to the origin of the anal. Caudal forked. Caudal peduncle twice as long as deep. Scales $56-60 \frac{10-11}{7}, 3$ between the lateral line and the root of the ventral. Silvery, brownish on the back; more or less distinct dark vertical bars on the side of the body, about ro in number; dorsal blackish at the end.

Total length, I 55 millim.

Several specimens from the north end of Lake Tanganyika.

\section{Barilius taNganick.-Blgr. I900. (Fig., p. i65.)}

Depth of body equal to length of head, 41 times in total length. Ifead a little over twice as long as broad, with straight declivous upper profile; snout very pointed, not extending below the lower jaw, once and a half the diameter of the eye, which is contained $5 \frac{1}{3}$ times in the length of the head; interorbital width once and a half the diameter of the eye; mouth extending to below the posterior border of the eye; no barbels; the naked space between the preopercle and the sulorbitals about : the width of the latter. Gill-rakers short, io on lower part of anterior arch. Dorsal III. Io, originating at equal clistance from the occiput and the root of the caudal, the posterior third of its base alove the anal; its anterior rays are longest, measuring a little more than half the length of the head. Anal III. I7, strongly notched, with rounded anterior lole, the longest rays of which measure $\frac{2}{3}$ the length of head, whilst the posterior rays measure barely $\frac{1}{1}$. l'ectoral pointed, $\frac{3}{4}$ length of head, not reaching the ventral, which extends to the rent. Caudal forked. Caudal peduncle a little over twice as long as deep. Scales $\mathrm{S}_{2} \frac{13}{7}, 4$ between the lateral line and the root of the ventral. Silvery, olive on back; 16 or 17 blackish vertical bars on each side of the body, equally distant from the median dorsal line and from the lateral line.

Total length, 260 millim.

Described from a single specimen from north end of Lake Tanganyika.

\section{SILURIDA.}

I. Clarias robecchil.-Vincig. I 893. 



\section{Clakias liocephalus. - 13lgr.}

Vomerine teeth in a narrow band, without posterior process. 1)epth of $1 x x d y$, 5 $\frac{1}{2}$ times in total length; length of head, 5 t times. Head smooth, covered with suft skin, slightly longer than broad; occipital process very short, angular: diancter of eye, 3 times in length of snout, 6 times in interurlital width; maxillary larleel as long as the head, nasal larbel a little shorter; inner mandilular harlecl flength of head. Dorsal 70. Anal 5\%. Caudal free. l'ectoral \& length of head, not extending to the vertical of origin of clorsal fin. Uniform blackisls loruwn.

Total length, So millim.

Described from a single specimen from kinyamkolo.

\section{Chrisichthys cranchil.-Leach, i8io.}

\section{Chrisichthys miriodon.-Blgr. igoo.}

Depth of body, $4 \frac{1}{2}$ times in total length; length of head, 31 to $3 \frac{1}{2}$ times. Ilead broad and much depressed, ! longer than broad, rough on the vertex and occiput; snout broadly rounded, scarcely projecting beyond the lower jaw, $\frac{1}{3}$ length of head and twice the diameter of the eye, which is contained 6 times in the length of head and 2 to 2 times in the interocular width; the occipital process, which is rough like the occiput, in contact with the interspinous shield; nasal barlsel, 1 or $f$ the diameter of the eye; maxillary barbel a little more than half the length of the head; inner mandibular barbel, $\frac{1}{3}$ length of the head, outer a little less than half. Vomero-pterygoid teeth very fine and closely set, as are also the pritmaxillary and mandibular teeth, forming a loroad, horseshoe-shaped, uninterrupted land ; its width in the middle a little less than that of the primaxillary land, lut increasing at the sides, where it much exceeds the latter. Dorsal I. 6; spine, rugose, not serrated, nearly half the length of the head and 3 to $\frac{1}{3}$ the length of the longest soft rays. Adipose dorsal, a little longer than deep, its base ${ }_{3}^{2}$ that of the rayed dorsal and $\frac{1}{3}$ the distance which separates it from the latter. Anal IV. 8-9. I'ectoral spine a little longer and stronger than the dorsal, feebly striated, and learing on its inner edge about twenty strong retrorse serrix. Ventral not reaching the anal. Caudal deeply notched, with obtusely-pointed lobes, the longest rays measuring double the length of the median. Caudal peduncle $I_{3}^{\prime \prime}$ to twice as long as deep. Olive-lorown above, white beneath.

Total length, 470 millim.

This description is taken from three large specimens, one received from Alluertville by the Congo Museum, through Captain Hecq, one from Tembwi, and one from Kinyamkolo, obtained during the second Tanganyika expedition. Compared with specimens of $C$. cranchii of similar size, $C$. myriodon differs lyy its smaller and more numerous teeth, the greater posterior width of the romero-pterygoid land, the larger eye and the more strongly serrated pectural spine. It has also a higher numlere of vertebric (20-27).

$$
\text { " } 2
$$

Sume young specimens, measuring up to 130 millim., collected at Kibwesi, in 


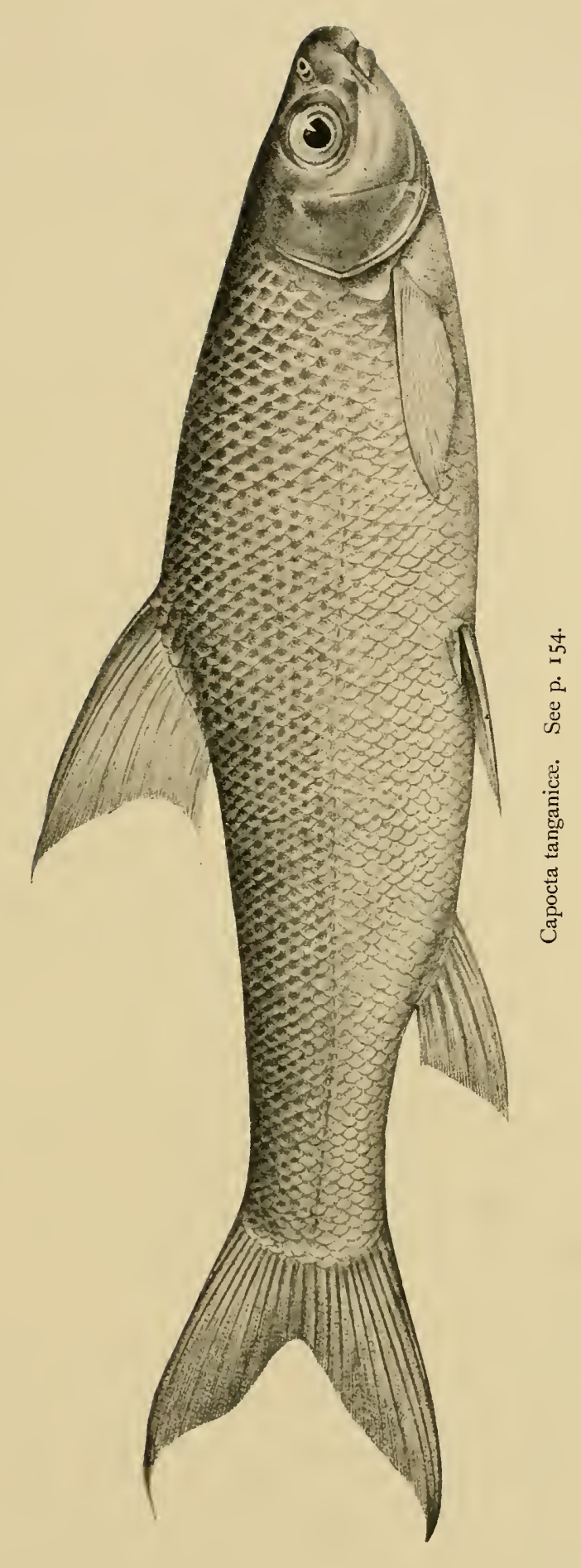


deep water, may, I think, le referred to this species. The depth of the loody is 5 or 6 times in the total length; head, for $\frac{1}{3}$ longer than loroad: cliameter of the eje, $3 \frac{1}{2}$ to $3 \frac{1}{2}$ times in the length of the head, 11 to $1 \frac{1}{8}$ in the interocular width; maxiltary bartsel, ? to 3 the length of the head; vomero-pterygoid teeth forming a narrow subcrescentic band, slightly interrupted mesially. lase of adipose dorsal, $\frac{1}{2}$ or ${ }_{s}^{2}$ its distance from the rayed dorsal; anal IV. S. IO: 7 to 9 sery large retrorse serre on the inner side of the pectoral spine. A blackish spot at the end of the dorsal, and another on each lobe of the caurlal.

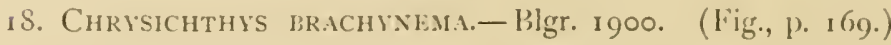

Depth of body, 4 to 5 times in total length; length of head, $3 !$ to $3 \frac{1}{2}$ times. Head broad and much depressed, $\frac{1}{b}$ or $\frac{f}{6}$ longer than broad, covered with thick smooth skin; snout much flattened, twice as broad as long, bruadly rounded, pro. jecting a little beyond the lower jaw, its length $\frac{1}{3}$ that of the head; diameter of the eye, I $1 \frac{1}{2}$ to twice in the length of the snout, 5 or 6 times in the length of the head, and 2 or $2 \frac{1}{2}$ in the interocular width ; occipital process hidden under the skin, but reaching the intcrneural shield; nasal barlel as long as or slightly longer than the diameter of the eye in the young, $\frac{2}{3}$ the diameter of the eye in the adult; maxillary barbel, $\frac{1}{2}$ or $\frac{1}{3}$ the length of the head; outer mandibular barbel, $\frac{1}{2}$ or $\frac{1}{3}$ the length of the head; inner, $\frac{1}{4}$ or $\frac{1}{5}$. Vomero-pterygoid teeth forming a loroad crescentic or horseshoe-shaped band, uninterrupted or narrowly interrupted mesially; this land as broad as the premaxiltary band in the adult, also widening behincl, narrower and more tapering behind in the young. Dorsal 1. 6, spine very feet,ly serrated in front and behind, covered with a thick skin, its length $\frac{2}{5}$ that of the head and a little shorter than the soft rays. Adipose dorsal, $1 \frac{1}{2}$ to twice as long as deep, its base hardly equal to that of the rayed dorsal and $\frac{1}{3}$ or $\frac{1}{2}$ its distance from the latter. Anal IV. S-9. I'ectoral spine thicker and longer than that of the dorsal, armed on its inner side with strong retrorse serra. Ventral not reaching the anal. Caudal deeply notched, with obtusely pointed lolses, the longest rays twice to twice and a hatf as long as the middte ones. Caudal peduncle $\mathbf{I}_{2}^{\frac{1}{2}}$ to $\mathbf{I}_{3}^{2}$ as long as deep. Olive above, white beneath.

Total length, 400 millim.

Described from several specimens from Kalamlo and Usambura.

This species is also closely allied to $C$. cranthii, lut may lue distinguished from it by the absence of rugosities on the skull, the shorter head, and the shorter mandilsular barbels.

\section{Alchenoglanis miscutatus.-Geoffr. i\$29.}

Obtained at Kalambo ; also far out, in deep water.

\section{Anolopterus Platrilir.-Githr. 1864.}

Described from two specimens from marshes near Mlity.

The occurrence of this species in Nyassa has recently leen recorded, and it has also been described by Vaillant as Chimarhoglanis leroyi from Mrogoro torrent, Urugaru .lountains, East Africa. 


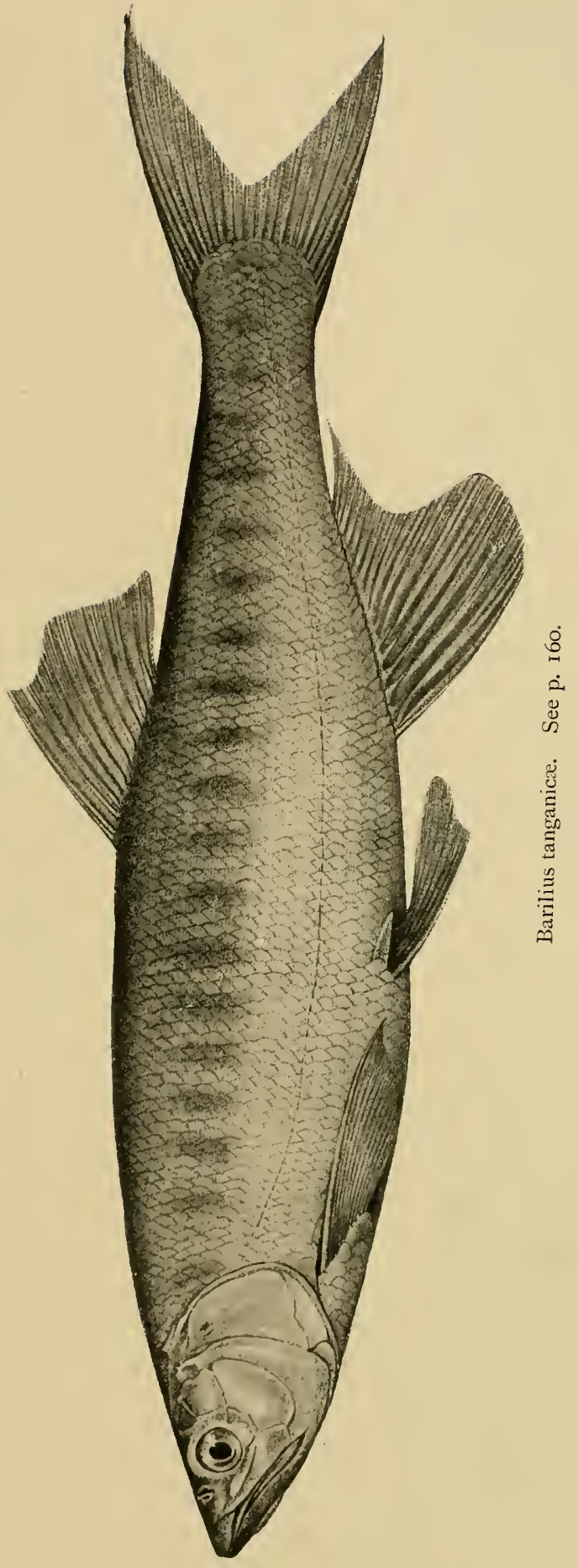




\section{SYNODONTIS GRiNulost's, - Blgr. 1900 . (Fig., p. I67.)}

liody feebly compressed, its depth equal to the length of the head, and contained 3 to $3 \frac{1}{2}$ tinies in the total length. Head not or but slightly longer than broad, feebly depressed, covered with granular asperities ; frontal fontanclle rather narrow: snout rounded, a little more than hatf the length of the head ; eye directed upwards, its diameter $5 \frac{1}{2}$ to 6 times in the length of the head, $2 \frac{1}{2}$ to $2 \frac{2}{3}$ times in the width of the interocular region, which is slightly convex; no occipital keel. Lips morlerately developed ; maxillary barbel simple, as long as or a little longer than the head, and not extending beyond the anterior third of the pectoral spine; mandibular laarlets inserted on a straight transverse line, the outer $\frac{3}{3}$ or $\frac{2}{3}$ the length of the head and thrice that of the inner, both with very short branches, especially near the lase, where they are tubercular. Premaxillary teeth small and numerous, forming a broal band ; anterior mandibular teeth small, feebly curved, hardly $\frac{1}{3}$ the diameter of the eye, and numbering 40 to 42 . Gill-cleft not extending inferiorly beyond the base of the pectoral fin. Occipito-nuchal shield rugose, tectiform, a little longer than broad, ending in two rounded points which extend to the level of the base of the first soft dorsal ray. Humeral process covered with granular asperities, keeled, narrow and sharply pointed, extencling nearly as far back as the occipito-nuchal shield. The skin of the whole body, including the adipose fin, covered with small, closely-set, granular papillix. Dorsal I. 7 ; spine rather strong, If times as long as the base of the fin, striated and armed lehind with 10 to 15 retrorse serrie.

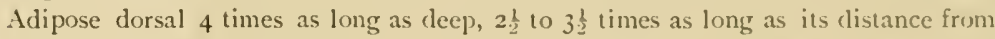
the rayed dorsal. Anal III. S. l'ectoral spine very strong, as long as that of the dorsal, striated, feebly denticulate on the anterior border, with 15 to 17 strong retrorse serre on the posterior border. Ventral not reaching anal. Caudal deeply notched. Olive above, yellowish beneath; dorsal, anal and paired fins black in front, orange behind; caudal black, with a broad orange posterior margin.

Total length, 230 millim.

Described from three specimens from the north end of Lake Tanganyika, in rather deep water.

\section{Sradodontis multipunctatus.-Blgr. 1900. (Fig. facing p. 174.)}

Pramaxillary teeth in 5 or 6 irregular transwerse series; mandibular teeth in a single series of 16 , feebly curved, simple, measuring hardly $\frac{1}{3}$ diameter of eye. Depth of body 3 times in total length; length of head, $3 \frac{2}{3}$. IIeal scarcely longer than broad, slightly convex on the crown; snout rounded, less than half length of head, twice as long as eye ; eye supero-lateral, well visible from above, its diancter $4 \frac{1}{2}$ times in length of head, twice in interorbital width. Gill-cleft very narrow, not extencling below base of pectoral. Maxillary barbel simple, reaching a little beyond anterior third of pectoral spine: mandibular larbels strongly fringed, outer a little more than twice as long as inner, and half as long as maxillaries. Dorsal II. 7 ; spine strong, a little shorter than the head, strongly serrated behind in its distal half. Adlipose fin low, a little shorter than the head, twice as long as its distance from the dorsal. Humeral process simply granulate, sharply pointed, not extending quite so far as the occipito-nuchal shield, which is 1 ? as long as broad, 


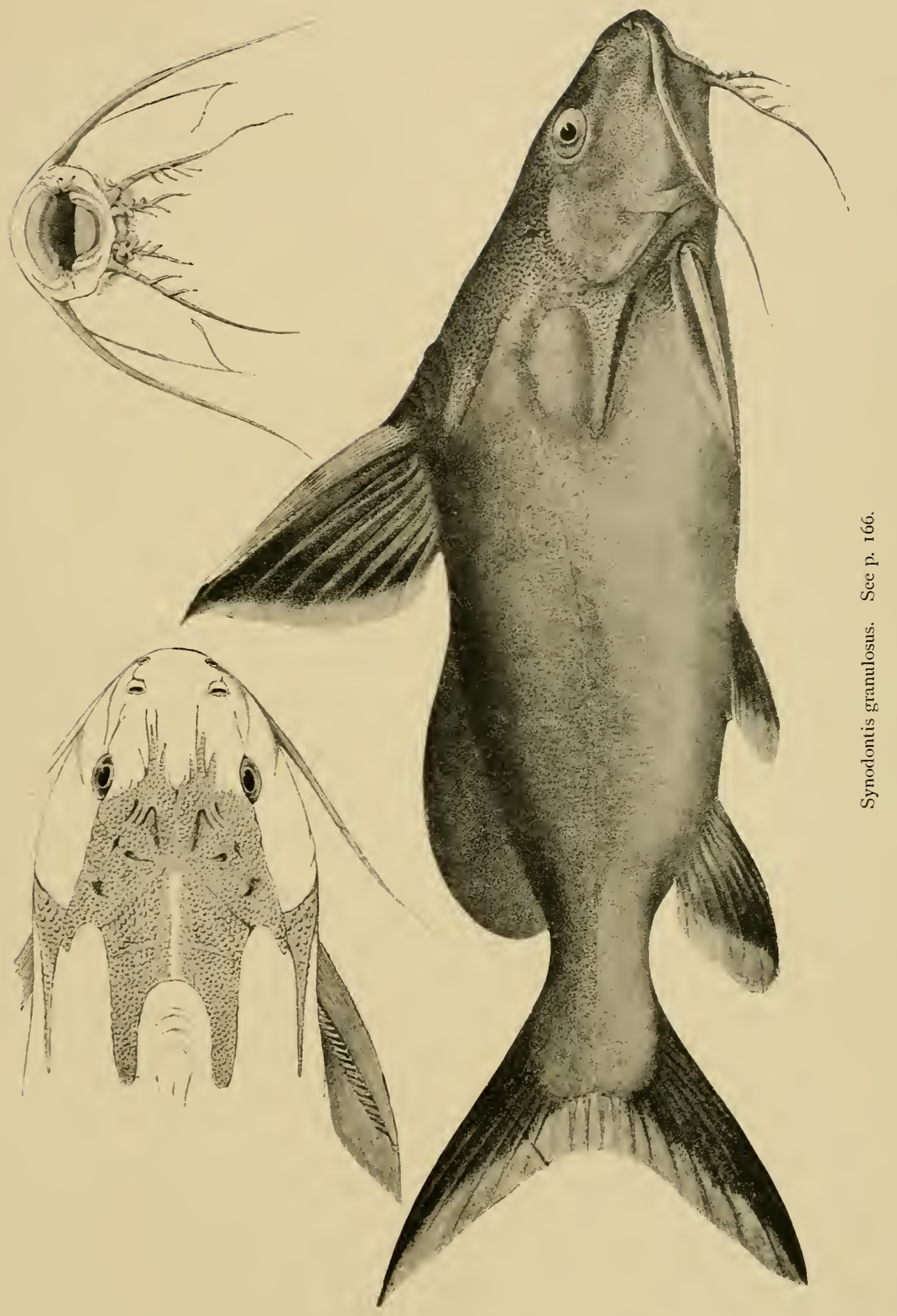


and reaches the first soft ray of the dorsal. Anal 11I. 7. Caudal deeply bifurcate. Skin smooth. l'ale reddish lorown aloove, with very numerous blackish brown round spots, which are smaller on hearl and nape; lower parts and larlecls white unspotted ; ventrals yellow; dorsal and caudal broadly erlged with yellow.

Total length, 240 millim.

Described from a single specimen from Sumbu.

23. Malapterleus electricus. Jacép. I SOI.

Kalamlю.

\section{CVPRINOHONTIDA:}

24. Haplochllus tanganicines.-Pigr. 1900. (Fig., p. i 8 I, lower.)

Body compressed, its depth 4 times in total length; length of head, $4 \frac{1}{3}$ times. Snout depressed; lower jaw projecting beyond the upper; eye a little longer than snout, a little shorter than interorbital width, 3 times in length of head. Dorsal 13 , originating at equal distance from the head and the caudal fin ; the first ray corresponds to the ISth scale of the lateral line; posterior rays longest, ${ }_{3}^{2}$ length of hearl. Anal 28, originating below extremity of pectoral. l'ectoral $\frac{4}{3}$ length of head, extending far leyond root of ventral. Caudal feebly emarginate. Caudal peduncle twice as long as deep. Scales 42 in a longitudinal line, $I$ in a transverse line, silvery, with a darker lateral stripe; dorsal and anal with greyish horizontal streaks.

Total length, So millim.

Described from a single specimen from Mlbity liucks.

\section{SERRANII)A.}

25. Lates micrólepis.-Blgr. i 898 . (Fig., p. 171.)

Originally described from young specimens, I55 millim. long. The adult, measuring 800 millim., and weighing 14 lls., has, as could be expected, very different proportions, and is of a uniform dark silvery colour. The eye is contained 9 times in the length of the head, which is $\frac{1}{3}$ of the total ; longest dorsal spine, $\frac{1}{2}$ length of head. Caudal peduncle and caudal fin as in the young.

Native name, "Sangala."

\section{CICHIIJA:}

\section{LAMPROLOGUS TETRACANTHUS. B Blgr. 1899.}

\section{Lamprologus elongatus.-Blgr is98. (Fig., p. 213 , upper.)}

Six to $\delta$ large canine teeth in front of each jaw, followed ly a loroad band of minute villiform teeth; lateral teeth very small. Depth of bodly 4 times in total length; length of head 2 ? to $2 !$. Snout twice as long as cliameter of eye, which 


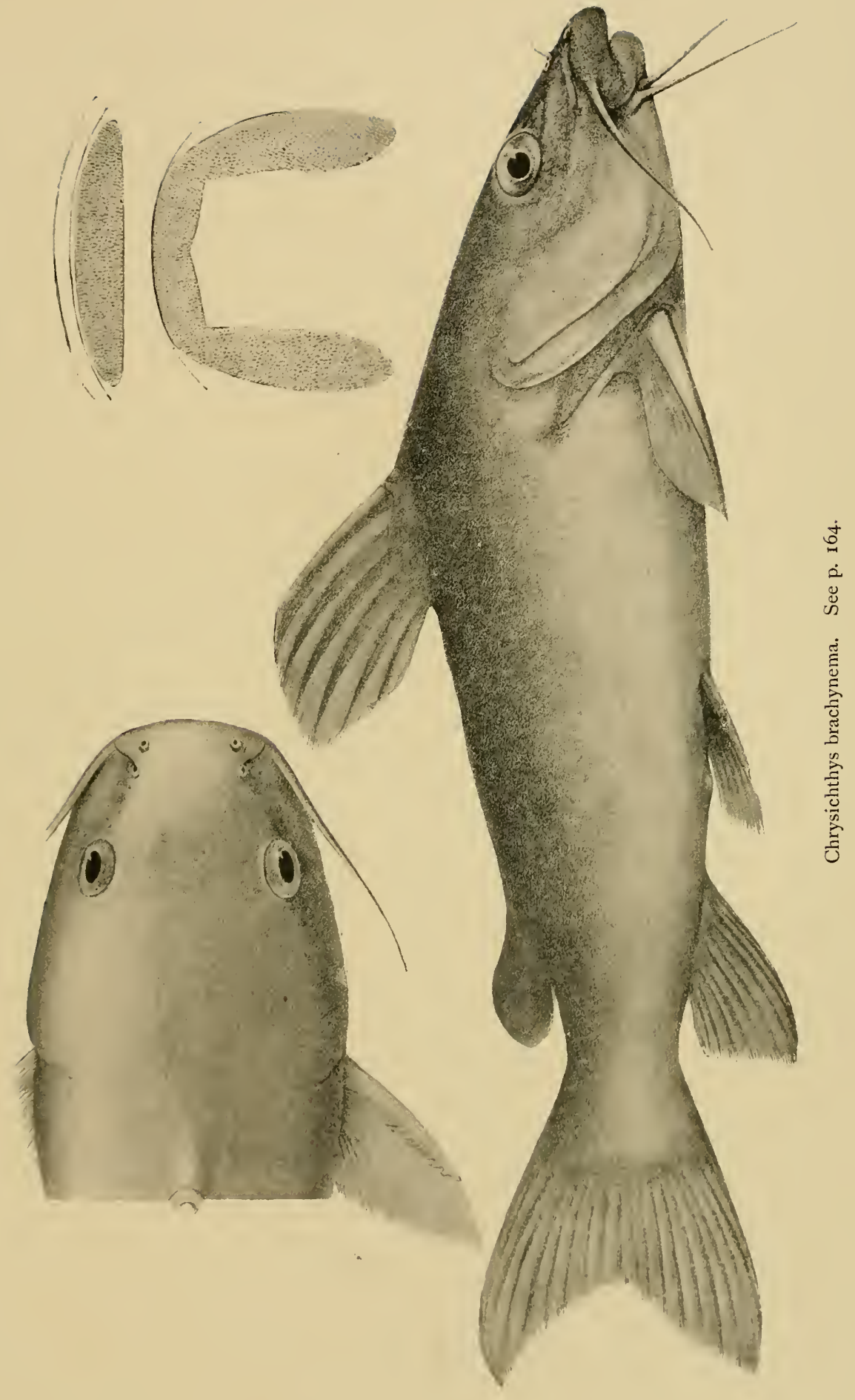


is 5 times in length of head and equals interorbital width: maxillary extending to below anterior border of eye; cheeks naked; opercles and reciput scaled. (Gill-rakers moderately long, 12 on lower part of anterior arch. Dorsal .11111. IO-II ; spines slightly increasing in length to the last, which measures a length of head; longest soft ray's half length of head. l'ectoral half length of head. Ientral reaching vent. Anal V. 8; spines increasing in length to the last, which eyuals longest dorsal. Caudal truncate. Caudal peduncle is as long as deep. Scales $90-95 \quad \begin{gathered}\text { 10 } \\ 22-28\end{gathered}$; lat. I. $\begin{gathered}44-56 \\ 20-30\end{gathered}$ brown, with darker spots, having a tendency to form cross-bars; caudal fin with round dark spots between the rays.

Total length, 113 millim.

Described from one specinen from .llbity kocks, and one from Kinyamkolo.

\section{LaMprologus tretocephalis. - Plgr. I 899.}

\section{L.AMPROLOGUS modestus.-Blgr. 1898 . (Fig., p. I S r, upper.)}

A few large curved canine teeth, tipped with brown, in front of each jaw, followed by a band of minute teeth; lateral teeth very small. Depth of body $3 \frac{1}{3}$ to $3 \frac{2}{s}$ times in total length, length of head 3 to $3 \frac{1}{3}$. Snout a little longer than diametcr of eye, which is $3 \frac{1}{2}$ to 4 times in the length of the head and equals interorbital width : maxillary extending to below anterior border of eye; checks naked; opercles and occiput scaled. Gill-rakers very short, 7 on lower part of anterior arch. Dorsal XX. 8.9; spines increasing in length to the last, which is not quite half length of head; middle soft rays prolonged 32 to 33 length of head. I'ectoral alout length of head. Ventral prolonged into a short filament. Anal V. 6.7; spines increasing in length to the last, which is as long as middle dorsals ; middle soft ray's prolonged, like the dorsals. Caudal truncate. Caudal peduncle as long as deep. Scales $36-40 \frac{5-6}{12-14}$; lat. I $\frac{24-25}{7-11}$ uniform brown; soft dorsal and caudal fins with round black spots between the ray's.

Total length, 75 millim.

Described from a single specimen from Mlbity liocks.

\section{LAMPROLOGUS LEMARII.-Blgr. I 899. (Fig., p. 199, upper.)}

A few moderately large curved canine teeth in front of each jaw, followed by a narrow band of minute teeth ; lateral teeth very small. Depth of body $3 \frac{1}{2}$ tines in total length, length of head $2_{4}^{3}$. Snout slightly longer than the diameter of the eye, which is $3^{\frac{1}{3}}$ times in length of head and nearly double interorlital width; maxillary extending to slightly bejond vertical of anterior loorder of eye ; cheeks and occiput naked; a few small deciduous scales on the opercles. Gill rakers short, 9 on lower part of anterior arch. Dorsal Xi.. 7 ; spines equal from the fifth, which measures a little more than $\frac{1}{3}$ length of head and ${ }_{4}^{3}$ longest soft rays. l'ectoral ${ }_{5}^{3}$ length of head. Ventral reaching origin of anal. Anal VilI. 5; spines 


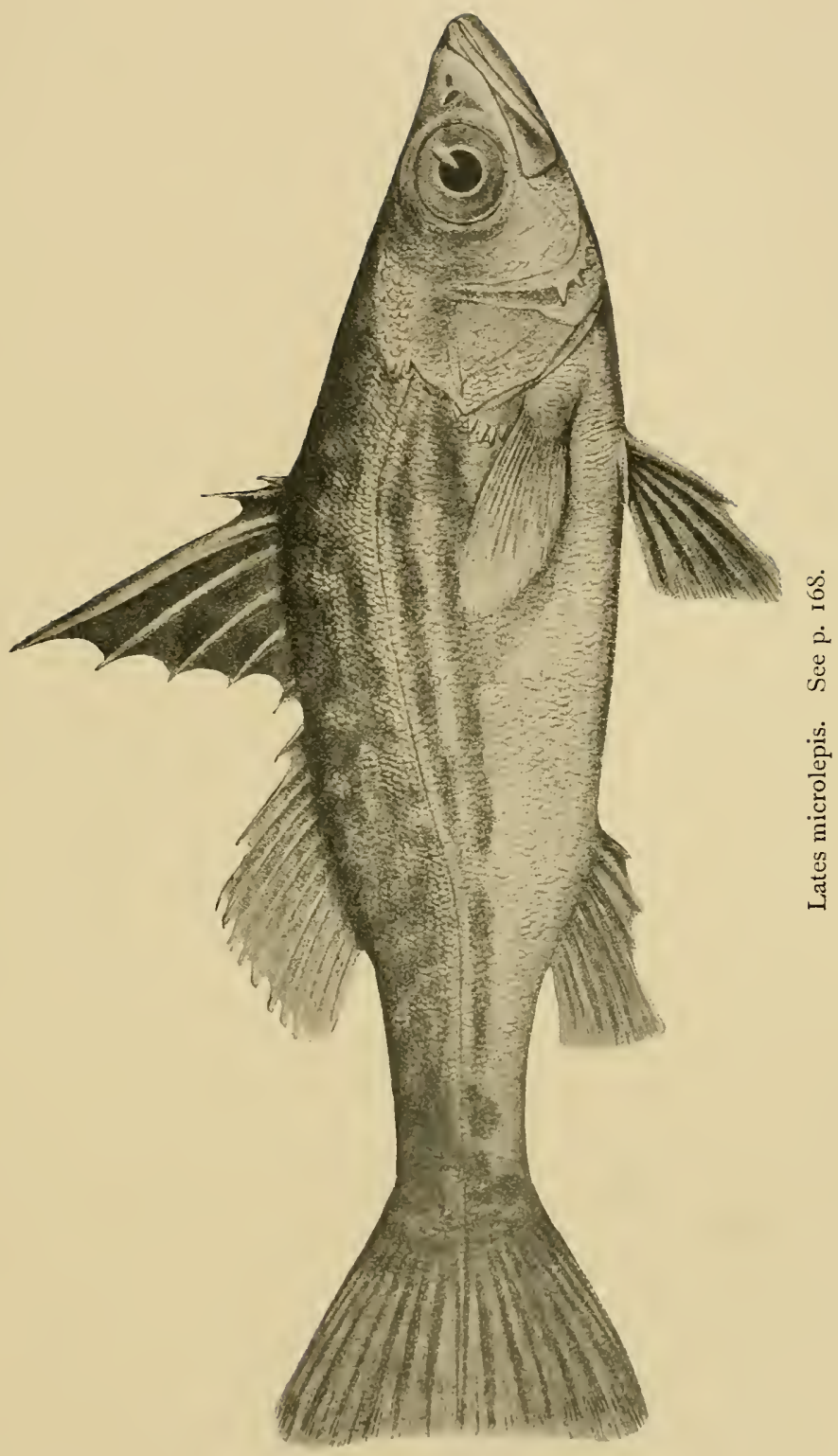


increasing in length to the last, which slightly exceeds longest dorsals. Caudal rounded. Caudal peduncle a little longer than deep. Scales $4 S^{10-11}$; lat. I. $\frac{30}{17}$. l'ale brown, most of the scales dark-edgred; a blackish obliqe lar from below the anterior third of the eye to the maxillary; a large l, lackish opercular spot; three olligue blackish lands, descending forwards, on each side of the back, extending on the base of the dorsal; dorsal and anal tipped with blackish.

Total length, 107 millim.

Described from a single specimen.

This species takes its place in the series letween L. moorii and L. congrocksis.

31. LAMPROLOGUS IIECQUi.--B Blgr. I 899.

\section{LiMPROLOGUS MOORII.-Blgr. 1898. (Fig., p. 203, upper.)}

Nine or to equal, moderately large conical tecth in front of each jaw, followed lyy a narrow hand of minute teeth ; lateral teeth very small. Depth of loody $2 \frac{1}{2}$ times in total length, length of head 3 to $3 \frac{1}{5}$. Snout as long as diameter of eye, which is 3 to $3 !$ times in length of head and equals interorlital width ; maxillary extending to below anterior border of eye; cheeks with small, deciduous scales; opercles and occiput scaled. Gill-rakers short, 9 or 10 on lower part of anterior arch. Dursal XIX.-XX. S-9; spines slightly increasing in length (1) the last, which measures nearly half length of head; middle soft rays prolonged at least 3 length of head. Pectoral 3 to $s$ length of head. Ventral prolonged intu a long filament. Anal VII.-VIII. 6-7; spines increasing in length to the last, which is a little longer than the Iongest dorsal; middle sofi rays prolonged into filaments. Caudal rounded. Caudal peduncle as long as deep. Scales 33-35 $\frac{5-7}{11-12}$; lat. I $\begin{array}{r}24-28 . \\ 9-13\end{array}$ Dark brown ; fins blackish.

Total length, 93 millim.

Described from several specinens from Mllity Rocks and Kinyamkolo.

33. LAMPROLOGUS BREVIS.---Blgr. 1899.

34. LAMPROLOGUS COMPRESSIClES.-Blgr. 1899. (Fig., p. 205, upper.)

A few moderately large curved canine tecth in front of each jaw, followed by a narrow band of minute teeth; lateral teeth very small, curved. Depth of body $2 \frac{1}{4}$ to $2_{5}^{3}$ times in total length, length of head $22_{3}^{3}$ to 2$\}$. Ilead very strongly compressed, with concave upper profile; snout a little longer than diameter of eye, which is 4 times in length of head and equals $I_{2}^{2}$ interorbital wiclth; maxillary extending to below anterior border of eye : cheeks naked, opercles and occiput with small scales. Gill-rakers moderately long, 15 on lower part of anterior arch. Dorsal XX.XXI. 6; spines increasing in length to the sixth, which measures half length of head, the posterior a little shorter; longest soft rays a little lunger than longest spines. I'ectoral $\frac{1}{2}$ to $\frac{a}{s}$ length of head. V'entral prolonged into a 


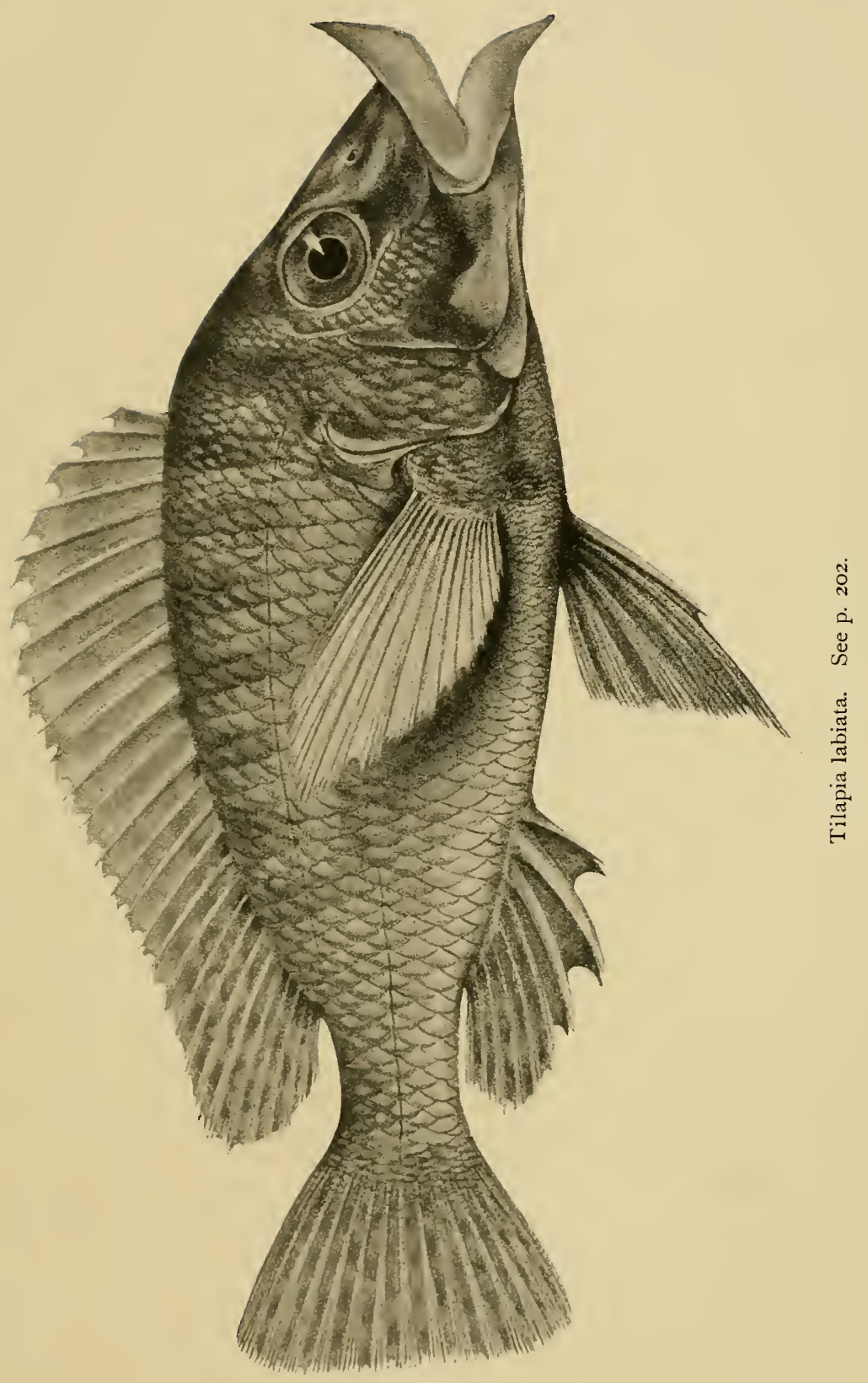


filament. Anal X. 5 ; spines increasing in length to the last, which equals the last dorsal ; longest suft rayss so length of heatl. Caudal rounded. Caudal pecluncle as long as deep. Scales $32-33 \frac{5}{12}$; lat. I. $\frac{22-23}{9-10}$. lirown, with indistinct traces of five darker bars; pectoral bright yellow, other fins blackish towards the border.

Total length, $S_{3}$ millim.

Described from two specimens from Kinyamkolo.

\section{LAMPRologus Fasciatus.-Blgr. 1898 . (Fig., p. I 87 , lower.)}

A few moderately large curvel canine teeth in front of each jaw, followed by a narrow band of minute teeth; lateral teeth very small. Depth of hody 4 times in total length, length of head 3. Snout as long as the diameter of the eye, which is 3 times in length of head and equals $I_{2}^{1}$ interorbital width; maxillary extending to below anterior border of eye ; cheeks naked ; opercles and occiput scaled. Gillrakers short, 12 on lower part of anterior arch. Dorsal XIX. 8 ; spines increasing in length to the last, which measures ${ }_{s}^{8}$ length of head and nearly equals longest soft rays. Pectoral $\frac{1}{2}$ length of head. Ventral reaching vent. Anal X. 6 ; spines increasing in length to the last, which slightly exceeds longest dorsal. Caudal rounded. Caudal peduncle as long as deep. Scales $46 \frac{5}{10}$; lat. I $\frac{24-26}{23-26}$ Yellowish, with II dark brown bars, the first across the vertex; fins greyish; dorsal and anal edlged with blackish.

Total length, 70 millim.

Described from a single specimen from Kinyamkolo.

\section{LAMPROLOGUS FURCifer.-Blgr. I Sg8. (Fig., p. 199, lower.)}

A few large curved canine teeth in front of each jaw, followed by a moderately broad band of minute villiform teeth ; lateral teeth very small. Depth of body 4 to $4 \frac{1}{4}$ times in total length, length of head $2 \frac{1}{3}$ to 3 . Snout as long or a little longer than the diameter of eye, which is $3 \frac{1}{2}$ to $3 \frac{2}{3}$ times in length of head and exceeds interorbital width; maxillary extending to below anterior fourth of eye; cheeks and opercles with deciduous scales. Gill-rakers short, I6 on lower part of anterior arch. Dorsal XX.-XXI. 7-8; spines increasing in length to the last, which mensures ${ }_{5}^{2}$ length of head; middle soft rays produced; ${ }_{3}^{2}$ to $\frac{3}{4}$ length of head. Yectoral 3 length of head. Ventral reaching vent or origin of anal. Anal VI. VII. 6; spines increasing in length, the last nearly as long as last dorsal; middle soft ray's produced. Cauclal deeply notched, crescentic. Caudal pecluncle I $\frac{1}{2}$ as long as deep. Scales $50-54 \frac{6-7}{16-17}$; lat. I. $\frac{32-34}{22-31}$; lower lateral line often nearly complete. Dark brown, with very indistinct blackish bars on the borly; dorsal and caudal with round black spots between the rays; tips of the caudal lobes whitish.

Total length, 125 millim.

Described from three specimens from Kinyamkolo, and one from Mllity Rocks. 


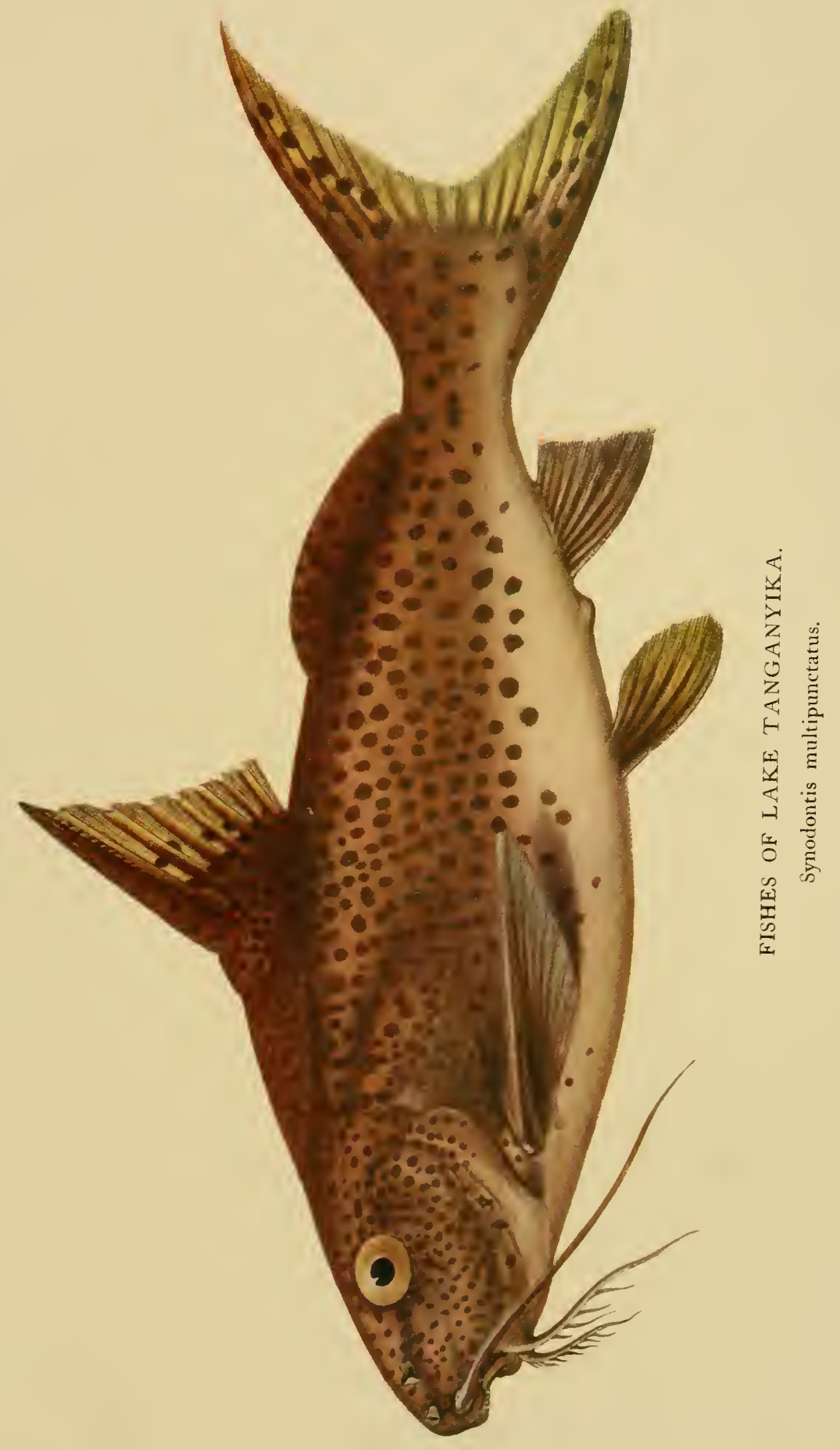





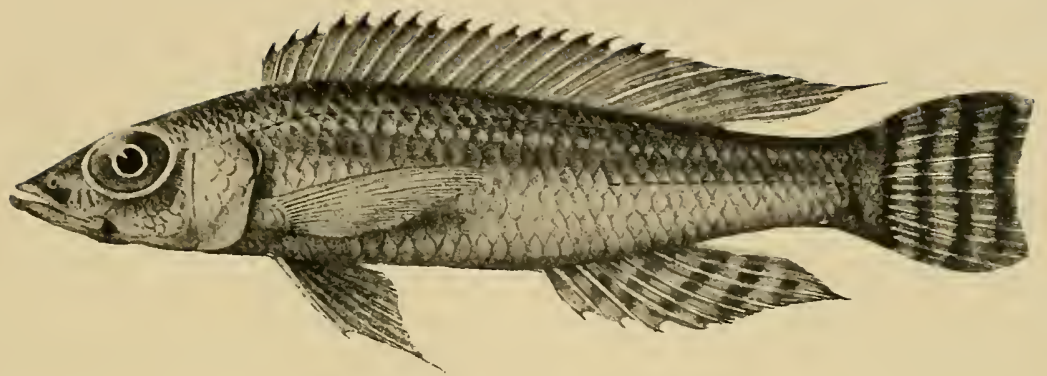

Paratelapia calliara. See p. ${ }^{7} 78$.

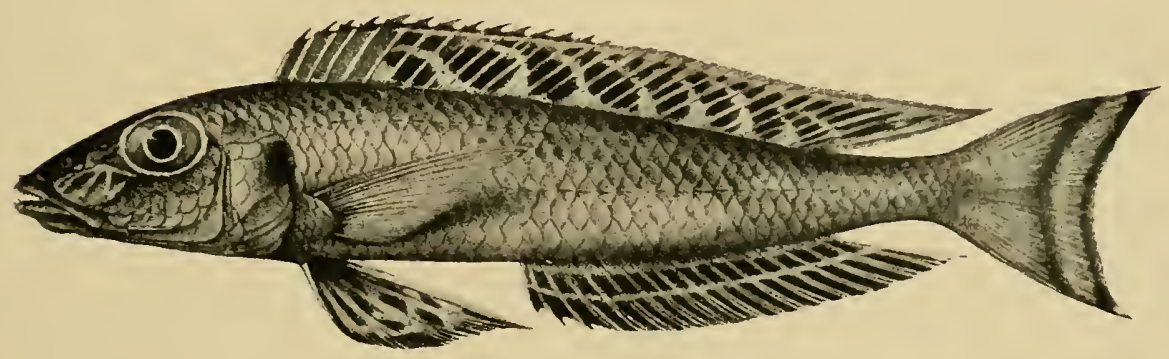

Ectodus longianalis. See p. ISS.

Another specimen figured on p. 205.

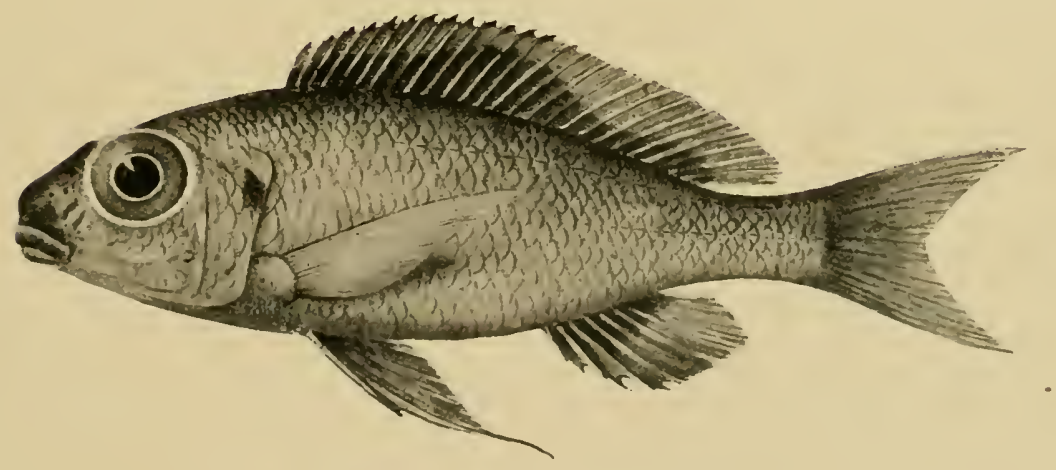

Tilapia boops. See p. 204. 


\section{Julidochromis ornatus. - Blgr. i 898 . (Fig., p. I $8_{5}$, upper.)}

Four or 6 canines in each jaw, tipped with brown. Depth of borly 4 to 4 t times in total length, length of head $3 !$ to $3 \frac{1}{\text {. Snout }}$. S to twice as long as diameter of eye, which is $4:_{2}^{l}$ to 5 times in length of head and $1 \frac{1}{2}$ in interorbital width ; maxillary extending to below nostril ; checks naked ; opercles scaled. Gill-rakers very short and few. Dorsal XXII.-XXIV. 5; spines equal from eighth or tenth, length of head; longest soft rays $\frac{1}{2}$ to ${ }_{3}^{2}$ length of head. I'ectoral about $\frac{2}{3}$ length of head. Ventral produced in a filament, reaching origin of anal. Anal VIII.-IA. 4-6; spines increasing in length to the last, which equals ${ }_{5}^{2}$ length of head. Cauclal rounded. Caudal peduncle as long as deep. Scales $45 \cdot 50 \frac{6-7}{12-13}$; lat. I. $\frac{26-29}{10-15}$ Yellowish, with three dark brown stripes on each side, the lower from the end of the snout to the base of the caudal, the upper along the lase of the dorsal; a large round dark brown spot on the base of the caudal; a small black spot at the base of the pectoral; anal edged with brown; caudal brown.

Total length, 85 millim.

Described from five specimens from Mlity Rocks.

The premaxillary groove is deep, and extends to the anterior third of the orbits, the occipital crest is low and continued forward to the pramaxillary groove; parietal crests are present, lut very feeble; the chain of suborbital bones is replaced by a ligament; the mandible is very massive, the lower surface flat, projecting as a keel on the sides. The rilss are inserted on a step of the transwerse processes, at a short distance from the centre; all bear epipleurals; only the last prixcaudal vertebra has a hemal bridge.

\section{Paratilapia vitTata. - Blgr. I901. (Fig., p. i 9 r, upper.)}

Depth of body $3 \frac{1}{3}$ to $3 \frac{1}{2}$ times in total length, length of liead 23 to 3 times. Profile of snout convex; lower jaw projecting beyond the upper; diameter of eye is to $I_{3}^{2}$ times in length of snout, 4 to $4 i$ times in length of head, and equal to interocular width; maxillary extending to below anterior border of eye; teeth in 3 or 4 rows, the outer much larger than the others; 3 or 4 series of scales on the cheek; large scales on the opercle. Gill-rakers short, Io to 12 on lower part of anterior arch. Dorsal XV.-XVI. 8-9; spines subequal from the seventh or eighth, which measures about $\frac{1}{3}$ length of head and $\frac{2}{3}$ longest soft rays. Pectoral pointed, about $\frac{2}{3}$ length of head. Ventral reaching vent or origin of anal. Anal III. 8-9; third spine longest, as long as middle dorsal spines. Caudal feebly emarginate. Caudal peduncle $1 \frac{1}{2}$ times as long as deep. Scales with finely denticulated border, $33-35 \frac{4}{\text { II }- \text { I } 2}$; lat. I. $\frac{20-2 I}{\text { IO-I } 3}$. Olive above, whitish beneath; a blackish stripe on each side above the upper lateral line, and a second from the opercle to the root of the caudal fin, passing over the lower lateral line; dorsal, anal, and caudal fins greyish or blackish, ventrals black in the males.

Total length 20 millim.

Described from several specimens. 


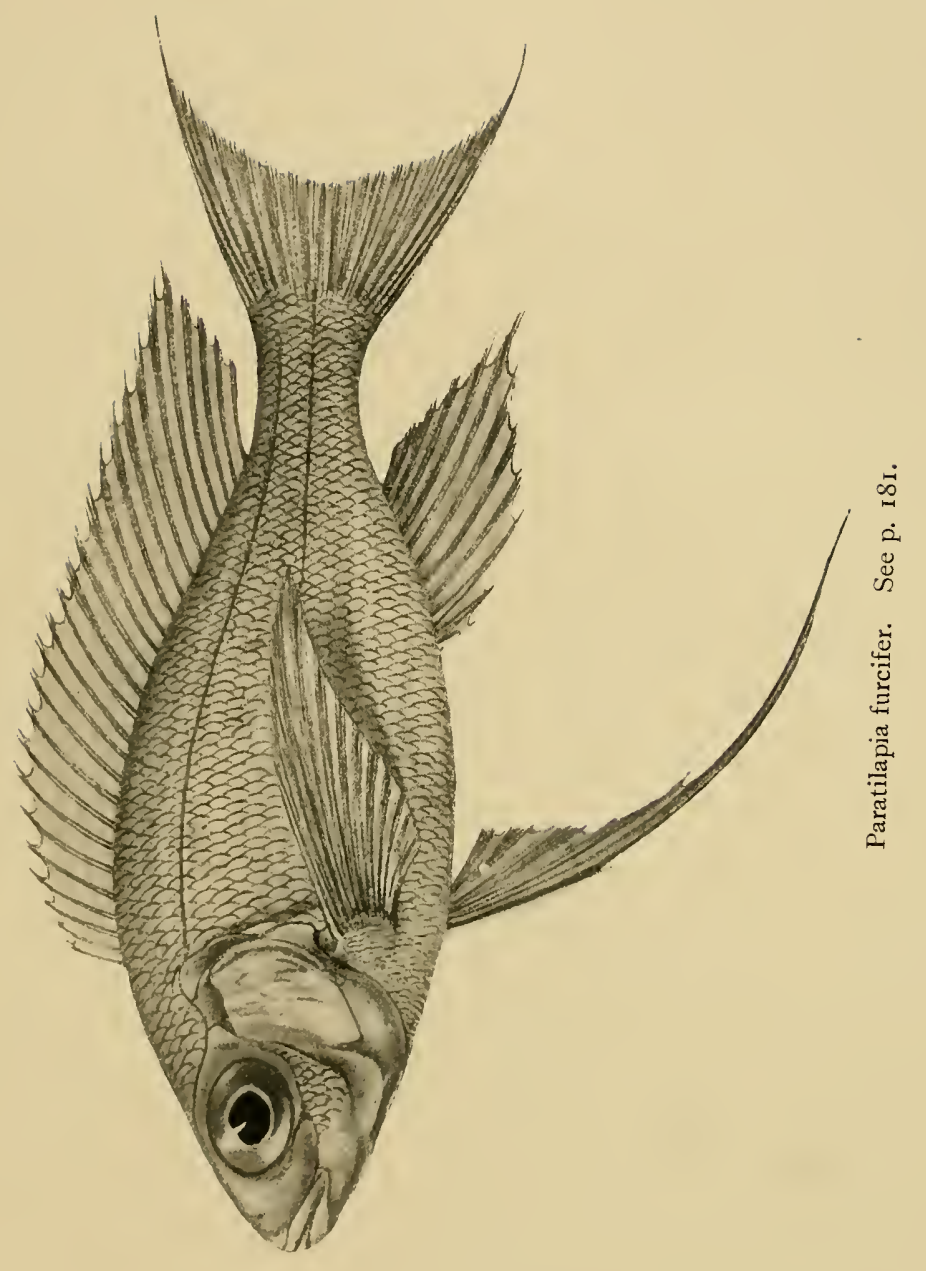




\section{P.iratilapia aurita.-Blgr. I901. (Fig., p. I95, middle.)}

Depth of lodly, 3 to 31 times in total length; length of head, 31 to $3 \hat{3}$ times. Snout short, as long or a little shorter than the eye, with slightly curved upper profile; lower jaw not projecting beyond the upper; diameter of the eye, $3 \frac{1}{t}$ to 3 times in length of head, equal to or greater than interocular width; maxillary extending to below anterior fourth or third of cye; teeth in 2 or 3 rows, the outer much larger than the others; 4 or 5 series of scales on the cheek; large scales on the opercle. Gill-rakers short, Io or 12 on lower part of anterior arch. Dorsal XV.XVII. 9-10; spines increasing in length to the last, which is a little less than half length of head; the longest soft rays produced into filaments, and only a little shorter than head. l'ectoral pointed, as long as head. V'entral produced in a filament, and extending to vent or beyond. Anal III. \&; third spine stronger and shorter than the last dorsal spine. Caudal feebly emarginate. Caudal peduncle, $1 \frac{1}{2}$ times as long as deep. Scales with finely denticulate border, $35-36 \frac{3-4}{9-10}$; lat. 1. $\frac{22-25}{14-1 S^{*}}$. Brownish, with or without oblique cross lars of mother-of-pearl or silvery white, sometimes with ill-defined dark lars across the lack; a rery distinct, bluc-black opercular spot; dorsal and anal grey or blackish, often striated or spotted with white; the membrane between the dorsal spines edged with black; anal sometimes blackish.

Total length, I 30 millim.

Described from numerous specimens from Msambu.

40. Paratilapia bloyeti.-Sauv. $S_{3} S_{3}$.

41. Paratilapia Pfefferi.-Blgr. 1898. (Fig., p. 205, middle.)

Teeth small, in 3 series in each jaw, forming a narrow band, outer largest. Depth of body equal to length of head, $22_{3}^{2}$ times in total length. Snout with straight upper profile, as long as eye, the diameter of which is $3 \frac{1}{3}$ times in length of head and equals $\mathrm{I} \frac{1}{3}$ interorbital width; maxillary extending to below anterior border of eye; 3 series of scales on the cheek: large scales on the opercle. Gill-rakers rather long, II on lower part of anterior arch, the larger spatulate. Dorsal XVI. 8; spines increasing in length to the sixth, which measures a little less than $\frac{2}{2}$ length of head and nearly equals longest soft rays. Pectoral $\frac{1}{b}$ length of head. Ventral reaching origin of anal. Anal III. 7 ; third spine longest, as long as longest dorsal. Caudal feebly emarginate. Caudal peduncle $1 \frac{1}{2}$ as long as deep. Scales very finely denticulate on the edge, $33^{3}$; lat. I. $\frac{2 \mathrm{I}-22}{12-13}$. I'ale olive aloove, silvery beneath, with seven darker vertical bars; fins greyish brown.

Total length, 76 millim.

Described from a single specimen from Kinyankolo.

\section{Paratilapla Calliur.1-Blgr. I901. (Fig., p. I 75.)}

Depth of body 4 to $4 \frac{1}{2}$ times in total length; length of head, 3 to $3 \frac{1}{2}$ times. Snout pointed, with straight upper profile, as long as or a little shorter than the 
eye, the diameter of which is double the interocular width, and is contained 3 to $3 \frac{1}{3}$ times in length of head; lower jaw projecting beyond the upper; maxillary extending to below anterior fourth of eye; teeth small in two rows; 2 or 3 series of scales on the cheek; large scales on the opercle. Gill-rakers moderately long, i 5 on lower part of anterior arch. Dorsal XVI.-XVII. IO; spines increasing in length to the last, which measures $\frac{2}{5}$ or $\frac{1}{2}$ length of head ; longest soft rays $\frac{2}{3}$ or $\frac{3}{4}$ length of head. Pectoral pointed, a little shorter than head. Ventral reaching vent. Anal

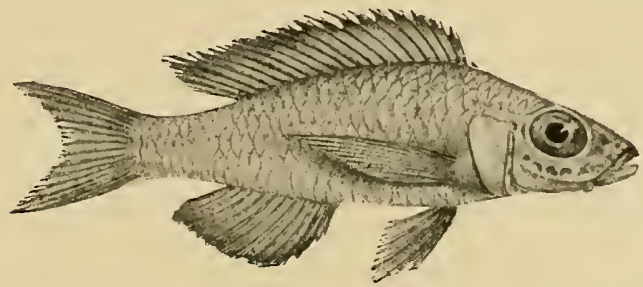

Trematocara marginatum. See p. 192.

III. 7-8; third spine longest, a little shorter than last dorsal spine. Caudal feebly emarginate. Caudal peduncle $\mathbf{I}_{\frac{1}{2}}$ times as long as deep. Scales with finely denticulate border, $37-40, \frac{2-3}{9-10}$; lat. I, $\frac{25-29}{13-17}$. Pale brownish above, silvery beneath ; a blackish opercular spot ; dorsal and anal edged with black ; 4 or 5 black hars across the caudal; young with black bars across the dorsal.

Total length, i io millim.

Described from several specimens from Kalambo.

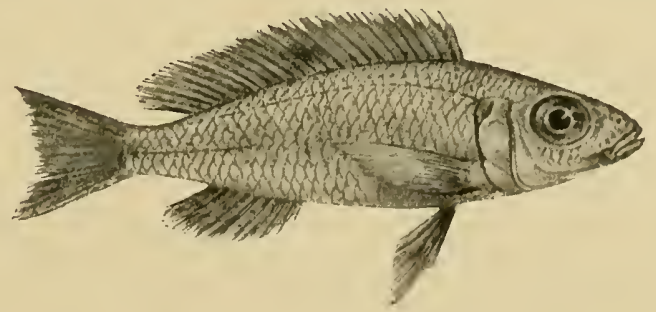

Ectodus descampsi. See p. I86.

\section{Paratilapia macrops.-Blgr. i 898 . (Fig., p. i 85. )}

Teeth small, in 3 series in each jaw, forming a narrow band, outer largest. Depth of body three times in total length; length of head, $22_{3}^{2}$ to 3 . Snout with straight upper profile, a little shorter than the eye, the diameter of which is 2.3 times in length of head and exceeds interorbital width; maxillary extending to leclow anterior horder of eye; 2 or 3 series of scales on the cheek; large scales on the opercle. Gill-rakers short, II on lower part of anterior arch. Dorsal XVI. 
10-12 : spines increasing in length to the sisth, which measures a little less than $\frac{1}{2}$ length of head and equals longest soft rays. l'ectoral as long as head. Ventral extending a little beyond origin of anal. Anal III. 6-7; third spine longest, a little shorter than longest dorsal. Caudal with crescentic emargination. Caudal peduncle as long as deep. Scales very finely denticulate on the edge, $33-34 \frac{3}{10}$; lat. 1, $33-17$; upper lateral line complete, extending to base of caudal. I'ale brownishalove, silvery beneath; a series of five indistinct dark blotches on each side of the loody ; spinous dorsal edged with brown above.

Total length, 70 millim.

Described from two specimens from Kinyamkolo, and one from Mbity kocks.

Closely allied to I'aratilapia ffefferi: distinguished by the larger eje, the complete upper lateral line, the longer pectoral, and the more strongly emarginate caudal. Connects $P$. ffefferi with $I$ '. a'enlralis, which represents a more aberrant type.

\section{Paratilapia vextralis.-Blgr. i 898. (Fig., p. 203, lower.)}

Teeth very small, in two series in both jaws, the outer and larger tipped with brown. Depth of body, $22_{3}^{2}$ to 3 times in total length; length of head, 3 . Snout with curved upper profile, a little shorter than the eye, the diameter of which is 2 ? to 2.3 times in length of head and exceeds interorbital width : maxillary extending to below anterior fourth of eye : $\mathbf{t}$ wo or three series of scales on the cheek ; large scales on the opercle. Gill-rakers rather long, lanceolate, I7 to I9 on lower part of anterior arch. Dorsal XII.-XIII. 13-14; spines increasing in length to the eighth or ninth, which measures nearly $\frac{1}{2}$ length of head and $\frac{3}{4}$ or $\frac{4}{5}$ longest soft rays. Pectoral a little longer than head. Ventral much produced, extending far beyond the origin of the anal, especially in the males, in which it may reach the end of the caudal. Anal III. 9-10; third spine longest, about $\frac{2}{3}$ length of head ; middle soft rays produced, nearly as long as head. Caudal deeply emarginate, crescentic. Caudal peduncle $1 \frac{1}{2}$ as long as deep.

\section{Paratilapia dewindt. - Blgr. i S99. (Fig., p. 207, upper.)}

Teeth very small, in three or four series in both jaws, the outer scarcely larger and not tipped with brown. Depth of body equal to length of head, nearly 3 times in total length. Snout with curved upper profile, shorter than the eye, the diameter of which is $2_{3}^{2}$ to $2 \frac{3}{4}$ in length of head, and exceeds interorbital width; maxillary extending to below anterior fourth of eye; wo or three series of scales on the cheek; large scales on the opercle. Gill-rakers rather long, lanceolate, I7 or IS on lower part of anterior arch. Dorsal XII.-XIII. 12.13; spines increasing in length to the eighth or ninth, which measures $\frac{2}{3}$ or $\frac{1}{2}$ length of head and ${ }_{4}^{3}$ longest soft rays. Pectoral a little shorter than head, extending as far as origin of anal. Ventral produced into a long filament extending beyond origin of anal. Anal III., 9 ; third spine longest, $\frac{2}{5}$ length of head; middle soft rays produced, as long as ur a little shorter than head. Caudal deeply emarginate, crescentic. Caudal peduncle, $I_{3}^{1}$ as long as deep. Scales finely denticulate on the edge, $37-3 S \frac{4}{13} ;$ lat. $1, \frac{29-30}{14}-15$ upper latcral line not reaching base of caudal. Grey above, white beneath; four 
yellowish stripes along each side; pectorals yellowish; other fins dark grey or blackish.

Total length, 100 millim.

Described from three specimens. Native name, "Likuko."

This species is named in memory of the distinguished young geologist, Dr. De Windt, attached to Lieut. Lemaire's expedition, who was accidentally drowned in

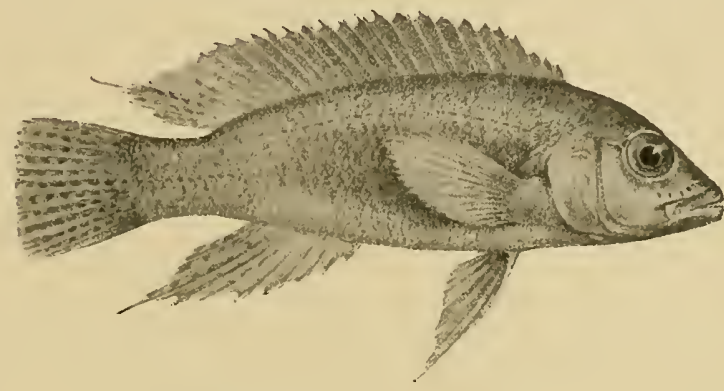

Lamprologus modestus. See p. I70.

Lake Tanganyika. It is very closely allied to $P$. ventralis, Blgr., from which it differs in the dentition and in the shorter pectoral fin.

\section{Paratilapia furcifer, sp. n.-Blgr. i 898 . (Fig., p. I 77 .)}

Teeth very small, in three series in both jaws, the outer largest and tipped with brown. Depth of body equal to length of head, 3 times in total length. Snout with curved upper profile, a little shorter than the eye, the diameter of which is $2 \frac{2}{3}$

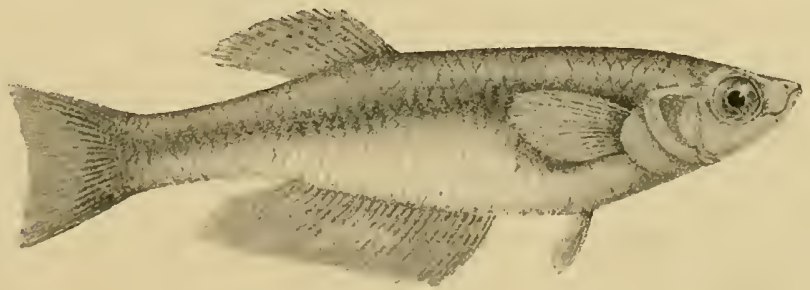

Haplochilus tanganicanus. See p. I68.

to $2_{4}^{3}$ times in length of head and slightly exceeds interorbital width ; maxillary extending to below anterior border of eye; two or three series of scales on the cheek; large scales on the opercle. Gill-rakers rather long, lanceolate, 15 or 16 on lower part of anterior arch. Dorsal XIII., 13-14 ; spines increasing in length to the ninth, which measures a little less than $\frac{1}{2}$ length of head; some of the soft rays produced, nearly as long as head. Pectoral a little longer than head. Ventral 
much produced, extending nearly to caudal. Anal III., 9; third spine longest, a length of head; middle soft rays produced, like the dorsals. Caudal deeply emarginate, crescentic, the rays at the angles produced. Caudal peduncle, It as long as deep. Scales finely denticulate on the edgre, $60 \cdot 63 \frac{4-5}{16-17}$; lat. I, $\frac{54-55}{28-32}$; upper lateral line nearly complete, extending on the caudal pecluncle. Jluish alove, white lencath : a few ill-defined yellow streaks along the loxly ; some yellow marllings on the postocular part of the head ; fins white, with some yellow streaks on the dorsal and anal, and letween the ventral and caudal rays.

Total length, I ro millim.

Described from two specimens from Kinyamkolo.

Closely allied to $P$. ventralis ; distinguished by much smaller scales.

\section{Paratilapia stexosomi. - Blngr. igoi. (Fig., p. 2i I.)}

Body very strongly compressed, its depth equal to the length of the head and contained 23 to 3 times in total length. I'rofile of snout descendling in a straight or slightly convex line; lower jaw projecting beyond the upper; diameter of eyc nearly equal to length of snout or interocular width, $3 \frac{1}{3}$ to $3 \frac{1}{2}$ times in length of head; maxillary not extending to below anterior border of eye; teeth small, in two or three rows, the outer very slightly larger than the others; two series of scales on the cheek; very thin scales on the opercle. Gill-rakers rather long and closely set, I9 to 23 on lower part of anterior arch. Dorsal XV., I3; last spine longest, ${ }_{b}^{2}$ length of head; soft rays longer, sometimes produced into filaments. l'ectoral pointed, a little shorter than head. Ventral reaching vent. Anal III., I2-13; third spine longest, a little stronger, lut shorter than last dorsal spine. Caudal deeply emarginate. Caudal peduncle nearly twice as long as deep. Scales without marginal denticulation, $60-68 \frac{6}{16}$; lat. I, $\frac{54-58}{3 \mathrm{I}-34}$. Brownish above, silvery beneath, with or without blackish spots and longitudinal bands; dorsal blackish at the end.

Total length, 220 millim.

Described from several specimens from Mlaswa and from the south end of lake Tanganyika.

\section{Paratilapia leptosona.-lilgr. 1898. (Fig., p. $20 \mathrm{I}$, lower.)}

Teeth small, in three series in the upper jaw, in four in the lower, outer largest. Depth of lody, 4 to $4 \frac{1}{3}$ times in total length; length of head, 3 . Snout with straight upper profile, as long as or a little longer than the eye, the diameter of which is $3 \frac{2}{2}$ to $3 \frac{2}{3}$ times in length of head, and equals interorbital width ; maxillary extending to below anterior border of eye, or not quite so far ; two series of scales on the cheek ; opercle covered with scales. Gill-rakers long, slender and close set, 20 on lower part of anterior arch. Dorsal XII., I4-15; spines increasing in length to the last, which measures ${ }_{5}^{2}$ length of head, and is nearly as long as the soft rays. I'ectoral ${ }_{4}^{3}$ length of head. Ventral reaching origin of anal. Anal III., IO-12; thirrl spine longest, a little shorter than longest dorsal. Caudal feebly emarginate. Caudal 


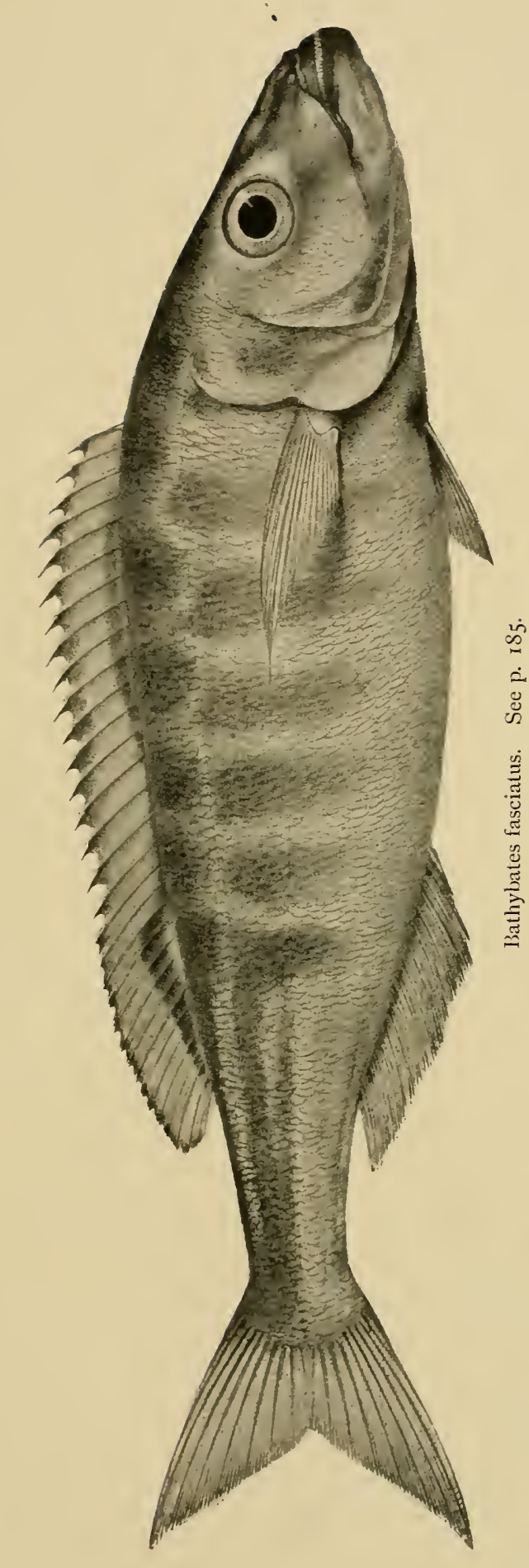


peduncle twice as long as deep. Scales very finely denticulate on the edger, 39-40 $\frac{2-3}{1 \mathrm{I}}$; lat. I, $\frac{27-3 \mathrm{I}}{\mathrm{II}-13}$. Brown, lighter bencath; dorsal and anal with or without brown longitudinal streaks; caudal spotted with black or brown at the base.

Total length, 87 millim.

Described from two specimens from Kinyamkolo and two from .llbily kocks.

\section{Paratilapia nigripinnis.-Blgr. I901. (Fig., p. 195, lower.)}

Depth of body 4 times in total length, length of head 3 to 3 t times. Snout with straight upper profile, as long as diameter of eye, which equals interucular width, and is contained $3 \frac{1}{3}$ times in length of head; mouth extremely protractile; maxillary extending to below anterior border of eye; tecth very small, in threc rows; two or three series of scales on the check; opercle covered with scales. Gill-rakers long and thin, closely set, 20 on lower part of anterior arch. 1)orsal XV..XVII., II ; spines increasing in length to the last, which measures $\frac{2}{3}$ length of head; soft rays longer. Pectoral pointed, as long as head. Ventral reaching origin of anal or beyond. Anal III., 8-9; third spine as long as the last dorsal. Candal deeply emarginate, the lobes produced into filaments. Caudal perluncle twice as long as deep. Scales with denticulate border, 39-40 $\frac{3}{11} ;$ lat. I $\frac{29-30}{13-16}$. Dark brown, lighter beneath; fins blackish, the caudal edged with white alowe and beneath.

Total length So millim.

Described from several specimens from Msambu.

This species is very closely allied to $I$ '. leprosoma, but is distinguished lyy the number of rays in the dorsal and anal fin (D. XV.-AVII. II, A. III. 8-9, instead of D. XII.-XIV. I4-I6, A. III. IO-I2).

\section{Bathybates FEROX.-Blgr. I S98. (Fig. facing p. 184.)}

Teeth long, sharp, fang-like, wide apart, in four series in the upper jaw, in three in the lower. Depth of body 4 times in total length, length of head 3 times. Snout long and strongly compressed, with convex upper profile; eye large, its diameter $I_{b}^{2}$ times in length of snout, $3 \frac{1}{2}$ in length of head, and a little greater than interorbital width; maxillary not quite reaching to below anterior border of eye ; five series of small scales on the cheek; large scales on the opercle. Gill-rakers moderately long and slender, 13 on lower part of anterior arch. Dorsal XIV. I6; spines rather feeble, slender, subequal from the fifth, which measures 2 length of head; longest soft rays $\frac{1}{3}$ length of head. Pectoral ${ }_{4}^{3}$ length of head. Ventral not reaching vent. Anal III., I6; spines short and feeble. Caudal deeply forked, middle rays not half as long as outer. Caudal peduncle nearly twice as long as deep. Scales small and irregular, especially lelow the lateral lines, $7 \mathrm{~S} \frac{7}{3} \mathrm{~s}$; lat. I $\frac{78}{44}$, the upper extending from the opercle to the caudal, the lower from below the last dorsal spines to the caudal. I'ale bluish green, iridescent above, white 


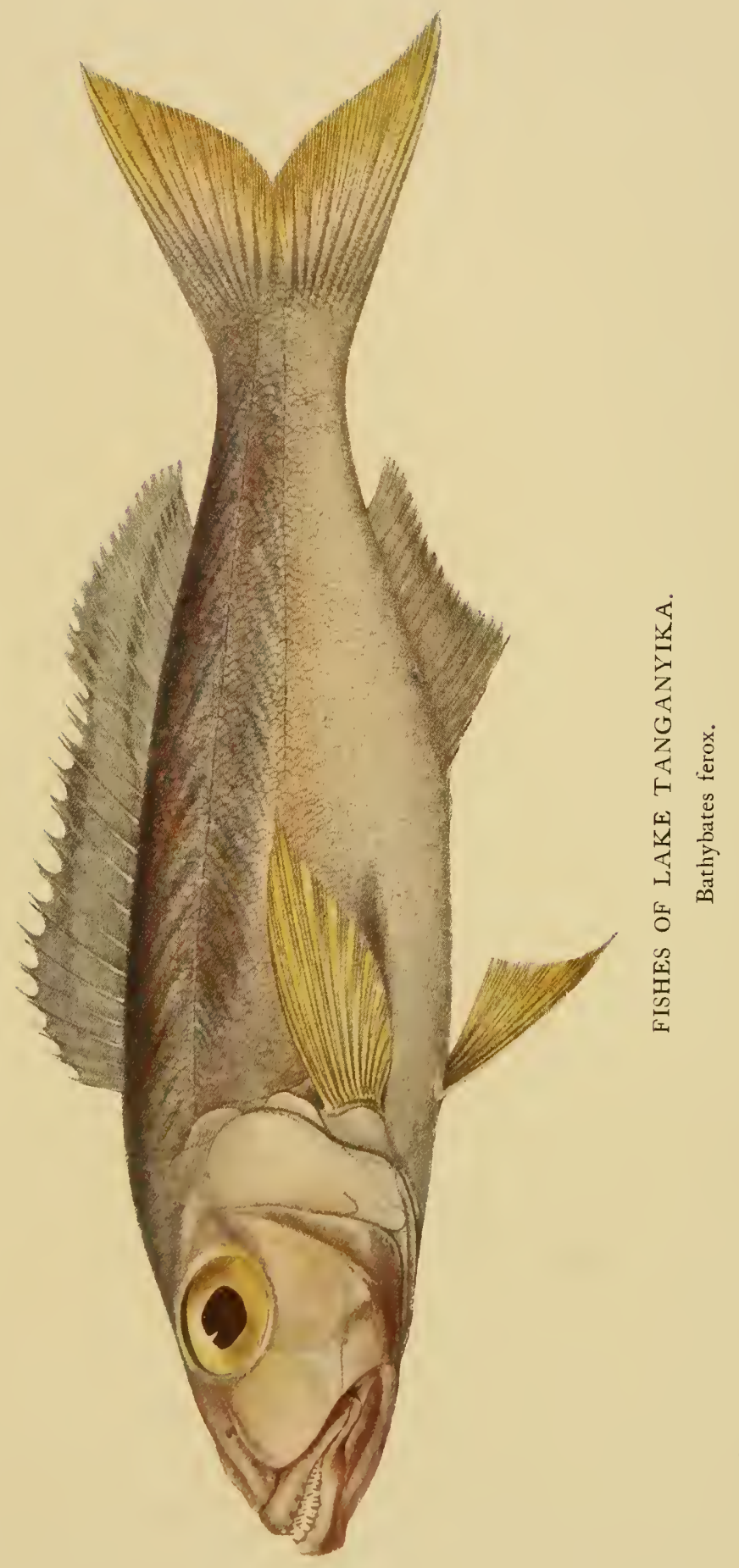



below; dorsal and anal bluish grey; ventrals and caudal yellowish; pectorals yellow; two dark streaks on the dorsal.

Total length, 275 millim.

Described from a single specimen from Kinyamkolo, taken at a depth of 400 feet. The specimen is a female with ripe ova; these are of large size, measuring $3 \frac{1}{2}$

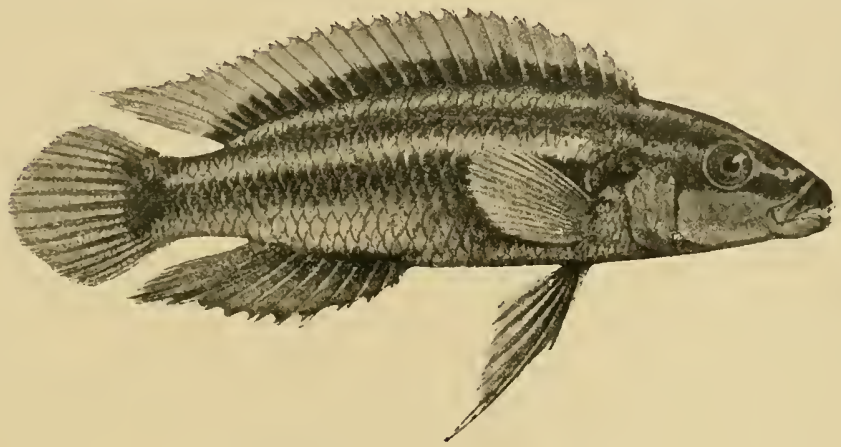

Julidochromis ornatus. See p. 176 .

millim. in diameter. The stomach contains a small partially digested fish of the genus Paratilapia, as first ascertained by a sciagraph kindly prepared by Messrs. Gardiner and Green, through which it was possible to compare the structure of the vertebral column, with that of other members of the family Cichlide. The insertion of the ribs is typical, viz., sessile, except on the last three pracaudal

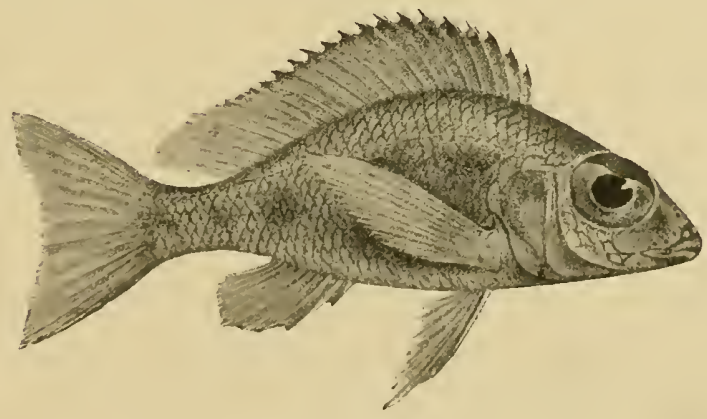

Paratilapia macrops.

vertebre; the transverse processes are short and in front of the ribs. The number of vertebre agrees with that of the more elongate species of Paratilapia.

\section{I. Bathybates fasciatus.-Milgr. igor. (Fig., p. 183.)}

Depth of body $4 \frac{1}{3}$ times in total length, length of head 3 times. Shape of head similar to that of $B$. ferox, but eye smaller, its diameter about twice 
in length of snout, 5 times in length of he:t, and $1 \frac{1}{2}$ in. interocular width ; eight series of small scales on the cheek; larger scales on the opercle. Fingliteen gill-rakers on lower part of anterior arch. Dorsal XVII. 16; spines suberual from the fifth, which measures : length of liead: longest soft rays : length of hearl. Pectoral pointed, 3 length of head. Ventral not half as long as the distance between its lase and the vent. Anal III. I8; spines very weak. Caudal forked. Caudal peduncle twice and a half as long as deep. Scales very small, 140 in a longitudinal series alove the upper lateral line, $\frac{11}{25}$ in a transierse series; lat. $1 \frac{75}{45}$ Brownish above, white beneath; a series of large, rounded blackish spots on each side of the back above the lateral line, alternating with a series of vertical blackish bars on each side of the body; on the tail, from the middle of the soft dorsal, the spots unite into a band which extends to the caudal, and the vertical bars likewise fuse to form a lateral band; a blackish spot on the opercle, another at the base of the ventral: (wo black bands on the dorsal, a basal and a marginal.

Total length, 340 millim.

Described from a single specimen from the west coast at Teml wi.

This second species of the remarkable genus Bathybates differs from its congener in the smaller eye, the more numerous gill-rakers, and the smaller scales.

\section{Pelantochromis polilepis.--Bigr. 1900.}

Depth of body $2 \frac{1}{2}$ to $2 \frac{2}{3}$ times in total length, length of head 3 to $3 \frac{1}{3}$ times. Snout with straight upper profile, $I_{3} \frac{1}{3}$ times diameter of eye, very deep, its length not exceeding the width of the preorlital region; diameter of eye $3 \frac{1}{t} 03$ ? time in length of hearl, equal to or a little greater than interocular width; maxillary extending nearly to below anterior border of eye; teeth very small, in four or five irregular rows in both jaws, the outer somewhat larger; four or five series of scales on the cheek; larger scales on the opercle. Gill-raliers short, lamellar, denticulate, 14 or 15 on lower part of anterior arch. Dorsal $\mathrm{XV}$...1I. 14-15; spines sulsequal from the sixth, which measures $\frac{2}{5}$ or a little more than $\frac{1}{3}$ length of head. l'ectoral pointed, falciform, at least as long as head. Ventral reaching rent, the outer ray produced into a filament. Anal III. 8; third spine much stronger than dorsal spines, nearly $\frac{1}{2}$ length of head. Caudal rather deeply emarginated. Caudal peduncle a little longer than deep. Scales with denticulate border, $55 \cdot 55 \frac{\frac{6-7}{3}}{18}$; lat. I $\begin{array}{r}25-31 \\ 47-4\end{array}$, the upper extending to below the last spines or the first soft ray's of the dorsal, the lower originating a little behind the shoulder and extending to the caudal fin. Body golden, olive on the loack, purplish streaks along the dorsal and caudal fins, sometimes forming a wide-meshed network.

Total length, 300 millim.

\section{Ectodus descampsi.-Blgr. 1898. (Fig., p. 179, lower.)}

Depth of lody $3 \frac{1}{2}$ times in total length, length of head 3 . Snout short, with curved upper profile, slightly shorter than the eye, the diameter of which is $2 \frac{t}{6}$ in 


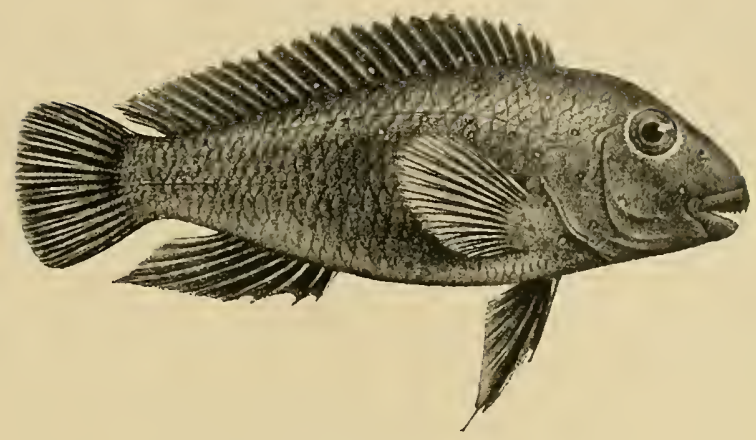

Eretmodus cyanostictus. See p. 210.

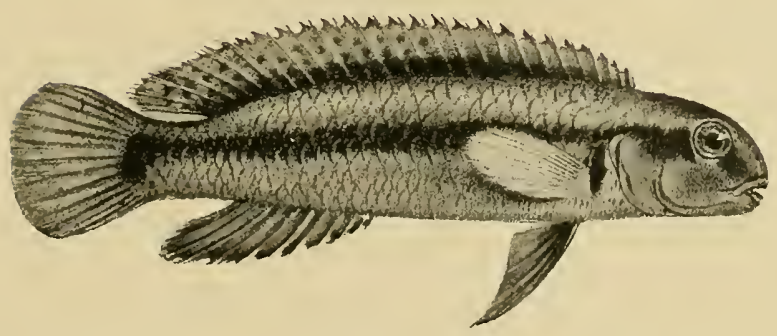

Telmatochromis vittatus. See p. I94.

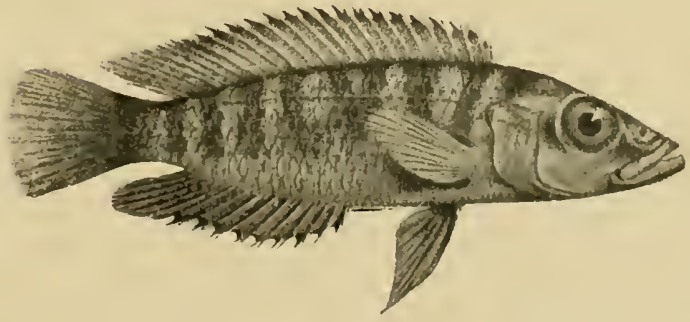

Lamprologus fasciatus. See p. 174 . 
length of head and equals $1 \frac{1}{2}$ interorbital width; maxillary extending to letween nostril and eye; two series of scales on the check: opercle naked. Gill-rakers shurt, II un lower part of anterior arch. Dorsal XIII. 13; spines slender, increasing in length to the last, which is aloout ${ }_{3}^{2}$ length of head and little shorter than the soft rays. Anal III. 8 ; third spine slightly shorter than lungest dorsals. P'ectoral oltusely pointed, $\frac{2}{3}$ length of head. Ventral reaching vent. Caudal cinarginate. Caudal peduncle $1 \frac{1}{2}$ as long as deep. Scales $35 \frac{3}{11}$; lat. I $\frac{27}{14}$. Pale brown alover, yellowish beneath; fins yellow; a round blackish spot on the hinder part of the spinous dorsal.

Total length, 60 millim.

Described from a single specimen.

\section{Ecronts Mlinogexis. - Blgr. I 898 . (Fig. p. 193, middle.)}

Depth of loody 5 to 5 times in total length, length of head $3 !$. Snout long, with nearly straight upper profile, $\mathbf{I}_{3}^{2}$ diameter of eye, which is 4 times in length of head, and equals or slightly exceeds interorlital width; maxillary extending (1) between nostril and eye; three series of scales on the cheek; deciduous scales on the opercle. Gill-rakers short, 12 to 13 on lower part of anterior arch. I)orsal XIII.-XIV. 17 ; spines slender, increasing in length $(1)$ the last, which is about $\frac{2}{3}$ length of head; last soft rays produced, at least half length of head. Anal III. 13 ; third spine $\frac{1}{3}$ length of head. Pectoral pointed, a little shorter than head. Ventral reaching origin of anal. Caudal deeply emarginate. Caudal peduncle twice as long as deep. Scales $43-44 \frac{3-4}{10} ;$ lat. I $\frac{30-31}{14-16}$. Grey above, white below; dorsal scales with a pale blue central spot; a llackish opercular spot; chin and branchiostegal membrane blackish; dorsal grey, with whitish streaks and spots, and a large oval blackish spot in the middle of the spinous portion; anal grey, streaked with whitish; pectoral and caudal jellowish, the latter with crescentic dark bands; rentral blackish at the end.

Total length, r 10 millim.

Described from two specimens. Native name, "Losorclla."

\section{Ectodus loxglaxalis.-Bouleng. I 899 . (Fig., pp. 205 and 175.)}

Depth of body 5 times in total length, length of head 3. Snout long, with slightly convex upper profile, $1 \frac{1}{2}$ diameter of eye, which is $3 \frac{1}{2}$ times in length of head and nearly $1 \frac{1}{2}$ interorbital width; maxillary extending to between nustril and eye ; three series of scales on the cheek; deciduous scales on the opercle. Gillrakers short, 12 on lower part of anterior arch. Dorsal XV. 15; spines slender, increasing in length to the last, which is $\frac{1}{3}$ length of head ; soft rays slightly longer, the last not produced. Anal III. 17; third spine length of head. l'ectural pointed, : length of head. Ventral nearly reaching origin of anal. Caudal deeply: emarginate. Caudal peduncle twice as long as deep. Scales $44^{3}$; lat. $1 \frac{31}{17-18}$ lirownish above, whitish beneath; a l,ackish opercular spot; a lateral scries of rather indistinct dark spots; dorsal greyish; other fins yellow.

Total length, 97 millim. 


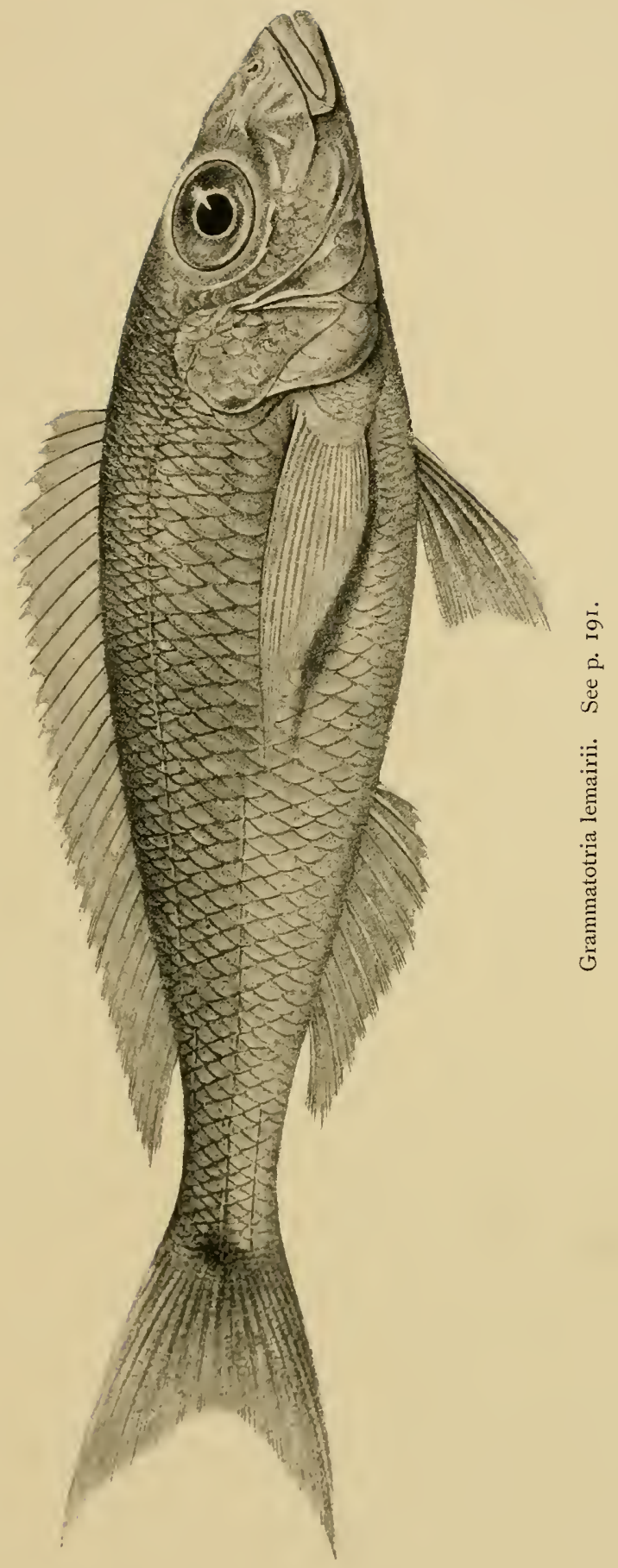


Described from a single specimen, with the mouth and pharynx full of advanced embryos. *

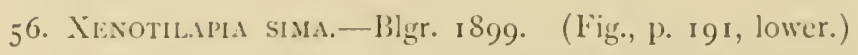

Depth of body 4 times in total length, length of head 31 . Snout very short and deep, with very steep convex upper profile; eye very large, oval, its diameler? length of head and much greater than interorlital width; mouth nearly straight, horizontal, extending to below anterior lorder of eye ; three or four series of scales on the cheek; deciduous scales on the opercle. Gill-rakers very short, l,road, truncate, nine on lower part of anterior arch. Dorsal XIV..XV. I2; spines sulecqual from the fifth, $\frac{1}{3}$ length of head; longest soft ray's $\frac{2}{3}$ length of heacl. l'ectoral acutely pointed, as long as head. Ventral with the inner ray produced and reaching a little beyond origin of anal. Anal III. II ; third spine $\frac{1}{3}$ length of head. Caudal with deep crescentic notch. Caudal peduncle twice as long as deep. Scales strongly ciliated, $40.4 \mathrm{I} \frac{3-4}{10-1 \mathrm{II}}$; lat. I $\frac{32-36}{21-22}+$ Pale brownish, with a few round darker spots; a blackish opercular spot; a shining golden spot on the suls-opercle; dorsal greyish, other fins yellowish.

Total length, 105 millim.

Described from two specimens. Native name, "Lufuina."

\section{Xenotilapia ornatipinvis.-Blgr. ig01. (Fïg., p. 207 , middle.)}

Depth of body nearly equal to length of head, $3 \frac{1}{3}$ to $3 \frac{2}{2}$ times in total length. IIead quite similar to that of Lenotilafia sima. Fifteen to 17 gill-rakers on lower part of anterior arch. Dorsal XIII-XV. I2-13; spines sulequal from the fifth or sixth, ${ }_{5}^{2}$ length of head. Pectoral pointed, as long or a little longer than the hearl. Ventral not reaching anal. Anal III $7-8$; third spine ${ }_{5}^{2}$ length of head. Caudal deeply notched, crescentic. Caudal peduncle $\mathrm{I}_{3}^{2}$ times as long as detp. Scales with denticulate border, $34-37 \frac{3}{10}$; lat. I $\frac{28-32}{13-18 .}$. Pale brownish; a more or less distinct silvery lateral band; spinous dorsal black-edged; large blackish spots or oblique bars on the dorsal; upper lobe of caudal edged with lslackish; a cherronshaped blackish band lower down on the caudal, disposed asymmetrically.

Total length, I Io millim.

Described from sereral specimens from Killwesi.

This species is easily distinguished from . Tenotilafia sima by the shorter body, the fewer anal rays, and the lower number of scales in a longitudinal series.

The skeleton of Xenotilapia is very similar to that of Eitodus. There are likewise three low crests on the back of the skull, the vertebre number $13+22$ in Xenotilafia sima, $\mathrm{I}_{4}+20$ in Cenotilafia ornatifinnis, and the ribs are remote from the centres.

* Further details of the characters of this genus are given by .Mr. Boulenger from additional specimens brought home by me on the second Tanganyika expedition.Trans. \%oo. Soc. Lon., Vol. xvi., I'art 3, p. I54, from which a second figure of the species is given on p. 175 present work. 


\section{Grammatotria Lemairil.-Blgr. 1899. (Fig., p. I89.)}

Depth of body 4 times in total length, length of head 3 . Snout with slightly convex upper profile, $\mathrm{I}_{2}^{\frac{1}{2}}$ diameter of eye, which is $3 \frac{2}{3}$ in length of head and equals

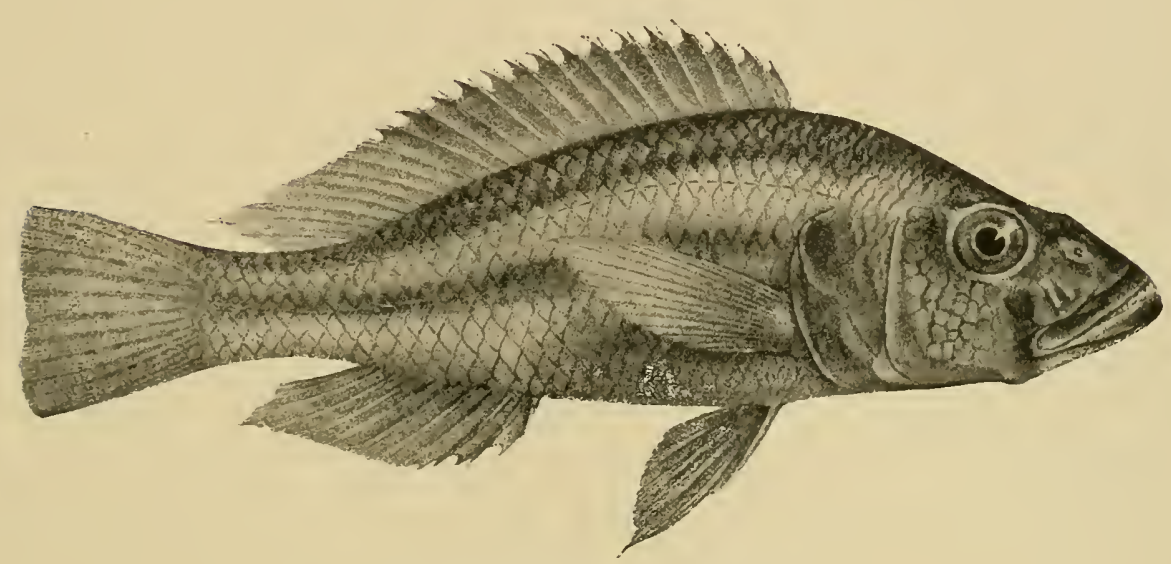

Paratilapia vittata. See p. 176.

interocular width; maxillary extending to between nostril and eye ; three series of scales on cheek; opercle covered with scales. Gill-rakers short, I2 on lower part of anterior arch. Dorsal XV. I4; spines slender, equal from the fifth, which measures

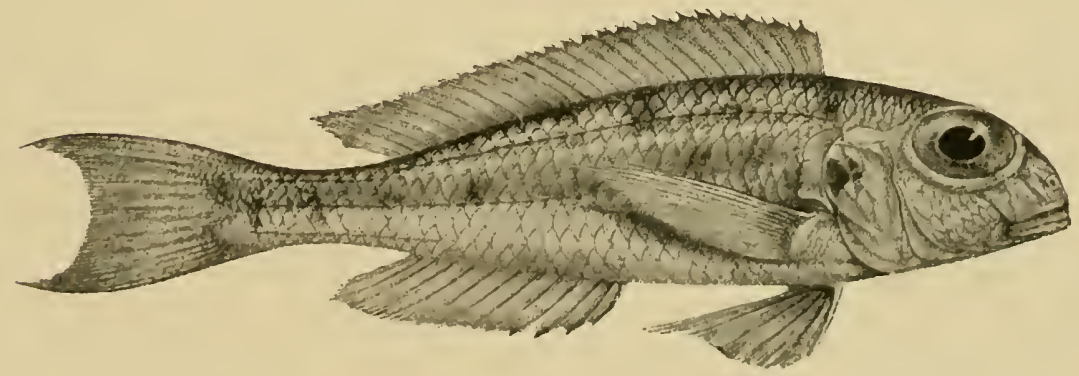

Xenotilapia sima. See p. 190.

nearly l length of head; soft rays not longer than the spines. Pectoral acutely pointed, nearly as long as head, extending as far as origin of anal. Ventral reaching vent. Anal III. IO; third spine a little stronger and shorter than longrest 
dorsals. Caudal with deep crescentic notch. Caudal peduncle $2 ! 3$ as long as deep. Scales $55 \frac{6-7}{13}$; lat. $\frac{48-52}{13-15}$. l'ale brown above, jellowish beneath; a small dark brown opercular spot; a round brown spot on caudal peduncle at root of caudal fin ; dorsal fin greyish, the soft portion with round white spots, other fins yellowish.

Total length, 175 millim.

Described from a single specimen. Native name, "Murungi."

\section{Trematocara marginatum.-Blgr. 1899. (Fig., p. 179, upper.)}

Depth of body $3 \frac{1}{2}$ times in total length, length of head $2 \frac{2}{3}$ to 3 . Snout with curved upper profile, shorter than the eye, which is $2 \frac{1}{2}$ in length of head and exceeds interocular width; mouth extending to below anterior border of eye ; cheek naked; a few deciduous scales on the opercle; nasal, frontal, prie- and suborbital, prieopercular, and mandibular bones with very large and deep cavities separated ly narrow septa and covered with a thin skin. Gill-rakers short, 10 on lower part of anterior arch. Dorsal X. II; spines ${ }_{5}^{2}$ length of head, a little shorter than the longest soft rays. Pectoral acutely pointed, as long as head. Ventral reaching origin of anal. Anal III. 10; third spine nearly as long as dorsals. Caudal with deep crescentic notch. Caudal peduncle $1 \frac{1}{2}$ as long as deep. Scales cycloid, 30? ; lateral line reduced to a few (six or seven) short tubes in the upper series. P'ale brownish above, white beneath; a bluish lateral stripe ; fins jellowish, dorsal and anal edged with blackish.

Total length, $6_{3}$ millim.

Described from two specimens. Native name, "Lilowe."

\section{0. 'Trematocara UNimaculatum.-Blgr. i901. (Fig., p. 201, upper.)}

Depth of body 3 to $3 \frac{1}{2}$ times in total length, length of head $2 \frac{2}{3}$ to $2 \frac{3}{3}$ times. Snout with curved upper profile, as long as or a little shorter than the eye, the diameter of which is nearly double interorbital width and contained 3 to 3 i times in length of head; mouth extending to below anterior border of eye; cheek naked; a few deciduous scales on opercle; nasal, frontal, preorlital, sulorbital, prixopercular, and mandibular bones cavernous, with large cavities covered with thin skin and separated by narrow septa. Gill-rakers short, 17 on lower part of anterior arch. Dorsal X.XII. 9-II ; spines increasing in length to the sixth or seventh, which measures $\frac{1}{2}$ length of head; soft rays scarcely longer. l'ectoral very pointed, as long as or a little longer than the head. Ventral reaching origin of anal. Anal III. $7 \cdot 5$; third spine nearly as long as dorsals. Caudal deeply notched, crescentic. Caudal peduncle nearly twice as long as deep. Scales 30-323; lat. I. 5-I4. Silvery, l,rownish alove, a large rounded black spot on posterior third of spinous part of dorsal, rarely followed by a second.

Total length, 120 millim.

Described from several specimens from the Usambura Market. 


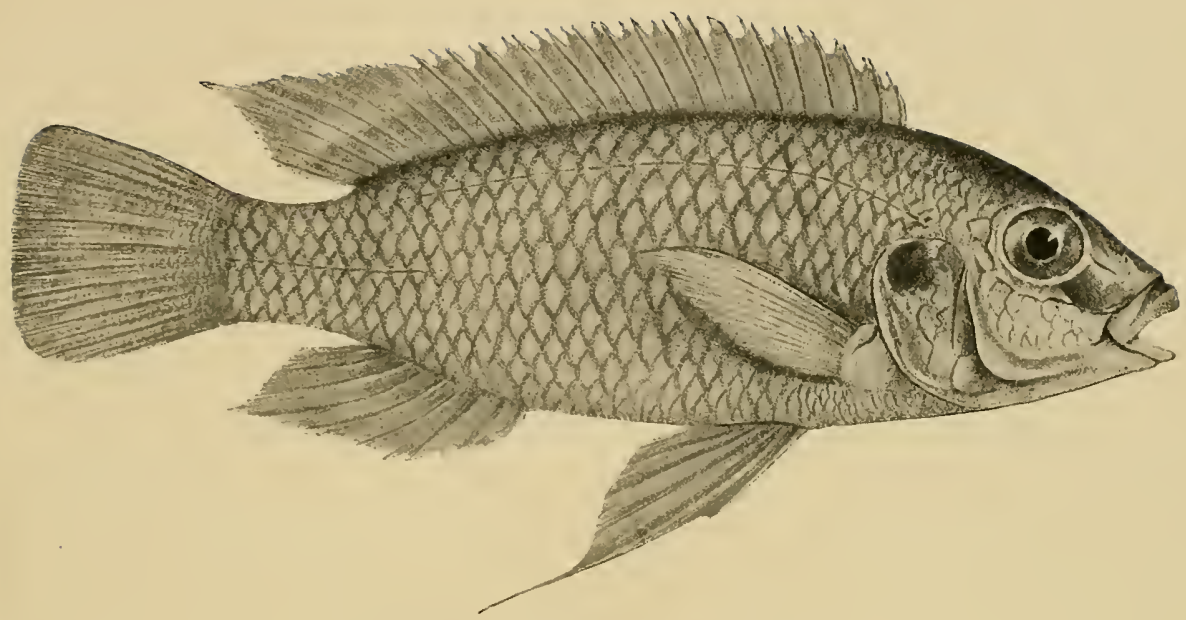

Gephyrochromis moorii. See p. 196.

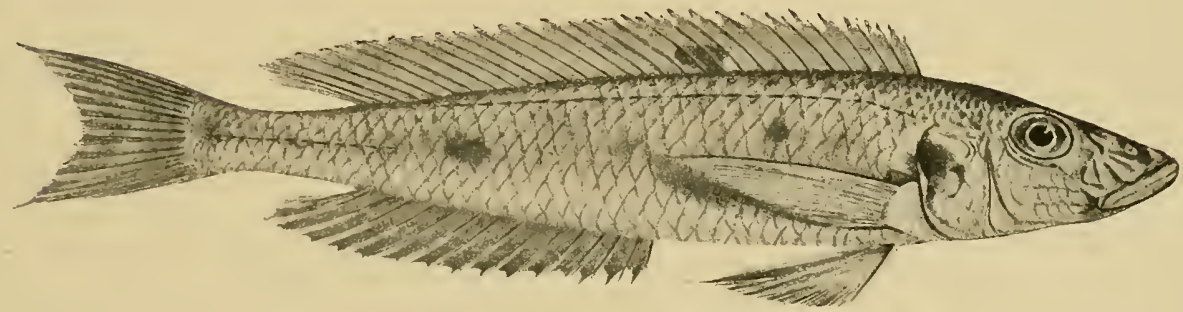

Ectodus melanogenys. See p. I88.

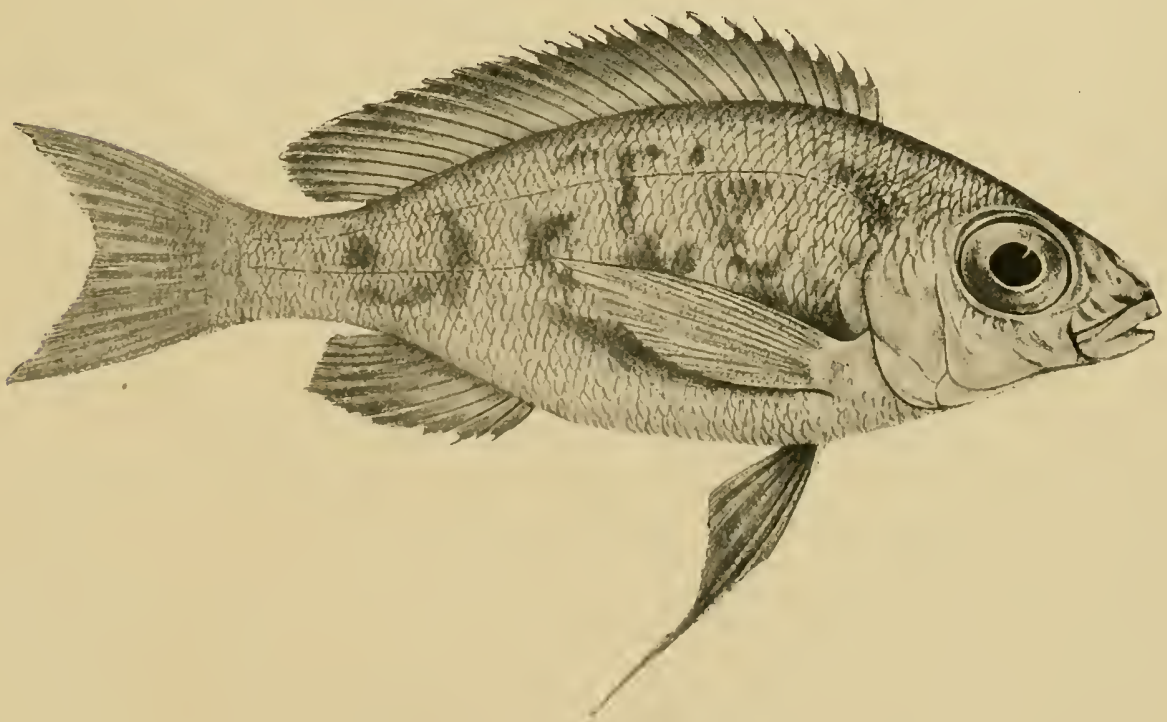

Tilapia grandoculis. Sce p. 206. 


\section{I. Telearatochroms vittates.-Blgr. isgS. (Fïg. p. I $S_{7}$. Middle.)}

Twelve to I6 enlarged conical teeth, tipped with brown, in the outer row in each jaw. I) leth of body $4 \frac{1}{1}$ to $4 \frac{2}{3}$ tines in total length, length of hearl 4 . Snout descending in astrong curve, as long as or a little longer than the diameter of the eye, which is $3 \frac{2}{3}$ to 4 times in length of head and equals interorlital width; maxillary extending below nostril; head naked, opercle with a few deciduous scales. Gillrakers very short and few. Dorsal XXI. NXII. $S$; spines increasing in length to the last, which equals $\frac{1}{2}$ length of head; soft rays a little longer. l'ectoral 3 length of head. Ventral produced into a short filament, reaching origin of anal. Anal VII. 5-6; spines increasing in length to the last, which equals last dorsal. Caudal rounded Caudal peduncle as long as deep. Scales $45-52 \frac{6}{16}$; lat. I $\frac{25-29}{13-15}$. Vellowish, with a dark brown lateral stripe from the upper lip, through the eye, to the base of the caudal, where it expands into a spot; another dark brown stripe from the vertex along the base of the dorsal; a few brown spots on the dorsal. Anal edged with black; a dark lrown bar at the lase of the pectoral, which is white.

Total length, 78 millim.

Described from two specimens from .llbity Rocks.

\section{Telmatochromis teMPORAlis.-Blgr. isgS. (Fig. p. 204.)}

Eight to 12 enlarged conical teeth, tipped with brown, in the cuter row in each jaw. Depth of body $3 \hat{1}$ to $3 \frac{1}{2}$ times in total length; length of head 3 to 31 . Snout descending in a strong curve, $1 \frac{1}{2}$ times as long as the diameter of the eye, which is $4 \frac{2}{2}$ times in length of head and a little less than interorlital width; maxillary extending to below anterior burder of eye; head naked, or with a few decidunus scales on the opercles. Gill-rakers very short and few. Iorsal XX..XXI. 6-7; spines increasing in length to the last, which equals $\frac{1}{1}$ to length of head ; middle soft rays produced, $\frac{2}{3}$ to ${ }_{3}^{3}$ length of head. l'ectoral $\frac{2}{8}$ length of head. V'entral produced into a filament, extending beyond origin of anal. Anal VI.-VII. 6.7; spines increasing in length to the last, which equals or slightly exceeds last dorsal ; soft rays produced, like the dorsals. Caudal rounded. Caudal peduncle as long as deep. Scales $43-46 \frac{6}{12}$; lat. I $\frac{25}{9-17}$. Brown with small round darker spots between the dorsal, anal, and caudal rays : a dark horizontal streak lechind the eye ; a dark bar at base of pectoral.

Total length, $\$_{5}$ millim.

Described from three specimens from Kinyamkolo, and one from Mllity Rocks.

The deep anterior groove of the skull, in which the ascending processes of the premaxillaries are received, extends to the anterior third of the orbits, and the strong occipital crest is prolonged forward to it ; parietal crests are entirely alsent ; the chain of suborbital bones is very slender. None of the rilss are sessile, lxing inserted on a step at the back of the transierse processes of the vertelore at a short distance from the centre; all lear epipleurals ; only the last precaudal vertelura has a hamal loridge. 


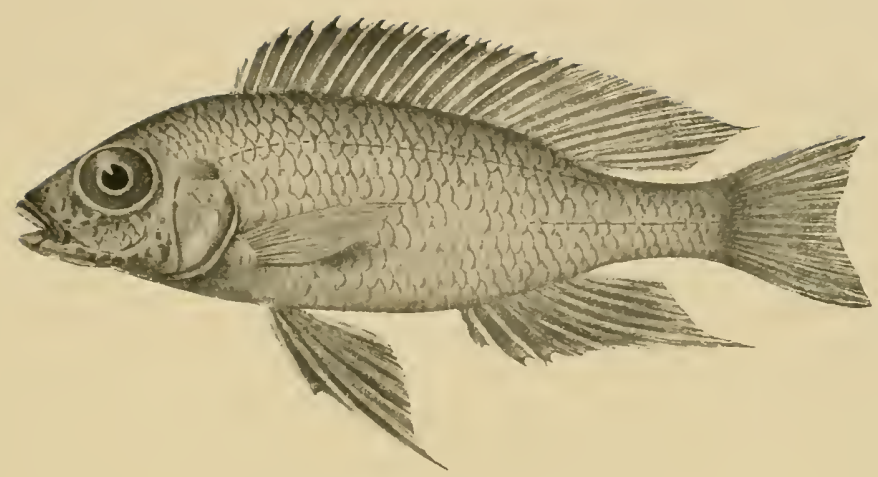

Tilapia trematocephala. See p. 204.

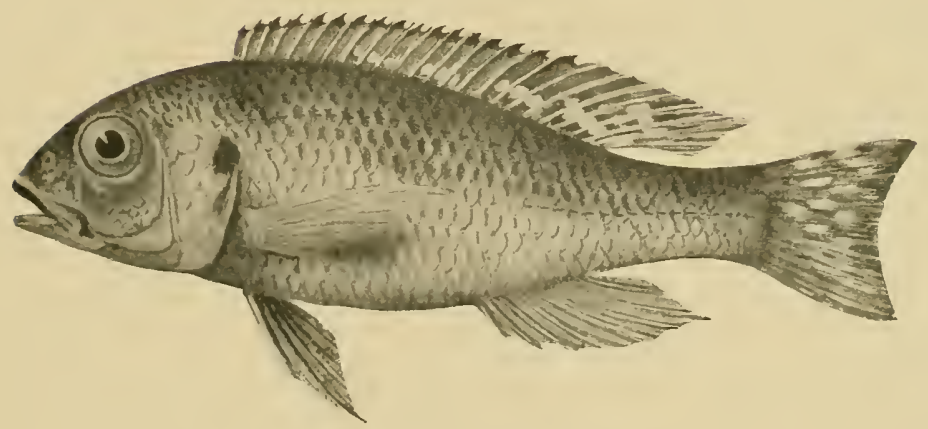

Paratilapia aurita. See p. 178.

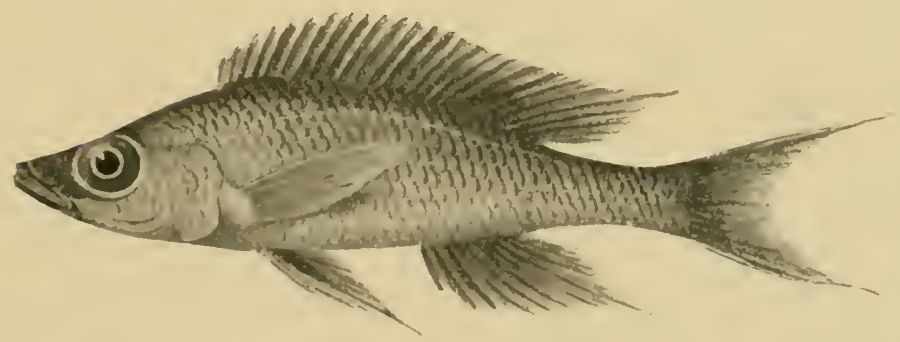

I'aratilapia nigrepinnis. See p. 184. 


\section{Gephytochromis MOORH.-- Blgr. 1901. (Fig. p. 193.)}

Depth of body equal to length of head, 3 times in total length. Snout with slightly convex upper profile, as long as the diameter of the eye, which is contained $3 \frac{1}{3}$ times in length of head, and equals interocular width; maxillary extending to letween nostril and eye; 56 conical teeth, with lorown points, in the upper jaw; three series of scales on the cheek; larger scales on the opercle. Gill-rakers short, I3 on lower part of anterior arch. Dorsal XVII. 8 ; spines increasing in length to the last, which measures ${ }_{5}^{2}$ length of head and $\frac{2}{3}$ longest soft rays. l'ectural nearly as long as head. Ventral produced into a long filament, extending beyond origin of anal. Anal III. 7 ; third spine longest, a little shorter than last dorsal spine. Caudal rounded. Caudal peduncle as lung as deep. Scales $30 \frac{3}{11}$; lat. I. $\frac{22}{13}$. Uniform pale brown.

Total length, I20 millim.

Described from a single specimen from the north end of Lake Tanganyika.

\section{Tropheus mOORiI.-Blr. IS98. (Fig. p. IO9. Lower.)}

Teeth minute, those of the outer series tipped with lrown and numbering about 50. Depth of body $2 \frac{1}{2}$ to $2 \frac{2}{3}$ times in total length, length of head $3 \frac{1}{1}$ to $3 \frac{1}{2}$. Snout descending in a strong curve, as long as or a little longer than the diameter of the eye, which is $3 \frac{1}{2}$ to 4 times in length of head, and equals $\frac{2}{3}$ to ${ }_{4}^{3}$ interorl,ital width; mouth extending to below anterior border of eye ; four series of scales on the cheek ; large scales on the opercle. Gill-rakers short, II or 12 on lower part of anterior arch. Dorsal XXI. 5-6; spines increasing in length to the sixth, which measures not quite half length of head; longest soft rays ${ }_{3}^{2}$ to ${ }_{1}^{3}$ length of head. P'ectoral as long as head. Ventral produced into a short filament, reaching leyond origin of anal. Anal VI. 5-6; spines increasing in length to the last, which slightly exceeds longest dorsal. Caudal slightly notched. Caudal peduncle as long as deep. Scales $30-32 \frac{3}{12}$; lat. I $\frac{22-25}{11-12}$. Dark brown; a large bluish-white blotch on each side; belly reddish brown; fins blackish.

Total length, iro millim.

Described from five specimens from Kinyamkolo.

The occipital crest is very strong, and the parietal crests are produced on the frontals. The insertion of the rilss is as described in the preceding genera Telmatochromis and Eretmodus.

The mouth and pharynx of one of the specimens contains four eggrs of very large size, the vitelline sphere measuring four millimetres in diameter, with an embryo in an advanced stage of development. The egg of the I ifteen-spined Stickleback (Gasterosteus spinachia), hitherto regarded as the largest Teleostean egg in proportion to the size of the animal, measures only three millimetres in diameter. Isesicles the Siluroids of the genera Arius and Galeichthys, which have very large eggs, at least two species of Tilapia were known to give shelter to their eggs in the manner noticed above-viz., T. simonis Gthr. (Chromis paterfamilias, Lortet), as observed by Professor Lortet in Lake Tiberias, and $T$. nilotica, Cuv., as nuticed by me in a 


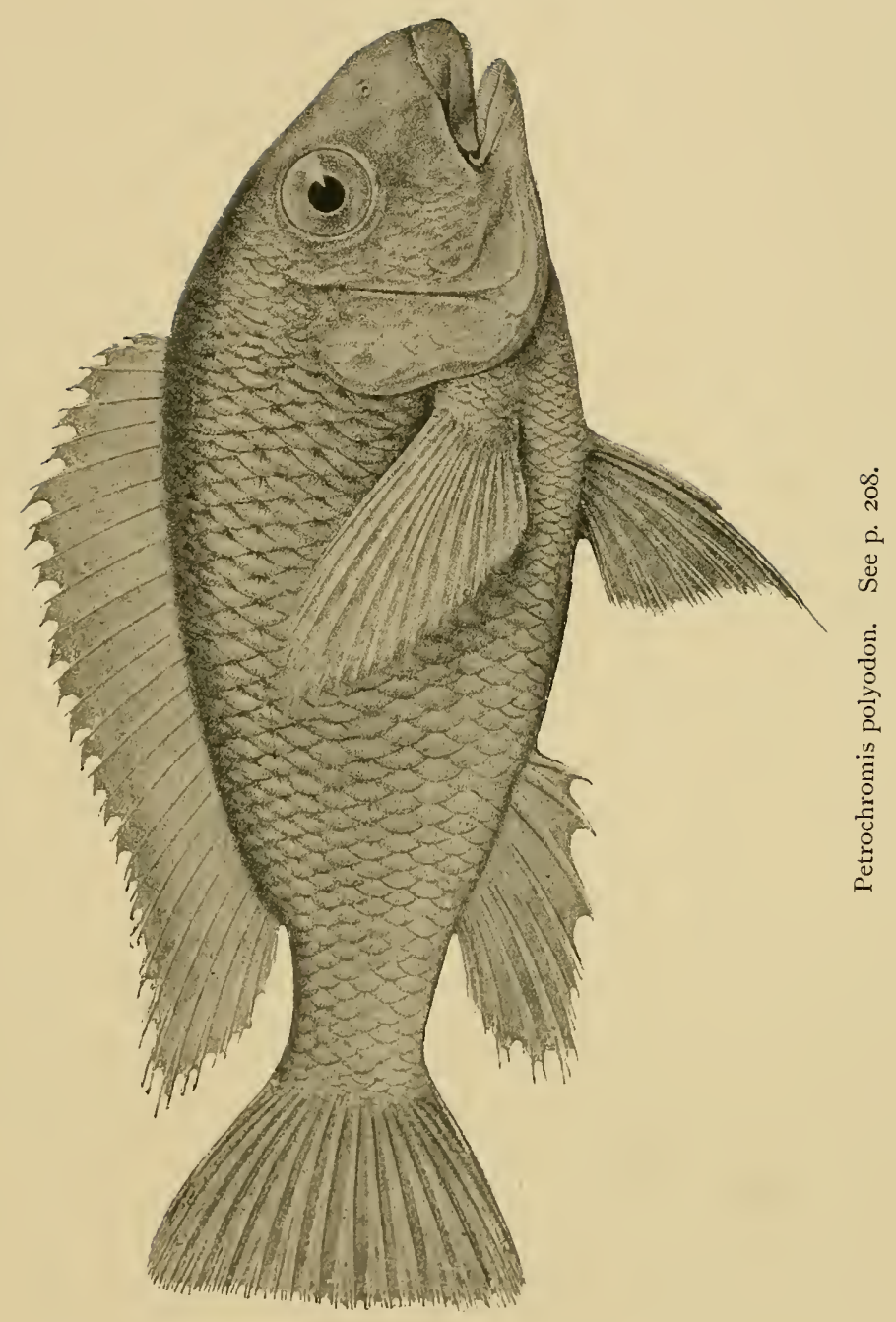


specimen, collected by Canon Tristram in the same lake. liut these eggss, proxluced ly fishes of the size of our common perch, are very numerous, and measure only ahout 2 millim in diameter. It has, lesides, been olserved in these Tilafic, as well as in the Situroids, that the function of protecting the eggre devolves on the mate sex, while, 10 my surprise, the Tanganyika fish proved on autopsy 10 be a female. Whether this is constantly so, or whether either parent takes to the nursing duties, remains to be ascertained loy examination of a larger number of specinens. I am all the more disposed to think the latter possilsility will be confirmed, from the fact that a specimen of Tilafia nilotica with the pharynx fitled with embryos lectongs to the female sex, white Dr. Lortet's olservations on $T$. simonis had led to the letief that specimens carrying egrgs in that manner are invariably males.

It is here necessary to recall the observation contained in Livingstone's "I ast Journals" (rol. ii. p. 17), that the "Dagala" or "Nsipé" of Lake Tanganyika, a small fish two or three inches long and very like whitebait, is said to emit egges by the mouth. The comparison of this fish to whiteluait excludes the possibility of the one here described being the "Dagala" or "Nsipé," which will probally prove to be a Cyprinodont, if not actually the Haplochilus tanganicamus described below.

65. Tropheus anneCtexs. - Blgr. 1900.

66. Simochromis magrama.-Gthr. I 893.

67. Tilapia Nilotica.-L. 1757.

68. Tilapia burtoni.-Gthr. i 893.

69. Tilapia HORII.-Cthr. I 893 .

70. Tilapia RUBropunctata.-Blgr. I 899. (Fig. facing p. 204.)

Teeth very small, in 4 or 5 series in loth jaws, outer bicuspicl, separated from the series of smalter tricuspid teeth ly a rather widle interspace. Depth of body 3 times in total length, length of head $2 \frac{2}{3}$. Snout, with straight upper profile, twice as long as diameter of eye, which is $4 \frac{1}{2}$ times in length of head and equals interorbital width; mouth large, ${ }_{3}^{3}$ width of head, extending to letween nostril and eye; a few deciduous scales on the cheek; large scales on the opercle. Gill-rakers short, rather slender, 12 or 13 on lower part of anterior arch. Dorsal XI. 9 ; spines equal in length from the sixth or seventh, measuring $\frac{1}{3}$ length of head and $\frac{2}{3}$ longest soft ray's. l'ectural oltusely pointed, $z$ length of head, not extending to origin of anal. Ventral reaching vent. Anal III. 7; third spine a little shorter than longest dorsals. Caudal truncate. Caudal peduncle as long as deep. Scales mostly cycloid, a few on the sides of the borly below the lateral line fincly denticulate, $32-33_{11-12}^{4-5}$; lat. $1 \frac{22}{12-13}$. Olive-trown above, pale yellow beneath; dark cross-bars on the back; each scale of the back and sides with a central vermilion spot; head spotted and marbled with dark purplish brown; lower jaw and lower part of opercular region bright yellow; dorsal and caudal fins bright 


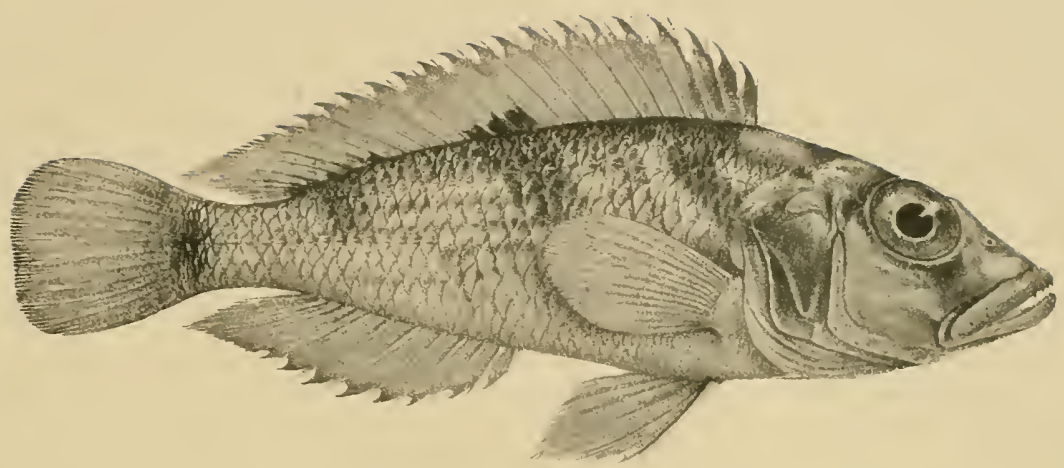

Lamprologus lemairii. See p. I7o.

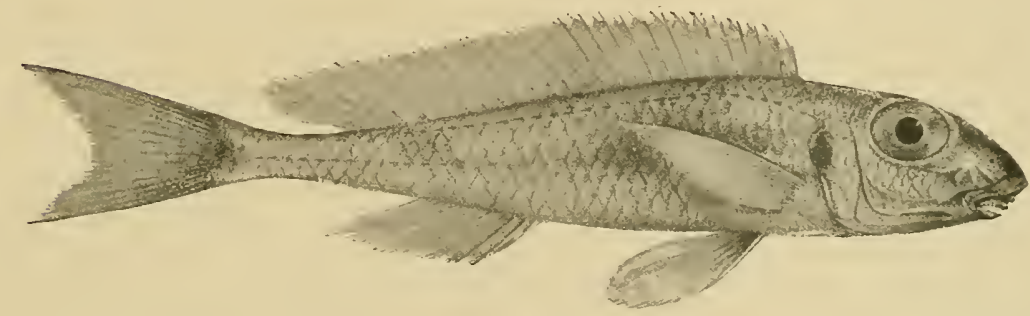

Asprotilapia leptura. See page 210.

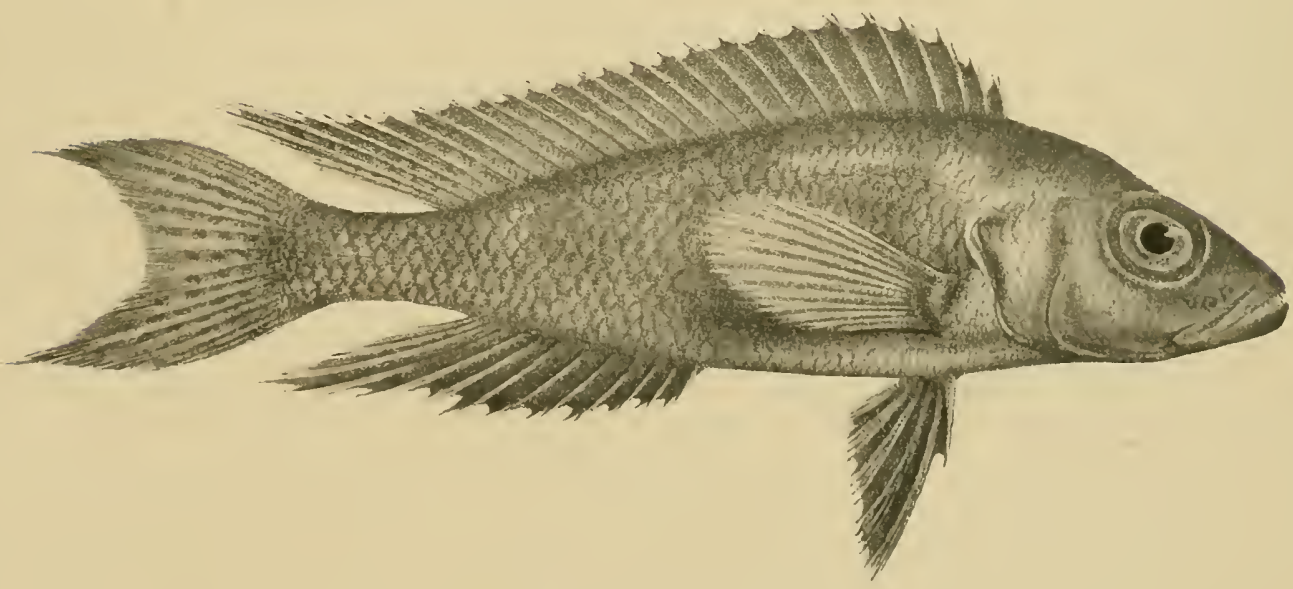

Lamprologus furcifer. See p. I74. 
yellow, spotted with dark lrown; pectoral yellow; branchiostegal incmbrane, pectoral region, outer edge of ventrals, and anal vermilion-red.

Total length, 120 millim.

Two specimens of this handsomely coloured fish, which bears the native name "Kasanga . Malengi," on .I. Dardenne's coloured sketch.

\section{Tilapia D.IRDExili. - Blgr. I 899. (Fig. facing p. 200.)}

Teeth very small, in 4 or 5 series in both jaws, outer licuspid, separated from the series of smaller tricuspid teeth by a rather wide interspace. 1)epth of loxly 3 to $3 \frac{1}{3}$ times in total length, length of head $3 \frac{1}{3}$ to $3 \frac{1}{2}$. Snout, with strongly curverl upper profile, little longer than the diameter of the eye, which is $3 \frac{1}{1}$ times in length of head and equal to or a little less than interorisital width; mouth small, s

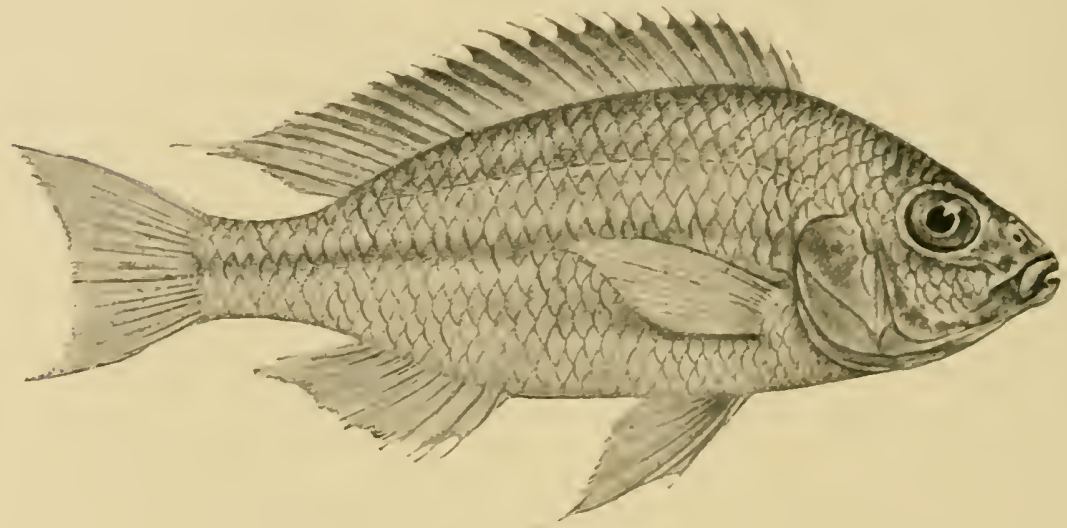

Tilapia pleurotaenia. See p. 202.

width of head, extending to letween nostril and eye; 5 or 6 series of scales on cheek; large scales on the opercle. Gill-rakers short and thick, I3 on lower part of anterior arch. Dorsal XIX. 10 ; sixth to ninth spines longest, not quite half length of head, a little shorter than longest soft rays. l'ectoral acutely pointed, as long as or slightly shorter than the head, not extending to origin of anal. Ventral reaching vent, or not quite so far. Anal III. 8; third spine as long as and much stronger than longest dorsals. Caudal feebly emarginate. Caudal peduncle $\mathrm{I}_{3}^{2}$, or $\mathrm{I}_{4}^{3}$ as long as deep. Scales, mostly ctenoid, $37 \frac{5}{\mathrm{II}}$; lat. I. $\begin{aligned} & 24-25 \\ & 17-19\end{aligned}$. Vellowish olive above, silvery beneath, with 10 or II dark dorsal cross-lars, the first letween the eyes; yellowish streaks along the scries of scales: fins yellowish, dorsal with some olive marblings, pectoral and anal red at the base.

Total length, I 55 millim.

Descrilsed from two specimens Native name, "Sangani." 


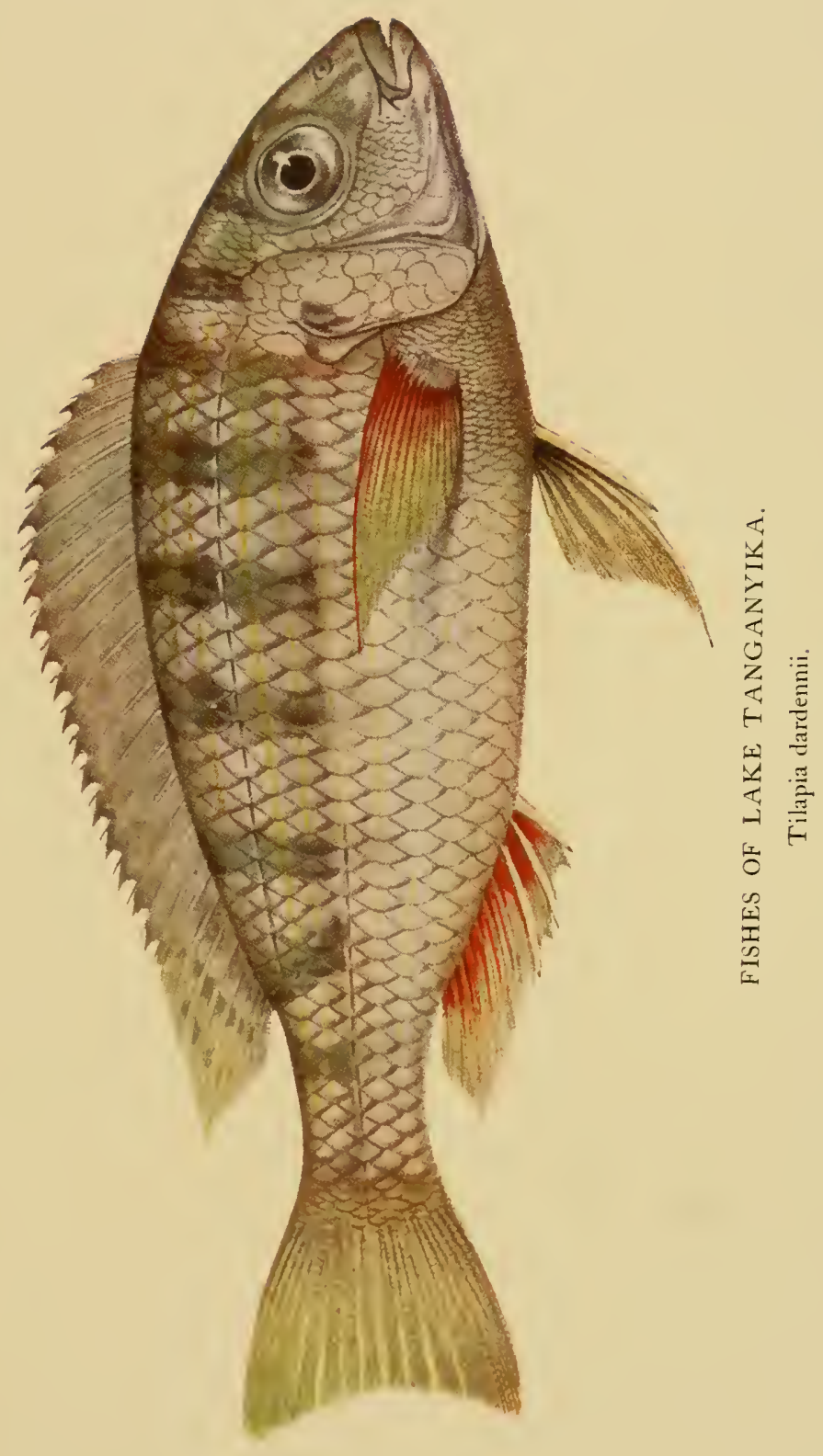





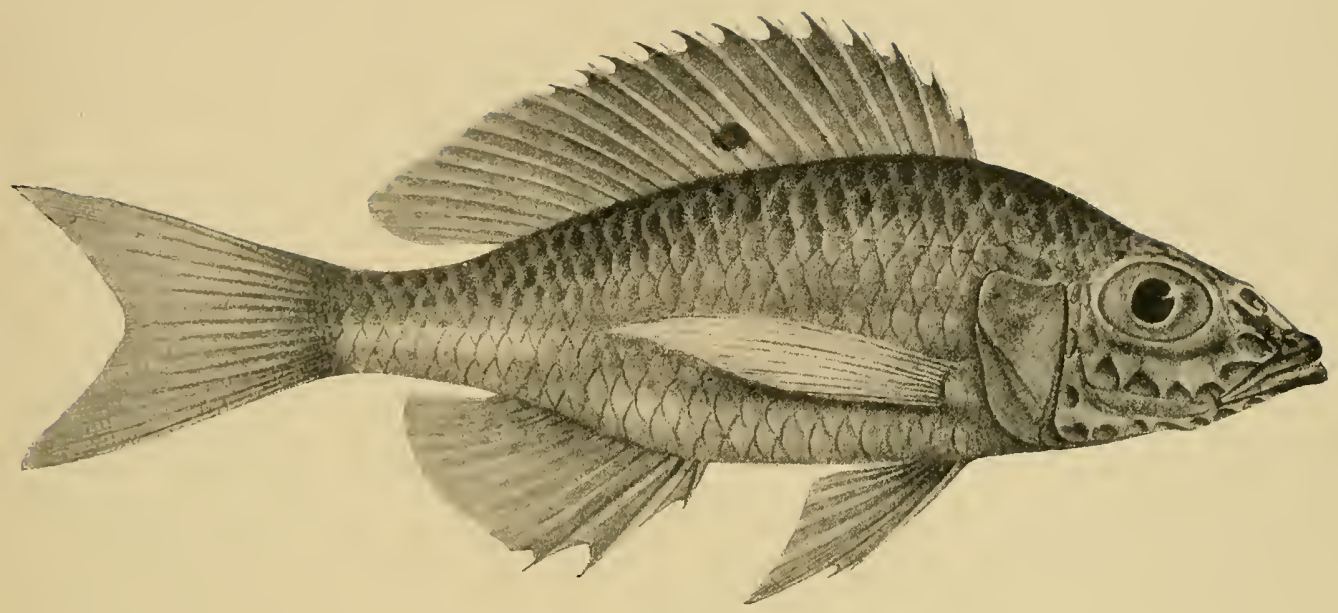

Trematocara unimaculatum. See p. 192.

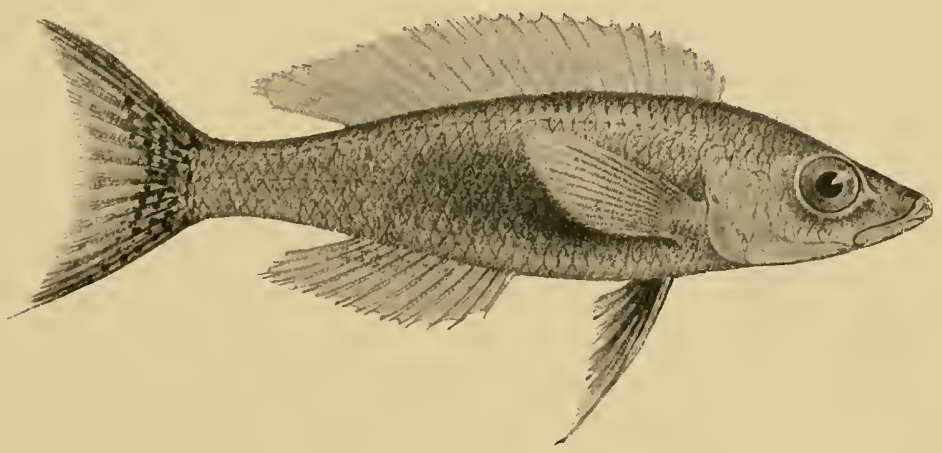

I'aratilapia leptosoma. See p. I82. 


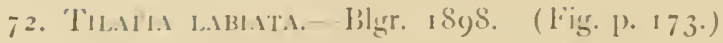

Outer teeth rather large, feelly notched; inner teeth very small, tricuspiel, in 3 or 4 series. Depth of borly equal to length of hearl, 23 to 2$\}$ times in total length. Snout, with straight upper profile, $1 \frac{1}{1} 10 \mathrm{~s}$ d diameter of eye, which in $3 \frac{1}{1}$ to 4 times in length of head and equals interurlital width: maxillary not extending to below anterior border of eye; 3 or 4 series of scales on the cheek; large scales on the opercle; lips very strongly developerl, both producerl into a large triangular lole in front. Gill-rakers moterate, 15 on lower part of anterior arch. Dorsal XVIII. IO; midklle dorsal spines longest, alout ${ }_{3}^{2}$ length of heal, and a little shorter than longest soft rays. I'ectoral ${ }_{6}^{3}$ to ${ }_{b}^{4}$ length of hearl. lentral reaching origin of anal. Anal III. 6-7; third spine longest, as long as longest dorsal, slightly shorter than longest soft rays. Caurlal truncate. Caurlal peduncle slightly longer than deep. Sicales fincly denticulate on the loorder, $33-35 \frac{5-6}{12-13}$; lat. 1. $\frac{22-25}{13-15}$. I'ale olive, with 10 more or less distinct darker cross-bars; fins of greyish brown; dorsal sometimes with ollique dark and light streaks; caudal with numerous round dark spots between the rays.

Total length, 170 millim.

Described from four specimens from Kinyamkolo.

This species is easily recognisalble by the extraordinary development of the lips, which bears a curious resemblance to that observed in the Central Imerican Ilicros labiatus. It appears to be nearest allied to Ctcnochromis nuchisyuamulatus, Hilg, and C. Sauvagii, I'feffer, froni the Victoria Nyanza.

\section{3. 'Tilapla plelrotaxil.-Plgr. igor. (Fig. p. 200.)}

Depth of body $2 \frac{1}{2}$ to 3 times in total length, length of head 3 to $3 !$ times. Snosut, with profile descending in a straight line, as long as the diameter of the cye, which is contained $3 \frac{1}{3}$ to $3 \frac{1}{3}$ times in length of head, and exceeds a little interocular width ; mouth small, its width half or a little more than half that of head, extending to lectsw nostril, or between nostril and eye ; teeth very small, in 3 series, outer licuspicl; 3 or 4 series of scales on cheek. Gill-rakers short, Io to 12 on lower part of anterior arch. IOorsal XV.XIII. II-12; last spine longest, a little less than half length of head; longest soft rays ${ }_{3 j}^{2}$ length of head. I'ectoral pointed, a little shorter than the head, not quite reaching origin of anal. Anal III. S-10; thirr spine a little shorter than last dorsal spine. Caudal deeply notched and crescentic. Caudal peduncle $1 \frac{1}{2}$ as long as deep. Scales very thin, without denticulation, $32-35 \frac{4}{\text { I1 }-12}$; lat. 1. $\begin{aligned} & 22-24 \\ & 10-15\end{aligned}$ Pale brown alove, white beneath; a blachish lateral stripe, from the opercle to the caudal ; fins greyish; small, round, white spots on soft dorsal and caudal.

Total length, I 10 millim.

Describer from several specimens from the north end of Lake Tanganyika, and from the mouth of the Kusisi River. 



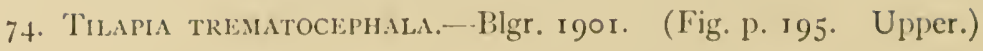

Depth of body equal to length of head, 3: times in total length. Snout, with slightly convex upper profile, a little shorter than cliameter of eye, which is contained 3 times in length of head and exceeds interncular width; mouth small, its width half that of head, extending to between nostril and eye ; teeth very small, in 2 rows, outer bicuspid; 3 series of scales on the check: large scales on the opercle; orifices of sensory canals on head remarkably large. Gill-rakers rather short, 13 on lower part of anterior arch. Dorsal XVI. I1 ; last spine lungest, half length of head: longest soft rays produced into filaments, half length of head. l'ectoral pointed, 3 length of head, not reaching origin of anal. V'entral produced into a filament, extending leyond origin of anal. Anal III. 9; third spine as long as

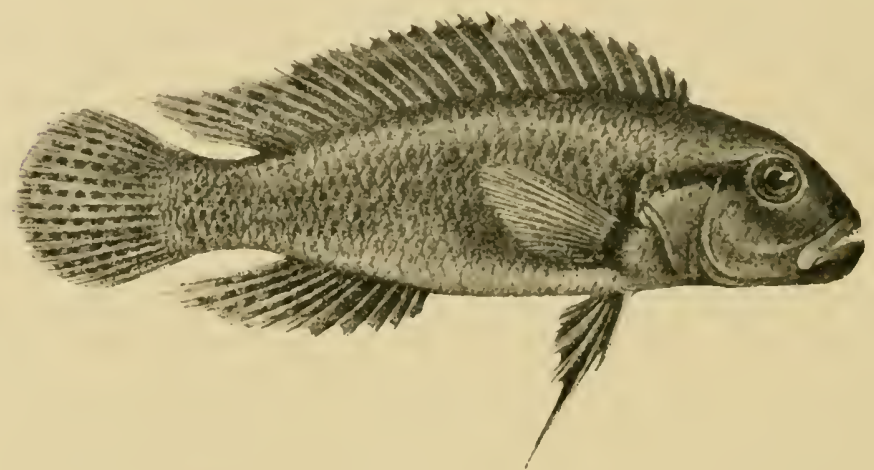

- Telmatochromis temporalis. See p. 194.

and stronger than last dorsal spine: some of the soft rays produced into filaments as in the dorsal. Caudal deeply emarginate. Caudal peduncle $i_{2}^{\frac{1}{2}}$ as long as deep. Scales very thin, without denticulation, $40 \frac{3}{10}$; lat. $1 . \frac{2 S}{\text { ? }}$. Brownish, dorsal and caudal greyish; rentrals and anal black, latter edged with white.

Total length, 90 millim.

Described from a single specimen from the north end of Lake Tanganyika.

\section{Tilapia boops.-Blgr. I901. (Fig. 3, P. I 75.)}

Depth of body equal to length of head, $3 \frac{1}{1}$ to $3 \frac{1}{3}$ times in total length. Snout with strongly convex upper profile, shorter than diameter of eye, which is 2 t times in length of head, and exceeds a little interocular width; mouth $\frac{2}{3}$ width of head, sub-inferior, not extending quite to below anterior border of eye; teeth very small, 

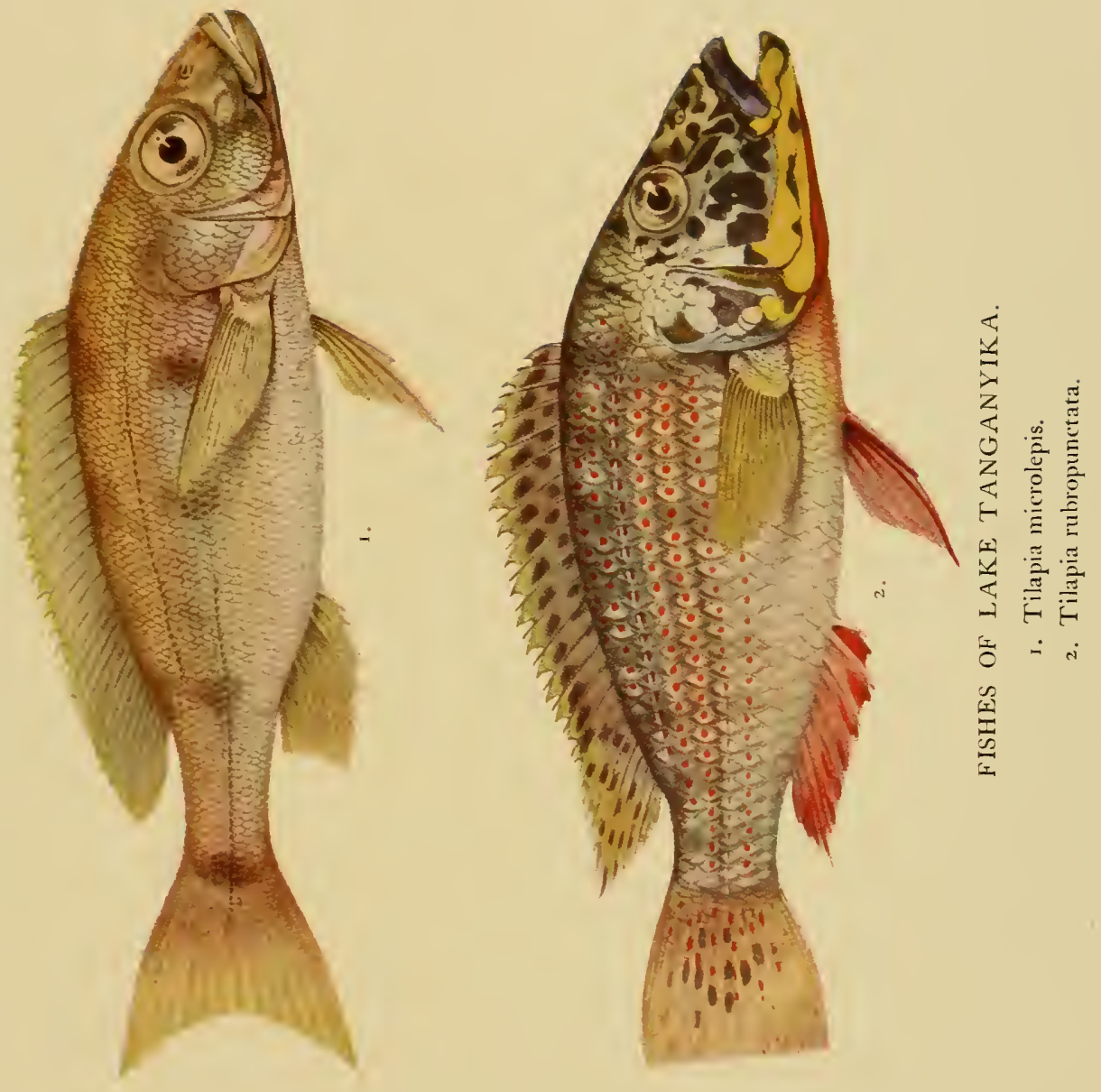



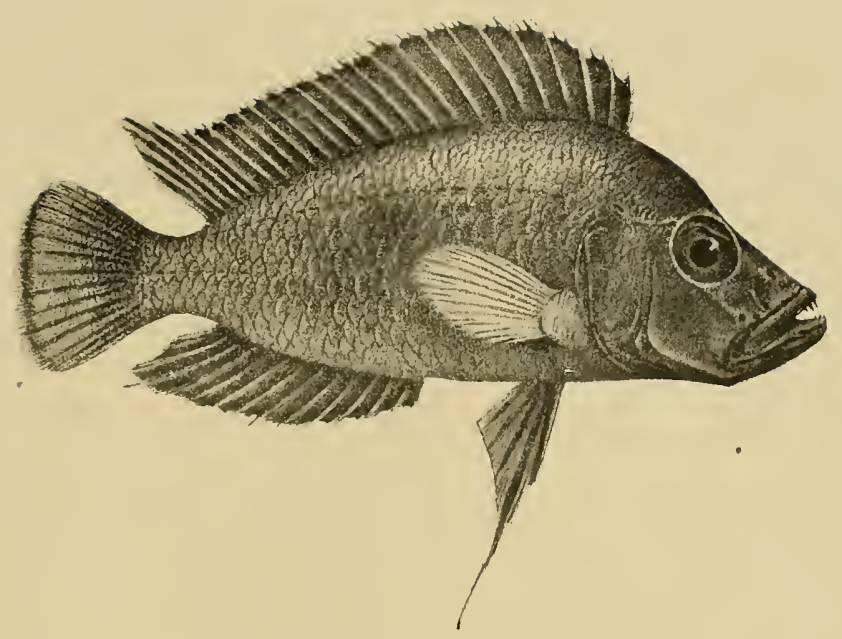

Lamprologus compressiceps. See p. I72.

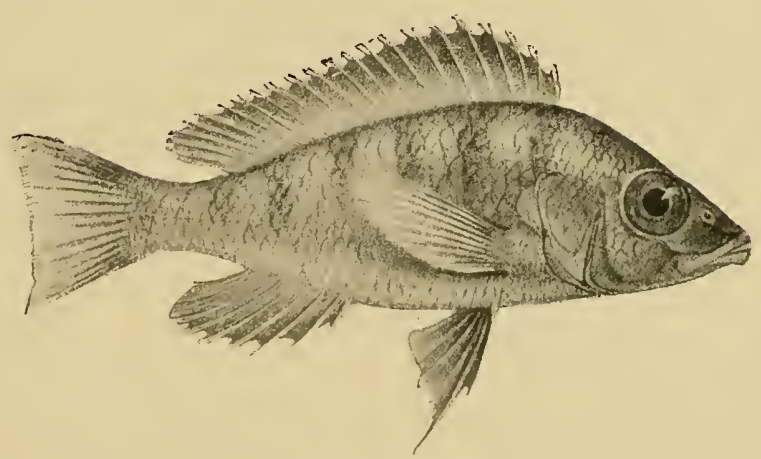

Paratilapia pfefferi. See p. 178.

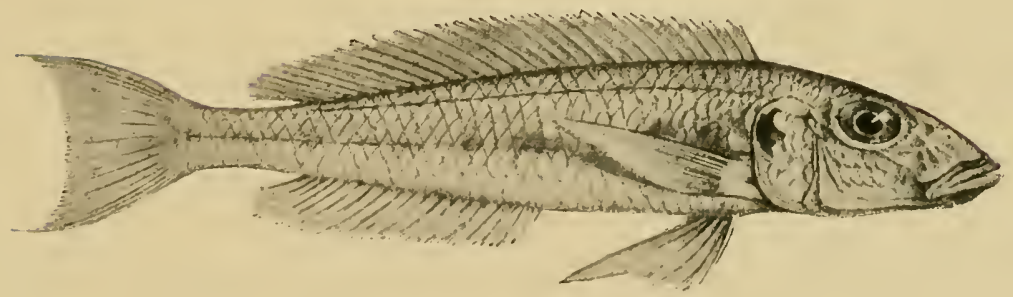

Ectodus longianalis. Sce p. 188.

Another specimen figured on p. 175 . 
tricuspid, in 3 rows; 2 or 3 series of scales on the cheek: large scales on the opercle. Gill-rakers short, I 3 on lower portion of anterior arch. Iorsal XII. .XIII. I4 ; spines slender, equal from the seventh, which measures nearly 1 length of head : soft rays scarcely longer. l'ectoral pointed, as long as head, reaching origin of anal. Ventral produced into a filament, extending lecyond origin of anal. Anal III. S-9; third spine as long as and stronger than longest dorsal spines. Caudal deeply emarginate, crescentic. Caudal peduncle nearly twice as long as deep. Scales thin, without denticulation, $39-40 \frac{5}{14-15}$; lat. I $\frac{34-35}{15-19}$. Brown aluse, white beneath; a blackish opercular spot.

Total length, go millim.

Described from two specimens from .1/ sambu.

\section{Tilapia Grandoculis. -Blgr. I \$99. (Fig. p. I93. Lower.)}

Teeth very small, in 4 or 5 series in both jaws, of outer series larger, bi- or tricuspid, and very obtuse. Depth of body $33^{3}$ times in total length, length of head 3 . Snout short, with rounded upper profile; eje very large, a little longer than the snout, its diameter $2 \frac{1}{2}$ in length of head, and slightly greater than the interorbital width; mouth small, $\frac{1}{2}$ width of head, extending to between nostril and eye ; a few deciduous scales on the cheek; larger scales on the opercle. Gill-rakers very short, rather thick, 17 on lower part of anterior arch. Dorsal XIII. 14: spines slender, equal in length from seventh, measuring ${ }_{3}^{2}$ length of head, and a little shorter than longest soft rays. Pectoral falciform, slightly longer than the head, extending as far as origin of anal. Ventral prolonged in a long filament extending lecyond origin of anal. Anal III. IO; third spine shorter lut stronger than longest dorsals. Caudal with deep crescentic notch. Caudal peduncle a little longer than deep. Scales mostly ctenoid, $63 \frac{?}{25}$; lat. I $\frac{58-60}{32-36}$. Brown almwe, with ill-defined darker spots, whitish beneath; pectorals yellowish; other fins blackish towards the edge.

Total length, i15 millim.

Described from a single specimen.

\section{Tilapia microlepis.-Blgr. i 899 . (Fig. facing p. 204.)}

Teeth very small, in 4 series close together in both jaws, outer larger, biscupicl, with a principal and a small lateral cusp. Depth of body $3 \dot{j}$ to 4 times in total length, length of head 3. Snout, with straight or slightly comvex upper profile, If the diameter of the eye, which is nearly 4 times in length of head and equals interorbital width; mouth moderate, its width ${ }_{5}^{8}$ that of the head, extending to letween nostril and eye; 7 or 8 rows of scales on the cheek; larger scales on the opercle. Gill-rakers short, rather thick, 13 or 14 on lower part of anterior arch. Dorsal XVI.-XVII. 14-I5; spines sub-equal in length from the fifth or sixth, measuring $\mathrm{I}_{3}^{1}$ length of head and a little shorter than longest soft rays. P'cctoral acutely pointed, $\frac{3}{4}$ length of head, not extending to origin of anal. lentral widely separated from vent. Anal III. 9; third spine as long as and a little strongrer than 


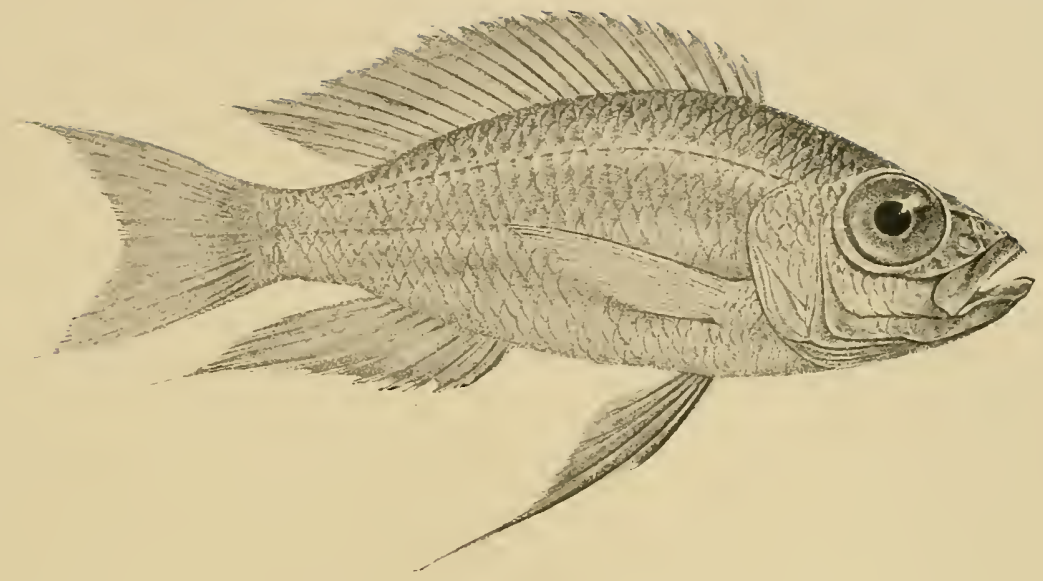

Paratilapia dewindti. See p. I80.

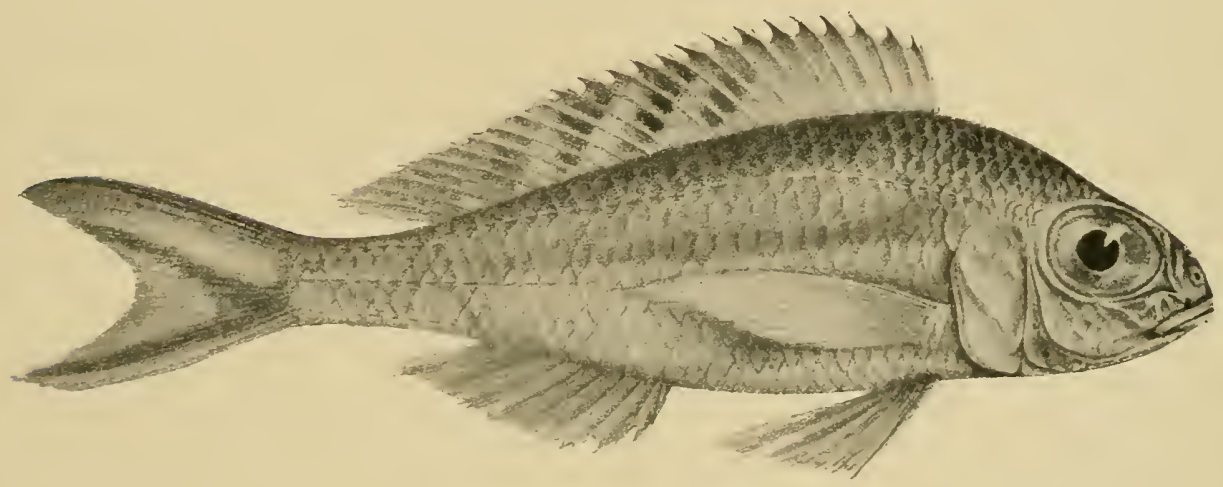

Xenotilapia ornatipinnis. See p. 190.

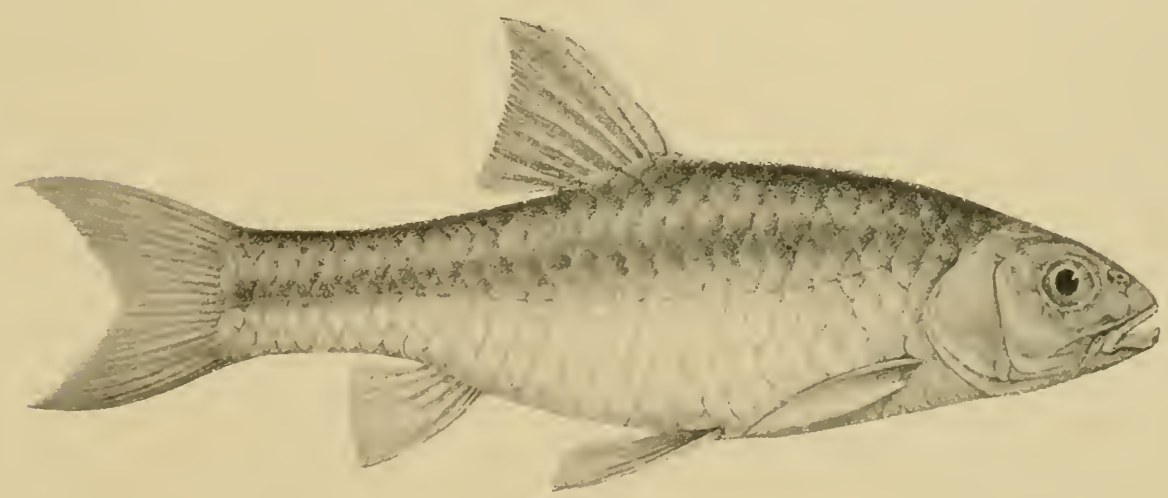

Bartus serrifer. See p. I5s. 
the longest dorsals. Caudal with deep crescentic notch. Caudal peduncle twice as long as deep. Scales cycloid, So-90 $\frac{10}{29-30}$; lat. $1 \frac{46-49}{38-42^{\circ}}$. l'ale olive-brown above, white below; faint dark luars across the lack and four round diurk spets on each side, the last at the rout of the caudal ; fins yelluwish.

Total length, 1 is millim.
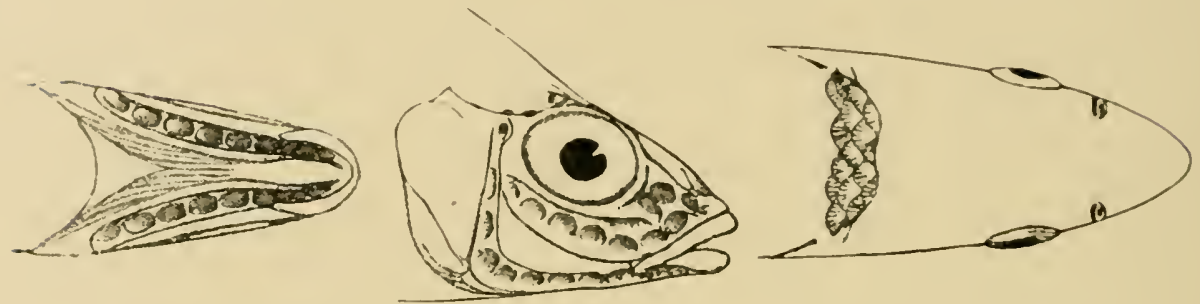

Described from two specimens. Native name, "Mocupi."

As in Tilapia desfontainesi, the dentition of this species may be regarded as connecting Tilapia with P'aratilapia.

\section{Petrochromis polyodon.-Blgr. i 898 . (Fig. p. i 97.)}

Crowns of teeth brown. Depth of body $2 \frac{1}{2}$ to $2 \frac{2}{3}$ times in total length, length of head $2 \frac{3}{4}$ to 3 times. Snout, with convex upper profile, $1 \frac{1}{2}$ to $I_{3}^{2}$ diameter of eye,

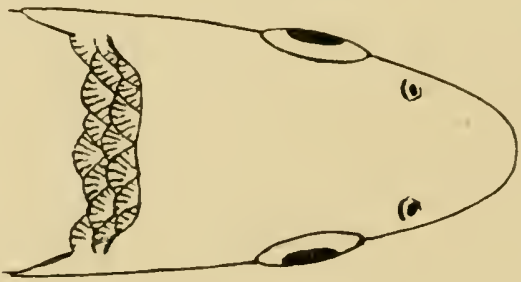

Barilius moorii. See p. 158.

which is 4 to $4^{\frac{1}{2}}$ times in length of head and $1 \frac{1}{2}$ in interorbital width; mouth hardly extending to below anterior border of eye ; 4 or 5 series of scales on the cheek; large scales on the opercle. Gill-rakers very short, 12 or 13 on lower part of anterior arch. Dorsal XVII.-NVIII. 8-9; spines increasing in length to the sixth or seventh, which measures about $\frac{2}{3}$ length of head; longest soft rays s ${ }_{b}^{8}$ to $\frac{2}{3}$ length of head l'ectural nearly as long as head. Ventral reaching vent or origin of anal. 


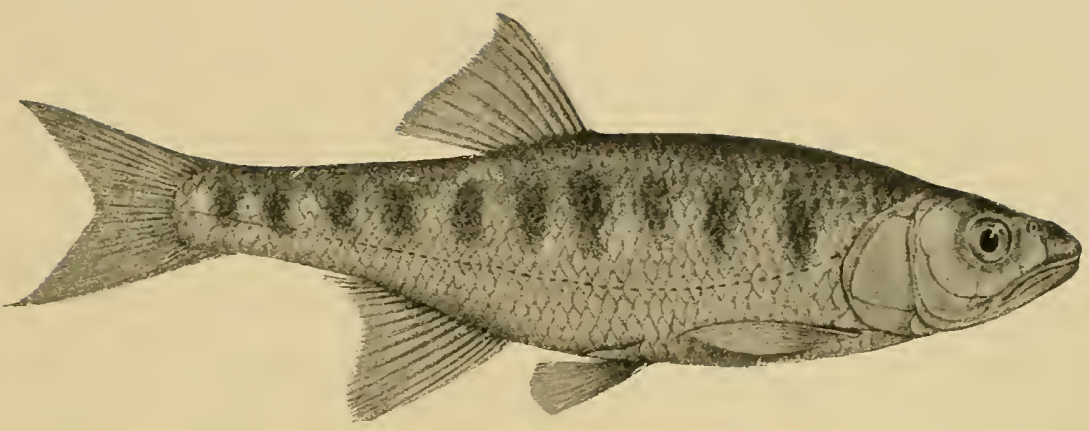

Barilius moorii. See p. I5S.

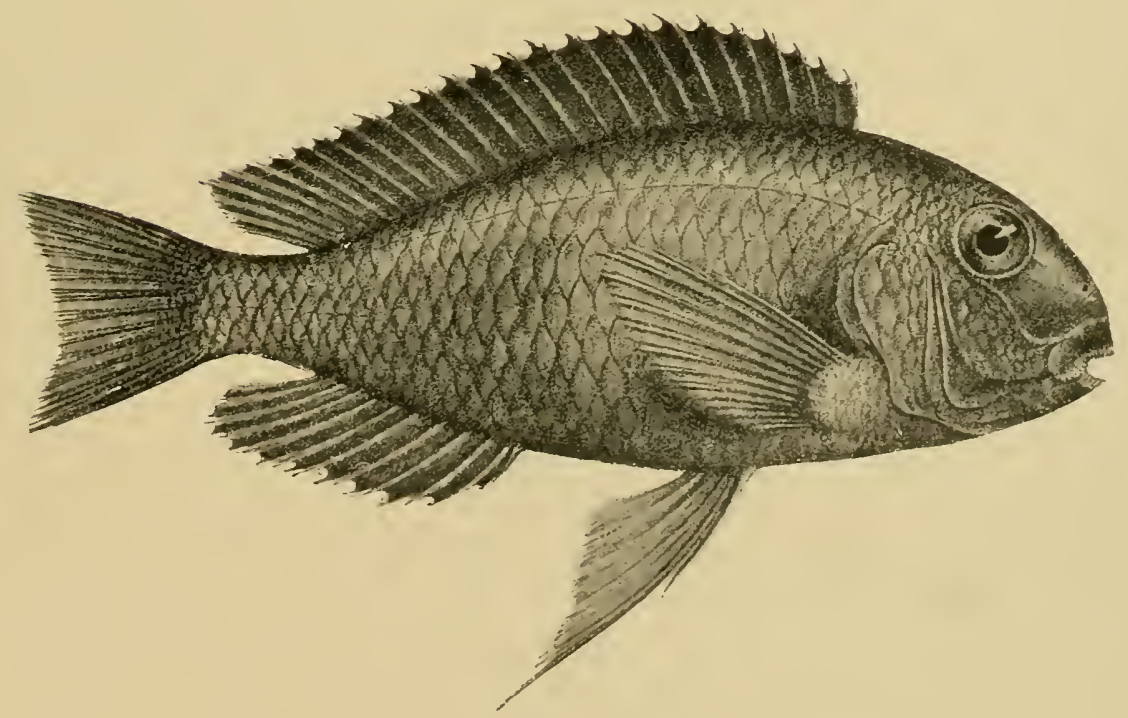

Tropheus moorii. See p. 196. 
Anal III. 7-S; third spine longest, as long as longest dorsal. Caudal truncate. Caudal peduncle as long as deep. Scales $32-34 \begin{gathered}3-4 \\ 12-13\end{gathered}$; lat. $1 \begin{aligned} & 22-24 \\ & 13-17^{7}\end{aligned}$ Olivebrown, whitish beneath; fins grey or blackish.

Total length, 135 millim.

Described from two specimens from Kiny:amkolo, and two from Ilbity Rocks.

The promaxillary and mandilular bones are very massive, and the maxillary is much reduced in size; the ascending processes of the pramaxillaries extencl to between the anterior borders of the orbits and are received in a deep excaration, (1) which the strong occipital crest extends; the parietal crests are produced forwarels as far as the frontals; the preorbital is large, and the chain of suborhitals very slender. Only the first rib is absolutely sessile, the following being attached to the back of the transierse processes at a short distance from the centre; the epipleurats extend to the twelfth rib; the last two pricaudal vertebre form a hamal loridge.

79. Petrochromis taxginic.t,-Cithr. i $S_{93}$.

\section{So. Asprotilapa leptura. - Blgr. i90i. (Fig. p. 199. Middle.)}

Body rather feelbly compressed, its depth 5 times in total length; length of hearl 4 times in total length. Snout sub-conical, strongly projecting beyond the mouth, its length $\frac{1}{3}$ that of the head; eye very large, its diameter equal to length of snout and nearly twice interorbital width, $2_{5}^{3}$ times in length of head; width of mouth ${ }_{b}^{3}$ that of head; 36 teeth in suter row of upper jaw; 3 series of small scales on the clieek; larger scales on the opercle. Gill-rakers very short; tulsercle-like 15 on lower part of anterior arch. Dorsal XIV. 12 ; spines slender and sub-equal, ${ }_{b}^{2}$ length of head, soft rays a little longer. l'ectoral pointed, a little shorter than head. Ventral reaching vent. Anal III. S ; third spine nearly as long as dorsals. Caudlal deeply emarginate, crescentic. Caudal peduncle 3 times as long as deep. Sicales strongly denticulate, $3^{S} \frac{2}{11}$; lat. I. $\frac{27}{20}$. Brown, darker on the snout and vertex; a blackish opercular spot; fins greyish.

Total length, 95 millim.

Described from a single specimen from .1/sambu.

\section{Si. Eretuodus cranostictus.-Blegr. 1898 . (Fig. p. i 87 . Upper.)}

Eight or to transwerse series of teeth in each jaw, the crowns reddish brown. Depth of lody equal to length of head, 3 times in total length. I'rofile of smout curved ; length of snout $1 \frac{1}{2}$ to twice diameter of eye, which is $4 \frac{1}{3}$ to 5 times in lengrth of head, and a little less than interorbital wicth; mouth extending to lectow nostril; cheeks and opercles naked. Gill-rakirs short, 9 or ro on lower part of anterior arch. Dorsal XXIII.-XXV. 3-5; spines sub-cyual from the sixth, $1 \frac{1}{3}$ length of head, a little shorter than soft ray's P'ectoral 3 length of head. lentral reaching rent. Anal III. 6-7; third spine longest, a little honger than dursals; soft rays 


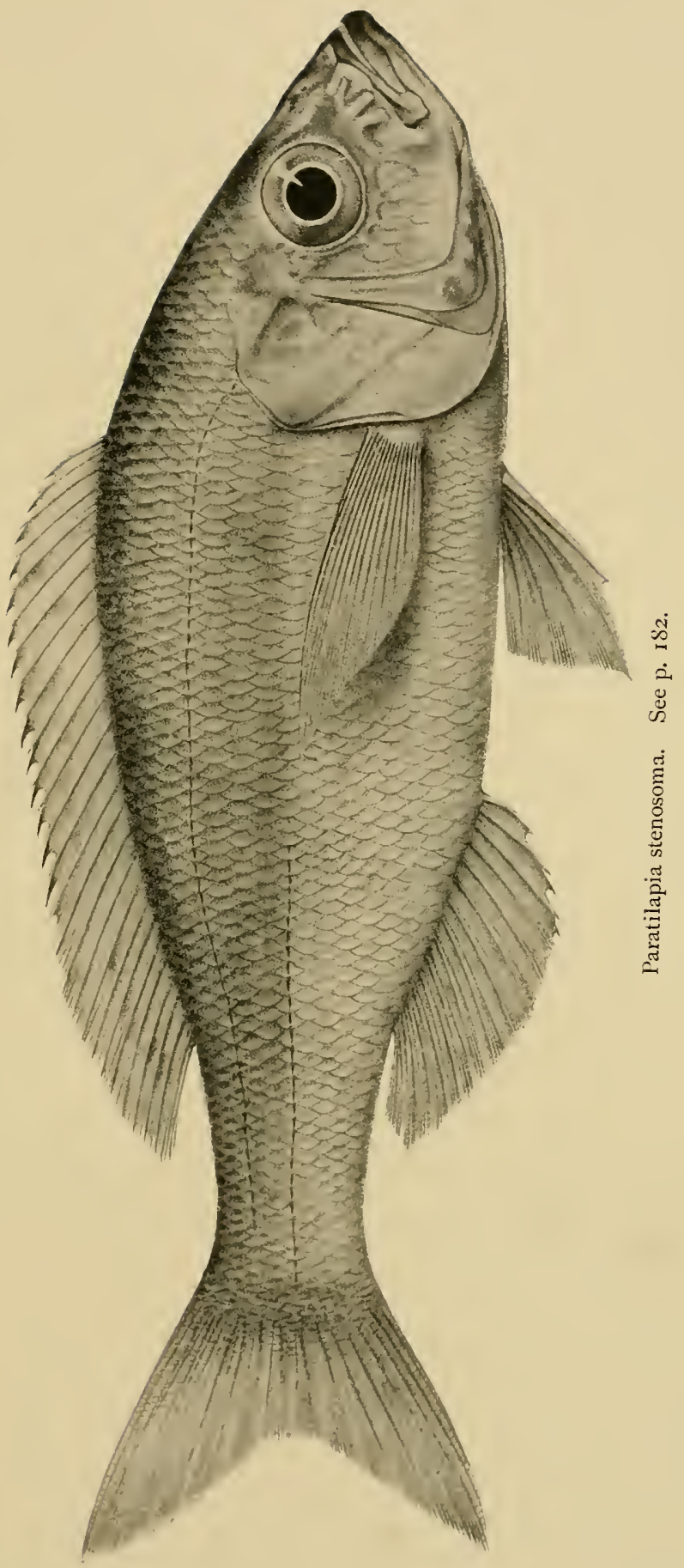


aloout ${ }_{3}^{2}$ length of head. Caudal rounded. Caudal perluncle deeper than Iong. Scales $32 \cdot 35 \frac{3}{11-12}$; lat. 1 $\frac{22-23}{6-9}$. 13lackish brown, with scattered pale blut dots ; belly yellowish.

Total length, 75 millim.

Described from five specimens from Mbity kocks and three from Kinyamkolo.

The toothed portions of the pramaxillary and mandible are much developed in depth, in a manner suggestive of the Sparide and Scaridie, and the teeth are implanted in sockets. The deep triangular groove for the reception of the presmaxillaries extends to between the orbits, and the occipital crest is prolonged to it ; the parietal crests are produced on the frontals; the preorlital is large, and the chain of suborbitals very slender. The pharyngeal teeth have long, slender shafts and conical brown cusps. The rilss are attached to the lack of sliort transverse processes ; all but the last one support epipleurals; the last four pricaudal vertcbra have a homal bridge.

\section{Spathodus ERIthrodon.-Blgr. rgoo.}

\section{Perissodus microlepis. - Blgr. is98. (Fig. P. 2i 3. Lower.)}

Ten teeth on each side of the premaxillary, 9 on each sicle of the mandil)le. Depth of body $2{ }_{3}^{2}$ times in total length, length of head $3 \frac{1}{1}$. Snout a little longer than diameter of eye, which is 4 times in length of head, and almost equals interurbital width; lower jaw projecting; maxillary extending to below anterior lorder of eye; 3 series of scales on the cheek; large scales on the opercle. Gill-rakers rather long, I 4 on lower part of anterior arch. Dorsal XVIII. IO; spines increasing in length to the last, which measures $I_{b}^{2}$ length of head; longest soft rays ? length of head. Pectoral ${ }_{4}^{3}$ length of head. Tentral not reaching vent. Anal III. $S$; third spine longest, nearly as long as longest dorsal ; longest soft rays half length of head. Caudal truncate. Caudal peduncle $1 \frac{1}{2}$ as long as deep. Scales $65 \frac{5}{20}$; lat. I 44 . Uniform dark reddish brown; a blackish opercular spot.

Total length, 100 millim.

Described from a single specimen from Mlbity Rocks.

\section{Xexochromis hecqui.-Blgr. 1899.}

Three specimens from Usambura. Grows to a length of 270 millim. D. XVI. XVII. IO-II ; A. III. 9-10; Sq. $64-67 \frac{6}{20}$; lat I $\begin{aligned} & 53-60 \\ & 35-43\end{aligned}$.

85. P'LECODUS PARADOXUS.-Plgr. i SqS.

D. XIX. I4; Anal III. 12. Depth of body 4 times in total length, length of head $4 \frac{1}{2}$ times. Eye large, longer than snout, $\frac{1}{3}$ length of head, $1 \frac{1}{1}$ interorlital width; maxillary extending to below anterior third of eye; 3 series of scales on the cheek. Sc. $65 . \frac{6}{17}$; lat. $1 \frac{50}{40}$.

Total length, 90 millim. 


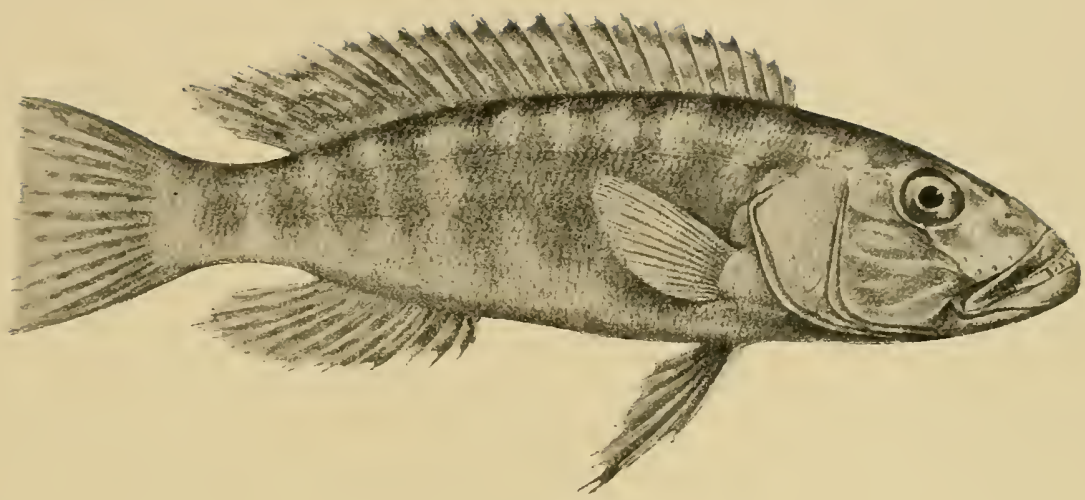

Lamprologus elongatus. See p. I68.

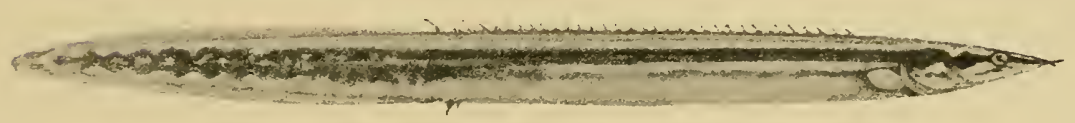

Mastacembelus tæniatus. See p. 216.

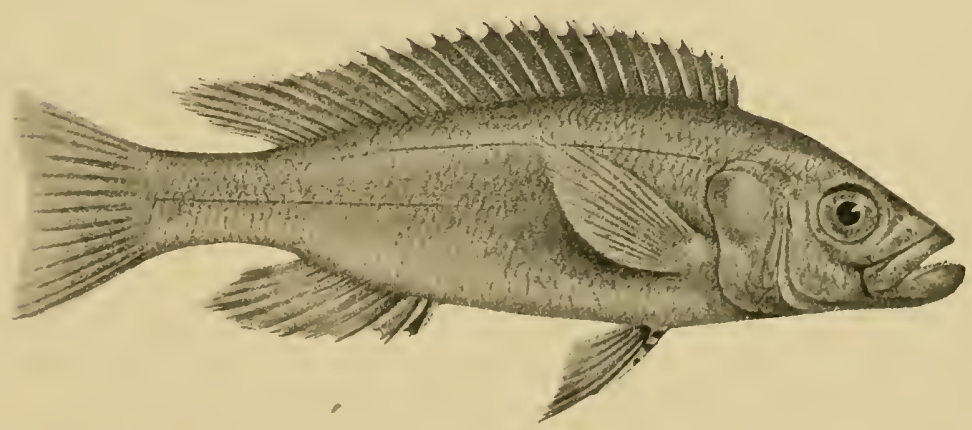

P'erissodus microlepis. See p. 212. 


\section{MASTACEMBEIIDE.}

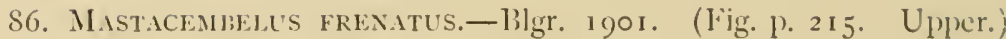

Depth of body $I_{3}$ times in total length, length of head $S_{3}^{2}$ times. Vent equally distant from end of snout and from caudal fin, separated from head lyy a space expal to $3 \frac{2}{3}$ times length of latter. Snout 3 times length of eye, producerl into a trifid appendlage, the length of which exceeds a little diameter of eye; luccal cleft extending to below anterior border of eye; no prapereular spines. Dorsal and anal confluent with caudal, which is short and rouncled; dorsal XVIII. 85; anal II-90; first spine very short, second I length of hearl; distance between first dorsal spine and head $\mathbf{I}_{3}^{2}$ times length of latter. Pectoral ? length of head. Scales extremely small, 22 between origin of dorsal and lateral line. Yellowish brown above, marbled with darker, yellowish beneath; a dark brown streak on each side of the head, passing through the eye; two brown hars across the caudal.

Total length, 250 millim.

Described from a single specimen, a female full of osa from the north end of Lake Tanganyika.

\section{S7. Mastacembelus MOORII. - Blgr. i $S_{9}$. (Fig. p. 215 . Lower.)}

Depth of body 14 times in total length, length of head (without rostral appendage) $6 \frac{1}{3}$ times; vent equally distant from end of snout and base of caudal; length of head $2 \frac{1}{3}$ to 3 times in its distance from rent, and $\frac{1}{2}$ in its distance from first dorsal spine. Snout 3 times as long as eye, ending in a trifid dermal appendage which is a little longer than eye ; cleft of mouth extending to below centre of eye : no preopercular spines. Vertical fins united with the rounded caudal. Dorsal I.IV.XXVII. 70-80; spines very short. Anal II. 70-80. l'ectoral t length of head. Scales very small, 30-35 between origin of soft dorsal and lateral line. Brown, tail with a wide-meshed blackish network; dorsal and anal whitish; with a vertical series of blackish spots or vertical bars; anal and caudal edged with blackish.

Total length, 440 millim.

Described from two specimens from Mbity Rocks.

This species has been compared with.$M$. marmoratus, Perugia, from the Congo, which differs in the more slender lxxly (its depth contained 20 times in the total length) with larger scales, the shorter tail, the longer rostral appendage (measuring twice the diameter of the eye), and the higher number (30) of dorsal spines.

S8. Mastacemialus eldipsifer.-Blgr. i $\$ 99$.

89. Mastacembelus Taxganice.-Ghrt, i 993. 

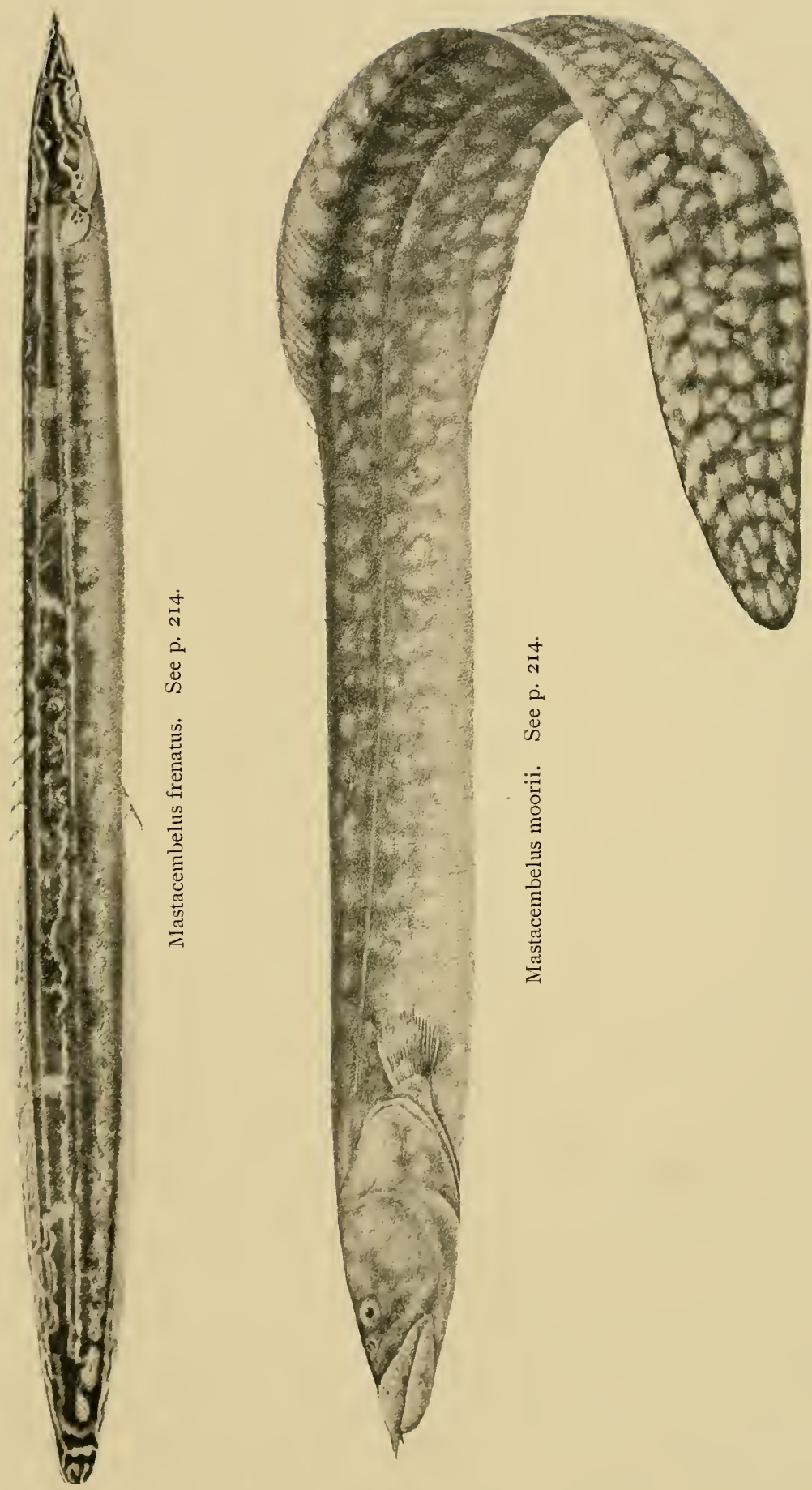

ป

i

\&

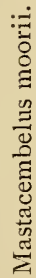


yo. Mastackmbeus texiatus.-Blgr. 1901. (Fig. 1) 213 . Middle.)

1)epth of borly 13 times in total length, length of hearl 6.t times. Vent expually; distant from head and from caudal fin, separated from head hy a space e(pual to 3 times length of latter; snout twice as long as eye, ending in a trifil appendage as long as latter; buccal cleft extending to leclow anterior burder of eye: no prixopercular spines. Dorsal and anal fins confluent with caudal, which is shrort and rounded; dorsal XXXIII. 85; anal I1. 85 ; first anal spine extremely slust, second as long as last dorsal. I'ectoral ! length of head. Scales extremely small, 25 between origin of dorsal and tateral line. Vellowish, a brown lateral land from the end of the snout, through the eye to the caudal region, where it widens, its borders become sinuous, and it bears some yellow spots.

Total length, 105 millim.

Described from a single specimen from north end of Lake Tanganyika.

91. Mastacemileus ophidium.-Gthr. I 893. 


\author{
CHAP'TER X. \\ THE FAUNA OF LAKE TANGANYIKA.
}

MOLLUSCA.

THE molluscan section of the fauna of Lake Tanganyika consists, as will have been seen from the lists given on

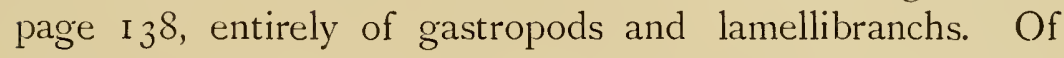
the latter group little can be said except that the number of distinct specific forms supposed to be related to the genus anio is somewhat remarkable.

The gastropods, on the other hand, form a series which is nowhere even simulated, much less repeated, in any of the other fresh-waters of the world. We find, however, upon consideration of the lists of forms, that a number of the Tanganyika gastropods belong to genera which we might expect to encounter in the fresh-waters of any of the continents. To this normal series belong the following specific types :-

Limnea debaizei Bgt.

Isidora coulboisi Bgt.

I'hysopsis africana Krauss.

, tanganyicie Marts.

Planorbis sudanicus Marts.

Ampullaria bridouxi ligt.

$$
\text { , ovata ()l. }
$$

Lanistes jouberti Bgt.

Vivipara trilirata Marts.

Cleopatra guillemei ligt.

Bithynia humerosa Marts.

Melania tuberculata Miill.

, tanganyicensis L. Sm.

, horei E. Sm.

The nature of the genera containing all the above species is at the present time quite well known to naturalists, 
and as their identification is sufficiently easy, it is unnecessary to enter here into a description of their specific representatives. It only remains to remark that, as is generally the case with the great African lakes, the normal fresh water molluses found in Tanganyika are in a specific sense distinct from the representatives of the same genera occurring in the neighbouring lakes. But besides these well-known forms, the lake also contains no fewer than it 4 individual gastropodean types which, when judged by their conchological characters, have appeared to be generically distinct. Thus we find already in the literature the names Typhobia, Bathanatia, Limnotrochus, Chytra, Paramclania, Bythocoras, Tanganyicia, Spekia, Nassopsis, Syrnolopsis, Stanley'a, and Neothauma, while there is no doubt that the unique form, Melania admirabilis (Fig. I) should be added to this list, for it is not only peculiar to the lake but conchologically indistinguishable from the form known as Cerithium subscalariforme, which occurs as a fossil in some of the marine Jurassic beds. In dealing with the molluscan section of the fauna of Lake Tanganyika we are thus confronted with a unique assemblage of molluscan forms all the members of which, so far as is at present known, are wholly restricted to the confines of the lake. Our first knowledge of the existence of this singular group in the lake dates back in its origin to some of the earliest explorations in the African interior. It was, in fact, Spelic, during Burton's celebrated expeclition to Tanganyika, who originaily picked up the shells of some of the above types on the beach, and two of these particular specimens, after finding their way into the British Muscum, were described by S. P. Woodward * under the titles of

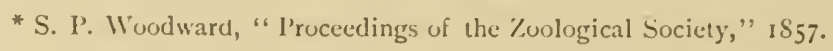


Nassopsis nassa, and Lithoglyphus zonatus, the first being supposed at the time to represent an aberrant form of the great tropical and sub-tropical family the $M e$ laniada. Although nothing whatever but the shell was in his hands at the time, Woodward went further than this in the determination of the relationships of these molluscs, relegating Nassopsis to the sub-genus of the Melaniada, Melanella. Subsequently, in $\mathrm{I} 880$, a much more extensive collection of shells was brought to England by the captain of the small steamer which the London
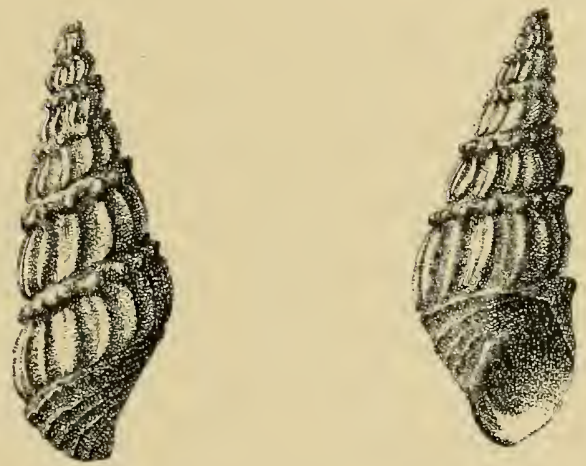

Fig. I.-Back and front view of the shell of Mclania admirabilis-Cerethium subscalariforme.

Missionary Society had put on the lake, and the still empty shells which were thus obtained were figured and described by Mr. Edgar Smith in I88r. Smith, like Woodward, drew attention to the extraordinarily marine aspect of these forms, specially pointing out the unique trochiform character of the shell of Limnotrochus, and the almost exact conchological identity which subsists between the shells of the Tanganyika Syrnolopsis and the marine genus Symola. Speaking of the curious marine appearance of these shells, Smith also drew attention to the 
conclusion at which Joseph Thomson had arrived concerning the past history of the Central African regrion round Tanganyika during his famous journeys, and suggested the possibility that when more was known about the animals which these new shells contained, we might have to regard the region as the site of some former extension of the sea.

The gastropod shells peculiar to Tanganyika, which were described by Smith, from the coliections of Coocle Hore, Thomson, and including those already described by IVoodward, were represented by the following generic forms:- Typhobia, Limnotrochus, Spcliar, Stanlcya, Tanganyicia, Nassopsis, Ncothauma and Mclania admirabilis. Through the collections made by the French missionaries and others, further varieties of these forms were subsequently added, and from the specimens which gradually accumulated in the Paris Museum, the conchologist, Bourguignat, described a very large number of new species and genera, but the characters which were used by this author as sufficient to define species and genera have not generally been held to be valid, even in a conchological sense; they throw no light on the matter in hand, and it is not necessary to discuss them further here.

In 1895 , when the first Tanganyika expedition started, our knowledge of the molluscan fauna of the lake had not advanced, we knew nothing of the anatomical characters of any of the animals belonging to the unique shells which the lake had been shown to contain, and consequently the purely conchological determination of their affinities was, as Smith frankly implied, to be considered, to a great extent, provisional. During the first Tanganyika expedition I obtained material for the complete anatomical study of the genera Typhobia, Limnotrochus, Neothauma, Spelia, 
Nassopsis, and Tanganyicia as well as for the two new and very striking genera to which I gave the names Bathanalia and Bythoceras. During the second Tanganyika expedition I obtained the material for the investigation of a further number of these forms, namely, Melania admirabilis, Chytra, Paramelania damoni, Paramelania crassigramulata, Stanleya, and a new species of the genus Bythoceras. No new generic forms were added during the second Tanganyika expedition, and I think it very

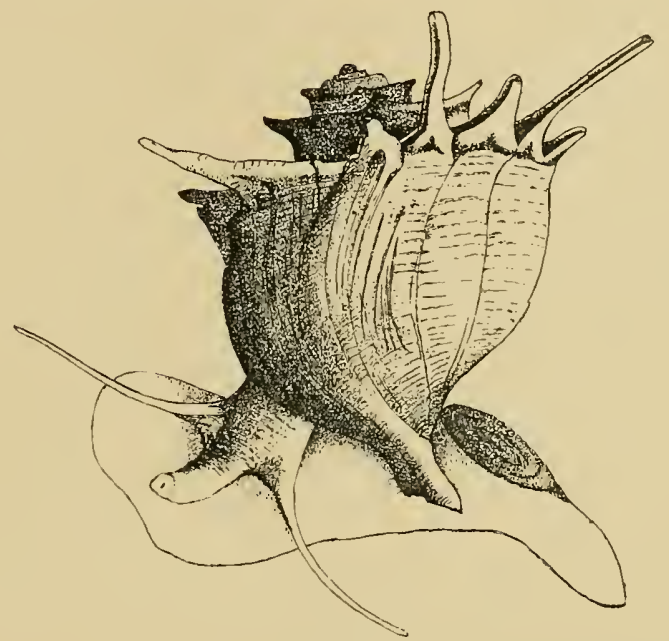

Fig. 2.-Living Typhobia horci.

doubtful whether any more will be obtained in the lake. At the present time, then, there remains only Symolopsis, the anatomical affinities of which cannot be clecided. Accounts of the anatomical characters of several of the halolimnic gastropods have already appeared by me in the Proceedings of the Royal Society, the Quarterly Journal of Microscopical Science, and in the Proceedings of the Zoological Society, but, owing to our departure in IS99 on the second Tanganyilia expedition, these lescriptions 
have not yet been completed, and I propose to treat the whole subject fully here. It is also intended that the descriptions of the anatomy and the conclusions respecting the affinities of the halolimnic gastropods given in this

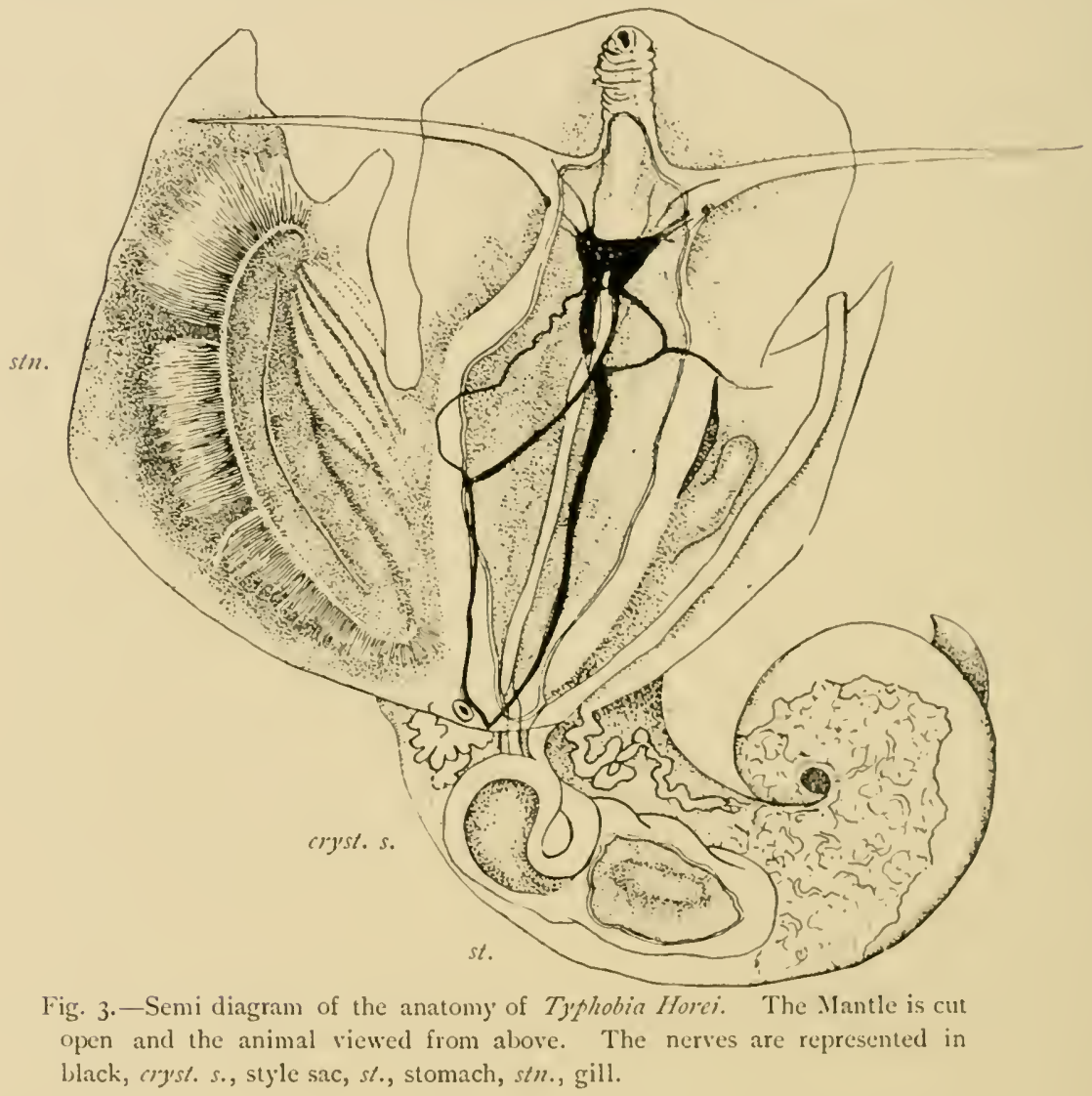

work shall be understood to supersede any others which I have already published. In what follows there will be found, in the first place, a description of the structure exhibited by each of the different halolimnic molluscs, and, in the second, a discussion of their affinities, based 
on what we now know about the prosobranchiate mollusca in general.

TIPHOBIA, SAITH.-T. HOREI (FIG. 2).

The genus Typhobia is represented solely by the unique form $T$. horei which occurs generally in the deep water of Tanganyika, in a hundred fathoms and upwards, and on the muddy portions of the floor of the lake. The animal which is of considerable size possesses the remarkable sheli represented on page $22 \mathrm{I}$, and the conchological characters

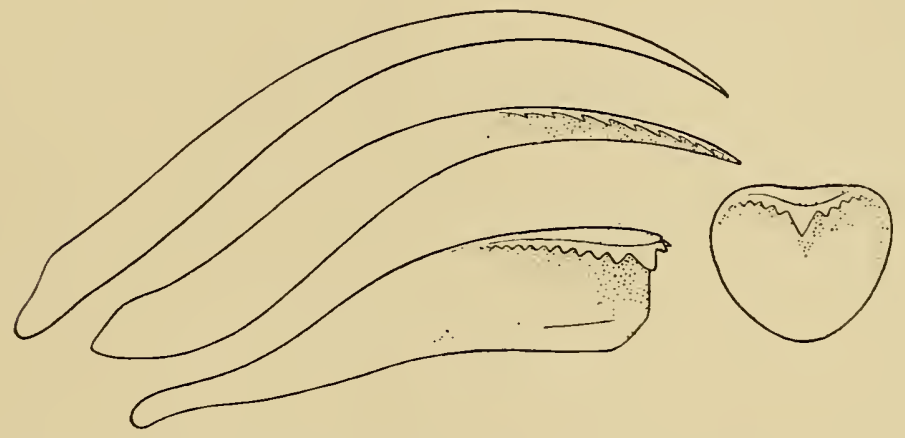

Fig. 4. - Lingual dentition of Typhobia horei. A single row of the teeth on the left side. ( $X$ I50.)

which different individuals display may vary widely. Typhobia, like all the remaining halolimnic gastropods is prosobranchiate, and the mantle cavity presents the same arrangement of the parts which is usually found in the less specialised Taenioglossa, Aporrhais for example. There is one gill (Stenidium) composed of simple triangular leaves and below this a long rope-like osphradium (Fig. 3). The renal aperture is at the extreme upper end of the mantle cavity, and the intestinal and reproductive apertures open on the right, and on the extreme front of the mantle 
skirt. The snout is short, wrinkled, and pigmented, and the eyes, which possess lenses, are situated on a long tapering tentacle on each side of the head. The buccal mass in Typliobia is not large, and the rasping teeth which are arranged in innumerable transverse rows on the tongue present the characteristic elements represented in Fig. 4.

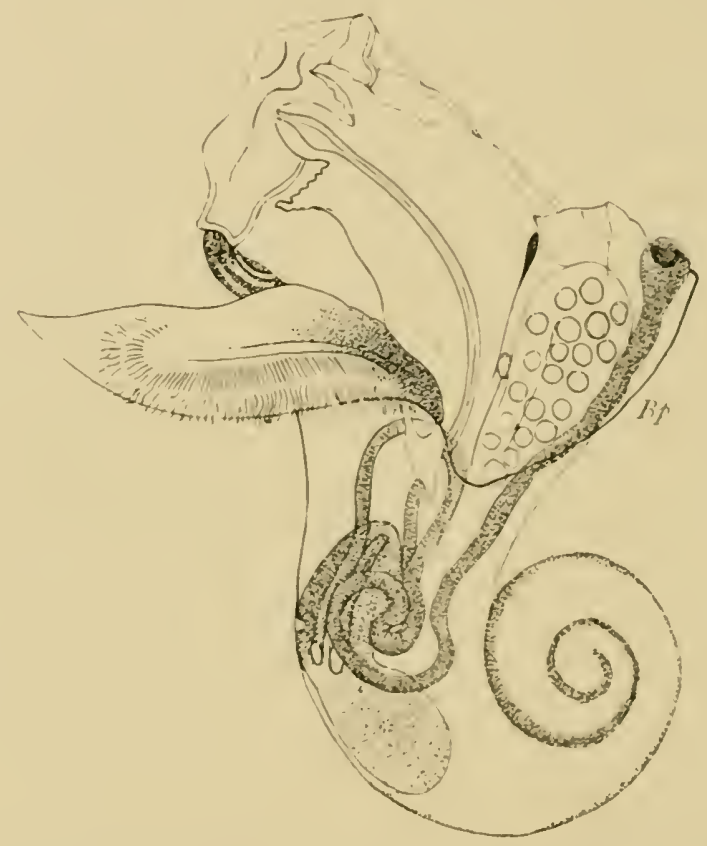

Fig. 5.-Seni diagram of the anatomy of Typhobia horci. The Mantle laid open and the digestive tube shaded.

The ova are seen in the brood pouch, $\mathrm{BP}$.

where the lateral teeth on the left side, and the median tooth are shown. Following the alimentary canal, the buccal mass is succeeded by a long narrow asophagus, which receives the ducts from two very simple, pouch-like: salivary glands, and passes quite straight back into the stomach. The stomach in Typhobia is very characteristic 
and interesting, being divided into an anterior and a posterior chamber. The osophagus enters on the left almost at the constriction which separates these two stomachic chambers, the intestine leaving from the same region below. The posterior chamber of the stomach contains a large valvular fold, and the bile-duct opens into it from beneath. The walls of the posterior stomachic chamber, like those of most gastropods, are thin, but beyond the

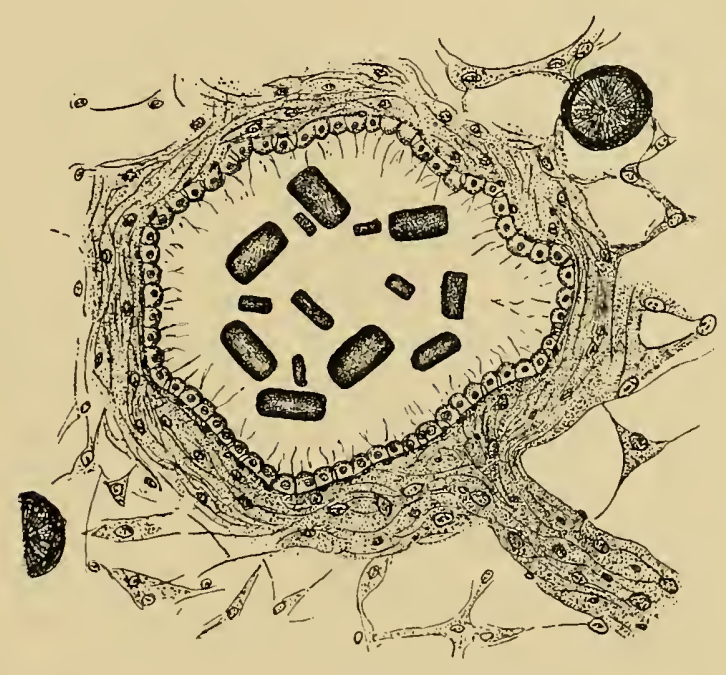

Fig. 6.-Section of one of the otocysts of Typhobia horei $(\times 206)$.

constriction which separates the two stomachic chambers one from another, the walls of the anterior chamber are found to be very thick, and the chamber itself contains a long, clear, transparent body, loose in the cavity, the so-called crystalline style. The kidncy is situated behind and around the heart, and the digestive gland occupies the greater part of the space in the upper coils of the body. The heart consists of an auricle receiving 
the blood from the gill, and a muscular ventricle, which is connected with a typical posterior and anterior aortic trunk.

In Typhobia, the nerves are arranged on the plan presented in such well-known types as Cerithium and Strombus, both the cerebral and pleural ganglia are all above the œsophagus, and are closely applied together (Iiig. 3). The cerebro-pedal and pleuro-pedal cords are of medium length. The pedal ganglia are rather long and cord-

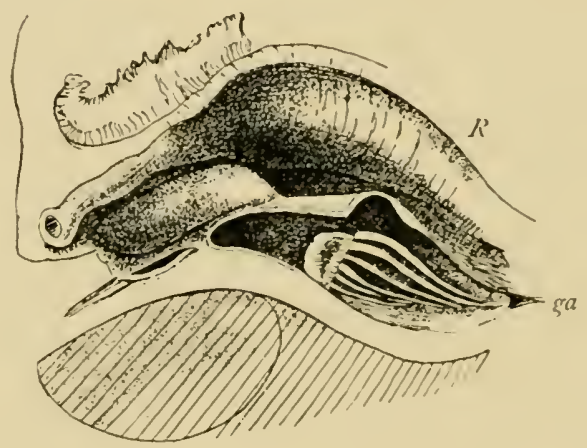

Fig. 7.-Part of the mantle cavity of Typhotia horei, showing the rectum $\left(K^{2}\right)$ and the genital duct in the male (g.a.).

like, and are connected together by some ladder-like connections. The otocysts (Fig. 6) are large, and the otocyst nerves very short; the otocysts being, in consequence, very high up in the head. The otoliths are numerous and each shaped like a barrel. In Typhobia, as in Cerithium and Vermctus, the subintestinal ganglion has become approximated to the left pleural, while the supra-intestinal ganglion and its cord spring from the right pleural, both retaining their usual 
characteristics. There is a secondary connection between nerves springing from the supra-intestinal ganglion and the left pleural, so that the animal is what has been termed dyaloneurous on the left, and I have lately found that in some specimens a similar dyaloneurous connection can be
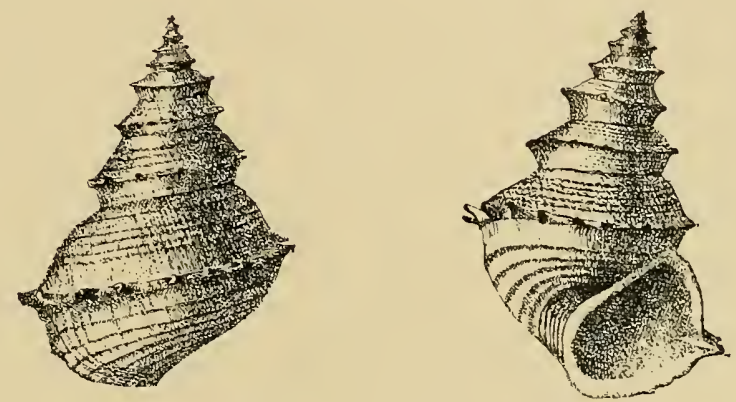

Fig. 8. - Back and front view of Bathanalia howesii.

traced on the right. The animal is viviparous, and the genital gland occupies the upper surface of the terminal body coils, resting upon the liver. The sexes are distinct, and in the male there are two forms of spermatozoa, as in Murex and Vivipara. The genital duct is, in both cases,

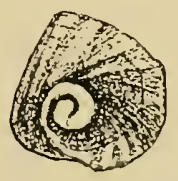

Fig. 9.-Operculum of Bathanalia howesii.

not much coiled; in the male, it runs along the angle between the right side of the mantle and the body. Near its extremity (Fig. 3) it is connected with, and surmounted by, a hollow muscular organ and then opens by a large slit-like aperture just beneath the anus. In the 
female that portion of the genital duct which lies within the mantle cavity is dilated so as to form a large broad pouch, in which the ova go through their later stages of development. (Fig. 5).

\section{BATHANALIA, MOORE,-B. HOWESII (FIG. 8).}

The remarkable form to which I gave the name Bathanalia howesii is also an inhabitant of the deep water of

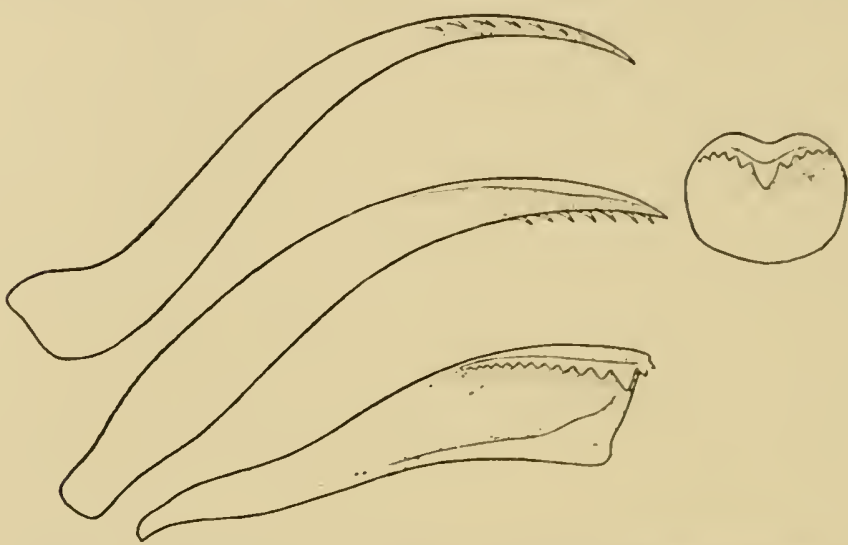

Fig. Io.-A single row of the lingual teeth of Bathanalia howesii.

Tanganyika throughout the southern third of the lake. It is characterised chiefly by its shell which, in all essential conchological characters, is identical with several marine Jurassic fossils that have been described under the name Amberlcya. Except for its widely different shell, Bathanalia is structurally identical with Typhobia, even the lingual teeth presenting only the minor differences seen on comparing Figs. 4 and 10.

CHYTRA, MOORE.-CHYTRA KIRKII (FIG. II).

The anatomy of this remarkable form was worked out 
by Miss Digby. * Originally the empty shell had been described and figured by Smith in the Proceedings of the Zoological Society for I $S S \mathrm{r}$, and was placed by him in the genus Limnotrochus, together with Limnotrochus thomsoni
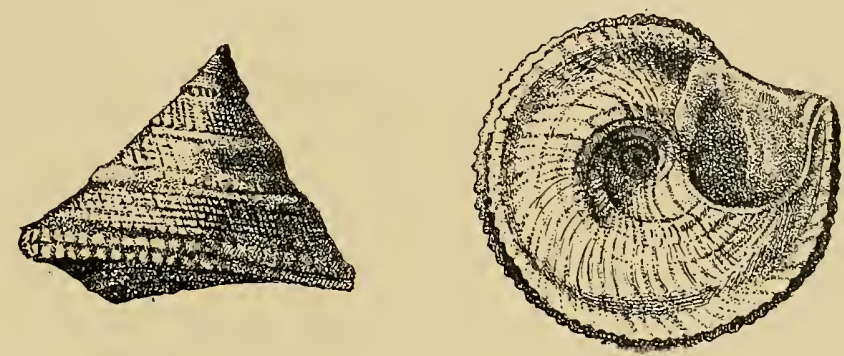

Fig. II.-The shell of Chytra kirkii. From the side and from below ; slightly enlarged.

In 1897 , however, I had occasion to show that the latter form not only differs considerably from kirkii, but is also comparable to the old Jurassic fossil known as Littorina sulcata, whereas kirkii closely resembles some of the

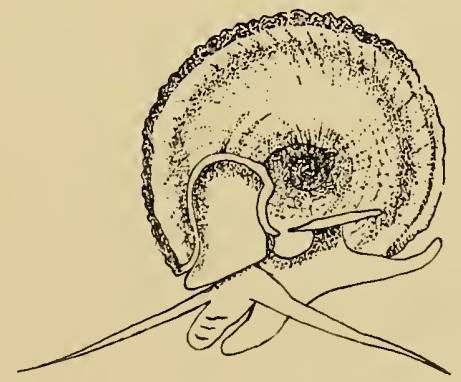

Fig. I2. - Living animals of Chytra kirkii.

Jurassic Xenophoridæ. On this account I separated kirkii from Limnotrochus altogether and placed it in the new genus Chytra. The investigation of the anatomy of Chytra

* Miss L. Digby, "Journal of the Linnean Society," 1902. 
lirkii by Miss Digby has fully confirmed the necessity for such a change, as the following account of her results will show.

The shell of Chytra kirkii (Fig. I I) is remarkably solid, closely resembling both that of Solarium and Yenophora.

The animal is superficially like that of Typhobia, but is

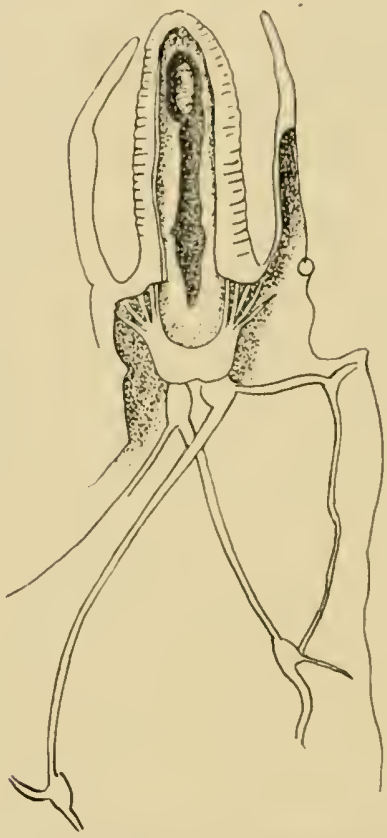

Fig. 13. - The nervous system of Aporrhais pes felicani exposed from above for com. parison with that of Chytra, p. 232.

modified in accordance with the peculiar shape of the shell, in the same manner as the animal of Xenophora. The teeth on the tongue are highly peculiar and closely resemble those of Capulus, even in minor details. The tentacles are long and slender, and the eyes sessile upon their outer bases. The snout is not long, and like that of 
Aporrhais. In fact, the whole of the visceral anatomy of Chytra closely resembles that of Aporrhais and its allies.

The buccal mass is small and the radular sac a mere expansion of the alimentary tube. The nervous system closely resembles that of both Aporrhais and Capulus. The cerebral ganglia are closely approximated together, and the pleural ganglia are closely applied to them. The supra-intestinal cord is long, the left pleural being united by a long cord to the left pallial nerve as in Fig. I 5. The
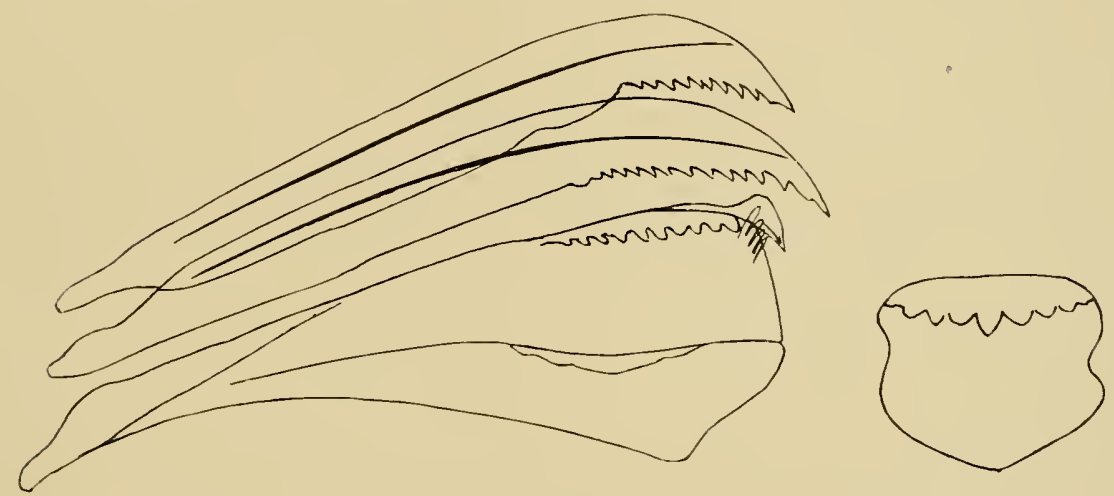

Fig. 14. -A single row of the lingual teeth of Chytra kirkii (X I $\left.{ }^{50}\right)$.

sub-intestinal cord is shorter and the sub-intestinal ganglion is directly connected with the right pleural ganglion by a long zygoneurous connection; the right pallial nerve arising independently from the right sub-intestinal ganglion. Viewed from the side, the cerebro-pedal and pleuro-pedal cords are short, like those of Capulus.

The osophagus is nearly straight and leads into the stomach, which is divided into two chambers, the anterior chamber containing a crystalline style. On the floor of the posterior chamber there is a conspicuous longitudinal 
valvular fold which becomes doubled near the aperture of a bile duct, and then passes, as in Trochus, into a small, but quite well developed, spiral cacum. Except for the presence of the anterior chamber, which appears to be absent in the genus Trochus, Cliytra possesses a stomachic apparatus

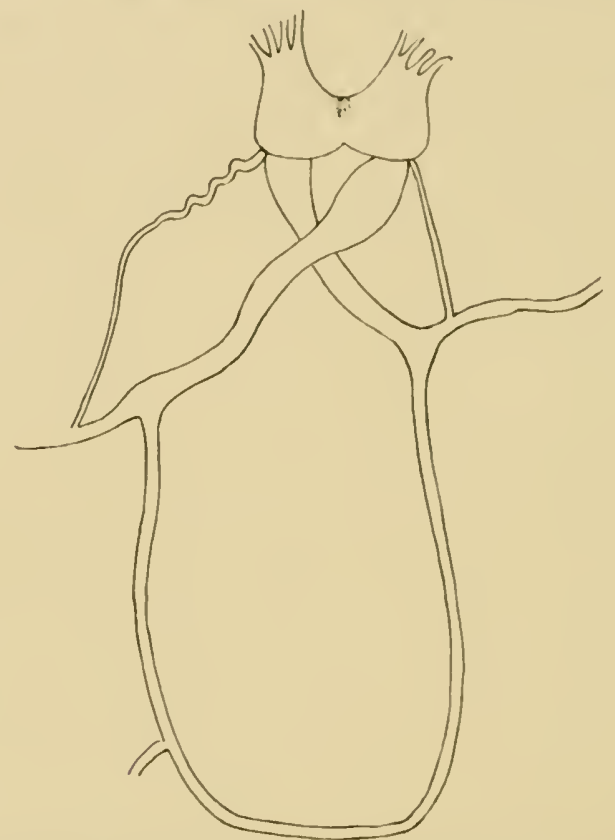

Fig. 15. - The nerrous system of Chytra kirkii dissected from above. (From a drawing hy Miss Dighy.)

strictly comparable to that in the majority of the Rhipidoglossa, including Pleurotomaria itself.

The intestine leaves the stomach on the left, and after a characteristic double twist, enlarges into the rectum. This enlarged rectum is filled with complex glandular folds, but narrows again before it opens at the anus, which has a distinctly modified rim.

The heart has the typical Trnioglossate characters, and 
the gill and the gill leaves are identical with those of Aporrhais. The kidney lies around and below the heart,

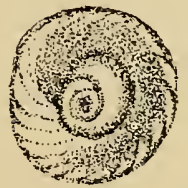

Fig. I6.-Operculum of Chytra kirkii.

and opens, as in Aporrhais and Capulus, at the extreme upper end of the mantle cavity. The liver is large, occupy-
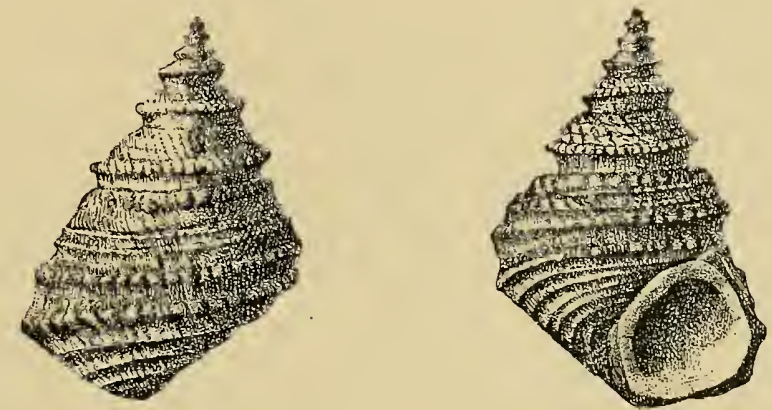

Fig. 17.- - Two views of the shell of Limnotroihus thomsoni $\left(+\frac{1}{2}\right)$.

ing much of the upper part of the visceral hump, and on its outer surface there is lodged the flattened foliated mass of

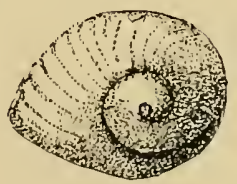

Fig. I8A.-Operculum of Limnotrochus thomsoni.

the genital gland. The duct of this leads without much coiling into the mantle cavity, where, in the female, it enlarges, and is related to a curious glandular (?) organ 
which corresponds in position and appearance to that encountered in the same place in Xcnophora.

The animal does not appear to be viviparous.

\section{LIMNOTROCHUS, SMITH.-LIMNOTROCHUS THOMSONI}

(FIG. I 7 ).

As I have previously stated, the shell of this animal (Fig. I7) was originally described by Smith. During the first Tanganyika expedition, only one badly preserved
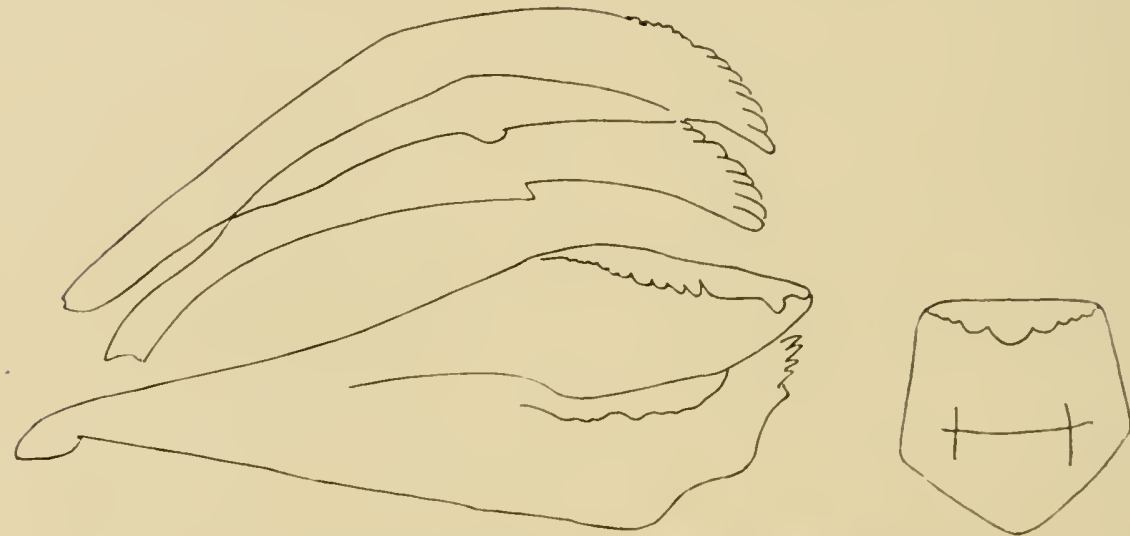

Fig. 18. - The lingual dentition of Limnotrochus thomsoni $(\times 150)$.

specimen was obtained; but during the second, five specimens in good condition were dredged, not, however, without much trouble and in the southern portion of the lake. As in the case of Chytra, the anatomical material obtained was examined by Miss Digby, from whose results I have condensed the following description.

The tentacles are shorter than in Cliytra, and the snout and body more pigmented. The snout is short, and the buccal mass much farther back than in Chytra. The operculum is curiously oblong in shape, litterinoid and concave. 
The lingual dentition (Fig. I 8 ) presents some of the features of that of Chytra, but it differs considerably from that form, more so in fact than is usually the case in closely allied mollusca.

In the general structure of the mantle complex, Limnotrochus is similar to Chytra.

The nervous system of this genus differs considerably from that of Chytra. In the first place, the cerebral ganglia are separated by a distinct commissure. The supra-

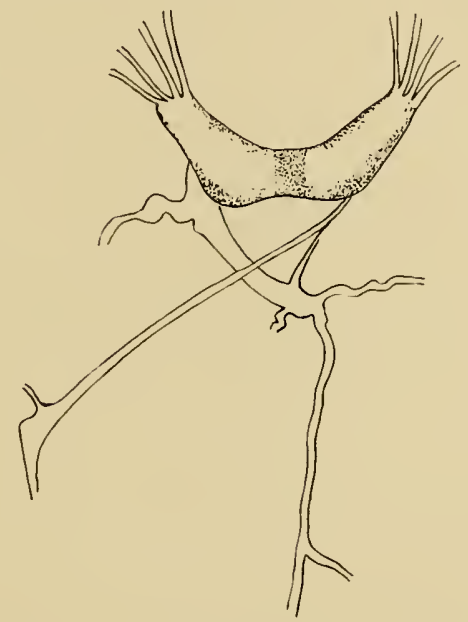

Fig. 19. - The nervous system of Limnotrochus thomsoni dissected from above. The pedal ganglia not shown. (From a drawing by Miss Digby.)

intestinal cord is fairly long, and there appears to be a distinct dyaloneurous relationship of the pallial nerves on the left. The sub-intestinal cord is shorter than in Chytra, and the sub-intestinal ganglion is directly connected with the right pleural ganglion by a rather stout and short commissure; the animal being, consequently, according to Bouvier's definition, strictly zygoneurous on the right. Another striking peculiarity of the nervous system of Limnotrochus is apparent on making a lateral inspection of 
the nerves, the pleural ganglia extending posteriorly and ventrally to such a degree that they are almost fused up with the pedal ganglia. In consequence of this, the ceropedal cords are relatively very much longer than the reduced cerebro-pleural. The otocysts are in the usual position behind and above the pedal ganglia; and the otoliths are numerous and sharply rectangular.

The radula of Limnotrochus (Fig. IS) is distinctive of the genus, its most striking feature being the blunt protuberance seen on the outer edge of each lateral tooth. The mouth leads into a very short buccal mass, into the posterior portion of which there open two very diminutive and simply saccular salivary glands. The oesophagus is straight, except for one sharp bend just before it enters the stomach.

Like that of Chytra the stomach of Limnotroclus is divided into two chambers, the anterior one being constricted off from the stomach proper by a thickened and nearly circular annulus. The anterior chamber contains a crystalline style; the walls of the anterior stomachic chamber, or style sac, are thick, while those of the posterior chamber are, relatively, thin. In the latter, in the stomach proper, there is a conspicuous median fold, which as in Trochus and Chytra becomes duplicated, surrounds the aperture of a bile duct and then passes backward into a very well developed spiral cacum.

The intestine leaves the stomach on the right, and after characteristically twisting twice round the style sac, passes directly away through the mantle cavity to the anus. The kidney is large, lying below and around the heart, and opens by a minute aperture at the upper angle of the mantle cavity, the heart itself having the normal Tanioglossate characters. 
The reproductive apparatus of Limnotrochus is similar to that of Typhobia and Chytra. The genital gland lies upon the liver in the upper portion of the spire, whence the genital duct passes without much coiling, until it finally enlarges in the mantle cavity and opens below the anus. The enlarged portion of the genital duct is related to a glandular (?) organ as it is in Chytra, Typhobia and Xenophora.

The animal does not appear to be viviparous.

BYTHOCERAS, MOORE B. IRIDESCENS (FIG. 2 I).

Like Nassopsis, the genus Bythoceras, so far as is at present known, is exclusively restricted to Tanganyika,

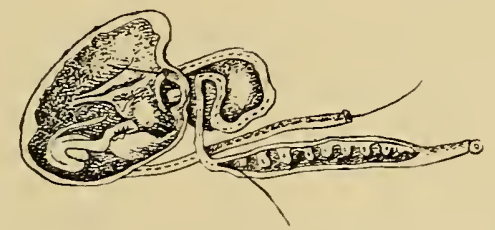

Fig. 20.-Stomach of Limnotrochus thomsoni. The enlarged rectum is seen below.

and as a member of the halolimnic fauna of that lake is of considerable interest. The shell of this form when adult is distinguished by the peculiar horns above and below the mouth (Fig. 2I). It is sometimes covered with a brown epidermis, but more often quite white and naked. Although conchologically so similar to the genera Nassopsis and Paramelania, it has, as we shall immediately see, no morphological relation to the former of these types. Bythoceras is also interesting, because it presents us with more numerous points of correspondence with forms such as the genus Tympanotomus, which exists elsewhere, and the anatomy of which is known, than is the case with the 
majority of the halolimnic forms. Bythoccras is at present represented in Tanganyika by two species, B. iridescens (Fig. 2I) and B. minor (Fig. 24), both of which I dredged living at great depths* in the southern portion of the lake. Taking Bythoceras iridescus as our type, we find that when young the shell does not possess the characteristic spines. Nor has it the peculiar pearly thickening of the mouth invariably present in the olcler
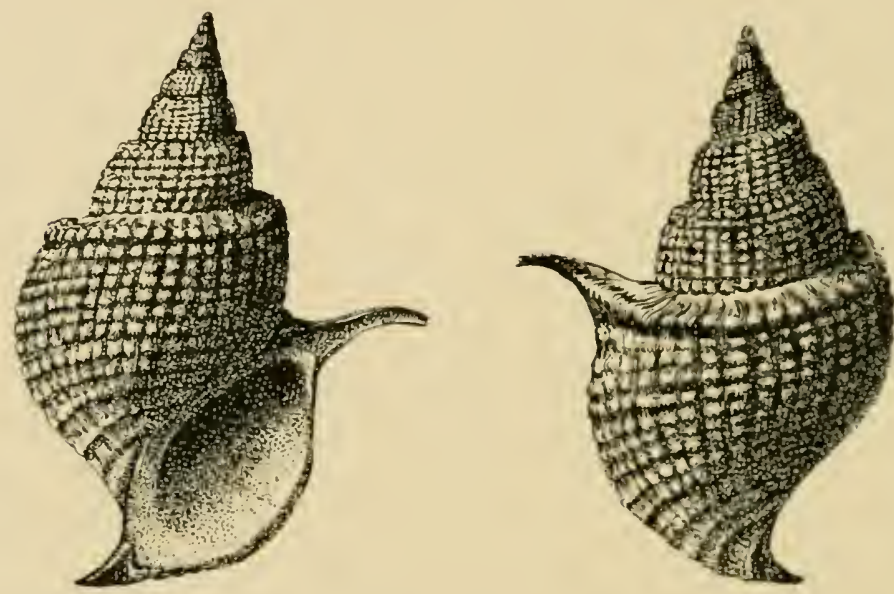

Fig. 21. - Bythoceras iridescins. The shell front and lack $\left(X \frac{1}{2}\right)$.

forms. In the young condition the shell is extremely similar to that of Paramelania, and I am inclined to think that the figure of Paramelania crassilabris, given by Professor E. von Martens in his work, "Beschalte Weichthiere, Deutsch Ost-Afrikas" (Pl. VI. Fig. 38 ), is, in reality, that of a young Bythoceras iridescens.

The outward appearance of the animal is extremely similar to that of Cerithium vulgatum, with the exception 
that there is less pigmentation of the foot, which is nearly white in the Tanganyika species.

The snout is short, wrinkled, richly covered with black pigment and non-protrusible. The tentacles are short, and the eyes are situated on the posterior cases of these organs, and not separated from them on subsidiary papillæ as in Nassopsis. The buccal mass is small and the radular sac short, being reduced, as in the case of Typhobia and Tan-

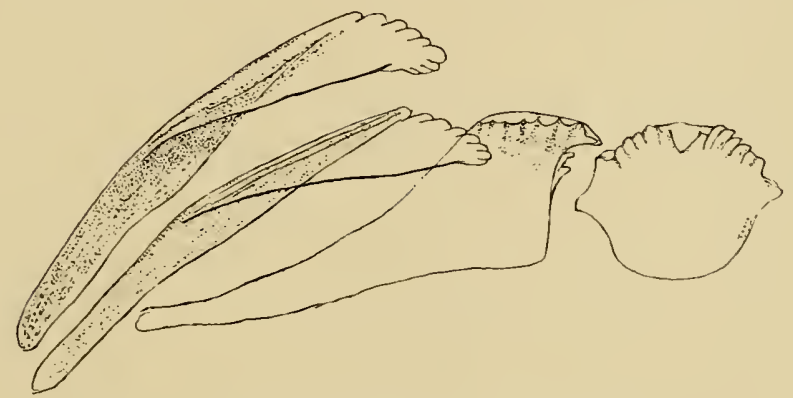

Fig. 22.-The lingual dentition of Bythoceras iridescens.

ganyicia, to a small swelling on the floor of the œsophageal tube *

The radular dentition is extremely interesting, a single row of teeth being represented in Fig. 22. The outer and inner lateral teeth distinctly resemble those of the Melanoplanaxoid type, which I described $\phi$ in considering the relationships of the genus Tanganyicia, and are something similar to those of the "Neomelanian" group of the brothers Saracin; $\neq$ while the admedian tooth is peculiar, owing to the presence of two small subsidiary denticles on

* Compare figure of Tansanyicia rufofilosa (Fig. 32).

+ Loc. cit.

† "Die Siisswasser-Mollusken von Celebes" (Wiesbaden, C. W. Kreidal's Verlag), I SgS. 
the inner face (Fig. 22), a very peculiar feature, and one which is only exemplified in the radula of Tympanotomus. The presence of this peculiarity, together with the general

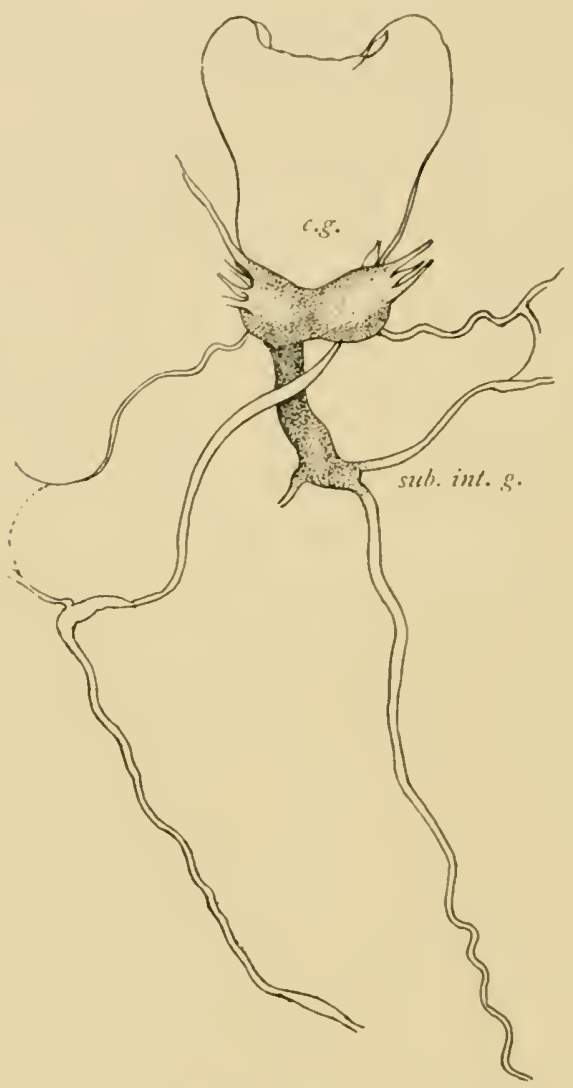

Fig. 23. - The nerrous system of Bythoceras iridescens, as seen from above. c.g., Cerebral ganglion. sub. int. g., Subintestinal ganglion.

character of the radula, should certainly be regarded as of weight in diagnosing the nearer affinities of this form. And, as we shall see in placing it along with Tympano- 


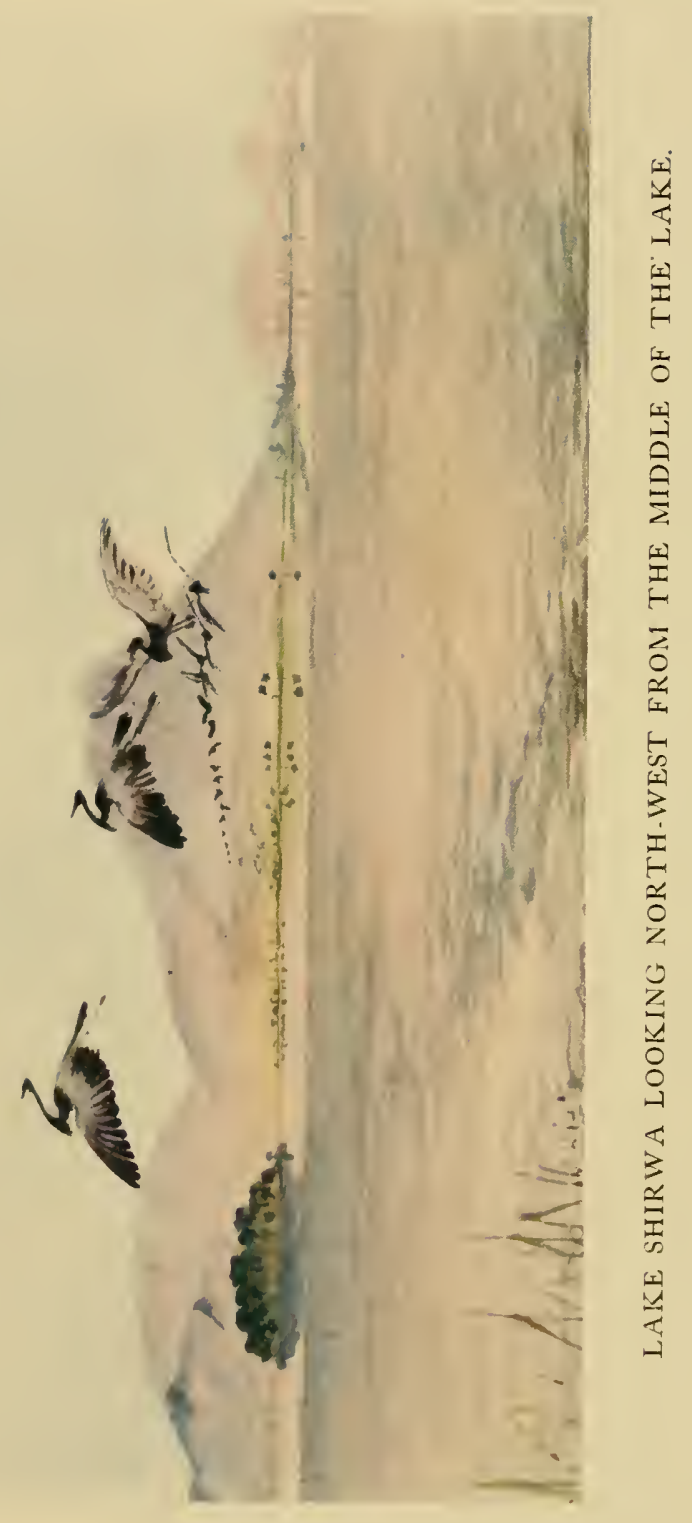



tomus, it is certainly in accord with the rest of the animal's morphological peculiarities.

The œsophagus and salivary glands are in all ways similar to those of Typhobia, * but these characters are common to so many different kinds of gastropods that they are of little value from a special morphological point of view.

The stomach has two chambers, the anterior of which contains a style. The intestine is simple, and in Tanganyicia takes the course represented in Fig. 32. The rectum is not dilated, nor beset with any accessory gland. The bile ducts seem to open by two very small apertures upon the base of the posterior stomachic chamber. Stomachic valves are feebly, if at all, developed. The liver is large, and occupies much the same position as Nassopsis (see below). The excretory organ occupies a place in front of and above the heart and opens by a minute pore at the extreme upper end of the mantle cavity, Fig. 29.

The heart has the usual tænioglossate characters, consisting of an auricle, ventricle, and aortic trunk; but the last structure is much less developed in Bythoceras than in many forms-as, for example, in the genus Typhobia.

The nervous system in Bythoceras (Fig. 23) is very interesting, since it is absolutely unlike that possessed by the genus $N$ assopsis, and closely simulates the type described by Bouvier $\phi$ as typical of the genus Cerithium. It also strongly resembles that of the genus Tanganyicia. Viewed from above, Fig. 23, the cerebral ganglia are seen to be closely fused together, while the left pleural and sub-intestinal ganglion, as in Cerithium, form a single massive trunk, which at its hinder extremity gives rise to the sub-

"Loc. cit., "Quart. Journ. Micr. Sci.," Vol. 4I, 189\$, p. 190.

† “Ann. Dis. Sci. Nat.," 1887, pp. 131-135, pl. vii. 
intestinal and visceral nerve cords, and to the right pallial nerve, Fig. 23. From the right pleural ganglion a nerve passes out to the mantle, and a branch from this anastomoses with a branch on the pallial nerve just described. In like manner, on the left, the pleural ganglion gives birth to a nerve on that side, Fig. 23, which passes out and probably anastomoses with a twig given off from the supra-intestinal ganglion, but I was not able to trace this nerve throughout its entire course.

Unlike the sub-intestinal ganglion, the supra-intestinal
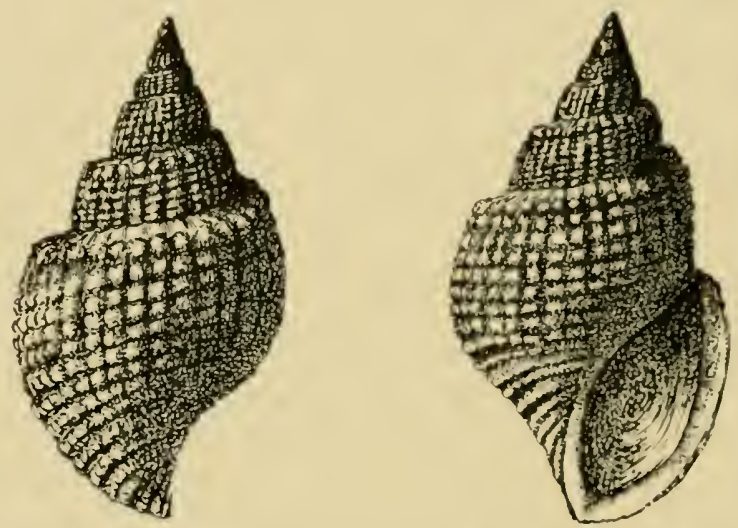

Fig. 24. - Fythoceras minor shell front and back. The right-hand figure showing the characters of the operculum.

is carried on a very long supra-intestinal connective, Fig. 23, exactly as it is in Cerithum or Aporrhais. Viewed from the side, the cerebro-pedal and pleuro-pedal connectives are seen to be of considerable length, rather longer than the same structures in Voluta, but not so long as those in Nassopsis or in Strombus. The pedal ganglion has the bulbous form encountered in the true Cerithiida, and in like manner there pass from the lower extremity of each pedal ganglion two predominent foot nerves. 
The otocysts lie behind the pedal ganglia, and the otocyst nerves pass directly behind the cerebro-pedal and pleuro-pedal connectives to the cerebral ganglia on each side. The otocysts are not large, and are round, as distinguished from those of Nassopsis. The otoliths are small, rectangular or barrel-shaped, and numerous.

The reproductive apparatus is very simple, and in both sexes consists of a genital gland which occupies the upper surface of the two last whorls of the animal's body. This

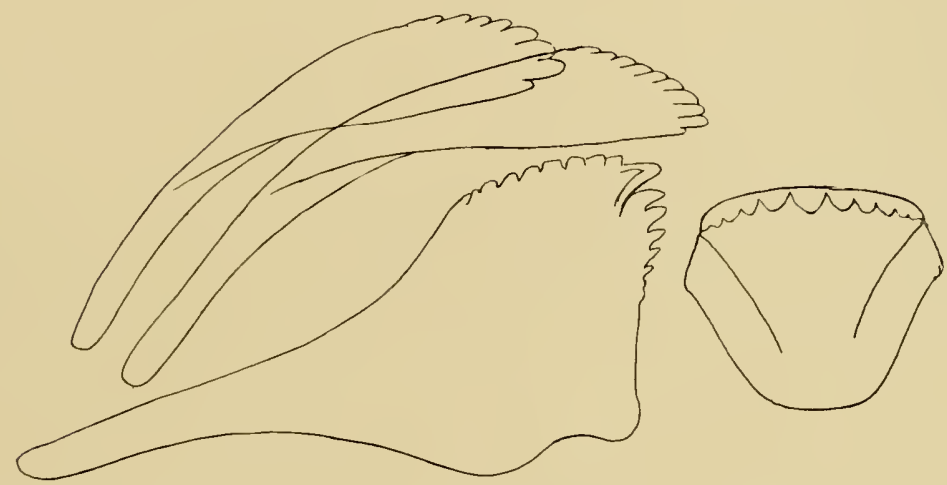

Fig. 25.-Lingual dentition of Paramelania aamoni.

gland is put in connection with a large non-convoluted oviduct or vas deferens, as the case may be, by a number of fine tubes; and both ducts pass beneath the intestine and open just behind the anus in a large slit.

The genital duct in both sexes is much enlarged within the mantle cavity, somewhat in the manner of the same structure in the genus Typhobia. But in Bythoceras it is quite destitute of the singular organ which I described as an evertible penis in the male Ty'phobia.* 
B. MINOR, MOORE (FIG. 24).

During the second Tanganyika expedition a new species of Bythoceras was obtained, which has not yet been figured or described, and to which I have given the above distinctive name (Fig. 24). This form is somewhat smaller than $B$. howesii and possesses a less marked epidermis. In other respects it does not differ from the original type of the genus.

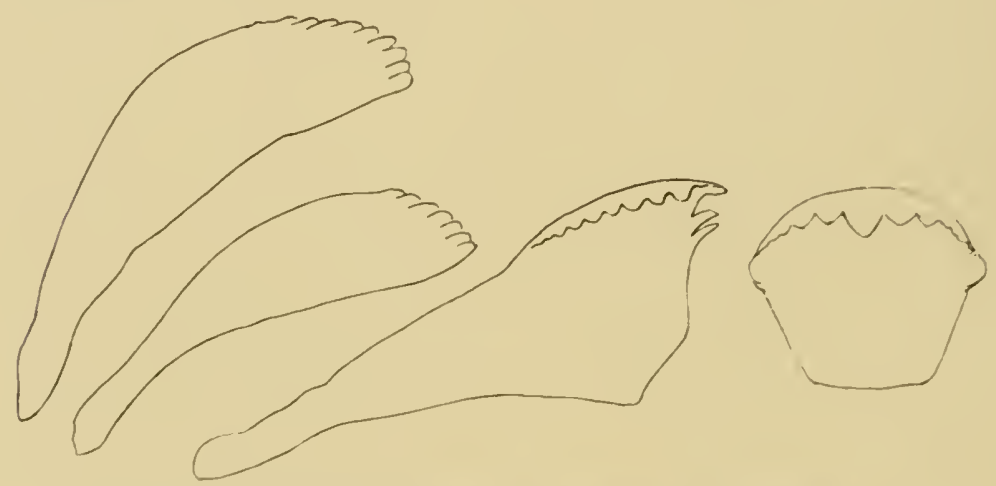

Fig. 26. - The lingual dentition of Paramelania crassigramulata.

PARAMELANIA, SMITH.-P. DAMONI (FIG. 27).

In its general structural peculiarities, the genus Paramelania closely resembles Typhobia and the preceding group of forms, but it differs from them all in several marked peculiarities. Thus, the shell (Fig. 27) is highly characteristic, and in form and sculpture indistinguishable from the old marine Jurassic form Purpurina bellona; it has also generally more apparent epidermis, though the living shells may at the same time be quite without.

In the mantle cavity the parts are arranged almost 
exactly as they are in Typhobia, the operculum even showing once more the typical peculiarities of Typhobia (compare figure on p. 222). The buccal mass and the salivary glands, the anterior ganglia and the nerves all present the same disposition and appearance as in Typhobia. The teeth (Fig. 26) on the radula, however, are not like those of any of the preceding forms, the elements forming a new type of dentition which we shall meet with again in several other halolimnic forms closely allied to Paramelania. In the remainder of its visceral anatomy, in the character of
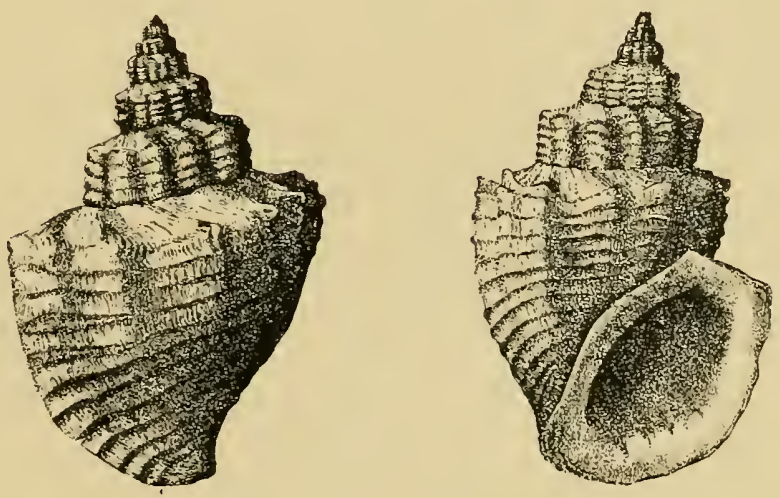

Fig. 27.-Shell of Paramelania damoni $\left(+\frac{1}{2}\right)$.

the intestine, in the possession of an anterior stomachic chamber and a crystalline style, Paramelania is in all respects similar to Typhobia, but like Limnotrochus and Chytra it does not appear to be viviparous.

\section{P. CRASSIGRANULATA, SMITII.}

This form is in all respects closely similar in the structure of its soft parts, shell, operculum and radula, to P. damoni. (Sce Figs. 25 and 26.) 


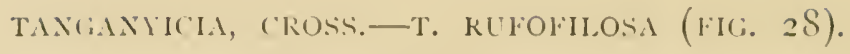

Upon the shore rocks and flourishing among the surf and the breakers of Lake Tanganyika there are several species of small molluscs, which in the fauna of the lake fill the place of the Littorinas and Noritinas of the sea shores, and among these littoral forms there occurs in great abundance the animal, to the empty shell of which Cross gave the name of Tanganyicia. In its shell (Fig. 28) Tanganyicia somewhat resembles a small $N$ atica, but it lacks the callous characteristic of most, if
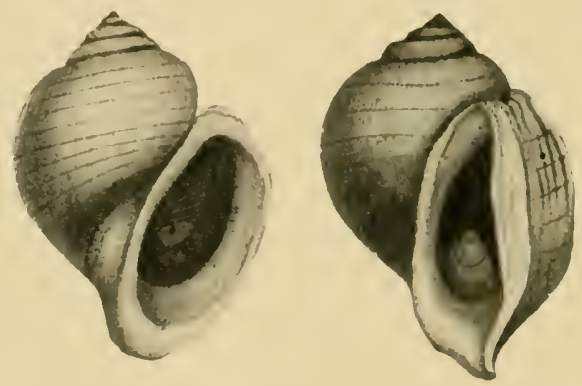

Fig. 28. - The shell and operculum of Tangarityicia iufofilosa.

not all, the shells of the true Naticas. In the general arrangement of the parts within the mantle cavity, the character of the snout, head, and tentacles, in the position of the renal, reproductive, and alimentary apertures, and in the character of its gill, this animal (Fig. 29) very much resembles Typhobia ; the osphradium is, however, somewhat foliated at its outer end, and in the female the rectum is provided with a large rectal gland. In both sexes the genital aperture is placed farther back than in any of the preceding forms, and in the male we encounter, for the first time among the halolimnic gastropods, an unmistakable 
spermatic groove (Fig. 29) running from the opening of the genital duct along the body and on to the foot below

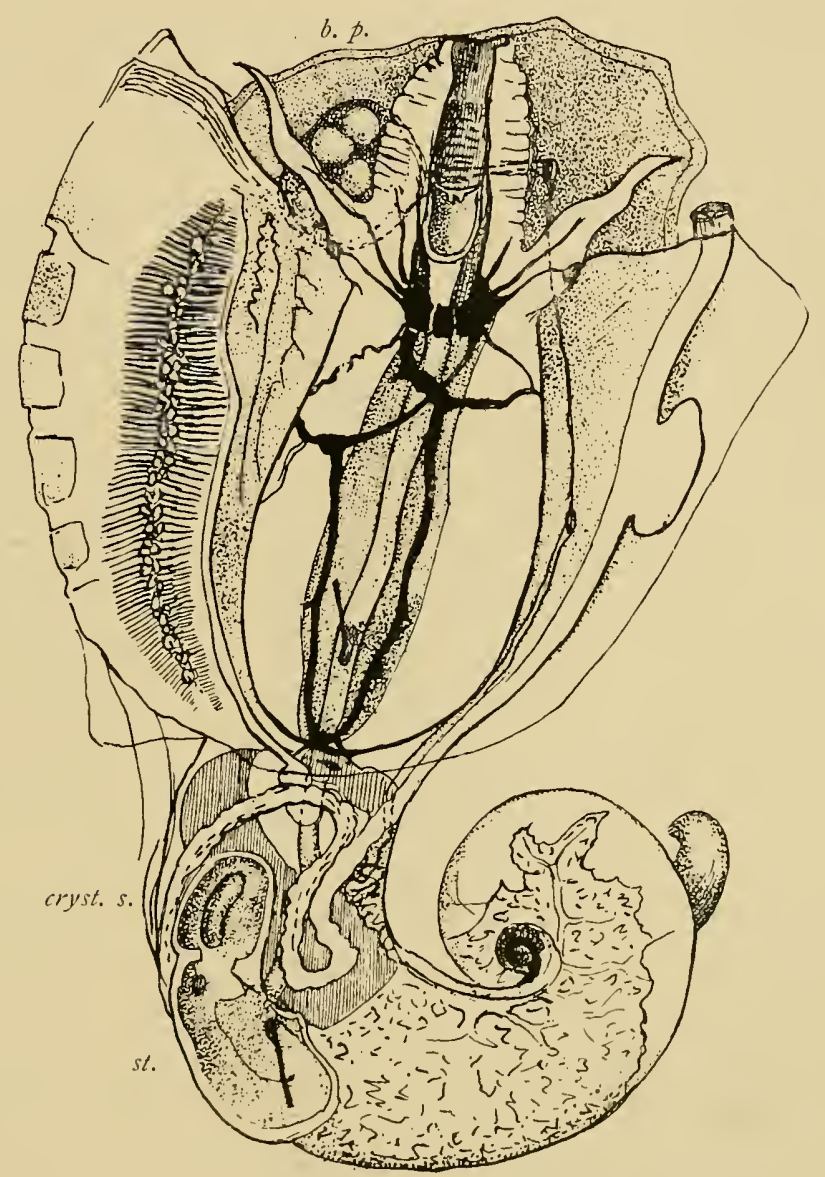

Fig. 29. - Semi diagram of the anatomy of Tanganyicia mifofilosa.

The mantle opened from above, and the nerves in black; cryst. s., crystalline style; st., stomach ; b. f., broorl pouch.

the tentacles on the right side, just as it does in Strombus, Pteroceras, or Littorina. In the female Tanganyicia this genital groove is also present, and leads from the genital 
aperture to a small opening below the left eyc. The opening communicates with a canal, and the canal passes

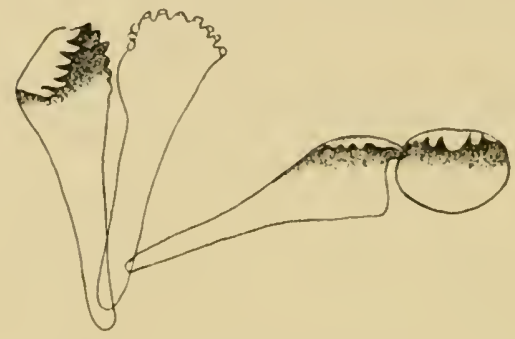

Fig. 30.-The lingual dentition of Tanganyicia rufofilosa.

to the right under the buccal mass in the upper part of the foot quite out to the left of the body, where it expands
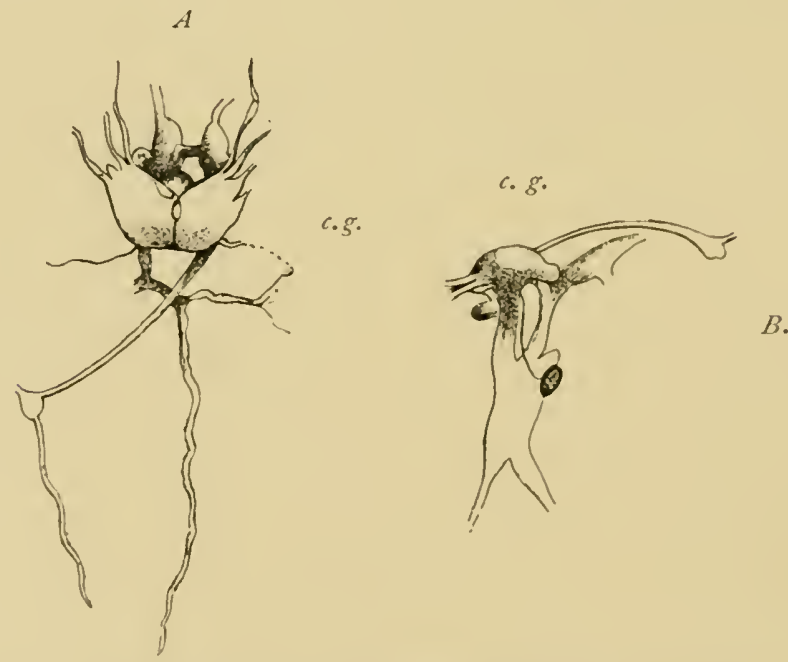

Fig. 31.-Nervous system of Tanganyicia mfofilosa. A., From above. $B$., From the left side. $c . g$., Cerebral ganglia in both figures.

into a large sub-circular sac, which in the specimens I examined was filled with young in various stages, and 
evidently functioned as a brood pouch. The buccal mass is very much reduced in Tanganyicia, appearing only as a slight dilation of the alimentary tube, and the tongue and the teeth (Fig. 32) are both proportionately small, the denticles having the characters represented in Fig. $3 \mathrm{I}$. The nervous system (Fig. 3I), the ganglia, their cords

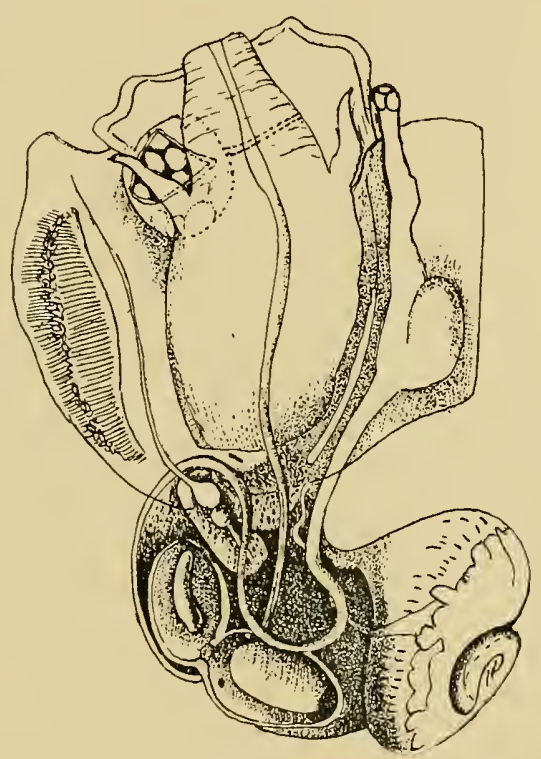

Fig. 32.--Semi diagram of the digestive system of Tanganyicia mefoflosa.

and connectives, are all arranged in the typical cerithoid plan, just as in Typhobia or Cancellaria. But there is in the brain of Tanganyicia a curious median lobe situated between the cerebral ganglia and looking forward, which I have never found elsewhere. Except for the addition of the large rectal gland in the female Tanganyicia, and the reduction of the buccal mass in both sexes, the whole alimentary canal (Fig. 32) is built on precisely the 
same form as in Typhobia and all the rest of the halolimnic molluscs that we have considered, and as it is with the alimentary canal, so it is with the rest of the animal's visceral anatomy.

\section{NASSOPSIS, SMITH.—N. NASSA (FIG. 33).}

During life this mollusc inhabits the surface rocks of Tanganyika, and its shells are always richly encrusted with the green alga which clothe the rocks for a considerable depth. It is sluggish, and appears to browse within a
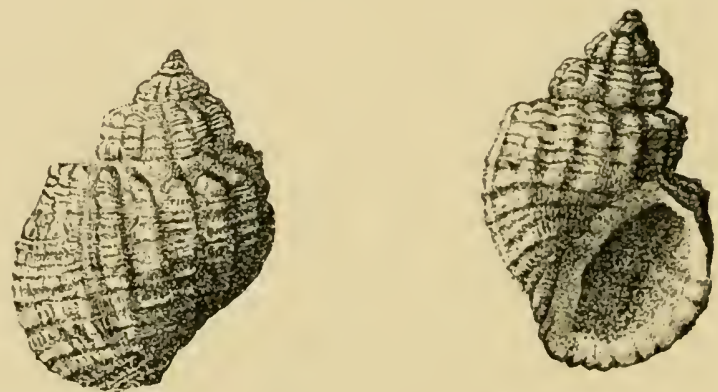

Fig. 33.-Shell of Nassopsis nassa.

very limited area, like the Patellas of the ocean beach. The foot is broad, somewhat pigmented, and quite white in places; the snout is broad, black, and wrinkled, not protrusible, but retractile. The tentacles are short and black, and the eyes are not carried on the tentacles themsclves, but on secondary papilla at their posterior bases. There is a well-developed mucous gland in the mantle cavity, and the animal, unlike the genus Spekia, is viviparous. There is a tolerably well-developed buccal mass; the radular sac is of average length, and the salivary glands are somewhat tortuous, simple saccular organs. The radular dentition is strong (Fig. 36). From a portion of the radula 
obtained by Smith, Guatkin referred it to the types approximating to the genus Cerithium, while Smith himself remarked upon its similarity to the radula of the Planaxidæ. It also corresponds very closely to the radulæ

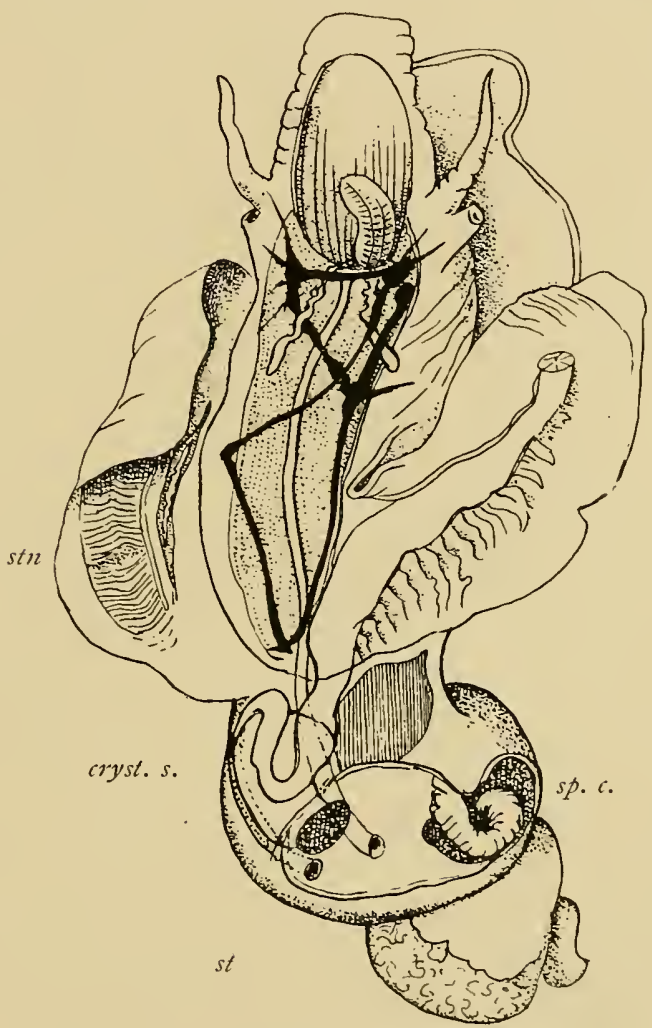

Fig. 34.-Semi diagram of the anatomy of Nassopsis nassa. The mantle has been cut open from above, and the nervous system is seen from above in black. Opposite $s t n$., the gill ; cryst. s., crystalline style; sp. c., spiral cxecum; st., stomach.

of several Littorinas. The œsophagus is long, narrow, and simple, and leads into a large stomachic chamber, on the walls of which there are numerous glandular folds, and a very curious and striking spiral cacum on the 
floor, between the folds of which the curiously rectangular orifice of a single bile duct opens. Besicles this stomachic chamber there is an anterior diverticulum into which the large stomach opens by a tubular aperture, through which a bristle may be passed, and in this anterior stomachic chamber there lies an almost spherical crystalline style.

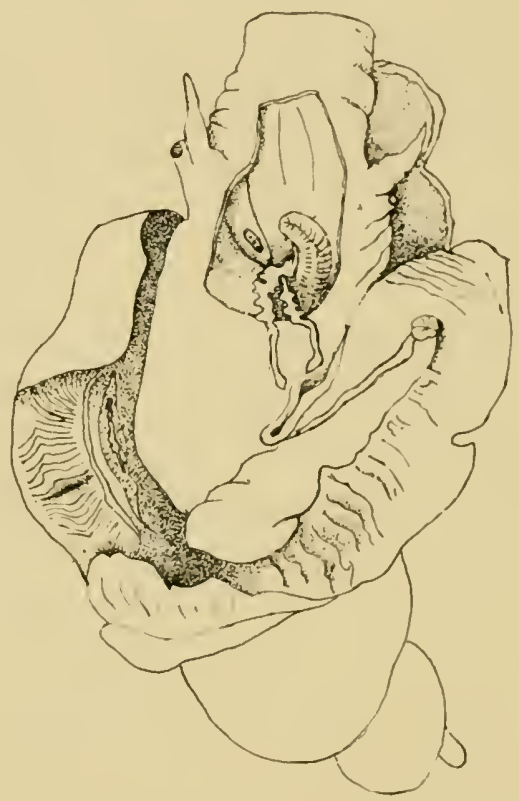

Fig. 35. - The animal Nassopsis nassa from the dorsal aspect. The mantle has been cut open from above, and the radular sac exposed.

The intestine passes out of the stomach beneath the tubular aperture between the posterior and anterior stomachic chambers, as indicated in the drawing on page 251. The intestine is coiled in the manner seen on page $25 \mathrm{I}$, and towards its rectal extremity it contains a number of glandular folds and striae.

The liver is large, and occupies the lower two-thirds of 
the last two whorls of the animal's body. There is a single bile duct, opening, as has already been stated, in the posterior chamber of the stomach.

The heart has the normal tænioglossate characters, and consists of a thin-walled auricle, a thick-walled ventricle, and a short aortic trunk. Between the auricle, ventricle, and aortic trunks there are the usual valves. The gill of Nassopsis is of average length, very simple in structure, and consists of a large number of low, broad, triangular leaves, the apices of which are not produced into filamentous pro-

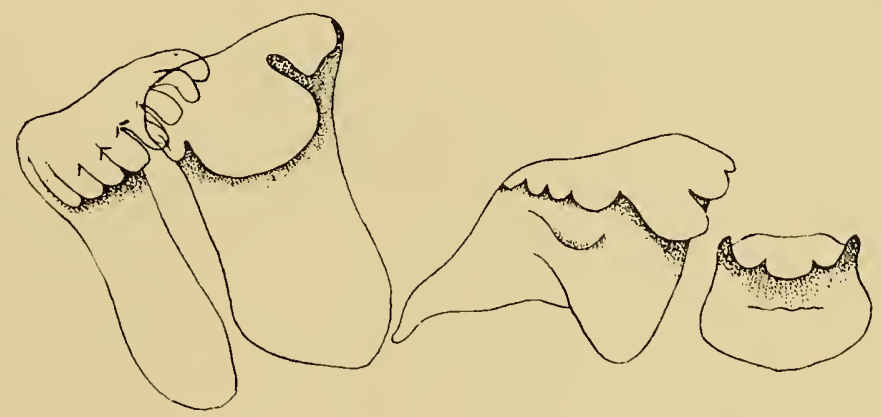

Fig. 36. - The lingual dentition of Nassopsis nassa.

cesses, nor ornamented in any way. The osphradium is long and simple; it lies in a groove at the base of the gill, and shows no tendency to become pectinated or modified in any way either before or behind.

The nervous system of Nassopsis (Fig. 37) is extremely interesting, being one of the most archaic tænioglossate types at present known. The cerebral ganglia are widely separated from one another, and the pleural ganglia are not only separated from the cerebral ganglia, but on the sides of the œsophagus, the cerebro-pleural connectives being consequently of considerable relative length. The supra-intestinal cord springs directly from the right pleural ganglion, passes 
up over the œsophagus, and carries the supra-intestinal ganglion. From the left pleural ganglion there passes a fine nerve towards the supra-intestinal ganglion, which appears to form a dyaloneurous connection with a derivative of the supra-intestinal nerves. 'Towards the right the sub-intestinal connective passes from the left pleural ganglion bencath the œsophagus straight to the sub-intestinal ganglion. This ganglion is directly connected with the right pleural ganglion

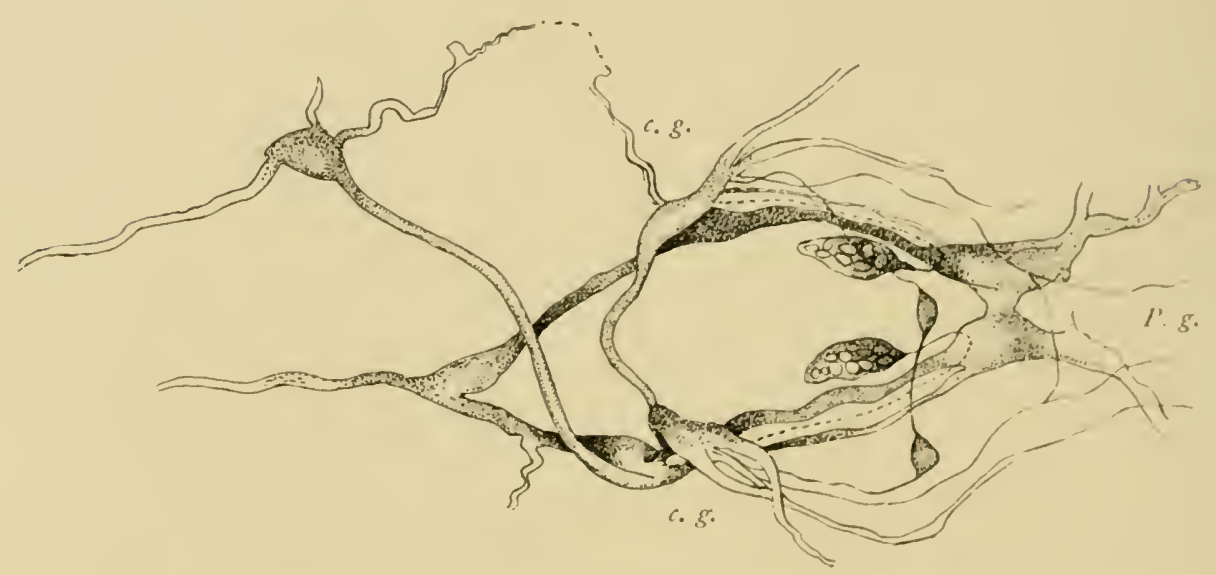

Fig. 37.-The nervous system of Nassopsis nassa. c. g., Cerebral ganglia. I'. g., l'edal ganglia.

by a thick cord, and the nervous system is therefore strongly zygoneurous on the right. Above, the cerebral ganglia give off a number of anterior nerves, which are distributed to the buccal mass and the parietes of the head. Among these there are conspicuous the tentacular nerves, which pass separately to the tentacles and ocular papilla. The buccal ganglia are situated on the lateral walls of the buccal mass, and are united to the cerebral ganglia by connectives. Near the origin of the buccal nerves there arise two fine nerves, one from each cerebral ganglion, which pass forward along 
the walls of the body, and then bend down, uniting with each other below the mouth. This connection appears, therefore, to be unquestionably the labial commissure described by Bouvier as characteristic of a number of the Archi-tænioglossate and Rhipidoglossate types.

The cerebro pedal connectives are long, and altogether the length of the cerebro-pleural, cerebro-pedal, and pleuropedal connectives gives to the nervous system the longicommissurate character described by Haller.

The pedal ganglia (Fig. 37) are united by a rather small

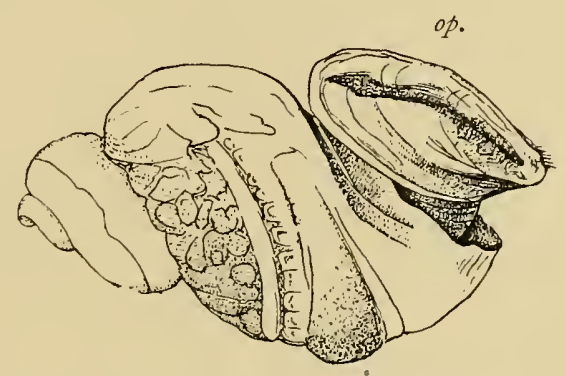

Fig. 38. - The animal of Nassopsis nassa removed from its shell to show the characters of the operculum, $o p$.

connection, and are prolonged into the foot along the course of two well-developed scalariform pedal cords. Between these pedal cords there exist ladder-like connections similar to those found between the pedal cords of Cyclophorus.

The otocysts in Nassopsis are relatively immense. They are situated well up on the course of the pedo-pleural connectives, and the otocyst nerves pass obliquely from them towards the cerebral ganglia. The otoliths are small, numerous, and rectangular, with the faces slightly convex.

The reproductive apparatus in Nassopsis is somewhat 
similar to that of Ty'phobia, both male and female apparatus occupying the same position as the body wall. In the male the genital gland occupies the upper surface of the apical whorl in the body, and is connected by several channels with a nearly straight vas deferens. This latter structure opens without any modifications along its course by a slitlike aperture. In the female the ovary occupies the sime position as the male gland, and in like manner it is con-

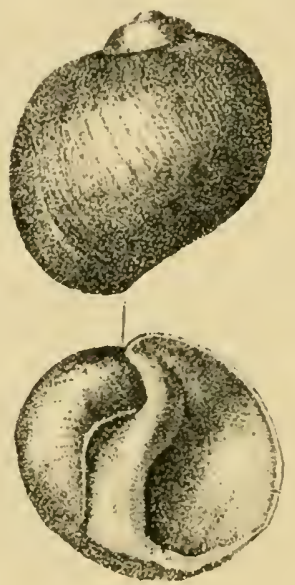

Fig. 39.--Shell of Spekia zonata.

nected with the nearly straight oviduct, the lower portion of which, or that which lies within the mantle cavity, forming a brood chamber where the eggs go through their later stages of development, the animal being viviparous.

SIEKIA, CKOSS. - S. ZONATA. (FIG. 39).

The shell of this remarkable molluse is represented in Fig. 39, and it is certainly most curious that no attention has been drawn by any of the conchologists to 
the extremely naticoid character which it presents, for the shell of this species is so completely similar to that of numerous fossil naticoid forms that, had it appeared fossilised instead of having been found living in a great freshwater lake, there is not the slightest doubt that it would have been placed in one of the numerous fossil genera which are supposed to group themselves about the living Naticas. The oblique aperture, and the tendency of the outer wall of the mouth to be continued as a cup-shaped ring round the bases of the older shells, are exactly what is observed in many fossil Naticas; while the presence of a very pronounced umbilical opening, which is more or less

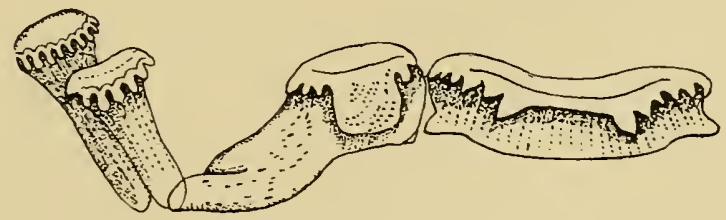

Fig. 40.-Lingual dentition of Spekia zonata.

filled up with a deposit of callous substance, are features which are generally regarded as almost diagnostic of naticoid shells.

The external appearance of this form is superficially similar to that of Tanganyicia mfofilosa. The foot is rather less broad, and the snout is not so much pigmented; but, apart from the naticoid appearance of the shell, it is only in the internal anatomy that we begin to appreciate the wide morphological differences which exist between these forms.

In Spekia zonata the buccal mass is well developed, and the radular sac is conspicuous, but not of any considerable length. There are two very strong muscles attaching the buccal mass to the body wall, and the salivary glands are 
long and simple. The radular dentition is characteristic, and very strongly developed. A single row of teeth is represented on page 257 . It will be at once seen that the characters of these teeth are highly suggestive of those of a number of well-known forms. In gross detail the radular dentition is very similar to that occurring in various forms of Anchylotus figured by Troschel. The predominant denticle on the admedian tooth is well developed in zonata, as indeed it is in a very large number of dissimilar forms;
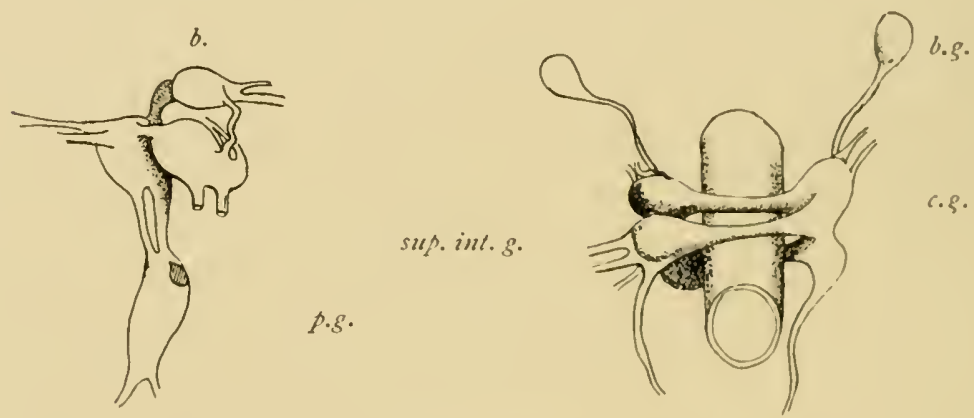

Fig. 41.-Nervous system of Spekia zonata. a. from above; $b$. from the side; $b . g$. buccal ganglion; $c . g$. cerebral ganglion; sup. int. g. supra intestinal ganglion; $p \cdot g$. pedal ganglion.

and an exactly analogous and widely prevalent feature is presented in the difference of size and character between the denticles on the heads of the outer and inner lateral teeth. Perhaps, however, the most notable feature which the radula presents is the peculiar structure of the median tooth. The outer surface of this tooth is concave, like the median tooth in Anchylotus, Thiara, Melania breis (Dorb.), and Melanopsis. But it differs from all these forms in having no predominant median denticle, there being instead two lateral predominant denticles and a median concavity. The only forms which appear to possess this peculiarity of 
the median tooth are the different species of the genus Sigaretus.

In Spekia zonata the œsophagus leads into a double stomach, of which the anterior chamber contains a crystalline style; but it is so small and so little elongated that at first sight it does not seem to have the characters which this structure usually presents.

The intestine takes the course represented in figure 42 , and communicates with a dilated rectum, opening. in the usual way just within the border of the mantle.

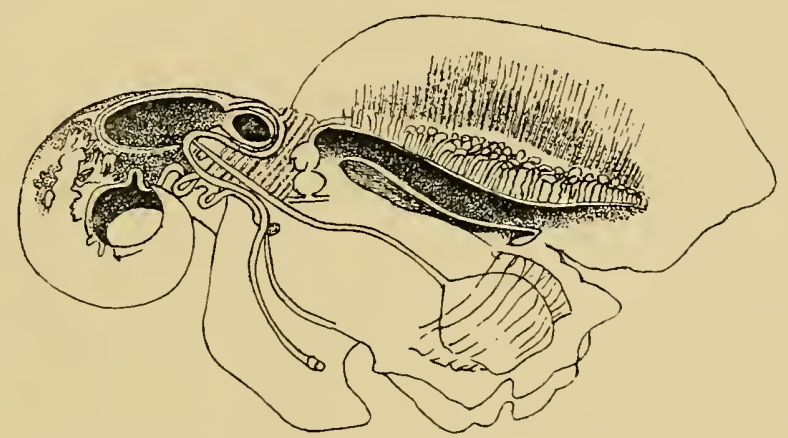

Fig. 42. - Semi diagram of the anatomy of Spekia zonata.

The heart has the regular tænioglossate characters. In $S$. zonata, owing to the naticoid shape of the body, there is a forward displacement of the internal viscera, which results in the pulmonary vein not going directly forward to the base of the stenidium, as in Tanganyicia rufofilosa and most other Prosobranchs, but in its being bent slightly backwards in a more or less acute curve before it reaches the base of the gill. This relative displacement of the heart and gill is fully described by Haller in the Naticas Trochita radians, Eirgaa plana, Crepidula peruviana (Lam.), Tanacus unguiformis (Lam.), and Crucibulum (sp. ?), and it is curious to find that this displacement has 
proceeded less in Speliz than in any of the forms which Haller figured

The gill in S. zonata is very much like that of the genus

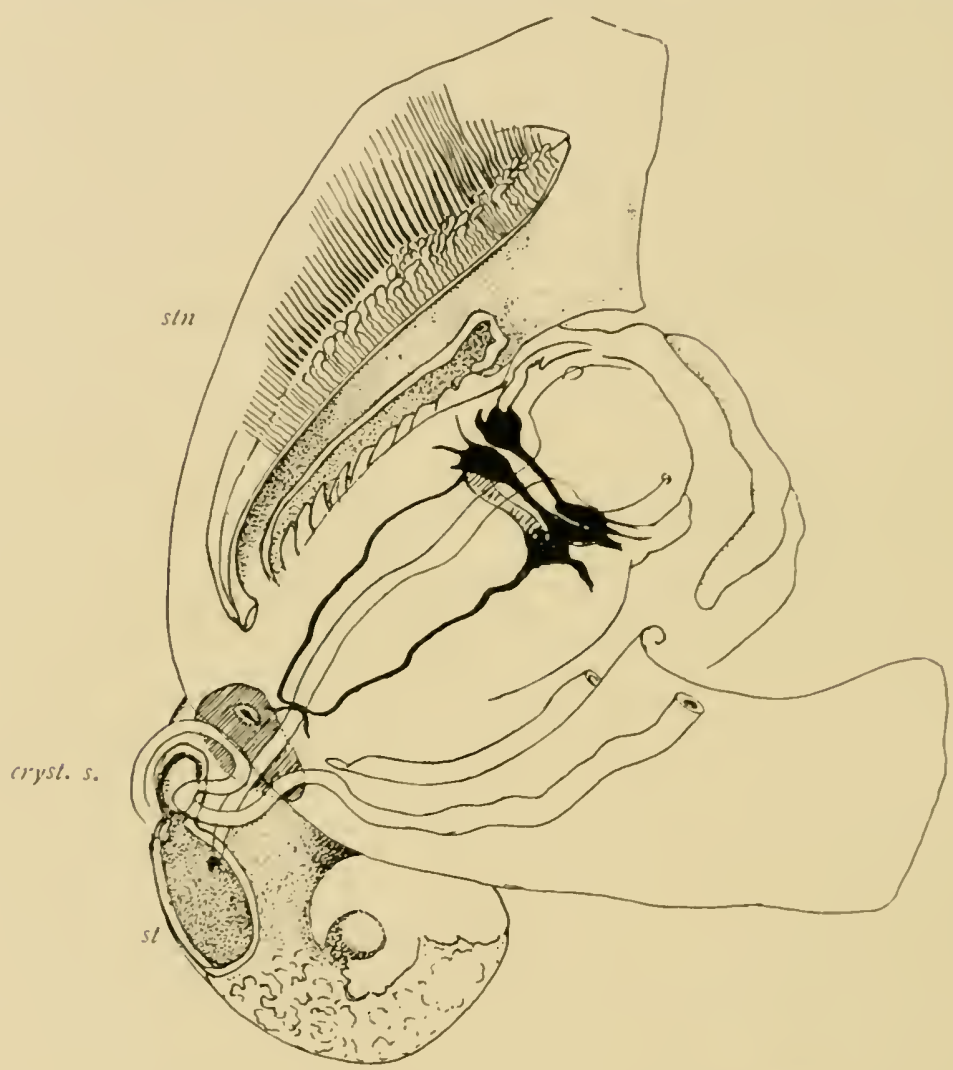

Fig. 43.-Seni diagram of the anatomy of Spetia zonala. The mantle carity has been opened from above, and the nerves are represented in black. Opposite s/ the stomach ; stn. the gill; clyst. s. the crystalline style.

Tanganyicia. The leaves are similarly broad, low, and triangular, and their apices are prolonged into the same littorinoid finger-like processes.

Such processes are figured by Haller in the gills of 

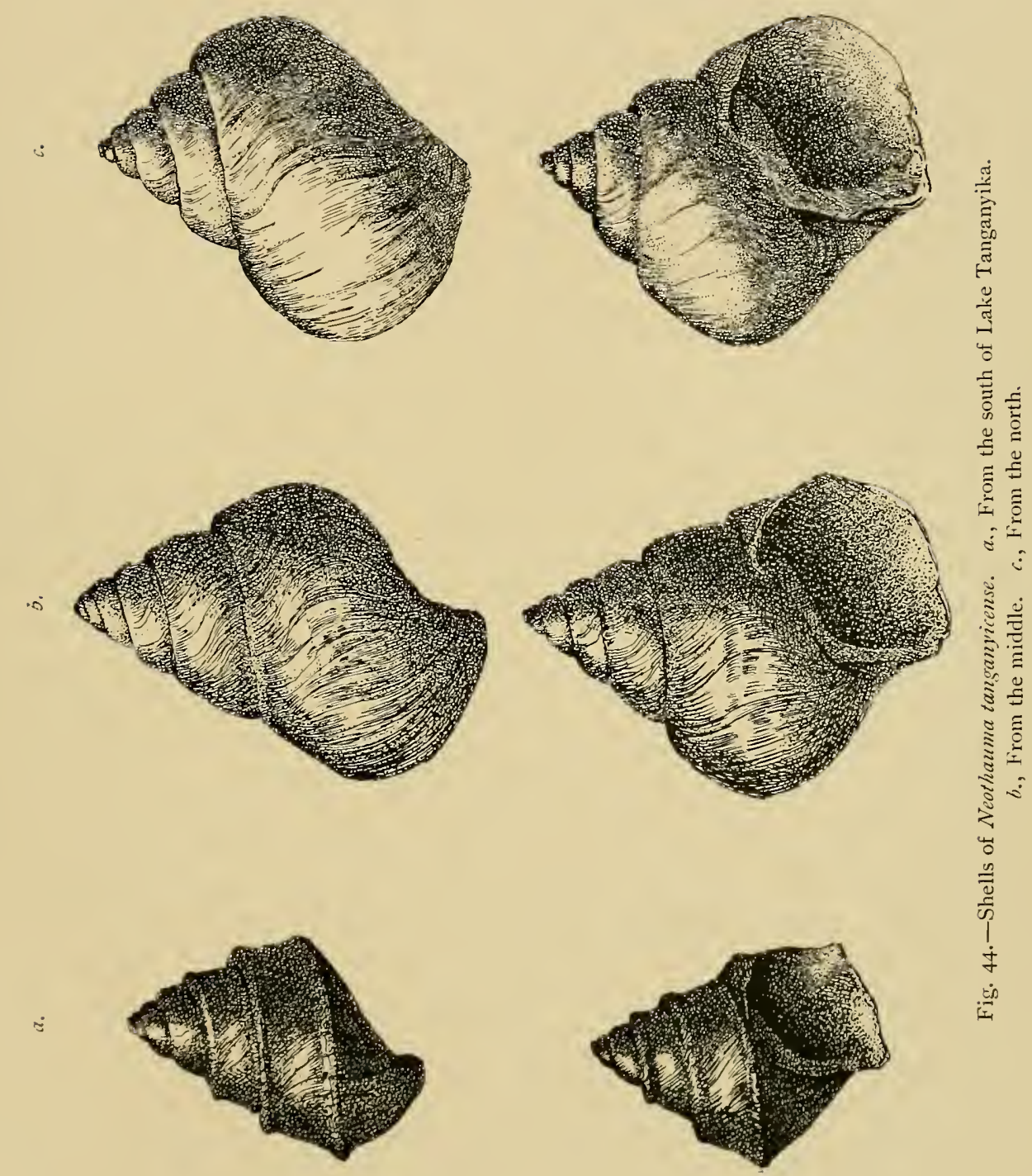
Natica lineata: they are present in the gills of Littorina, but curiously enough they are not represented in Haller's figure of the gill of Sigaretus neritoides (Lam.).

The osphradium is lodged in a groove beneath the gill; it is simple, and slightly but distinctly tending to become pectinated. At the outer extremity it is curiously bent downwards and back, exactly repeating in this the condition of the same organ in Sigaretus neritoides and Natica lineata as represented by Haller.

The nervous apparatus of $S$. zonata is remarkable, the whole completely simulating in every detail that of Lamellaria perspicua, as figured and described by Bouvier and Haller.

The cerebral ganglia are united by a short but distinct commissure, and are almost completely fused with the pleural ganglia. The right pleural ganglion gives rise to a nerve cord which passes upwards and directly across the axis of the animal's body. It almost immediately expands into a ganglionic mass, which represents the supra-intestinal ganglion.

This ganglion is in turn connected with the left pleural by the commissure. The nervous system is therefore completely zygoneurous on the left. From the left pleural ganglion a nerve cord passes almost parallel to and below the supra-intestinal commissure to a ganglionic enlargement which represents the sub-intestinal ganglion on the right. This ganglion is in direct connection with the right pleural ganglion by short connective. The nervous system is therefore completely zygoneurous on both sides. All these details could be made out by dissection alone, but the animals were so small that, for confirmation, I resorted to sections. In all essential details the nervous system just described corresponds with that of Lamellaria. 
The reproductive apparatus very much resembles that of Littorina, the genital gland occupies the upper part of the apical body whorl, and in the male is related to a simple vas deferens which opens at the extreme upper end of the mantle cavity. The opening is, however, prolonged as a

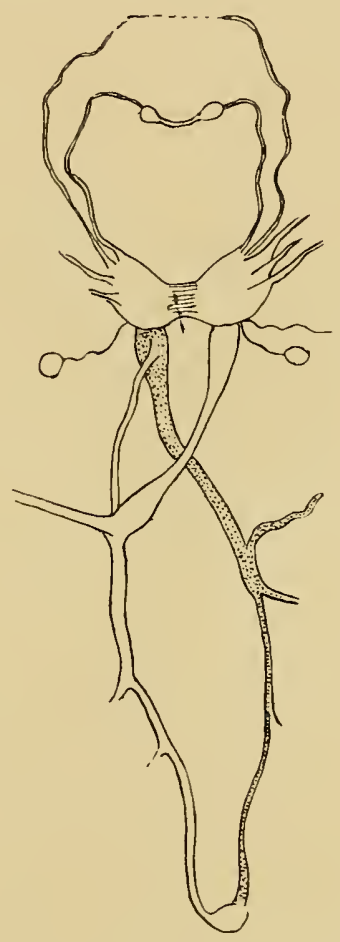

Fig. 45.-Nervous system of Neothauma tanganyicense from above.

ditch or groove, overhung by a flap, and terminates somewhat forward on the body-wall.

An exactly similar state of affairs is present in Littorina, and I found it also very well defined in the specimen of Faunus. In all essential details the female apparatus of 
Zonata repeats that of the make, but there is neither an external groove nor pouch.

NEOTHAUMA, SMTH.-N. TANGANICENSE.

An examination of the animal contained in the remark-

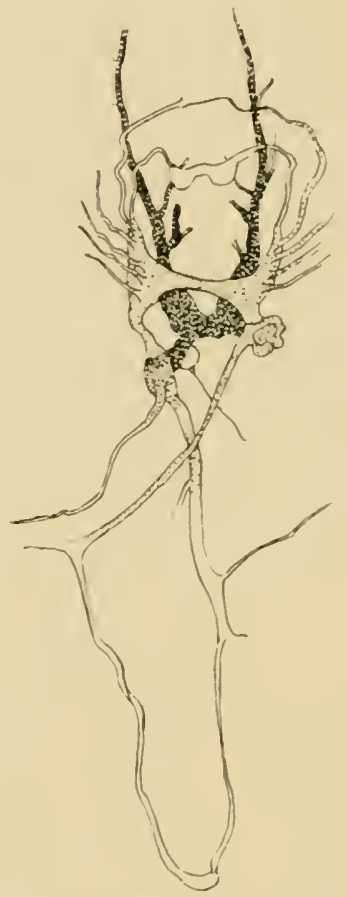

Fig. 46.-Nervous system of

Vivipara from abore.

able shell to which Smith applied the name Neothauma, and some details of which I have already published in the Proceedings of the Zoological Socicty, has established the fact that Neothauma is a close ally of the genus Viripara. It differs, however, from Vivipara in several details which are quite sufficient to allow the mollusc to continue to be 
considered as generically distinct from Vivipara. The chief of these distinctions are found in the size of the animal, the remarkable characters of its shell, and in the cirrangement of its nerves.

In the nerves we find a very pronounced difference from Vizipara constituted by the existence of a strongly marked zygoneurous connection on the animal's left side, while at the same time the cerebral ganglia are closely approximated together and the pleurals are applied to them below, instead of being separated from the cerebrals in the manner so characteristic of the Vivipara. (Compare Figs. 45 and 46.)

Neothauma remains therefore generically distinct from Vivipara, but it is doubtful whether it should be regarded as a member of the Halolimnic group.

Stanleya appears to be related to the nerilidx, and therefore is probably not a member of the Halolimnic group. 


\section{CHAPTER XI.}

\section{THE FAUNA OF LAKE TANGANIKA.}

OF THE NATURE OF THE HALOLIMIC GASTROPODS.

TuRNing from the foregoing survey of the structure presented by the halolimnic gastropods to the question of what relationship they bear to the different types of prosobranchiate molluscan organisation with which naturalists are acquainted, it is necessary, in the first place, to sort out the halolimnic forms themselves into separate groups, for it will have become apparent that some of these exhibit more or less close affinities one with another, while others do not.

Thus the genera Typhobia and Bathanalia are unquestionably close allies, and we may consequently speak of them as characterising a Typhobian group. Limnotrochus and Chytra show closer affinities with each other, than with Typhobia and Bathanalia, and thus may be said to constitute a Limnotrochoid group. IVe saw, further, that the genera Paramelania and Bythoceras, although they bore certain relationships to the members of both the above groups, were quite distinct from either of them, and, consequently, these genera form a third or Paramelanian group. Further, we found that Tanganyicia, although it bore a certain resemblance to all the preceding forms, was quite distinct from any of them, and forms in itself a fourth, 
or Tanganyician, type of structure; and lastly, in like manner, Spekia and Nassopsis are quite distinct from all the other members of the halolimnic series, and consequently form a Spekian and Nassopsian form of organisation, which we shall have to consider. We have, in short, six different types of gastropodean structure, the affinities of which it is desirable to attempt to determine and come to some conclusion as to what they are. It will have become apparent to anyone who has read the preceding descriptions, and who at the same time also happens to be au fait with the existing researches concerning the anatomy of the proso. branchiate mollusca in general, that it is a highly remarkable fact that all these halolimnic forms, notwithstanding their wide structural diversity, present the same peculiarities in the form and arrangement of their alimentary parts. Thus they all present a short, straight œsophagus, a similarly, and curiously coiled intestine, which leaves a stomach with two chambers, the anterior chamber containing in each case a crystalline style. Such a similarity of their alimentary parts might conceivably mean one of two things. It might be due to similarity of physiological conditions which affect them all in Lake Tanganyika, or it might be due to all of them having diverged from ancestral forms which possessed such an arrangement of their alimentary parts. That this curious similarity in the alimentary tract in all the halolimnic gastropods is not due to physiological agencies, i.e, is not the product of similar conditions acting to produce the same kind of stomach in diverse organisms, is, I think, capable of being made quite clear. In the first place, the halolimnic gastropods live under widely different conditions, some being shore-dwellers, and thriving in the scorching tropical sunshine, and the rough surf which usually beats upon the rocky shores of Lake Tanganyika, 
while others are inhabitants of the quiet dark water which covers the deep floor of the lake. In the second place-and it is this fact which will carry most weight-the type of alimentary canal which the halolimnic gastropods present is not confined to them, but is present in part or in its entirety in very widely divergent oceanic forms. IVe have only to compare the alimentary canal of Typhobia with that of Strombus to see that both are built entirely on the same plan. In each there is a straight asophagus, a curiously bent intestine, a stomach with two chambers and a crystalline style. Still further, we find that the possession of an anterior stomachic chamber and a crystalline style is not confined to the prosobranchiate mollusca; it occurs also, and presents the same relationships in the Lamollibranchiata, and, when we realise this fact, there can, I think, be little doubt, as the investigations of Collier, Huxley, Woodward and myself have tended to show, that the type of alimentary apparatus which is found in the Lamellibranchiata, in Strombus, Pteroceras, Bithynia, and which now turns up again in every member of the halolimnic group, is indicative of a retention in them all of a primitive type of organisation which once belonged generally to the older molluscan forms.*

As a group, then, and, taken as a whole, one of the most remarkable characters which the gastropods of the halolimnic series possess is, that they all present a similar and primitive character in the arrangement of their alimentary apparatus, and consequently appear to be a series of forms which retain the characteristics of a time when most gastropods

* This view has been strikingly confirmed by a comparison recently made by one of my students and myself between the gastric apparatus of Spirula, Nautilus and Nassopsis, whereby it was shown that the style sac of the Gastropods is unquestionably present in the ancient Cephalopods as well. I'ro. Koy. Soc., vol. 70, p. 231 . IS92. 
possessed a similar primitive type of alimentary canal. Or, in other words, it would appear that we have in these features a clear indication that the halolimnic mollusca are primitive as a whole. When, however, we try to push their relationship further, we find that owing to the present unsatisfactory state of our knowledge of the Prosobranchiate group of gastropods, it is by no means so simple an affair as one might suppose, even after having carefully examined the anatomy of each of the members of the halolimnic series to determine satisfactorily with what recognised groups their affinities really lie. Something of the nature of these difficulties will become apparent if we consider the following facts. In the first place, Typhobia and Nassopsis have been already said to belong to the Melaniadæe by the conchologists, but from what we now know about the very wide morphological difference which distinguishes the organisation of Typhobia from that of Nassopsis, it is quite clear that both these organisms cannot possibly be regarded as belonging to the same family. If one of them is a Melania, the other is not. And, as a matter of fact, what is a Melania? The genus Melania was founded by Lamarck upon the Madagascan species, Melania amamula, but as Bouvier rather plaintively points out, there is not one single anatomical feature which can be said to distinguish $M$. Amarula from Cerithium vulgatum, a form which, according to existing classifications, is relegated to another family, the Cerithida. Melanopsis, as Bouvier found, is as widely separated from the type of Melania in one direction as Nassopsis is from Typhobia in another; and these few examples will, it is trusted, bring to light the fact that the so-called group, the Melaniadae, is no real group at all ; as it exists in the literature of to-day it is an entirely heterogeneous assemblage 
of Prosobranchs, which have simply been lumped together through the still prevailing and pernicious habit of using conchological characters to distinguish species, and also because, as Bouvier remarks, a large number of forms, the wide anatomical differences between which are not apparent in their shells, have a fresh-water habit, and have, in consequence, been supposed to belong to a single morphologicai group.

If we take Melania amarula as a typical Melania, the Typhobia group in Tanganyika has nothing to do with the Nelaniadre at all. All the members of this group are at once and completely dissociated from such a form-(I) by the character of their radulæ; (2) by the gastric structures which I have described, and which neither $M$. amarula nor any of the other known members of the so-called Mclania group possess; ; and (3) by a number of minor details, including the possession of an introvertible penis in the Tanganyika forms, the peculiar property of the. Typhobia group, and of which there is no trace whatever in M. amarula.

The radula of Typhobia and the radula of Bathanalia are remarkable, and are closely similar to the typical radule of the genera Xenophora, Strombus and even Capulas. In the characters of their nervous system the members of the Typhobia group approach both Melania amarula and Cerithinm, for they exhibit the shortening of the subintestinal cord, and the approximation of the left pleural and sub-intestinal ganglia, which is a characteristic of these,

\footnotetext{
* Since the above was written an examination of some of the so-called Melanias from the East Indian Islandi has shown that these, at any rate, possess a rudiment of the style sac, an olservation which tends to show that divergent and old types have, in different regions, independently taken to the fresh water of the land as memlers of the secondlary fresh-water series to which I have alluded in the second chapter of this work. The structure is also present in Turritella communis.
} 
and also of a number of divergent forms, such as Natica, Capulus, Cancellaria and Struthiolaria. In minor details the nervous system of the Typhobia group approaches more closely to that of Capulus and Cancellaria than it does to that of either Cerithium or $M$. amarula, while in the: curious features of their gastric apparatus all the members of the Typhobia group are really closely approximated to such forms as Strombus and Pteroceras and Aporrhais.

The members of the Typhobia group thus present a type of organisation which appears to stand at the parting of the ancestral ways of such widely divergent marine groups as those characterised by the following genera: Strombus, Pteroceras, Cerithium, Struthiolaria, Cancellaria, Aporrhais and Capulus; for each of these diverse, marine, modern gastropods contain, underlying their own peculiar specialisation, more or fewer of the characters which are compounded in the members of the Typhobia group.

A similar and still more interesting result is obtained from the comparative study of the two genera Chytra and Limnotrochus. The whole anatomy of Chytra is singularly like that of Capulus. We have in both forms the same arrangements of the nerves, the pallial connectives being identical in both genera. So also the radula of Chytra is curiously like that of Capulus, and it corresponds even in minor details with the ally of Chytra, Hippuyx. Chytra, however, differs from both these genera, and all their more remote naticoid allies in the possession of a style sac. And what is even more remarkable, in the retention in its stomach of a well-developed spiral cacum, a structure which, so far as I know, is only present in Nassopsis elsewhere among the Tanioglossa, but which, as is well known, is a characteristic feature of the stomachs of the more primitive Rhipidoglossa, such 
as Pleurotomaria and Trochus. ${ }^{*}$ From the character of the nervous system and the radula of Chytra we should have no difficulty in deciding at once that it comes very near the genus Capulus and its modern allies. But since it is not superficially modified either in its shell or foot, and retains the two very primitive characters in its alimentary apparatus which have just been described, and which neither the living Capulida nor their allies are known to possess, it is obvious that Chytra is ancestral with respect to them. But further, Chytra is possessed of many points of resemblance to Xenophora, and this rescmblance is by no means confined to the shell. The nervous system of Chytra may be said to stand half-way between that of Capulus on the one hand and Xenophora on the other. In the same way Chytra shows in the character of its foot an incipient stage in the modification which reaches its maximum in Strombus and Aporrlacis and their modern allies. These considerations indicate that we have in Chytra a form which quite satisfactorily connects up two fairly ancient marine groups, for it possesses the characters of Capulus and its allies, and also those of the Xenophorida themselves.

In Limnotrochus we have, as I have pointed out, an ally of Chytra, and the same inferences may be drawn from its structure.

'Turning now to the group of gastropods composed by the genera Paramelania and Bythoceras and their subordinate species, we find that all these forms, both in their radulae and nerves, present us with features which are distinctly similar to those of Cerithium; but they are at once dissociated from the Cerithoid group of Prosobranchs, by the peculiarities of their gastric apparatus and their posses-

- It has since been found in a reduced condition in Turritclla communis. See paper by W. B. Kandles, "Anat, Anz." 1902 ; Bd. xxi., p. 201. 
sion of crystalline styles. They are probably correctly regarded as a group of rather primitive Cerithoids, which anteceded both the Amarula type of Melanias and the
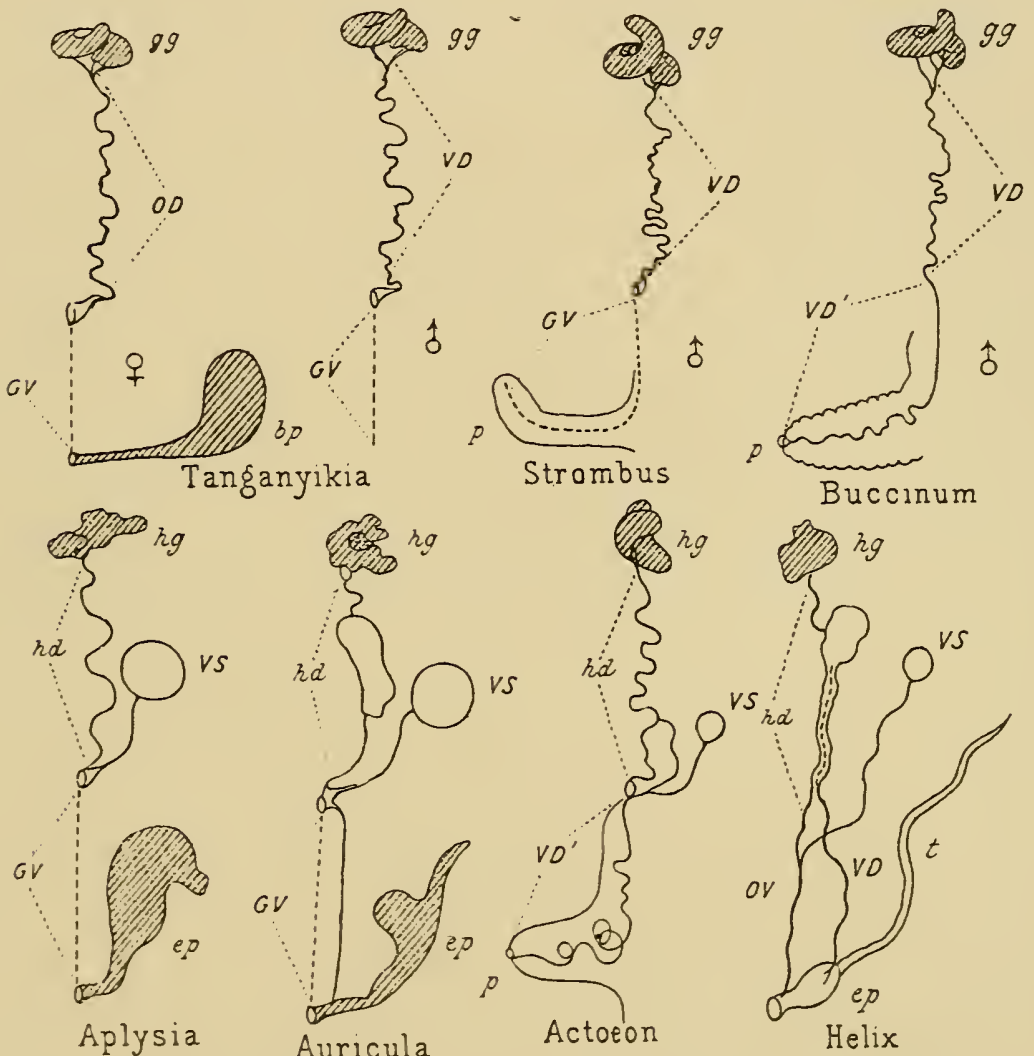

Diagram to show the modifications witnessed in the reproductive apparatus in a number of divergent gasteropods. $g \cdot g$, Genital gland. $V \cdot D$, Vas differens. $\quad 0 . D$, Oviduct. $G . V$, Genital groove. $\quad$ T.D, Enclosed portion of vas differens. b.f, Brood pouch. p, Penis. h.g, Hermaphrodite gland. h.d, Hermaphrodite ducl. I.S, Seminal vesicle. e.p, Evertable penis.

modern Ceriths, which are found now inhabiting the seas.

Tanganyicia is much more difficult to place; it possesses 
the Cerithoid nervous system and a feebly developed radula, the teeth of which might with equal propriety be regarded as approaching several diverse forms. In this group the most remarkable feature which is exhibited consists in the genital groove, which here leads into a brood pouch in the foot, on the left sicle of the head, a condition of things which may be simulated but is not repeated in any other form hitherto examined. If, however, the comparison which I have already drawn between the groove and the brood pouch in Tanganyicia; the somewhat different but analogous arrangement in $M$. episcopalis; the fragmentary appearance of parts of this apparatus in such forms as Strombus and Littorina; and the similar arrangement of grooves and introvertible penes in Opisthobranchs, be correct, we must conclude that Tanganyicia possesses an archaic character which may be encountered in part, or in entirety, in widely diverse molluscan types. See fig. on p. 273. Tanganyicia may thus be said to exhibit the morphological characteristics which we should attribute to those earlier members of the Prosobranchiate group which anteceded the modern forms typified by such genera as the Strombus and Cerithium of to-day.

In Spekia we have a form which, in its nerves, is unquestionably a naticoid, but which, in the absence of a number of the more specialised naticoid structures, such as the glandular masses related to the osophagus, and so on, is unquestionably simple; and the same conclusion is forced upon us, both by the early Cerithoid character of its radula and possession of the archaic gastric apparatus and crystalline style, characteristic of all the halolimnic forms. Speria would in many ways appear to be very like a primitive Rissoa.

Turning now to the last, and perhaps the most interest- 

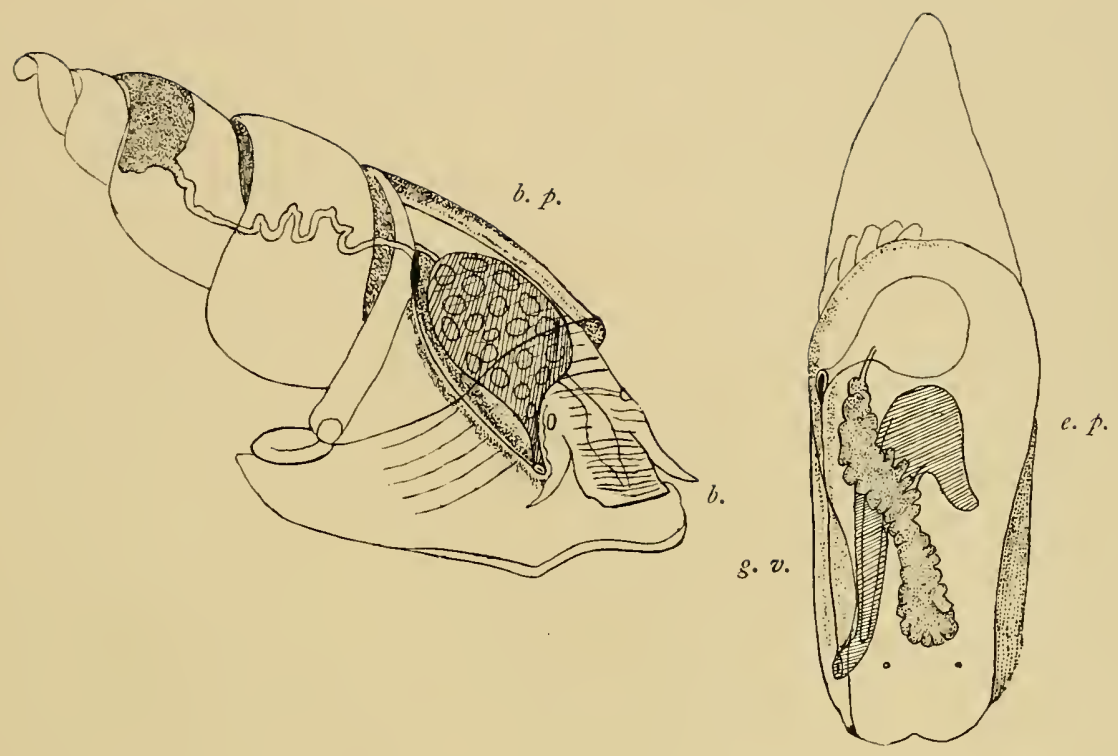

c.

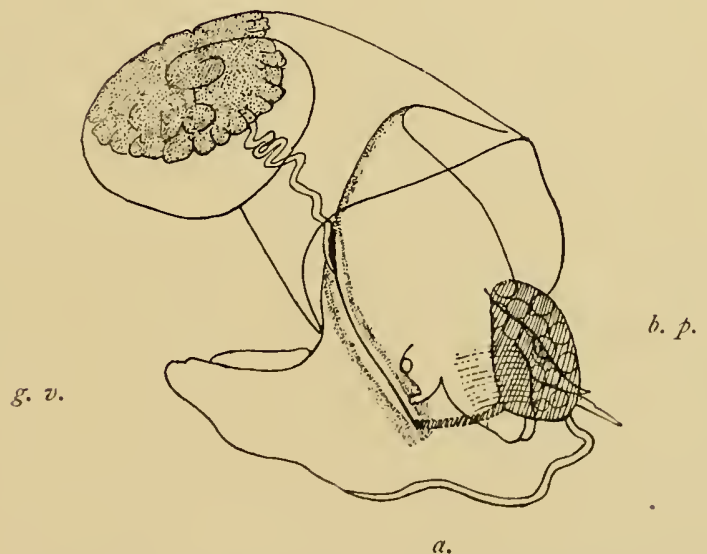

Diagram showing at $a$ and $b$ the arrangement of the genital grooves and brood pouch in Tanganyicia rufofilosa and Mclania episcopalis. Compared with the opisthobranch Auricula c. g. $v$., Genital groove. b. p., Broud pouch. $\ell . p_{\text {., }}$ evertable penis. 
ing of the halolimnic gastropods, $N^{\prime}$ assopsis, we find ourselves confronted with a type of organisation which, from a morphologist's point of view, is at once important and unique. The radula of this form is somewhat like that of the genus Viripara, but it is much more closely similar to that of a number of Littorinas; in like manner, the nerves are arranged upon a plan which at once recalls the more primitive types of the Prosobranchiata and even the Rhipidoglossa themselves. To make this quite clear, I would, in the first place, point out that if we consider the disposition of the anterior ganglionic masses in the different groups of the Prosobranchiata, we find that in all the forms of the Rhipidoglossa, both diatocardiate, and monatocardiate, and their derivatives, the pleural ganglia are below the osophagus and closely applied to the pedal ganglia. And I have, consequently, spoken of this condition of the nervous system as being hypoathroid. In $N^{\prime}$ assopsis, Viripara, and some other forms of archi-tanioglossa, the pleural ganglia are more or less half-way between the cerebrals above and the pedals below the cesophagus. The ganglia are scattered, and I have, consequently, spoken of this condition as being dystenoid. In all the higher Tanioglossa and their derivatives, such as the Ptenoglossa, the Toxoglossa, and the Rachiglossa, the pleural ganglia are intimately related with the cerebral ganglia, both the cerebrals and the pleurals forming an almost indistinguishable ganglionic mass. And, in consequence, we may speak of this condition of the nervous system as being epiathroid when compared with the other two.

Nassopsis, like Vivipara, appears thus to stand half-way between the primitive Rhipidoglossate types and the higher Trenioglossa and their derivatives; and this conclusion is further driven home by the presence in $N^{T}$ assopsis of 
a labial commissure, which, as Bouvier has shown, is a special feature of the Rhipidoglossa and their allies. But, not only is Nassopsis an archi-tanioglossan in the character of its nerves, we find, as I have shown above, that this type has a most unique and primitive gastric apparatus; which, like Chytra, unites at the same time the presence of a style sac, and a style with the spiral stomachic cæcum common to the Rhipidoglossa. Nassopsis is thus, on anatomical examination, shown clearly to be a new type of archi-tænioglossa, and, consequently, a genus which will be of great value in the future study of the relationships of the different sections of the Prosobranchiata. As a matter of fact, Nassopsis, in the Rhipidoglossate character of its stomach, together with the possession of a crystalline style, is a much more striking archi-tænioglossate form, than even Vivipara itself.*

Having followed these matters relating to the affinities of Nassopsis, we have completed the consideration of the structure of the halolimnic gastropods in Tanganyika; and so far as our knowledge of the vast hordes of Prosobranchs which live in the sea and the fresh-water of the earth at the present time make such an attempt possible, we have estimated the affinities of the different individual members of the halolimnic group. None of these molluscs, as we have seen, appear capable of being regarded as in any way related to the fresh-water molluscs which exist elsewhere in the world to-day; while the whole group presents us with an array of characters which at once carries them back to the position of ancestors of the numerous forms, chiefly marine, which their structure appears distinctly to fore-

\footnotetext{
* For the reasons stated in the last chapter, I have not included the genera Niothaumus and Stanleya in the halolimnic group, while for Symolopsis we have as yet not sufficient material for a complete investigation.
} 
shadow. As a whole, they possess, not the structural peculiarities which we should expect to find in either the ancestors or the derivatives of the modern fresh-water molluscs, but they do possess those which we should expect to find in the individuals surviving as a relic fauna of some very ancient sea. 


\title{
CHAPTER XII.
}

\author{
THE FAUNA OF LAKE TANGANYIKA.
}

\section{CRUSTACEA.}

THE crustacean section of the fauna of Lake Tanganyika consists, so far as is at present known, of four conspicuous types. We have in the first place two genera represented by two species of aquatic crabs, Platythelphusa armata and Limnothelphusa maculata. The first of these was obtained by the French missionaries, and very briefly described several years ago by Milne Edwards in Paris. The second was acquired during the first Tanganyika expedition, being subsequently examined and described by Mr. Cunnington. Besides these crabs, there are two genera of prawns again represented by two single species-namely, Limnocaridina tanganyike and Palcmon moorei, both obtained also during the first Tanganyika expedition. All these four species are peculiar to Tanganyika, and apparently do not occur in any of the other great African lakes. There are besides a number of minute forms present in the lake which are widely dispersed throughout Africa, but since there is nothing remarkable about these, and since they appear to be 
quite well known, I have not dealt with them in the pre sent work.*

Limnothelphusa maculata was found in the deep water o Tanganyika, and the particular specimens examined and described by Mr. Cunnington were obtained to the south and west of the lake in water varying in depth from 500 to 600 feet. They were brought up in the dredge clinging to Neothauma shells and other objects, and were very active. I have, however, obtained the crab throughout the lake.

Platythelphusa armata was obtained by me only off the west coast of Tanganyika in nets and dredges which were being worked in water of about 20 fathoms. The prawns were found occasionally throughout the lake, and in the following descriptions of the above specific types I have but slightly adapted the material contained in the papers of Messrs. Cunnington, Calman and Milne Edwards. See bibliographs of expeditions at end of volume.

\section{LimNothelphusa MaCUlata + (Fig. I.).}

Regions and sutures on carapace moderately marked. P'ostero-lateral regions exhibiting an irregular series of small, slightly oblique and granular ridges. Postfrontal crest distinct, with median notch and partial lateral interruptions, but not extending to margins. Antero-lateral margins shorter than postero-lateral, armed with 2-3 spines, in addition to that at the outer angle of the orbit. Second joint of antenna extending to under border of front, and bearing a short flagellum. Chelipeds in the male unequal, subequal in the female ; merus rather short, trigonous, with spine on outer margin ; carpus with two spines on inner margin. Ambulatory legs rather long and slender. Colour (in spirit) light yellowish-l,own, with dark brown or reddish spots.

* It should be noted further that the same species of Thelphusa which are found about the shores of Nyassa and other great African lakes, occur also alout Tanganyika, lut since these crabs are practically terrestrial, I have omitted them from the Tanganyika list.

† Cunnington, "Prc Zoo. Soc.," Part III., I 899, p. 698. 

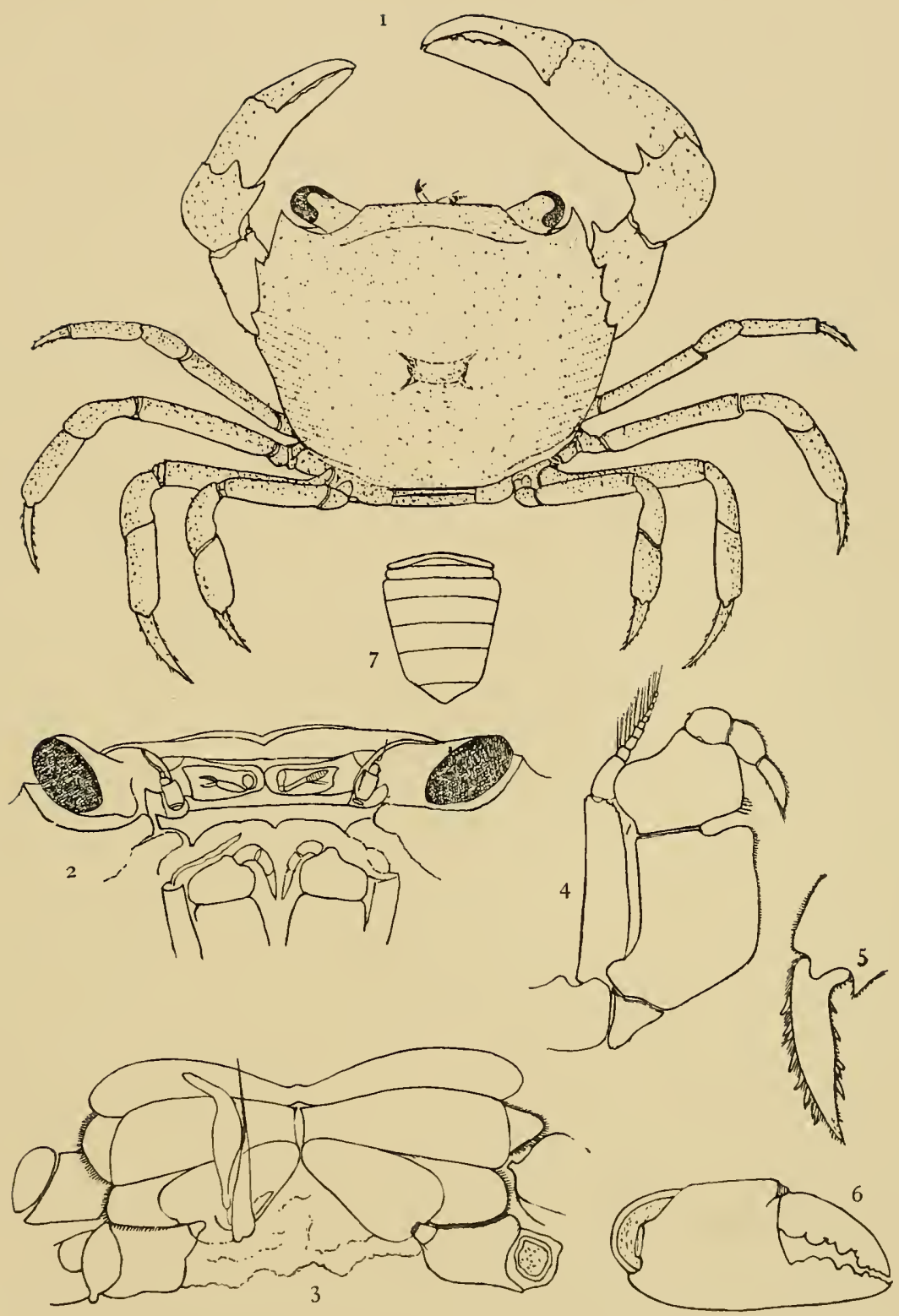

Fig. I.-Limnothelphusa maculata. I, Adult male, general view from above. $\times 21.2$, Ventral view of the anterior portion to show the relations of buccal frame, epistome, antennules, and antennx. 3, Ventral view of posterior portion of thorax, abdomen removed showing ahdominal appendages and male genital papille. 4, External maxilliped. 5, Dactylus of walking leg, to show the nature of the spinules. 6, Terminal portion of cheliped. 7, Male abdomen. (After Cunnington.) 
Dimensions as follows :-

Adult male (largest specimen) :

Length of carapace

Breadth of carapace

Length of larger cheliped.

Length of second amlulatory leg

Adult female :

Length of carapace . . . . 11.5

Breadth of carapace. . . . . . . . . 13.6

Length of cheliped . . . . . . . about 12.8

Length of second ambulatory leg . . . about I4.I

While the carapace is here, as throughout the Thelphusine group, broader than long, that condition is somewhat less pronounced, giving an effect of greater squareness. The great relative breadth of the front and size of the orluits are features also specially noticealsle, even at first sight. The prominent and distinct condition of the subocular tooth (Fig. 2,) seems characteristic, while a crenulated subocular margin forms a further point of difference from other members of the group. The antennules, with their large basal joints, are situated in the normal transverse position, and the antenne occupy the interior orbital hiatus. The external maxillipeds, while Thelphusine in character, and having well-developed palp-bearing exopodites, are, as will be seen from Fig. 4, certainly distinctive. The respiratory apertures, often so noticeable in its allies, are in Limnothelphusa very inconspicuous. In Fig 6 the rather finely dentated condition of the chelipeds may be seen, as also the fact that they end in sharp points tipped with a somewhat transparent yellowish cap of dense chitin. The styliform dactyli of the ambulatory legs, too, are furnished with longitudinal rows of spinules (Fig. 5) similarly tipped. That the male genital apertures (Fig. 3) are situated on papillix on the basal joints of the last pair of ambulatory legs may be easily marle out on removal of the abdomen. The abdomen itself is in both sexes distinctly seven-jointed (Fig. 7), and in the normal manner covers at its base the whole width of the sternum. As is also the case among its nearest allies, the penultimate segment of the abdomen is the longest. Nine pairs of gills of the perfectly normal type are sern on dissection.

One feature in which the specimens exhibit marked individual variation is the development of spines on the antero-lateral margins of the carapace. The presence of three spines in all is, perhaps, the most common condition; but additional more or less distinct spines may exist between these prominent ones, the culminating condition being that shown on the left side in the largest male specimen (Fig. 1 ). This individual is quite asymmetrical as regards these spines, a well-developed fourth and a suggestion of a fifth occurring on the left border, while the right edge shows only a partially developed fourth. This would suggest that a process either of multiplication or reduction of the lateral spines may he going on, since the largest specimens show what would be an extreme condition in either case.

Affrities.-Limnothelphusa finds its nearest allies among the Thelphusidze. Of the three sections into which Ortmann has sub-divided the group, the I'seudothelphusine and the Trichodactyline may be at once dismissed, as differing most markedly in the character of their external maxillipeds. This excludes the New 
World forms, leaving only, in the section Thelphusinæe, those typical of the Old World, though occurring also in Australia. The principal points of resemblance to, and difference from, the members of this group, which this Tanganyikan crab presents, may be conveniently stated in tabular form.

Points of resemblance to the Thelphusinæ :-

(I). Presence of distinct post-frontal crest.

(2). Conditions of sutures on carapace.

(3). Form of external maxillipeds.

(4). Character of chelipeds.

(5). Spinuliferous condition of ambulatory dactyli.

(6). Normal seven-jointeả nature of abdomen.

Points of difference from the Thelphusinæ:--

(I). Length of carapace more nearly equal to the breadth.

(2). Carapace considerably less vaulted.

(3). Antero-lateral margins relatively longer.

(4). Greater breadth and less deflection of front, with larger size of orbits and eyes.

(5). Second joint of antenna not distorted by deflexed front.

(6). Spotted nature of test.

Two genera only-Parathelphusa and Thelphusa-are included by Ortmann under the heading Thelphusine. Of these, Parathelphusa was originally supposed to be typically Indo-Nalayan in distribution, but in 1887 A. Milne-Edwards included under this heading several forms originally described as Thelphusa from the African continent. The genus Thelphusa is widely distributed over all parts of the Old World. Comparison with the large number of specimens belonging to these two genera in the collection of the British Museum showed that there are no forms which would seem to be closely allied to Limnothelphusa, but so far as general appearance goes, the specimens of Parathelphusa certainly agree most nearly. The latter have a carapace more elongated in proportion, have larger spine-bearing antero-lateral margins, and are considerably more flattened. The front, too, though deflexed, is less so than in Thelphusa. On the other hand, however, in several of the described species the abdomen of the male is of the so-called "hour-glass" shape, while in all one spine only seems to be developed on the carpal joints of the chelipeds, and the second antennal joint is distorted in the common manner. The condition of the chelipeds is, however, in some species of Thelphusa strictly comparable with that of Limnothelphusa, so that in this respect we may consider the new form as occupying a somewhat intermediate position between these two oldestablished genera.

Two other little-known genera, however, Hydrothelphusa and Platy'thelphusa, must apparently also be included in the group, though they are not mentioned by Ortmann. Of these, the former, from the streams of Madagascar, was first described in 1872 by A. Milne-Edwards. The description, however, was very brief, and though he has since given a further account, as well as a figure of the dorsal aspect, our information is still unfortunately very incomplete. The front here, instead of being deflexed, is said to be almost horizontal, while the carapace is onsiderably flattened 
and nearly quadrilateral. Only a single tooth, however, is present on the antero. lateral margin, in addition to that at the outer angle of the orlsit. With this the description of Platythelphusa, which actually comes from 1.ake Tanganyika, agrees in the main, lut the antero-lateral margins are, in contradistinction, multi-dentatc. Several figures of this form are given, but they are not, unfortunately, all one could wish. The figure of the antenne suggests that we ase clealing with a simple undis. torted condition of the joints, such as I have seen nowhere else lut in I Limnothelphusa, but the right and left antemne do not even agree one with another, according to the drawing. The fourth pair of walking legs presents a peculiarity in being rather short, while the terminal joints are somewhat flattenerl and expanded, presumably for swimming purposes.

Of the manner in which Limnothelphusa attained its present rlistribution in Lake Tanganyika there are two possible views. Either from a land Thelphusan it has become converted gradually into a wholly aquuatic type, or it may have entererl the lake more or less directly from the sea, at some time when a connection between thein was far more close than at present. It is generally accepted that the I andCrabs have descended from ancestors with a littoral habit, so that there would he no direct objection to the supposition that this creature has merely retained its primitive aquatic character, rather than regained it after adaptation to a terrestrial mode of existence. We can only come to a conclusion on this head by estiulating how far the general structure of the animal suggests simplicity on the one hand, or, on the other, specialization. The arched or vaulted condition of the branchial regions of the carapace in Thelphusa is evidently a specialization in connection with aerial respiration. That such prominent vaulting does not here exist is not surprising, lut though it is perhaps conceivable that this character, once attainerl, might be lost again on change of environment, it is, I think, more probable that such a conclition was never reached by Limnothelphusa. Again, as regards the less prominent deflection of the front in the latter, the condition appears rather primitive than secondarily acquired; while the simple nature of the second antennal joint, as compared with that of Thelphusa, which so much suggests a distortion produced ly. the frontal downgrowth, also supports this view. The greater number of spines occurring on the antero-lateral margins is a further feature, capable, however, of two possible interpretations. The carapace in but few species of Thelphusa bears more than one, and that a less prominent spine. If, then, we are dealing with a multiplication of marginal spines, we have an indication of greater specialization than that met with in Thelphusa, an indication contrary to the tendency of the other evidence. The other possible explanation, then, that a reduction towards the extreme condition of Thelphusa is in progress, would seem far more probal,le ; and it is a noticeable fact that the marine and littoral Crabs, from which we may suppose this form has been derived by comparatively slight modifications, are far more spinous than any of the modern terrestrial or flusiatile forms. Thus, while I'laty. thelphusa and Limnothelphusa would appear to be the most primitive of these Old World genera, Parathelphusa, in the less pronounced arching of the carapace and the more numerous lateral spines, would come as intermediate between them and the most specialized condition of Thelfhusa.

On the causes which have contributed to the present-day distribution of these genera, a word or two may be said. It is no very recent conception that Marla- 


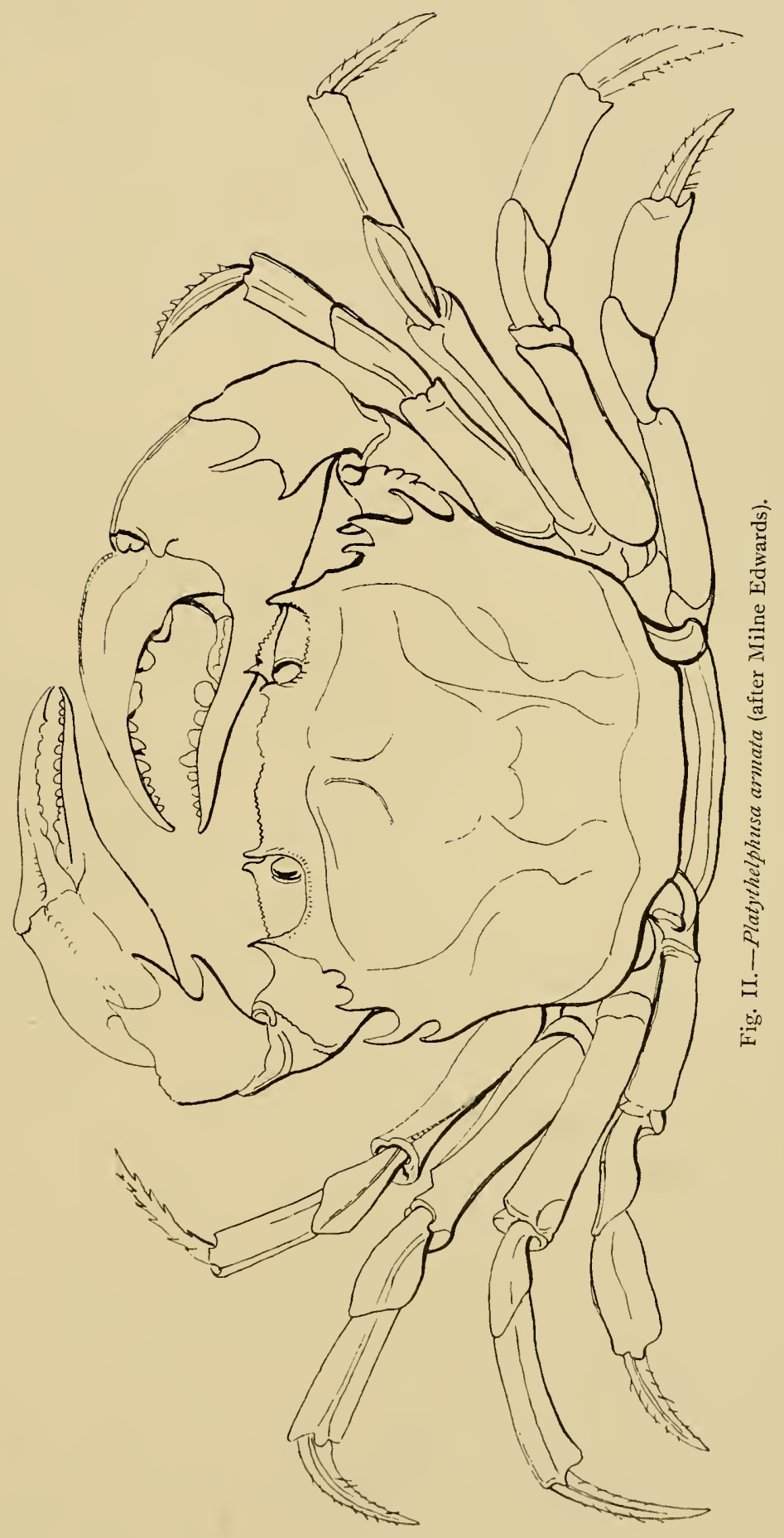


gascar and, through this island, the south of Africa itself, was perhaps at some remote period connected in a tolerably close manner with India. The present fauna of Madagascar, which shows marked Oriental affinities, lears this out; and from considerations of geological facts, particularly as regards the possession of a common flora in Carboniferous times, Blanford, following Suess and Neumayr, is inclined to regard the idea of a great continent, embracing Australia, India and South Africa, as by no means improbable. The evidence for such a land-connection is not confined to beds of quite such ancient date, however, for loth in Jurassic and Cretaceous times the fauna of the two areas is distinctly suggestive of the same continuity. If, then, we may imagine the ancestral Thelphusa as living on the shores of this early continent, in which the present Lake Tanganyika was represented as a narrow bay or fiord, it is not unreasonable to suppose that while Limnothelphusa, and perhaps Platy/helphusa, staying in the lake, retained most nearly the ancestral characters, IJydrothelphusa and Parathelphusa, still largely aquatic in habit, would resemble them more nearly than Thelphusa, many species of which spend most of their time upon land.

PLATYTHELPHUSA ARMATA (FIG. II).

The external characters of this remarkable crab have been briefly described by Milne Edwards, "Annales des Sciences Naturelles Zoologie," Tome III., p. I47, but as he had no example of the male, and at the time was not aware of the peculiar interest attaching to the Tanganyika fauna in general, it is to be hoped that the animal will be more studied in the near future, more especially so since the peculiarly marine aspect of the crab at once struck Milne Edwards himself. Thus he says: "This fresh-water crab presents such a great resemblance to certain marine or brackish species belonging to the Grapsides . . . that we might be tempted to relate it to them but for the development of the abdomen and the absence of metamorphosis." It is, however, obviously open to question how far such marks of distinction should be allowed weight.

Limsocaridina tanganite: * (Fig. III).

Description.-The rostrum (Figs. I-2) is very long and slender, gently recurved, varying from about $I_{\frac{1}{3}}$ to twice the length of the carapace, and extending beyond

* Calman, "Proc. Zoo. Soc.," I899. 


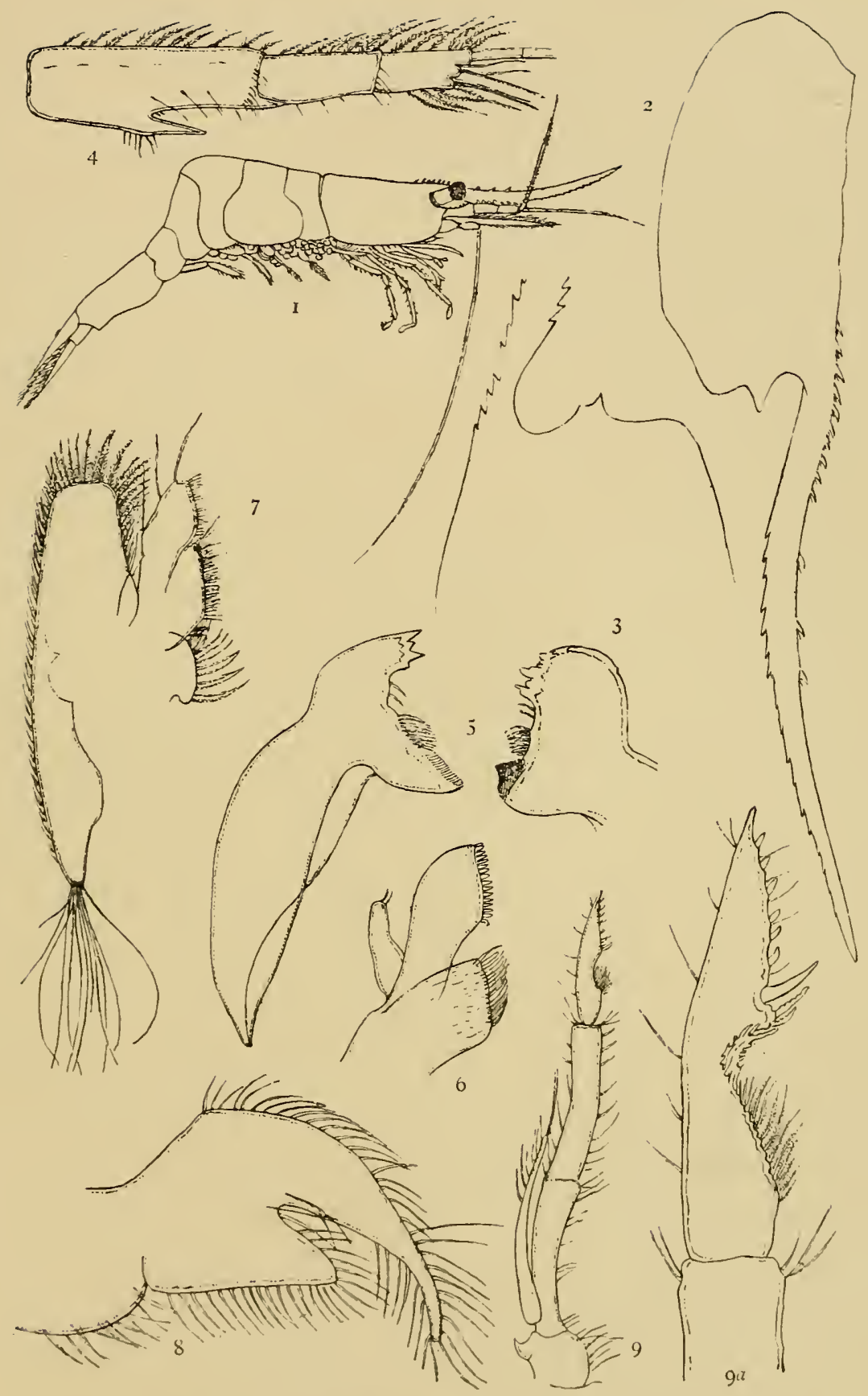

Fig. III.-Limnocaridina tanganyikio. I, Adult from the right $\times 3$. 2, Carapace and rostrum. 3, Caradina avyckii (Hickman) anterior part of carapace. 4, Peduncle of antennule. 5, Mandibles. 6, First maxilla. 7, Second maxilla. 8, First maxilliped. 9, Third maxilliped. 9a, Terminal joint of third maxilliped. (After Calman.) 
the antennal scale by $\frac{1}{3}$ to nearly $\frac{1}{2}$ its length. There are from $12-15$ teeth on its upper edge, three (rarely $(w 0)$ of which are lehind the orlit. The tecth lecome more widely spaced distally, and the last one is generally separated by rather less than half the length of the rostum from the simple, sharply pointed tip. The lower margin of the rustrum lears from ro-20 teeth, which extend quite to the tip. Below the orbit the anterior margin of the carapace is produced into a triangular tooth, lut there is no "antennal" spine such as is present in most species of Caridina, e.g., in C. wyckii (Fig. 3). A little way back on the side of the cara. pace, and below the level of the sub-orbital tooth, there is a well-marked "hepatic" spine. The lower anterior corner of the carapace is evenly rounded, and these is no pterygostomial spine.

The peduncle of the antennules (Fig. 4) falls short of the dista! tooth on the outer margin of the antennal scale. The first joint is about equal in length to the two succeeding joints together. The basal spine is small and slender, its tip falling short of the distal end of the joint by $\&$ the length of the joint. The short spine on the distal end of the first joint reaches to about is the length of the succeeding joint. The ocular peduncle is rather shorter than the first joint of the peduncle of the attennule.

The mandibles (Fig. 5) are somewhat dissimilar on the two sides. The cutting. edge is separated from the molar process by a shallow emargination, within which are set two stout sete (in C. wy ckii there is a row of about 10), followed at a little distance by a thick brush of finer sete just in front of the molar process.

The first maxille (Fig. 6) differ from those of Caridina, and such allied genera as Aty $a$ and Atyachly'za, in the smaller size of the two inner lolses, the inner edges of which are much shorter, while the lobe which in these genera represents the exoporl is here absent.

The second maxilla (Fig. 7) also depart somewhat from the type characteristic of the Alyidis. In the other members of the family the middle lobe of the endugnath (the proximal division of the lacinia externa in Boas's nomenclature) is very much expanded, overlapping both the other lobes and presenting a very long, straight, inner edge. In the present form this lobe is much smaller, its inner edge leing hardly longer than that of the clistal lobe, which it does not overlap. The proximal lobe, as in the other Alyide, is large and is overlapped for a short distance by the middle lolse. The scaphognathite is truncated anteriorly and produced to a point posteriorly, where it bears, as usual in this family, a tuft of very long, slender setix, hooked at the tip lut not presenting the curious swelling and tooth near the base which characterise these setre in C. wyckii.

In the first maxilliped (Fig. 8) the exopod tapers gradually from the base with hardly an indication of the external lobe (marked $a$ by Buas) present in Caridina as in most Eukyphota. The spipod, rudimentary in Carilina, scems to be quite absent.

The third maxillipeds (Fig. 9) extend forward as far as the end of the first joint of the peduncle of the antennules. There is on the outer surface of the coxal joint a conical curved papilla similar to, lut smaller than, the papilla (1) which the epiporl of this appendage, here absent, is attacherl in C. wy yckii. The exopod exceeds in length the joint from which it springs. The terminal joint is shorter than the penultimate joint, and presents a remarkable structure (Fig. $9 a$ ). About the middle 
of its length there is a deep excavation of the inner side, a little beyond which distally stands a stout curved spine; a double row of strong toothed spines smaller than the preceding, and gradually diminishing in size, fringe the distal margin of the notch; the oblique posterior or proximal margin is fringed with feathered or pectinate setæ. Beyond the notch, the inner margin of the joint bears a series of 6-7 short spines leading up to the pointed apex of the limb. I am not aware that an arrangement similar to this is found in other Atyidi. In C. wyckii there is only a rery slight concavity of the inner margin of the joint, clothed with numerous spines and setæ.

The first pair of perieopods (Figs. IO, IOa) do not reach to the terminal joint of the third maxillipeds. The ischium and merus are short and subequal. The carpus is conical in shape, rather more than one-half as broad as long, about equal in length to the merus, and slightly longer than the palmar portion of the hand; it is slightly excavated distally on the inner side (Fig. IOa). The hand is long and narrow, the breadth being about one-third of the length. The fingers are slender, longer than the palm, spoon-shaped, but acutely pointed as seen from the side, instead of truncate as in $C$. wy'ckii. The opposed margins bear series of small stout spinules increasing in size towards the tip, but there is no strong terminal hook as in C. wyckii. The brushes of setre borne by the fingers are rery scanty compared with those of $C$. wyckii.

The second peræopods (Fig. II) reach forward as far as the tip of the third maxillipeds. The ischium is a little longer than the merus and about equal to the carpus. The latter is cylindrical and only slightly wider distally. The hand is longer than the carpus by one-third the length of the latter, and its breadth is less than one-quarter of its length. The fingers are very long and slender, about twice as long as the palm, sharply pointed, and with scanty terminal brushes.

The third pair of peræopods extend beyond the third maxillipeds when turned forward, and the last pair fall short of them. The dactylus is one-third to two-fifths the length of the propodus. The dactylus of the last pair (Fig. $13^{a}$ ) is similar to the preceding two pairs, having only a slightly larger number of spines on its inner margin, the numbers being from II to 15 in the case of the third and fourth perreopods, and from 16 to 19 in the last pair. In Caridina the dactylus of the last perreopods is longer and bears much more numerous series of spines than do those of the preceding two pairs. In a specimen of $C$. wy ckiz, for example, the dactyli of the third and fourth pairs bore seven and eight spines respectively, while the dactylus of the fifth pair was half as long again and had a row of 39 spines.

In the female, the first pair of pleopods (Fig. I4) have the endopod rather slender, pointed, and more than half the length of the exopod. In the male (Fig. I5), the endopod is a short orate leaflet about one-quarter the length of the exopod. In nearly all the specimens of both sexes the first pair of pleopods are turned forward, with the exopod lying above and external to the bases of the posterior perzopods. According to F. Muller ("Kosmos," IX. ISSI, p. I II), this is the position taken by these appendages in the living Atyoida, and he states that they serve to protect the entrance to the branchial chamber, the fringe of marginal setie acting as a sieve to exclude mud, \&.c.

In the second pleopods of the male (Figs. $17,17 \alpha$ ), the affendix masculina is a little shorter than the afpendex interna, and bears a number of stout spines. 
The telson (Fig. I 8 ) is about as long as the inner plates of the uropeck, with straight sides, tapering to the oltusely pointed tip which lears four spines, two short external and two longer internal, letween which latter spring threc plumose setie. On the dorsal surface of the telson are two pairs of spinules. In $C$. wirkii the tip of the telson bears eight spines, and the dorsal surface three pairs of spinules.

The gills are four in number on either side, three pleurol,ranchs, corresponding to the second, third and fourth perienpods, and one which I leclieve to be a pleurobranch (though it is difficult to determine the precise point of insertion) alowe the first pereopod. There are no epipods on the maxillipeds or peritopods, unless we regard as a rudimentary epipod the small papilla at the lase of the third maxilliped described above. In tabular form the arrangement is :-

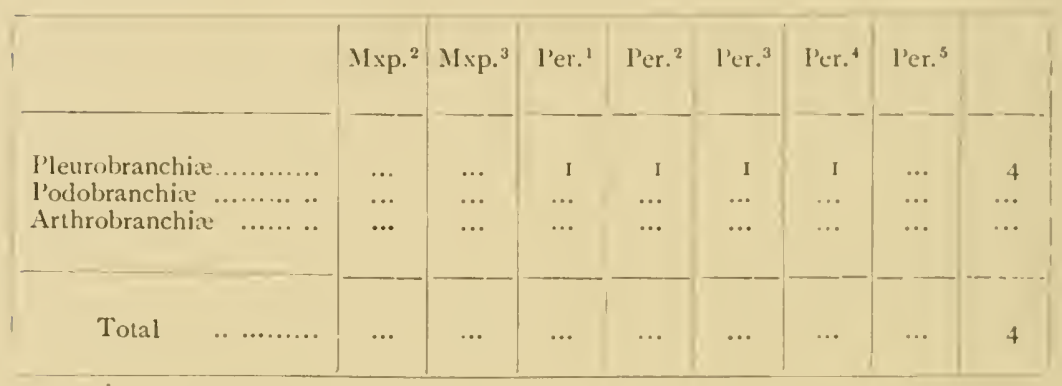

The statements of various authors as to the branchial formula of the genera of Atyidic are somewhat conflicting, but all agree in giving a larger number of gills and a complete series of epipods as far as the fourth perreopods.

In $C$. wyckit and $C$. typus I find the following arrangement:-

\begin{tabular}{|c|c|c|c|c|c|c|c|}
\hline & $M x p .^{2}$ & $M \times p .^{3}$ & ''er.' & Per. $^{2}$ & l'er." & l'er.' & l'er. ${ }^{3}$ \\
\hline 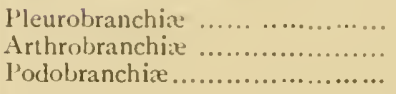 & $\begin{array}{l}\cdots \\
\cdots \\
1\end{array}$ & $\begin{array}{r}\cdots \\
2 \\
\text { ep. }\end{array}$ & $\begin{array}{l}\text { I } \\
\text { I } \\
\text { ep. }\end{array}$ & $\begin{array}{l}\text { I } \\
\cdots \\
\text { ep. }\end{array}$ & $\begin{array}{c}1 \\
\cdots \\
\text { ep. }\end{array}$ & $\begin{array}{l}1 \\
\cdots \\
\text { ep. }\end{array}$ & $\begin{array}{l}\mathbf{I} \\
\cdots \\
\cdots\end{array}$ \\
\hline
\end{tabular}

This agrees with the formula for Atya. Claus states that Troglocaris lacks the arthrolrancl of the first perzopod. According to Boas, Alyithyra desmarestii has no arthrol)ranch on the first per:eopod, and only one on the third maxilliped.

The males are usually somewhat smaller than the females, and have as usual the pleural plates of the aldomen less deep. In the female the two flagella of the antennule are of about equal length, and about twice as long as the peduncle, the outer flagellum being slightly thickened for about two-thirds of its length. In the male both flagella are much elongated, the outer being longer than the inner, and 
in uninjured specimens measuring more than four times the length of the peduncle, or about one-half the length of the body. The thickened basal part is more distinct than in the female. I have not observed any sexual difference in the armature of the walking-legs or of the maxillipeds, nor in the shape of the anterior margin of the carapace, such as are described by Muller in Atyoida.

The eggs carried by the females are ovoid in form, measuring about .1 $8 \times .27 \mathrm{~mm}$.

Total length of largest specimen $(q), 23 \mathrm{~mm}$.

Many specimens of this form were collected in shallow water.

Comparing the new form with the other genera of Atyide as revised by Ortmann ("Proc. Acad. Nat. Sc.", Philad, 1894, p. 397), we find that (like all other higher Atyidx) it differs from Xiphocaris, Troglocaris, and Aty"ephy'ra in the absence of exopods from all the peræopods. It resembles Caridina and differs from Aty $a$ and Atyoida in the fact that the carpus of the second peræeopods is not excavated distally. It further agrees with the majority of the species of Caridina in the compressed and serrated rostrum, which, however, is much longer than in any species except $C$. gracilirostris de Man. It appears to differ from all except C. singhalensis Ortm. and C. brevirostris Stm. in the absence of a distinct antennal spine on the front of the carapace, and it certainly differs from all the species of Caridina, and, I believe, from all the other Atyidia, in the possession of a hepatic spine. The differences noted above in the shape of the first maxilla, the first maxilliped, and especially of the second maxilla, may possibly be of generic importance, as may also the fact that the dactylus of the last perropods does not differ markedly from those of the preceding pairs.

The most striking and important character, however, is the reduction of the branchial system. This has not been examined (so far as I know) in Xiphocaris, but the closely-allied Troglocaris possesses eight gills (Claus). Atyaphyra, seven (Boas), Atya scabra and Caridina wyckii and typus, nine; while there is no reason to anticipate any very great divergence in the closely-allied Atyoida or among the numerous species of Caridina which have not been examined in this respect. Further, all the forms hitherto examined possess (with a possible exception, as above noted, in the case of Atyoida) a complete series of epipods on the thoracic appendages. In the present form there are only four gills and no epipods at all.

While there appears to be room for a further revision of the Atyidre based on a more complete examination of their morphology than that recently given by Ortmann, it seems plain that the form now described stands sufficiently far apart from the other members oi the family to require the creation of a new genus for its reception.

\section{Palimon MoORei, ${ }^{*}$ (Fig. 4.-20).}

Description.-Rostrum (Fig. 20) horizontal, a little longer than the peduncle of the antennules and equal to or sherter than the antennal scale. The nearly straight upper edge bears II-I 3 teeth, of which three are on the carapace, the fourth being just over or a little in front of the posterior margin of the orbit. The distal tooth is close to the tip. The lower margin lears 3-4 teeth, the first being above the end of the first joint of the antennular peduncle. The usual antennal and

$$
\text { * Calman, "Pro. Zoo. Soc.," I\$89. }
$$


hepatic spines are present on the carapace, the surface of which is elsewhere smouth. The third maxillipeds extend beyond the peduncle of the antenna by the length of their last joint. The first pereopods (Fig. 21) extend to or a little lejond the lip) of the antennal scales. The carpus is rather longer than the merus, and more than half as long again as the hand.

The second peritopod of a male specimen (Fig. 22) is alout two-thirds the length of the loody, and the distal end of the merus extends to leyond the midklle of the antennal scale. The carpus is equal in length (o) the merus, somenhat expanded distally, where the breadth is alout one-fifth of the length. The hand is rather wider than the distal end of the carpus, not perceptibly compressed (the two diameters are about as $5: 6$ ), a little less than twice the length of the carpus. l'alm shorter than the carpus, and rather shorter than the fingers. Fingers straight, meeting along their whole length; inner margins with smouth cutting-crlgres, without any trace of teeth save a single very minute tubercle near the lase of the dactylus. The surface of the whole limb bears widely-scattered very minute setit : on the distal part of the carpus and on the inner side of the paim are a number of small spinules. The succceding pairs of perreopods are long and slender, the fourth pair extending leyond the antennal scale. The dactylus is nearly one-third the length of the propodus.

End of telson (Fig. 24) with a sharp median point, longer than the outer lut shorter than the inner pair of terminal spines.

Seven specimens, most of them very imperfect, are in the collection ; only one of the large chele is preserved. One specimen is a female carrying ova. The species was dredged at a depth of 50 fect.

Length of largest specimen ( 8 ), $25 \mathrm{~mm}$.

Length of origerous female, $23 \mathrm{~mm}$.

Length of specimen figured $(\delta), 18 \mathrm{~mm}$.

Length of second perieopod of same, $11.5 \mathrm{~mm}$.

The species appear to fall into the group Eupalimon as defined ly Ortmann (Zool. Jahrb., Abth. f. Sy'st. v. I\$91, p. 696), in which the second perieperels are cylindrical, while the equality of the merus and carpus of these appendlages and the characters of the telson will bring it into proximity with such species as I'. scabriculus Heller and I'. endehensis de Man. I'. niloticus koux, the only species known from North America, is somewhat similar to the present form, hut, so far as can be judged from the more or less defective figures and descriptions of Roux (Ann. Sc. Nat. xxviii. I $\$ 33$, p. 73, pl, vii. f. 2) and Klunzinger (\%eitschr. f. wiss. Zool. xvi. 1 866, p. 357, pl. xx.), appears to present distinctive characters. Both these authors figure the rostrum with a very convex upper edge. Klunzinger gives the number of serrations as $\frac{9-1}{1-2}$, Roux figures $\frac{11}{5}$. According to the figures of both authors, however, not more than one tooth appears to le lehind the orlit. Both show the carpus of the and pereopod to le distinctly shorter than the merus, and much more than half the length of the hancl. Klunzinger's figure of the cleta shows it to be more slender, with the palm less inflated and the fingers longer than in our species.

Neither of the species can le depended on as throwing any light on the general question of the origin of the Tanganyika fauna. The grenus I'alemon contains 


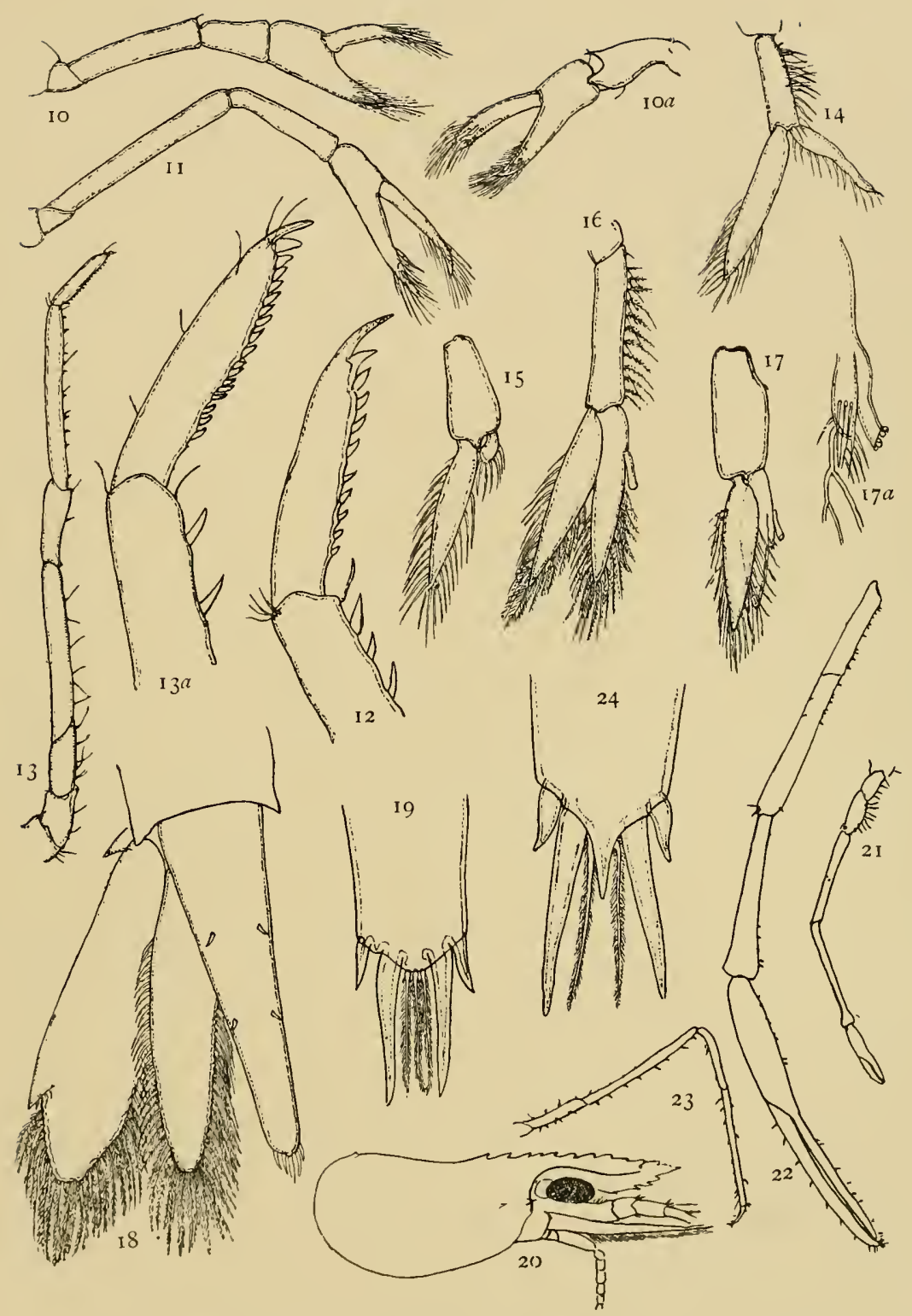

Fig. 4.-Limnocaridina Tanganyike and Pakemon moorci. 10, First pereopod, outer side. IO $a$, Inner side. I1, Second peraopod. 12, Dactylus of fourth peraopod. 13, Fifth percopod. 13a, Dactylus of same. 14, First pleopod of female. 15, First pleopod of male. 16, Second pleopod of female. 17, Second pleopod of male. 17a, Appendix masculina and appendix inferna. I8, Tail fan. I9, Apex of telson. 20, Paliemon moorei. Carapace. 21, First peræopod (more highly magnified). 22, Second peræopod. 23, Fourth perieopod. 24, Apex of telson. (After Calman.) 
about 50 species, of which only two are said to be marine. It is closely allied to Leander, in which, conversely, the marine species greatly preclominate, while both genera have numerous allies among the littoral fauna.

Limnocaridina belongs to the Alyidie, a circumtropical family of freshwater forms whose probably somewhat distant allies are supposed by (Ortmann to be found in the deep-sea Acanthephyridie. It is a near ally of Cirridina, an extensive genus, of which one species is known from the West Indlies, while the rest occupy countries bordering on the Indian Ocean from S. Africa to Australia ; one species occurs in the Nile and the rivers of Algeria. One species, $C$. wyckii, has a range extending from East $A$ frica to Queensland and Celebes. It is noteworthy from the point of view of the present case that Caridina is not known to occur in West Africa. Our form from Tanganyika is in the meantime an isolated species, and the characters that it presents are not those of a primitive type, but rather of a somewhat specialized form. 


\section{CHAPTER XIII.}

THE TANGANIIKA POLYZOAN.

An examination of the shells dredged up in Lake Tanganyika, upon which there were visible organic incrustations, has revealed the fact that, besides sponges, the lake fauna presents at least one species of polyzoan. The organism in question was first observed upon a Paramelania shell, which had been dredged in about twenty fathoms of water off the east coast, and upon the surface of which there was visible a cellular incrustation, looking, under a lens, very like a Flustra colony, but somewhat more irregular. Moreover it would be seen that the tubes of the cells were prolonged outwards and of considerable length. The colony covered about a square inch of the shell, and upon others there were subsequently found smaller colonies and individual groups of two or three cells. In all cases, however, they presented the irregular branched outline seen in the figure given on page 296, the organism tending to form a loose mat covering the surface upon which it grew.

This polyzoan is gymnoleamatous, and is consequently of great interest, since up to the present time only a very few forms of gymnoleamata, Paludicella Victorella and the like, have ever been found in fresh water. The Tanganyika species does not correspond, however, with any of the above forms, and it is of further interest, since it presents 


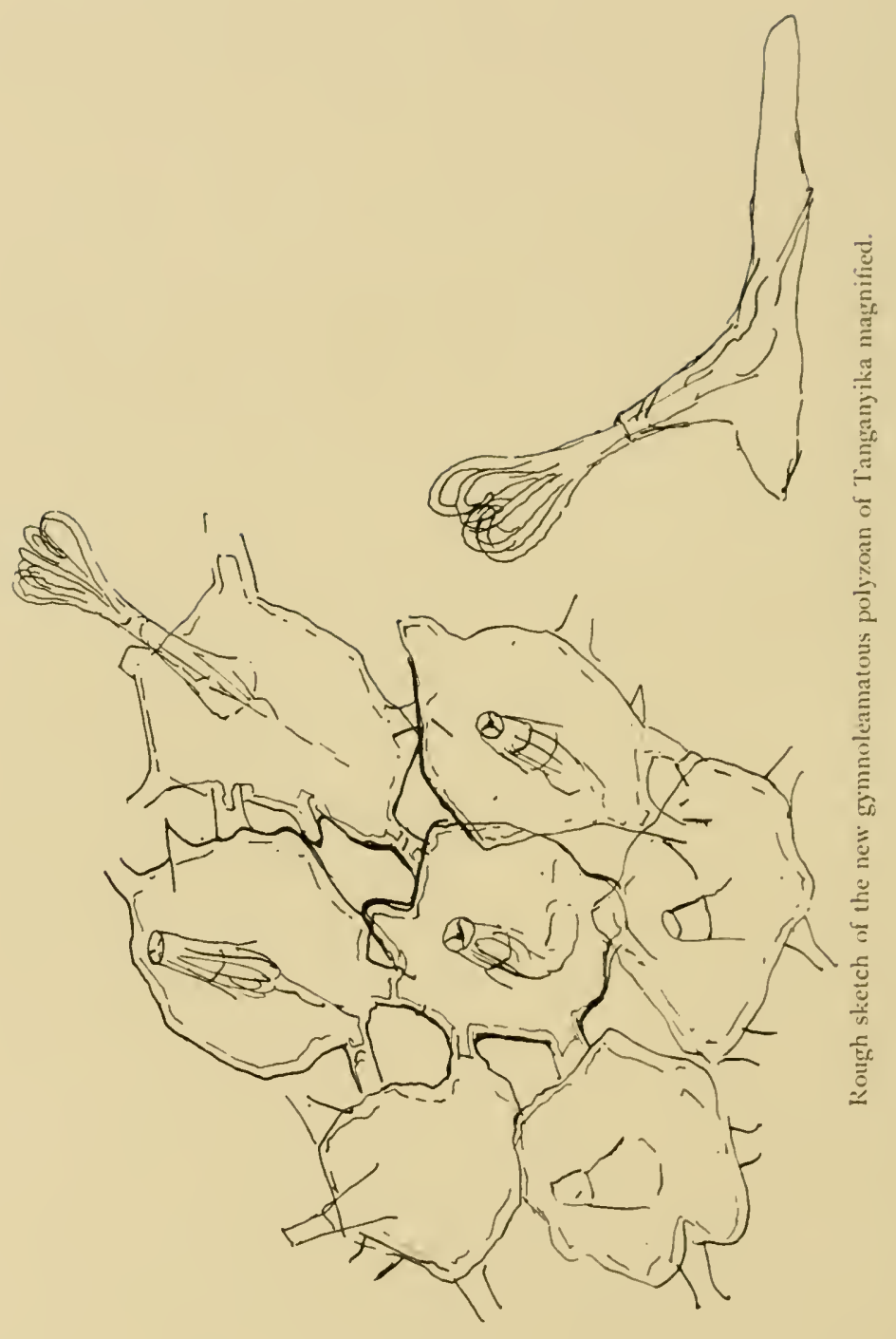


us with the first instance of an incrusting gymnoleamatous fresh-water form. So far as I have been able to compare it with the known marine forms of the gymnoleamata, this new species from Tanganyika does not exhibit a close identity with any of them. The colony in its general character, and in some special features of the individuals of which it is composed, is not at all unlike the marine genus Arachinitim, and but for the greater irregularity of the ceils and the longer tubes which are associated together in the Tanganyika species, I should have been inclined to place it in that genus. Still, considering its remarkable habitat, these structural distinctions, and also that I have not yet had time to completely investigate the matter, I think that the method least open to objection is to form a new genus for its reception, and I therefore propose the generic and specific names of Arachnoidia ray lankesteri, leaving a fuller description of the organism for a separate memoir. 


\section{CHAPTER XIV.}

\section{THE TANGANYIKA JELLY TISH.}

The remarkable organism, Limnocnida tanganyica, or the Tanganyika jelly fish which originally caused interest to centre in the question of the nature of the aquatic faunas of the great African lakes, was first observed, as I have said, by Dr. Böhm and afterwards by Von Wissmann. Finally by the efforts of Mr. Frederick Moir, who forwarded osmic acid and spirit to Central Africa, Mr. Swann succeced in preserving some specimens on the Lake. The material thus obtained was sent to Dr. Guinther at the British Museum, who in turn handed it for examination to his son. The result of this examination appeared later in two papers, a short general account of the animal's anatomy published in "The Annals and Magazine of Natural History," and some further details which subsequently appeared in "The Quarterly Journal of Microscopical Science."

As these accounts have now been in the literature some years, it has appeared to me to be unnecessary to go into details with respect to the structure of the adult animal in the present work. It will suffice to say that the jelly fish is a true Craspidote Medusa, as Böhm originally described it ; that when adult it varies between the sizes of a one and a two-shilling-piece; that it is during life nearly as flat as these respective coins, and that it carries its long tentacles 
stiffly arrayed above the bell in the manner represented in Fig. I. It is a truly pelagic form, being often encountered in the deep open water of Lake Tanganyika, where it is seen slowly pulsating at all depths, and during life is so glassy as to be almost invisible. Its chief anatomical peculiarities are constituted by the broadness and shortness of the

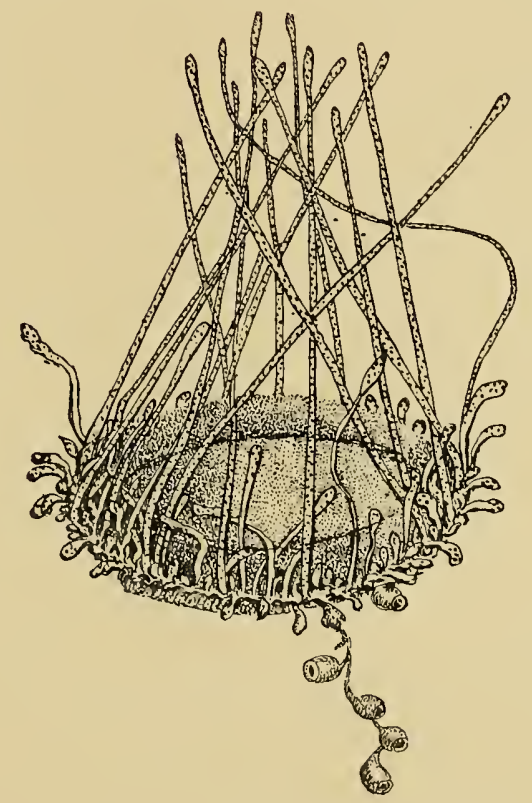

Fig. I.-Living asexual adult of the Tanganyika medusa, enlarged about one-third. To the right is seen a string of buds becoming detached.

manubrium, the diameter of which is generally about twothirds that of the whole disc. It is also so short that, when the animal is alive, it does not project beyond the velum. In association with these peculiarities we have a great development of mesoglea, forming the large lens-shaped mass that partially fills up the gastric cavity, and which, by its transparency, gives the organism the form of a ring 
when floating in the water and seen from above it, only the edge of the opaque manubrium and the adjacent circle of tentacles being visible. The radial symmetry is extremely simple, there are often in the adult only four short canals leading from the base of the gastric cavity. 'The animal is provided with remarkable marginal sense organs described by Mr. Giunther, and which are curiously like those of the only other fresh-water jelly fish about which anything definite is known, namely, Limnocodium sowerbii.**

Some of the tentacles are long and hollow, adhering at their bases for some distance to the outer surface of the disc, and these longer tentacles are symmetrically arranged between shorter tentacles in such a manner that several series of regularly alternating lengths are always to be found on a single specimen.

The animal forms asexual buds upon the manubrium, and at certain seasons distinct male and female individuals present clusters of sexual elements in the same position.

$U_{P}$ to the time of my own examination of Tanganyika nothing was known of the life history of this jelly fish, but I have been able to acquire a considerable body of information respecting this, and I am strongly inclined to believe that the organism, like some of the marine narcro medusa, is altogether without a hydroid phase. The following are, however, the facts:-I was able to observe the medusa in Tanganyika throughout the months of April to November, but it should be borne in mind that Tanganyika is so long that the climate differs in the south from that of the north of

* This is the form which mysteriously appeared and disappeared in the Victoria Regia tanks in the Botanical Society's Gardens at Regent's Park. It was described by I'rofessor Allman and l'rofessor Kay Lankester. It may' possibly have been introduced anong estuarine water plants from the rivers of South America: but it has never leen rediscovered there, and it has now gone. 
the Lake. In the south there is a long dry season lasting from May to September, then a short wet season lasting for some two or three weeks, then a spell of fine weather which usually continues till about the end of November, when the great rains begin, and these finally terminate in a succession of heavy thunderstorms and furious nocturnal gales during the early days of May. In the north, that is in latitude $3^{\circ} 30^{\prime}$ south, the seasons are more equal; the September rains

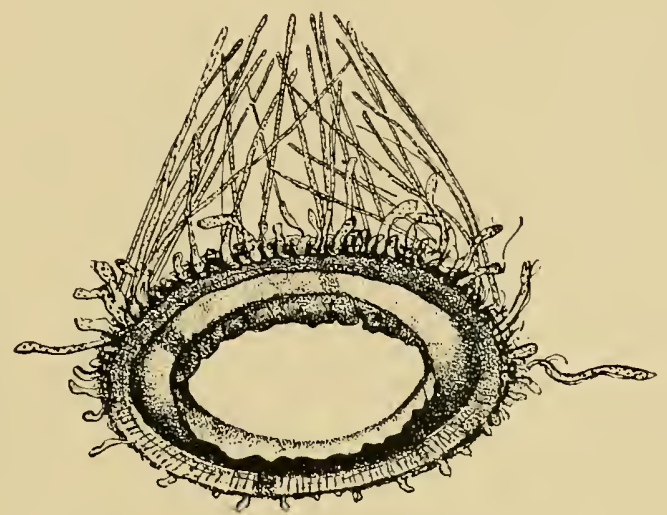

Fig. 2.-Living sexual adult of the Tanganyika medusa, showing the character of the manubrium.

begin sooner and last longer, while the long rains of the south are proportionately shortened, so that in this portion of the lake we really experience the true climate of the equator, where there are two short wet seasons and two short dry seasons, the rains occurring whenever the sun passes overhead on its way north and south.

The jelly fishes, however, do not differ in the phase of their life cycle in different parts of the lake, and consequently it is really incorrect to say that their metamorphosis corresponds in any way directly with the seasons. 
If we examine the lake in April, we find that there are very few meduse to be obtained; in fact the natives, who, unlike most Europeans, take a considerable interest in these matters, told me to begin with that there were none to be found at this time of the year, but after I had captured a large specimen myself, they informed me that they knew there were a few, but it took a great deal of trouble to find them till later in the season, and that, considering the state of the weather and the character of their boats, they had thought it better that I should be misinformed. They then volunteered some further rather startling and by no means incorrect, information. A well-made naked old man stood up upon a rock and gave me the following account:- "You white man," he said, "have come from far, from the cold land of the white men who smell like game; you come here with your long neck stretched out looking on the ground for that which is no use; you have seen many lakes in the countries to the south, in Nyassa land, where a little childlike white man is chief, but all the lakes you have seen are different from Liemba (Tanganyika) : they are blind lakes, asleep, Liemba, on the other hand, has the eyes, one of which you have just found. In the rain Liemba also sleeps; but when the clouds dissolve, and the night wind dies down before daylight as at this season, Tanganyika awakes like us, to look at the moon and the stars, and the lake is then full of eyes." This somewhat remarkable native statement I found, however, as a matter of fact, to be true. During the end of the wet season at the south end of Tanganyika, that is in March, only a very few large meduse are to be found. These solitary adults have thick, well-developed manubriums, and, if they are carefully examined, it is found that the outer wall of this structure is studded all over with 
small knobs, these knobs being, in reality, the initial rudiments of future medusoid buds. As the season advances such rudiments go through a rapid metamorphosis, they become definite hollow evaginations leading from the gastric cavity. The little pouches thus formed thicken at their apices, and an invagination of the ectoderm of the manubrium takes place at these points, each invagination becoming cut off from the exterior. The ectodermal lining of
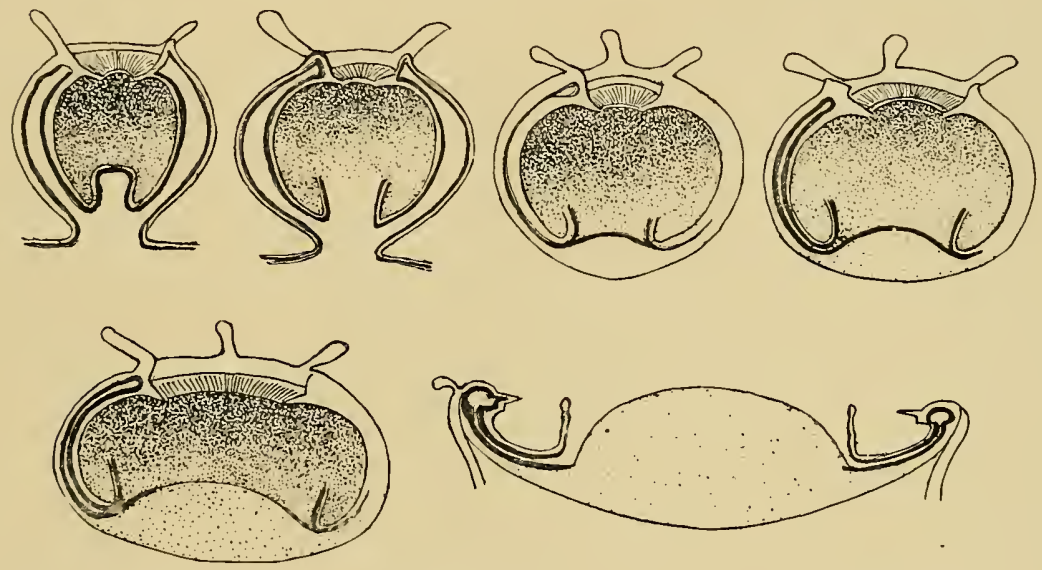

Fig. 3. - Semi-diagramatic representation of the formation of asexual buds of the Tanganyika medusa. The thick black line is the endoderm.

these cavities becomes the ectoderm of the interior of the bell and the manubrium of the growing bud, as well as forming the inner surface of the imperforate velum. Still later a second, shallower invagination takes place, forming the mouth of the bell, and within this the four primary tentacles are at first folded inward towards the centre of the velum. About this time the endodermal lining of the parental manubrium (which projects into the bud from its gastric cavity and forks into four radial canals) becomes thickened and folded, so as to form a rounded boss projecting into the 
cavity of the first ectodermal invagination of the bud, and quite visible from without. This is the rudiment of the manubrium of the bud. See Fig. 3. About this time the velum becomes perforated in its centre, the four primary tentacles stand stiffly out, and each small medusa, although still not fully formed and attached to the parental manubrium, pulsates with great vigour. By this time the bud has become much constricted off at its base, and as this tendency becomes greater the endodermal cavity of the manubrial boss breaks through into the cavity of the bell. forming the new manubrium, the gastric cavity of the parent opening for a short space of time actually on to the exterior, through the velum of the bud (Fig. 3). Finally the bud becomes completely detached, and at the point of separation there arises a rapid thickening of the mesoglia which forms the rudiment of the lens characteristic of the adult. This rapid thickening gradually pushes the endoderm lining the bud's gastric cavity up into the gastric cavity, which becomes continually wider and more and more filled up with the growing lens, until the endoderm lining the floor of the stomach is actually pierced, a small circular portion of the lens protruding through the endodermal lining into the gastric cavity itself as in Figs. 3 and 5. This protrusion rapidly increases, so that eventually the endoderm merely lines the walls of the shallow and widely-open manubrial tube and a circular ditch round the bulging lens. In buds which have been produced asexually in this manner it is found that, even before the above stage has been reached, their manubriums are already studded with a new generation of buds, which in turn go through the same process.

There is, however, sometimes to be observed, especially in the solitary parental forms, an interesting modification of 
this process. Instead of the evaginations of the manubrial wall of the parent leading into single buds, these evaginations branch, so that a short string of buds are, as it were, attached to a hollow pipe, and before the manubriums of these buds have broken through, the string of vigorouslypulsating individuals becomes detached, and for a time floats and swims about, presenting a singular analogy to a Siphonophoran (cf. Fig. I). Eventually the individual buds become constricted off from one another, and the

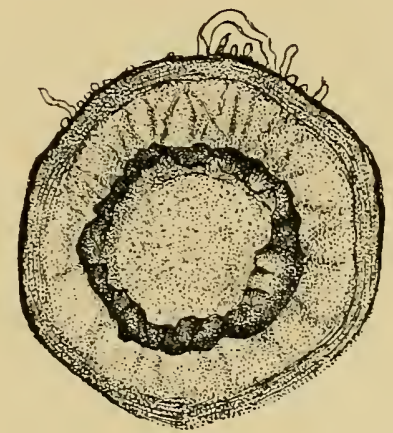

Fig. 4.- Toung asexual bud of the Tanganyika medusa $\times 10$, showing the base of the gastric cavity still lined with endoderm.

final stages of their evolution seems to be the same as that witnessed in the case of the sessile buds.

Returning now to the consideration of the life-history of Limnocnida, it has been seen that at the end of the wet season, that is in March, there are a few adult meduse in the lake which are only to be found with great difficulty. Such individuals begin about this time to bud, asexually, in the manner I have just described, and the buds thus formed, themselves produce buds, this process being repeated through many generations, so that in June and July the lake 
swarms with meduse; vast shoals of them, as I found, extending for miles and miles, and containing individuals of all sizes, but nearly all of them presenting manubriums which were covered with hundreds of minute developing buds. On the other hand, as the season advanced, more and more of the meduse encountered were not quite in this condition, and these distinguished individuals presented a

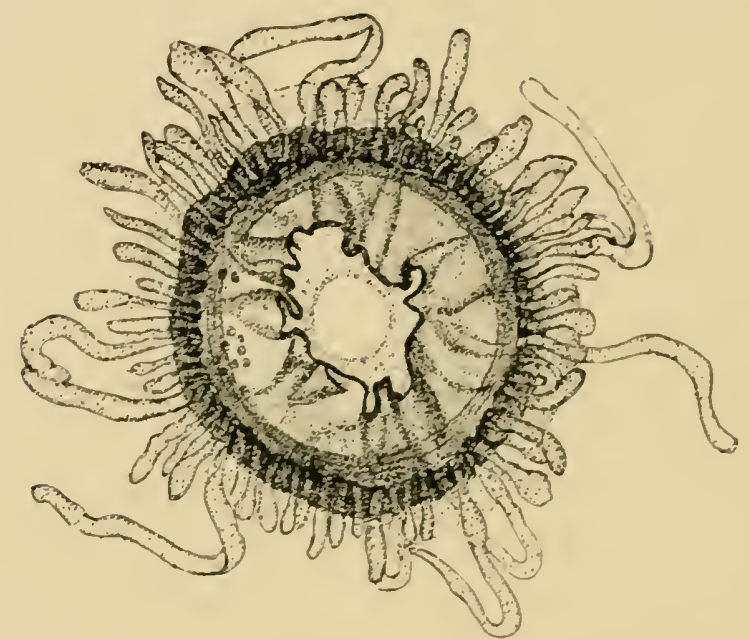

Fig. 5.-Kather older asexual bud $\times$ 5: showing lens break. ing through the endoderm lining the base of the gastric cavity. To the left there are to be seen on the outer surface of the iolded manubrium a group of a succeeding gencration of asexual buds.

very curious appearance indeed, many being almost, if not quite, destitute of manubrium. By an examination of numbers of individuals as the season advanced, I was soon led to the conclusion that this amanubriate condition was produced by the animals actually shedding the whole of the outer portion of the manubrium wall during the process of casting off their innumerable buds. Others again, during this period, were found with well-developed manubriums 
and had no buds. In such forms, however, sexual elements were already being developed in the manubrium walls. Still later in the season the budding process came gradually to an end, the lake swarmed with jelly fishes, and a large proportion of them were still almost destitute of any manubrium at all; but at the same time an increasing proportion were becoming completely manubriated and sexual. On my first expedition to Tanganyika this was as far as I

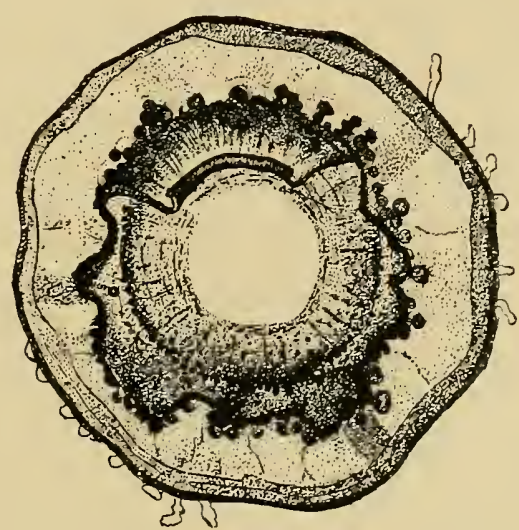

Fig. 6.-Still older asexual bud, showing succeeding generation of asexual buds upon the manubrium, a portion of which has already been shed, $\times 3 \frac{1}{2}$.

could carry the life cycle, but on the second I picked the story up again, finding that during September and October the manubriated individuals gradually disappeared, the manubriums being gradually re-formed, while sexually mature individuals now swarmed. 'The ova and spermatozoa were evacuated, and later I found numbers of small planulæ and small medusx which were growing rapidly; but these showed no tendency to form buds during the autumn, and had, without doubt, been formed from the fertilised ova of the sexual forms. There thus appears to be a distinctive 
life cycle in Limnocnida, and this cycle is complete without any hydroid phase, in fact, no hydroid was ever found in the lake, although I searched persistently for them. This being so, the many peculiarities which the life-cycle presents are at once striking and significant. At the present time, however, I do not think it advisable to attempt to dilate upon the medusx's proximate affinities, as I intend to return to this matter in a special memoir. But it may be useful to point out that the animal has most conspicuously primitive attributes, coming in this sense exactly into line with the halolimnic gastropods. It is certainly a marine derivative, probably from its life-history related to the Narco-mediusa of the ocean. 


\section{CHAPTER XV.}

THE SPONGES OF LAKE TANGANYIKA.

THE sponges which were obtained during the Tanganyika expeditions from that lake itself appear to consist of three distinct forms. Two of these new species were examined and described by Mr. Richard Evans under the names of Spongilla moorei and Spongilla tanganyike; but besides these among the material obtained during the first expedition there were encountered the spicules of a third form embedded in the mud of the lake. The character of these spicules, it seems, might, with equal propriety, suggest that the sponge to which they belong is allied either to the New World genus, Uruguaya or to the Congo genus Potamolepis. As, however, nothing but the spicules had been obtained, Mr. Evans left the form unnamed. During the second Tanganyika expedition a small specimen of this third species was dredged alive from great depths adhering to a Paramelania shell, and this material was sent eventually to Herr Weltner in Berlin, who replies that the sponge is undoubtedly a new form, the framework being very similar to Spongilla böhmii. The sponge, however, still remains nameless, and as this is most inconvenient, I propose the specific term weltneri, leaving the form for the present as a member of the genus Potamolepis. 


\section{SI'ONGILLA MOOREI (R. EvanS).}

This sponge grows on the shells of various mollusca, and partially covers them as a crust. The upper surface is raised into lotes or mound-like clevations, which in no case are more than half an inch above the general surface, and which are usually no more than an eighth of an inch above the shallow depressions which separate them. The surface texture of the preserved sponge is somewhat woolly in appearance, though this is probaluly the result of the broken condition of the dermal mem. brane, for it has been olserved that some of the fragments preserved in flemming's fluid are smooth, and the spicules of the skeleton, though supporting the dermal membrane, do not in the natural condition penetrate it.

An osculum is situated at the tip of each of the lobes or mound-like clevations of the surface of the sponge. This opening measures about an eighth of an inch in diameter, and underlying it there is a fairly large gastral cavity. The dermal pores are small, as usual, and are situated on the flanks of the lobes as well as in the intermediate depressions.

(2) The SkEletox. - In treating of the skeleton or the supporting part of the sponge, first, the spicules will be described; secondly, the arrangement of the spicules to form fibres, and of the fibres at large to form the skeleton, and thirclly, the spongin which binds the fibres together.

(A) The Sproules. - In order to facilitate description, the spicules will be divided into three classes, the ordinary division into "megascleres," and "microscleres" being intentionally avoided, because it is, to say the least, douluful whether the small, smooth spicules are microscleres or young megascleres.

The three classes of spicules are :--

(a) Diactinal monaxons, which taper to a sharp point, either gradually (amphinxea) or more rapidly (amphitornota), and are without swellings on their shaft. The former are al ways straight, the latter curved (Fig. $I-a$.).

( $\beta$ ) Sinilar straight amphioxea or curved amphitornota, with distinct swellings on the shaft (Fig. $1-d$.).

$(\gamma)$ Irregular systems formed by the fusion of spicules belonging to class $a$. (Fig. I).

(a) The straight amphiosea taper gradually into a sharp-pointed end (Fig. I - b.), while the curved amphitornota, which are far more numerous, taper much more abruptly into a similar point (Fig. $1-C$ ). Both the straight amphioxea and the curved amphitornota are highly variable in thickness, and exhiljit all stages of development. The axial thread is of even thickness throughout its whole length in all these spicules.

(B) In addition to being slightly more slender than the spicules already descrilsed, the main feature of these spicules is the presence of a number of swellings which varies from one to five. As a rule they are situated symmetrically with regard to the middle point of the spicule ; that is, if there is only one swelling it is situated at that point, lut if there are two they are placed one on each sicle of that point, and at equal distance from it ; and similarly the symmetry is maintained when there are three, four or five swellings. The absence of the symmetrical arrangement, as seen 


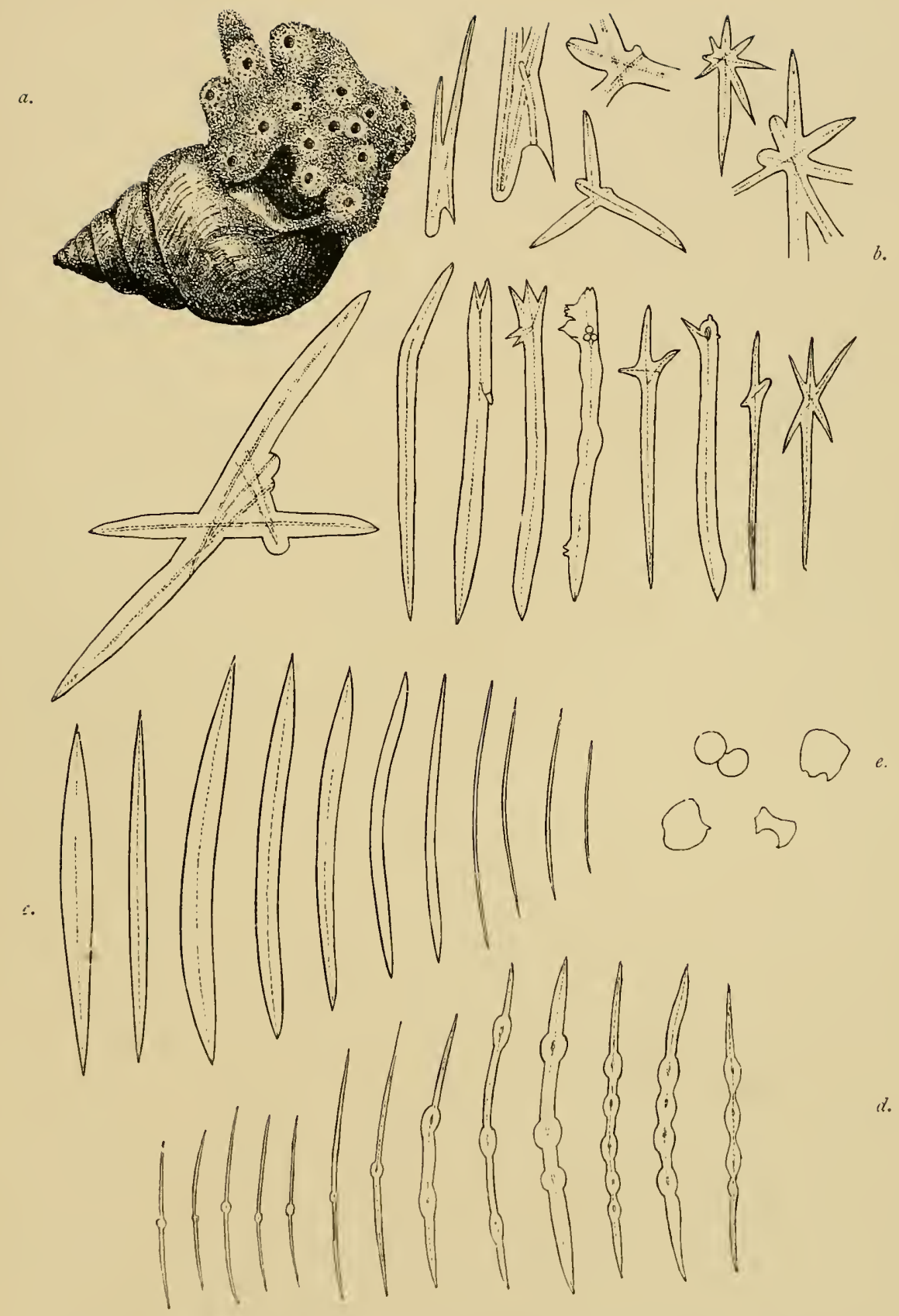

Fig. 1.—a., Spongilla moorei growing upon a shell. b., A number of irregularly shaped spicules. c., Amphioxea and amphitornota, without swellings. d., Amphioxea and amphitornota, with swellings. $c$, Masses of silica. 
in Fig. I-d., is very exceptional. The axial thread, in contrast to spicules of class (a.), present a dilation corresponding to each swelling on the spicule.

(r) The spicules of this class are of variable and irregular form, since the individual amphioxea or amphitornota which form them may fuse at any point and at any angle (Fig. $\mathrm{I}-b$.). As a rule these compound systems are formed from spicules from class $(a$.$) , though occasionally a spicule of class (\beta)$ is found to take part in their formation.

With regard to their origin, two suppositions are possille; first, that they are the result of irregular growth, and branching of a single spicule derived entirely from a single scleroblast; secondly, that they arise by fusion of spicules primitively distinct, and formed each by its own scleroblast. Fig. $1-b$. might be taken as evidence of the former view, but such forms as that represented in Fig. $\mathrm{I}-b$. render such a supposition highly improbable, to say the least. The view that these spicular systems are of compound origin receives strong support from the way in which their axial threads cross one another instead of branching. If these irregularities arose as outgrow ths from one spicule formed in onc mother cell, it might well be expected that their axial threads should be also formed as outgrowths from that of the main spicule; but this is certainly not the case in many spicules of our Spongilla, as can lee seen trom the figures. In another sponge, which is probably a monaxonid of the family Axinellidee, viz., T'ricentrinm muricatum (1'allas 1756), Ehlers, 1870 (=I'lectronella papillosa, Sollas, 1879), there are lranched spicules iu which the axial threads are continuous throughout, a fact which may indicate that the spicules themselves owe their form to branching. It seems clear, therefore, that the irregular spicules of Spongilla moorei have, in many cases, been produced by fusion. Judginent must be suspended for the present with regard to those systems in which no discontinuity can be detected in the axial threads of the component spicule rays; such spicules may be simply branched. The question cannot be decided until the actual origin of the spicules has been studied; and the same may be said for Tritentrimn. Since now it has been shown that the triradiates and quadradiates of the Ascons are formed by fusion, there is no inherent improbability in a similar process occurring in other cases.

Spicules of a similar character to the compound systems here described have been figured lyy many authors in various Spongillide (Spongilla aspinosa, l'otts) Lubomirskia intermedia, Dybowski). All these authors regard them as abnormalities, lut in moorei they are so frequent that they must le considered as a normal feature of the species. It is possible that in other Spongillidie these systems have not received the attention they deserve.

In addition to the spicules described above there are small masses of silica in Spongilla moorei, comparable with those found in Spongilla asfinosa (Fig. $\mathrm{I}-e_{\text {. }}$ ).

(B) Tile Arrangement of the Spicules to form Fibres, letc. - The spicules which form the polyspiculous fibres leelong mainly to the first and third classes above described. Spicules of the first class form the greater part of the filses, while others lie about in the sponge tissue, presenting for the most part an irregular method of arrangement, though many such spicules are placed sis as to bridge over the spaces between the fibres in a perfectly definite way. Spicules of the secund class, which are far less numerous than those of the first, seldom participate in the formation of the fibres, but, as a rule, lie scattered irregularly between the fibres. 

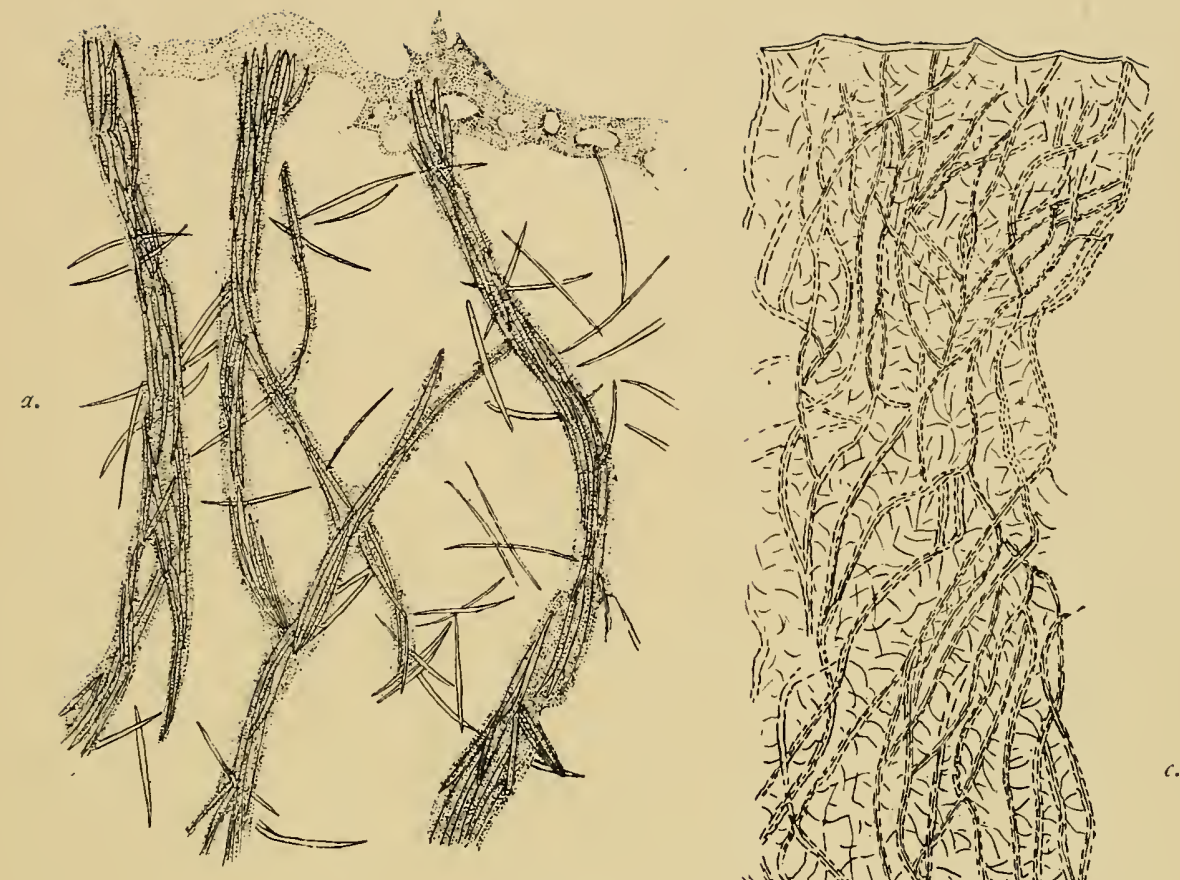

, n 110 ,

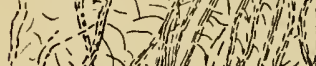
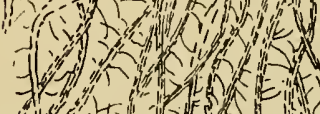

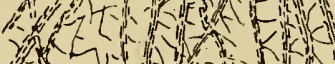
3 A

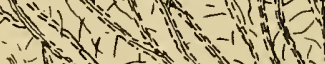
in 1 4 1

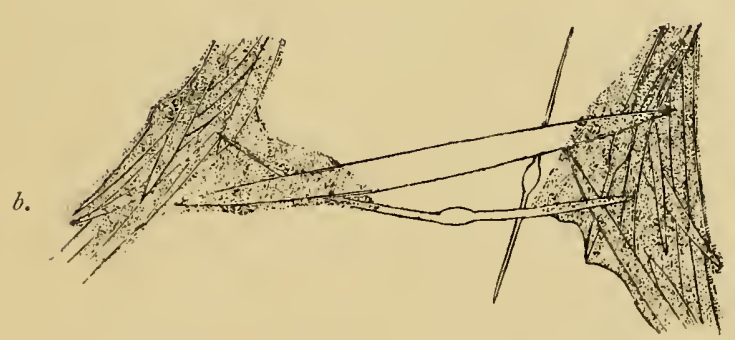
A (ic) on- $1,2,-1,1$ y 4 N=1
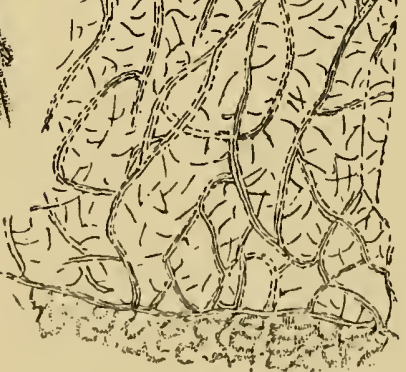

Fig. 2. - $a$., The skeleton of Spongilla moorei near the surface in section $\times 200$. $b ., A$ portion of two fibres $\times 800$. c., The skeleton as seen in section from the base to the upper surface. 
The spicular systems of the third class are seldom found in any other position than in the fibres.

As a rule, the spicules are arranged in the fibres with their axes parallel to one another, and in the deeper parts of the sponge the connecting spicules are rather numerous, and more strongly developed than in the more superficial parts. The connecting spicules are usually the most strongly developed spicules in the whole sponge as regards size, differing, however, only in thickness from the smooth, curverl amphitornota which constitute the fibres (liig. 2-a.). Speaking generally, the largest spicules of the first class, together with a few of the second and all the third, form the fibres and the connecting links between them, while the smaller spicules belonging to the first, and nearly all those belonging to the second class, are scattered about irregularly in the meshes between the filbres. The smallest spicules of all seem to be absolutely independent of the skeletal meshwork, and this is the strongesi argument that can be adduced in favour of the view that they are microscleres and not young megascleres.

The arrangement of the skeleton at large is reticulate. The most general feature of the general conformation of the fibres is the way they pass from the surface of fixation of the sponge to the dermal membrane which they support Along their course from one surface to the other they present a wavy appearance, often dividing and again reuniting, approaching the dermal membrane nearly always at right angles, and in many cases expanding into a lrush-like structure which supports that membrane (Fig. 2-c.). In some of the largest lobes of the sponge the fibres nearest the centre pursue a straight course, while those furthest from that position curve outward, so as to form supports to the dermal membrane which covers the flanks of these mound-like elevations. Owing to this arrangement a longitudinal radial section of one of these lobes presents an almost fan-like appearance, as regards the skeletal fibres.

(C) THE SPOAGIN. - All the skeletal fibres of this sponge are enclosed in a distinct sheath of spongin, which is greatly thickened at the points where the connecting spicules occur, these being either partially or completely surrounded by it (Fig. 2-b.). Not only are the filbres and the connecting spicules enclosed in a sheath of spongin, but the surface of the sponge is covered by a thin layer or cuticle of the same substance, which dips down between the cells of the dermal membrane and communicates with that which envelopes the fibres (lig. 2-a.).

(3) The Caxal Srstem. - Owing to the fact that the material which had been preserved for histological study of the sponge had been shaken considerably in moving from place to place, a great number of cells had, apparently, lsecome loose, and were found lying in the spaces of the canal system. In consequence it was impossible to make a complete and thorough study of that system, though individual cells were in many places nicely preserved; nor is Spongilla, for other reasons, a favourable olject for the study of the canals in the Monaxonida.

The canal system in Spongilla moorei belongs to the type usually described as the thircl. The dermal pores, which are situated on the flanks of the mound-like elevations of the surface and in the intermerliate depressions, are small, and open into the subdermal cavity, which is lined by flattened epithelium, and considerably reduced by the passing through of the skeletal fibres, which are enclosed in a sheath of spongin, which is covered by cells of the epithelial layer. 
The inhalant canals which pass from the subdermal cavity into the chambers are narrow and difficult to make out. In some cases these canals are short, owing to the flagellated chambers being situated close to the floor of the subdermal cavity. Those canals which pass into the chambers which are situated more deeply in the sponge are long and narrow, following a winding course, and keeping nearly always between the chambers and the fibres of the skeleton. On their way down into the deeper parts of the sponge they give off branches which open into the chambers by way of prosopyles, which are so small that it is almost impossible to make them out. The apopyle was easily distinguishable as a wide opening, communicating directly with the wide exhalant canals, and occupying nearly a fourth of the surface of the otherwise almost spherical flagellated chamber, which is lined by collar-cells with nuclei situated at their bases. The canals of the exhalant system are much wider than those of the inhalant, and, as a rule, occupy a central position between the fibres. As they pass down into the deeper parts of the sponge they converge and unite together, forming wider canals, which are few in number, and which open into the somewhat spacious gastric cavity, which communicates with the exterior by way of an osculum situated at the summit of each of the mound-like elevations of the surface.

(4) The Gemmule.-The gemmules, which are few in number and scattered about singly, are spherical in shape and small in size, measuring only $.35 \mathrm{~mm}$. in diameter. They have a thin coat, which is not surrounded by spicules specially characteristic of the gemmule, but by the ordinary skeleton spicules. Their cellular contents present the same characters as do those of the common species of Spongilla, and each individual cell is full of the two kinds of granules which are quite characteristic of the cells of Spongillid granules. It is just possible that, had the material been preserved later in the year, the gemmules would have been more numerous, though there would appear to be no absolute necessity for the production of genmules, since the sponges live at a depth of three hundred fathoms and cannot possibly be either dried or frozen.

THE AFFINITIES OF " SPONGILLA MOOREI."

The presence of the gemmule is the most important character tending to fix the position of Spongilla moorei among the Spongillidx. Gemmules have been described in marine sponges, and this fact diminishes the importance of the existence of gemmules in a newly-discovered sponge as a character supposed to be distinctive of the Spongillidxe (Topsent). It appears that there is no special feature in the structure of the skeleton of Spongilla moorei that would cause it to be separated from the Chalinidx had it been a marine sponge. It most decidedly possesses more spongin 
than the Spongillidie are usually supposed to have. As a matter of fact, it is difficult to make out what structural reasons there are for retaining the family Spongillidie. It is not at all improbable that, when they are more carefully studied, they will be distributed among the several genera of the Homorrhaphidae. But as our knowledge has not yet attained a stage which will enable us to do this, it is deemed advisable for the present to place this new species among the Spongillidre, and to retain that assemblage of sponges as a family, however artificial it may be.

Spongilla moorci appears to be more closely related to Spongilla aspinosa (Potts) than to any other species of the Spongillina. Both species agree in possessing spicules which are smooth, straight or curved, and for the most part rather abruptly pointed. Malformed spicules, as they are described by Potts, are found in both, but they appear to be more numerous and more complicated in Spongilla moorci than in Spongilla aspinosa. Further, both species produce gemmules which are small in size, spherical in shape, and supplied with a thin crust which is not protected by spicules characteristic of the gemmule, but by the ordinary skeleton spicules. Though the gemmules are few in Spongilla aspinosa, they are more numerous than in Spongilla moorci, a feature which may be explained either by the lesser importance and consequent scarcity of the gemmule in the latter species, or simply by the season at which the material was collected.

Spongilla aspinosa differs from Spongilla moorci in that it possesses small flesh spicules, which lie on the dermal membrane and among the smooth, slender skeleton spicules. These small spicules are not found in Spongilla moorei, unless they are represented by those which are drawn in Fig. 2-b., which is probably the case. However, it must be admitted, 
as has been done by Potts, that in both cases these small spicules may be young megascleres, and not microscleres. The only distinction obtaining between megascleres and microscleres, viz., that the former are bound up in the general skeleton of the sponge while the latter lie scattered about freely, is a functional rather than a morphological character, and seems to break down in the Spongillidx, whose Homorrhaphid ancestors were probably without microscleres. The consequence of this is the impossibility of deciding definitely the true character of certain spicules. It seems, however, a safe conclusion that these small spicules are the same in Spongilla moorei as in Spongilla aspinosa, though in the former they are not found in the dermal membrane, their place being taken by the cuticular layer of spongin which covers the surface.

The form of growth of these two species appears to differ. Spongilla aspinosa is provided with long, slender, cylindrical branches which occasionally subdivide. These branches grow from a thick basal membrane. Spongilla aspinosa, however, at times forms merely a sheet which envelopes the support on which it grows, while Spongilla moorei in all the specimens examined presented this appearance.

The spongin has not been described in Spongilla aspinosa, and therefore neither comparison nor contrast is possible.

The colour of Spongilla aspinosa is said to be green, a fact which is the result of the position in which it grows, for Spongilla lacustris and Ephydatia miilleri and furviatilis may be either green or brown, according as they grow in direct sunlight or in the shade. Owing to the depth at which Spongilla moorei lives, the green colour of Spongilla aspinosa is wanting. 
SPONGIIA TANCANYKR: (Krans).

Owing to the fact that there was but a small piece of this sponge among the material collected, it is impossible to make any statements with regard to its external form, but it must have been closely similar to that of Sfongilla moorei, otherwise the difference would have heen detected. But although thus, the two sponges are similar to one another in their habits of growth ; they are strikingly dissimilar in the charactess of their individual spicules, though the general arrangement of the spicules in the fibres and of the fibres at large is strikingly alike.

The description of this species must, of necessity, be lorief. The same plan will be followed, as far as possible, as in the case of the description of Spongrilla moorei.

(I) The skeleton will be described under the following headings:-

(A) Spicules.

(B) Arrangement of Spicules, etc.

(C) Spongin.

(A) SPICULES. - It may be safely stated that there are megascleres and microscleres in this sponge. The megascleres consist of amphistrongyla and amphitornota, which are, for the most part, thickly covered with small spines. In addition to these there are a few smooth or sparsely-spined amphioxea (Fig. 3-b.). The microscleres are much slenderer than the megascleres, though they almost equal them in length. They are always smooth and slightly curved (Fig. 3-a.).

(B) Tine Gexeral Arrangismext. - The arrangement of the spicules does not differ materially from that already described in Sfongrilla moorei. The spiny anphistrongyla and amphitornota, together with a few smooth or sparsely-spined amphioxea, are arranged with their axes parallel to one another to form the skeletal fibres. These divide and again reunite, producing an arrangement which is usually described as being reticulate. The fibres are connected together in many places by spicules which bridge over the intermediate spaces. These spicules are the largest in the whole sponge, as a rule, as was found to be the case in Spongilla moorei. In addition to these there are many spicules, both spiny and smooth, which appear to lie about more or less freely in the tissues. The slender microscleres are nowhere connected with the fibres, but lie absolutely free in the tissues.

(C) Tine Sposgrn.-The spongin is not so highly developed in Spongilla tanganyike as in Spongilla moorei. The former, therefore, in this respect resembles more closely the ordinary species of Spongillidie than the latter appears to do. The spongin does not appear to extend to the surface, and the layer which covers the fibres is correspondingly thin. The greater development of spongin occurs at points where the fibres branch or reunite, and at the places where the connecting spicules penetrate the fibres.

(2) The Gemmule. - Though there was lut a small piece of this sponge, it happened to contain several gemmules. These are devoid of spicules, but are surrounded by the ordinary skeletal spicules and the microscleres; they possess a thin coat, is in Spongilla moorei, and are spherical and of small size. As regards their cellular contents, they present the ordinary characters of the simongillid gemmule. 

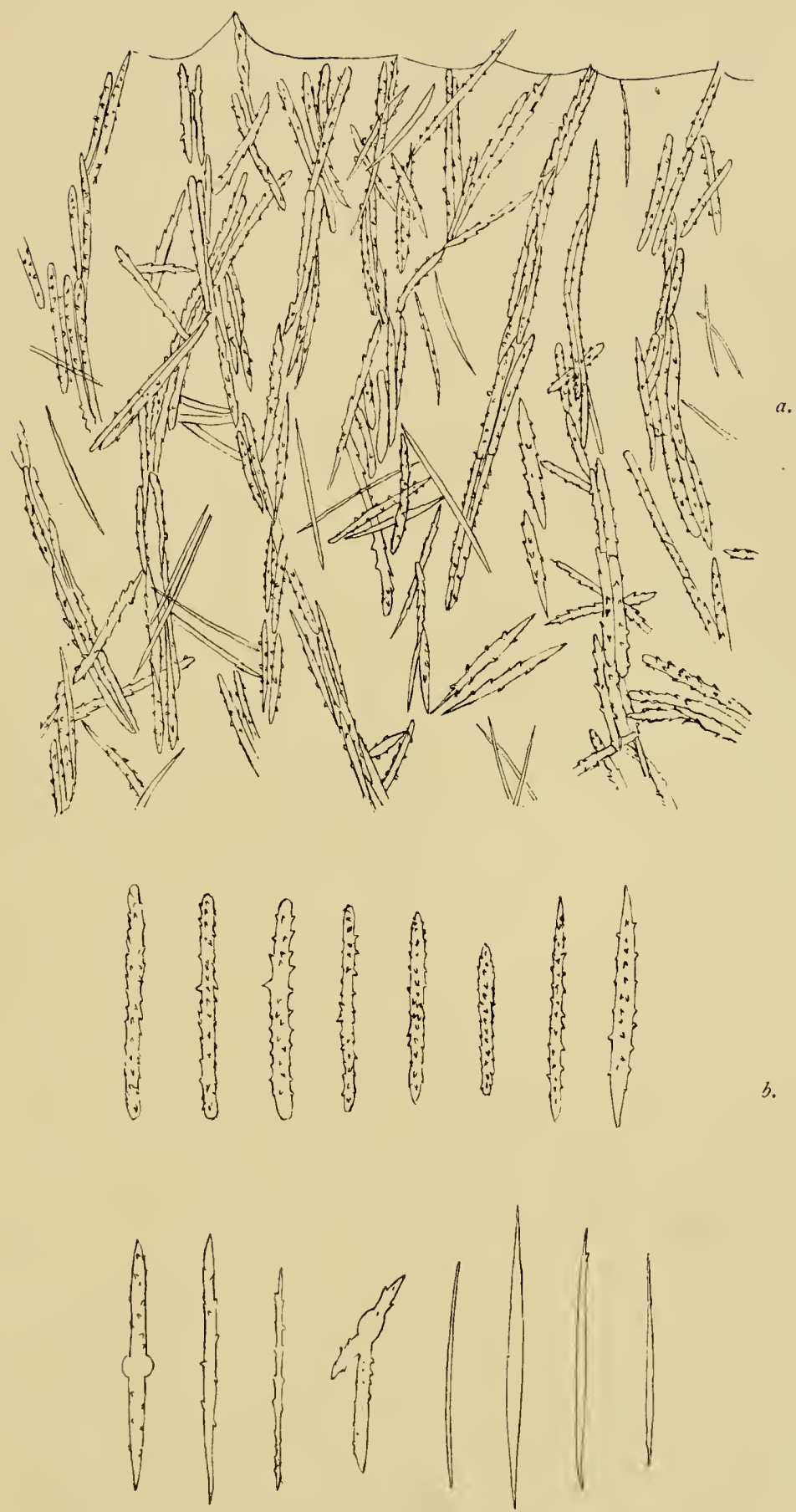

Fig. 3.-a., $\Lambda$ portion of the skeletor of Spongilla Tangranvike. b., Spicules of Spongilla Tanganyikr. 


\section{AFFINITIES.}

This subject must be considered from two aspects. In the first place, the character of the gemmula must be taken into consideration, since the grouping of the Spongillidie into the three sub-families, Spongillina, Meyeninat and Lubomirskina, and the division of the sub-families into genera, usually adopted, depends on these characters. In the second place, the spicules are of great importance, as presenting a close resemblance to the spicules of Lubomirskia intermedia var. a (Dybowski, cf. pl. iv., fig. 3, b), which belongs to the sub-family Lubomirskina.

(A) The Gemule. - The gemmule of Spongilla tanganyike lacks the amphidiscs which surround the gemmule of the Meyenina. It therefore appears that the species cannot belong to that sub-family. But it equally lacks the small spicules which are usually found in close relation with the gemmule of the Spongillinx. Potts, however, places Spongilla aspinosa among the Spongillina, in spite of the fact that its gemmules lack characteristic spicules. If this arrangement be followed, the absence of such spicules from Spongilla moorei and Spongilla tanganyike should not be considered as a barrier against including these species among the Spongillina. But the inclusion does away with the importance of the presence of special gemmule spicules as a sub-family character.

The thin coat of the gemmule resembles that found in Spongilla moorei, Spongilla aspinosa and others of the spongillina, and has no similarity to the thick coat of the gemmule of the Meyenina. The characters of the gemmule, therefore, as far as they go, point to this new African species as being one of the Spongillinit. 
(B) The Spicules.-It is generally stated that the skeletal spicules of the several species of the Spongillidæ have no characters of higher than specific value. It is difficult to make out from the literature of the family how far such a statement is justified. However, the spicules of Spongilla tanganyika possess such characters that it is almost impossible to believe that they have not a wider application. This sponge, considered from the point of view of the skeleton, seems to present a certain amount of affinity with a few species of the Spongillinæe on the one hand and of the Lubomirskinæ on the other.

The megascleres of the greater number of species arrayed under the sub-family Spongillinæ are sharp-pointed, that is, they are either amphioxea or amphitornota. There are, however, a few species which possess spicules with rounded ends, that is, amphistrongyla. The species in question are Spongilla nitens (Carter), Spongilla böhmi (Hilgendorf) and Spongilla loricata (Weltner), to which may be added Spongilla tanganyike, now described for the first time. Spongilla tanganyika, therefore, seems to be more closely related to these species, so far as the characters of the skeleton are concerned, than to any other species of the Spongillinæ. Of the three specie named above it appears to present closer affinity with Spongilla böhmii than with either of the other two, for in Spongilla nitens and in Spongilla loricata the amphistrongyla are smooth, while in both Spongilla böhmii and Spongilla tanganyike they are spiny. In the former the spines are more thickly set at the end, which is a special feature of the megascleres of some species of the Lubomirskina, and which may point to a certain amount of affinity in that direction, while in the latter they are evenly distributed over the whole spicule. In Spongilla böhmii the megascleres are curved as in Spongilla nitcns, 
Spongilla loricata and most of the Lubomirskia, while in Spongilla tanganyike they are straight. However, there is among the Lubomirskina a varicty of Lubomirskince intermedia, described by Dybowski as var. a, in which the spicules are spiny and almost straight. The spines are evenly distributed, and in many cases the ends of the spicules present the amphistrongylote character. Another feature of Lubomirskia intermedia agreeing with Spongilla tanganyike is that the microscleres are smooth and almost equal to the megascleres in length. In Lubomirskia bracilifera and Lubomirstia papyracea the spicules are Amphistrongylote, though in the former the spines are arrayed at the ends of the spicules, in contrast with those of Spongilla tanganyike, but to a certain extent agrceing with those of Spongilla böhmii, while in the latter the spines are evenly distributed over the shaft of the spicule, in contrast with those of Spongilla böhmii, but similar to those of Spongilla tanganyike.

From these points of comparison it seems that Spongilla tanganyike, as well as Spongilla böhmii, must be closely related to the Lubomirskince. Had it not been for the presence of the gemmule in the small piece of Spongilla tanganyike, I should certainly have placed it among the Lubomirskina. On the other hand, were the gemmules to be found in any species of the Lubomirskinie, the 'Tanganyika form would have to be removed from that sub-family as at present defined. Consequently, I venture to suggest that the sub-family Lubomirskinat should be abolished and the species contained in it placed under the Spongillina, which then could be arranged into a number of gencra according to the character of their megascleres. 


\section{POTAMOLEPIS WELTNERI, MOORE.}

With respect to this chrious form nothing more can at present be said than that it is a sponge growing in the deep water of lake Tanganyika; that in the single specimen obtained it appears as a thin brown encrustation on a Paramelania shell ; that it has thick, slightly curved spicules which, unlike those of Potamolepis leubnitsice, are slightly swollen at the ends, and that in general the enlarged ends of these spicules are micropunctate. It should, however, be noted that the characteristic spicules of this new form are closely similar to those of the old fossil genus Renieria.

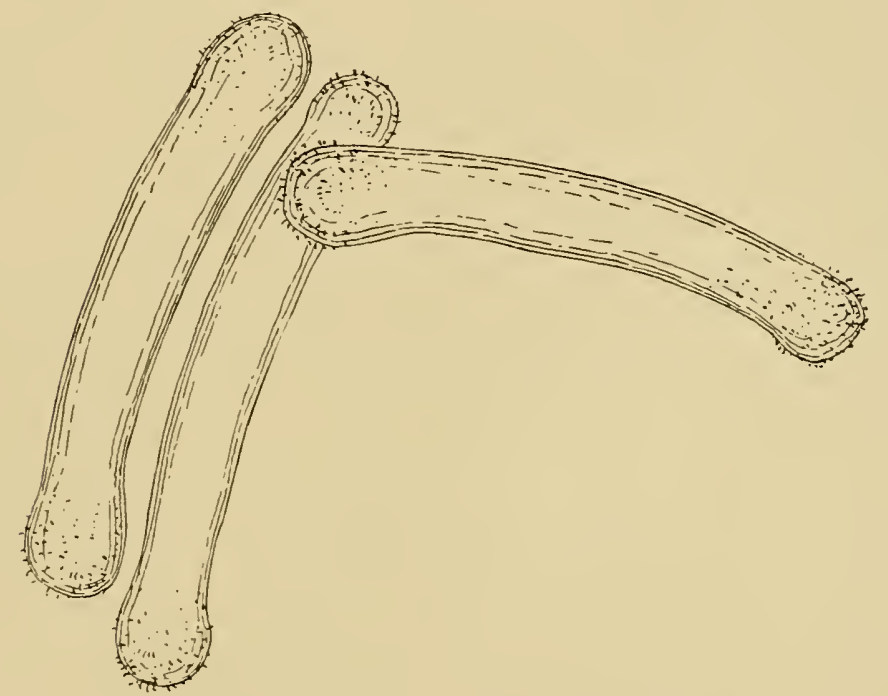

Fig. 4.--Spicules of Potamolepis IVeltneri.

\section{PROTOZOA.}

With respect to the unicellular organisms which are found in Lake Tanganyika, I have encountered only two forms which seem to call for any special mention. It may be remembered that, in Livingstone's diary of his last journey, the explorer noticed that at times the surface of Tanyganyika was at times covered with what he called a "yellow scum," and which, he says, he thought to be of "vegetable origin." 
I have encountered this scum repeatedly on the lake, the clear green for miles appearing as if tinged with a fine golden dust, the minute particles of which this is composed reflecting the bright sunlight, like the crystals of some yellow precipitate.

Upon examination these yellow clouds were found to consist of a large infusorian which at first sight looked exactly like a peridinium, having the characteristic equatorial groove, but on closer scrutiny the whole organism was found to be covered with long cilia which projected in lines from the pore-like apertures in the plates of the skeleton. But for the groove the animal would thus compare with a large colpodium.

Whatever it really is, this organism is a most conspicuous object. I have never seen it in any of the other lakes, and it appears to be as characteristic of Tanganyika as the rest of the members of the Halolimnic group.

Associated with the above form, and also present in the surface scum, there is a large condylostoma, the affinities of which are not doubtful; and besides these two conspicuous and characteristic protozoa, there were found about twenty recognisable types belonging to those groups which have habitually been encountered in the fresh-waters of the tropics. 


\section{CHAPTER XVI.}

In the preceding chapters of this work we considered first what may be called the problem of fresh-water faunas in general. That is to say, we examined the nature of such faunas in the more remotely separated land-masses of the globe, and by such an examination it was shown, that in spite of the wide variations which often seem to characterise such assemblages of living forms, there is, nevertheless, clearly to be discerned, an element of similarity underlying whatever apparent local diversity may be presented.

In the second place, an attempt was made to directly "get at" both the meaning of this wide-spread similarity, and of the local variations with which it is often accompanied. A quantity of morphological evidence was cited, which seems to indicate that the components of the universal freshwater series are somewhat archaic in character, and at the same time palæontological evidence was discussed which seems to show that the organisms belonging to this primary fresh-water series are, when speaking palæontologically, of the same date. In other words, there was found to be evidence which indicates that most, if not all, the primary fresh-water organisms became differentiated about the same time. It was shewn further, that the period at which the primary series emerged from the general fauna of the sea, was synchronous both with a singular multi- 
plication of new forms in the occan and the extinction of old ones.

No recognised cause, such as the struggle for existence between different types, could be assigned for these three synchronous phenomena occurring as they have done. But it was shewn that there has gone forward in the sea itself, a physical change which there is lirect experimental evidence to shew would be competent to produce metamorphoses of just this kind in a host of diverse animals living in it. The gradually increasing salinity of the ocean could act as an agent whereby some forms would be definitely killed out, some restricted to the fresh-waters of the globe, while the changed conditions produced by the increasing salt, might act as a stimulus towards variation, thereby producing a host of new forms, such as that witnessed among the ammonites at the close of the secondary and the beginning of the tertiary rocks.

Taken in conjunction with other matters, such as those referred to by Professor Sollas, respecting the impossibility of the free swimming larvae of numbers of marine organisms ever getting from the ocean into fresh-water; the hard conditions of fresh-water emphasized by Semper ; and the fact that some animals, such as prawns, can, and have successfully at all times, colonized the fresh-ivaters of the land from the sea-coast; the view brought forward was found to be capable of giving a tenable and satisfactory explanation of the very remarkable and constant peculiarities which the fresh-water faunas of the globe present.

These matters were however discussed, as I have already expressly stated, merely in order that some clear grasp of the nature and peculiarities of fresh-water faunas, and the probable meaning of these peculiarities, might be obtained before attempting to attack the special problem 
which is presented by the mixed fauna of Lake Tanganyika, of the present day.

Whatever opinion may be held respecting the view that the salinity of the ocean has been a prime factor in producing some of the characteristics which the fresh-water and marine faunas of the present day actually possess, is a matter which is wholly independent of the particular Tanganyika problem with which this work is primarily concerned.

These more general subjects were merely introduced in order that some foreseen confusions might possibly be avoided, and the ground made clearer, for the consideration of the Tanganyika problem itself. But before finally approaching this particular problem by a systematic examination of the different components of the fauna of Tanganyika, and the other African lakes, I dealt generally with what is known of the geology of the districts of Central Africa. This course was necessary, in the first place, because our conceptions of the country have been somewhat altered by the observations acquired during the Tanganyika expeditions. No support has been lent by these to the view that the marine origin of the halolimnic fauna of Lake Tanganyika is opposed to our knowledge of the geological nature of the African land-mass. On the contrary, it was shown that there was no evidence whatever against such a view, and that there is a good deal which, more or less, distinctly favours it.

These preliminary matters have been considered, the fauna of the great African lakes was described, and subsequently the halolimnic fauna was defined as something distinct from the general fresh-water fauna of the African continent. In the first place, it was shown to be a group of organisms of diverse nature, but a group all the 
invertebrates belonging to which have this peculiarity, they are rigidly restricted to the confines of Lake Tanganyika, or to the waters which are, or have been, in direct connection with it.

In attempting now to form some definite conception of what this halolimnic group really is, its geograpinical isolation and restriction to one special African depression is among the most remarkable features that the group presents, and it is all the more remarkable because, as we have seen, the halolimnic group does not hold possession of Tanganyika to the exclusion of the general African fresh-water fauna. On the contrary, the normal African fresh-water fauna is found to co-exist along with it in full force, the members of this normal fresh-water fauna of Tanganyika presenting no greater specific differences from the animals constituting the freshwater fauna of Nyassa than we find also to subsist between the fauna of Nyassa and that of the Victoria Nyanza, or between the Victoria Nyanza and Lake Rudolf. Further, the geographical isolation which characterises the more conspicuous members of the halolimnic group such as the Medusa and the gastropods, characterises also, as we saw in Chapter VII., a number of animals which might under certain conditions be considered as belonging to the secondary fresh-water series of a continent. To this section of the halolimnic fauna of Tanganyika belong the sponges, the protozoa, the prawns and the crabs, and the majority of the fishes characteristic of the lake. In the case of the invertebrate section of this class, they have, however, none of them been found elsewhere, and as they can be viewed as marine organisms, since they have closely allied forms which habitually live in the sea at the present time, it was pointed out that they are to be 
regarded as belonging to the halolimnic group, although they have not the strikingly marine attributes characteristic of the other members of this series. At the same time, and in Chapter VII., it was emphasized that although the fishes which now inhabit Tanganyika all belong to what have become exclusively fresh-water forms, the fish-fauna of the lake differs entirely in character from the fish-fauna of any others of the great lakes of Central Africa, and it was further shown that the majority of a large section of this fish-fauna, the Cichlidæ, is wholly restricted to the confines of Tanganyika. Actually about half the Old World species of this family being endemic in the lake even now. In this way it was rendered evident that one of the chief peculiarities of the more striking members of the halolimnic group, namely, their geographical isolation, is shared equally by a section of the fishes, and consequently that these fishes were in one sense as distinctive of the fauna of the lake as the more striking invertebrate halolimnic animals themselves. Or in other words, it was found that Lake Tanganyika possesses a fish-fauna which is distinctive and characteristic of that lake, and is wholly unlike the fish-fauna of any other of the great African lakes. From these considerations tions I was inclined, as I pointed out in Chapter VII., to regard at any rate the endemic Cichlidx, and probably the ancient Ganoids, together with some of the Caricinidx as the remaining and somewhat scattered piscine portion of the halolimnic fauna; the wide dispersal of these animals being due to the obvious migratory capacities of fishes when compared with the invertebrate section of the halolimnic group.

Turning now to the consideration of the nature of this group of animals, so many of which are obviously 
marine in character, and the invertebrates belonging to which are peculiar to Lake Tanganyika: the ganoids, Polypterus and Protopterus, which I have included in the halolimnic series, are old and primitive forms. Among the Cichlidae which are peculiar to the lake there are, as Mr. Boulenger has shown, forms which appear to be among the most primitive living representatives of the group. The crabs characteristic of 'Tanganyika were found by Mr. Cunnington to be among the most primitive of the thelfusoid series. ${ }^{*}$ The prawns peculiar to the lake have, as Mr. Calman remarked, nothing specially primitive about them. But prawns belong to an ancient paltentological group. The long list of gastropods belonging to the halolimnic group exhibit a diversity of structure which is truly surprising. In the case of Nassopsis, Chytra and Limnotrochus, we have new and really archaic forms, possessing characters which indicate that they are directly related to the di-branchiate forms. The rest of these molluses are almost equally peculiar, and seem to be little specialized members of the great marine groups of the present day, which are typified by such genera as Strombus, Xenophora (Onustus), Natica and Cerithum. The Gymmoleamatous Polyzoan Arachnoidia is only known from Tanganyika, it belongs to a group, of which only one or two species are known to inhabit fresh or brackish water, while at the same time it is structurally quite different from any of these few which have elsewhere succeeded in maintaining themselves in lakes and streams.

* With respect to the large Tanganyika crab, Plalythelfusa armala, it should be pointed out that Milne-Edwards when he described it (see Chapter. III.), remarked that but for the fact that its young went through no metamorphosis, the species would be more readily regarded as a member of several marine groups, and it is obviously open to question whether the fact of its young being without metamorphosis can legitimately be regarded as a distinctive feature. 
The jelly-fish in Tanganyika, as Mr. Günther and I have shown, is possessed of a remarkable primitive type of structure even among these forms.

The sponges which are peculiar to Tanganyika, Spongilla tanganyikae and $S$. moorei, might be regarded as having originated from fresh-water types, but they could, except for their fresh-water habitat, as Mr. Evans pointed out, be just as well associated with the Chalinidae, a marine family group, and like the prawns they are not found outside the confines of the lake. Potomolepis, a sponge common to Tanganyika and the Congo, is a highly peculiar form, and the chief fact of importance, regarding it in this connection, is that its spicules are identical with those of the old fossil genus Renieria which occurs extensively in the marine deposits of the secondary rocks. It is precisely the same with the Protozoa of Tanganyika, i.e., the remarkable Collpodium and Condylostoma peculiar to that lake.

In considering the meaning of the peculiarities which characterise the constituents of the halolimnic group, it is a fact of very great importance that the normal fresh-water components of the fauna of Tanganyika are in no way peculiar; they do not in the least stand as structural stepping-stones between the components of the general African fresh-water fauna and the members of the halolimnic group. This point has been referred to again and again while dealing with the anatomy of the different organisms which constitute the halolimnic group. Hardly any of these halolimnic types could, in fact, under any circumstances be regarded as modifications or specialisations of any of the recognised African fresh-water types. The halolimnic gastropods are quite incapable of being re garded as derivatives from the recognised fresh-water 
forms in the same sense that we might legitimately regard the miratesta found by the cousins Sarrasin in the deep water of Celebes as a modified form of the modern freshwater Opisthobranchs. The crabs are not the derivattives of the African thelphusoids, but structurally antecede them. The prawns cannot be viewed as being derived from any fresh-water crustacea which exist in the fresh waters of the interior of the African continent; for prawns have not been found elsewhere in the great African lakes. IVe cannot suppose that the Medusa has originated from any fresh-water form any more than it has originated de nowo in Tanganyika, nor can we view the gymnolaematous polyzoa as having originated from any of the phylactolemetus fresh-water forms.

From these considerations, based on the facts which are now available, it is quite clear that the halolimnic group can neither be regarded as an atavistic nor an anamorphic modification of the normal African fresh-water fauna. In the same way it will be found quite impossible to regard the marine aspect of the halolimnic fauna as the result of convergence, produced by the influence of some undefined conditions which may exist there. And I mention this specialiy, because such a view has recently been brought forward as a possibility in an essay on my incomplete researches by Professor Stromer.

The primary difficulty of any idea of convergence in such a case as this is, that its logical developments necessarily lead its advocates very much further than they probably ever intended to go.

If, for example, and waiving anatomical considerations altogether, we were to assume that the apparent specific identity which exists between the shells of the halolimnic gastropods and certain marine, Jurassic forms was a mere 
appearance, engendered by some unspecified conditions, what would become of palæontological determinations of shells in general ?*

We could understand, and accept it as a fact, that one form in the whole fauna of a lake had acquired the conchological characters of a form belonging to a fauna of a remote age, and yet be independent of it, as is probably the case with the Paramelania of Tanganyika and the Pyrgulifera of the upper chalk. But the chance of this sort of thing happening among a large number of forms in two faunas which have no connection is improbable in the extreme.

However, waiving for the present this whole comparison, and waiving as well the early marine characters of the halolimnic gastropods altogether, the advocates of convergence are still not by any means out of the wood. There are other marine organisms in Tanganyika besides gastropods; there are prawns, and sponges, and jelly-fish, and polyzoa, which are not found elsewhere in the lakes of Central Africa. Where did these things come from, and out of what fresh-water form could they possibly converge?

In order to account for the presence of the halolimnic fauna in Tanganyika through convergence, we must, in fact, either resuscitate the old doctrine of special creation or adopt Bastien's theory of heterogenesis, whereby a puppy could breed pigs. To the present writer the view that the

* In the comparison referred to, and with which I shall have to deal subsequently, I may point out that I took great trouble to consult all the experienced paliontologists who were available, in order that I might rot be accused of making a comparison which experienced palxontologists themselves would not. And, as I pointed out in the memoir dealing with this matter, the palrontologists thus consulted were unanimous in affirming that, so far as conchological identifications are ever justifiable, the above comparisons were so. In this matter I used, as I shall explain, the methods adopted and accepted by palxontologists, and, if these are not to be trusted, it is simply so much the wirse for palicontology. And it dues not prove convergence either. 
halolimnic fauna owes its origin to convergence seems, if possible, more hopelessly untenable than the idea that it has been directly metamorphosed out of an ordinary freshwater fauna, with which conception, of course, it is very analogous.

We are thus inexorably driven, by the evidence, to the conclusion that the halolimnic fauna is not only an assemblage of organisms which is distinct $c n$ masse from the normal fresh-water fauna of the great African lakes, but also that this group is distinct in origin from these.

Can it, however, be viewed as not so much a relic fauna of the ocean, but as a persistent remnant of a type of freshwater fauna which belonged to a departed era, and was once widespread over the African, and possibly other continental, land-masses?

This is a view which, at first sight, may appear to have some semblance of support. Thus it is known that, in the upper cretaceous fresh-water beds of Southern Europe and North America, there occur the remains of fresh-water faunas containing shells, which are not like those occurring generally in the fresh waters of to-day. And it was pointed out by the geologist White in America, and Tausch in Europe, that there occurs among these beds the very variable genus Pyrgulifera, some of the polymorphs of which appear to correspond with Smith's not too representative figure of the original Paramelania of Tanganyika.

From this very flimsy ground, Dr. Gregory advanced the view that the whole halolimnic fauna of Tanganyika might correspond to these cretaceous fresh-water stocks, and that it was a remnant of them. However, to give any semblance of probability to this view, two things are necessary. It must be shown that the fresh-water fauna of the type occurring in the upper cretaceous beds of Southern Europe 
was, at any rate once, wide-spread in Africa; and that a large percentage at least of the halolimnic shells correspond to those in the upper cretaceous fresh-water beds.

Dr. Gregory was consequently of opinion, before the second Tanganyika expedition started, that we should encounter the halolimnic fauna in other African lakes; or at least in the old lake deposits which occur in association with them, outside the region of Tanganyika altogether. This view, however, has entirely broken down, as it is now known we did not encounter the halolimnic fauna outside Tanganyika. It is not present in Nyassa, Shirwa, or even Kivu; it does not occur in Bangweolo or Mwero. It is not present in the Albert Edward, the Albert or the Victoria Nyanzas. It does not occur in Beringo, nor yet in Rudolf. Neither did we find the remains of the halolimnic forms in any of the numerous old lake deposits which we examined or heard of, throughout these regions.

There is thus, at the present time, not only evidence to show that the fresh-water fauna of the type of that occurring in the upper cretaceous beds is not now characteristic of the great African lakes, but, also, much to show that it never has been so at any time. Further, the comparison between the halolimnic shells and those of the Southern European and American fresh-water cretaceous beds rests, as I have said, upon the flimsiest ground. Solely, as a matter of fact, on the supposed identity between shells of the Paramelania of Tanganyika and the Pyrgulifera of these cretaceous beds.

I carefully examined all the figures of these shells, and all the fossil specimens contained in the collections of the British Muscum from these districts. But, beyond the Pyrgulifera, could find no other shells among the cretaccous 
series which bore the slightest resemblance to any of the halolimnic forms.

Finally, Tausch, by the extensive comparisons which he made, has unconsciously shown that the single original comparison between Pyrgulifera and Paramelamia is itself radically untenable. He found that some forms of the so-called Pyrgulifera were more or less indistinguishable from the genus Mclanopsis, and, as he expressly states, he could arrange an insensibly graduated series of shells stretching from the typical Pyrgulifera, on the one hand, to the typical Mclanopsis on the other. The shell varieties of Pyrgulifora are thus indistinguishable from the shell varieties of Melanopsis. But the animal Mclanopsis bears no sort of relationship whatever to the animal Paramelania, and this is a fact of which Tausch was not aware.

The idea that the halolimnic fauna is the remnant of a cretaceous fresh-water stock is thus seen to be based on a single and also on an erroneous comparison, and it is consequently absolutely incapable of further development in any way.

We find, then, that all the hypotheses which we have as yet considered, and which from time to time have been advanced to account for the presence and character of the halolimnic group-namely, the direct metamorphosis of a normal fresh-water stock, convergence of certain members of a fresh-water stock, special creation and hetrogenesis, operating among a fresh-water stock, and finally the persistence of an extinct fresh-water stock, although they may be all quite intelligible, and even possible, in other cases, are each quite inapplicable to the actual facts of the special problem presented by the presence of the halolimnic group in Tanganyilia as it now exists. Without invoking special creation and hetrogenesis, we cannot explain the exist- 
ence of the jelly-fish, the gymnolæmatous, polyzoa, the prawns, the sponges and the gastropods which are peculiar to Tanganyika, along any of these lines. Yet these organisms are in Tanganyika, they are not elsewhere in the great lakes of the African continent; they must have got into Tanganyika from some place or medium in which these sorts of animals habitually live; and there is no place or medium in which these animals habitually live, except the sea.

Along all the lines of enquiry which we have examined, the explanation of the existence of the halolimnic group in Tanganyika is beset with insuperable difficulties, first in one direction, then in another. But, if we leave all these hypothetical explanations entirely on one side, and follow the direct and simple evidence afforded as to the origin of the halolimnic animals, through the characters of these animals themselves, the whole difficulty vanishes at once. The jelly-fish, prawns, sponges and gastropods, etc., are at once perfectly intelligible, if we regard their presence, as in fact it is, indicative of the past extension of the sea into the African interior.

We are, therefore, inexorably driven by the force of facts to view the halolimnic organisms of Tanganyika as having emanated from the sea; or, to put the matter another way, the zoological characters of the halolimnic animals, and the facts of their distribution, show that the sea has been connected with Tanganyika in the past. That is to say, the characteristics of the halolimnic group throw light upon the past history of the African land-mass; and $I$ wish to be quite clearly understood in this connection. We have seen that there actually is no geological evidence which militates against the view that Tanganyika may have been connected with 
the sea; but even if there were such evidence, unless it was of the most positive and trenchant kind, not mere negative appearances, I should regard it as being quite worthless in the face of the positive zoological facts of the case.

It would seem in fact that it is inherently impossible to arrive at any positive geological evidence which would actually veto the possibility of the sea having reached Tanganyika. For example, suppose it could be shown definitely that there were no marine deposits in a certain county in England, is that fact in itself proof positive that it has never been below the sea? The problem is not one which, it appears, can be solved along geological lines; but the facts of zoology are before us, and are plain enough to anyone who likes to take the trouble to understand them; and if the negative geological appearances of Central Africa remain and in reality cannot be brought into accord with them, this simply shows the impotence of the geological, as compared with the zoological, methods of research. Zoological evidence having, in fact, to be brought forward to indicate to geology the gross outline of the past history of Africa, and the way out of the theoretical entanglements in which it is at present wrapped up. 


\section{CHAPTER XVII.}

In what precedes we have seen that the structural characters of the organisms constituting the halolimnic group, and the distribution of that group, show that these animals have originated in the first place independently from the general fresh-water fauna of Africa. And in the second that they have arisen from some sea which normally contained some such types as these. It remains for us now, therefore, to ascertain, further, if there is evidence to show in what direction and from what part of the ocean Tanganyika was originally stocked with marine life. While finally we shall have to see if there is also evidence which will indicate the age of the sea-fauna, to which the halolimnic group originally belonged. In proceeding with these inquiries, it is, however, necessary to revert temporarily to certain considerations respecting the distribution of the fish-fauna in the lakes and rivers of Africa; for, up to the present time, this matter has never been treated adequately, yet the facts with respect to it throw a most important sidelight on the two particular points we are about to discuss. It will be remembered that in Chapter VIII. I pointed out that it is a mistake to view the fish-fauna of Tanganyika as having nothing strange about it, and I showed that there is some reason for regarding the Polypterus and Protopterus of Tan- 
ganyika, some of the Charicinida, and most of the Cichlida, as in all probability representing the now scattered piscine portion of the halolimnic fauna.

In approaching this matter we must, as I have insisted already, bear in mind that most fishes are active, migratory animals, and that, once established in the fresh-waters of a continent at any one point, are sure to rapidly spread through the water-systems of the interior, which in all great land-masses are often, temporarily, more or less connected together. Yet, in spite of this, as I have shown in Chapter VIII., more than half the Old IVorld's species of Cichlida are peculiar to Tanganyita at the present time.

Palaontology is as yet silent with respect to the origiin of this group; but it is more than probable that its forerunners were once widely spread in the sea, and from these facts it would seem that we must draw a conclusion similar to the inference which we might draw from the distribution of blow-flies we knew to have emanated from maggots in a piece of rotten meat in one of the rooms of a house. If we found a few blow-flies in one of the rooms of our supposed house, and in another more, and in another a whole swarm, we should infer that the rotten meat was in that particular room. And in the case of the Cichlid fishes, believing their forerunners to have been once in the sea, but finding that in the Old World they are now restricted to Tanganyika, and are distributed more and more sparsely as we radiate over the Old World from this lake, we must infer that the sea in which they used to exist must have been in the neighbourhood of Tanganyika.

Considering the distribution of the families of fish which are now present in Tanganyika, they are all more or less 
interesting ; the Cichlidæ, as we have seen, abound in Tanganyika, they are distributed more sparsely over the rest of Africa and in South-eastern Asia, but they abound also in the rivers of South America. Of the other families of fish which occur in Tanganyika, the Siluridæ are apparently cosmopolitan; and many types belonging to the group are at the present time marine. The Cyprinodontidæ are peculiar to Europe, Asia and America.

The Cyprinidæ to Europe, Asia and North America.

The Characinidx to Africa and Central and South America.

The Polypteridæ only to certain parts of Africa, including Tanganyika.

The Lepidocirenidæ to Africa and South America.

The Mormyridæ are peculiar to Africa.

The Mastacembelidæ to Africa and Southern Asia.

The chief feature of the distribution of these families which occur in Tanganyika now, is thus seen to be that they belong to groups which are found to be specially related to both sides of the Atlantic as it now exists. I see no reason to dispute the view originally put forward by Dr. Günther, that the fresh-water fish-fauna of Central Africa has radiated from the region of the great lakes. For this view seems to be strongly supported by the evidence produced by Mr. Boulenger, who has shown that the Cichlidx of Tanganyika are among the more primitive of that group, and when we consider the above features of the distribution of the fishes, together with the facts, that there are marine animals in Tanganyika, and that the early representatives of these fishes were marine, there appears to be a very strong indication, indeed, that the fish-fauna of Tanganyika, as well as some portion of the fish-fauna of the American 
continents, arose from a sea which, like the Atlantic, originally occupied a position somewhere between the two.

The fact that the consideration of the distribution of the fish-fauna of Tanganyika points to this fauna having originated in a sea lying to the west of that lake, is extremely interesting; for we saw, when dealing with the geology of these districts, that the distribution and character of the aqueous deposits of the region of Tanganyika point to the west as the only direction in which there seems any likelihood of there having been a former extension of the lake, or a junction between it and a sea covering a part, or the whole, of the unique Congo basin.

A similar indication is afforded when we study the life now found in the Congo. Thus, it is known, that one of the remarkable sponge of Tanganyika, Potamolepis, inhabits the lower reaches of the river. A certain number of fishes are common to both waters, while the mollusc Paramelania of Tanganyika is extremely similar in its anatomy to the genus Tympanotamus, occurring low down in the Congo, in its fresh-water, and also in the sea on the west coast.

We have also the fact that far up the Congo in its freshwater there occur red Algx, corresponding to the red sea-weeds of the ocean. But by far the most interesting fact yet brought to light about the Congo fauna, has resulted from Mr. Boulenger's investigation of the fishes which were collected in different parts of the river by the officials of the Congo Free State.

It was shown, as a result of this investigation, that the Congo contains fifty-one species of the typical African family, the Mormyridx. The Congo, in fact, repeating with respect to this group the same peculiarities which Tanganyika exhibits with respect to the Cichlidx. By far 
the greater number of the species of the Mormyridx are endemic in the Congo.

On the whole, then, these facts appear to indicate that Tanganyika was originally stocked with halolimnic animals from a western sea, of which the great lake itself, and the vast back-waters of the Congo, may be said to be the last remains. From these regions, those fishes which were able to withstand the vicissitudes imposed by the physical changes which have brought about the modern appearance of the Continent, have wandered in all directions, varying

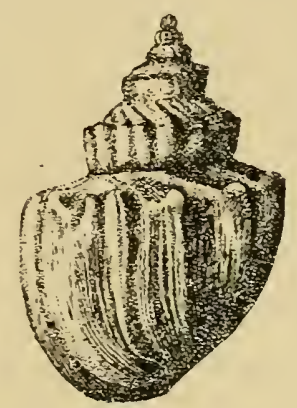

Example of a typical Pyrgulifera from the upper chalk of Ajka. From a specimen in the British Museum.

as they went. But the bulk of the species of these fish are still found confined within this region even to the present day.

It simply remains for us now, therefore, to ascertain whether there is anything in the nature of the halolimnic animals still surviving in Tanganyika, which will enable us to determine to what age and type of sea-fauna they belong.

It has been seen that one of the characteristic anatomical features of the animals belonging to the halolimnic group is, that they all possess characters which could be ascribed to the ancestors of numerous existing marine forms, or, in other 
words, they still retain the characters of a fauna belonging to some departed age. This being so, it also becomes apparent that it is at any rate possible that some of the hard parts of these halolimnic animals, the shells of the gastropods for example, the spicules of the sponges, and so on and so forth, may present the structural peculiarities which typify the same kind of organisms belonging to some particular palreontological epoch. As a matter of fact, even before I was assured of the really primitive character of the halolimnic invertebrates, I had become convinced, while still upon the shores of Tanganyika, that the strange shells peculiar to the region were very similar to some other shells either living or extinct which I had already seen elsewhere, and on searching through the conchological representatives of the different geological eras, it was found that the very remarkable facics which the shells of the halolimnic gastropods possess, is unmistakably again presented by a similar number of gastropods, which are characteristic of the deposits left by the old Jurassic seas. In following up this line of investigation we have been greatly indebted to Mr. Hudleston, who allowed me to examine and have drawings made of the suitable specimens contained in his unique collection of Jurassic forms. From this collection, and from that contained in the British Museum, it was possible to find types which correspond often in a specific sense with the shells of the living halolimnic group. And in order that the reader may fully appreciate the nature of this comparison, I have reviewed in sequence the different corresponding types.

Beginning with the genus Paramclania from Tanganyika, we find that, among the numerous fossil remains of gastropods in the marine Jurassic deposits, there are a number of allied forms to which the generic name of 
Purpurina has been given, and which have generally been considered as belonging to the Rhipidoglossa. The specimens of Purpurina bellona which I examined in Mr. Hudleston's collection, and a fine example of which is represented below, are closely similar to the living shells
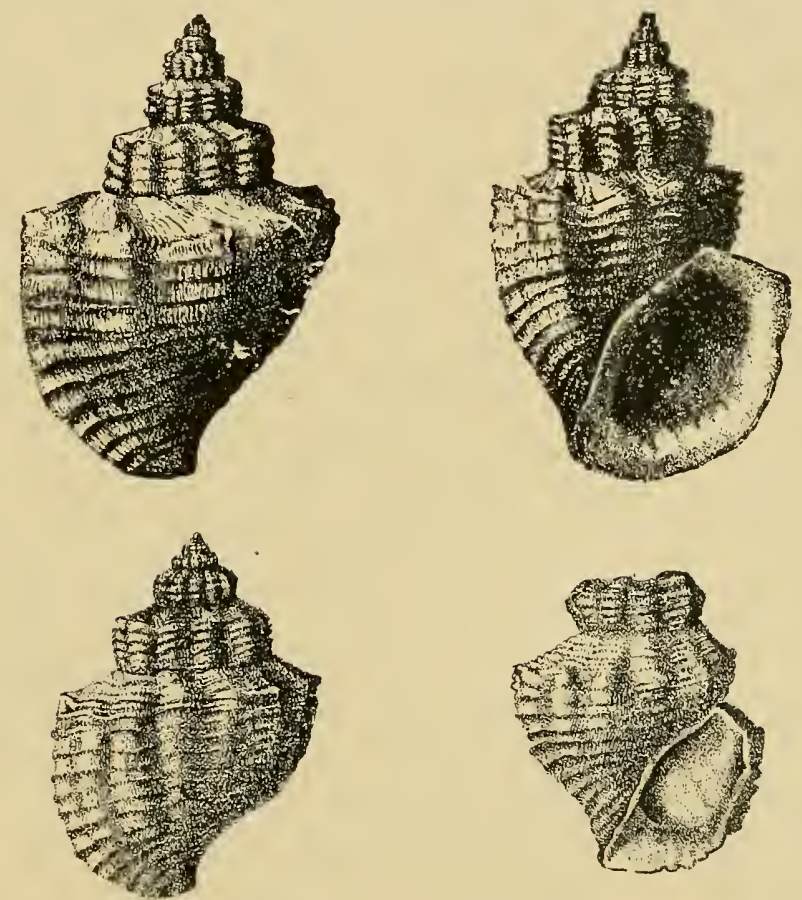

Paramelania damoni, upper figure, compared with Purpurina bellona, lower, a marine Jurassic fossil.

of Paramelania damoni of Tanganyika, and the living form has been represented side by side with the Jurassic fossil in the above figure. In this, as in other cases, I consulted Mr. Edgar Smith with respect to the value of such a comparison in a conchological sense, and he assured me that, even within a specific range, there is no valid conchological distinction between the shell of the living 
Tanganyika form and that of the old Jurassic deposits. Among the marine oolite there is a type of shell which is closely similar to, but quite distinct from, Purpurina bcllona, and which has received the name Purpurina infata. Hudleston, in his monograph on the Jurassic gastropods, did not separate these two forms from one another, but he figured the types, of which the two shells are characteristic, upon different plates. It has long been a moot point among conchologists whether Smith's genus, Paramclania, was really distinct from Woodward's Nassopsis, and when we compare the two forms of Purpurina, to which I have just referred, with the two living Tanganyika types, we find that, not only is Purpurina bellona conchologically indistinguishable from Paramclania damoni, but also that Purpurina infata corresponds equally closely with $N$ assopsis nassa (see Figs. on p. 347, upper and lower).

In the same marine Jurassic series of gastropods there is another characteristic type of shell which has been grouped together under the generic name Ambcrley'a. The genus was originally formed by Morris and Lycett, but was subsequently modified by Hudleston, and, as amended by him, the generic diagnosis runs as follows:- "Shell turbinate, more rarely trochoid, rather thin, imperforate or nearly so ; sub-elongate, frequently turreted; sutural space wide; ornamented with spiral bands, usually spinulous or nodular, some of which are prominent. The interspaces are finely striated, the strix being slightly oblique to the axis. Sometimes these fine lines are strong enough to represent fine axial ribs. Base rounded, spirally ribbed and marked by fine radial striæ; aperture sub-oval, but varying according to age, in the adult more or less rounded, so as to become sub-oval or sub-circular ; there is usually a considerable deposit of callus ; outer lip thin, often crenulate." 
This description would certainly absolutely answer for that of one of the new types which $I$ found in Tanganyika, and to which I gave the generic name of Bathanalia (p. 348, lower). Although the Jurassic genus Amberleya shows a considerable range of specific variation, all its species have essentially the same characteristics as the two
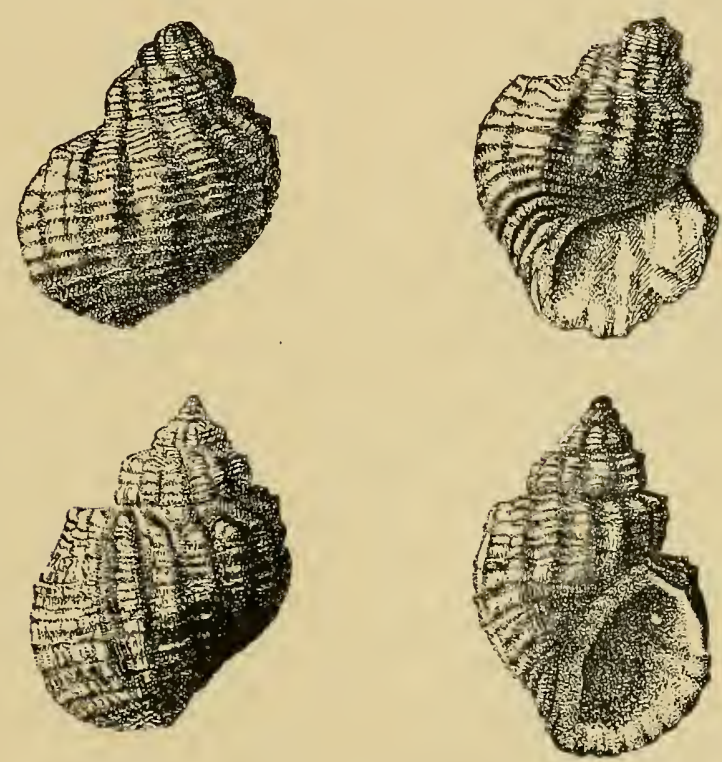

Purpurina inflata, upper, compared with Nassopsis nassa.

varieties represented in the upper figures on the next page. The thin shell, the absence of all trace of epidermis, and the character of the whorls, as well as the scilpture and the character of the mouth, are all essentially the same in Bathanalia as they are in Amberleya; the only point in which they differ is in the character of the columella, that of Bathanalia being generally open, while that of Amberleya is always closed. I have, however, consulted Mr. Edgar Smith and others about this, and he assures 
me that such differences cannot be upheld as generically distinctive, more especially as the amount of umbilical opening in Bathanalia varies a good deal in extent from shell to shell. We may, therefore, conclude that, conchologically, Bathanalia and Ambcrley'a are the same.
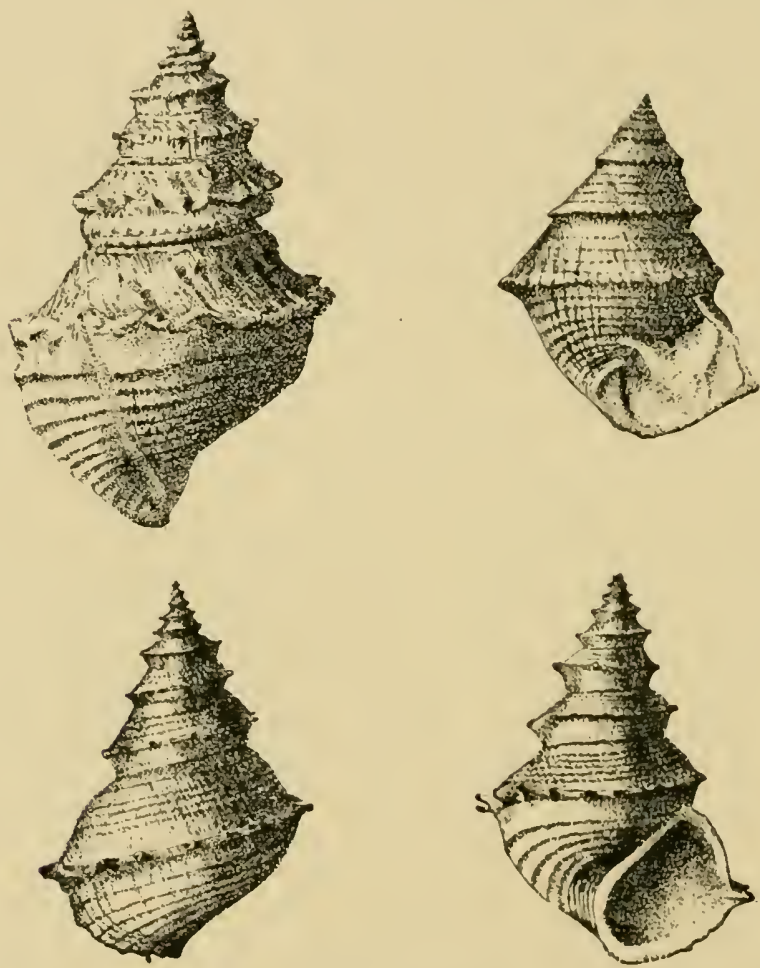

- Two varieties of Amberleya, upper, compared with Balhanalia houesi, lower.

Among the Jurassic fossil gastropods there are a number of forms which are typified by the so-called Littorina sulcata, and if the figures of the two specimens of this form given on p. 349 , lower, be compared with the back and front view of the shell of Limnotrochus thomsoni from Tanganyika given on the same page, it will be realised how closely the 
living and the dead forms correspond. Not only do the above halolimnic forms find their almost exact Jurassic parallels, it appears also that the remarkable shell of the Tanganyika genus, Chytra, is repeated among the varieties of the Jurassic genus Onustus (=Xenophera). Again we find that the shells of the Tanganyika genus, Spekia
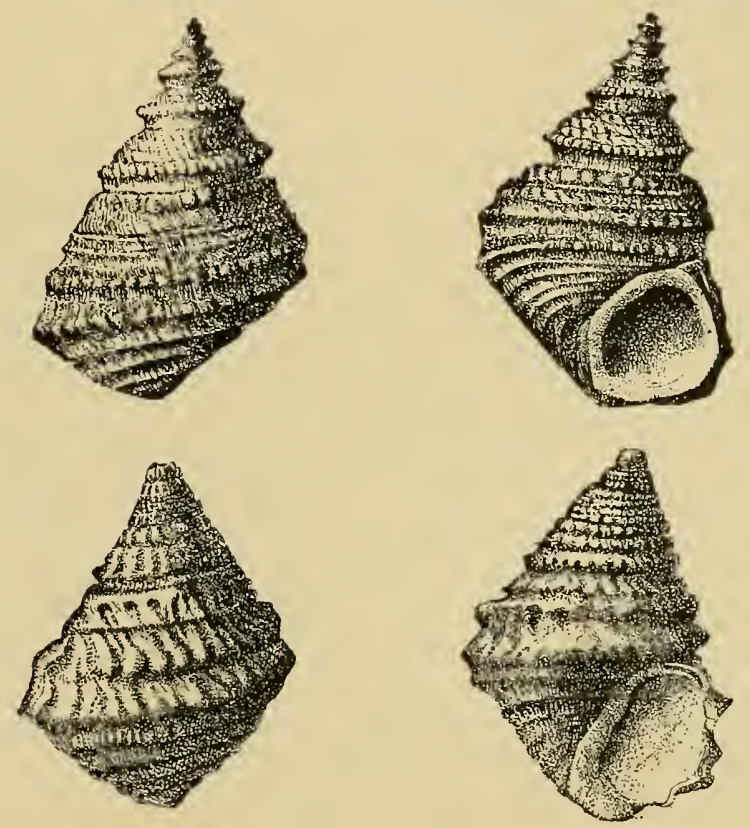

Limnotrochus thomsoni, upper, compared with Littorina suliata, lower.

(p. 35 I), are practically indistinguishable from the fossil remains of the shells of the marine Jurassic genus Neridomus represented on the same page. Nor does the comparison end here. There is among the gastropods of the halolimnic group a very remarkable and characteristic shell which Smith named Melania admirabilis. It is a Cerithoid form totally unlike any other living type which is known, but 
it has been found by comparison that it is practically indistinguishable from the inferior Oolitic fossil known as Cerithium subscalariforme. The above examples of the existence of a minute similarity between the shells of the halolimnic group and those of the Oolitic seas are sufficiently striking, but it should still further be pointed out that even the genus Typhobia, of Tanganyika, is matched
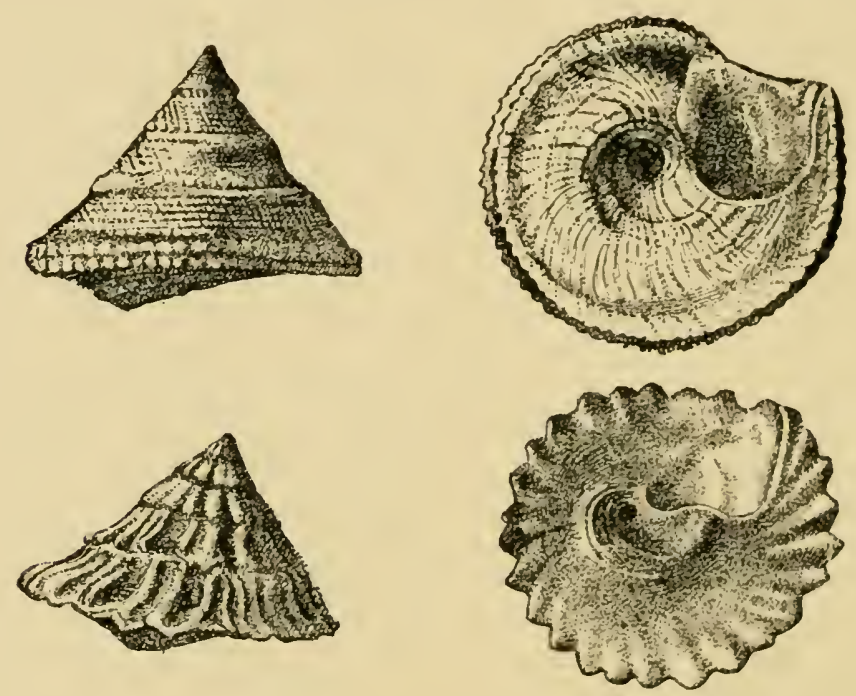

Chytra kirkii, upper, compared with a marine Jurassic onustus, lower.

by an Oolitic fossil genus Purpuroidia, from which it is very difficult, if not impossible, on conchological grounds, to distinguish it. From these comparisons it will be seen that we have numerous genera of gastropods belonging to the halolimnic series of Tanganyika, which are conchologically indistinguishable from an equal number characteristic of the Oolite seas, and it will certainly be admitted that in this method of stating the fact we do not, in reality, do justice to the comparison at all, for it is unquestionably a 
very surprising fact that every one of the halolimnic gastropod genera should contain one or more forms which are indistinguishable from corresponding Jurassic types, or, in other words, that the gastropodean section of the halolimnic fauna of Tanganyika should correspond en bloc with the gastropodean remains left by the Jurassic seas. We have, in fact, here something which is obvious and tangible, and which, at any rate, on the face of it looks
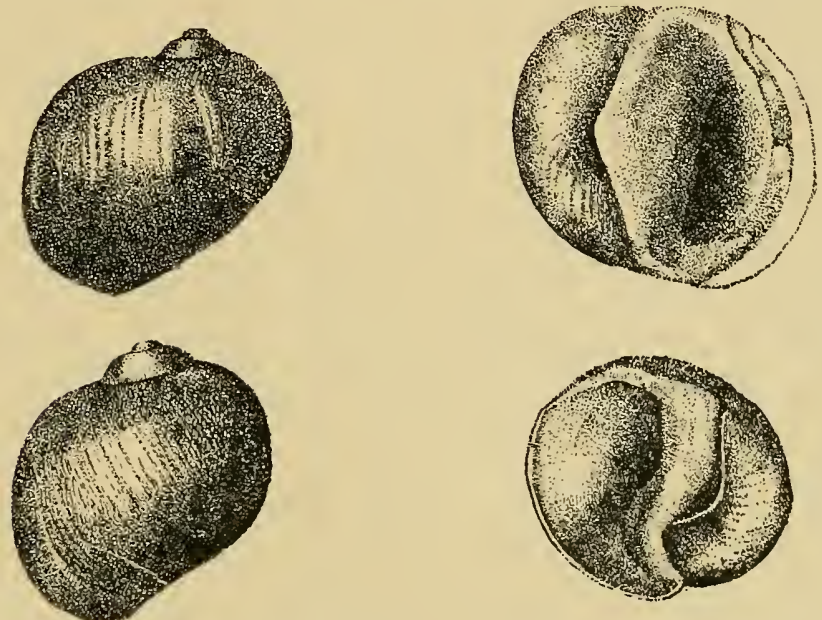

Spekia sonata, left, compared with an example of the Jurassic genus Neridomus, on the right.

as if it would lead directly to the solution of the whole Tanganyika problem with which we have been concerned. What it is requisite to ascertain further is whether, under the circumstances, such a comparison is justifiable, or, in other words, are there any geological or palæontological considerations which will render it impossible, or, at any rate, extremely unlikely that in Tanganyika we should encounter Jurassic forms persisting to the present day. So far as I can ascertain, there is no 
valid geological, zoological, or palxontological objection to such a state of things having occurred, and I think the geological position in regard to the matter is correctly summarised in the following paragraph, which appears in Huxley's discourse upon persistent geological types:"For anything that geology or palxeontology can show to the contrary, a Devonian fauna and flora in the British islands may have been contemporaneous with the Silurian life in North America, and with a carboniferous fauna in Africa;" and so also, for anything which geology or palreontology can show to the contrary, there may still be in Tanganyika a Jurassic fauna existing contemporaneously with the general modern fauna of to-day. If, then, the comparison between the Oolitic and the Tanganyika gastropods is as good as the comparisons upon which palæontologists are accustomed to regard the fauna of different deposits as of the same age, we have precisely as much reason for regarding the halolimnic and the marine Jurassic faunæ as similarly identical.

I have already shown in what precedes that, so far as conchological determinations of generic and specific identity are possible under any circumstances, the comparisons between the Jurassic and halolimnic shells are quite as good, if not better, than most of the palcentological determinations upon which palæontology is content to rest assured.

It is, however, not so much in the nature of the comparison as in the number of corresponding points between the two faunx, that the importance of the above comparison will in reality be found to lie. We could, of course, regard it as not unlikely that one shell in a great lake like Tanganyika might have become modified so as to repeat the shell form of a gastropod belonging to the Jurassic seas, and 
we could still regard it as a somewhat surprising coincidence if two or three modern types had done the same; but when, as in the case of the halolimnic shells, we find that more than half a dozen genera, all the halolimnic genera in fact, contain types which are indistinguishable from marine Jurassic forms, the likelihood of such a correspondence being a mere coincidence becomes improbable in the extreme. There is thus in this comparison direct and weighty evidence as to what the halolimnic fauna really is, and it remains for us to consider whether the character of the halolimnic animals
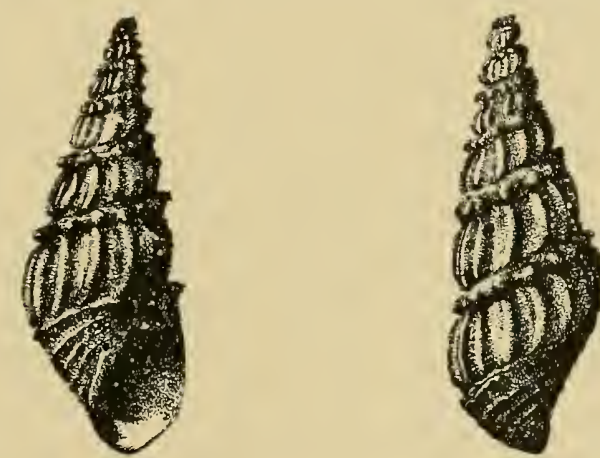

The Melania admirabilis of Lake Tanganyika.

other than the gastropods can be readily fitted in with this somewhat startling indication that Tanganyika practically represents an old Jurassic sea. The facts upon this head are somewhat meagre, but they are certainly not without significance. Thus the ganoid polypterus at least had allies in the Jurassic seas. Most of the teleostian fishes appear to have arisen later, but they probably had emerged about that time, and we obviously need not suppose that the lake would become suddenly cut off from a western ocean. The prawns, crabs and jelly-fishes of the halolimnic group are all forms which might very well have belonged to a Jurassic series, while the sponge Potamelepus is not 
without interest in this connection; for the spicules of this genus are highly peculiar (see Chap. XV.), and are quite indistinguishable from the old marine genus Renicria, common in the Silurian epoch. There is thus obviously nothing in the character of the halolimnic animals which is opposed to the idea that they, together with the gastropods, belong to some such ancient sea-stock as the foregoing comparisons suggest; while the positive ancestral anatomical characters possessed by the majority of the gastropods, by the jelly-fish and the crabs, is in exact accordance with this view.

From a consideration of the matters dealt with in the preceding chapters, it will have been seen that along all the lines of investigation that have been pursued, the result reached is practically in every case the same. Thus an investigation of the geological characters of Central Africa showed that there was no foundation in fact for the Murchison hypothesis, and that there was evidence of vast disturbance in the region of the great lakes. It consequently showed also further, that there is no positive evidence of any sort or kind against the view that the sea at some fairly remote period may have extended as far as the present site of Tanganyika. 'The study of the fauna of the Great African lakes showed that there is a typical African fresh-water fauna common to them all, and that to this the peculiar halolimnic fauna of Tanganyika bears no sort of relationship, and is so to say superadded. So also the examination of the halolimnic animals themselves shows almost in every case that they possess the positive attributes of primitive forms, often directly anteceding in their structure certain modern marine types. In this way we arrive at the conclusion that the lake must have been stocked with a sea fauna very long ago; so 
long ago, in fact, that the animals composing this fauna are now for all practical purposes so many lingering shadows of the past, and consequently the discovery of the identity which exists between the halolimnic and marine Jurassic shells is after all nothing but what we might have been led to expect from a consideration of other lines of evidence; the comparison merely puts the finishing touch to a series of investigations, all of which persistently converge towards the same point and gives us a direct indication of the geological age during which Tanganyika ceased to be directly stocked with organisms from the ancient seas.

$\mathrm{Up}$ to the present time this brings us to the conclusion of the whole matter, but it may be useful to briefly recapitulate the broader results of the foregoing enquiries.

It has been seen that a vast succession of related geological changes have gone on throughout the equatorial regions of Africa, and that up to the present time these changes have resulted in the incipient formation of a great mountain chain. These same changes have gone on at different times, and where there were once obviously vast and deep depressions, the old aqueous deposits of the interior have been broken and thrust up into the crests of the Great Central African Range, now thousands of feet above the sea. There is no evidence of the extension of Tanganyika to the north or east, but there is, as we have seen, an obvious probability that it did extend to the west along the Congo depression. The geology of the districts west of Tanganyika and of the upper and lower portion of the Congo basin thus afford a most promising field for future exploration, and the same may be said of the whole Congo system, for so far as it is at present known, it has yielded the most intensely interesting results.

During the course of the geological changes which have 
taken place in Central Africa, Tanganyika probably, along with a portion of the Congo basin, became a more and more land-locked sea, and in the course of time the water in these areas became freshened, and consequently a large section of the old marine fauna died out, while those fishes which could withstand the change migrated to a certain extent throughout the fresh-waters of the Continent. On the other hand, the invertebrate survivors of this old marine fauna remained almost exactly where they originally were, and as the present conditions of the land were gradually assumed, the ordinary fresh-water fauna of Africa gradually struggled into Tanganyika, and thenceforth has lived, along with the old halolimnic remnant, as it does to-day. 


\section{N D E X.}

AETHERIA， I 5 I

$$
, \quad \text { elliptica, I } 3 \text { I. }
$$

Affinities of Aporrhais, 27 I .

", Arachnoidia, $33^{\circ}$.

", Bathanalia, 266, 270, 347 .

,. Bythoceras, 266, 272.

, Chytra, 228, 230, 245, 266, 27 I, $272,277,349$.

, kirkii, 228 .

halolimnic fauna, the, $35 \mathrm{I}$.

Hipponyx, 27 I.

Jurassic gastropods, the, $35 \mathrm{I}$.

Limnotrochus, 266, 27I, 330, 348.

Lubomirski, 32 .

Melania admirabilis, 349 . , amarula, 272.

Nassopsis, 230, 267, 269, 27 I, 346.

Oolitic fossils, the, 350 .

Onustus, 330, 349 .

Opisthobranchs, the, 274 .

Paramelania, 266, 272, 336, 342,346 .

damoni, 345, 346 .

Planorbis, 276.

P'teroceras, 27I, 272.

Purpurina bellona, 345, 346 . , inflata, $345,346$.

P'urpuroida, 350.

I'yrgulifera, 336 .

Rachiglossa, the, 276.

Rhipidoglossa, 277, 345 .

Rissoa, 274.
Affinities of Spekia, 267, 274, 349.

" Sponges, the, of Tanganyika, $309,315,321,322,323$.

,, Spongilla moorei, 315, 32I, 33 I.

, , $\quad$ tanganyikæ, 320, $321,322$.

, Strombus, 270, 330.

", Taenioglossa, 271, 276.

,, Tanganyiciæ, 266, 273.

, Tanganyika polyzoan, the, 297

, Toxiglossa, the, 276 .

, Trochus, 272.

," Tympanotamus, 343 .

,, Typhobia, 266, $27 \mathrm{I}$.

, Vivipara, 277.

, Xenophera, 270, 349.

Africa, central, geological characters of, 354,355 .

, , geological changes still going on in, 107.

,, , presence of ancient sea in, 68 .

", shaped like a hog's back, 39.

African aqueous deposits, position of, 66 .

, , , , , extent of, 65.

,, flora, perplexing nature of, I07.

", fresh waters, characters of, I39.

,, , , examination of, I9.

" ganoids, 10.

", halolimnic fishes, 340.

," interior, aqueous deposits in the, 55 .

", , broad conclusions on the geological nature of, 69 . 
African interior, changes in, past and present, 54 .

, , , , grooves in, 40.

"Lakes, the faunce of, 121, 140, 141.

, , , , physiographical features of the, 146.

, , pleistocenes of, 65 .

" lankl-mass, its modern nature, 49

", , formation of the, 60 .

, landscape gardener, IOI.

," mountain building, 49 .

, normal fresh-water fauna, $32 S$.

, Park-lands, 107.

, , , , description of, 10 S.

, , , , geographical position of $108,109$.

,, , a puzzle to all explorers, IoS, 109 IOI.

, physical phenomena, simplicity of, 49 .

,, sandstones, extent of, 65

, , , old, 65 .

", scenery, artificial aspect of some, 108 .

,, watersheds, change in, 87 .

Albert Edward Nyanza, altitude of the, $S 9$,

I 30.

, , , .. , depression of the, $5 \mathrm{I}$.

, . . , , , fauna of the, $\delta 9$, 130.

, , , , , fishes of the, 130

, , , , , its former connection with Kivu, 89.

, , , , , molluscs of, 19.

," , , , , section through, a, 94 .

Albert Nyanza, altitude of, 129.

$$
\begin{gathered}
, \quad, \quad, \quad \text { fauna of, } 129,147 . \\
, \quad, \quad \text {, fishes of, } 129 . \\
, \quad \text { march to, from the Moun. } \\
\text { tains of the Moon, } 114 . \\
, \quad, \quad \text {, molluscs of, 19. } \\
\quad, \quad \text { and Mountains of the Moon, } \\
\text { types of flora between, } 114 .
\end{gathered}
$$

Alestes basemose, 132.

,, imberi, 124.

,, lemairii, $12 S$.

," macrophthalmus, 12S, 154

, $\quad$ nusse, 132.

,, rueppellii, 131 .

Alluvial plains, important facts in connection with, IOS.IIg.

, = , south of the Allhert Edward Nyanza, 86.

Altitude of Albert Edward Nyanza, the, 130 , , Nyanza, 129.

, Mountains of the Moon, the, IO2

", , , , opinions of the older explorers on the, 102.

reached on the Mountains of the Moon, 102.

Amberleya, 349 .

Amphibolites in the Mountains of the Moon, 101 .

Ampullaria, 151.

$$
\begin{aligned}
& \text { " bridouxi, } 217 . \\
& \text {," bukobre, } 131 . \\
& \text {,, emini, I3I. } \\
& \text {,, erythrostoma, } 130 \text {. } \\
& \text {," gordoni, } 13 \mathrm{I} \text {. } \\
& \text {,, gradata, I25. } \\
& \text { ", nyanzie, } 13 \mathrm{I} \text {. } \\
& \text {, ovata, I3 } 1,217 . \\
& \text {," stuhlmanni, } 129 .
\end{aligned}
$$

Ancestral characters of fresh-water fauna, 15 .

Ancylus, 125.

$$
\text { ," stuhlmanni, I31. }
$$

Andes, southern, compared to Great Central African range, 39.

Animals, halolimnic, ancestral type of, 343

Anoplopterus platychir, 124 .

Apennines in relation to volcanoes, 36 .

Aporrhais, 223.

, , affinities of, $271,272$.

Aqueous deposits of African interior, the, 55.

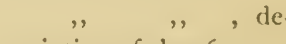
scription of the, 65 . 
Aqueous deposits of African interior, extent of the, 66 .

$, \quad, \quad, \quad \begin{aligned} & \text { sition of the, } 66 . \\ & \text { of Nyassa, types of, } 43\end{aligned}$
$\quad 65$.
$\quad, \quad \begin{gathered}65 \\ \text { of Tanganyika, } 35,62, \\ 65,66,80 .\end{gathered}$

Arachnoidia ray lankesterii, description of, 297.

Asprotilapia leptura, description of, 210

Auchenoglanis, I 28.

," biscutatus, description of, I 64.

Auvergnes in relation to the Alps, 36 .

\section{BAGRUS MERIDIONALIS, I 24.}

Bangweolo, Lake, fauna of, I 27.

$$
\text { , , , , similar in character to }
$$$$
\text { the V. Nyanza, I 3I. }
$$

Barbus altianalis, description of, $\mathrm{I} 56$.

$$
\begin{aligned}
& , \quad \text { edwardianus, I } 30 . \\
& " \quad \text { fergussonii, I } 30 . \\
& " \text { pagenstecheri, I } 30 . \\
& ", \quad \text { platyrhinus, description of, I } 56 . \\
& " \text { serrifer, description of, I } 58 . \\
& , \quad \text { trimaculatus, I } 24 .
\end{aligned}
$$

Barilius moorii, description of, 158 .

,, guentheri, I24.

,, tanganyicæ, description of, 160 .

Basin of the Congo, 342 .

Bathanalia, 218, 221.

, , affinities of, 266, 270, 344,

347,348 .

", , character of, 347 .

", compared to the Jurassic fossil

$$
\text { Amberleya, } 228 .
$$

,, , description of, 228.

Bathybates fasciatus, description of, 185 .

$$
, \quad \text { ferox, description of, } 184 \text {. }
$$

Baumann, explorations of, 79 .

Beringo, Lake, the fauna of, 144 .

Bithynia humerosa, I 25, I3I.

$$
\text { , stanleyi, I } 25 .
$$

IB̈̈hm's discovery of jelly-fishes, 2.

Boulenger, investigations of, concerning the Congo fishes, 330,342 .
Bourguignat, 220.

Bouvier, researches of, $270,277$.

Burton, Sir Richard, expedition of, I.

\section{CAPOËTA TANGANYICE, DESCRIP-} TION OF, I 54

Capulus, affinities of, 270, 271, 272.

Caspian sea, 30

Caucasus, the, formation of, 35,36 .

Cause of extinction of the ancient marine types of fauna, 17 .

Celebes, mollusca of, I3, I4.

Chad, Lake, I39.

Chalky deposits on Nyassa, 43 .

Chasms, deep valleys, 39 .

Characinidæ, I 35 .

$$
\begin{aligned}
& , \quad \text {, distribution of, } 34 \mathrm{I} . \\
& , \quad \text { in Nwero, I28. } \\
& , \quad \text { in Nyassa, I 24. } \\
& , \quad \text { in Tanganyika, I 54. } \\
& , \quad \text { in Nictoria Nyanza, I3 } 1 .
\end{aligned}
$$

Character of Amberleya, 349 .

Chytra, 218

,, affinities of, $230,245,266,27 \mathrm{I}$, 272,349 .

, kirkii affinities, 230, 232, $33 \mathrm{I}$.

,, ,, , description of, 228 .

Cichlidæ, I35.

,, , Albert Edward Nyanza, of the, I 30.

,, , Congo, of the, 136 .

", , cosmopolitan nature of the, 34I.

,, , description of in Tanganyika, I68.

, , distribution of, 19.

,, , halolimnic, 340 .

, , Nwero, of, I28.

", , Nyassa, of, r 24.

, , Rudolf, of, 132 .

,, , Tanganyika of, 10, 136, 329.

, , Victoria Nyanza, of the, I 30 .

Citzarmus geoff reyi, I32.

Clarias layera, $\mathbf{I} 30$.

, lazeras, I 3 o.

", l,iocephalus, description of, 162 .

,. moorii, 13 . 
Clarias mossambicus, I 32 .

," robechii, desription of, 160.

Cleopatra exarata, I 30.

, gruillemei, 131, 217.

, pirothi, I 29, I 30.

Clinate of Kivu, I 28.

$$
\text { , Nyassa, } 123 .
$$

Coal at I'emlıa, 66.

Colpodium, 331 .

Committee, Tanganyika, formation of, 8 .

Conchological species, 270 .

Condylostema, 131, I 39 .

Conglomerates on Tanganyika, 48 .

Congo, The, 34 .

, basin, 342 .

, , $\quad$ an ancient sea, 343 .

,, , cichlid fishes in the, 136 .

,, , fishes in the, 342 .

,, , geology of, 355 .

,, , jelly-fishes reported in, I 40.

,, , sea prohably extended over the, I 46.

,, watershed, 97, 136.

Continental and island florix, 147, 148 .

Copeporls in Nyassa, 12.4 .

Corbicula asta1tina, 125 .

,, radiata, $125,129,130$.

Corematodus shiranus, I 24 .

Cralss, fresh-water, of Nyassa, 125.

,, , of Tanganyika, description of, 280 , 286 .

Cretaceous fresh-water fauna, 334, 335, 336.

Crustacea of Tanganyika, 279.

Cyclops in Nyassa, 124.

Cyprinidae, 135 .

,, , Albert Edward Nyanza, of the, I 30 .

,, , distribution of, $34 \mathrm{I}$.

, , Nyassa, in, 124.

, , Rudolf, in, 132 .

, , Tanganyika, of, description of, 154.

," , Victoria Nyanza, in, 130

Cyprinolontidae, I 35.

$$
\begin{array}{ll}
, & \text {, description of, I68. } \\
, & \text {, distribution of, } 34 \mathrm{I} . \\
, & \text {, Nyassa, of, I } 24 .
\end{array}
$$

Cyprinodontidx, Victoria Nyanza, of, I $3 \mathbf{I}$.

Cyrotocara moorii, I 24 .

DEAD SIA, THE, A EURICOIIC F()I.I), 40.

Depth of soundingss on Nyassa, 123.

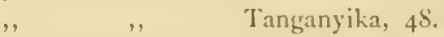

Deposits, aqueous, in the African interior,

$$
55,74 \text {. }
$$

, , , Masswa on Tanganyilia, at, 69 .

, , , modern lake, on Tanganyika, $8 \mathbf{r}$.

, , , Mount Waller, near, 7 I .

, , , old, on Nyassa, 35.

, , , ,, ,, Tanganyika, 35.

, , , position of the African, 66.

,$\quad$, limestone, 62 .

,, , sandstone, 35 .

,, , similar to Drummond's berls on Tanganyika, $71,74$.

,, , south of Nyassa, $7 \mathbf{I}$.

,, , south and north of Tanganyika, 71 .

,, , vast extent of, 66 .

Depressions, formation of, 39.

,, not formed by ice, 34 .

, noticed by explorers, 39.

Descriptions of the halolimnic gastropods, $22 \mathrm{I}$.

Distribution of the Cichlide, 19.

Discognathus johnstoni, I 30.

I) istichodus, 132 .

Docemodus johnstoni, I24.

Downthrust in the Nyassa Valley, 53.

Drakensberg Mountains, 35 .

Drummond's leeds, $65,69,72,74$.

EARTII MOVEMENTS, LINEAR, 36. ,, , , Nyassa, in, 42

Eastern eurycolpic fold, 40.

Echinoderms found north of Nyassa, 72.

Ectodus descampsi, description of, I 86 .

,, longianalis, ,, , 188.

", melanogeny's, ,, , I 88 .

Effect of salt on fresh-water organisms, 23,24 . 
Elevation and depression in the Great Central Range, 35 .

Emergence of the primary fresh-water series, I 7.

Engraulicypris pinguis, 124.

Ephydatia muilleri, 31 7 .

Eretmodus cyanostictus, description of, 210.

Etna in relation to the Apennines, 36.

Eupera parasitica, I3I.

Euphorbia trees, their part in the formation of park-lands, I I5, I I 7 .

Eurycolpic fold, definition of, 50 .

$$
\begin{aligned}
& , \quad, \quad \text { valley, formation of a, } 43 \text {. } \\
& \text {,, folds of Central Africa, } 76 \text {. } \\
& \text {, , } \quad \text { compared to the canals of } \\
& \text { Mars, } 52 . \\
& \text {, compared to rills on the } \\
& \text { moon, } 52 \text {. } \\
& \text {,, , extent of } 85,86,93 \text {. } \\
& \text {,, , eastern, the, } 40 \text {. } \\
& \text {,, , formation of, by lateral } \\
& \text { pressure, } 50 \text {. } \\
& \text {, , floor of, } 82 \text {. } \\
& \text {,, , inter-relationships of, } 50 \text {, } \\
& 5 \mathrm{I} \text {. } \\
& \text {,, , position of, } 7 \text {. } \\
& \text {, running to the Red Sea, } \\
& \text { I } 32 . \\
& \text {,, structural features of, } \\
& \text { 42-50. } \\
& , \quad,, \text {, unique character of, } 5 \mathbf{I} \text {. }
\end{aligned}
$$
52.

Evidence as to the nature of the halolimnic fauna, 353, 354 .

Examination of the Great African Ridge, 40.

Experiments on marine faunæe, 12.

Existing conceptions of the origin of freshwater faunæ, I3.

Extent of the eurycolpic folds, $40,42,45$

FAULTING ON NYASSA, 35, 42.

Fauna, Albert Edward Nyanza, of the, 89 , I33, I44. ,, Albert Nyanza, of, I29, I44, I47.
Fauna, Bangweolo, Lake, of, I27.

,, , Beringo, Lake, of, I44.

,, , Congo, of the, I39, 142.

, , distinctive character of the halo-

limnic, 334 .

,, , general fresh-water, 325.

,, , halolimnic, the, evidence to account for, 352,354 .

, , , of Tanganyika, 328, $34 \mathrm{I}, 342,350$.

, , the, has emanated from the sea, 337, 339,342 .

,, , hypotheses to account for, 336 .

,, , primitive character of the, 330 .

, , Kela, Lake of, 127 .

,, , Kivu, Lake of, 87, I28.

,, , lacustrine, compared to an island flora, I47-I 5 I.

, , lakes, of the, enquiry into the nature of, $3 \mathbf{I}$.

, , Mwero, Lake of, 127, I44.

, , Nyassa of, 3, 1 24, I25, I 26, 147.

, , , no marine relics among the, 72.

, Rudolf, Lake of, 132.

, Rukwa, Lake of, 73, I2I.

, Shirwa, Lake of, 3, 23, 126.

, Tanganyika, of, 9, I 33, I40.

,$\quad$, age of, $325,343$.

343 .

, compared to that

Mwero, I34.

, description of, 217 . , distinctive characters of, 143 . , fishes of, 134 . , Jurassic type of the, 73,344 . , marine aspect of, I $4 \mathrm{I}$.

,, , Victoria Nyanza, of the, I44.

Faunas of the African Lakes, do not migrate, 145. 
Faunas of the African Lakes, number of species in the, 146 .

Rivers, 139.
Fergusson, altitude reached by, on the Mlountains of the Moon, IO2. ", , geological investigations of, in Africa, 55 .

Fishes of the Albert Edward Nyanza, 130.

," ," Nyanza, I29.

,, , cichlid, distritution of, 19.

,, , Congo, of the, 342 .

,, , ganoid, found by Drummond, 62, 72.

," , halolimnic, the, of Africa, 340.

,, Mwero, of, 128.

", Nyassa, of, 124.

,, , Tanganyika, of, $134,135,152$.

$,, \quad, \quad, \quad$, list of, 136 .

,, , Triassic remains of, 62.

,, , Victoria Nyanza, in the, 130.

Flora of Central Africa, perplexing nature of, 107.

, , types of, between the Albert Nyanza and Mountains of the Mloon, II4.

Floras, island and continental, 147, 148 .

, , , compared to lake faunas, 147.

Folds in the earth, formation of, 30, 69, $70,71,98,123$.

Fossils, Jurassic, 345 .

,, , marine oolitic, 346 .

Fossilized remains north of Tanganyika, 82.

Fülleborn, observations of, on Rukwa, 73 .

Fundulus taeniopygus, 13 I.

GANOIDS, ro, 330.

Gardener, landscape, in Africa, I07.

Gastropods of Tanganyika, 141, 217.

$, \quad, \quad, \begin{gathered}\text { affinities of, } \\ 269 .\end{gathered}$
,$\quad$ affinities with
o c e a n i c
forms, 268.

Gastropods of Tanganyika, ancestral cha-

racters of, 277,278 .

$$
\begin{aligned}
& \text {, , , isolation of, } \\
& 320 . \\
& \text {, , , , halolimnic, } \\
& \text { " the, } 266 . \\
& \text {, , , , Jurassic paral- }
\end{aligned}
$$

Geneva, valley of, 34 .

Geographical exploration needed, 7.

," fact, an important, 136.

Geological changes in Africa still going on, 107.

, change in Africa, evidence of, II 8 .

, character of Africa only parti. ally known, 56 .

character of Central Africa, 354,355 .

, conceptions of Sir R. Murchi. son, 32.

,, construction of Africa, 33 .

, features of Africa, 31 .

, $\quad$ impermanence of Africa, evidence of park-lands on the, I 7 .

", investigations of Mr. Fergusson, 55.

, observations of White and Tausch, 334, 336 .

, = , the Tanganyika lixpeditions, 327.

, period of the beginning of the eurycolpic folds, 69 .

theories, older, disagree with geological facts, $3 \mathbf{I}$. 
Geological types, Huxley's discourse on, 352.

", views, the older, 32 .

, nature of the African interior, broad conclusions on, 69 .

Geology of the Congo, 355 .

,$\quad$,
,$\quad$,
,$\quad$,

Rusisi valley, 82 .

Shirwa district, 57 .

Southern section of the

African interior, 56 .

Gephyrochromis moorii, description of, I 96.

Gnathonemus stanleyamus, I28. .

Götzen, explorations of, 79 .

Grammatoria lemairii, description of, I9I.

Great African Central range, 34 .

$$
\begin{aligned}
& \text { ", , elevation and de- } \\
& \text { pression in, } 35 \text {. } \\
& \text {, , , examination of, } 40 \text {. } \\
& , \quad, \quad \text {, extent of, } 33 \text {, } \\
& \text {, } \quad, \quad \text {, formation of, } 68 \text {. } \\
& \text {, , , , upthrust in, } 39,98 \text {, } \\
& \text { IOI. } \\
& \text {, , , volcanoes in rela- } \\
& \text { tion to, } 36 \text {. }
\end{aligned}
$$

Gregory, explorations of, 34 .

HALOLIMNIC FAUNA, 9, I4I, I43, $327,328,329$.

, , , , affinities of, 35 , 352 .

, , , ancestral type of, 34I.

", ,, distinctive characters of, 334 .

,, , evidence concerning the, 353,354 .

", , hypotheses to account for, 336 .

,, , marine origin of, 337 , 339,343 .

, , meaning of its peculiarities, $33 \mathbf{I}$.

,, , primitive characters of the, 330 .

,, , Tanganyika of, I39, I40, 141, 150.

fishes of Africa, 340 .

, gastropods, nature of, 266.
Haplochilus johnstoni, 124.

Hemitilapia oxyrhynchus, I24.

Herbst, experiments of, 28 .

Hipponyx, affinities of, 27 I.

History of the continent, 8 .

Hog's back, geological form of the continent, 39.

Huxley's discourse on geological types, 351.

Hypotheses, various, to account for the halolimnic fauna, 336 ,

Hydrocyon forskalii, I 32 .

,, lineatus, I28, 154 .

\section{INVESTIGATIONS OF SEMPER}

AND SOLLAS, I 2.

Isidora coulboisi of Tanganyika, 217 .

,, forskali, І 3 І.

, nyassana, 125 .

", strigosa, $\mathbf{1} 3 \mathbf{I}$.

, succineoides, I25.

,, transversalis, I $\mathbf{3} \mathbf{I}$.

", trigona, I3I.

Island floras compared to lake faunas, I47I5I.

Islands, probable group of ancient, 68 .

JELLY-FISH OF TANGANYIKA, I33, I4I, 287.

, , , description of, 298.

, , , , life history of, $301,305$.

, , , native description of, a, 302 .

," , reported in the

Jolly, conclusions of, 26. Congo, 140.

Jordan, the valley of, a eurycolpic fold, 40. Julidochromis ornatus, description of, 176 . Jurassic fauna of Tanganyika, 74.

," gastropods, affinities of, $35 \mathrm{I}$.

" parallels among the gastropods of

Tanganyika, 349 .

, shell Amberleya, 346. 
KA A A WE, SANDSTONES OF GRliGORI AT, 66.

Karisimbi, height of, $S_{5}$.

Léla, lake, fauna of, 127.

lienia, 33 .

, in relation to the Great Central kange, 36 .

Kilima Njaro, in relation to the Great

Central liange, 33, 36 .

Kirungo cha gongo, height of, 86 .

Kivu, Lake, altitude of, $8_{3}, 89$.

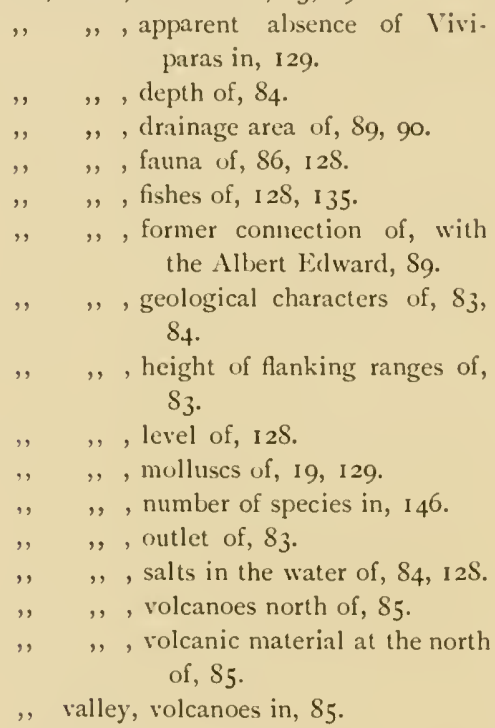

Kohlschitter, Dr., investigations of, in the eurycolpic valleys, 5o, 73 .

Lota Kota, section through the districts of, 4 I.

\section{LABEO FORSKALII, I 30.}

," mesops, 124.

,, rueppellii, I 30.

, victorianus, I 30 .

Iakes, African, deposits near the, 55, 62 .

$$
\begin{gathered}
, \quad, \quad, \quad, \quad, \quad \begin{array}{c}
\text { compared to is- } \\
\text { land floras, }
\end{array} \\
147, \text { I } 4 \text { S. } \\
,, \quad \text {, north of Tanganyika, } 7 \text {, So. }
\end{gathered}
$$

Lakes, African, relative ages of the, 70 . , ,, , traditions of the clisiap. pearance of, 90.

Lamellaria perspicua, affinities of, 262. Lamelliluranchs of Tanganyika, 72, 217. Lamprologus lrevis, description of, 172 .

$\begin{array}{llll}\text {, compressiceps, } & ,, & , 172 . \\ ,, & \text { elongatus, } & ,, & , 168 . \\ ,, & \text { fasciatus, } & ,, & , 174 . \\ ,, & \text { furcifer, } & ,, & , 174 . \\ ,, & \text { hecqui, } & , & , 172 . \\ ,, & \text { lemairii, } & ,, & , 170 . \\ ,, & \text { modestus, } & ,, & , 170 . \\ ,, & \text { tetracanthus, } & , & , 168 . \\ \text {, } & \text { tetrocephalus, } & , & , 170 .\end{array}$

Lanistes ellipticus, 125.

,, jouberti, 217.

, olivaceus, 125.

, ovum, 125.

, schweinfurthi, I 3 I.

Lates microlepis, elescription of, 168.

,, niloticus, 132 .

Lepidosirenidie, 1 30, 13 I.

$$
\begin{array}{ll}
, & \text {, description of, } 154 . \\
,, \quad \text {, distribution of, } 3+1 .
\end{array}
$$

Limestone deposits, 62 .

Limnea, 16, I 8, 2 I.

,, debaizei, 131, 217.

, natalensis, 125 .

,, nyanzie, 131 .

Limnocaridina tanganyikie, 279.

Limnochniclia, life history of, 305 .

Limnotrochus, 2 I 8, 219.

,, , affinities of, $245,248,266$, $271,272,348$.

, kirkii, affinities of, 229.

,, thomsoni, 229, 234, 235 , $236,237$.

,, , , description of, 234.

Limnothelphusa maculata, 279.

$$
\text { , , , description of, }
$$
2 So.

Littorina, 263, 274, 276 .

," , affinities of, 276 .

, sulcata, 24 S.

, , , affinities of, 348 . 
Livingstone's scum, I 38,324 .

Loeb, experiments of, 25 .

Lithoglyphus zonatus, 219 .

Lubomirska, affinities of, 322 .

\section{MALAPTERURUS ELECTRICUS,}

DESCRIPTION OF, 168.

Marine appearance of the Tanganyika fauna, I, 74, I4I, I42, 2 I 9.

" faunas, II, 30 .

, , , transformation of, into fresh.water faunas, $\mathbf{I} 2$.

, $\quad$ gastropods, Jurassic series of, 346 .

Nastacembelidx, I24, I 35, 34 I.

$$
\begin{aligned}
& \text { of Tanganyika, descrip- } \\
& \text { tion of, 214. } \\
& \text { in the Victoria Nyanza, } \\
& \text { I } 30 .
\end{aligned}
$$

Mastacembelus, I30.

", ellipsifer, description of, 214.

, $\quad$ frenatus, 2 I 4 .

", moorii, description of, 2 I 4.

,, ophidium, ," , 216.

, shiramus, I 24.

" taeniatus, ," ,2 2 6.

,, tanganyicæ ", ,2 24.

Nedusa, 298, 308, 328 .

Melania, I6, I8, 21.

, admirabilis, affinities of, 273 .

, amarula, affinities of, 269,270 ,

273.

arcuatula, I25.

", episcopalis, affinities of, 274 .

, horei, 217.

" liricincta, 129.

, nodicincta, I25.

,, pergracilis, 125 .

", polymorpha, I25.

,, simonsi, I25.

, tanganyicensis, 2 I 7 .

,. tuberculata, I25, I29, I 30, I3 I,

217.

turritispira, 125 .

Melanella, 2 I9.

Melaniadx, 219.

Melanopsis, affinities of, 336 .
Mountain building in Africa, 49.

regions of Central Africa, 34 .

Mountains of the Moon, altitude of, I02,

I 06.

, , , , , , , opinion of the older explorers on, 162 .

, , , , , , , opinion of Sir H. Johnston on, I 32.

,, , , paper in

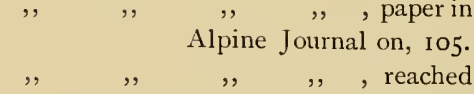
on, 102.

,, , , , , age of, 94 .

$, \quad, \quad,, \quad$ and the Livingstone Range, 98.

, , , , , , formation of, 98 .

, , , , , geology of, 94, 98.

, , , , , glaciers on, IоI.

, , , , , march from, to the Albert $\mathrm{Ny}$.

, , , , , section through, a, 97 .

, , , , , snowline on the, Ior.

, , , , , upthrust, violent on the, 98 , Ior.

, , , , , views of Stuhlmann, Stairs and $\mathrm{Scott}$ Elliot on, 98 , IOI.

Mount Waller, geology of, I2, 7I.

NASSOPSIS NASSA, 82, 218, 219. , , affinities of, 230, 234, 24I, $250,267,27 \mathrm{I}, 277,346$.

Natica, 16. , , affinities of, 270,330 .

Neubola bloyettyi, 132 .

Neothauma, S2, 2 IS. , , affinitics of, I28, 264 . 
Neothauma, varieties of, in Tanganyika, 149, 150.

Nyanzas, the, number of species in the, 146.

Nyanza, Albert Edward, the, I 30.

., ," ,, , altitude of, I30.

, , , , , fauna of, 130 144.

, ,, the, altitude of, 129.

" , , fauna of, $129,144$.

," Victoria, character of, 131 .

, , , , fauna of, 130 .

Nyassa, aqueous deposits abnut, 35, 43, 65 .

, , baobab beaches on, 70, 121 .

", deposits, south of, $7 \mathrm{I}$.

, , downthrust on, 53 .

,, , extent of, 122.

," faulting on, $42 \mathrm{I}$.

,, , fauna of, $3,73,121,124,125,126$, 147,328

,, , fishes of, I 24.

,. floor of, sinking, 44, 70, $7 \mathrm{I}$.

,, , geological characters of, 35, 43, $58,6 \mathrm{I}, 7 \mathrm{O}$.

, , level of, changes in, 70, 122, 123 .

, , number of species in, 146.

,, , park-lands of, 108.

, , position of, 35

," , post pleistocene activity round, 43 .

", sandstones, 42, 61, 62 .

, , section, a, through the south of, 40 .

" , " north of, 42 .

" and Shirwa, 70

"valley, 4I, 42, 48, 49, 73, 122.

, , , upthrust in, $43,49,55$.

ONUSTUS, AFFINITIES OF, 330.

Oolitic fossils, affinities of, $346,350,352$. Opisthobranchs, affinities of, 274 .

Origin of fresh-water faunas, 11, I2, 13, $15,17,18,20$.

PAL.MION MOOREI, 29 I.

Palxontological evidence of first appearance of fresh - water faunas, 16,25 .
I'aramelania, 218

,$\quad$, affinities of, $266,336,342$, 344 . crassigranulata, 150 . ", , description of, 245 .

crassilabris, of von Martens, 238.

damoni, affinities of, 130 , 272,346 .

,, , description of, 244 .

of Tanganyika, 334, 336 . , variations in, 150.

['aratilapia aurita, description of, 178 , bloyeti, 128 .

,, , description of, 178 .

calliura, description of, 178 .

cavifrons, 130.

dewindti, description of, 180 .

dimidiata, 124.

furcifer, description of, $18 \mathrm{I}$.

intermedia, I24.

leptosoma, description of, 182 .

livingstonii, 12.4.

longiceps, 124 .

longirostris, I30.

nacrocephala, 128 .

macrops, description of, 179 .

moeruensis, 128 .

modesta, 124 .

nigripinnis, description of, $1 S_{4}$.

nototania, 124.

pfefferi, description of, 178 .

retrodens, 130.

robusta, 124

serranus, 130 .

stenosoma, description of, 182 . ventralis, description of, 1 So. vittata, description of, 176 .

l'ark-lands, African, I07.

,, , a clue to the formation of, 113 .

, , description of, 108.

", , and the struggle for existence, 118.

, attempts to account for the existence of, 110. 
Park-lands, England and Europe, the, of, I IO.

, , Euphorbias, the part played by, in the formation of, I I 5 , I 7 .

" , explanation of their formation, I I 4, II 5, II 7 .

, , expression of physical change, the, II 7 .

, , geographical position, Io8, I09.

, , Nyassa Tanganyika, the, of, IOS.

,, , puzzle to all explorers, a, IOS, IO9, IIO.

Pelotrophus microcephalus, I 24.

, microlepis, I24.

Pemba, coal of, 66.

Perissodus microlepis, description of, 212.

Persistence of ancient forms, 6 .

Petrochromis andersonii, I29.

, nyassæe, I 24.

", polylepis, description of, I 86

", polyodon, ,, , 208.

,, tanganicre, ,, , 2 I0.

Pholides, apparent borings of, 84 .

Physical change, importance of, in zoo$\log y, 28$.

features of Central Africa, 9.

Physopsis africana, 125, 217.

, oroidia, I3I.

,, tanganyicæ, 217 .

Planorbis, I6, I8, I25, I29.

,, , affinities of, 276 .

, adowensis, I29.

, apertus, $\mathbf{1} 29$.

," choanomphalus, I3I.

, sudanicus, I30, I3I, 217.

, victoria, I $3 \mathbf{I}$.

Plateau of Tanganyika, 8o.

Platythelphusa armata, 279.

$$
\text { , , , , description of, } 280 \text {, }
$$
286.

I'lains, alluvial, south of Albert Edward Nyanza, 86.

Plecodus paradoxus, description of, 212 .

Pleurotomaria, affinities of, 272.
Pleistocenes, African lake, 65.

Polypteridæ, I 35 .

$$
\begin{aligned}
& , \quad \text {, distribution of, } 34 \mathrm{I} . \\
& \text { in Tanganyika, description } \\
& \text { of, I } 54 .
\end{aligned}
$$

Polypterus, 330 .

, belongs to the halolimnic group, 340 .

" congicus, 154 .

, in Lake Rudolf, 132.

, sencgalus, 132 .

Polyzoa, I3I.

, arachnoidia, affinities of, 330 .

,, , Tanganyika, of, I4I.

,,$\quad$, Victoria Nyanza, of, I3 3 .

Polyzoon of Tanganyika, description of, 295.

Post pleistocene activity round Nyassa, 63 .

Potamolepis found in the Congo, 342. , weltneri, description of, 323 .

Prawns in Lago di Garda, 15.

, of Tanganyika, I42, 279, 330.

Primary fresh-water fauna, I 5, 16, 30 .

Prosobranchiata, 16, 276.

Protopterus athiopicus, I3O, I3I, I 54.

, annectens, I 31 .

Protozoa of Tanganyika, I 38,323 .

Purpurina bellona, affinities of, 345 .

, inflata, ,, , 345, 346 .

$, \quad, \quad, \quad$ of the marine oolite, 346 .

Purpuroidia, affinities of, 350 .

\section{QUARTZITES ABOUT TANGANY. IKA, 48 .}

RACHIGLOSSA, 276.

Red Sea, 35 .

,$\quad$ in a eurycolpic fold, 4O, I32.

, , volcanoes in floor of, 45 .

lihipidoglossa, affinities of, 271, 276, 277, 345 .

Ridge of the grcat central chain, doulble cusped, 45 .

Risson, affinitics of, 274 .

Rivers of Africa, their fauna, 139.

, , , recent changes in, So. 
River systems of Africa, 34 .

Rucky Mountains, 33, 36 .

lkuchuru river, fauna of, 139.

Rudolph lake, fauna of, 132 . $, \quad,$, , fresh-water fauna of, 328 .

Rukwa, fauna of, 127.

,, , molluscs of, 19.

,, , sandstones of, 52, 62 .

Rusisi, fauna, 139.

, river, $\delta_{3}$.

,, valley, geology of, $8 \mathbf{2}$.

kuwenzori, 33.

SALINITY OF TIIE SEA, 28, 29.

Salt, effects of, on fresh-water organisms, $23,2.4$.

,, , experiments of Herbert, 25.

$$
\begin{array}{lll}
, & , \quad & \text { Loeb, } 25 . \\
, & ,, & \text { Vernon, } 25 .
\end{array}
$$

, , increase of, in the sea, 26, 27, 28,

$$
29,326 .
$$$$
\text { ,, , , , in Shirwa, } 22 .
$$

Sandstone deposits, 65, 66, 68, 85 .

$$
\begin{aligned}
& \text { of Karagwe, Gregory, } 66 . \\
& , \quad \begin{array}{l}
\text { of Mwero, } 62,65 . \\
\text { of Nyassa, 61, 62. }
\end{array} \\
& , \quad \text {, old African, } 81 . \\
& \text { of Rukwa, } 62,65 . \\
& , \quad \text { scarps on Nyassa, } 42 . \\
& \text { of Tanganyika, 48, 62, 65, } \\
& \quad 66, \text { So. }
\end{aligned}
$$

Saracin Brothers, investigations of, 239 .

Scarps, gigantic, on Tanganyika, So.

Scenery, artificial aspect of, 108 .

Schilbe mystus, 128 .

Scott Elliott, 34, 79, 102.

Sea, ancient, of Western Africa, $3+3$.

,, , changes of salinity in, 2I, 26, 27, 28, 326.

,, , former extent of, over Africa, 68.

," , , extension over Congo, 140.

, $\quad, \quad, \quad$ Nyassa, $72,7+$.

", , probalsle date of separation from Tan' ganyika, 74 .

,, , the Red, 79 .

Seasons, wet and dry, on Tanganyika, zor .
Secondary fresh-water faunas, 15, 30 .

Section through North Nyassa and great central ridge, 142 .

, , , South Nyassa and great central ridge, 140.

, , Rukwa, 45.

Semliki valley, 94.

, , fauna of, 139 .

Semper and Sollas, investigations of, 12.

Serranidae, 135, description of, 168. ,, of Lake kudolf, I 32.

Shales on Tanganyika, 48 .

Shells of Tanganyika, 220.

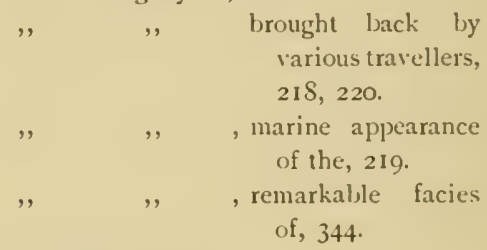

Shiri, fauna of, 139.

Shirwa lake, 21, 26.

,, , , fauna of, $3, \mathrm{I} 26$.

,, , , geology of, 57 .

, , , lake deposits of, 58 .

,, ,, , salt in, 22, 126.

Siluridie, 341, 135 .

," description of, 160 .

" of Mwero, I25.

" of Nyassa, 12.4 .

Simochromis diagramma, description of, 198.

Sinking of floor of Nyassa, 4.4.

Snow line on Mountains of the Moon, IOI.

Sollas and the solution of fresh-water fauna problem, 15.

Spatha kirkii, 125.

,, nyassensis, I 25.

, trapezia, 131 .

Spathodus erythrodon, description of, 212.

Species, number of, in proportion to size of lake, 146, 147, 150.

Speke, shells brought from Tanganyika ly; I, 2IS.

Spckia, affinities of, $218,250,256,258$, $259,260,267,27.4,349$.

,, , description of, 256 . 
Sphaerium nyanzæe, I3I.

stuhlmanni, I 3 I.

Sponges, spicules of, $32 \mathrm{I}$.

, of Tanganyika, description of, 309, 310, 318, 323 .

Spongilla aspinosa, affinities of, 316,317 .

" lacustris, 317.

", moorei, affinities of, 309, 310, $315,321$.

,, tanganyikæ, affinities of, 320 , $33 \mathrm{I}$.

description of, 318 .

Stairs, explorations of, in Mountains of the

Moon, IO2.

Stanley, explorations of, 79 .

Stanleya, 2 I 8.

Stanley's rush drains, 83 .

Stromboli in relation to the Apennines, 36 .

Strombus, I6.

,$\quad$, affinities of, 270, 272, 274, 330 .

Structure of the African continent, 8 .

Struthiolaria, affinities of, I $7 \mathrm{I}$.

Stuhlmann, explorations and views of, 79 ,

98, 102.

Suess, opinions of, 6, 40, 79 .

Swamps, papyrus, near Kivu, 83 .

Synodontis afrofischeri, I 30.

, citernii, I32.

", granulosus, 66 .

", multipunctatus, description of, I64.

" ornatipinnis, I25.

, schali, I.32.

" zambeziensis, I24, I25.

" zanzibaricus, 132 .

Syrnolopsis, 218, 2 I9.

TANIOGLOSSA, AFFINITIES OF

THE, I6, 20I, 27 I.

Tanganyicia, 218 .

,, , affinities of, 246, 248, 249, $266,273,274$.

Tanganyika, aqueous deposits, old, near, 35 .

" , ancestral type of the fauna of, 344 .

, Arab traditions concerning its outflow, 90.
Tanganyika characinidre, description of,

I 54 .

, , cichlid fishes in, 136 .

, cichlidæ, 329.

, connected formerly with the sea, 3 .

crabs, description of the, 280 , 286.

", $\quad$ crustacea, 279.

$" \quad$, depth of, 48 .

", description of the valley of, 8o, $8 \mathrm{I}$.

expeditions, date of the first,

220.

, geological observations made on the 55,327 . primary object of the, 79 . reasons for, 3 .

", , fall in the level of, 90.

, , fauna of, 9, I 33 .

", , , age of the, 343 .

, ,, , distinctive character of, I4I.

,, , marine character of, I4I.

,, , type of, $73,343,344$. , fishes of, I 34,135, I 36 , 152 .

,, , description of the, I 54-216.

, gastropods of, I4I, 217 .

,, , affinities of, 269.

,, , alimentary systems of, 267 .

, , , ancestral characters of, 268,277 .

, gneiss and schist on, $\mathbf{S}_{\mathbf{I}}$.

", halolimnic fauna of, 9, I 50 218,331 .

, halolimnic fauna, characters of, solve the Tanganyika problem, 33I, 337.

lamellibranchs, 72, 217 .

lepidosirenidx, I 54 .

, level of, changes in, 90 . 
Tanganyika, modern lake deposit near, 8 I.

, molluscs, conchological characters of, 333 .

, $\quad, \quad$ of, 19, 125, 21 7-265.

, , neothauma, affinities of, in, I 28 .

, , , varieties of, 149.

, , normal fresh-water molluscs of, 217.

, , number of species in, 133 , I 46 , I 54 .

, , outflow of, into the Congo, 90 .

, , paramelania of, I 50.

, , plateau the, So.

,, polyzoa, I4I.

", polyzoan, description of, 295 .

,, , the site of a former sea, 220.

", , sponges of, description of, 309 , 310, 315, 3I $8,321,322,323$.

unio, the genus, 217 .

, upthrust on, 49,8 I.

valley, $46,48,49, \delta_{3}$.

, rolcanoes north of Kivu, effect of, on, 90 .

, wet and dry seasons on, 301 .

Telmatochromis annectens, description of,

194.
vittatus,,,$\quad 194$.

Tilapia aurata, 124.

, boops, description of, 204.

,, burtoni, 128, 135.

,, , , description of, 198 .

,, callipterus, 124.

, dardennii, description of, 200.

, grandoculis, description of, 206.

, horei, description of, 198 .

,, johnstoni, 124.

,, kirkii, I24.

, labiata, description of, 202.

, lateristriga, I 24.

," lethrinus, 124 .

, microlepis, description of, 206.

,, mossambica, 124.

, natalensis, 128 .

, nilotica, I2S, I $30, \mathrm{I}_{3} 2$

", , , , description of, 198.

", nuchisquamulata, I 30 .
Tilapia obliquidens, 130 .

," pleurotænia, description of, 202

", polyacanthus, I2S.

", rendalli, 124 .

", rubropunctata, description of, 198 .

,. sauvagii, I3O.

" shirana, I 24.

,, squamipinnis, 124.

," subocularis, 124.

," tetrastigma, 124 .

," trematocephala, description of, 204.

," williamsi, 124.

," zillii, I32.

Trematocara marginatum, description of, I 42. unimaculatum, ,, 192.

Triassic remains of fish, 62, 69 .

Trochus, affinities of, 272.

Tropheus moorii, description of, 196.

Tympanotomus, affinities of, 237, 240, 342 . Typhobia horei, 2 I8.

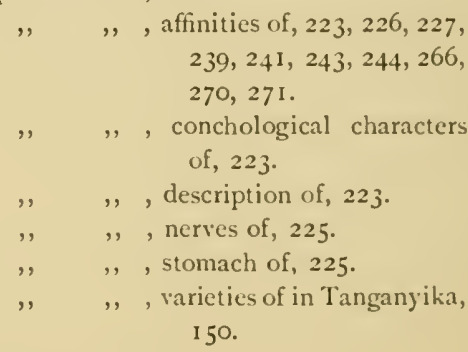

UNIO ACUMINATUS, I 29.

,, bakeri, 129.

,, borellii, 125 .

, genus of Tanganyika, 217.

,, hypsiprymnus, 125.

", kirkii, I25.

,, lechaptoisi, 125.

,, liederi, 125.

, mossambicensis, 125 .

,, multicolor, $13 \mathrm{I}$.

,, ngresianus, 130 .

, nyassaensis, 125.

,, stuhlmannii, 130.

Universal fresh-water faunas, I4. 
Upthrust in Tanganyika still going on, 87 . , violent, in the Mountains of the Moon, 98, IOI.

Ural mountains, 33 .

VALLEY OF NYASSA, $4 \mathrm{I}$. Tanganyika, 46 .

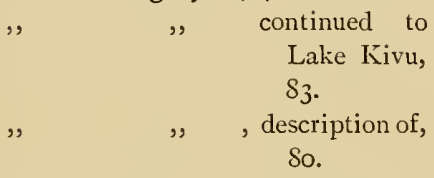

Valleys of the African Lakes, ages of, I I, 70.

, , ,, , position of the, 7 .

Vegetation north of Tanganyika, $8 \mathbf{2}$.

Vernon, experiments of, 25.

Vesuvius in relation to Apennires, 36 .

Victoria Nyanza, altitude of, I3I.

\begin{tabular}{|c|c|c|}
\hline " & comparable to & Bang- \\
\hline & $\begin{array}{c}\text { weolo, I3I. } \\
\text {, fauna of, I3O, } 32 \mathrm{~S} .\end{array}$ & \\
\hline & molluscs of, I9. & \\
\hline & plateau, 94 . & \\
\hline & , valley of, 132. & \\
\hline vipar & $\mathrm{I} 6, \mathrm{I} S, \mathrm{I} 9,2 \mathrm{I}, \mathrm{I} 5 \mathrm{I}$. & \\
\hline , & affinities of, $265,267,277$. & \\
\hline " & constricta, I3I. & \\
\hline$"$ & meta, I3I. & \\
\hline$"$ & Mwero, of, I2S. & \\
\hline ", & phthinotropis, I3I. & \\
\hline$"$ & $\begin{array}{l}\text { rubicunda, I29, I3I. } \\
\text { unicolor, I } 25, \mathrm{I} 30, \mathrm{I} 3\end{array}$ & \\
\hline & & \\
\hline
\end{tabular}

Volcanic dam North of Kivu, 84 .
Volcanoes, 36 .

," , active, north of Kivu, $\delta_{4}$.

", cause of in the floor of the eurycolpic fold, 52 .

, in the floor of the Red Sea, 45 .

,, near mountain chains, 36 .

, north of Kivu, ages and height of, $8_{5}, 86$.

,, , Nyassa valley, in the, 44,45 .

" south of the equator, 4 .

, , Tanganyilia valley, in the, 45 .

\section{WATERMARKS AND ANCIENT}

BEACHES ROUND THE NY-

ANZAS, \$9.

Watershed of the Congo, 97.

Watersheds of the Congo and the Nile, I 36. ,$\quad$, recent changes in, $\delta \circ, \delta 9$.

Wilde, altitude reached by, on Mountains of the Moon, IOz.

XENOCHROMIS HECQUI, DESCRIP.

TION OF, 2 I 2.

Xenophora, affinities of, 270, 272, 330 .

Xenotilapia ornatipinnis, description of. 190.

, sima, description of, Igo.

ZAMBESI, 34 .

,, , fauna of, 139.

Zomba, 2 I.

Zoology of the great lakes, $3 \mathrm{I}$.

", , importance of physical changes in, 28 . 



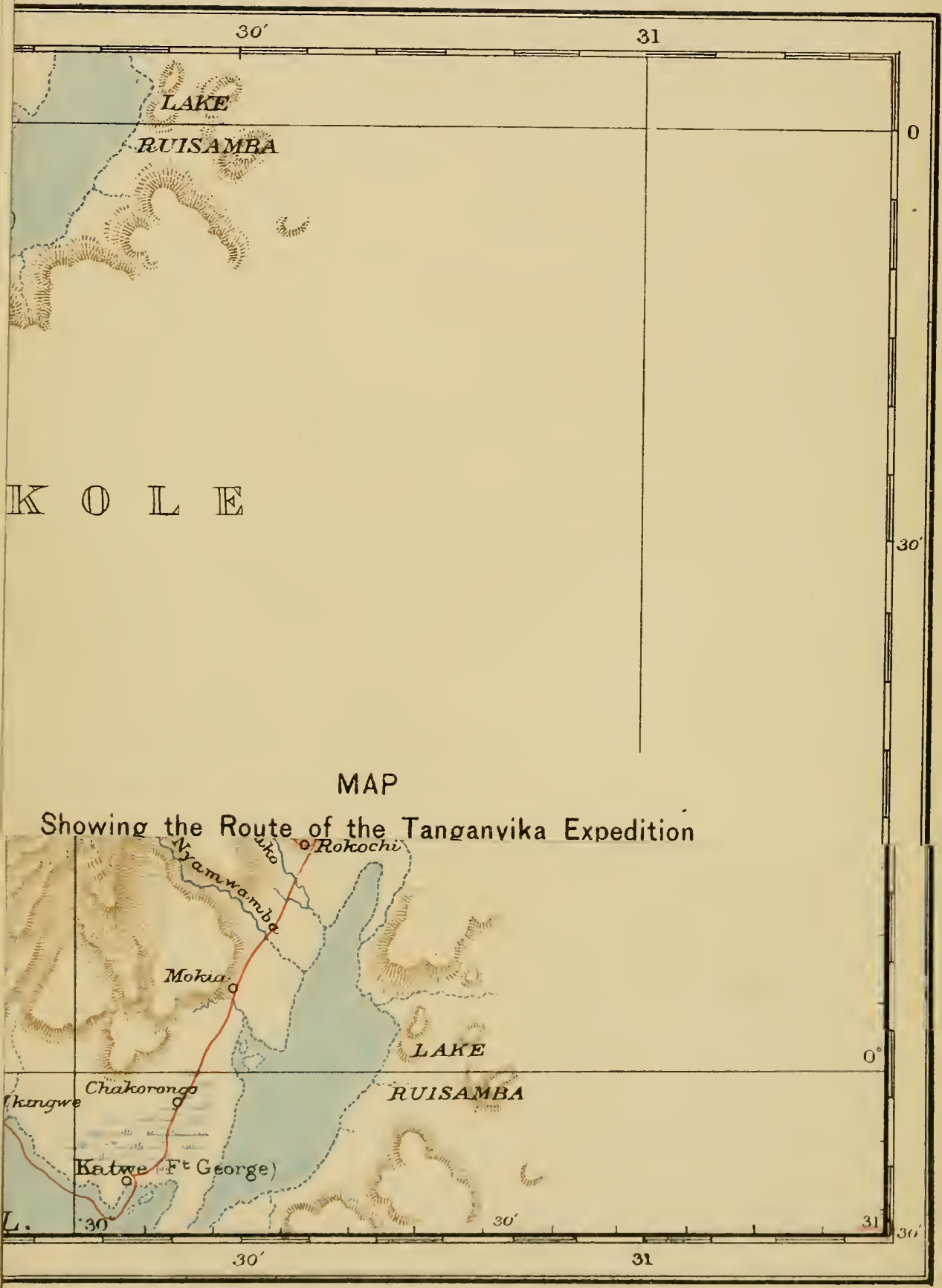

al Society. 



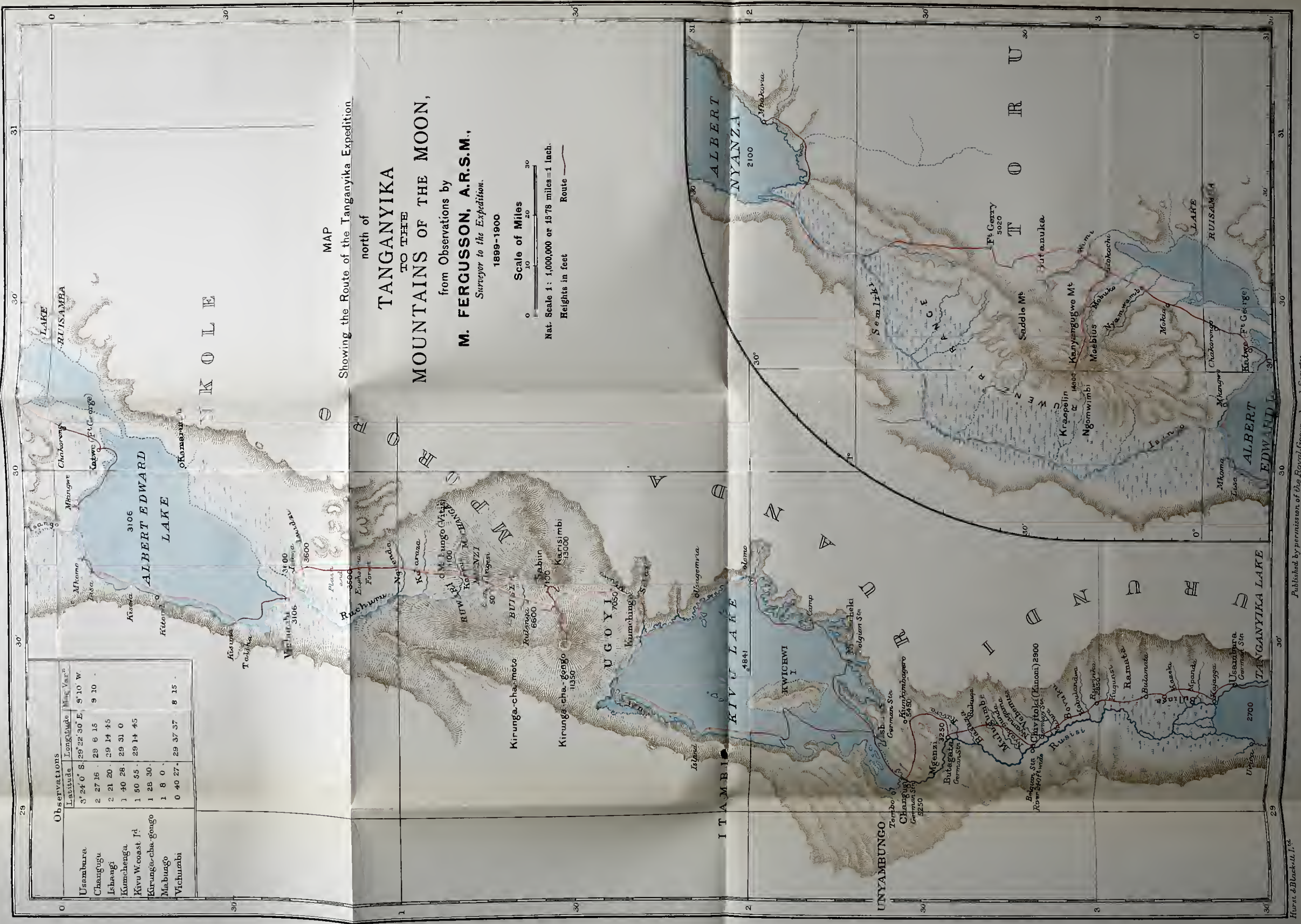





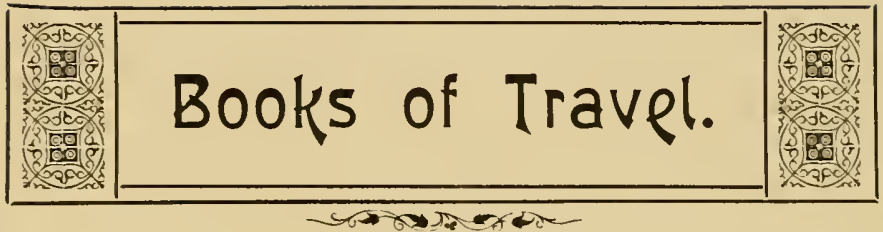

\section{NEW AND IMPORTANT WORK.}

In I rol., royal 4 to, containing numerous Illustrations in Colour, and in Black and White, from Drawings and Photographs by the Author and others. Several Maps, Diagrams, \&c., Price 25s. net.

\section{THE TANGANYIKA PROBLEM.}

An Account of the Researches undertaken concerning the Existence of Marine Animals in Central Africa. By J. E. S. MOORE, F.R.G.S., Author of "To the Mountains of the Moon," \&c.

This new and important work upon African Exploration contains the first account of the investigations which were undertaken during the Tanganyika Expedition, concerning the existence of jelly fishes and other marine animals in Lake Tanganyika. It is in fact the first definite account of the Zoology and the Geology of the Great Lake Region of Africa, and of the extraordinary chain of evidence which has led to the belief that Tanganyika represents the old Jurassic Sea.

The present work contains the only illustrated description of the fishes and other animals which inhabit the Great African Lakes.

LONDON: HURST AND BLACKETT, IIMITED. 
BOOKS OF TRAVEL-continued.

\section{AN INTERESTING BOOK OF TRAVEL.}

In I vol., demy Sro, containing numerous Illustrations from I'lotographs by the Author. l'rice 10s. 6d. net.

\section{Travels in North and Central China.}

By Jolix Gkixr likcis.

\section{NEW WORK BY MISS BETHAM-EOWARDS.}

In I vol., demy Swo, with Coloured Illustrations from Paintings l,y

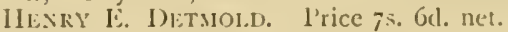

\section{East of Paris:}

SKETCHES IN THE GATINAIS, THE BOURBONNAIS, AND CHAMPAGNE.

By M. BETIAJI-EDWARus, Author of "France of To-day," sc.

"Plensant aubling sketches, by oue who knows France as do few Furlish writers, anu] lowes her. Four alelestely colourerl illustrations from original paintines by fleury 1. Detmolil aila tos the clarme of the volume."-The Oullock.

" Miss Lirwarils writes rery clearly anl lielitly, she also writes of what she has herself seen anl hearl, which is always an alvantage." - The Globe.

\section{NEW AND IMPORTANT WORK.}

\section{Travels in Space:}

\section{A HISTORY OF AERIAL NAYIGATION.}

By E. SFin: Valentixe and F. L. Towlixson, With an Introrduction by Sir II RAs MAXis, I. A.S. In I vol, demy Swo, profusely Illustrated with Reproductions from l'hotographs and Old I'rints. I'rice 10 s. $6 \mathrm{~d}$. net.

"A book of ahsorbine isterest, ofTering as it does an ahmost conplete summary of the efforts of luman conrage, ingenuity, anl perseseranee towarls tlie goal of acrial uavigation."-Daily Telegruph.

"Ihe first attempt that has been male to give a comscentire arenunt of the many notable experiments in acrial locomotion. The mative is eminmtly instructive." -Tht Globe.

LONDON : HURST AND IBLACKETT, IAMITED 


\section{NEW WORK ON ANTARCTIC EXPLORATION.}

In I vol., demy Sro, with numerous Illustrations from Photographs taken by the Author. New Charts of the South Polar Regions, Sc. Extra Cloth, Price I2s. net.

\section{To the South Polar Regions.}

\section{EXPEDITION OF $1898=1900$}

By Louis Bernacchi, F.R.G.S.

\section{NOTE. -MR. BERNACCHI is a member of the "Discovery" Expedition now at the Antarctic Regions.}

"The book is welcome as a substantial contribution to our scanty knowlerge of the region with which it leals, and there is mucl in the narrative that will interest the general reader."-The Times.

"This narrative, which is as simple as may be, has the entbralling interest which any first-hand narrative of danger and adventure must always carry." -l'ull Mall Guzette.

"The hook may be commended as a pleasant aul faithful account of what must have been an extremely dismal adventure."-Daily Chronicle.

\section{To the Mountains of the Moon:}

Being an Account of the Modern Aspect of Central Africa and some little-known Regions traversed by the Tanganyika Expedition in 1899 and 1900. By J. E. S. MOORE, F.R.G.S. In I vol., crown 4to, fully Illustrated ty Photographs and Drawings made by the Author. A Coloured Frontispiece and three Maps. In a specially-designed cover, gilt top. Price 2 Is. net.

\section{EXTRACT: FRON SOME IREVEW:}

"Mr. Moore's account of his journeyings from the mouth of the Zambesi to the Mountains of the Jroon, by way of the great chain of lakes, is vastly entertaining. The book is something more than a traveller's tale, and may be strongly recoumended for gencral perusal."-St. Jumes's Gazelte.

"The greatest charm of Mr. J. E. S. Moore's 'To the Mountains of the Moon,' apart from its raciness of narrative, lies in its descriptions of strange tropical secnery, storms nul fever-larlen swamps. The numerous tirawings and photographs give an excellent inleg of the equatorial regious and their marvellous skies aud distances."-Acudemy.

"Some goorl illustrations from the anthor's pencil and camera add to the attractivenes of a book which, outsile its scientific interest, has matter of gravc import for the missionary, the alininistrator, and the would-be investor."-Duily Chronicle.

"Into the details of the great journey it is impossible to enter, but apart from Mr. M(x)re's conclusions on one or two questions of Imperial interest, his book can be heartily welcomed as a valuable addition to the literature of a subject of engrossing importance. Though a naturalist first of all, he does not orerwlichu us with siekening eatalogues of the flora and fauna of the conntries traversel, nor does he cxaggerate tritling-though sometimes cxasperating-alventurcs into shimllery hairbrealth escapes. The book is berlutifully illustraterl."-Gilusqonc //erwlil. 


\begin{tabular}{|c|c|c|}
\hline 8 & . . SIDíscellancous . . & $\begin{array}{ll}58 \\
89\end{array}$ \\
\hline & . IPublícations. & \\
\hline
\end{tabular}

$\operatorname{archo0}$

NEW WORK BY SIR W. MARTIN CONWAY.

In I vol., demy 8vo, with numerous Illustrations. I'rice 7s. 6d, net.

\section{Early Tuscan Art:}

FROM THE 12th TO THE 15th CENTURIES.

By SiR W. MARTIN CONWAY, Slade P'rofessor of l'ine Art in the University of Cambridge.

\section{MR T. H. S. ESCOTT'S NEW WORK.}

In 2 vols., demy 8vo. Price 15 s. net.

\section{Gentlemen of the House of Commons.}

By T. II. S. Escott, Author of "England-its P'eople, l'olity, and J'ursuits," "l'ersonal Forces of the l'eriod," fic., \&.c.

\section{NEW WORK ON ROCK CLIMBING.}

In I vol, demy Svo, with numerous Illustrations. I'rice 75. 6il. net.

\section{Crag and Hound in Lakeland.}

By Cinude Bexsos, Member of the Climbing Club. 


SMITHSONIAN INSTITUTION LIBRARIES

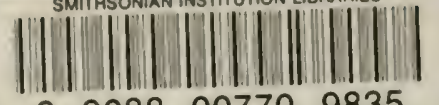

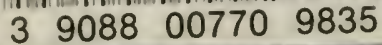

